\title{
Environmental policy and technical change : a comparison of the technological impact of policy instruments
}

Citation for published version (APA):

Kemp, R. P. M. (1995). Environmental policy and technical change : a comparison of the technological impact of policy instruments. [Doctoral Thesis, Maastricht University]. Datawyse / Universitaire Pers Maastricht. https://doi.org/10.26481/dis.19950101rk

Document status and date:

Published: 01/01/1995

DOI:

10.26481/dis.19950101rk

Document Version:

Publisher's PDF, also known as Version of record

\section{Please check the document version of this publication:}

- A submitted manuscript is the version of the article upon submission and before peer-review. There can be important differences between the submitted version and the official published version of record.

People interested in the research are advised to contact the author for the final version of the publication, or visit the DOI to the publisher's website.

- The final author version and the galley proof are versions of the publication after peer review.

- The final published version features the final layout of the paper including the volume, issue and page numbers.

Link to publication

\footnotetext{
General rights rights.

- You may freely distribute the URL identifying the publication in the public portal. please follow below link for the End User Agreement:

www.umlib.nl/taverne-license

Take down policy

If you believe that this document breaches copyright please contact us at:

repository@maastrichtuniversity.nl

providing details and we will investigate your claim.
}

Copyright and moral rights for the publications made accessible in the public portal are retained by the authors and/or other copyright owners and it is a condition of accessing publications that users recognise and abide by the legal requirements associated with these

- Users may download and print one copy of any publication from the public portal for the purpose of private study or research.

- You may not further distribute the material or use it for any profit-making activity or commercial gain

If the publication is distributed under the terms of Article $25 \mathrm{fa}$ of the Dutch Copyright Act, indicated by the "Taverne" license above, 


\section{Environmental Policy and Technical Change}

A Comparison of the Technological Impact of Policy Instruments 


\section{Promotores:}

Prof. dr. L.L.G. Soete

Prof. dr. A. Nentjes (Rijksuniversiteit Groningen)

\section{Leden van de beoordelingscommissie:}

Prof. dr. W.E. Steinmueller (voorzitter)

Prof. dr. J.G. Backhaus

Prof. dr. J.B. Opschoor (Vrije Universiteit Amsterdam)

Kemp, Renatus Paulus Maria

Environmental policy and technical change : a comparison of the technological impact of policy instruments /

Renatus Paulus Maria Kemp. - Maastricht : Universitaire

Pers Maastricht. - III

Proefschrift Maastricht. - met lit. opg. - Met samenvatting in het Nederlands.

ISBN 90-5278-149-4

trefw.: milieubeleid / alternatieve technologie /

economische modellen

(c) 1995, R.P.M. Kemp, Maastricht 


\section{Table of Contents}

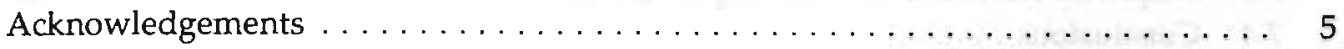

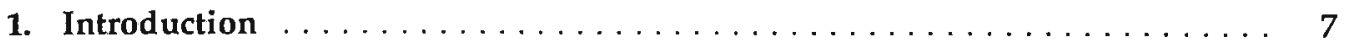

1.1 Problem and Research Methods $\ldots \ldots \ldots \ldots \ldots \ldots \ldots \ldots \ldots$

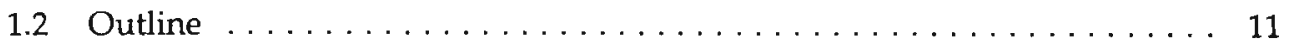

1.3 Technology Definitions $\ldots \ldots \ldots \ldots \ldots \ldots \ldots \ldots \ldots \ldots \ldots \ldots \ldots \ldots \ldots$

PART I THEORETICAL MODELS OF INNOVATION AND DIFFUSION . .

2. A Critical Survey of Innovation Models in Pollution Control . . . . . . . . 24

2.1 Models of Innovation in Pollution Control . . . . . . . . . . . . 25

2.2 A Critical Assessment of the Innovation Models . . . . . . . . . . 61

2.3 Conclusions . . . . . . . . . . . . . . . . . . 73

3. New Models of Innovation in Pollution Control . . . . . . . . . . . . . 56

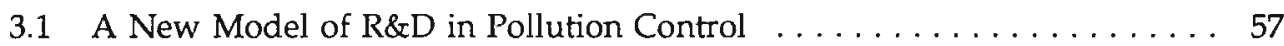

3.2 A Model of Regulator Behaviour and Innovation in Pollution Control . . 62

4. An Interpretative Survey of Technological Diffusion Models . . . . . . . 73

4.1 Introduction . . . . . . . . . . . . . . . . . 73

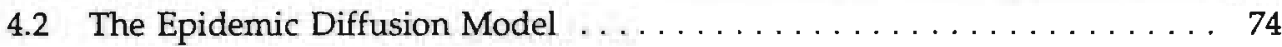

4.3 Rational Choice Models of Technological Diffusion . . . . . . . . . 83

4.4 A Comparison of Technological Diffusion Models . . . . . . . . . . . . 87

5. The Diffusion of Environmentally Beneficial Technological Innovations . . . 97

5.1 The Adoption of Environmentally Beneficial Innovations ......... 98

5.2 Two Diffusion Studies of Environment-Saving Technological Innovations . 100

5.3 A Simple Threshold Diffusion Model for Environment-Conserving Technol-

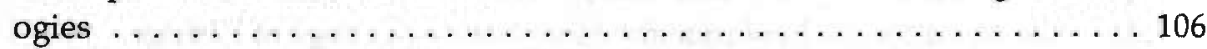

5.4 The Diffusion Effects of Different Policy Instruments $\ldots \ldots \ldots \ldots \ldots 116$

PART II EMPIRICAL STUDIES OF THE TECHNOLOGICAL IMPACT OF ENVIRONMENTAL POLICIES

6. The Diffusion of Biological Waste-Water Treatment Plants in the Dutch Food

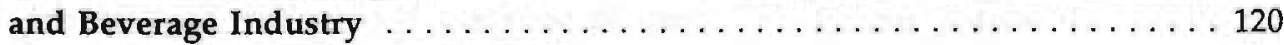

6.1 Waste-Water Policy in the Netherlands . . . . . . . . . . . . . 120

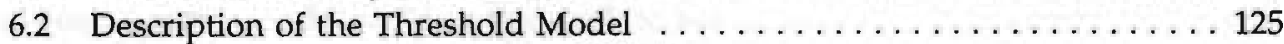

6.3 Empirical Results from the Threshold Model ................ 133

6.4 Model Results from Three Epidemic Models . . . . . . . . . . . . . 153

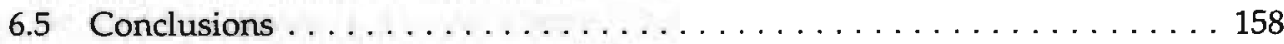


7. The Diffusion of Thermal Home Insulation in the Netherlands . . . . . . 165

7.1 The Threshold Model for Thermal Home Insulation . . . . . . . . 168

7.2 Empirical Results from the Threshold Model . . . . . . . . . . . . . 171

7.3 Empirical Results from Three Epidemic Models $\ldots \ldots \ldots \ldots \ldots \ldots 180$

7.4 Conclusions . . . . . . . . . . . . . . . . . . . . . 192

8. Three Case Studies of Cleaner Technologies . . . . . . . . . . . . . 203

8.1 The Decision to Develop and Adopt a Cleaner Technology . . . . . . . 203

8.2 Empirical Results from Three Case Studies . . . . . . . . . . . . 207

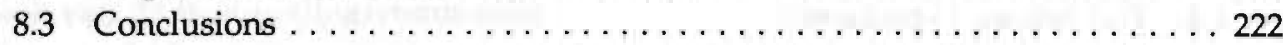

9. Empirical Results of other Technology Studies . . . . . . . . . . . 225

9.1 Technology Effects of Environmental Regulations in the U.S. . . . . . . 225

9.2 The Technological Impact of Environmental Subsidies $\ldots \ldots \ldots \ldots .230$

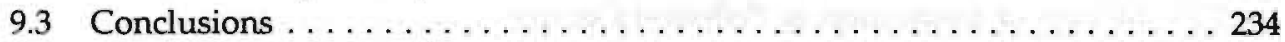

PART III THE PROBLEM OF TECHNOLOGICAL REGIME SHIFTS $\ldots \ldots \ldots 235$

10. Continuity and Change in Technological Regimes ............. 236

10.1 Patterns in the Evolution of Technology ................ 236

10.2 The Socio-Economic Dimension in the Stability of Technological Regimes . 242

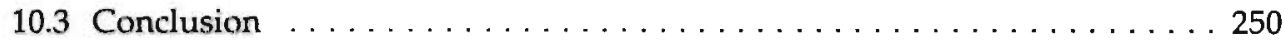

11. Understanding Technological Regime Shifts . . . . . . . . . . 252

11.1 Determinants of Radical Technological Change . . . . . . . . . . 252

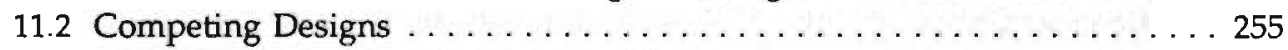

11.3 The Shift into a New Technological Regime ............... 257

11.4 Firm Behaviour and Technological Regime Shifts . . . . . . . . . . 259

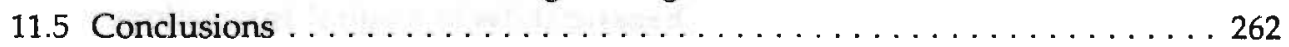

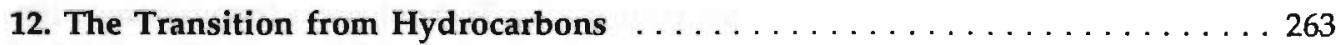

12.1 Greenhouse Warming and Energy Technologies . . . . . . . . . . 263

12.2 The Need for an Evolutionary Model of Technological Change . . . . . . 265

12.3 Technological Pathways to a More Sustainable Energy Future . . . . . . 269

12.4 Defining Energy Technology Policies . . . . . . . . . . . . . 271

12.5 Strategic Niche Management . . . . . . . . . . . . . . . 279

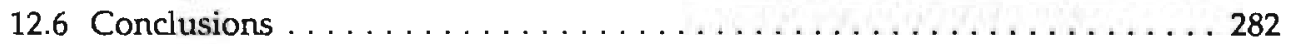

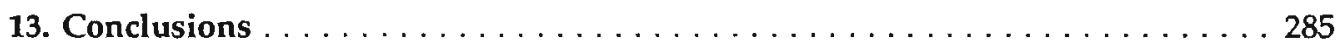

References ................................ 293

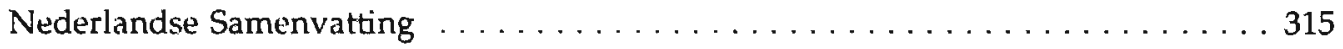

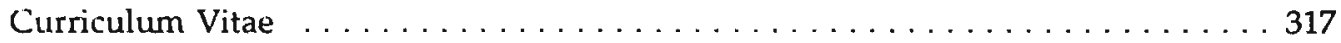




\section{Acknowledgements}

Little did I know about technology and the environment when I came to Maastricht in 1987 to work at the University of Limburg. What events or contingencies led me into writing this PhD thesis? One important event was the establishment of MERIT in December 1987. MERIT is a research institute of social and economic aspects of technological change. Environmental issues were not part of the original research plan but the topic of "technology and the environment" was close enough to the technology and policy issues studied at MERIT. Another lucky event was that the topic of technology and the environment was put on the national policy agenda in 1989. That year marked the start of a research project with the Institute for Environmental Studies for the Dutch ministries of the Environment and Economic Affairs on policy instruments to stimulate clean technology.

The completion of this $\mathrm{PhD}$ thesis owes a great deal not only to the above events but also to various people, and I am grateful to them for their support and help. First, I would like to thank my promoters, Luc Soete and Andries Nentjes. Their support and comments contributed greatly to the successful completion of this $\mathrm{PhD}$ thesis. I am also grateful to the members of the examining committee, Ed Steinmueller, Jürgen Backhaus and Hans Opschoor, who offered many valuable suggestions for improvement of this work. I would also like to thank Arthur van Soest from the University of Brabant and Paul Diederen from the University of Warwick for their comments on earlier drafts of the diffusion chapters.

At MERIT, there were also a lot of people that helped me write this thesis, and I want to single out a few of them for specific contributions. First of all Wilma Coenegrachts, whose door was always open and who helped me out in matters going beyond administrative management. I also want to thank Mieke Donders, Silvana de Sanctis and Ellen Boulanger for secretarial support. Furthermore, at MERIT, I benefitted greatly from discussions with Bart Verspagen, Huub Meijers, Adriaan van Zon, Thomas Ziesemer and other members of the productivity group about technical change and economic theory, and from their and Ton van Moergastel's assistance in getting the most out of computers. Special thanks are due to the people I have worked with over the years in joint research projects: Keith Smith from STEP, Ian Miles, Mark Boden and Penny Street from PREST, Frans van de Loo from CML, and Frans Oosterhuis, Xander Olsthoorn and Harmen Verbruggen from IVM. Working with them helped me to expand my views, and it was also a great pleasure.

I am indebted to each and everyone of them. But the one person who made the greatest contribution of all is Corien Gijsbers, my wife. Without her this book would not have been possible, and I dedicate this book to her and our children, Laurie and Steven. Finally, I would like to thank my secondary school teacher and friend René Kusters, who, probably without knowing it, was an important influence. It was he who led me into the field of economics. I never guessed that it would take me where I am now. 
Abstract analysis of institutional arrangements that would be 'optimal' in idealized situations is at best only one useful heuristic for the main work, and at worst a diversion from it (Nelson and Winter 1982: 404). 


\section{Chapter 1}

\section{Introduction}

We currently witness a heightened concern over the natural environment. Although problems of pollution and resource depletion are not new, the accumulation of longlived pollutants and rapid extraction of depletable resources are a major cause for concern. Whether current growth paths will destroy life-supporting functions of the natural environment in an important way and will cause the economy to run out of natural resources in the foreseeable future is unclear. There is much uncertainty about these issues, and there will continue to be uncertainty about the consequences of environmental change and the exact nature of environment-economy relationships. We do know, however, that the possible impact of the build-up of pollutants and depletion of natural resources can be great or even dramatic.

In the debate over environmental degradation, two totally different views stand out: that the current environmental problems are caused by 'too much' technology and that we must adapt to the perceived environmental crisis by radically changing our behaviour, or that the problem is one of 'not enough' technology, in the sense that we need more environmentally benign technologies that preserve the natural environment. Whether technology will save us - to use a popular phrase - is unclear. This will depend on public and private support for environmentally beneficial technologies and the extent to which further growth in population and economic output will compromise per capita emissions reductions and a more efficient use of natural resources.

Understanding the change process in technology, and how technological change may be redirected towards more environmentally benign directions, is of great importance in designing efficient policies for environmental protection. As Adam Jaffe and Robert Stavins write:

In the long run, the development and wide-spread application of new technologies can greatly ameliorate what, in the short run, sometimes appears to be overwhelming conflicts between economic well-being and environmental quality.

Or, as Allen Kneese and Charles Schultze wrote almost twenty years ago:

${ }^{1}$ Adam B. Jaffe and Robert N. Stavins, 1990, Evaluating the Relative Effectiveness of Economic Incentives and Direct Regulation for Environmental Protection: Impacts on the Diffusion of Technology, paper for the WRI/OECD-Symposium "Toward 2000: Environment, Technology and the New Century", June 13-15, 1990, Annapolis, Maryland, p.1. 
Over the long run, perhaps the most important single criterion on which to judge environmental policies is the extent to which they spur new technology toward the efficient conservation of environmental quality. ${ }^{2}$

How various environmental policy approaches (taxes, tradeable pollution permits, subsidies, information supply) affect the decisions of economic agents to develop and use more environmentally benign technologies is the main subject of this study.

\subsection{Problem and Research Methods}

The use of the natural environment as a common property resource with a low or zero price, especially in its role as a recipient of environmentally hazardous emissions and waste, enables individual polluters to shift the environmental costs to others, including future generations. In this context, technical change is induced to favour the use of common property resources, a result formally worked out by Kerry Smith (1972) and Roger McCain (1978). ${ }^{3}$ Government intervention is mostly needed to make sure that polluters reduce their environmentally hazardous emissions to socially more efficient levels.

This raises the question of how public policy may be used to redirect technical change toward more environmentally benign directions. For example, are environmental regulations a good way to promote technological innovation and diffusion of environmentally prefereable technologies? Or are incentive-based policies, such as pollution taxes, subsidies and tradeable quota, a better way to foster environmentally benign technical change? These issues will be examined in this thesis. How will this be done? This is an important question, because the research method chosen may have an important bearing on the results.

Within the economics of technological change there are two relatively well-developed approaches: the neoclassical approach in which the decision to develop and adopt a new technology is seen as an economic cost-benefit decision under uncertainty, and the evolutionary or Neo-Schumpeterian approach, which builds on the work of Joseph Schumpeter. Each approach has its own virtues and weak points. The advantage of neoclassical economics is that it is based on simple assumptions about economic behaviour. A rise in the price of an input, or a tax on pollution, will cause firms and households to economize on the use of the input, or to reduce pollutant emissions. In neoclassical models, economic actors are not constrained by cognitive limitations, by their technological capabilities, by institutional constraints (or even laws of nature) to respond

2 Allen V. Kneese and Charles L. Schultze, 1975, Pollution, Prices and Public Policy, Washington, p.82.

${ }^{3}$ V. Kerry Smith, 1972, The Implications of Common Property Resources for Technical Change, European Economic Rewiew, 3(4): 469-479; and Roger A. McCain, 1978, Endogenous Bias in Technical Progress and Environmental Policy, American Economic Review, 68: 538-546. 
to changes in the price and demand structure. By making these (heroic) assumptions about human behaviour it is possible to derive theorems and test economic relationships. The apparatus is well-developed and may be applied to almost any problem. Economists have used this method to analyze and compare firm incentives for innovation in pollution control technology under different control regimes.

For some problems, however, the neoclassical model is less appropriate. For instance, if we want to understand radical change in technology or technological regime shifts, where an important part of the technological system and the social and organisational context changes, the neoclassical world of perfect information (or probabilistic uncertainty) and optimisation is less appropriate. As each technological regime implies different technical interrelationships, linkages with information networks, different engineering skills and practices, and all kinds of institutional changes, a different type of approach is needed - an approach that looks at the ways in which innovations are technically and economically linked, and that considers the ways in which institutions (economic, social and political) shape and limit economic decisions and technological choice. In such a case, the evolutionary or Neo-Schumpeterian model of technological change - developed by Richard Nelson, Sidney Winter, Chris Freeman, Luc Soete, Giovanni Dosi, Stan Metcalfe and Jerry Silverberg - is more appropriate."

Central to economic evolutionary theory is that optimal behaviours and technologies cannot be determined $e x$ ante on the basis of economic calculus but are selected $e x$ post in the selection environment - they are selected ex post by the evolution of social needs, the actions of other firms and organizations, new discoveries in technology and science, and government interventions, much more than they are selected by the choices of economic actors that look into the future. It shares with biological evolution theory the distinction between variation and selection. In the economic world, variations are inventions (or technological innovations) that are selected or not selected (taken up) by the market. It differs from biological evolution theory in that the variations are generated by the deliberate choices of economic actors rather than by a stochastic process, although chance often plays a role. Another difference is that the selection environment is influenced and altered by firms' activities and strategies. This means that in the economic world the feedbacks between variation and selection are less mechanistic than in the biological world; there are goals and intentions and there is learning, organisation and

\footnotetext{
${ }^{4}$ Neo-Schumpeterian and evolutionary approaches to technology are put together in Giovanni Dosi, Chris Freeman, Richard Nelson, Gerald Silverberg and Luc Soete (eds.), Technical Change and Economic Theory, London: Pinter Publishers. A more recent book is Paolo Saviotti and Stan Metcalfe (eds.), 1993, Evolutionary Theories of Economic and Technological Change, Reading: Harwood Academic Publishers. Classical works in the evolutionary tradition are Thorstein B. Veblen, 1898, Why is Economics Not an Evolutionary Science?, Quarterly Journal of Economics, 12: 373-397; Joseph A. Schumpeter, 1939, Business Cycles. A Theoretical, Historical, and Statistical Analysis of the Capitalist Process, 2 vols, New York: McGraw-Hill; Kenneth E. Boulding, 1978, Ecodynamics. A New Theory of Societal Evolution, Beverly Hills, London: Sage Publications; and Richard R. Nelson and Sidney G. Winter, 1982, An Evolutionary Theory of Economic Change, Cambridge (Mass.): Bellknap Press;
} 
strategies..$^{5}$ In this study, the evolutionary model will be applied to the problem of technological regime shifts. As in most studies, the term 'evolutionary' will be used in a rather loose sense; it refers to a process of gradual and cumulative change along certain paths or trajectories, in which a change in the selection environment may cause the system to develop into a new direction, i.e., there is path-dependency and there are bifurcations. That is, in this study, the evolutionary terms of variation and selection will not be used much; instead, we will talk about the co-evolution of technology and the socio-economic context from which it emerges and focus on the importance of institutions and technical and economic relationships in the rate and direction of technological change. This means that our approach is closer to the more 'institutional' approach to technology of Richard Nelson, Chris Freeman, Giovanni Dosi and Luc Soete, than to the 'evolutionary modelling' approach of Jerry Silverberg and Bart Verspagen. ${ }^{6}$

This thesis will use neoclassical notions and tools and ideas from evolutionary theory. To some extent, we will combine the two approaches. For instance, in developing our own neoclassical models of innovation and diffusion of environmentally beneficial technologies we have sought to bring in more realistic elements of technology development and application in the whole discussion - while keeping the theoretical analysis manageable. Examples of such refinements are, in the innovation models: the introduction of regulator uncertainty about the technical feasibility and economic costs of pollution control policies, the distinction between (curative) end-of-pipe technologies and (preventive) process-integrated technology, and the introduction of time in the analysis. In our diffusion model, consumer preferences are not held constant but may shift over time, the purchase costs and variable costs of using the new technology may change (in part as a result of policy interventions), and post-innovation improvements may enhance the attractiveness of the innovation. Although the models are still recognizable as neoclassical models, there are 'enriched' with evolutionary elements. In our discussion of technological regime shifts, we introduce neoclassical elements of rational choice and optimization, things that are neglected in the evolutionary model that assumes that firms apply rules of thumb and are unable to respond adequately to changes in the demand and cost structure. In diffusion studies, we will both estimate a rational choice model and epidemic models that are more evolutionary in nature. The use of different research methods also enables us to analyze the robustness of the results of the technological impact of policy instruments.

${ }^{5}$ A discussion of the evolutionary paradigm and technical change is in Chris de Bresson, 1987, The Evolutionary Paradigm and the Economics of Technological Change, Joumal of Economic Issues, 21(2): 751-762; and in Chris Freeman, 1991, Innovation, Changes of Techno-Economic Paradigm and Biological Analogies in Economics, Reoue Economique, 42(2): 211-232.

"Examples of evolutionary models of technical change are Gerald Silverberg, Giovanni Dosi and Luigi Orsenigo, 1988, Innovation, Diversity and Diffusion: A Self-Organisational Model, Economic Journal, 98: 1032-1054; and Bart Verspagen, 1993, Trade and Knowledge Spillovers in an Evolutionary Model of Growth Rate Differentials, in Adolf Wagner (ed.), Dezentrale Entscheidungsfindung bei externe Effekten, Tübingen: Franke verlag. 
As a last general point, we want to stress that this study is not confined to environmental technology in a narrow sense, as either a pollution control device, re-use system or an environmentally improved product. Although the innovation and diffusion processes of such devices and products will be studied in the following chapters, the project will move beyond these types of environmental technologies by also looking at the possibilities of achieving shifts in technology systems. Examples of shifts in technology systems that may bring considerable environmental benefits are: a switch away from hydrocarbon-based energy supply, conversion and end-use technologies (toward renewables and vehicles powered by batteries or fuel cells), or the replacement of car commuter traffic by interactive telecommunication systems. Thus, the thesis will also explore the broader question of how complex technology systems evolve and change, and how public policy may be used to induce and sustain a shift towards more environmentally sustainable technological regimes.

We will now define the subject of this thesis in more detail. The aims of this thesis are threefold:

i) to analyze and compare the effects of various pollution control instruments (emission standards, effluent charges, subsidies, tradeable pollution permits) on innovation in pollution control technology;

ii) to analyze the effects of different policy approaches to limiting environmentally hazardous emissions on the diffusion of environment-saving processes and products;

iii) to examine the problem of technological regime shifts.

Problem i) will be analyzed in neoclassical innovation models. Problem ii) will be analyzed in a rational choice diffusion model and two econometric studies. The technological impact of environmental policies will furthermore be examined in three case studies. The problem of technological regime shifts will be studied from an evolutionary or NeoSchumpeterian perspective.

\subsection{Outline}

This thesis consists of three parts and a concluding chapter. Part I contains theoretical models of the impact of pollution control instruments on the development and diffusion of environmentally preferable technologies. Part II presents the results of empirical investigations of the technological impact of environmental policies. It contains empirical results from statistical tests of the impact of policy instruments (effluent charges and investment subsidies) on the technological diffusion of biological waste-water treatment plants and thermal home insulation in the Netherlands. It also contains a literature 
review of empirical studies into the effects of past environmental policies on the development and adoption of cleaner technologies and the findings of three case studies: CFC substitutes, low-solvent paints and membrane filtration. Part III analyzes the problem of technological regime shifts; it looks at patterns in the evolution of technology and the factors that account for continuity and discontinuity in technical change, and explores how public policy may be used to induce a transition away from fossil fuels. We will now give a short overview of the content of the different chapters.

Chapter 1 outlines the aims of the project and the research methods that are used. It also provides a taxonomy of technical change (incremental and radical innovations, new technology systems) and of environmental technology (end-of-pipe versus processintegrated technology, clean and cleaning technology, etc.).

Chapter 2 gives a critical overview of the existing (neoclassical) theoretical literature about the relationship between environmental policies and innovation in pollution control technology. The theoretical models are divided into two groups: first, the graphical models that analyze firm incentives for doing R\&D in pollution control (where innovation in pollution control is modelled as a downward shift of the marginal cost curve of pollution abatement); and second, the micro-economic models of $R \& D$ in pollution control.

Chapter 3 advances two models of government-induced innovation in pollution control. The first model analyzes the R\&D behaviour and abatement policy of a polluting firm under different regulatory regimes (emission standards, taxes, subsidies, tradeable quota). The innovator is a (myopic) polluter who tries to minimize current costs, which consist of pollution abatement costs, $R \& D$ costs and transfer payments relating to pollutant emissions. The second model is an extension of Nentjes' model of innovation in pollution control. The model analyzes the effects of policy instruments on innovation in a political economy model of regulator behaviour, in which the (risk-averse) control agency maximizes a utility function which is a function of emission reduction, environmental costs and uncertainty.

Chapter 4 contains an interpretative survey of technological diffusion models, making a distinction between epidemic and rational choice diffusion models. In the epidemic models, the aggregate diffusion pattern of a technological innovation is the result of the epidemic spread of information through personal contact, whereas in the rational choice (or equilibrium) diffusion models, the diffusion process is the result of economic decision making by prospective adopters. In the rational choice models, the diffusion process is caused by exogenous changes in the heterogeneous adopter environment (the obsolescence of capital goods, charges in input prices) and changes in the technology, rather than the result of epidemic learning and bandwagon effects. The reason for giving an overview of diffusion models is to find out what model is most suitable for explaining the diffusion of technological innovations that conserve environmental qualities.

Chapter 5 analyzes the diffusion of environmentally beneficial technological innovations. It discusses two technological diffusion studies of environment-saving technolo- 
gies. The chapter also advances a threshold diffusion model with (epidemic) learning that is used to analyze the impact of various policy instruments (taxes, subsidies, information supply) on the aggregate diffusion pattern of a low-emission (or energy-saving) process or product. The model is a rational choice model with (epidemic) learning.

Chapters 6 and 7 present the empirical findings of the threshold diffusion model developed in chapter 5 and of three epidemic models (the logistic, Gompertz and Bass models). The models are applied to the technological diffusion of biological waste-water treatment plants in the Dutch Food and Beverage industry (chapter 6) and the diffusion of double glazing and cavity wall insulation across owner-occupied and rented houses built before 1976 in the Netherlands (chapter 7). The models allow us to determine statistically the technological diffusion effects of effluent charges and investment subsidies, which has not been attempted before.

Chapter 8 presents the findings of three case studies of cleaner technologies: i) CFC substitutes, ii) low-solvent paints and coatings, and iii) membrane technology for the metal-plating industry. The chapter examines the impact of government policies on the development and adoption of environmental technologies in each of the case studies. Chapter 9 gives a literature overview of the technological impact of past environmental policies in the United States, the Netherlands and Denmark.

Chapter 10 examines the possibilities of inducing radical change in technology, as opposed to modification of existing products and processes or adoption of end-of-pipe technologies. It presents an overview of current understanding of the nature and direction of technological change, which emphasizes the notion of a system - i.e., that technologies should be seen as part of an integrated system of production and consumption rather than as individual products or processes. It discusses various technology concepts (like technological paradigms and regimes) that are used to account for the ordering and structuring of technology, and provides an explanation as to why the 'greening of technology' is likely to be a gradual and rather slow process, despite the strong public call for it.

Chapter 11 discusses shifts in technological regimes as opposed to changes within a technological regime - where a technological regime refers to the whole complex of scientific knowledge, engineering practices, process technologies, infrastructure, product characteristics, skills and procedures which make up the totality of a technology. Key factors in inducing technological regime shifts are identified and discussed, using historical examples to illustrate theoretical arguments. It also examines the relationship between radical change in technology and firm behaviour.

Chapter 12 examines the problem of how public policy may be used to begin and sustain a transition away from the hydrocarbon regime, the energy system based on fossil fuels. The final chapter draws conclusions about the technology effects of environmental policies and about the best policy instrument(s) to foster innovation and diffusion.

In what respects is this study an original contribution to the existing literature? In our view, the main contributions are: 
First, an extensive survey and discussion of existing micro-economic models about regulation-induced innovation in pollution control. Our discussion of this literature is critical in nature, not because we believe the models are of little value, but because they neglect a number of important aspects of technological change and for not considering the policy-making process in the context of technological uncertainty.

Second, the development of a theoretical model that describes a firm's R\&D behaviour in pollution abatement under different control regimes and a further development of Nentjes' model of regulatory behaviour and innovation in pollution control. Nentjes' original model is extended by widening the range of policy instruments open to the control agency (pollution taxes, tradeable permits instead of standards) and by including technology features (sunk costs, end-of-pipe versus process-integrated technologies) in the discussion.

Third, the development of a theoretical diffusion model for environmentally beneficial technological innovations that enables us to analyze the technological impact of pollution taxes, R\&D subsidies and information dissemination on the aggregate diffusion pattern of an environmentally desirable innovation. The technological diffusion of environment-saving innovations is a seriously underresearched area.

Fourth, an empirical application of the new diffusion model and three epidemic models to two types of environmentally beneficial technologies: biological waste-water treatment plants in the Dutch Food and Beverage industry and thermal insulation (in the form of double glazing and cavity wall insulation) of the existing housing stock (built before 1976) to determine econometrically the impact of public policies and other variables on the aggregate diffusion pattern.

Fifth, three case studies of environmentally beneficial technologies: CFC substitutes, low-solvent paints and coatings and membrane filtration, with a focus on the technological impact of government policies.

Sixth, a further refinement of the evolutionary model of technological change, which views technical change as a cumulative and historically contingent process, proceeding in quite specific directions, dependent on economic incentives, engineering ideas and institutional structure. Here we discuss continuity and discontinuity in technological regimes, and how public policy may be used to achieve a swift and smooth transition away from the existing energy regime based on fossil fuels as the primary energy source, into a new regime for energy technologies, involving other energy sources, conversion technologies and energy-using technologies.

\subsection{Technology Definitions}

The previous sections outlined the aims, methods and organisation of the book. Important concepts like innovation, diffusion, environmental technology were introduced without an explicit discussion of what they mean in the context of this thesis. We will now define several technology concepts that are used extensively throughout this study. 
In the study of technology, the following conceptual distinctions are common. First, the distinction between technical change and technological change, between technique and technology. A technique is a tangible method of production. Technology is the body of knowledge about techniques, but it is frequently used to encompass both the knowledge itself and the tangible embodiment of that knowledge. ${ }^{7}$ Another distinction is that between invention and innovation. Following Schumpeter, they are defined by Chris Freeman in the following way: an invention is an idea, a sketch or model for a new or improved device, product, process or system; it is the elaboration of a new technical principle. Inventions may often (though not always) be patented but they do not necessarily lead to technical innovations (in fact the majority do not). An innovation in the economic sense is accomplished only with the first commercial transaction involving the new product, process, system, or device. ${ }^{8}$

At the basis of many if not most modern inventions lie research and development activities that are undertaken in firms, government laboratories, and universities, although they also may be the result of research by independent inventors. Commercial new products and processes are commonly produced in firms, often but not always on the basis of research and development activities; innovations invariably also involve other, non-R\&D activities such as prototype development, tooling up, design, market research and so on. But what constitutes an innovation? Again closely following Schumpeter, Stephen Kline and Nathan Rosenberg divide innovation in five categories: first, a new or improved product, second, a new process of production, for example a computer-numerically controlled (CNC) machine or the oxygen steelmaking process, third, the substitution of a cheaper material, newly developed for a given task in an essentially unaltered product, fourth, the reorganisation of production, internal functions, or distribution arrangements leading to increased efficiency, better support for a given product, or lower costs, and fifth, an improvement in instruments or methods of doing innovation. ${ }^{9}$

In this study, the term innovation is primarily used for a new or improved product, process or the use of a new or different material. That is, we concentrate on technological rather than organisational or other (such as marketing) innovations. This does not imply that the last two categories are unimportant or uncommon. The fourth category in particular constitutes an important class of innovations being responsible for large cost efficiencies. It is through organisational changes and other kinds of social innovations that the welfare gains of the first three categories of innovations are often realised.

Invention and innovation constitute the first two stages of technological change. The third stage of technological change is the diffusion stage: the adoption and use of the

\footnotetext{
${ }^{7}$ Chris Freeman, 1982, The Economics of Industrial Innovation, 2nd Edition, London: Pinter Publishers, p.4

${ }^{8}$ Ibid, p.7.

${ }^{9}$ Stephen J. Kline and Nathan Rosenberg, 1986, An Overview of Innovation, in R. Landau and N. Rosenberg (eds.), The Positive Sum Strategy, Washington D.C.: National Academic Press, p.279.
} 
new technology over time. The diffusion phase is very important from the viewpoint of productivity and social welfare since it is adoption and implementation which gives the innovation economic significance. Although the distinction between invention, innovation and diffusion is important from a conceptual point of view, it should be noted that the three stages are all strongly related. The invention determines largely the technical characteristics of the innovation and the costs of producing it; the diffusion process is highly contingent on the economic advantages offered by the innovation; and improvements in the innovation often stem from user experience during the diffusion phase. We return below to the significance of this inter-relatedness.

Up until now, innovations have being characterised in terms of their functions within the productive system. For our purposes, another dimension of innovation is far more important: the extent to which an innovation constitutes a radical departure from the past. It is plain that there is a significant distinction to be made between technological changes which modify and improve a technology based on an existing technical principle, and changes which introduce an entirely new technology to an industry.

A common way of discussing this is in terms of "radical" versus "incremental" innovations. Many students of technological change have come up with similar concepts for the various types of innovations. Usher speaks of "epochal" and "secondary" inventions; Mensch speaks of "basic innovations" instead of "radical innovations". Similarly, Joel Mokyr speaks of microinventions and macroinventions. Microinventions are defined as "the small incremental steps which improve, adapt, and streamline existing techniques already in use, reducing costs, improving form and functions, increasing durability and reducing energy and raw material requirements". Macroinventions are "those inventions in which a radical new idea, without clear precedent, emerges more or less ab nihilo".10

Mokyr further notes that "whereas in terms of sheer numbers microinventions are far more frequent and from an economic point they account for most gains in productivity, the importance of macroinventions in technological history is crucial (...) without novel and radical departures, the continuous process of improving and refining existing techniques would run into diminishing returns and eventually peter out"."

Freeman and Perez, like others, make a distinction between incremental and radical innovations, but extend the notion of radicality into the area of social and economic impacts $^{12}$ Incremental innovations are relatively minor changes of processes and products that occur more or less continuously. They may often occur, not so much as the result of deliberate R\&D but stemming from experiences of engineers in the production

${ }^{10}$ Joel Mokyr, 1989, Twenty-Five Centuries of Technological Change: An Historical Survey, London: Harwood Academic Publishers, p.7.

${ }^{11}$ Ibid, p.7.

${ }^{12}$ The following description of incremental and radical innovations and new technology systems and techno-economic paradigms is taken from Chris Freeman and Carlota Perez, 1988, Structural Crises of Adjustment, Business Cycles and Investment Behaviour, in Dosi et al., op cit., pp.45-47. 
process or as a result of initiatives and suggestions by users. They are frequently associated with scaling up of plant and equipment and quality improvements of products and services. Although their combined effect is extremely important in the growth of productivity, no single incremental innovation has dramatic effects.

Radical innovations on the other hand are discontinuous events and in the modern period are usually the result of deliberate $R \& D$ in enterprises and research activities in university and government laboratories. They are unevenly distributed over sectors and over time. Examples are nylon or 'the pill'. Over a period of decades they may have dramatic effects, i.e., they do bring about structural change, but in terms of their aggregate economic impact they are relatively small and localised, unless a whole cluster of radical innovations are linked together.

When innovations are technically and economically linked, Freeman and Perez speak of new technology systems. Changes in technology systems affect several branches of the economy and give rise to entirely new sectors. Their use often requires organisational and managerial innovations. An example is the cluster of synthetic materials innovations, petro-chemical innovations, machinery innovations in injection moulding and extrusion, and innumerable application innovations introduced in the 1920 s till the 1950s.

When changes in technology systems have such pervasive effects that they affect either directly or indirectly almost every other branch of the economy, Freeman and Perez speak of a techno-economic paradigm (or technological revolutions). A techno-economic paradigm involves a combination of interrelated product and process, technical, organisational and managerial innovations, embodying a quantum jump in potential productivity for all or most of the economy and opening up an unusually wide range of investment and profit opportunities. Such a paradigm imposes a unique new combination of decisive technical and economic advantages.

Information and Communication Technology (ICT) is an example of such a paradigm which came to replace the paradigm of energy and material-intensive mass production. The term "paradigm" is used to describe the radical transformation of the prevailing engineering and managerial common sense for best productivity and most profitable practice, which is applicable in almost any industry (i.e., it is a meta paradigm). Further, each new techno-economic paradigm involves a particular input or set of inputs (the "key-factor" of the paradigm) which fulfils the following functions: clearly perceived low and rapidly falling relative cost, an almost unlimited supply over long periods, and a clear potential for the use or incorporation of the new key factor or factors in many products and processes throughout the economic system.

After this taxonomy of 'normal' technological change, we will now define environmental technology. Environmental technology may be broadly defined as each technique, process 
or product which conserves environmental qualities. ${ }^{13}$ Environmental qualities may be conserved directly, through the treatment of pollution, re-use of waste material, and they may be conserved in an indirect way by technologies and materials that are less environmentally harmful than comparable processes, products and substances. Environmental technologies may be grouped into four categories: ${ }^{14}$

i) Pollution control technologies that prevent the direct release of environmentally hazardous emissions into the air, surface waters or soil examples of such technologies are fluegas-desulphurisation and biofilters;

ii) Off-site re-cycling and treatment of waste - for instance the treatment of effluent in collective waste-water treatment plants, the clean-up of polluted soils and the upgrading of waste material by firms to make it suitable for re-use;

iii) Process-integrated changes in production technology, input material changes and good housekeeping that reduce the amount of pollutants and waste material that is generated during production and diminish the usage of environmentally harmful materials;

iv) Environmentally beneficial products like zero-emission motor vehicles, lowsolvent paints that are less damaging to the natural environment.

Pollution control technologies are also known as abatement technologies and as "end-ofpipe" or "add-on" technologies for the reason that they are typically added to the production. They are usually placed against process-integrated changes in production practices. Analogous to the distinction between "end-of-pipe" and "process-integrated" technology (which is at the firm level) a distinction can be made between clean technology

13 Examples of environmental qualities are: pristine air, safe drinking and swimming water, natural resources that are available for production, the beauty of the landscape, biodiversity, etc. Environmental conservation is not something that should be pursued per se, i.e., at any cost. Whether or not environmental qualities should be conserved depends on the economic valuation of these qualities, which depends on people's preferences and wealth. It also depends on the importance of envirunmental functions for our well-being and the possilibities for substitution that are available.

14 Tweede Kamer, 1982, Milieu en Technologie in Nederland (Environment and Technology in the Netherlands), Tweede Kamer zitting 1981-1982, 17386, nr.2, Den Haag, p.14. See also Jacqueline J. Cramer and Johan Schot, 1989, Problemen rond innovatie en diffusie van milieutechnologie belicht vanuit een technologie-dynamica perspectief (Problems of innovation and diffusion of environmental technology from a technology dynamics perspective), paper for the workshop "Ontwikkeling en implementatie van milieutechnologie", Utrecht, 12 sept 1989; OECD, 1985, Environmental Policy and Techmical Change, Paris; Nicholas Ashford, 1993, Understanding Technological Responses of Industrial Firms to Environmental Problems: Implications for Government Policy, p.277, in Environmental Strategies for Industry: International Perspectives on Research Needs and Policy Implications, edited by Kurt Fisher and Johan Schot, Washington D.C.: Island Press. 
and cleaning technology. Clean technology consists of process-integrated production changes that prevent pollution or reduce the use of environmentally harmful materials, of recycling technology and of cleaner consumer products. Cleaning technology consists of end-of-pipe technology and clean-up technology like waste-water treatment plants and municipal waste facilities. Clean technology is preventive whereas cleaning technology is curative. ${ }^{15} \mathrm{~A}$ more detailed overview of pollution prevention techniques is in Figure 1.1.

It must be noted that environmental technologies - even pollution prevention techniques - are not environmentally benign in the strict sense of the word. The manufacturing and operation of environmental technologies requires scarce material inputs and (usually fossil-based) energy; their application leads to waste problems, both at the time of their operation and at the end of their service life. The determining feature of an environmental technology is that it emits less than comparable products or processes or that emissions and waste material from manufacturing are treated in such a way that the resulting waste stream causes less environmental damage. Thus, also environmental technologies have adverse environmental effects and one may object for good environmental reasons against the adoption of particular environmental technologies (especially against end-of-pipe technologies that commonly give rise to environmental waste problems). Of course, the net impact on the natural environment must be positive, otherwise there is little sense in making polluters adopt such devices.

This is also the main reason why the term "environmental technology" will not be used much in this study. In the following chapters we will usually speak of environmentally desirable (or preferable, environment-saving or -friendlier) technologies, or speak of cleaner technologies. The latter categories are also broader than "environmental technology". For instance, a train is considered an environmentally desirable technology (compared to automobiles or airplanes) whereas it is not regarded as an environmental technology. Sometimes we use the term environmentally sustainable technologies (or sustainable technologies) when the environmental impact is so low that their application does not pose an environmental hazard.

${ }^{15}$ The distinction between different types of environmental technology is not always clear: waste material captured by end-of-pipe technologies may be used as an input, add-on technologies sometimes require changes in the production process or input substitution, etc. In this respect, Hartje and Lurie argue that the distinction between end-of-pipe and process-integrated technologies should not be considered a dichotomy but rather as a "continuum of technical change" (Volkmar J. Hartje and Robert L. Lurie, 1984, Adopting Rules for Pollution Control Innovations: End-of-Pipe versus Integrated Process Technology, International Institute for Environment and Society (IIUG), Wissenschaftszentrum Berlin, p.6). Similarly, Mensink et al speak of a "sliding scale of prevention" (A.J. Mensink, C.H.A. Quarles van Ufford, J.M.M. Veeken, 1988, Naar een preventief milieubeleid: onderzoek naar belemmeringen en mogelijkheden van preventie bij de houtconserverings- en galvanische industrie, (Towards preventive environmental policies: A study into the barriers of and opportunities for prevention in the Wood-Preservation and Metal-Plating industries, Nijmeegse Milieukundige Studies nr.1, KUN, Nijmegen, p.1). 


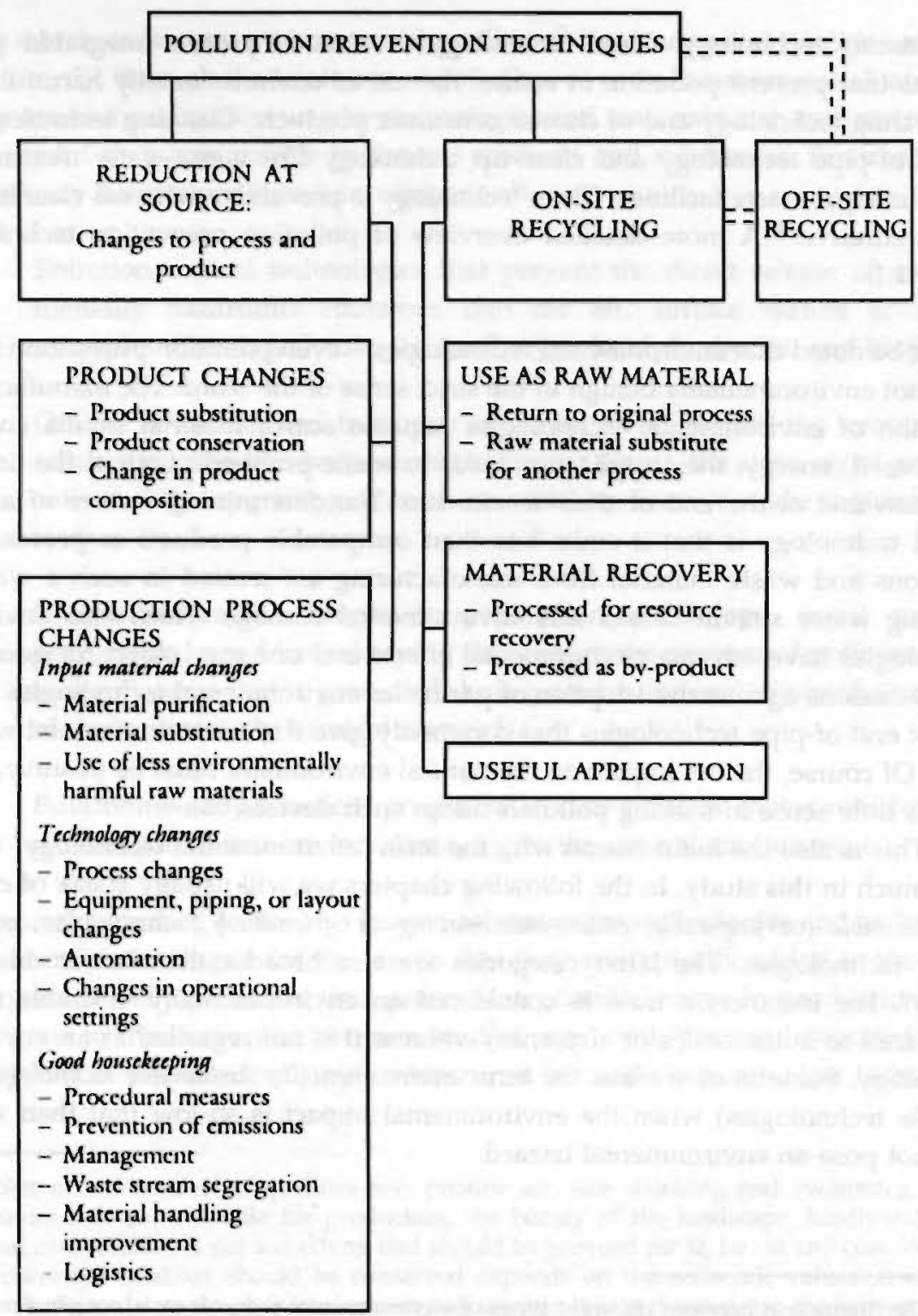

Figure 1.1. Techniques for the prevention of waste and emissions. Source: Dieleman and de Hoo $(1993$, p.250).

Table 1.1 gives an overview of the environmental technologies that are investigated in this study. It demonstrates that the study covers all kinds of environmentally beneficial technologies across different adopter populations. 


\section{Technology}

Firms/organisations

\section{Adopter population}

Consumers

A. Production process changes

i. end-of-pipe

ii. process-integrated

Waste-water treatment

systems (Chapters 6 and 8)

CFC-recycling (chapter 8)

Membrane technology (Chapter 8 )

B. Product changes

i. product reformulation

CFC-free cooling systems (Chapter 8)

Low-solvent coatings (Chapter 8 )

ii. product substitution

Rock wool instead of foams (Chapter 8 )

CFC-free cleaning agents (Chapter 8)

CFC-free aerosols and refrigerators (Chapter 8)

Low-solvent paints (Chapter 8)

Thermal home insulation (Chapter 7)

\section{New technology systems}

renewable-intensive energy system (Chapter 12)

Table 1.1. Overview of technology studies in this study 


\section{PART I}

Theoretical Models of Innovation and Diffusion 


\section{Chapter 2}

\section{A Critical Survey of Innovation Models in Pollution Control}

There is a considerable literature that analyzes economic properties of pollution control instruments. Such studies can be placed in one of three broad groupings: 1) static efficiency analyses of pollution control instruments, 2) political/regulatory feasibility assessments of policy instruments; and 3) the impact of pollution control instruments on technological change. ${ }^{1}$ Most studies are concerned with the static efficiency of pollution control instruments and - to a lesser extent - the political feasibility of various regulatory regimes. How different environmental policy instruments influence innovation in pollution control is a relatively neglected area of research. ${ }^{2}$ This neglect is surprising, because most economists would probably agree with Adam Jaffe and Robert Stavins that

the effect of public policies on the process of technological change may, in the long run, be among the most significant determinants of success and failure in environmental protection. ${ }^{3}$

It is thus important to know the differential technological innovation effects of policy instruments for environmental protection. To analyze the relationship between environmental policies and innovation in pollution control, several models have been developed, starting with Richard Zerbe's article in 1970. ${ }^{4}$ This chapter sets out to give a (critical) overview of the different theoretical models of government-induced innovation in pollution control.

The structure of this chapter is as follows. Section 1 describes the most important models about the impact of environmental policy instruments on technological innovation in pollution control. A distinction is made between the models that analyze firm incentives for innovating in pollution control and the R\&D models. Section 2 compares the differ-

${ }^{1}$ Scott R. Milliman and Raymond Prince, 1989, Firm Incentives to Promote Technological Change in Pollution Control, Journal of Environmental Economics and Management, 17, p.249.

${ }^{2}$ Paul B. Downing and Lawrence J. White, 1986, Innovation in Pollution Control, Journal of Environmental Economics and Management, 13, p.18.

${ }^{3}$ Jaffe and Stavins, op cit., p.1.

4 Richard O. Zerbe, 1970, Theoretical Efficiency in Pollution Control, Western Economic Journal, 8: 364-376. 
ent innovation models. It examines the assumptions that underlie the models and explores the implications of a relaxation (or rejection) of these assumptions. As the title of this chapter indicates, our assessment of this literature is critical. The theoretical models are viewed critically, not because we believe that the models are of little value, but because they neglect a number of important aspects of technical change and environmental policy such as innovator gains from diffusion, and problems of uncertainty and lack of information, which are central elements in the regulator-innovator relationship. The final section summarizes the main findings.

\subsection{Models of Innovation in Pollution Control}

Policy instruments aimed at limiting environmentally hazardous emissions can be divided into three categories: First, instruments of direct regulation like emission reduction standards, technology standards, product standards or bans. Second, incentive-based instruments (pollution fees or taxes, subsidies, tradeable pollution permits) that rely on price incentives. And third, communicative instruments such as information supply and moral suasion. Environmental protection may also be achieved through government investment (in the form of municipal waste treatment plants and reforestation) and the choice of administrative mechanisms (administrative unit, enforcement). ${ }^{5}$

The theoretical literature on the relationship between policy instruments and innovation in pollution control falls into two categories: first, graphical models that analyze firm incentives for innovation in pollution control, and second, R\&D models of innovation in pollution control. Examples of the first category are Zerbe (1970), Wenders (1975), McHugh (1985), Downing and White (1986) and Prince and Milliman (1989). ${ }^{6}$ Examples of the second category are Magat $(1978 ; 1979)$ and Mendelsohn (1984). ${ }^{7}$ The distinction between these two types of models is not a sharp analytical distinction. Both models assume optimisation within a partial context. $R \& D$ behaviour could be introduced in the graphical models through a cost function for $R \& D$.

${ }^{5}$ An overview of environmental policy approaches is in William J. Baumol and Wallace E. Oates, 1979, Economics, Environmental Policy and the Quality of Life, Englewood Cliffs: Prentice-Hall, pp.218219.

${ }^{6}$ Zerbe, op cit; John T. Wenders, 1975, Methods of Pollution Control and the Rate of Change in Pollution Abatement Technology, Water Resources Research, 11(3): 393-396; Richard McHugh, 1985, The Potential for Private Cost-Increasing Technological Innovation Under A Tax-based Economic Incentive Pollution Control Policy, Land Economics, 61(1): 58-64; Downing and White, op cit; and Milliman and Prince, op cit.

${ }^{7}$ Wesley A. Magat, 1978, Pollution Control and Technological Advance: A Dynamic Model of the Firm, Joumal of Environmental Economics and Management, 5: 1-25; Wesley A. Magat, 1979, The Effects of Environmental Regulation on Innovation, Low and Contemporary Problems, 43(1): 4-25; Robert Mendelsohn, 1984, Endogenous Technical Change and Environmental Regulation, Journal of Environmental Economics and Management, 11: 202-207. 


\subsubsection{The graphical firm incentive models}

The grapical firm incentive models set out to assess firm incentives for innovation in pollution control under different regulatory regimes. Firm incentives for innovation in pollution control are measured as the cost savings in firm abatement costs. These cost savings are in three forms: 1) direct costs of abatement (equipment expenses, operating costs); 2) associated transfer losses (payments made by the firm such as emission taxes); and 3) associated transfer gains (payments made to the firm, such as emission subsidies or patent royalties) ${ }^{8}$. Except for the model of Milliman and Prince (1989), firm incentives for innovating in pollution control are analyzed only for a polluting firm. The innovation is firm-specific and only to be used by the innovating firm to reduce its pollutant emissions. In the analyses, firm incentives for promoting technological change across regulatory regimes are compared and ranked. The central idea behind such analyses is that the cost savings under the different regulatory regimes are indicative for the probability that innovation in pollution control will occur.

Two types of approaches are used within the "firm incentive" literature; those that assume specific cost functions for pollution control (before and after innovation), as in Wenders (1975), Mendelsohn (1984) and McHugh (1985), and those that use general cost functions, as in Zerbe (1970), Downing and White (1986) and Milliman and Prince (1989). ${ }^{9}$ Innovation in pollution control is modelled as a downward shift in the marginal cost curve of emission reduction - not just for some inframarginal units of control. ${ }^{10}$ Polluters are profit maximizers, which means that the polluting firm will pursue innovations at the margin up to the point at which the marginal gains are equal to the marginal costs of innovation. In the models, the regulator is assumed to possess perfect knowledge about the marginal conditions (the marginal cost curves and the damage function), which allows it to realize the socially optimal amount of emission reduction (before and after the innovation is available).

The basic model is presented in Figure 2.1. $M C$ (or $M C_{E R}$ ) is the firm marginal cost curve of emission reduction and $M D$ is the marginal damage curve of emission reduction (which mirrors the social gains from emissions reductions). The marginal cost curve of controlling emissions is usually assumed to be upward sloping at an increasing rate ( $\partial^{2} M C / \partial q^{2}>0$ where $q$ is emission reduction). $M C^{\prime}$ is the new marginal cost curve for abatement. The socially optimal outcome is where the marginal costs of emission reduc-

${ }^{8}$ Milliman and Prince, op cit, p. 251.

"The term "general" for the second type of models is somewhat misleading. The general cost functions for pollution abatement have certain mathematical properties (such as positive first and second derivatives with respect to abatement output). The general models, do not, however, assume an explicit mathematical expression (such as a quadratic function) for the (marginal) cost function of pollution abatement. Since firm incentives for innovation are determined through graphical analysis, they may be also referred to as "graphical models". chapter.

${ }^{10}$ The latter is analyzed in McHugh, op cit, the results of which will be discussed later in this 
tion are equal to the marginal social value of emission reduction, which is at the intersection point of $M C$ and $M D$ before innovation (and of $M C^{\prime}$ and $M D$ after the innovation).

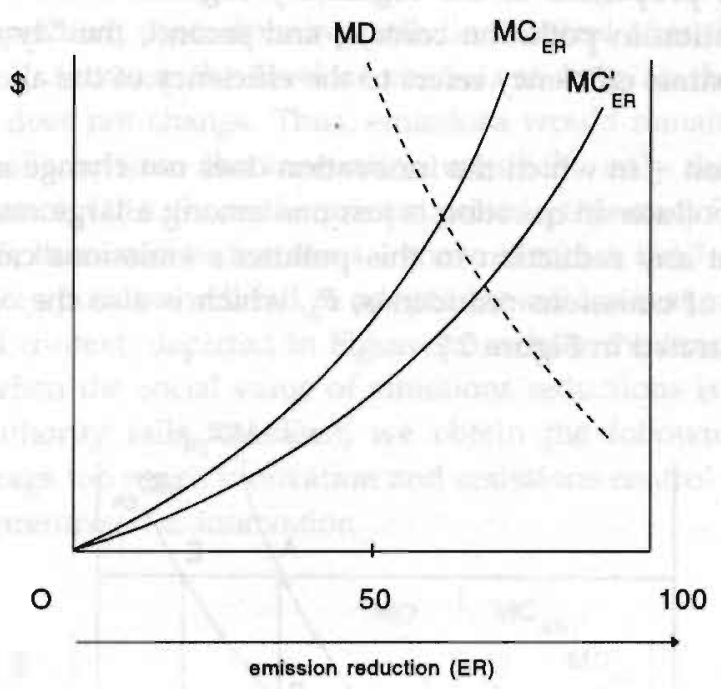

Figure 2.1. Marginal costs and benefits curves from emission reductions. Source: Downing and White (1986)

\subsubsection{The general firm incentive models}

The general firm incentive models of innovation in pollution control do not assume a specific mathematical expression for the marginal cost curve of pollution abatement (before and after innovation). They do, however, assume a few properties of the marginal cost functions of pollution abatement: that it is continuous and upward sloping ( $\partial M C / \partial q>0$ where $q$ is emission reduction). We will discuss the two most comprehensive models in the general firm incentive literature, that of Downing and White (1986) and that Milliman and Prince (1989), which both extend the model of Zerbe (1970).

\section{Downing and White's model}

The model of Downing and White (1986) analyzes the effects of four pollution control methods (effluent fees, emission control subsidies, marketable permits, and direct regulation) in three contexts. First, the situation where the marginal conditions are not changed (i.e., the reduction in the polluter's emissions can be valued at the existing social value of emissions reductions). Second, the situation where the innovation changes marginal conditions, but the control authority fails to adjust. And third, the case where innovation changes marginal conditions and the control authority adjusts properly (which is 
referred to as "ratcheting"). In all cases, it is assumed that the innovating polluter correctly predicts the reactions of the government authority and bases his innovation decisions on that prediction.

Two important properties of the regulatory regimes are investigated: first, the incentives for innovation in pollution control, and second, the "dynamic efficiency" of these incentives. Dynamic efficiency refers to the efficiency of the allocation of resources after the innovation.

The first situation - in which the innovation does not change marginal conditions - applies when the polluter in question is just one among a large number of emitters of the pollutant, so that any reduction in this polluter's emissions can be valued at the existing social value of emissions reductions, $P_{7}$, which is also the optimal effluent fee. This situation is illustrated in Figure 2.2.

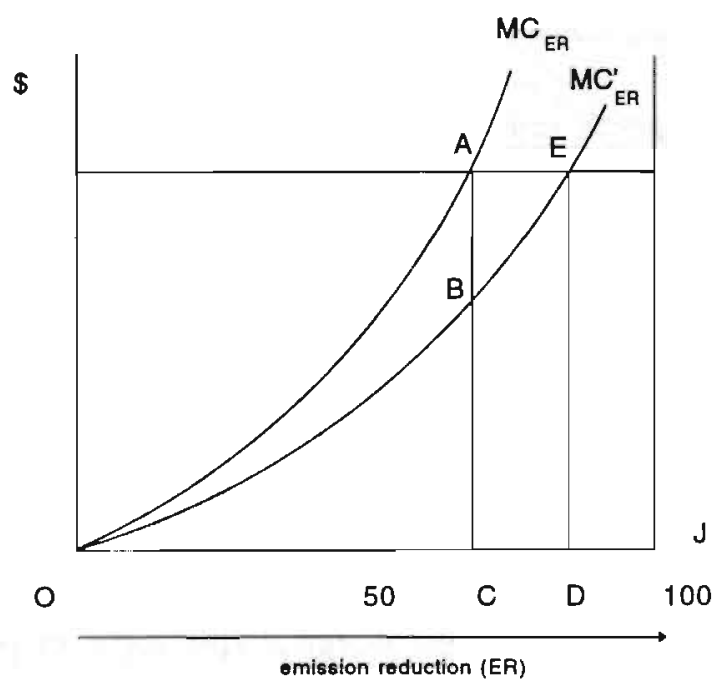

Figure 2.2. Marginal costs and benefits from emission reductions. No change in marginal conditions. Source: Downing and White (1986, p.20).

Under the effluent fee system, a profit-maximizing polluter, contemplating emissions control after the innovation, would pursue control to the point where the marginal cost of control per unit equals the effluent fee per unit - i.e., a control level of $O D$. At that point, the gains to the polluter from the innovation are the sum of the cost reduction at the previous control level $(O A B)$, plus the reduction in effluent fee payment $(A E D C)$, less the extra control costs incurred (BEDC). Thus, the net gains to him are $O A E$. Thus, the innovator gains are equal to the social benefits from innovation. The polluter will pursue innovation to the point of $\triangle R D=\triangle O A E$, where $R D$ is the R\&D costs. 
It can be shown quite easily that an emission reduction subsidy equal to $P_{1}$ and a marketable emission permit sold at $P_{1}$ give results identical to those of the effluent fee: the gains to the profit-maximizing polluter are $O A E .{ }^{11}$ Firm incentives for innovation under direct regulation are different however. Under a regime of direct regulation, the profit-maximizing polluter, contemplating pollution control after the innovation, would have no incentive to increase the level of control, as long as the regulatory level of allowed emissions does not change. Thus, emissions would remain at the level $C J$, and the gains to the polluter from the innovation would be only the cost savings at the existing level of control, $O A B$. Since the private gains in this case, $O A B$, are less than the social benefits, $O A E$, there will be instances - those in which $O A B<R D<O A E$ - where the profit-maximizing polluter will fail to adopt innovations that are socially desirable.

In the second context, depicted in Figure 2.3, where the innovation changes marginal conditions (when the social value of emissions reductions is no longer $P_{1}$ but $P_{2}$ ) but the control authority fails to adjust, we obtain the following results. Economic instruments encourage too much innovation and emissions control and direct regulation provides too few incentives for innovation.

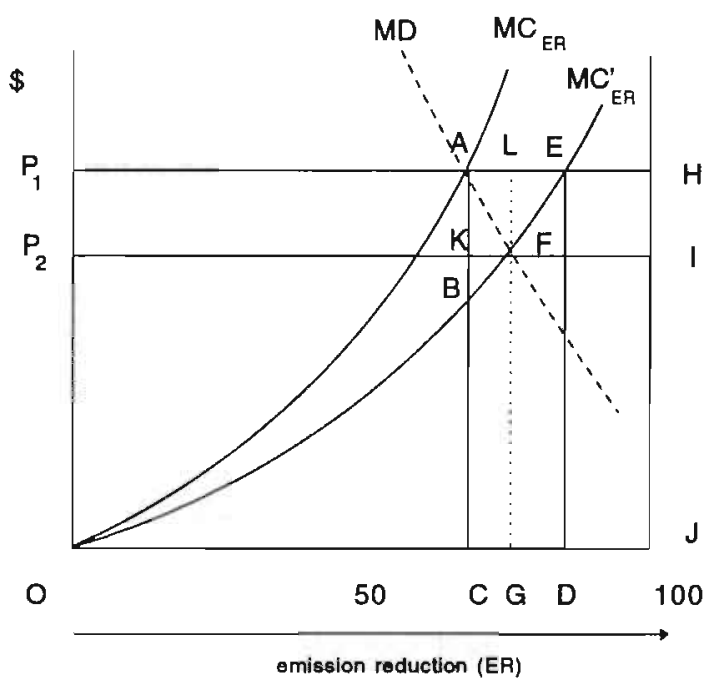

Figure 2.3. Marginal costs and benefits from emission reductions where the innovation changes marginal conditions. Source: Downing and White (1986, p.24).

The reason for this overencouragement of innovation is that the social value of subsequent emissions reductions above $C J$ are worth less to society than $P_{1}$ when the marginal

"The gains to the polluter are cost savings $O A B$, plus the extra revenues from the subsidies or the sale of excess permits $(A E D C)$, less the extra costs of control (BEDC). 
damage curve is downward sloping. This conclusion is reached under that assumption that the innovation is specific to the innovation polluter and cannot be transferred to any other polluter.

In the third context, where the innovation changes the marginal conditions and the pollution control authority makes the socially appropriate adjustments ("ratcheting") the results are somewhat different from those in the second situation. Optimal agency response implies that the effluent fee or the emission reduction subsidy are lowered from $P_{1}$ to $P_{2}$ or that the number of marketable permits is reduced to GJ. In the case of ratcheting, the effluent fee again causes an excessive amount of innovation. This excessive incentive arises because the decreases in inframarginal effluent fee payments are transfers from a social perspective but provide an incentive for the innovator. The excess incentive is muted somewhat if there are other polluters, who reduce their emissions in response to the lower fee.

In contrast, ratcheting results in too little innovation under the regimes of emission reduction subsidies and marketable permits. This is due to the reduction in revenues from subsidies and from selling permits. Direct regulation also provides too little incentives, just as in the two other situations. Again, this deficiency arises because of the inadequate reflection of the social gains from emissions reduction in the incentive structure of the polluter subject to direct regulation. Reactive regulation of this kind provides even less incentive for innovation than do the nonreactive regulations.

The effects on innovation of the four methods of pollution control, in the three contexts, are summarized in Table 2.1. The consequences for emissions control are summarized in Table 2.2 .

$\begin{array}{ll}\text { effluent fees subsidies } & \begin{array}{l}\text { marketable direct regulation } \\ \text { permits }\end{array}\end{array}$

\begin{tabular}{|c|c|c|c|c|}
\hline $\begin{array}{l}\text { No change in marginal } \\
\text { conditions }\end{array}$ & optimal & optimal & optimal & deficient \\
\hline $\begin{array}{l}\text { Change in marginal } \\
\text { conditions; no ratcheting }\end{array}$ & excessive & excessive & indeterminate & deficient \\
\hline $\begin{array}{l}\text { Change in marginal } \\
\text { conditions; ratcheting }\end{array}$ & excessive & deficient & deficient & deficient \\
\hline
\end{tabular}

Table 2.1. Incentives for innovation under various pollution control arrangements. Source: Downing and White (1986, p.28) 


$$
\begin{gathered}
\text { effluent fees subsidies marketable direct regulation } \\
\text { permits }
\end{gathered}
$$

\begin{tabular}{lllll}
\hline $\begin{array}{l}\text { No change in marginal } \\
\text { conditions }\end{array}$ & optimal & optimal & optimal & too high \\
$\begin{array}{l}\text { Change in marginal } \\
\text { conditions; no ratcheting }\end{array}$ & too high & too low & indeterminate & too high \\
$\begin{array}{l}\text { Change in marginal } \\
\text { conditions; ratcheting }\end{array}$ & optimal & optimal & optimal & optimal
\end{tabular}

Table 2.2. Emissions levels under various pollution control arrangements.

Source: Downing and White (1986, p.28)

\section{Milliman and Prince's model}

The model of Milliman and Prince (1989) extends Downing and White's model and that of Zerbe (1970) in several ways. First, they assess firm incentives to promote the entire process of technological change: innovation and technological diffusion. Thus, their model analyses incentives for pollution control innovations in a multi-firm setting in which non-innovating firms may adopt a discovery, which in turn may require regulatory control adjustment in order to maintain optimal efficiency conditions for abatement. Second, the model considers five regulatory regimes: direct control, emission subsidies, emission taxes (fees), free marketable permits and auctioned marketable permits (Downing and White only considered the first four regimes). Third, their analysis assesses incentives to promote optimal agency response via political lobbying or information withholding, for both innovating and non-innovating firms. And finally, the authors examine technological change incentives for both non-patented and patented innovations, and for innovations which occur outside the polluting industry.

The model assumes a large number $(N)$ of identical firms in a competitive industry, each discharging a homogenous emission into a body of water, air or land. In addition, it is assumed that the regulator possesses perfect information on current abatement technology, but lags in perceiving a discovery and political pressures prevent the regulator from imposing optimal agency response prior to the completion of diffusion.

The model of Milliman and Prince is depicted in Figure 2.4. Total industry emission per time period, $E$, is the regulatory control variable. It has a maximum (unregulated) value of $E^{m}$, and is initially set at the socially optimal rate of $E^{*} . M D$ and $M C$ are the industry marginal damages and abatements costs associated with incremental changes in $E$. Innovation (step 1 ) initially shifts the industry marginal cost curve for abatement from $M C$ to $M C^{\prime}$, generating social gains equalling area $E^{m} A B$ at the original level of control; diffusion (step 2) shifts this curve still further to $M C^{\prime \prime}$, creating addi- 
tional gains of area $E^{m} B C$; and optimal agency response (step 3) reduces the emission level from $E^{*}$ to $E^{* \prime}$, with additional gains equalling area $C A D$.

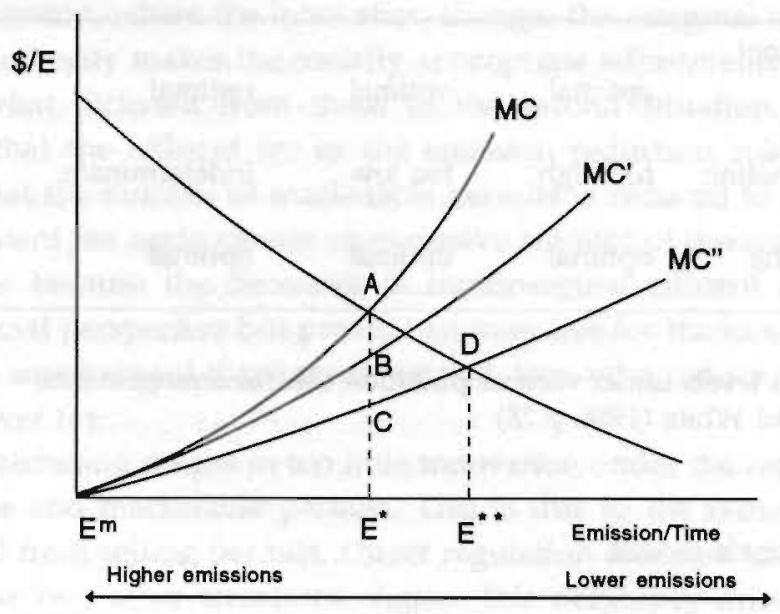

Figure 2.4. Social gains from technological change in pollution control. Source: Milliman and Prince (1989, p.248).

Milliman and Prince go to great pains in assessing and ranking firm incentives to promote technological change in pollution control for polluting innovators, non-innovators, and outside suppliers under two appropriability regimes: with and without patent protection, before and after optimal agency control - for all five regulatory regimes. We will briefly discuss their findings, by looking at the results and the rationale behind them.

The first case that Milliman and Prince consider is that of a non-patented innovation (for which the innovator cannot receive royalties), which is developed by a polluting firm. When there is no diffusion of the innovation and no agency response, the results are equal to those of Downing and White. Direct control leads to smaller cost savings than incentive-based regimes (which all cause equal cost reductions).

The ranking of firm incentives for the innovator however changes when the nonpatented innovation is adopted by other firms. Then the auctioned permits yield higher cost savings due to the lower permit price (the innovating firm has to buy permits), whereas the free permits system results in a (relative) loss to the firm because diffusion reduces revenues from selling permits by driving the permit price down. Under the other regimes, diffusion of the non-patented innovation causes no change in the cost savings for the innovator. All non-innovators that adopt the innovation benefit from cost savings, with auctioned permits providing the highest cost savings. 
The effects of optimal agence response are also analyzed in the model. Optimal agency response imposes industry losses under all regimes, except for emission taxes. This is because optimal agency response reduces the emission tax rate, while under the other regimes optimal agency response means tighter emission standards, lower subsidies, and fewer permits. Hence, the emission tax regime is the only policy which encourages firm promotion of control adjustment. When the potential innovator looks across the entire process of technological change (including optimal agency response), only emission taxes and auctioned permits clearly generate abatement cost reduction for non-patented innovations (under the other regulatory regimes this is uncertain).

The model furthermore analyzes the situation of patented innovation, in which the innovator receives a set percentage of all cost reductions accruing to non-innovators from patent use, including any beneficial changes in transfer gains or losses. For the innovating polluter the rankings are similar to those obtained in the absence of a patent, with auctioned permits and emission taxes providing incentives that are equal to or better than those associated with the other regimes. However, in the regimes other than emissions subsidies, the non-innovators may oppose control adjustment whereas the innovator favours such a step.

The (patented) innovation may also be supplied by an outside supplier instead of a firm in the polluting industry. When the innovator is an outside supplier firm, diffusion rankings are similar to previous results. In this case, however, control adjustment is favoured by the outside firm innovator under direct control and free permits, may be opposed with auctioned permits, and is definitely opposed under emission taxes. In contrast to the results for an industry innovator, overall innovator gains from the entire process of technological change are unambiguously positive for under all regimes, as the outside firm earns patent royalties without paying any direct costs or transfer payments.

A summary of relative rankings and the attitudes of innovators and non-innovators towards optimal agency response is given in Table 2.3. It shows that relative rankings under emission taxes and auctioned permits are equal to, or higher than, rankings under direct controls, free permits, and emission subsidies in all cases, except for control adjustment with a non-industry innovator. Moreover, only emission taxes and auctioned permits clearly reward positive gains to an industry innovator from the entire process of technological change (see Table 2.2). Thus, the analysis suggests that emission taxes and auctioned permits are better facilitators of technological change.

As regards to the question: "Which regime is more attractive from the vantage point of dynamic efficiency, emission taxes or auctioned permits?", the authors note that emission taxes have the important advantage that they induce firm promotion of control adjustment, so the social gains from this step may be more rapidly realized, and firmregulator conflicts could be reduced. On the other hand, control adjustment may not be favoured by other parties. Since adjustment means lowering the tax, this action tends to increase emissions and may be strongly opposed by environmental special interest groups and the regulatory agency. Control adjustment may also reduce emission tax revenues, thus fostering further regulator resistance. 
regulatory regime

\begin{tabular}{lllll}
\hline direct & emission & free & auct. & emission \\
controls & subsidies & permits & permits & taxes
\end{tabular}

\section{Innovation}

\section{Diffusion}

2. Innovator, non-patent

3. Non-innov, non-patent

4. Innovator, patent

5. Non-innov, patent

6. Outside firm, patent

Optimal agency response

7. Industry, non-patent

8. Con. adj. stance

9. Innovator, patent

10. Con. adj. stance

11. Non-innov, patent

12. Con. adj. stance

13. Outside firm, patent

14. Con. adj. stance
5

$\begin{array}{ll}2 & 2 \\ 4 & 2 \\ 4 & 2 \\ 4 & 2\end{array}$

$\begin{array}{cc}2-5 & 2-5 \\ \text { oppose } & \text { oppose } \\ 1-4 & 5 \\ \text { uncertain } & \text { oppose } \\ 2-5 & 2-5 \\ \text { oppose } & \text { oppose } \\ 1 & 4 \\ \text { favour } & \text { oppose }\end{array}$

1

$\begin{array}{ll}2 & 5 \\ 2 & 4 \\ 2 & 5 \\ 2 & 4 \\ 2 & 4\end{array}$

5
4
5
4
4

2-5

oppose

$1-4$

uncertain uncertain uncertain

2-5

oppose

1

favour
1

2

2

2

2

2

$\begin{array}{cc}2-5 & 1 \\ \text { oppose } & \text { favour } \\ 1-4 & 1-4 \\ \text { uncertain } & \text { uncertain } \\ 2-5 & 1 \\ \text { oppose } & \text { favour } \\ 3 & 4 \\ \text { uncertain } & \text { oppose }\end{array}$

Table 2.3. Summary of relative rankings of the incentives to promote technological change in pollution control and the attitude towards optimal agency response. Source: Milliman and Prince (1989, p.257).

In contrast, under auctioned permits, significant innovator gains will occur more rapidly (from diffusion) and are not dependent upon control adjustment. Proper emissions tightening still allows for positive innovator gains from the entire process of technological change. Optimal agency response (in the form of fewer permits) will also be favoured by envirommental special interest groups and possibly the public agency. This leads Milliman and Prince to conclude that depending upon the particular policy setting being examined, the incentive mix of auctioned permits may be superior to the incentives generated by emission taxes.

\subsubsection{The specific firm incentive models}

After having discussed the general firm incentive models, we now consider the innovation models that assume explicit mathematical expressions for the costs of pollution abatement. 


\section{Wenders' model}

Wenders (1975) analyzes the impact of improvement in pollution abatement technology on the costs of a polluting firm producing under three pollution control regimes: a tax per unit of pollution emitted (where tax is used as another word for fee or charge), a subsidy per unit of emission reduction and finally emission standards. As in Downing and White (1986), innovation in pollution control is firm-specific, the firm tries to minimize its costs (abatement costs plus tax payments minus any subsidies) and the pollution control agency possesses full information about the marginal cost and damage functions.

The costs of abatement depend on the percentage of pollution abated, the amount of pollution emitted before any abatement and the level of technology, which is represented by parameter $\alpha$. The cost of abatement is assumed to rise at an increasing rate with percentage abatement and innovation in pollution control is modelled as a set percentage change in the parameter $\alpha$. Thus, it is assumed that the pollution abatement curve shifts downward as a result of "a lump of technological change in pollution abatement".

Two kinds of situations are considered in the analysis of Wenders: the case in which the pollution control board does not change either the emission standard or the tax-subsidy rate as a result of the innovation, and the case of control adjustment. As in the general model of compliance innovation discussed before, both taxes and subsidies offer more inducement to innovate than the emission standard approach - the economic rewards being equal under emission taxes and subsidies. Furthermore, if the pollution control board reacts to the improvement in abatement, then the inducement to innovate for the firm operating under the corrective tax becomes greater than the inducement for firms operating under the subsidy or the emission standards, which is exactly the same result found in Downing and White (1986) and Milliman and Prince (1989). The reason for this is easy to comprehend: although the analysis assumes a specific cost abatement curve, this cost curve satisfies the properties of the general cost curve, and, as in the general models, innovation is modelled as a downward shift of the (whole) marginal cost curve.

Unlike the former analyses, however, Wenders also considers the case where the firms can change the form of the cost abatement function, besides its position. If firms are able to control the direction of their $\mathrm{R} \& \mathrm{D}$, and thus change the shape of the pollution abatement curve, firms operating under either emission controls or a corrective subsidy will prefer innovations which raise the established level of pollution abatement as little as possible, whereas firm operating under a tax will prefer the kind of technological change that raises the optimal level of abatement as much as possible.

\section{McHugh's model}

McHugh (1985) analyzes the implications of technological indivisibilities (or lumpiness) for the dynamic efficiency of tax-based, economic instruments. While in the former models assumed that innovation in pollution control would shift the marginal cost curve 
of pollution abatement downward, and that the cost-minimizing firms could control its emissions up to the point where the emission charge equals the marginal control costs, here pollution control technologies are discrete, and identified with a particular control efficiency. McHugh divides technological innovations in pollution abatement into two types: "technology stretching" innovation and "inframarginal cost-reducing" innovations. "Technology stretching innovations are those which lead to a higher proportion of potential emissions controlled at an acceptable cost. Inframarginal innovation are those which control a lower proportion of emissions than the currently employed control, but at a cost low enough to induce firms to switch to a control technique which controls a lower amount of emissions."12

McHugh analyzes the possibility of cost-inefficiencies when technological change in pollution control is of the inframarginal type. In his model there are two sectors: the affected sector, in which the inframarginal technological innovation occurs, and an unaffected sector. Given any existing tax rate or permit price, the firms in the first sector may find it more attractive to use the new inframarginal technology and reduce the level of emissions it controls, since the marginal cost of the presently employed technology has increased above that tax rate. This may induce the pollution control authorities to raise the level of the tax to meet the emissions reductions goal. As a result of this, total industry's compliance costs (resource plus transfer costs) may increase, which means that a tax-based environmental policy may lead to dynamic inefficiencies.

\subsubsection{RED models of innovation in pollution control}

We will now describe the R\&D models of pollution control: Magat (1978) and Mendelsohn (1984). In these models, the optimal amount or rate of innovation in pollution abatement technology can be calculated.

\section{Magat's model}

Magat's model (1978) analyzes the effects of two types of pollution control policies (effluent taxes and effluent standards) on the path of technological change chosen by a firm which produces an effluent by-product. In this model, the firm may invest resources to improve its abatement technology, its production technology, or both. The purpose of the analysis is to extend the static analysis of effluent taxes and standards: to include their effects on both the rate and the direction of technical advance.

The model considers the behaviour of a price-taking firm which employs a single variable input to produce a single product. The production process results in an effluent byproduct, whose abatement requires the use of the variable input. The firm also engages in an $R \& D$ programme to improve its current technology of output production and effluent abatement. Magat advances a Kennedy-based model of induced, "product-

${ }^{12}$ McHugh, op cit, p.59. 
augmenting" technical advance in which R\&D effort is allocated between technological advancement in output production and effluent abatement. In the model, improvements in the output production and effluent abatement technologies are represented by changes in the output production augmentation parameter $A$ and in the effluent abatement augmentation parameter $B$ along an innovation possibilities frontier. ${ }^{13}$ For each level of R\&D spending this frontier describes the tradeoffs available between improving output production technology and advancing effluent abatement technology: a high decrease in $A$ (which reflects a great improvement in output production) is only possible if the increase in $B$ (the improvement in effluent abatement technology) is low, and vice versa. Magat's figure of the innovation possibilities frontier is in Figure 2.5. ${ }^{14}$

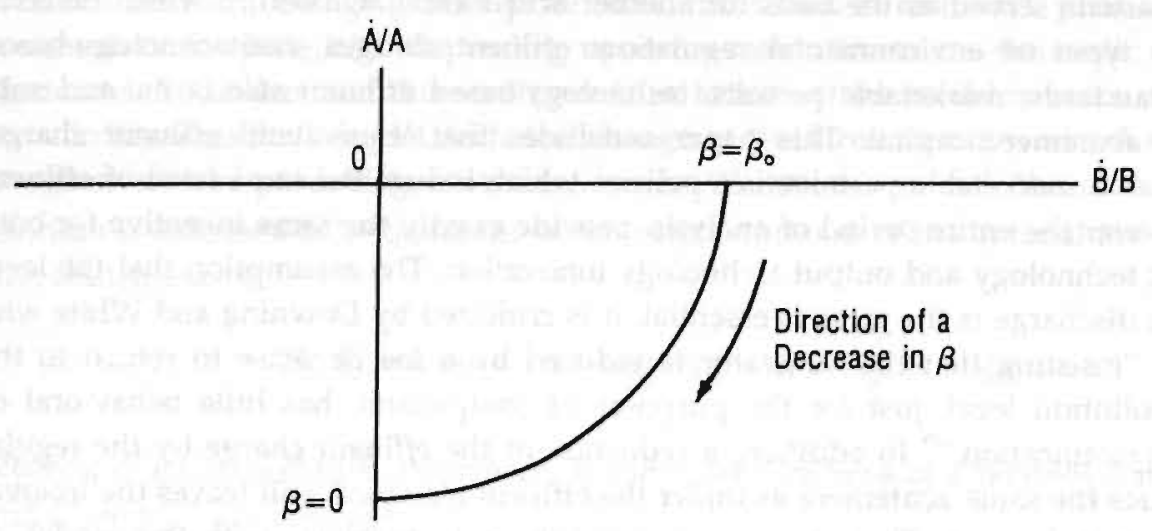

Figure 2.5. The innovation possibilities frontier. Source: Magat (1978).

Magat analyzes the time path of production, effluent discharge and the rate and bias of $R \& D$, both under a constant effluent tax and a constant effluent standard. We will not go into the details of the model, but only give the main results. Both the constant tax and standard will induce a "typical" firm to undertake an expanding R\&D programme. The

\footnotetext{
${ }^{13}$ In fact, Magat's model is the Kamien and Schwartz model (1969) of induced factor augmenting technical change, except that the input and output roles have been reversed (cf. M.I. Kamien and N.L. Schwartz, 1969, Induced Factor Augmenting Technical Progress from a Micro Economic Viewpoint, Econometrica 37(4): 668-684.

${ }^{14}$ Improvements in the output production and effluent abatement technologies are represented by a decrease in $A$ and an increase in $B$, respectively. This follows from the observations that: i) for the same labour and effluent rate a lower level of $A$ allows a higher output rate, and ii) for the same labour and output rates a higher level of $B$ allows a lower effluent discharge rate (p.4). Parameter $\beta$ indicates the 'direction' or 'bias' of technical change.
} 
allocation of $R \& D$ between output augmentation and effluent abatement augmentation depends on the elasticity of transformation $\sigma$, which measures the ease of substituting labour between producing output and abating effluent. ${ }^{15}$ "When labour substitutability is difficult $(\sigma<1)$ the constant standard induces a direction of technical advance which converges to a pattern of augmenting both technologies, whereas the constant tax induces a pattern of ever-increasing (relative) allocations to output technology augmentation and ever-decreasing (relative) allocation to effluent abatement technology augmentation. On the other hand when labour substitutability is easy $(\sigma>1)$ the constant tax induces a pattern of ever-increasing (relative) allocations to effluent abatement technology augmentation while the constant standard leads to a direction of technical advance which diverges toward relatively more output technology augmentation or diverges toward relatively more effluent abatement technology augmentation (depending upon the initial value of the direction)". ${ }^{16}$

The article served as the basis for another article (Magat, 1979) in which he compares five types of environmental regulation: effluent charges, nontechnology-based effluent standards, marketable permits, technology-based effluent standards, and subsidies for abatement capital. This paper concludes that 'equivalent' effluent charge, standards and marketable permits, i.e., policies which induce the same level of effluent discharge over the entire period of analysis, provide exactly the same incentive for both abatement technology and output technology innovation. The assumption that the level of effluent discharge is the same is essential. It is criticized by Downing and White who write that "insisting that the innovator is induced by a fee decrease to return to the original pollution level, just for the purposes of comparison, has little behavioral or normative justification. ${ }^{177}$ In addition, a reduction of the effluent charge by the regulator to induce the same abatement as under the effluent standard, still leaves the innovator with a transfer gain. These however are not the only problems with this model, as we will see in the next section.

A new element, not discussed before by the other authors, is the distinction between technology-based and nontechnology-based effluent standards. Nontechnologybased effluent standards create a stronger incentive for abatement technology innovation than technology-based effluent standards, unless the benefits from the use of new abatement technologies can be appropriated by their owners and unless regulatory agencies quickly revise their regulations based on the new abatement technologies.

1. The elasticity of transformation is defined as the reciprocal of a proportional change in the ratio of the marginal products of labour in producing the two products (output and effluent) with a proportional change in the output-effluent ratio (p.6).

to Magat, op cit, pp. 21-22.

"Downing and White, op cit, pp. 22-23. 


\section{Mendelsohn's model}

The model of Mendelsohn (1984) extends Martin Weitzman's analysis of regulation under uncertainty. ${ }^{18}$ Weitzman's model analyzes the efficiency of quantity and price rules for the situation where the regulator is uncertain about the costs and benefits of regulation. The model shows that when the regulator is uncertain about the locus (but not the slope) of the linear marginal cost curve, quantity regulations are likely to be more efficient than price regulations if (and only if) the marginal cost curve is relatively flat (as compared to the slope of the linear damage function). This contradicts the traditional economist's argument that price rules, such as emission taxes in environmental policy, are more efficient than quantity rules.

Mendelsohn adds endogenous technical change to Weitzman's model of regulation under uncertainty. Mendelsohn finds that quantity rules tend to encourage more efficient levels of technical change. Under price rules, firms tend to overreact, producing either too much or too little R\&D depending upon the realization of the stochastic element of the model. To understand this result, we have to look at the model in more detail.

In Mendelsohn's model, technical change is measured as a downward shift in the marginal cost of producing abatement. As in Weitzman's model, the abatement cost function is assumed to be quadratic in the neighbourhood of the optimal level of pollution abatement $\hat{q}$

$$
C(q, \theta)=a_{0}(\theta)+\left(C^{\prime}+\alpha(\theta)\right)(q-\hat{q})+\frac{C^{\prime \prime}}{2}(q-\hat{q})^{2}
$$

where $q$ is actual pollution abatement, $a_{0}$ and $\alpha$ are functions of a random component $\theta$, and $C^{\prime}$ and $C^{\prime \prime}$ are constants.

The functional form for the total abatement cost function implies that the marginal cost function of pollution abatement is linear (as in Weitzman's analysis). Similarly, the total benefit function is assumed to be quadratic in the neighbourhood of $\hat{q}$ and, just as the cost function, contains a stochastic element $(\eta)$ :

$$
B(q, \eta)=b_{0}(\eta)+\left(B^{\prime}+b_{1}(\eta)\right)(q-\hat{q})+\frac{B^{\prime \prime}}{2}(q-\hat{q})^{2}
$$

It follows directly from this equation that the marginal benefit function $\partial B(q, \eta) / \partial q$ is linear - just as it follows from the quadratic form of the cost function that the marginal cost function is linear. It is assumed that this (linear) marginal benefit function, and also the marginal cost function, are known to the regulator except for an additive error term (with mean zero).

${ }^{18}$ Martin L. Weitzman, 1974, Prices vs. Quantities, Reoiew of Economic Studies, 16: 477-549. 
Technical advances $R D$ is measured as a downward shift in the marginal cost of producing abatement. The cost of research and development is assumed to be quadratic in $R D$ :

$$
F(R D)=f R D^{2}+k(\gamma) R D
$$

After having specified the cost and benefit functions, we now consider the rules chosen by the regulator and the response of the firm to these rules. Mendelsohn's model assumes that the quantity and price rule chosen by the regulator equate the expected marginal costs and benefits of pollution abatement. In response to these rules, and the realization of the stochastic terms, the firm is assumed to minimize its costs. It can minimize its abatement costs either by doing R\&D and by choosing its abatement output (the latter, of course, is only possible under the price rule). Differentiating the total cost function with respect to $R D$, setting the derivative equal to zero, gives the optimal amount of R\&D:

$$
R D=\frac{q-\hat{q}-k(\gamma)}{2 f}
$$

Equation (4) demonstrates that the optimal amount of R\&D depends on the realization of the stochastic element in the R\&D cost function and the firm's optimal level of abatement. In the case of a quantity rule (emission standard), $q$ equals $\hat{q}$, so the optimal amount of $R D$ depends on $k(\gamma)$ and $f$ only. ${ }^{19}$ Under the price rule (an emission tax which equals the expected marginal costs) the firm also chooses its abatement output (besides the amount of R\&D). This optimal quantity $q$ minimizes total costs (the sum of abatement costs and R\&D costs). Substitution of the optimal amount of R\&D in the cost function and minimization of the cost function with respect to $q$, gives the optimal $\tilde{q}$ under the price rule: ${ }^{20}$

$$
\tilde{q}=\hat{q}-\frac{\alpha(\theta)+k(\gamma) /(2 f)}{C^{\prime \prime}-1 /(2 f)}
$$

The optimal $q$ under the price rule, $\tilde{q}$ depends on the realization of the stochastic term in the abatement cost function $(\theta)$ and in the R\&D function $(\gamma)$, and further on the size of $f$ and $C^{\prime \prime}$. Thus, the firm is assumed to know the actual costs of pollution abatement and research and development, which is quite a strong assumption, especially for $R \& D$. The expected relative advantage $\Delta_{T}$ of the ex ante price rule over the quantity rule is defined as:

${ }^{19}$ Note that the firm will only undertake $R \& D$ under the quantity rule if $k(\gamma)$ is negative (a negative $k(\gamma)$ implies that $R \& D$ is relatively cheap).

${ }^{20}$ And not: $q=q-\frac{\alpha(\theta)+k(\gamma) /(2 f)}{C^{\prime \prime}-(1 / 2) f}$ as in Mendelsohn. 


$$
\Delta_{T}=E[B(\tilde{q}, \eta)-C(\tilde{q}, \theta, \gamma)-(B(\hat{q}, \eta)-C(\hat{q}, \theta, \gamma))]
$$

It can be shown that the expected advantage of prices over quantities $\left(\Delta_{T}\right)$, given uncertain costs and benefits function of pollution abatement and uncertain R\&D cost curves, is described by the following expression: ${ }^{21}$

$$
\Delta_{T}=\frac{\left(B^{\prime \prime}+C^{\prime \prime}-1 /(2 f)\right)}{2\left(C^{\prime \prime}-1 /(2 f)\right)^{2}}\left(\sigma^{2}+d^{2} /\left(4 f^{2}\right)\right)
$$

To understand this result, we have to go back to Weitzman's result (where there is no technical change). Weitzman's coefficient of the comparative advantage of prices over quantities is:

$$
\Delta_{T}=\frac{\left(B^{\prime \prime}+C^{\prime \prime}\right)}{2\left(C^{\prime \prime}\right)^{2}} \sigma^{2}
$$

Without technical change, the expected net advantage of prices over quantities is positive whenever the slope of the marginal cost function, $C^{\prime \prime}$ (which is greater than zero), exceeds the slope of the marginal benefit function, $B^{\prime \prime}$ (which is less than zero). Thus, price rules are optimal when the marginal cost curve is relatively steep, whereas quantity rules are to be preferred when the marginal benefit curve is relatively steep. Weitzman's result also states that the only uncertainty that matters to the regulator who tries to maximize the expected efficiency is the regulator's uncertainty about the true cost function. The uncertainty about the benefits from pollution control $(\eta)$ does not matter (under the extra assumption that the random terms of the costs and benefits function are uncorrelated). This is one of the most important theorems of the economic theory of regulation. ${ }^{22}$

After having described the (correct) model results, it is now possible to interpret Mendelsohn's result concerning the (expected) advantage or disadvantage of price rules (as compared with quantity rules) when there is endogenous technical change. Endogenous technical change alters the coefficient of comparative advantage in favour of quantity rules. Quantity rules tend to encourage more efficient levels of research and development than price rules when the benefits of technical change depend upon uncertain

${ }^{21}$ This result differs from the result given by Mendelsohn:

$$
\Delta_{T}=\frac{\left(B^{\prime \prime}+C^{\prime \prime}-(1 / 2) f\right)}{2\left(C^{\prime \prime}-(1 / 2) f\right)^{2}}\left(\sigma^{2}+d^{2}\right)
$$

${ }^{22}$ Adar and Griffen (1976) have derived the same result as Weitzman. Their analysis directly addresses the choice of policy control instruments, whereas this is a special case of Weitzman's analysis. Furthermore, the linear form for the marginal costs and benefits functions does not follow from the quadratic form of the total costs and benefits functions, but is assumed directly. (Zvi Adar and James M. Griffin, 1976, Uncertainty and the Choice of Pollution Control Instruments, Journal of Enoironmental Economics and Management, 3: 178-188). 
abatement levels. Uncertain R\&D costs, on the other hand, favour neither tool ex ante, but only increase the importance of choosing the better tool.

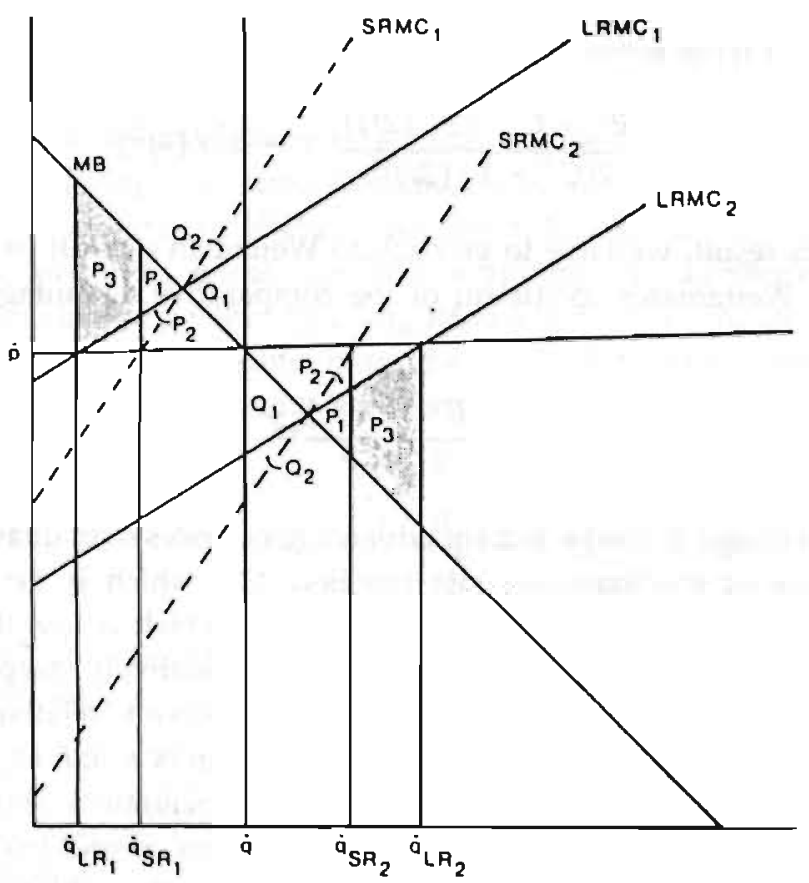

Figure 2.6. The efficiency of price and quantity rules under uncertainty when there is endogenous technical change. Source: Mendelsohn (1984, p.206).

Mendelsohn also provides a more intuitive explanation of the model's results, which is depicted in Figure 2.6. The firm is limited to just one of two equally probable short-run marginal cost curves $S R M C_{1}$ and $S R M C_{2}$. If there is no technical change, the short-run marginal cost curve is also the long-run marginal cost curve. The regulator choosing price and quantity rules, which equate marginal benefits with expected marginal costs, selects either $\hat{q}$ or $\tilde{p}$ Given the quantity rule, the firm responds by producing $\hat{q}$. Without technical change, this output yields an ex post loss of $Q_{1}+Q_{2}$. With technical change, the ex post welfare loss drops to $Q_{1}$. Given the price rule, the firm responds by producing $\bar{q}_{S R_{1}}$ or $\tilde{q}_{S R_{2}}$ without technical change and $\tilde{q}_{L R_{1}}$ or $\tilde{q}_{L R_{2}}$ with technical change. Without technical change, the ex post welfare loss under the price rule is $P_{1}+P_{2}$. Comparing the two rules without technical change, prices are preferred if $Q_{1}+Q_{2}>P_{1}+P_{2}$. Thus, the relationship depends on the relative slope of the marginal benefit and cost curves. If the marginal cost curve is relatively steep, prices are preferred; if the marginal 
benefit curve is relatively steep, the quantity rule is to be preferred (the Weitzman result).

Figure 2.6 shows that technical change produces cost reductions of $Q_{2}$ and $P_{2}$ for quantity and price rules, respectively. The size of $Q_{2}$ and $P_{2}$ depend on the relative slopes of the marginal cost and benefit curves. Technical change, however, induces an additional welfare loss with price rules, $P_{3}$. Thus, firms overreact to the price rule, producing too much or too little abatement output, which in turn stimulates too much or too little R\&D. This leads Mendelsohn to the conclusion that, over the long run, the quantity rule induces more efficient levels of technical change. ${ }^{23}$

\subsection{A Critical Assessment of the Innovation Models}

In the previous section, we gave an overview of different models of the impact of pollution control instruments on innovation in pollution control. The outcome of the firm incentive models is that economic instruments (effluent fees or emissions taxes, emissions reduction subsidies and tradeable pollution permits) offer more inducement to innovate than direct regulation. Under economic regulation, the innovator is able to exploit an extra gain by reducing its emissions. This is because the marginal benefits of such extra emissions reductions (which are in the form of a reduction of tax payments, subsidies for emission reduction or revenues from selling permits) exceed the marginal costs of emission reduction. Under direct regulation there is no incentive for the polluter to reduce emissions beyond the original level of emissions control, because the marginal benefits to the firm of such a step are zero. These results are under the assumption that the innovation in pollution control allows for emissions control at lower marginal costs for each level of emissions control, which may be too strong an assumption. Moreover, this result is derived under the assumption of perfect information. When there is uncertainty about the costs and benefits from pollution abatement, these results may not hold.

This section provides a critical discussion of the models in section 1 . Our criticism should not be taking to mean that we oppose formal analysis, or that we think that the earlier-described models are of little use. On the contrary, we view the existing models as being helpful in understanding the important and complex technology-environmental policy relationship, precisely for what they are meant to do: to explore the logical implications of certain assumptions about technology, market conditions and economic behav-

${ }^{23}$ It should be noted that Mendelsohn's figure is not quite correct. In the figure, the long-run marginal cost curve (i.e. the marginal cost curve after innovation) is the same for both regimes. The marginal cost curve after innovation under the price rule is: $\frac{k(\gamma)}{2 f}+C^{\prime}+\alpha(\theta)+\left(C^{\prime \prime}-\frac{1}{2 f}\right)(q-q)$ whereas under the quantity rule it is: $\frac{k(\gamma)}{2 f}+C^{\prime}+\alpha(\theta)+C^{\prime \prime}(q-q)$. Since $f>0$, the marginal cost curve under the price rule is less steep than under the quantity rule. 
Our criticisms of the models amount to six issues: 1) the neglect of innovation in pollution control by outside suppliers, the neglect of innovator gains from diffusion, and the neglect of other forms of environmentally beneficial technological change, 2) the representation of pollution abatement technology in innovation models, 3) problems of implementation and optimal design of pollution control instruments, 4) the reciprocal nature of the regulator-innovator relationship, 5) the representation of the firm, and 6) the assumed tradeoff between innovation in pollution control and innovation in production technology.

\subsubsection{The neglect of innovation by outside suppliers and innovator gains from diffusion}

With the exception of the model of Milliman and Prince (1989), innovation by special outside suppliers and diffusion of pollution control technologies is not considered in the theoretical literature. This is a serious limitation because innovations in pollution control are often (if not mostly) supplied by special outside suppliers, and innovator gains usually result from the sale of the new technology rather than from lower abatement costs for the innovator. In relation to this, the dynamic efficiency and social benefits of the compliance innovation depends on the widespread employment of the innovation and is based less on the cost gains of the individual innovator. Below, we will pay attention to these aspects and explore their implications for the choice of pollution control instruments.

As mentioned before, the model of Milliman and Prince is the only model that analyzes the incentives for an outside supplier firm to develop and supply the innovation. These incentives are compared to those of a polluting firm. Milliman and Prince find that without control adjustment by the regulator, the relative ranking of innovator incentives for an outside firm is similar to that for a polluting innovator that holds a patented discovery. Auctioned permits and emission taxes and subsidies provide the strongest incentives for the innovator, and direct regulation and free permits the lowest. However, this situation changes after control adjustment. Under optimal agency response, firm incentives for the outside supplier are highest under direct control and free permits, whereas for the polluting innovator no conclusions can be drawn (except that emissions subsidies provide the lowest incentives for innovation). Thus, if the control agency does not know who is in the best position to develop an innovation - the polluter or an outside supplier - no qualitative conclusions can be drawn with respect to the best policy instrument to stimulate innovation in pollution control.

Another aspect of technical change that is typically neglected in the models is the technological diffusion and innovator gains from selling the technology to other firms. The only model that considers innovator gains from the technological diffusion of the technology is Milliman and Prince. It does not consider however the rapidity of the technological diffusion and the factors responsible for the time-intensive uptake of the innovation. Although this is perfectly understandable, the technological diffusion of innovations is an subject of its own, the policy instruments may influence the timing of 
purchases, and affect innovation gains and the dynamic efficiency. If the diffusion process is more rapid and the innovation is widely applied, innovator gains will be high. In this respect, emissions standards may provide stronger innovator gains than emission taxes because they leave polluters less choice with respect to emissions reductions and technologies for achieving this. However, if the standards are based on available technologies, which is usually the case, then they will provide very little innovator gains. A discussion of the diffusion process of environmental technologies under the various regulatory regimes is in chapter 5.

Finally, the innovation models only analyze innovations in pollution control technology aimed at reducing pollutant emissions of production. The development of environment-friendlier materials and consumer products is not discussed, although both types of innovations constitute important categories, which may be promoted or obstructed by different factors. Demand for cleaner consumer products, for instance, depends less on government regulation (despite the free-rider problem) and may be obstructed by specific problems such as lack of information and unfavourable appropriability conditions (see chapter 8 ).

\subsubsection{The representation of pollution control technology}

In the graphical models of Zerbe (1970), Downing and White (1986) and Milliman and Prince (1989), and also in the model of Wenders (1975), innovation in pollution control is modelled as a downward shift in the marginal cost curve of pollution abatement. In these models, innovation in pollution abatement technology allows the polluting firm to reduce its marginal abatement costs for each level of emissions control. This is a very strong assumption about the nature of technology which is seldom fulfilled in real life. As pointed out by McHugh:

the unique aspect of the equipment used to control emissions, giving rise to potential cost decreases in the face of technological innovation, is that each control technology is typically identified with a particular "control efficiency", or percentage of emissions which that technology will control. Control efficiencies are embodied in the design of the equipment and cannot be altered in any perceptible way by the devotion of additional labour or material inputs to further control. ${ }^{24}$

The way in which innovation in pollution control technology is modelled is not trivial: it has implications for the innovation effects of environmental policies and the efficiency of the various control regimes.

For instance, McHugh himself demonstrates that if technological innovation is of the inframarginal cost-reducing type that allows for cost reductions only at a lower level of control, that total private costs for industry may be higher if firms have different cost

${ }^{24}$ McHugh, op cit, p.59. 
abatement functions. This illustrates the limitations of the microeconomic concept of a representative firm used in the models above.

Mendelsohn's conclusion about the dynamic efficiency of quantity and price rules also critically depends on the way in which innovation in pollution control is modelled. If technical change is of the inframarginal type instead of the "technology-stretching" type, the conclusions about the optimality of price and quantity rules are exactly the opposite. If $L R M C$ in Figure 2.6 is the marginal abatement cost curve before technical change and $S R M C$ represents the cost curve with technical change, price rules instead of quantity rules will tend to produce more efficient levels of pollution abatement. Therefore, it is important to know how innovation in pollution control is likely to change the abatement cost function. For instance, is innovation in pollution control of the technology-stretching type or of the inframarginal cost-reducing type? Little empirical research has been done on this issue. Casual observation, however, suggests that innovation is typically of the technology-stretching type, with a higher control efficiency. But this may be due to the use of direct regulation (in the form of emission standards) by pollution control authorities - regulations that have become more strict over the years. If effluent fees had been used instead of emission standards, more technologies of the inframarginal cost-reducing type, which offer cost savings at lower levels of abatement, would have been available and adopted by polluting firms.

Similarly, Wenders (1975) argues that if the innovating firm can change the form of the cost of abatement function, then the firm may prefer different kinds of technological change. Under a tax regime, a polluting firm will prefer the kind of technological change that raises the optimal level of abatement as much as possible (which helps reducing its effluent tax payments). This suggests that the regulatory regime may affect the choice of particular pollution abatement technologies.

This issue is believed to be important, since in practice there are usually many technological solutions for reducing pollutant emissions. Not only do these technological solutions differ in a technical sense, but they also differ in terms of costs, control efficiency and environmental impact. In this respect, an important distinction is that between "end-of-pipe" technologies and "process-integrated" technologies. Process-integrated changes prevent pollutants from arising, whereas end-of-pipe technologies prevent the release of pollutants to air, water or land. In the past, in response to environmental regulation, especially end-of-pipe technologies were developed and used. ${ }^{25} \mathrm{~A}$ disadvantage of end-of-pipe technologies is that they usually lead to a transfer of environmental problems. This is because the treatment and isolation of pollutants by these technologies result in hazardous waste material, which creates an environmental problem of its own.

$\therefore$ According to Hartje and Lurie, the share of end-iff-pipe technologies in pollution control investment in Western Germany in the $1975-81$ period was between 67 and $78 \%$. In the United States, in the 1973-82 period, it was between $76 \%$ and $81 \%$ (Volkmar J. Hartje and Robert L. Lurie, 1985, Research and Development Incentives for Pollution Control Technologies, International Institute for Environment and Society (IIUG), Wissenschaftszentrum Berlin, p.14). 
Thus, it becomes important to investigate the factors that determine the choice of end-of-pipe technologies instead of process-integrated technologies (including in-process recycling); and, more specifically, if, and in what way, this choice is affected by environmental policy. This issue is investigated in Nentjes' model described in section 2 of the next chapter and in Hartje and Lurie (1984). According to Hartje and Lurie, government subsidies for pollution control (special depreciation allowances and pollution control bonds) favoured end-of-pipe systems, because they require easily recognizable pollution control technologies. One may add to this that the typical "norm" policy of the government, based on available, relatively well-known end-of-pipe technologies, also favoured the selection of end-of-pipe technologies. If economic instruments instead of direct regulation had been used, the share of process-integrated technologies probably would have been higher, since they leave the polluter more freedom in technology choices and the timing of investments.

To recapitulate, the results about the impact of various regulatory regimes on firm incentives to innovate in pollution abatement technologies very much depend on the modelling of innovation in pollution control. As we saw, if the technology is of the inframarginal type instead of the technology-stretching type, the conclusions may completely change. Furthermore, the models overlook that firms have a choice with respect to different types of pollution abatement technologies (process changes and end-of-pipe technologies), and that this choice is affected by the regulatory regime.

\subsubsection{Problems of implementation and design of pollution control instru- ments}

In the innovation models there are not problems of implementation and design of pollution control instruments. The regulator knows the optimal level of emissions control, which may be achieved by any instrument. Of course, we do not live in such a world: in practice, it is impossible for the regulator to calculate the optimal emmission fee, subsidy or quotum due to imperfect knowledge of the costs and benefits of emissions control. As a partial solution to this problem, the control agency may decide to choose an instrument with "fail-safe" properties. Price instruments may be preferred if the risk of high costs is relatively high and quantity rules may be preferred in situations where there is a danger of sudden and dramatic environmental change (the Weitzman result).

The implementation of policy instruments poses another wearisome problem. Environmental regulations are usually the result of political bargaining between different actors: politicians, government agency officials, citizens, environmental special interest groups and industrial polluters, all with different goals, interests and powers. ${ }^{26}$ Thus,

${ }^{26}$ Reasons for this bargaining are the lack of information about the costs of pollution abatement, insufficient ecological knowledge, the distributional consequences of environmental programmes, competition with other public programmes, and disagreement about values (Giandomenico Majone, 
what an economist may propose on theoretical grounds and what is politically feasible may be entirely different. This leads to a different perspective for comparing policy instruments.

The models in section 1 pay little attention to the policy making process of environmental policies. In Downing and White (1986), for instance, optimal agency adjustment ("ratcheting") is analyzed without a discussion of the political feasibility. The control authority possesses perfect information about the costs and benefits of improving environmental quality and about the relationship between emissions and environmental quality. Although the authors acknowledge that in a real-world situation this is unlikely, they do not explore the implications of imperfect information for environmental policy making and the behaviour of potential innovators.

The only model that compares firm incentives to promote or obstruct policy adjustment is that of Milliman and Prince (1989). The most important conclusions are: First, that control adjustment only clearly generates abatement cost reductions for the innovator of a nonpatented discovery under emission taxes and auctioned permits. Second, that the emission taxes regime is the only policy which encourages industry promotion of optimal agency response. Third, that if the innovation developed by the polluting firm is patented, conclusions are similar to the ones above, except for emissions subsidies (where control adjustment will be opposed by both the innovating and non-innovating firms). Fourth, that when the innovation is supplied by an outside firm, control adjustment is favoured by the outside firm innovator under direct controls and free permits, may be opposed with auctioned permits, and is definitely opposed under emissions taxes. And fifth, that the response by industry to control adjustment is opposite to that of the outside firm innovator under all regimes except emissions subsidies (where both are opposed) and possibly auctioned permits.

Thus, the incentives to promote or obstruct policy adjustment for the innovator and the polluting industry differ widely and are usually opposed. There is only one case where the innovator and industry both promote control adjustment: the situation where the polluting firm is the innovator and emission taxes are used. It may be clear that such a control adjustment will be strongly opposed by outside suppliers (since such a control adjustment would result in lower taxes and revenues for them), and probably also by environmental pressure groups and the agency itself. Thus, if control adjustment is important to the decision to develop an innovation, it matters a great deal who is the possible innovator.

The models also pay little attention to the design of policy instruments: the stringency, flexibility, differentiation, phasing, enforcement, and sanctions. This is remarkable because it is clear that these aspects influence the effectiveness and efficiency of the

1976, Choice Among Policy Instruments for Pollution Control, Policy Analysis, p.611). Majone adds to this that, "although one may object to bargaining and political compromise, bargaining remains the only known way of generating viable policies out of a welter of conflicting interests, ill-tested theories, and differentially distributed resources." 
policies. ${ }^{27}$ These aspects also determine the willingness of potential suppliers of pollution control technologies to develop these technologies and the willingness of polluting firms to adopt abatement technologies. Little systematic research has gone into this issue. More research is needed on the optimal design of policy instruments to stimulate innovation in and diffusion of cleaner technologies. ${ }^{28}$

More research should also be devoted to analysis of the political factors that determine the design of policy instruments. ${ }^{29}$ As noted before, environmental policy is likely to be influenced, or even captured, by special interest groups. Particularly polluter industries are known to exercise an important influence on environmental policies. In Giandomenico Majone's view, the performance of policy instruments depends even more on the institutional framework they are used in than on their technical characteristics.

The actual outcomes of environmental policies are affected more by the institutional arrangements emerging from the political process than by the technical characteristics of the instruments employed; to use a statistical image, the "within group" effects (the differential results obtained when the same tool operates under different institutional circumstances) dominate the "between groups" effects (the results of different tools used under approximately equal conditions). In other words, the significant choice is not among abstractly considered policy instruments but among institutionally determined ways of operating them. ${ }^{30}$

This means that policy analysts should pay attention to the opportunities of industry and other parties to influence the details of environmental policies when assessing the effects of a certain policy tool and when comparing different institutional arrangements.

${ }^{27}$ See Robert W. Hahn, 1989, Economic Prescriptions for Environmental Problems: How the Patient Followed the Doctor's Order, Journal of Economic Perspectioes, 3(2): 95-114).

${ }^{28}$ Jacqueline J. Cramer, 1990, De effecten van milieubeleidsinstrumenten op innovatie en diffusie van schonere technologieën (the effects of environmental policy instruments on innovation in and diffusion of cleaner technologies), concept report for integration project "Environment and Economy".

${ }^{29}$ In the words of Hahn: "We need to develop a deeper understanding of how politics is likely to affect environmental goals, the definition of property rights, the design of institutions, and transaction costs associated with different institutional designs" (Robert W. Hahn, 1993, Comparing environmental Markets with Standards, Canadian Journal of Economics, 26(2): 353).

${ }^{30}$ Majone, op cit, p.593. The idea of the institutional framework being important to the outcomes of government policies is developed into a process model of government policy by Hans Bressers. The process model takes as its starting point the characteristics of the different actors involved: their goals, knowledge and expertise, and relative power. Important actors are: legislators, government agencies, trade assocations, firms, special interest groups and consumers. This approach emphasizes the open nature of the policy process and the mutual dependencies between different parties. Bressers' process model of government policy is applied by Pieter-Jan Klok (1989) to unleaded gasoline and clean cars. 


\subsubsection{The circular relationship between environmental policy and innovation in pollution control}

The decision to develop a new pollution control technology with a higher control efficiency very much depends on the stringency of environmental policies. In turn, pollution control policies depend on the technologies available for reducing environmentally hazardous emissions and waste material. This means that there exists a circular relation between environmental policy and innovation in pollution control. The reciprocal nature of the relationship has received little attention so $\mathrm{far}^{31}$

Only two studies mentioned in section 1 pay attention to the fact that the control policies themselves may change as a result of the development of new abatement technologies: Downing and White (1986) and Milliman and Prince (1989). In these models, the effects of optimal control agency response ("ratcheting") are analyzed. For example, the regulatory agency may set a more strict emission standard when a new abatement technology with a higher control efficiency is available. Such a response may be critical to a firm's decision to engage in R\&D and develop an environmental innovation. Of course, the firm may also try to influence environmental policy through lobbying, but such attempts usually meet strong opposition from the polluting industry, which may claim that the new technology is too expensive and ill-suited for their activities.

A model that analyzes the policy-making process in the context of technological uncertainty about the costs of pollution abatement and the opportunities for innovation is Nentjes (1988). ${ }^{32}$ In his model, Andries Nentjes analyzes how the speed of innovation in pollution reduction is determined by a) the risk aversion of the environmental bureaucracy, b) its time preference, c) the uncertainties surrounding unexplored clean technologies, d) the expected length of the R\&D period, e) gaps in the range of unexplored clean technologies, $\mathrm{f}$ ) the expected costs of new technologies, and g) the maximum of abatement costs the regulator is willing to accept. Incentives for polluting firms and outside suppliers to develop an innovation in pollution control are compared. Nentjes finds that polluting firms have an incentive to comply less than fully when the environmental bureaucracy tries to impose a technology-forcing standard and they will try to delay the introduction of cleaner and more expensive abatement technologies. A description of the model is in chapter 3.

Firm-regulator interdependencies may also be analyzed in dynamic game models, as suggested by Milliman and Prince (1989). This has been attempted recently by people like Carraro, Laffont, Tirole and others. A good example is the study by Jean-Jacques

${ }^{31}$ A discussion of this reciprocal relationship is in Alan Irwin and Philip Vergragt, 1989, Rethinking the Relationship between Environmental Regulation and Industrial Innovation: The Social Negotiation of Technical Change, Technology Analysis and Strategic Management 1(1): 57-70.

32 Andries Nentjes, 1988, An Economic Model of Innovation in Pollution Control Technology, paper presented at the Annual Meeting of AAERE, New York, Dec. 28-30, 1988. 
Laffont and Jean Tirole into the innovation incentives of a tradeable pollution permit. ${ }^{33}$ Another example is Carlo Carraro and Domenico Sinicalco (1992) about the optimal investment subsidy to induce environmental innovation in an open economy. ${ }^{34}$ Innovation decisions of polluting firms in a oligopoly industry that are subjected to a pollution tax are studied in Carlo Carraro and Giorgio Topa (1991). ${ }^{35}$ They find that the timing of innovation is less than socially optimal and propose the use of an investment subsidy to accelerate the innovation process. The policy implications of asymmetric information are also analyzed. In the presence of asymmetric information, the subsidy must embody an information premium so that firms reveal their innovative capability. The game theoretic models provides an interesting and important addition to the theoretical models described in section 1. A disadvantage of the models is their analytical complexity and the fact that they assume some kind of 'superrationality' on the part of the different actors. They do not allow for a simple systematic comparison of different policy regimes.

Finally, there is another kind of regulator-polluter relationship which has received little attention; i.e., 'voluntary' agreements between industry and the regulatory agency in which the polluting industry promises to reduce the environmental burden of their activities. Such agreements, in the form of covenants, between the regulatory agency and the polluting industry are a new trend in environmental policy making in the Netherlands. In such a covenant (in Dutch, convenant), firms and industries promise to reduce their pollutant emissions within a certain period. Of course, the prospect of environmental legislation in the form of standards or taxes, which may be implemented if the industry fails to take satisfactory environmental measures, plays an important role here.

The use of covenants within environmental policy has several benefits: its flexibility regarding the measures to be taken by the individual polluters, which makes it a more efficient system, ii) no valuable time is lost with the law-making process, and iii) low administrative costs. Covenants also have disadvantages. Apart from the fact that the legal status of such arrangements is unclear, and opportunities for democratic control are limited, a "prisoner's dilemma" situation may be created. Although it may be beneficial to the industry as a whole to escape (inflexible) legislation, it will be attractive for individual firms not to comply.

\subsubsection{The representation of the firm}

In the theoretical models of government-induced innovation in pollution control, the innovating firm is a profit maximizer. Output is assumed to be constant and output

\footnotetext{
${ }^{33}$ Jean-Jacques Laffont and Jean Tirole, 1994, A Note on Environmental Innovation, Fondazione Eni Enrico Mattei discussion paper 42.94.

${ }^{34}$ Carlo Carraro and Domenico Siniscalco, 1992, Environmental Innovation Policy and International Competition, Environmental and Resource Economics, 2(2): 183-200.

${ }^{35}$ Carlo Carraro and Giorgio Topa, 1991, Taxation and the Environmental Innovation, Fondazione Eni Enrico Mattei discussion paper 4.91.
} 
price is not affected by changes in abatement costs. Thus, profit maximization comes down to cost minimization, unless, as in Milliman and Prince's model, there are extra innovation gains from selling the innovation. Essentially, a firm is represented by a (marginal) cost function, which may be shifted downward through innovation in pollution control.

At least three objections may be raised to such a representation of the firm. First, the environmental image of the firm may affect its product sales and affect the firm's ability to attract (high-skilled) workers. The environmental image of the firm and its products are gaining importance, and are increasingly exploited in marketing. Second, pollution control may be demanded by its employers or even by the firm's management who have goals and aspirations of their own. The demand by workers is partly explained by the fact that pollution control and workplace conditions are strongly related. And firm executives may be sensitive about negative publicity, not just for 'normal' business reasons but also for personal reasons. And third, the models assume that the firm knows the costs and benefits involved in pollution control and is able to optimize between them. In reality, the costs and benefits of pollution control and R\&D are uncertain, diverse and difficult to assess in any precise way.

The notion of maximization has been criticized by many authors, especially when it is applied to innovation activities. According to Nelson and Winter, the behaviour and actions of firms may be understood better in terms of firm-specific capabilities and typical decision rules (about how much R\&D will be done, the organization of work, etc.), than the optimization of an imaginary profit function. ${ }^{36}$

The idea of inflexible decision rules and production routines may explain why firms have up until now engaged so little in environmental management despite the cost reductions that may be realized. For instance, in the Netherlands, a governmentfinanced, in-depth study of available pollution prevention measures in firms in the food, electroplating, metal working and chemical industries and the (public) transport sector, showed that almost always cost-neutral or cost-reducing pollution prevention options were available. Implementation of these projects by the firms led to emission reductions in the range of $5-100 \%$, with an average reduction of $40 \%$. Of the 45 pollution prevention projects that were implemented, only three projects were cost-increasing, the others were cost neutral (19 projects) or cost reducing (20 projects). Of these 20 cost-reducing projects, 16 projects had a payback period of less than one year, yielding very large cost savings in some cases. Moreover, in many companies the preventive measures brought indirect benefits also, such as improvements in product quality. Obstacles encountered in the Project Industrial Successes with Pollution Prevention (PRISMA) were: conceptual obstacles, organization obstacles, lack of knowledge, technical obstacles and economic obstacles. ${ }^{\text {p }}$

26 Nelson and Winter, 1982, op cit.

${ }^{37}$ Hans Dieleman and Sybren de Huv, 1991, PRISMA: the Development of a Preventative, Multi Media Strategy for Government and lndustry, in Kurt Fisher and Johan Schot (eds.), The Greening of 
It is unclear whether these obstacles - many of which are concerned with institutional aspects - have certain implications for the choice of policy instrument. It may be that economic instruments make pollution problems and losses of material more visible and induce firms to engage in environmental management. There may also be room for communicative instruments like environmental care systems, environmental audits or requirements that force firms to communicate with the public (through information disclosure laws).

\subsubsection{The supposed tradeoff between innovation in pollution control and normal business innovation}

Magat's model (1978) analyzes the effect of pollution control policies upon the path of technological advance chosen by a polluting firm. The model assumes that there is a tradeoff between innovation in pollution control and innovation in production technology. Technical advance is allocated between technological advancement in output production augmentation and effluent abatement augmentation along a innovation possibilities frontier. This corresponds to economic presumptions that regulation stifles normal business innovation and obstructs economic growth. Without going deeply into this issue, we want to make a few critical remarks to the idea of such a tradeoff.

The idea that regulation leads to a diversion of innovation resources is only plausible when it is the polluting firm that engages in R\&D in pollution control and when such R\&D is financed out of the existing R\&D budget (which may be constant or a set percentage of turnover). It is hard to see the way in which R\&D in the pollution control industry affects the R\&D decisions of polluting firms. Since most pollution control technologies are developed by special firms in the pollution control industry, the assumed tradeoff between R\&D in pollution control and in production technology will be weak.

The weak relationship between environmental policy and normal business innovation is further affirmed by an OECD study that finds that, although there are examples where a R\&D-project in pollution control budget caused other innovation projects to be cancelled or delayed, environmental pressures often modify or accelerate a programme for improving production processes, because pollution abatement often joins the initial objectives of energy and raw material conservation. ${ }^{38}$

Other studies, summarized in Rothwell (1992), confirm this. His conclusion is that "the direct impact of regulation on the success or failure of individual innovation pro-

Industry: Research Needs and Policy Implications for a Sustainable Future, Washington D.C.: Island Press, pp. 245-275.

${ }^{38}$ OECD, 1985, op cit, p.88. 
jects was generally weak. Regulation was one of the many factors - and rarely the most important-influencing innovatory outcome".

To this we must add that even in those cases where regulation may have hampered innovation, as in the pharmaceutical industry, these effects should only be compared against a realistic alternative basis. As pointed out by Robert Leone, the industry probably would have devoted resources to improving worker health and safety even if there had been no Occupational Safety and Health Acts (OSHAct). This is because other social and legal pressures existed, such as large tort or products liability damage awards."

What about the possible tradeoff between environmental regulation and economic growth? Does this hold true? In our view, also this tradeoff is doubtful. First, environmental costs are only a small proportion of GNP (below 3 percent), even in countries that instituted relatively strict environmental policies like Japan and the United States. Second, and perhaps more important, even when national industries suffer from lower sales due to higher environmental costs, this is compensated for at the macro level by the production of pollution control technologies. ${ }^{41}$ In addition, there may be environmental constraints to current growth paths: pollution and soil erosion diminish agricultural productivity, people's health and productivity are negatively affected by detrimental environmental conditions, and the economy may run out of cheap resources. It is important to take this into account. As the study of Hung, Chang and Blackburn (1993) shows, when there are serious environmental constraints, pollution control is no longer a growth depressant. ${ }^{42}$

${ }^{39}$ Roy Rothwell, 1992, Industrial Innovation and Government Environmental Regulation: Some Lessons from the Past, Technowation, 12(7), p.454.

${ }^{40}$ Nicholas A. Ashford, George R. Heaton Jr. and W. Curtiss Priest, 1979, Environmental, Health, and Safety Regulation and Technological Innovation, in James M. Utterback and C. Hill (eds.), Technological Innovation for a Dymamic Economy, p.172.

41 According to a study of the Central Planning Bureau (CPB) in the Netherlands, the implementation of a 350 billion DFl investment programme in environmental technology in the 1990-2010 period would cause GNP (in constant prices) in 2010 to be $4.2 \%$ lower than the predicted increase of $99.4 \%$. If other countries adopt similar policies, the net effect on GNP is even positive $(+0.5 \%)$ (Tweede Kamer, 1989, Nationaal Milieubeleidsplan. Kiezen of Verliezen (National Environmental Policy Programme. To choose or to lose), publication 21137, nr.1-2, Den Haag, p.19). This illustrates that the net effects of environmental policies on GNP are likely to be small.

${ }^{42}$ Victor T.Y. Hung, Pamela Chang and Keith Blackburn, 1993, Endogenous Growth, Environment and R\&D, Fondazione Eni Enrico Mattei discussion paper 23.93. 


\subsection{Conclusions}

At the end of the chapter, we summarize the main findings. In the chapter we described the results of theoretic models that analyze and compare innovation in pollution control under different policy regimes. The main findings of the models are: first, that incentivebased instruments provide a greater spur to innovate in pollution control than direct control does (if the innovator is a polluter and the level of emission reduction before innovation is the same in all regimes); and second, that effluent fees (emission taxes) lead the polluting firm to do too much R\&D in pollution control and direct regulation too little R\&D when the marginal conditions of pollution abatement change as a result of the innovation. These results are derived under a number of restrictive assumptions: the innovation is firm-specific, the polluter is the innovator, and the innovation allows for cost reductions for all levels of abatement. If the innovation is supplied by an outside firm and the agency responds correctly to the change in marginal conditions, the results are different: incentives for innovation are highest under direct regulation and lowest under an emission tax.

The models can be subjected to several criticisms. First, innovator gains from diffusion are neglected in all models, except Milliman and Prince (1989). The model of Milliman and Prince is also the only model which considers political economy aspects of policies by looking at the stance of the innovator and industry towards control adjustment. The models do not analyze the policy-making process of environmental policies in the context of technological uncertainty and sectoral pressures. This is an important limitation because the stringency of the instrument which emerges out of the political process may be more important than the instrument choice. Third, there is no realistic account of the innovation process and technical change. The practical usefulness of the models as a tool for public policy is believed to be limited. 


\section{Chapter 3}

\section{New Models of Innovation in Pollution Control}

Pollutant emissions are examples of negative externalities in which the actions of one party inflict harmful effects on others without consideration or compensation. This results in a non-efficient allocation, as every economist knows. Policy makers that want to arrest environmental degradation are confronted with the problem how to achieve environmental improvements. A wide range of policy instruments for controlling pollutant emissions are available: emission reduction standards, pollution taxes, subsidies and tradeable pollution permits.

Properties of pollution control instruments have been analyzed in theoretical models by economists. As we noted in chapter two, most studies focused on the static efficiency of different institutional arrangements. The effects of pollution control instruments on technical change in pollution control received far less attention.

This chapter develops two models of government-induced innovation in pollution control. The first model analyzes the effects of various pollution control instruments (emission standards, taxes, tradeable permits, subsidies) on the amount of R\&D in pollution control and the level of emission reduction. The innovator is a profit-maximizing polluter who tries to minimize current costs, which consist of pollution abatement costs, $R \& D$ costs and transfer payments (tax payments minus subsidies received). The model is a neoclassical model in which information problems, time and the historical context play no role.

The second model analyzes the circular relationship between government policy and innovation in pollution control technology. It is a further development of Andries Nentjes (1988). The model considers not only the impact of policy on technical change in abatement technology but also the policy-making process, which depends on the innovation possibilities. The model assumes that there exists a technology choice curve of new technologies, of which the regulator has imperfect knowledge. In the model, the (riskaverse) regulator balances the utility of a reduction in pollution against the disutility of a lengthier compliance time and the increased uncertainty about the feasibility of a more stringent standard. Nentjes' analysis is extended by the introduction of particular technology characteristics and industry heterogeneity in the model. The chapter also analyzes the innovation effects of two incentive-based policy instruments: a pollution tax and a tradeable pollution permit. 


\subsection{A New Model of R\&D in Pollution Control}

The theoretical impact of environmental policies on innovation in pollution control has been analyzed for the most part in graphical models that compare firm incentives for innovation under various regulatory regimes - as in Zerbe (1970), Wenders (1975), McHugh (1985), Downing and White (1986), and Milliman and Prince (1989). The general conclusion from these models is that the benefits of technical change that reduces emissions are higher under market instruments than under direct regulation. Technical opportunities and the costs of developing new abatement technologies are exogenous. This means that the graphical models are not able to foretell whether firms will engage in $R \& D$ to produce a new abatement technology, and how much $R \& D$ they will undertake.

The R\&D behaviour of a polluting firm has been modelled in two models only: Magat $(1978 ; 1979)$ and Mendelsohn (1984), the details of which have been described in chapter 2. Magat's model is a dynamic model of factor-augmenting technical change, in which there is a tradeoff between technical change in pollution control and technical change in production technology. Mendelsohn is a static model which analyzes the effects of an emission reduction standard and a pollution tax on innovation in pollution control for the situation where the regulator is uncertain about the costs and benefits of pollution control.

Our model differs from the above models in that it analyzes the R\&D behaviour of a polluting firm not only under an emission reduction standard, pollution tax and tradeable permit but also under various subsidy schemes: an emission reduction subsidy, an $R \& D$ subsidy and the combination of an $R \& D$ subsidy with a pollution tax. The basic idea of the model is very simple: to reduce the costs of pollution control and any transfer payments related to polluting emissions, the polluting firm may engage in R\&D. How much R\&D the firm will undertake depends on the cost savings per unit of emission reduction and the R\&D costs. ${ }^{1}$ The costs of pollution control and R\&D are described by the following expression:

$$
C(E R, R D)=\frac{\alpha E R^{a}}{(R D+1)^{b}}+R D
$$

with $E R$ emission reduction $(0 \leq E R \leq 1), R D$ the amount of $R \& D(R D \geq 0)$, and parameters $a>1,0<b<1$, and $\alpha>0$. The abatement costs are described by the first term in the right-hand side of equation (1). As we can see, the abatement costs depend on the amount of R\&D: by doing R\&D the firm can diminish the costs of pollution abatement. To simplify our analysis, the units of emissions have been redefined so that one unit of

${ }^{1}$ Throughout the analysis we assume that the gains from $R \& D$ in pollution control consist of lower costs of pollution abatement and tax payments. $R \& D$ in pollution control dues not influence the sales of the polluting firm through a better environmental image nor does it provide the firm with extra gains from selling the innovation. 
pollutants would be emitted in the absence of any controls. The amount of R\&D is in dollars.

The cost function, net of transfer payments, is chosen so that it satisfies certain properties: $\partial C / \partial E R>0, \partial^{2} C / \partial E R^{2}>0, \partial C / \partial R D<0$, and $\partial^{2} C / \partial R D^{2}>0$ with $\hat{C}=\alpha E R^{a} /(R D+1)^{b}$ the abatement costs. This means that the costs of pollution abatement rise at an increasing rate with abatement and that returns of $R \& D$ are increasing at a decreasing rate; these are common economic assumptions about technology.

Under a regime of direct regulation, when there are no transfer payments, the firm will minimize the above cost function under the contraints $0 \leq E R \leq 1$ and $R D \geq 0$. Under a tax regime, when the firm has to pay a tax $p$ for each unit of pollution that is emitted, the cost function to be minimized is:

$$
C(E R, R D)=\frac{\alpha E R^{a}}{(R D+1)^{b}}+R D+p(1-E R)
$$

$$
\text { with pollution } \operatorname{tax} p(p \geq 0)
$$

Equation (2) is the same as (1) with the exception of the term $p(1-E R)$, the polluter's bil for emitting pollutants.

With respect to the shape of the two cost functions, it can be shown that the above cost functions are convex if (and only if) $a-b-1 \geq 0$ (see appendix). This is an important property because this allows us to judge whether or not the combination of $(E R, R D)$ that satisfies the necessary optimality conditions of the Lagrangian function is a (local) minimum or a sadlepoint. As the reader may verify, the cost functions are continuous differentiable functions of $R D$ and $E R$ (with $R D$ and $E R$ belonging to convex sets).

The Lagrange function for the cost function under a tax regime is:

$$
L(E R, R D, \lambda)=\frac{\alpha E R^{a}}{(R D+1)^{b}}+R D+p(1-E R)-\lambda(1-E R)
$$

The Kuhn-Tucker conditions, both necessary and sufficient for the problem at hand, are:

$$
\begin{gathered}
E R \geq 0, \quad \frac{\partial L}{\partial E R} \geq 0, \quad E R \frac{\partial L}{\partial E R}=0 \\
R D \geq 0, \quad \frac{\partial L}{\partial R D} \geq 0, \quad R D \frac{\partial L}{\partial R D}=0 \\
\lambda \geq 0, \quad \frac{\partial L}{\partial \lambda} \leq 0, \quad \lambda \frac{\partial L}{\partial \lambda}=0
\end{gathered}
$$


For $R D>0$ and $0<E R<1$ (which means that $\lambda=0$ ), we get the following results for $R D_{p}$, the optimal amount of R\&D, and $E R_{p}$, the optimal emission reduction (subscript $p$ stands for price rule): ${ }^{2}$

$$
\begin{gathered}
R D_{p}=\left(\frac{b^{a-1} p^{a}}{\alpha a^{a}}\right)^{\frac{1}{a-b-1}}-1 \\
E R_{p}=\left(\frac{b^{b} p^{b+1}}{\alpha a^{b+1}}\right)^{\frac{1}{a-b-1}}
\end{gathered}
$$

Minimization of equation (1) under the constraint $E R \geq E R$ (and the other constraints) gives the optimal amount of R\&D under direct regulation, $R D_{q}$ (where $q$ stands for quantity rule), and the optimal emission reduction $E R_{q}$ :

$$
\begin{gathered}
R D_{q}=\left(\alpha b E R^{a}\right)^{\frac{1}{b+1}}-1 \\
E R_{q}=E R
\end{gathered}
$$

with $E R$ the emissions reduction standard.

Thus, under a regime of direct regulation the firm will not reduce its emissions above the level of emission reduction that is required by law.

How do the above results under direct regulation compare with those under a tax regime? Will the polluting firm undertake more R\&D under a tax regime, and if so, how much more R\&D? What level of emission reduction will it choose under a tax regime and under a command and control regime? To allow analytic comparisons we go back to the situation where there is no innovation in pollution control, where the quantity rule and price rule cause the same amount of emission reduction. In a world of perfect information, with no technical change, the emission reduction under both regimes will be the same if the pollution tax $p$ equals the marginal cost of pollution abatement at the emission reduction standard: that is, when $p=M C(E R)$ which in our model is when $p=\alpha a E R^{\alpha-1}$. Substitution of $p=\alpha a E R^{a-1}$ in the expressions for $R D_{p}$ and $E R_{p}$ gives $R D_{p}$ and $E R_{\dot{p}}$

\footnotetext{
${ }^{2}$ For the optimal combination $(E R, R D)$ to be an interior solution (i.e. $R D>0$ and $0<E R<1$ ) it is necessary that $b \alpha \geq 1$.
} 


$$
\begin{aligned}
& R D_{p}=\left(b \alpha E R^{a}\right)^{\frac{a-1}{a-b-1}}-1 \\
& E R_{p}=\left(b^{b} \alpha^{b} E R^{(a-1)(b+1)}\right)^{\frac{1}{a-b-1}}
\end{aligned}
$$

It can be shown that $R D_{p}>R D_{q}$ and $E R_{p}>E R_{q}=E R$ for $R D>0$ and $0<E R<1$ (see appendix). Thus, under a price rule (tax regime), the firm will undertake more $R \& D$ and emission control than under direct regulation.

The optimal amount of R\&D and pollution abatement under a tradeable permit regime can also be determined. Suppose the firm gets $(1-E R)$ free permits. It it wants to pollute more it must buy extra permits, if it emits less it can sell the unused permits. Suppose the firm can buy and sell permits at a unit price of $p^{\prime}$. The cost function $C$ to be minimized is now:

$$
C(E R, R D)=\frac{\alpha E R^{a}}{(R D+1)^{b}}+R D+p^{\prime}(E R-E R)
$$

Minimization of equation (13) with respect to $E R$ and $R D$ gives the same results as under a tax regime, except that we now have $p^{\prime}$ instead of $p$. Thus, if $p=p^{\prime}$, that is, if the permit can be bought or sold at a unit price $p$, the optimal amount of R\&D and pollution abatement is exactly the same as under a tax regime. (If $p<p^{\prime}\left(p>p^{\prime}\right)$, the tradeable permit regime leads to more (less) innovation in pollution control.)

Thus, under a tax or tradeable permit regime the firm will undertake more R\&D and more pollution abatement than under a command-and-control regime. This result corresponds to findings of the graphical models. The reason why both the tax and tradeable permit regime offer more inducement to innovate than direct regulation is because under the incentive-based regimes, the innovator is able to exploit an extra gain by further reducing its emissions. This is because the marginal benefits of extra emissions reductions (in the form of a reduction of tax payments or revenues from selling pollution permits) exceed the marginal costs of emission reduction (the sum of abatement costs and R\&D costs). Under direct regulation there is no incentive for the polluter to reduce its emissions beyond the original level of emissions control since the marginal benefits to the firm of such a step are zero.

We will now examine the effects of various kinds of subsidies on the polluting firm's $\mathrm{R} \& \mathrm{D}$ behaviour and level of abatement. If the control agency pays an emission subsidy 
of $s$ per unit of emission control to the firm, the amount of $R \& D, R D_{s}$, and the amount of emission reduction, $E R_{\mathrm{s}}$, are:

$$
\begin{aligned}
& R D_{s}=\left(\frac{b^{a-1} s^{a}}{\alpha a^{a}}\right)^{\frac{1}{a-b-1}}-1 \\
& E R_{s}=\left(\frac{b^{b} s^{b+1}}{\alpha a^{b+1}}\right)^{\frac{1}{a-b-1}}
\end{aligned}
$$

Thus, if the tax rate equals the emission subsidy (i.e., if $p=s$ ) then the same amount of R\&D and emission control will be undertaken, a result found also in the graphical firm incentive models.

We will now analyze the innovation effects and amount of emission reduction under subsidy arrangements: a lump sum subsidy and an R\&D subsidy (combined with an emission tax). As one would expect, a lump sum subsidy has no effect on the amount of $R \& D$ that will be undertaken. (This is under the assumption that there are no financing problems for doing $R \& D$ and no alternative projects with a higher rate of return.) An R\&D subsidy, however, promotes innovatin in pollution control. When the firm receives an $R \& D$ subsidy, $s_{R D}$ (with $0<s_{R D}<1$ ), the cost function changes in:

$$
C(E R, R D)=\frac{\alpha E R^{a}}{(R D+1)^{b}}+\left(1-s_{R D}\right) R D
$$

Minimization of (16), under the restriction that $E R \geq E R$, gives the optimal amount of R\&D the firm will undertake if it receives an R\&D subsidy under direct regulation:

$$
R D_{s}=\left(\frac{b \alpha}{1-s_{R D}} E R^{a}\right)^{1}-1=\left(\frac{1}{1-s_{R D}}\right)^{\frac{1}{n+1}} R D_{q}+\left(\frac{1}{1-s_{R D}}\right)^{\frac{1}{b+1}}-1
$$

Since $(1 /(1-s))^{\frac{1}{n+1}}>1^{\frac{1}{n+1}}=1$, the firm will undertake more R\&D if this is subsidized than when it is not. This, of course, is also what one would expect. Combination of an R\&D subsidy with an emission tax gives a different result. The cost function the firm will try to minimize becomes:

$$
C(E R, R D)=\frac{\alpha E R^{a}}{(R D+1)^{b}}+\left(1-s_{R D}\right) R D+p(1-E R)
$$

Minimization of the cost function with respect to $R D$ and $E R$ gives:

$$
R D_{p, s}=\left(\frac{b^{a-1} p^{a}}{\left(1-s_{R D}\right)^{a-1} \alpha a^{a}}\right)^{\frac{1}{2-b-1}}-1 .
$$




$$
E R_{p, s}=\left(\frac{b^{b} p^{b+1}}{\left(1-s_{R D}\right)^{b} \alpha a^{b+1}}\right)^{\frac{1}{a-b-1}}
$$

Thus, as we can see, $R D_{p, s}>R D_{p}$ and $E R_{p, s}>E R_{p}$ for $p, s>0$, that is, the firm will undertake more R\&D and emission control if $R \& D$ is subsidized.

The results are all straightforward and not surprising. The model is nothing more than a small contribution to a well-established literature, the practical meaning of which is limited. Many of the criticisms advanced in chapter 2 apply to this model.

\subsection{A Model of Regulator Behaviour and Innovation in Pollu- tion Control}

In chapter 2, we gave an overview of theoretical models of innovation in pollution control. The common finding of most studies is that incentive-based environmental policy approaches (like effluent charges or taxes, subsidies and tradeable pollution permits) offer more inducement to innovate in pollution control than direct regulation. This result is derived under a number of restrictive assumptions. One important assumption is that the regulator possesses perfect information about the marginal costs and benefits from pollution abatement. The technological implications of regulator uncertainty about the costs and benefits of emissions reductions are examined in one model only, Mendelsohn (1984), for the special case where the regulator is uncertain about the locus - but not the slope - of the marginal cost curve of pollution abatement.

In actual practice, uncertainty about the costs and benefits of environmental measures usually prevents the regulator from determing the optimal level of pollution control, whereas practical problems of implementation, polluter's resistance and social pressures make it difficult for the control agency even to achieve a pollution abatement goal. A model of innovation in pollution control which considers the problem of uncertainty about abatement costs, especially for new technologies, and the control agency's preferences and attitude towards risk is that of Andries Nentjes (1988). Nentjes' model analyzes the emission standard set by an environmental agency and the effects on innovation in pollution control for the situation where the regulator is uncertain about the control efficiency, costs and time needed to develop new pollution control technologies.

In Nentjes' model, described in section 2.1, the regulator tries to maximize a preference function $U$ which is a function of $r$, the level of pollution reduction, $t$, compliance time, and $\phi$, a measure of uncertainty (which is a function of $r$ ). In choosing an emission reduction standard, the environmental agency balances the utility of a reduction of pollution against the disutility of a lengthier compliance time and the increased uncer- 
tainty about the feasibility of a more stringent standard. Thus, the regulator not only selects a level of pollution abatement but also gives the polluting firm time to comply with the emission reduction standard, which introduces a new element in the theoretical literature.

Section 2.2 extends Nentjes' analysis. In our model, the regulator may choose a different pollution control instrument: a pollution tax or a tradeable permit rather than an emission reduction standard. Furthermore we analyze how regulation affects the selection of different types of pollution control technologies: (curative) end-of-pipe technology versus (preventive) process-integrated technology. And finally, we examine the implications of sunk costs for the optimal level of emission reduction and compliance time. The final section gives the conclusions.

\subsubsection{Nentjes' model}

Nentjes' model is based on the economic theory of bureaucracy; it builds on the work of Ames (1965) and Niskanen (1971), in which the government agency is motivated not by the maximization of social welfare but by output maximization. ${ }^{3}$ In Nentjes' model, the goal of the control agency is to maximize pollution reduction. The agency, however, will not try to achieve emissions reductions at all costs: the abatement costs may not exceed a certain level, $k_{\max }$. As in real life, the control agency is careful not to impose too large costs on the polluting firm.

In the model, a higher control efficiency may be achieved through the use of new pollution control techniques. The range of pollution control technologies runs from wellknown and proven technologies to highly uncertain technologies with high control efficiencies. The different technological options open to a representative polluting firm are depicted in Figure 3.1.

Envelope $k=k(r)$ of the cost curves $k_{i}$ is the technology choice curve. The shape of the cost curves implies that the marginal costs of pollution abatement of the technologies are increasing $\left(\partial k_{i} / \partial r>0\right.$ and $\left.\partial^{2} k_{i} / \partial r^{2}>0\right)$. Figure 3.1 depicts the technology that is necessary to realize a certain level of abatement efficiency. In the model, only part of the envelope, interval $A B$, consists of existing technologies. The other part of the envelope, interval $B E$, represents expectations about new technologies with a higher control efficiency at lower costs. ${ }^{4}$

\footnotetext{
${ }^{3}$ E. Ames, 1965, Soviet Economic Processes, Homewood; and W.A. Niskanen Jr., 1971, Bureaucracy and Representatize Gooemment, Chicago.

- Note that the more advanced technologies are more expensive at low rates of pollution reduction. This reason for this is that the fixed costs (R\&D costs and installation) of new technologies are higher than for less advanced technologies.
} 


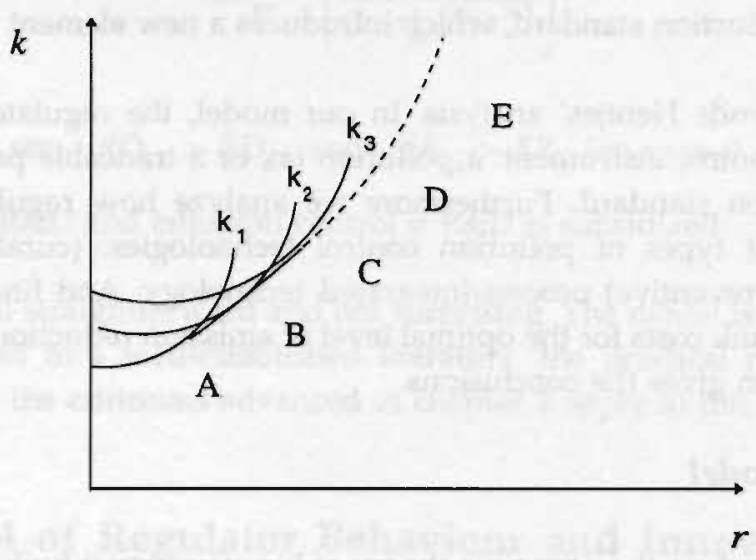

Figure 3.1. The technology cost curves. Source: Nentjes (1988, p.5).

An important element in the model is that the regulator is uncertain about the control efficiencies that may be achieved by the various technological options, and about the costs and time involved in producing these technologies. It is assumed that this uncertainty, represented by parameter $\phi$, increases along the envelope, going from $B$ to $E$. The regulator knows however that by giving the polluting firm more time to comply that the costs of producing the innovation may be reduced. In other words, there exists a time-R\&D cost trade-off.

After having described the model in general terms, we will now define it more formally. The regulator maximizes a preference function (21) under the constraints of the cost function (22), the compliance time function (23), the uncertainty function (24) and the cost ceiling (25).

$$
u=u(r, t, \phi)
$$

with $u_{r}>0, u_{r r}<0, u_{t}<0, u_{u}<0, u_{\phi}<0, u_{\phi}<0$

$$
k=k(r, t)
$$

with $k_{r}>0, k_{r r}>0, k_{t}<0, k_{i t}>0$, for $t>t_{\text {min }}$

$$
t=t(r)
$$

with $t_{r}>0, t_{r}>0$ 


$$
\begin{aligned}
\phi & =\phi(r) \\
\text { with } \phi_{r} & \geq 0, \phi_{r r}>0 \\
k & \leq k_{\max }
\end{aligned}
$$

The unknown parameters $r, t, \phi$ have to be solved from the above model. In Nentjes' paper, the focus in on $r$, the emission reduction standard, and on compliance time $t$.

Two regimes can be distinguished, depending on whether or not the cost ceiling is binding. When the cost ceiling is not binding, the formal problem is to maximize (21) under the constraints (23) and (24). Optimization gives:

$$
t_{r}=-\frac{u_{r}}{u_{l}}-\frac{u_{t}}{u_{t}} \phi_{r}
$$

Equation (26) implies that the standard is set at the level where the compliance time needed for one additional unit of pollution reduction $\left(t_{r}\right)$ is equal to the willingness of the regulator to allow more compliance time for additional pollution reduction $\left(-u_{r} / u_{t}\right)$ minus the impact of extra pollution abatement on uncertainty $\left(\phi_{r}\right)$, 'translated' into timecosts. The trade-off $\left(-u_{\phi} / u_{t}\right)$ measures the degree of risk aversion of the regulator.

Optimization of the preference function, under a binding cost ceiling, gives the same optimum condition (26). The interpretation of the optimum condition however is somewhat different. The trade-off $d t / d r=-u_{r} / u_{t}$ is now determined by the cost constraint $\left(d t / d r=k_{r} / k_{l}\right)$. A rise in control efficiency can be obtained at unchanged costs by accepting a longer compliance period and some additional uncertainty about the innovation result. Thus, even if the abatement costs of existing technologies are the maximum of what is acceptable to the regulator, technical change in pollution control is still possible if polluters are given time to comply with more strict regulation. Hence, the use of compliance time by policy makers may stimulate technological advance in pollution control.

In terms of Figure 3.1, the regulator may choose point $B$ on the technology choice curve, the best available abatement technology, or a point between $B$ and $E$ which means that the regulator imposes a standard which is tighter than the control efficiency of welltried abatement technology. The regulator will choose a point between $B$ and $D$ when there is a range of relatively cheap and well-explored technologies of which the uncertainty is believed to be relatively low. However, the disutility of increasing compliance time and uncertainty about the feasibility and costs of more advanced technologies keeps him from choosing a point between $D$ and $E$. Thus, a risk-averse regulator with a high time preference and a low cost ceiling will choose a point on the technology choice curve not far from point $B$. In such a situation there is little incentive for the polluting firm to develop innovations with a higher control efficiency. According to Nentjes, this has been 
the situation in Europe, where cost ceilings have often been chosen on the basis of wellknown and relatively cheap available abatement technologies.

\subsubsection{Extensions of Nentjes' model}

This section extends Nentjes' model in two ways: First, by studying the innovation effects of two other policy instruments, a pollution tax and a tradeable permit, and second, by examining the implications of environmental regulation for the nature of technical change (whether it is in abatement technology or process-integrated technology and whether it is incremental or radical). Furthermore, we will adapt some of the model's assumptions.

In Nentjes' model, both compliance time $t$ and uncertainty $\phi$ are a function of the level of emission reduction $r$. In our model, compliance time $t$ is not a simple function of $r$ but a control variable. By choosing a high $t$, the regulator reduces uncertainty about the feasibility of the standard and diminishes the costs of developing a technology with a higher control efficiency (due to the time-R\&D cost tradeoff). The reason behind choosing a high $t$ is that this allows the regulator to set a higher $r$ - the extra utility of which will be balanced against the disutility from a higher $t$. Our model also differs from Nentjes's model in that we abandon the assumption of a representative polluting firm but allow for industry heterogeneity with respect to the costs of pollution abatement ... which means that some firms may achieve emissions reductions at lower costs than others.

To summarize, we assume that $\phi$ and $k$ are a function of both $r$ and $t$. This means that we do not substitute $t=t(r)$ in the utility function but maximize $u$ with respect to $r$ and $t$. In addition, our analysis assumes that the industry is heterogeneous with respect to the costs of pollution control.

Redefining Nentjes' model gives:

$$
\begin{gathered}
u=u(r, t, \phi) \\
k=k(r, t) \\
\phi=\phi(r, t) \text { with } \phi_{t}<0 \\
k \leq k_{\max }
\end{gathered}
$$

The optimality conditions of the model are: 


$$
\begin{aligned}
& \frac{\partial u}{\partial r}=0 \Rightarrow u_{r}+u_{\phi} \phi_{r}=0 \\
& \frac{\partial u}{\partial t}=0 \Rightarrow u_{t}+u_{\phi} \phi_{t}=0
\end{aligned}
$$

These equations demonstrate that in the optimum, the marginal utility from extra emission reduction $r$ (or a shorter compliance time $t$ ) is compensated by the decrease in utility due to the higher amount of uncertainty caused by the extra emission reduction (or shorter compliance period). Combining equations (31) and (32) gives:

$$
u_{r}=u_{t}+u_{\phi}\left(\phi_{t}-\phi_{r}\right)
$$

We will now extend the analysis by broadening the range of possible policies open to the regulator. Rather than setting an emission reduction standard, the regulator may institute a pollution tax (or effluent charge) $p$ per unit of emission.

As in Nentjes' model, we assume that the regulator wants to maximize some utility function, but is uncertain about the costs of abatement and about the level of abatement that polluting firms will undertake in response to the tax. The model which describes regulatory behaviour under a pollution tax is given below:

$$
u=u(r(p), \phi)
$$

with $r(p)$ the expected emission reduction of an average firm in response to pollution tax $p$, and

$$
k=k(p)+p(1-r)
$$

with $k(p)$ the expected abatement costs for the polluting industry subject to tax $p$ and $p(1-$ $r$ ) the tax payments the industry has to pay for emitting pollutants. (For simplicity, we have redefined the number of emissions before abatement at 1).

$$
\begin{gathered}
\phi=\phi(r(p), k(p)) \\
k \leq k_{\max }
\end{gathered}
$$

Utility is a function of the expected emission reduction that will be produced by the polluting industry and of uncertainty. Note that there are two forms of uncertainty: uncertainty about the actual level of emission reduction and uncertainty about the industry's abatement costs. ${ }^{5}$ Both types of uncertainty are incorporated in the uncer-

5 The industry's abatement costs are the sum of the costs of pollution control of the individual firms. Transfer payments are not included in this sum. 
tainty function, whereas in Nentjes' model they are included in one parameter. For matters of comparison, the uncertainty function under direct regulation is changed in $\phi$ $=\phi(r, t, k)$.

Optimization of the agency's utility function $u(r(p), \phi)$ gives:

$$
u_{r} r_{p}=-u_{\phi}\left(\phi_{r} r_{p}+\phi_{k} k_{p}\right)
$$

The optimality condition under a command-and-control regime is:

$$
u_{r}=u_{t}-u_{\phi}\left(\phi_{r}+\phi_{k} k_{r}+\phi_{t}+\phi_{k} k_{i}\right)
$$

The interpretation of equation (38) is very much the same as that of equation (39). For the optimal level of the pollution tax, the expected extra utility from emission reduction from a higher tax is equal to the decrease in utility due to the greater uncertainty caused by the higher tax. This extra uncertainty consists of uncertainty about the industry's pollution behaviour and uncertainty about the costs of abatement.

There are also some differences between the optimality conditions in equation (38) and (39). The two most important differences are the differences in $k$ and $\phi$. As regards the difference in $k$, it is well known that direct regulation is not a cost-effective system for achieving emissions reductions when the costs of pollution abatement differ between firms. An emission reduction standard that requires all polluters to achieve the same amount of emission reduction is likely to impose large costs on some polluters and, as a result, to violate the economic efficiency condition which requires that the marginal costs of pollution abatement equal the marginal social benefits of abatement. ${ }^{6}$ Under the tax regime, however, a profit-maximizing polluter will only pursue emissions control to the point at which the marginal cost of emission control per unit equals the tax. That is, the firm cannot be forced to undertake emissions control of which the marginal costs are higher than the pollution tax. Thus, under a price rule, the same emission reduction may be achieved at lower abatement costs. This has a positive effect on the willingness of policy makers to set a tax with a high $r(p)$. However, the abatement costs are not the only environmental cost under a tax regime. Under a tax regime, polluters must pay a tax for emitting pollutants. This means that the total environmental costs for industry may be higher under a tax regime than under a command-and-control regime with $r(p)=$ $r$, despite the efficiency gains under a tax regime. This has received little attention in the economic literature. Firms and government authorities, however, are well aware of this: it explains the fierce opposition from industry against pollution taxes and the reluctance of policy makers to institute taxes unilaterally.

The implications of the above for the rate of technical change in pollution control are relatively straightforward. If the total environmental costs for industry under a tax

\footnotetext{
${ }^{6}$ Differentiation of emission reduction standards diminishes the disadvantage of cost inefficiency but leads to higher control costs for the control agency; it is also viewed as not fair if some firms are subjected to more strict standards than others.
} 
with $r(p)=r$ are higher than the costs under the uniform emission reduction standard, the regulator will institute a low pollution tax, that is, a pollution $\operatorname{tax}$ of which $r(p)<r$. This means that under a tax regime, due to the low level of the tax, firms will undertake less R\&D in pollution control than under a command-and-control regime. This conclusion differs from the common result of innovation models that pay no attention to the policy-making process. The tax regime only provides a greater spur to innovate when the efficiency gain from lower abatement costs exceeds the tax payments. In most circumstances this is not the case.

What about the innovation effects of a system of tradeable permits? Are they the same as those of the tax regime? The answer is no. A system of free tradeable pollution permits provides a greater spur to innovation in pollution control than a tax regime. It also provides a greater inducement to innovate than a command-and control regime. This is because a tradeable permit system combines the advantage of a tax system with that of a command-and-control regime: environmental improvements are achieved at the lowest costs and there is no uncertainty about the total level of emission reduction. In terms of our model, it means that $k\left(r^{t p}\right)<\max [k(r(p)), k(r)]$ and $\phi\left(r^{t p}\right)=\phi(r, t)<\phi(r(p))$ for $r^{t p}=r(p)=r$, with $r^{t p}$ the level of emission reduction under a tradeable permit regime. As a result, $r^{t p}>\max [r(p), r]$. This means that a free tradeable permit system provides the greatest spur to innovation in pollution control technology of the three systems. Note that when the government auctions the $\left(1-r^{5 p}\right)$ permits, the innovation effect would be higher, but this is not a realistic assumption: the regulator will not grant such a limited number of permits because this would impose high environmental costs on industry.

The effects of compliance time on innovation in pollution control technology also can be determined. As explained, compliance time reduces regulator uncertainty about abatement costs $\left(\phi_{i}<0\right)$, and helps to diminish the costs of entission jontrol (since $k_{s}<$ 0 ). Both effects result in a higher value for $r$ (the level of emission reduction at time $t$ ). In other words, as in Nentjes' model, compliance time has a positive influence on innovation in pollution control.

The model may also be used to assess the effects of different control regimes on the choice of pollution control technology, for instance, the choice between end-of-pipe or process-integrated technologies. As pointed out in chapter 5, process-integrated technologies suffer from a sunk cost disadvantage because usage of these technologies often requires the replacement of existing production facilities. If firms are forced to reduce their emissions in a relatively short period, they will decide for end-of-pipe technologies that can be added to the existing processes. This is exactly what happened in the 1970 s and 1980 s when environmental policy was oriented at achieving quick emission reductions by way of direct regulation. These regulations gave polluters little freedom with respect to timing and choice of environmental measures to reduce pollution. If incentivebased instruments like pollution taxes and tradeable permits had been used, the share of process-integrated technologies probably would have been higher.

Similarly, if firms are given (more) time to comply with more strict emission reduction standards, the sunk cost factor will become less important. In terms of the 
model, the difference between $k(r, 0)$ and $k(r, t)$ is higher for process-integrated technologies than it is for end-of-pipe technologies. Figure 3.2 illustrates this.

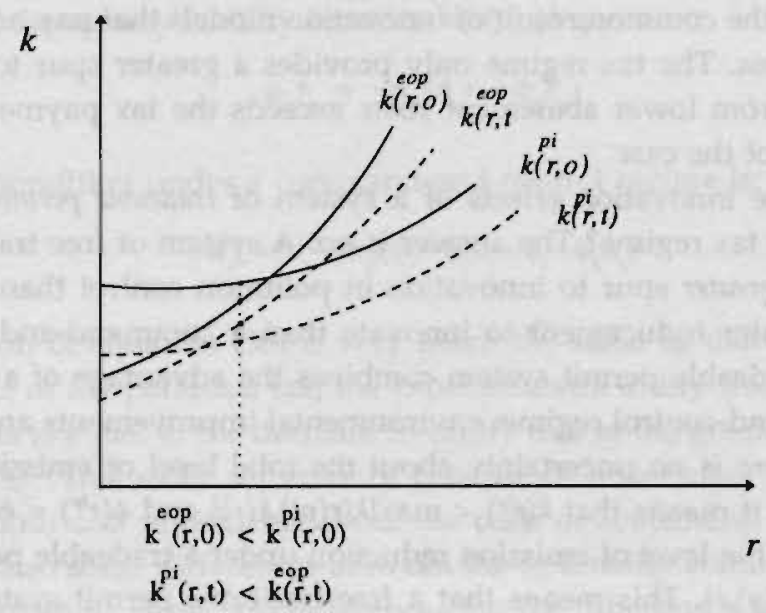

Figure 3.2. The abatement cost curves of an end-of-pipe (eop) and process-integrated (pi) technology for different $t$.

Figure 3.2 demonstrates that if firms are forced to comply immediately with an emission reduction standard $r$, they will adopt an end-of-pipe technology (since $\left.k^{\mathrm{op}}(r, 0)<k^{p i}(r, 0)\right)$. If they are given time to comply with the standard, they will choose the process-integrated technology (because $\left.k^{\mathrm{cop}}(r, t)>k^{p i}(r, t)\right)$. This means that compliance time is not only an effective way to foster innovation in pollution control but also stimulates the adoption of preventive process-integrated technologies. It furthermore illustrates how the design of policy instruments may be used to offset some of the disadvantages of particular instruments in effecting change in environmental technology.

The same arguments apply to the choice between incremental and radical innovations. The short-term costs of developing a radical innovation with large environmental benefits are usually high so that innovator firms will opt for incremental improvements of existing technologies. Again, innovation waivers and the use of economic instruments are a possible way out of this problem.

\subsubsection{Summary and conclusions}

In this section, we advanced a model of regulatory behaviour and innovation in pollution control. The model is believed to be interesting for considering the policy-making process in the context of technological uncertainty, something that the models in chapter 2 failed to do. The model, developed by Andries Nentjes, demonstrates, that the prefer- 
ence of a risk-averse regulatory agency for short-term environmental benefits has a negative impact on innovation in pollution control. One way to deal with this problem is to give firms time to comply with emission reduction standards through innovations waivers.

The model is then used to study regulatory behaviour and technical change under two incentive-based control regimes: a pollution tax and a tradeable pollution permit. It is shown that in most circumstances a tax regime provides less inducement to innovation in pollution control technology than direct regulation. This is because the government will set the tax at a low level in order not to impose too high environmental costs on industry. We then show that a free tradeable permit system that combines elements of both systems provides the greatest incentive to innovate in pollution control.

Finally, we examined the technological implications of different policy regimes on the nature of technical change. We find that direct regulation favours end-of-pipe technologies and incremental technology improvements. The overall conclusion of the model is that innovation waivers and tradeable quota are better instruments to promote innovation in pollution control than direct regulation is. Of course, to assess the merits and demerits of policy instruments one must also look at other aspects: the likelihood of interest groups to capture policies, transaction costs, and the commitment of the government to carry forward the programme over an extended period. 


\section{Appendix 3.A: Convexity of function $C(E R, R D)$}

Function $C(E R, R D)$ is convex if and only if: ${ }^{7}$

i. $\frac{\partial^{2} C}{\partial E R^{2}}+\frac{\partial^{2} C}{\partial R D^{2}} \geq 0$

ii. $\Delta(E R, R D) \equiv \frac{\partial^{2} C}{\partial E R^{2}} \cdot \frac{\partial^{2} C}{\partial R D^{2}}-\left(\frac{\partial^{2} C}{\partial E R \partial R D}\right)^{2} \geq 0$

Since $\frac{\partial^{2} C}{\partial E R^{2}}=\frac{\alpha a(a-1) E R^{a-2}}{(R D+1)^{b}}>0$ for $a>1$ and $\frac{\partial^{2} C}{\partial R D^{2}}=\frac{\alpha b(b+1) E R^{a}}{(R D+1)^{b+2}}>0$

function $C(E R, R D)$ satisfies the first condition.

With respect to the second condition:

$$
\begin{aligned}
& \Delta(E R, R D)=\frac{\alpha a(a-1) E R^{a-2}}{(R D+1)^{b}} \cdot \frac{\alpha b(b+1) E R^{a}}{(R D+1)^{k+2}}-\frac{\alpha^{2} b^{2} a^{2} E R^{2 a-2}}{(R D+1)^{2 b+2}} \Leftrightarrow \\
& \frac{\alpha^{2} a(a-1) b(b+1) E R^{2 a-2}}{(R D+1)^{2 h+2}}-\frac{\alpha^{2} b^{2} a^{2} E R^{2 a-2}}{(R D+1)^{2 b+2}}
\end{aligned}
$$

Thus, $\Delta(E R, R D) \geq 0 \Rightarrow a(a-1) b(b+1) \geq b^{2} a^{2} \Leftrightarrow(a-1)(b+1) \geq b a \Leftrightarrow a-1-b \geq 0$

\section{Appendix 3.B: The Ranking of $R D_{p}, R D_{q}$ and $E R_{p} E R_{q}$}

The optimal amount of R\&D under a price and quantity rule are:

$$
R D_{p}=\left(b \alpha E R^{a}\right)^{\frac{a-1}{a-b-1}}-1 \text { and } R D_{q}=\left(b \alpha E R^{a}\right)^{\frac{1}{b+1}}-1
$$

Since $a-1>a-b-1>0 \Rightarrow \frac{a-1}{a-b-1}>1$ whereas $\frac{1}{b+1}<1$ we get,

$R D_{p}>R D_{q}$ if $b \alpha E R^{a}>1$ (the necessary condition for $R D_{p}>0$ ).

Similarly, $E R_{p}=\left(b^{b} \alpha^{b} E R^{(a-1)(b+1)}\right)^{\frac{1}{a-b-1}}>\left(E R^{(a-b-1)}\right)^{\frac{1}{a-b-1}}=E R=E R_{q}$ for $R D_{p}>0 \square$

${ }^{7}$ M.H.C. Paardekoper and L.R.J. Westerman, 1978, Analyse I (Appendix), Theorem B.3, lecture notes, propedeuse Econometrics, Tilburg. 


\section{Chapter 4}

\section{An Interpretative Survey of Technological Diffusion Models}

The effectiveness of policy measures to limit environmentally hazardous emissions depends on the extent to which they induce polluters to reduce the flow of pollutant emissions. Although such emissions reductions may be achieved in various ways, they are usually realized through the application of pollution control technologies or the usage of low-emission processes and products. This implies that possible improvements in environmental qualities are a function of the rate of application or diffusion of environment-saving products and processes. The aim of this chapter is to give an overview of technological diffusion models and to theorize about the appropriate diffusion model for describing the growth in ownership of technological innovations.

This chapter is organized as follows. Section 1 introduces the two main models of technological diffusion: the epidemic and rational choice model. The epidemic model is described in section 2 . The rational choice model of technological diffusion is described in section 3. Section 4 examines which model may be used best to analyze the diffusion process of various sorts of technological innovations in different adopter environments. We will argue that there is no single best model for analyzing the diffusion of technological innovations. The choice of the appropriate diffusion model should be based on the characteristics of the adopter environment (whether potential adopters are consumers or firms), the economic characteristics of the technology (purchase price, operating costs, performance), and changes therein, and learning of potential users about the technology.

\subsection{Introduction}

What makes the diffusion of technological innovations an important issue for social study is that economic welfare depends on the rate at which new technologies are adopted and put into use. As Nathan Rosenberg writes: "new techniques exert their economic impact as a function of the rate at which they displace older techniques and the extent to which the new techniques are superior to the old ones". ${ }^{1}$ Although the above statement refers to productivity-increasing and utility-enhancing technological innovations, something similar applies to environment-saving innovations: that the environmental benefits of low-emission technologies are a function of the rate of applica-

${ }^{1}$ Nathan Rosenberg, 1976, Factors Affecting the Diffusion of Technology, in Perspectives on Technology, Cambridge: Cambridge University Press, p.189. 
tion of these technologies and the extent to which they are more environmentally benign than comparable processes and products.

Being a topic of considerable social and economic significance, the diffusion of technological innovations has been studied by sociologists, anthropologists, economists, and marketing and management scientists. In his 1983 book "Diffusion of Innovations", Everett Rogers reports of 3,085 diffusion publications, 2,297 of which were empirical research reports. ${ }^{2}$ The bulk of these studies were performed in a relatively short period, starting in the late fifties. The primary aim of such studies was, as Paul Stoneman writes, to rationalize why, if a new technology is superior, it is not taken up immediately by all potential users. $^{3}$

In the study of the diffusion of technological innovations, various theoretical models have been developed and employed to describe the diffusion of a wide range of technological innovations. These models of innovation diffusion can be divided into two broad categories: the epidemic diffusion models (divided into models that incorporate economic factors and those that do not), and the rational choice diffusion models in which the aggregate diffusion pattern is the result of economic decision making by individual adopters. In the first type of models, the system adjusts to a new equilibrium, whereas in the second type of models economic actors are in equilibrium.

\subsection{The Epidemic Diffusion Model}

The starting point of theoretical analysis of technological diffusion was the epidemic model stemming from mathematical biology. The epidemic model was used by economists Zvi Griliches (1957) and Edwin Mansfield (1961) and is still the most widely used model in marketing and management sciences. ${ }^{4}$ The characteristic property of the epidemic model is that the diffusion process of a technological innovation is being governed by an endogenous process of learning and taste formation through personal contact or observation. Just as an infectious disease may spread through contact of individuals, so will a new technology. Perhaps the best-known epidemic model is the logistic model. Both Griliches (1957) and Mansfield (1961) used the logistic model in their intra-sector and inter-industry diffusion studies. The logistic model is described by the differential equation:

${ }^{2}$ Everett M. Rogers, 1983, Diffusion of Innovations, New York: Free Press, p. XV.

${ }^{3}$ Paul Stoneman, 1983, The Economic Analysis of Technological Change, Oxford: Oxford University Press, p.65.

4 Zvi Griliches, 1957, Hybrid Corn: An Exploration in the Economics of Technical Change. Econometrica, 25: 501-522; and Edwin Mansfield, 1961, Technical Change and The Rate of Imitation, Econometrica, 29: 741-766 (also published as chapter 7 of his 1968 book Industrial Research and Technological Innooation: An Econometric Analysis, New York: Norton). 


$$
\frac{d n_{t}}{d t}=\beta \frac{n_{t}}{N}\left(N-n_{t}\right)
$$

with $n_{t}$ the number of individuals (consumers, firms) that have contracted the disease (adopted the innovation) at time $t, N$ the size of the population of people who may get the disease (the potential adopters), and $\beta$ the parameter reflecting the likelihood of contracting the disease. Thus, the number of new infections (adoptions) at period $t$ is equal to the number of uninfected persons (remaining potential adopters), $N-n_{t}$, multiplied by the probability of infection (adoption), which is the product of proportion of the populations infected (already adopters) at time $t, n_{t} / N$, and the parameter $\beta$, which is dependent upon a number of factors such as the infectiveness of the disease and the frequency of contact, both of which are assumed to be constant. Parameter $\beta$ may reasonably be called the speed of diffusion, though it is not the growth of diffusion. ${ }^{5}$

Equation (1) states that the number of (new) adopters is a function of the number that have already adopted the innovation, $n_{t}$, which reflects the idea that a basic characteristic of the epidemic model is imitative behaviour or "bandwagon" effects. It should be noted that whereas the probability of adoption increases over time, the number of new adopters decreases after a certain point (which is when $n_{i} / N=0.5$ ) due to the decreasing number of non-adopters. This leads to a bell-shaped frequency distribution for numbers adopting over time. The cumulative number of adopters is described by a sigmoid ( $S$ shaped) logistic curve which asymptotically approaches the saturation level $N .^{6}$ The logistic curve is depicted in Figure 4.1.

Most empirical investigations of the logistic model are straightforward, using linear regression analysis on the transformation of equation (1):

$$
\log \left(\frac{n_{t}}{N-n_{t}}\right)=\alpha+\beta t
$$

Both Griliches in his 1957 study of hybrid corn and Mansfield in his 1961 study of the diffusion of twelve innovations in American industry estimated the above equation (with an error term added on the right-hand side). In a second stage, the estimates of the speed of diffusion $\beta$ are used as the dependent variable in a cross-section analysis, to

${ }^{5}$ The above description stems from Colin G. Thirtle and Vernon W. Ruttan, The Role of Demand and Supply in the Generation and Diffusion of Technical Change, Chur: Harwood Academic Publishers, pp.80-81 (who base themselves on Stephen Davies, 1979, The Diffusion of Process Innovations, Cambridge: Cambridge University Press, pp.9-11).

${ }^{6}$ Solving equation (1) gives the number of adopters as a function of time:

$n_{t}=\frac{N}{1+\exp (-\alpha-\beta t)}$ with $\alpha$ the constant of integration. 
analyze the impact of certain industry characteristics and product characteristics (like the profitability of the innovation and investment costs) on the diffusion process. ${ }^{\text {? }}$

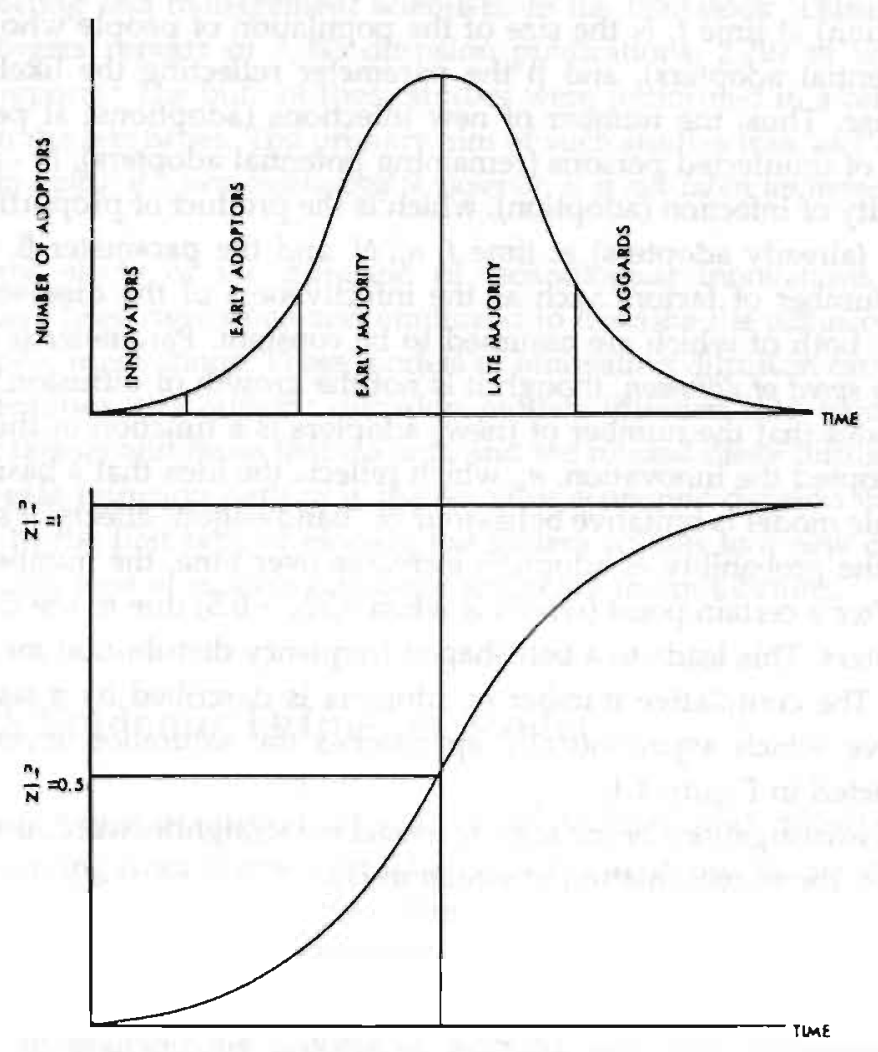

Figure 4.1. The logistic curve. Source: Thirtle and Ruttan (1987, p.81). ${ }^{8}$

Despite its wide application and its success in describing empirically the diffusion process of technological innovations, the logistic curve is based on a number of rather stringent assumptions. These are spelled out by Davies: First, the infectiousness of the disease must remain constant over time for all individuals. In other words, $\beta$ must be

${ }^{7}$ For a critical discussion of the empirical studies by Mansfield (1961) and Griliches (1957), see Davies op cit, pp.13-19 and Robert Dixon, 1980, Hybrid Corn Revisited, Econometrica, 48(6): 1451-1462, respectively.

${ }^{8}$ The distinction in adopter categories is from Rogers, op cit. 
constant. (If $\beta$ falls (increases) over time the growth curve will be positively (negatively) skewed.) Second, all individuals must have an equal chance of catching the disease. In other words, $\beta$ is the same for all groups within the population. Third, the population of adopters is constant irrespective of the changes that may occur in the adoption environment (shifts of preferences, changes in people's wealth) or in the technology (improvements, price changes). Fourth, the possibility of cures and reinfection (leading to multiple purchases) is ruled out. ${ }^{9}$

Other epidemic diffusion models that have been used (quite) extensively to describe empirically the aggregate diffusion pattern of a technological innovation are the Gompertz-model, a positively skewed model with an inflection point at $n_{t} / N=0.37$ (instead of 0.5 as in the logistic model), the lognormal model, and, especially in marketing, the Bass model. Of these models, the Bass model is most often used to predict future product sales. Several companies, including Eastman Kodak, RCA, IBM, Sears, and Hewlett-Packard, have employed the model and variations of it for forecasting purposes. ${ }^{10} \mathrm{~A}$ description of the Bass model is given below. ${ }^{11}$ As other epidemic models, the Bass model assumes that the central mechanism behind the diffusion patterns is the transmission of information through communication. However, unlike the logistic model, it makes a distinction between two means of communication: mass media and word of mouth. Adopters are divided into two groups: people that are influenced only by massmedia communication, called "innovators", and those that are influenced only by wordof-mouth communication, termed as "imitators". The Bass model derives from a hazard function (which gives the probability that an adoption will occur at time $t$ given that it has not occurred before) given in equation (4):

$$
\frac{f(t)}{1-F(t)}=p+q F(t)
$$

The density function of time to adoption is given by $f(t)$ and the cumulative fraction of adopters at time $t$ is given by $F(t)$. This basic premise states that the conditional probability of adoption at time $t$ (the fraction of the population that will adopt at time $t$ ) is increasing in the fraction of the population that has already adopted. As in the logistic model, this reflects learning and imitation on the part of potential adopters (internal influence). However, the conditional probability of adoption also depends on parameter $p$ which reflects an external influence, independent of the fraction of previous adopters.

${ }^{9}$ Davies, op cit, pp.11-13.

10 Frank M. Bass, 1980, The Relationship Between Diffusion Rates, Experience Curves, and Demand Elasticities for Consumer Durable Technological Innovations, Journal of Business, S51.

${ }^{11}$ The following description of the Bass model (1969) stems from Vijay Mahajan, Eitan Muller and Frank M. Bass, 1992, New Product Diffusion Models in Marketing: A Review and Directions for Research, in Nebojsa Nakicenovič and Arnulf Grübler (eds.), 1992, Diffusion of Technologies and Social Behaviour, Berlin: Springer-Verlag, pp.125-178 (the article was originally published in the Journal of Marketing, 1990, pp.1-26). 
For the purpose of comparison, we rewrite the Bass model in a form with which we are already familiar:

$$
\frac{d n_{t}}{d t}=p\left(N-n_{t}\right)+q \frac{n_{t}}{N}\left(N-n_{t}\right)
$$

If we compare equation (5) with (1) we see that the two equations are identical except for the term $p\left(N-n_{l}\right)$ on the right-hand side. In fact, the Bass model combines the negative exponential model used by Fourt and Woodlock (1960) and the earlier discussed logistic model. ${ }^{12}$ In the Bass model, the first term, $p\left(N-n_{t}\right)$, represents adoptions due to buyers who are not influenced in the timing of their adoption by the number of people that have already bought the product. This term gradually decreases over time due to the fact that the number of people that have not yet adopted at time $t, N-n_{t}$, is decreasing with time. The second term in equation (5), $q\left(n_{t} / N\right)\left(N-n_{t}\right)$, represents adoptions due to buyers who are influenced by the number of previous buyers. This term increases up to a certain point in time, after which it starts to decrease. Bass (1969) refers to $p$ as the "coefficient of innovation" and to $q$ as the "coefficient of imitation", although, as noted by Lekvall and Wahlbin (1973), it is probably better to speak of the coefficients of external and internal influence, respectively. ${ }^{13}$

Being a flexible diffusion model, the Bass model has been successfully applied in a number of empirical studies of the diffusion of new consumer durables. The model is interesting in that it allows for independent decision making on the basis of product information supplied by the producer through promotional advertising. In the logistic model, only word-of-mouth effects determine the aggregate diffusion pattern. The Bass model may also be used to analyze the effects of promotional advertising on the diffusion process, which has been attempted by some diffusion students.

There are, however, a number of problems with the Bass model. First, as noted by Tanny and Derzko (1988), the mathematical formulaton of the Bass model does not correspond to the original qualitative description of the diffusion process by Frank Bass in his 1969 article, in which there are two dichotomous classes of individuals (innovators and imitators) with inherently different response characteristics to new products. They rightly point out that the Bass model does not really abandon the assumption of a homogeneous population. What the model does is to distinguish between internal and external influence. As Tanny and Derzko write:

The Bass-model implicitly assumes that individuals in the population are homogeneous with respect to their behaviour regarding the adoption decision. That is, all individuals in the population implicitly must be assumed to have intrinsic innova-

12 L.A. Fourt and J.W. Woodlock, 1960. Early Prediction of Market Success for New Grocery Froducts, Iournal of Marketing, 25: 31-38.

${ }^{13}$ P. Lekvall and C. Wahlbin, 1973, A Study of Some Assumptions Underlying Innovation Diffusion Functions, Silridish Joumal of Economics, 75: 362-377. 
tive and imitative tendencies in some fixed, common proportion. Whether an individual ultimately adopts the product as a result of this tendency to innovate or through contact with an adopter is a process affecting all individuals in the same way. ${ }^{14}$

This induced Tanny and Derzko to reformulate the Bass model in line with the behavioural assumptions of its original description by Bass (1969) where innovators and imitators constitute two distinct but interacting subpopulations. Estimation of the twocompartment model, however, resulted in unsatisfactory model estimation results, which casts some doubt on the appropriateness of the innovator-imitator dichotomy. Secondly, several of the objections to the logistic model also apply to the Bass model (a fixed adopter population, the only diffusion mechanism is the transmission of information, constant diffusion parameters, the absence of differences in the propensity to adopt within each subpopulation, etc.).

The logistic model, the Gompertz model and the Bass model (or the generalized logistic as some people have called it) have been extended in several ways to mirror any specific form of the diffusion pattern. In marketing and management science, several flexible diffusion models have been suggested and empirically applied. ${ }^{15}$ In Hernes (1976), the constant diffusion parameter $\beta$ of the logistic model is replaced by a time-varying $\beta$ coefficient $\left(\beta=A b^{t}\right.$ in which $t$ stands for time). ${ }^{16}$ For values of $b<1$, the diffusion path is positively skewed and for values of $b>1$ it is negatively skewed. The model of Easingwood, Mahajan and Muller (1983) adapts the Bass model in that the coefficient of internal influence (the word-of-mouth effect) varies with the number of adopters (a factor $\left(n_{t} / N\right)^{\alpha}$ is added to $\left.q\right)^{17}$

Not surprisingly, these flexible diffusion models yielded better fits than the original models they extended. However, as being epidemic models dealing with the diffusion in the aggregate they can be subjected to a number of criticisms. These are summarized in a survey article by Paul Stoneman: i) the potential adopters are considered homogeneous, ii) information sources are all internal (i.e., information does not come from outside the set of adopters), iii) the decision-theoretic framework does not really capture the essence of decision making under uncertainty, iv) the technology is assumed not to

${ }^{14}$ S.M. Tanny and N.A. Derzko, 1988, Innovators and Imitators in Innovation Diffusion Models, Journal of Forecasting, 7: 225-234.

${ }^{15}$ For a survey of flexible epidemic diffusion models, see Vijay Mahajan and Robert A. Peterson, Models for Innovation Diffusion, Beverly Hills: Sage Publications, and the chapter by Mahajan ot al in the earlier-referred book Diffusion of Technologies and Social Change.

1h Gudmund Hernes, 1976, Diffusion and Growth - The Non-Homogeneous Case, Scandinavian Journal of Economics, 78: 427-436.

17 Christopher J. Easingwood, Vijay Mahajan and Eitan Muller, 1983, A Nonuniform Influence Innovation Diffusion Model of New Product Acceptance, Management Science, 2(3): 273-293. 
change over time, and v) the treatment of risk, uncertainty and information acquisition has been considered very inadequate..$^{18}$

A further drawback of the first generation of epidemic models is that they are silent about how the diffusion process is affected by changes in economic factors (purchase price, factor prices, profitability, incomes), this while the decision to adopt a technological innovation is largely an economic decision. ${ }^{19}$ There have been attempts however to incorporate economic variables explicitly into an epidemic model - instead of in an indirect way as in the studies by Griliches and Mansfield referred to previously. We will now describe some of these epidemic models in which the diffusion process is affected by changes in economic variates. Gregory Chow (1967) was perhaps the first who modified the epidemic model to incorporate other economic factors in a technological diffusion model in his study of the usage of general-purpose digital computers in the United States in the 1954-67 period. ${ }^{20}$ In his analysis, the diffusion process is the outcome of both epidemic learning and improvements in the quality-price ratio of the innovation that raise the equilibrium level. His model is a stock-adjustment model in which the growth of computer usage at time $t$ is proportional to the difference between the actual stock and the equilibrium stock.

In Stephen Glaister (1974), the diffusion speed $\beta$ is made a function of price $p^{21}$ Glaister analyzes the optimal price strategy and optimal advertising policy (when holding price constant) of a monopolist supplier. As one would expect in an epidemic model in which the diffusion process is driven by endogenous factors, it is optimal for the monopolistic supplier to set a low price initially (forward pricing) and engage in relatively heavy advertising in the early stages to encourage early growth of users.

In Dan Horsky and Leonard Simon (1983) the effect of advertising expenditures on the diffusion process is also analyzed. ${ }^{22}$ In the model, the probability of adopting by a potential adopter is a function of both word-of-mouth effects and advertising expenditures. Their model is a revision of the original Bass model, with $q$, the coefficient of external influence being a function of advertising expenditures.

I8 Paul Stoneman, 1985, Technological Diffusion: The Viewpoint of Economic Theory, mimeo, Warwick University.

${ }^{19}$ This leads Dan Horsky to say that while the epidemic models provide a theory why consumers do not simultaneously adopt a new consumer durable, "they lack a theory as to why consumers buy those durables in the first place" (Dan Horsky, 1990, A Diffusion Model Incorporating Product Benefits, Price, Income and Information, Marketing Science, 9(4), p.343.

${ }^{20}$ In fact, Chow applied two epidemic diffusion models: the Gompertz and the logistic (the logistic used by Chow is somewhat different from the logistic described earlier in that the right-hand side is multiplied by $N_{t}$ ).

${ }^{21}$ Stephen Glaister, 1974, Advertising Policy and Returns to Scale in Markets where Information is Passed Between Individuals, Economica, 41: 139-156.

${ }^{22}$ D. Horsky and L.S. Simon, 1983, Advertising and the Diffusion of New Products, Marketing Science, 2: 1-17. 
Bass himself extended his own 1969 model in a 1980 article. $^{23}$ The new Bass model is very interesting in that the diffusion process of a consumer durable is the result of price changes (through learning curve effects during the diffusion process) and shifts of the demand curves (due to contagion and learning) that are endogenous to the diffusion proces. The diffusion process is thus the result of interacting supply and demand factors. The model predicts that a period of falling price and increasing demand will be followed by a period of falling price and decreasing demand, a result that according to Bass is consistent with the empirical evidence for new consumer durables. ${ }^{24}$ The new Bass model is summarized graphically in Figure 4.2. ${ }^{25}$

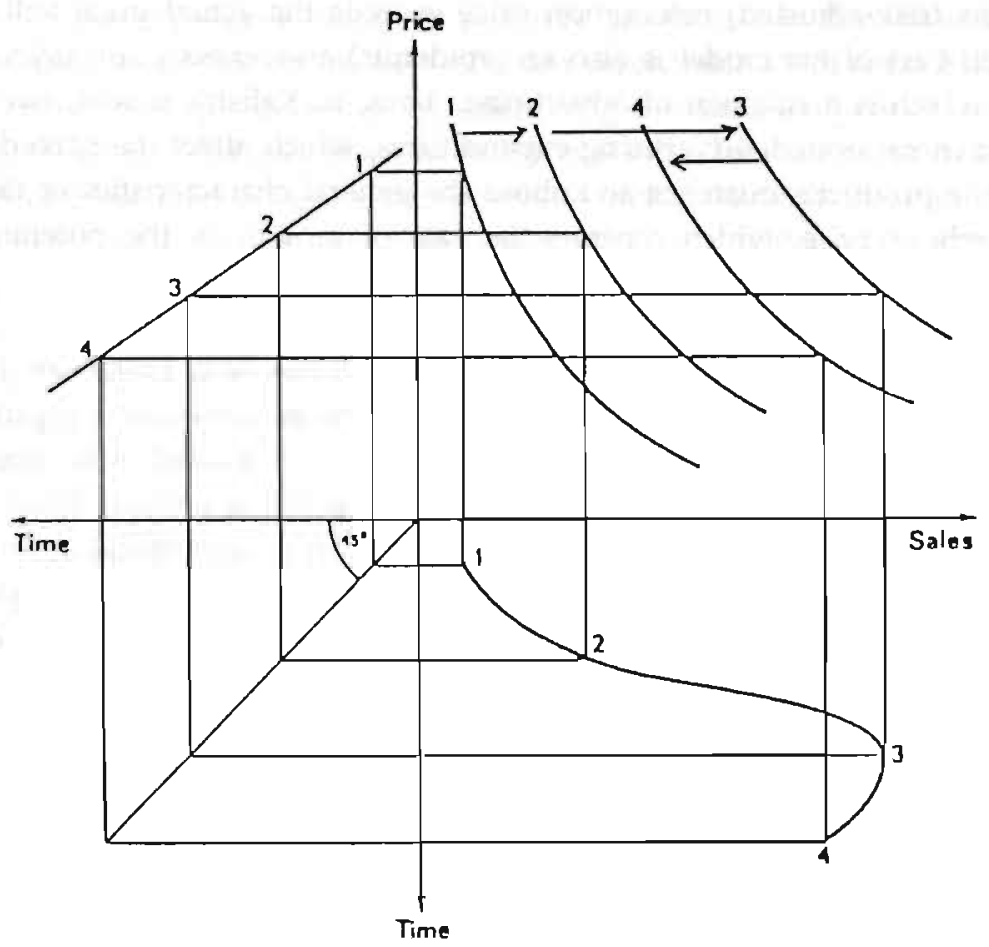

Figure 4.2. The Bass diffusion model with experience-curve effects and endogenous consumer leaming. Taken from: Thomas Russell (1980, p.370).

\footnotetext{
${ }^{23}$ Bass, 1980, op cit.
}

${ }^{24}$ Ibid, $\mathbf{S 5 5}$.

25 Thomas Russell, 1980, Comments on "The Relationship between Diffusion Rates, Experience. Curves, and Demand Elasticities for Consumer Durable Technological Innovations", Joumal of Business, 53: 569-573. 
Figure 4.2. demonstrates how shifts in the demand curve (depicted in the upper-right quadrant) and reductions in the price of the innovation (depicted in the upper-left quadrant) over time ( $t=1,2,3,4)$ trace out a sigmoid diffusion pattern. The demand curve is assumed to shift to the right for $t=2$ and 3 (due to information transfer and bandwagon effects), and to shift backwards at $t=4$ when demand for the innovation is saturated.

In Shlomo Kalish (1985), the population of potential adopters is made a function of the purchase price of the technological innovation. ${ }^{26}$ Kalish thus abandons the implicit assumption of most epidemic models of a homogeneous adopter population. In his model, the population is heterogenous with respect to their valuation of the product (reservation prices), due to income and taste differences. Only those of the population for which the (risk-adjusted) reservation price exceeds the actual price will adopt the new product. Part of his model is also an (epidemic) awareness information diffusion mechanism which is a function of advertising. Thus, in Kalish's model, two economic variables are incorporated: advertising expenditures, which affect the spread of awareness about the product's existence and about the general characteristics of the product; and the purchase price, which controls the rate of growth of the potential adopter population.

Another interesting epidemic model is that of Karshenas and Stoneman (1992). ${ }^{27}$ In their model (which nests the logistic model and the first Bass model), the probability of acquistion $\beta$ is a function of economic variables instead of a fixed parameter. Furthermore, the influence of previous adopters in terms of learning and/or social emulation gradually wears off, something which they consider to be a more realistic assumption as each individual has contact with only a limited number of individuals in society and as news about the existence and qualities of the new product becomes common knowledge through exogenous sources of information. As in the Bass model, an external factor is incorporated into the learning or emulation process. Unlike the standard epidemic model, the model by Karshenas and Stoneman does not assume a priori the dominance of an endogenous growth factor throughout the diffusion process. The relative strengths of the exogenous and endogenous forces may be determined empirically.

Whereas the above models in which economic factors are incorporated constitute a clear improvement over the original epidemic models, they still suffer from a rather weak decision-theoretic framework. As noted by Davies, " by dealing only with the behaviour of firms [or consumers] in the aggregate, it pushes aside many of the more

${ }^{26}$ Shlomo Kalish, 1985, A New Product Adoption Model with Price, Advertising, and Uncertainty, Management Science, 31(12): 1569-1585.

${ }^{27}$ Massoud Karshenas and Paul Stoneman, 1992, A Flexible Model of Technological Diffusion Incorporating Economic Factors with an Application to the Spread of Colour Television Ownership in the UK, Journal of Forecasting, 11: 577-601. 
interesting theoretical questions and substitutes a rather mechanistic hypothesis of behaviour". ${ }^{28}$ This has led some diffusion scholars to develop innovation diffusion models in which the diffusion pattern is the result of economic decision making by prospective adopters. It is to these models that we turn to now.

\subsection{Rational Choice Models of Technological Diffusion}

Although the epidemic models were able to describe empirically the aggregate diffusion patterns of technological innovations quite well, several people expressed doubts about its general relevance. As noted before, the rationale of the epidemic model is in learning through the endogenous spread of information. Although demonstration effects and learning from the experience of others certainly are factors in the diffusion of a new technology, their relevance as the key diffusion mechanisms was seriously questioned, especially by economists. Moreover, by addressing the diffusion process in the aggregate, the epidemic model is silent about one of the more interesting questions: Why do some firms or consumers adopt certain innovations more quickly than others? ${ }^{29}$

The reason why the epidemic diffusion models are not able to foretell who will be an early adopter and who will not is the absence of a causal explanation of behaviour. This has led some diffusion scholars (mostly economists but more recently also marketing and management scientists) to develop diffusion models in which the decision to adopt or not to adopt the innovation by potential users is explicitly modelled. The development of the diffusion models from individual adopter decisions reflects a trend towards giving macro models a micro-economic foundation and. ${ }^{30}$ Moreover, there is generally more consideration of supply factors (changes in purchase price, post-innovation improvements in the technology) in making firms and consumers adopt a particular innovation. In those models, the reason why potential adopters do not immediately

${ }^{28}$ Davies, op cit, p.35.

29 Ibid, p.15.

30 It is interesting to note that Zvi Griliches, one of the pioneers of the epidemic model, writes in a later comment that "if all variables describing individuals and affecting them were observable, one might do without the notion of diffusion and discuss everything within an equilibrium framework. Since much of the interesting data are unobservable, time is brought in to proxy for at least three sets of distinct forces: (1) the decline over time in the real cost of the new technology due to decreasing costs as the result of learning by doing and to cumulative improvements in the technology itself; (2) the dying-off of old durable equipment, making room slowly for the new, and, (3) the spread of information about the actual operating characteristics of the technology and the growth in the available evidence as to its workability and profitability" (Zvi Griliches, 1980, Hybrid Corn Revisited: A Reply, Econometrica, 48(6): 1463-1464). 
adopt the new product or technique is because it is not rational for them to do so. These models may be called rational choice diffusion models. ${ }^{31}$

In the rational choice models, the diffusion process of a technological innovationeither a process innovation or a consumer product - is the outcome of the calculated choices by prospective adopters who adopt the new product or process as soon as some stimulus variate exceeds a critical level (threshold). The rational choice models may be divided into two classes: perfect information models and models with (exogenous) learning. Threshold models like the probit and logit model and vintage models belong to the first category.

The probit model is perhaps the best-known model of the class of threshold models in which a discrete choice (such as adoption of a new product) takes place the moment at which an exogenous stimulus variable crosses a threshold. The rationale of the probit model (or logit model) is well-described by Paul David:

Whenever or wherever some stimulus variate takes on a value exceeding a critical level, the subject of the stimulations responds by instantly determining to adopt the innovation in question. The reason such decisions are not arrived at simultaneously by the entire population of potential adopters lies in the fact that at any given point of time either the 'stimulus variate' or the 'critical level' required to elicit an adoption is described by a distribution of values, and not a unique value appropriate to all members of the populations. Hence, at any point in time following the advent of an innovation, the critical response level has been surpassed only in the cases of some among the whole population of potential adopters. Through some exogenous or endogenous process, however, the relative position of stimulus variate and critical response level are altered as time passes, bringing a growing proportion of the population across the 'threshold' into the group of actual users of the innovation. ${ }^{32}$

David suggested the probit model to the diffusion of the McCorwick mechanical reaper in the American Midwest in the 19th century. The critical variate is farm size: for small firms below a critical threshold it is not profitable to adopt the product since the savings in wages due to a reduction in labour use do not exceed the cost of the reaper. However, as wage rates rise relative to the price of the reaper it becomes profitable for smaller firms to use the product. As a result, the critical level of farm size shifts to the left, thus tracing out a diffusion curve (see Figure 4.3).

${ }^{31}$ They are sometimes referred to as "discrete choice" models (as in Karshenas and Stoneman, op cit., p.578). We prefer the term "rational choice" models because it rational decision making by prospective adopters which distinguishes these models from epidemic models that lack an explicit causal explanation of market behaviour.

${ }^{32}$ Paul A. David, 1969, A Contribution to the Theory of Diffusion, Stanford Center for Research in Economic Growth, Stanford Centre for Research in Economic Growth, Memorandum 71. 


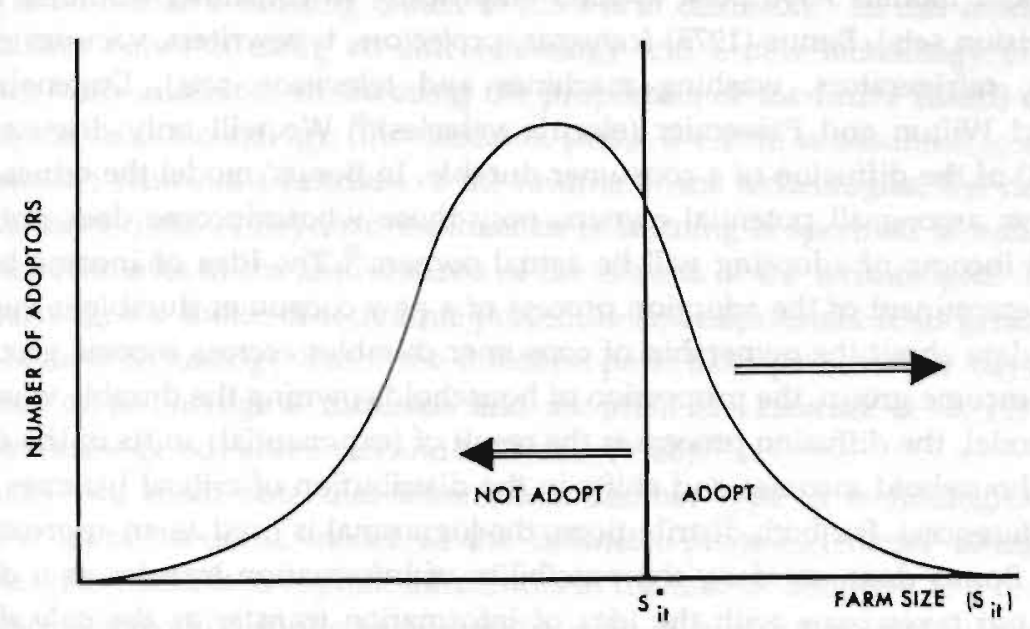

Figure 4.3. Relative frequency distribution of farm size. Taken from Thirtle and Ruttan (1987, p.111).

Stephen Davies has developed a similar model to explain the diffusion of industrial process innovations. The critical variate is firm size, which, as in David's model, is assumed to be lognormally distributed. In Davies' model (1979), post-innovation improvements change the critical level of firm size which (together with changes in firm size) yield a sigmoid diffusion curve. Whereas in David's model, increases in the relative wage rates predominantly control the diffusion process, in Davies' model it is postinnovation improvements of the innovation and learning that trace out a sigmoid diffusion curve. His model furthermore differs from David's model in that firms make decisions in a behavioural way by comparing the expected pay-off period to some critical pay-off period which varies with firm size. The model has been applied empirically to twenty-two process innovations in U.K. manufacturing industries in the post-war period. In his analysis, the innovations are divided into two groups. Group A consists of relatively cheap and simple innovations, while in group B innovations are expensive and complex with much opportunity for post-invention improvements. For group A innovations, Davies derives analytically a positively skewed cumulative lognormal and for group B innovations the symmetric cumulative logistic.

It is important to note that in the probit models learning and social interaction play a limited role. They are considered "equilibrium models" by Thirtle and Ruttan because in these models "the system has adjusted to the particular values of the variables at each point in time, rather than being out of equilibrium and approaching a distant final ceiling level of diffusion". ${ }^{33}$

${ }^{33}$ Thirtle and Ruttan, op cit, p.109. 
Threshold models have been applied empirically to consumer durables by Bain (1964) (television sets), Bonus (1973) (cameras, projectors, typewriters, vacuum cleaners, automobiles, refrigerators, washing machines and television sets), Dagenais (automobiles) and Wilton and Pessemier (electric vehicles). ${ }^{34}$ We will only discuss Bonus' model (1973) of the diffusion of a consumer durable. In Bonus' model the critical stimulus is income: among all potential owners, only those whose income does not exceed their critical income of adopting will be actual owners. ${ }^{35}$ The idea of income being an important determinant of the adoption process of a new consumer durable is supported by detailed data about the ownership of consumer durables accross income groups. For each higher income group, the proportion of households owning the durable was higher. In Bonus' model, the diffusion process is the result of (exponential) shifts in the distribution of real household incomes and shifts in the distribution of critical incomes (due to shifts in preferences). For both distributions, the lognormal is used as an approximation. To be sure, Bonus does not deny the possibility of information transfer as a diffusion mechanism but takes issue with the idea of information transfer as the only diffusion mechanism (or even the key mechanism).

Another rational choice or equilibrium model is the vintage model. In the vintage model, the capital stock is made up of machines of different ages (vintages) with different operating costs. Although the vintage model has not been fully developed as a diffusion model, it may be used to explain the non-instantaneous adoption of a "bestpractice" machine which is available to potential users. In the vintage model, old machines remain to be used as long as their revenues cover their operating costs or when the variable costs of the old plants are below the total annual costs of using the new plant. The diffusion process of the new technology is a function of factor price changes and the rate of capacity expansion.

Although the threshold and vintage models rightly stress the importance of changes in the heterogenous adopter environment (factor price changes, rising incomes) and/or changes in the innovation (post-innovation improvements and price changes) to the diffusion process, they can be subjected to a number of criticisms. Several of the models' shortcomings are pointed out by Paul Stoneman: First, the diffusion process is driven by exogenous changes in factor prices and no real attempt is made to endogenize such price movements; second, learning is given a very minor role, if any, in these models, because, basically, they assume complete information. ${ }^{36}$

A way of combining the idea of imperfect information and learning with rational decision making by individual adopters is by using an Bayesian learning model. An

${ }^{34}$ For exact references, we refer to Thirtle and Ruttan, op cit.

${ }^{35}$ Holger Bonus, 1973, Quasi-Engel Curves, Diffusion, and the Ownership of Major Consumer Durables, Journal of Political Economy, 81, p.657.

${ }^{36}$ Stoneman, 1983, op cit, p.104. 
example is Stoneman's learning model of intra-firm diffusion..$^{37}$ In this model, the firm faces a choice between using an old technology and a new technology of which the returns are both uncertain. In choosing the proportion of the firm's (fixed) output produced on the new technology (the diffusion path), the firm is assumed to maximize a utility function which is a function of the returns of the technologies, the risk involved and adjustment costs. A Bayesian mechanism of learning is specified in which the firm updates its estimates of the distributions of the returns of the technologies. The interaction of learning, the choice of technique procedure and adjustment costs generate a timepath of the new technology that is the diffusion path. Examples of other Bayesian learning models of technological diffusion and adoption are Lindner et al. (1979), Jensen (1982), McCardle (1985) and Oren and Schwartz (1988). ${ }^{38}$

Finally, we must note that there exists another type of technological diffusion model: the game theoretic model of the diffusion process. Jennifer Reinganum has shown that it is possible to explain differences in the time of adoption of a cost-reducing technological innovation in terms of a game with or without perfect information. She shows that even in the case of identical firms and complete certainty, there may be 'diffusion' of innovation over time, in the sense that firms do not adopt simulateneously the innovation. ${ }^{39}$ This result is derived on the assumption that the profitability of adoption decreases with the number of adopter firms and the assumption that the adoption costs decrease with time. Whatever one may think about such a model, a shortcoming is the absence of learning and risk reduction. Moreover, they are not able to derive sigmoid diffusion curves that are commonly observed. The practical meaning of game-theoretic diffusion models is thus limited at their current state of development.

\subsection{A Comparison of Technological Diffusion Models}

The reason for giving a rather extensive overview of the various diffusion models is to find out what model is most suitable for explaining the diffusion of an environmentsaving technological innovation and for analyzing the technological diffusion effects of various policy instruments. This section will argue that there does not exist a comprehensive theoretical diffusion model which captures all the factors that are likely to affect the decision of prospective adopters at any particular moment to adopt or not to adopt a

" Ibid, pp.77-88.

${ }^{38}$ R. Lindner, A. Fischer and P. Pardey, 1979, The Time to Adoption, Economics Letters, 2: 187-190; Richard Jensen, 1982, Adoption and Diffusion of an Innovation of Uncertain Profitability, Journal of Economic Theory, 27: 182-193; Kevin F. McCardle, 1985, Information Acquisition and the Adoption of New Technology, Management Science, 31(11): 1372-1389; and Shmuel S. Oren and Rick G. Schwartz, 1988, Diffusion of New Products in Risk-sensitive Markets, Journal of Forecasting, 7: 273-287.

${ }^{39}$ Jennifer Reinganum, 1981, On the Diffusion of New Technology: A Game Theoretic Approach, Review of Economic Studies, 58: 395-405. 
technological innovation. Such a model would have to incorporate the following factors (and the evolution thereoff): the technological and economic properties of the innovation (performance characteristics, its purchase price, costs of installation, operating costs); competitive and social pressures that induce or force potential buyers to purchase the innovation; consumer preferences and valuation of performance characteristics; people's perceptions of the innovation and attitudes towards the new technology; the availability of the innovation; attempts by suppliers and others to persuade people to buy a new technology; the search for information and reduction of risk, etc. It may be clear that it is impossible to develop an analytically manageable model in which all the above factors (or even a large subset of these factors) are incorporated in a non-superficial way. ${ }^{40}$

With respect to the spread of a technological innovation across a population of potential adopters, the key problem is what factors are responsible for the time-intensive diffusion process and whether these factors are exogenous or endogenous to the diffusion process. In the epidemic models it is endogenous changes that drive the diffusion process: the probability of adoption of a new product is increasing in the fraction of the population of potential adopters that has already adopted. In these models, learning and imitation are commonly considered as the key diffusion mechanisms. In the previous section, it was noted that the epidemic models, at least in their mathematical formulation, provided too simple an explanation for the spread of a new technology across a population of prospective adopters. Furthermore, the epidemic models lacked an explicit decision-theoretic framework from which the individual decisions to adopt or not to adopt can be understood."

10 At this point we should emphasize that the problem of the non-instantaneous adoption of a technological innovation relates to quite fundamental issues of human decision making and choice: whether individuals make decisions on the basis of a cost-benefit analysis, whether firms are maximizers or satisficers (and what it is that they maximize or satisfice), to what extent decision making is myopic and problem-oriented, whether or not people apply simple decision rules (rules of thumb) in complex decision situations, the ways in which social influences affect individual choices, and the role of perceptions, attitudes, personal judgements and interpretations (aspects that are being shaped by personal histories of potential adopters) in adopter decisions. It is not the purpose of this chapter to solve these issues, or to make an original contribution towards them, but we will touch upon these issues in our discussion of the rate of application of environmentally beneficial technological innovations.

11 This statement must be qualified: The logistic model used by Mansfield $(1961 ; 1968)$ is based on a (implicit) decision rule. And Davies (1979) derives the cumulative normal and lognormal growth curve from a model of decision making. Furthermore, in a recent article, Rabikar Chatterjee and Jehoshua Eliashberg have derived several 'epidemic' growth curves (like the logistic, the Gompertz and Bass growth curve) from a micro-economic model of the adoption process at the individual level (Rabikar Chatterjee and Jehoshua Eliashberg, 1990, the Innovation Diffusion Process in a Heterogeneous Population: A Micromodelling Approach, Management Science, 36(9): 1057-1079). A problem with these micro-economic models is that it is not clear what the exact contribution is of each of the variables in tracing out a diffusion growth curve. For instance, in Davies model (1979) it is unclear to what extent the growth curve is the result of learning or of post-innovation improvements since both factors are put into one parameter. 
In the rational choice models, the diffusion process is the result of exogenous changes in the (heterogenous) adopter environment and changes in the technology rather than the product of endogenous learning and taste formation. Although these models are right in emphasizing the role of changes in the adopter environment (changes in wage rates, the obsolescence of capital goods, increases in people's wealth etc.) and of possible improvements in the quality/price ratio of the technology, such changes are not independent of the diffusion process of the innovation. As noted by Stanley Metcalfe, "while some post-innovation improvements may be traced back to exogenous changes in knowledge, many arise from the experiences, incentives and bottlenecks which arise endogenously during the diffusion process". ${ }^{42}$ Furthermore, the diffusion process of a new technology is likely to affect the competitive conditions under which firms operate (for instance by increasing competitive pressure on non-adopters).

The central difference between the rational choice and epidemic models (or equilibrium and disequilibrium models), however, concerns the way in which agents acquire information relevant to their adoption decisions in a world of costly information and limited cognitive capacity. ${ }^{43}$ As Stan Metcalfe writes:

The key problem is not that adopters have full a priori information, although this is problematic enough. Rather the problem is the assumption of information sets which are given and interpreted independently from the process of diffusion. It is this which rules out any elements of fashion or bandwagon effects as an explanation of adoption. The appraisal by firms of an innovation is complete the moment the innovation is announced. Delay in adoption can only be the result of objective circumstances, not a failure to comprehend the significance of events. ${ }^{44}$

The above suggests that both endogenous and exogenous factors are involved in the spread of a new technology across a population of potential adopters, the relative importance of which will differ between innovations and adopter environments. Below, we will theorize about the relative importance of various diffusion mechanisms for different types of innovations and adopter environments. We will analyze how the diffusion process is likely to be affected by: (1) the characteristics of the adopters (in terms of goals, decision rules, their need for information, the financial resources available for the purchase of the new product, etc.); (2) the characteristics of the wider social and economic context (the fierceness of competition, social influences, whether there are competing technologies); and (3) the characteristics of the technological artefact (its price, technical characteristics, complexity, and the evolution of the quality/price ratio). On the basis of these factors, we will develop a number of hypotheses about the rate of application of environment-saving innovations and the evolution of the population of potential

\footnotetext{
2. J. Stanley Metcalfe, 1988, The Diffusion of Innovations, in Dosi et al, op cit, p.562.

${ }^{43} \mathrm{Ibid}, \mathrm{p} .567$.

${ }^{4}$ Ibid, p.566.
} 
adopters. Moreover, we will say something about what model may be used best to analyze the diffusion pattern of different types of technological innovations.

Let us start with the first element, the characteristics of the potential adopter and the adopter environment. It makes a big difference whether the potential adopter is a for-profit-firm, a not-for-profit organization or a consumer. ${ }^{45}$ We will limit our discussion to two types of adopters: for-profit-firms (hereafter shortened as firms) and consumers. A first difference between firms and consumers is to be found in the goals that they have. The behaviour of firms is heavily conditioned by the single objective of making profits (or the collorary goal of producing efficiently). Although the people that make up a firm may have goals and aspirations of their own, the need to make profits is of overriding importance since profits (the absence of losses) are a precondition for the firm's existence. The goals of consumers, on the other hand, are manifold; they range from purely physiological needs (food, clothing, shelter), to needs of comfort, entertainment, self-development, fulfilment of duties, and appreciation by others. The decisions and choices by consumers are to be understood from the relative importance of these goals and the sacrifices involved in achieving them.

Secondly, various kinds of knowledge are organized in firms: engineering principles of producer equipment, knowledge about the properties of materials used in the production, how to operate these machines, etc. This knowledge base of firms is constantly augmented and updated through applied research, contacts with suppliers, observations of competitors, the hiring of specialists, and special courses for employees. This implies that information problems about new technologies (their technical features) and the skills required for their operation are likely to be less of a problem for (knowledge-intensive) firms than they are for consumers. Furthermore, firms are more likely to engage actively in the search for information than consumers who may rely much more on casual observation.

Thirdly, competitive pressures force firms to produce efficiently. Whereas consumers may long resist or delay the purchase of a new product without putting one's life at stake, firms may be driven out of business if they are not keen enough to adopt a new technology in time. As a result, decision making in firms is likely to be more goaloriented and rational (based on cost-benefit analysis) whereas consumer decisions may be more traditional and subject to social influences.

As explained, the diffusion process depends not only on the characteristics of the adopter population but also on the characteristics of the technological innovation. If the innovation is expensive and complex, diffusion is bound to be slow, at least in the early stage. When a new technology is complex, potential adopters need time to evaluate the new technology and to acquire the necessary skills for using it. Such evaluation may be

${ }^{45}$ Examples of not-for-profit organizations are hospitals, schools, universities, ministries, clubs etc. Their goal is usually to serve a larger group (often the public). They differ from for-profit firms in that profits are not essential for their operation. (This does not imply that cost efficiency is not important, it usually is). Like consumers they have multiple goals. 
in the form of internal experiment, the collection of information by the firm itself, consultancy of outside specialists, or through the observation of the experience of others. All mechanisms of learning are commonly used, quite often simultaneously. The high costs of a complex innovation may also be a factor in the diffusion process, in delaying the adoption of a technological innovation. Risk-averse adopters are reluctant to buy a more expensive innovation even if the expected benefits from the usage of the innovation are correspondingly higher. Furthermore, financial means necessary for the purchase of a technological artefact may not be available within the firm, and time may be needed to raise such funds. The high costs of a technological innovation may pose a problem for small firms in particular. They may lack internal funds for the purchase of the innovation and they may suffer from scale disadvantages (due to the indivisibility or lumpiness of the innovation).

The diffusion speed also depends on whether the innovation is compatible with existing production processes and practices or requires the replacement of capital outlays and new skills. In the latter case, the rate of diffusion process depends on the rate at which older capital goods become obsolete and on the expansion of the market. Similarly, the diffusion of a new consumer good depends on the extent to which it is compatible with existing values, past experience and needs of potential adopters. ${ }^{46}$

The adoption of a durable, being a new production technique or a consumer product, furthermore depends on the time preference, risk aversion and discount rates (or maximum payback periods) of the potential adopters. Consumers are known to be extremely myopic in their decision making, they may apply implicit discount rates as high as $100 \%$. Firms are less myopic, they commonly apply rentability requirements above $10 \%$ or maximum payback periods of two to five years (depending on the expected economic service life of the innovation).

And finally, the adoption of a new technology depends on the profitability of the innovation: many studies find that the profitability of an innovation is an important determinant of the rate of the diffusion. ${ }^{47}$ The higher the profitability of a new production technique (other things being equal), the faster the diffusion process.

Up until now, we have discussed how various characteristics of the adopter population and certain attributes of the new technology affect the rate of application of technological innovations. Differences in the rate of adoption may be explained by differences in profitability, the expensiveness and complexity of the innovation, the compatibility with past practices and beliefs, etc. They do not explain why a firm or consumer adopts a

\footnotetext{
${ }^{46}$ Rogers, op cit, p.15.
}

${ }^{47}$ See, for instance, Griliches (1957), Mansfield (1968) and L. Nabseth and G.F. Ray (eds.), 1973, The Diffusion of New Industrial Processes. An International Study, Cambridge: Cambridge University Press. 
new technology at a particular moment. What we have been discussing is adoption theory, being an example of variance theory. ${ }^{48}$

To understand the actual purchase of an innovation by a potential adopter at a particular moment in time, we must look at the changes in the adopter environment and changes in the economic characteristics of the innovation. The actual adoption of an innovation at a particular moment may be the result of a better understanding of the technology, of changes in people's preferences, of changes in factor prices, the obsolescence of capital outlays, expansion of the market in which the technology is applied, increases in consumer wealth, changes in household characteristics (parenthood, settlement, etc.), post-innovation performance improvements and/or price reductions of the new technology (or changes in complementary technologies), and changes in the legal and institutional framework (like for instance environmental regulation).

To comprehend the diffusion process, we must ask ourselves the following questions: How important are incremental changes in the adoption environment and technology in inducing firms and consumers to adopt the innovation at a particular moment in time? Do small improvements in the performance characteristics of a technological innovation or gradual increases in people's wealth induce someone to purchase the new product at time $t$ rather than at time $t-1$ or $t+1$ ? As regards to learning: Does a marginally better understanding of a new product suddenly lead someone to purchase the product? Furthermore, if we believe learning is the key mechanism behind the aggregate diffusion pattern, how does it come about: is it through (stochastic) social interactions and advertisements or stem from the search for information by asking salesmen or consulting experts? If it is through word-of-mouth effects and advertisement, there is an important chance element involved. Other questions central to any understanding of adoption decisions are: How rational are people in making decisions about the purchase of an innovation or in their decision to search for information? To what extent is the decision to buy a new product whimsical and the result of an impulse? As a last point, what role do expectations play in making decisions (and how are they formed)?

The answers to these questions have important implications for the choice of diffusion models which may be used best to explain the diffusion pattern of a particular technological innovation across a population of potential adopters. We will argue that this choice of diffusion model needs to be based on what is believed to be the key diffusion mechanism: endogenous learning and consumer taste formation or exogenous changes in the innovation and adopter environment. Below we will theorize about the suitability of various diffusion models for analyzing the diffusion of different types of technological innovations across various populations of potential adopters.

48 The term "variance theory" is coined by Lawrence Mohr in his 1983 book, Explaining Organizational Bchavior, San Francisco: Jossey-Bass Publishers. In variance theory, the independent variables are both a necessary and sufficient condition for the outcome. An example of variance theory is the linear regression model in which the dependent variable (the outcome) is explained by the explanatory variables (including the error term). In process theory, on the other hand, the explanatory variables are necessary for the outcome but not sufficient: a probabilistic process is involved which determines the outcome. The epidemic diffusion model is an example of a "process" theory. 
We first consider the diffusion of a relatively simple and inexpensive innovation. For this type of innovation we consider learning as the key diffusion mechanism, although for consumer products endogenous taste formation (bandwagon effects) may also be a factor. For this type of innovation, the potential market does not depend importantly on changes in the adopter environment (such as increases in consumer wealth) or on changes in the innovation. An example of such an innovation is the ballpoint pen. Once it had been developed into a reliable product (which took some time), it diffused quite rapidly although its diffusion was delayed by social resistance and legal barriers - for instance, schools rejected it for quite some time for (disputable) educational reasons, official documents needed to be signed with a pencil. ${ }^{49}$ Since the diffusion of a simple and inexpensive innovation often depends on information transfer and bandwagon effects, the epidemic model may be used to describe the diffusion process. The choice of the epidemic model should be based on the 'infectiveness' of the innovation $\left(\beta_{l}\right)$ and on possible changes in the population of potential adopters $\left.\left(N_{\ell}\right)\right)^{50}$

If, however, the innovation is complex and expensive, the basic epidemic model may be inappropriate. Although learning may still be an important factor, other factors are likely to be important as well: price changes in factor inputs, improvements in the quality/price ratio of the innovation, the obsolescence of capital outlays, and increases in consumer wealth. For consumers, increases in income or wealth may be a precondition for an expensive innovation (usually a consumer durable) to be purchased, as may be price reductions and product modifications (for instance user-friendliness). In our view, there are two candidates for analyzing the diffusion of an expensive and relatively complex consumer durable: the threshold model in which adoption takes place the moment at which a variate crosses a critical threshold or the epidemic model in which the rate of adoption and/or the market potential is a function of economic factors.

The threshold model with income as the critical threshold may be used to explain the diffusion process of a consumer durable (something attempted by Bonus, 1973). It may be necessary, however, to incorporate price reductions and post-innovation improvements in the threshold model. Post-innovation improvements are a well-known and commonly observed phenomenon. When an innovation first arrives in the market, it is often ill-developed in terms of user needs. A better understanding of these user needs and of the technological possibilities for improvement allow the innovator to improve its product. On the other hand, the expectation of further improvements in the quality-price

${ }^{49} \mathrm{H}$. Baudet, 1986, Een vertrouzvde wereld. 100 jaar innovatie in Nederland (A familiar world. 100 years of innovation in the Netherlands), Amsterdam: Bert Bakker, p.10.

${ }^{50}$ If $d \beta_{t} / d t<0$ one may use a positively skewed diffusion model and if one has reason to believe that $\beta$ remains constant, one may use the logistic model. The specification of $N_{t}$ also has important implications for the model results. It seems incorrect to include people who at time $t$ are unaware of the existence of the new product in $N_{t}$. The specification of $N_{t}$ is known to constitute a serious problem, depending on a wide array of variables (people's preferences, real disposable income, price of the product, etc.). 
ratio may induce some adopters to delay their purchase. ${ }^{51}$ In addition to post-innovation improvements, price reductions may affect the rate and extent of adoption of a technological innovation. During the diffusion period, the price of new product tends to fall as the innovator supplier benefits from cost efficiencies in the production of the product and as competition between supplying firms becomes more intense. Prices may also be manipulated by the innovator supplier in strategic ways: it may decide to offer the new product at a low price initially to stimulate early market growth (a "market penetration" policy) or instead sell the product at a high price to skim user gains or consumer surplus (a "market skimming" policy).

A shortcoming of the threshold model remains the absence of a mechanism of information transfer and persuasion which may be necessary for adopters to purchase the new product. Especially if the new product is a radical innovation, people may be reluctant or simply unwilling to purchase the new product (radical innovations like television sets, automobiles are often regarded as unnecessary luxury goods, or even dangerous and unhealthy). Time and persuasion may be needed for a radically new product to become widely accepted. One way of introducing learning and taste formation in the model is to make the threshold a function of the proportion of adopters (being a proxy for endogenous learning and bandwagon effects). Instead of income, the willingness to pay of individual adopters could be made the critical threshold (as in Kalish's model (1985) of reservation prices). Strangely enough, this has been attempted by a few scholars only, despite the fact that the notion of "willingness to pay" is central to the demand theory.

If one has reasons to believe that the endogenous elements dominate the effects of exogenous changes (such as increases in consumer wealth, improvements in the quality/price ratio) one may decide not to employ a threshold model but to use an epidemic model which incorporates economic factors. These economic factors may be incorporated in the model in two ways: by changing the rate of adoption $\left(\beta_{t}\right)$ or by altering the population of potential adopters $\left(N_{1}\right)$. Thus, the rate of adoption (or the probability of acquisition) may be made a function of the purchase price, of improvements in the quality/price, of income, and possibly of some institutional variables (like credit rules). Similarly, the market potential of a new product is likely to be affected by changes in prices, postinnovation improvements, consumer wealth and by changes in people's preferences through which non-adopters become potential adopters (the opposite is also possible). It is difficult to determine a priori on the basis of theoretical arguments whether the above factors should be included in the rate of adoption or in the potential population, or in both. This is something that needs to be determined empirically. ${ }^{52}$

${ }^{51}$ Nathan Rosenberg, 1982, On Technological Expectations, Economic Joumal, 86: 523-35 (published also as chapter 5 of his book Inside the Black Box: Technology and Economics, Cambridge: Cambridge University Press, pp.104-119.

52 Wagner A. Kamakura and Siva K. Balasubramanian have investigated whether the impact of price changes on the diffusion process is achieved through an effect on adoption probability (the rate of adoption) or by changing the market potential. Using nested testing procedures, the relative 
If the potential adopters of a certain expensive and complex innovation are firms (or more generally organizations) rather than consumers, the epidemic model may be less appropriate. Endogenous taste formation is unlikely to be a factor in the diffusion process (the single most important goal of a firm is to make profits) and learning may be an important factor in the early stage of the diffusion process only ${ }^{53}$ If the new innovation requires the replacement of capital outlays, the vintage model may be appropriate. The diffusion process is then a function of the rate of economic obsolescence of older capital vintages and the expansion of the market in which it will be applied. Instead of a vintage model, one may use the probit and logit model to analyze the diffusion of a complex and expensive innovation. The cost/benefit ratio or maximum payback period (as in Davies' analysis) may be used as the critical threshold. ${ }^{54}$

Our conclusions about what model(s) may be used best for analyzing the diffusion of differing technological innovations across two adopter environments (consumers and firms) are summarized in Table 4.1.

superiority of twelve competing model specifications (all based on the original Bass model) is analyzed for six consumer durables (toasters, mixers, blenders, airconditioners, refrigerators, and vacuum cleaners). They found that prices affect the diffusion process only for relatively high-priced goods and that this is achieved through impact on the probability of adoption (Wagner A. Kamakura and Siva K. Balasubramanian, 1988, Long-term View of the Diffusion of Durables: A Study of the Role of Price and Adoption Influence Processes via Tests of Nested Models, Intemational Journal of Research in Marketing, 5: 1-13). The same problem has been analyzed by Dipak C. Jain and Ram C. Rao by estimating three models in which prices affect either market potential or the rate of adoption. They found that prices affected the diffusion process in the four applications of the models but since the models did not belong to a nested familiy they were not able to tell whether prices affect the market potential or the rate of adoption (or both). They tend to believe that it is market potential which is mostly affected by price changes although this is not really brought out by the model results (Dipak C. Jain and Ram C. Rao, 1990, Effect of Price on the Demand for Durables: Modelling, Estimation, and Findings, Joumal of Business and Economic Sitatistics, 8(2): 163-170).

${ }^{53}$ Management attitudes, however, may be a factor.

${ }^{54}$ It should be noted that the vintage model also belongs to the threshold models. 


\section{Characteristics}

of the innovation

\section{Population of potential adopters}

\section{Consumers}

\section{Firms}

\section{Simple innovations}

$$
\text { - epidemic model }
$$

Expensive and complex innovations

a. without price reductions and performance improvements

b. with significant price reductions and postinnovation improvements (due to dynamic scale and learning effects)
- epidemic model with $N$ being a function of $Y$

- threshold model with $Y$ and

learning mechanism

being a function of $p$ and $Y$

- threshold model with $p, Q$ and $Y$ and leaming mechanism
- epidemic model with $\beta$ and/or $N$
- epidemic model (for inter-firm diffusion)

- threshold model with learning
- vintage model

- epidemic model with $\beta$ and/or $N$

being a function of $p$ and $Q$

- threshold model with $p$ and $Q$ and learning

- vintage model with $p$ and $Q$

Table 4.1. Appropriate model(s) for analyzing the diffusion of technological innovations. 


\section{Chapter 5}

\section{The Diffusion of Environmentally Beneficial Technological Innovations}

This chapter examines the diffusion of technological innovations that conserve environmental qualities. The aims of this chapter are: First, to theorize about the diffusion process of environmentally beneficial technological innovations, in the light of what we have said in the previous chapter. Second, to discuss existing diffusion studies of environment-saving technological innovations. And third, to analyze the influence of various policy approaches on the rate of adoption of environment-conserving technologies in the context of a simple threshold model.

The chapter is structured as follows. Section 1 examines the difference between environmentally beneficial technological innovations and other technological innovations, and the likely technological diffusion of environment-saving innovations under different policy regimes. This is followed by a discussion in section 2 of two studies of the diffusion of environment-saving technological innovations: Hyder Lakhani's analysis of the technological diffusion of environment-saving techniques in the petroleum-refining industry, and Adam Jaffe and Robert Stavins' diffusion model of an energy-conserving technology. The final section advances a threshold model of the diffusion of an environmentally beneficial durable. The model is used to analyze the impact of different policy instruments on the technological diffusion of environmentally preferable technologies. Empirical results from this model are presented in chapters 6 and 7 .

\subsection{The Adoption of Environmentally Beneficial Innovations}

To what extent is the diffusion of environment-conserving technological innovations any different from that of other types of innovations? To answer this question, we must ask ourselves the following question: What is the difference between environmentally beneficial technological innovations and 'normal' innovations? As noted in chapter 1, the distinction between environmental technologies and technologies that produce cost savings or yield superior services to the individual user is not a sharp one. 'Normal' business innovations may have environmentally beneficial side-effects, and environmental technologies may yield non-environmental gains to the individual user (such as savings on materials use, higher product qualities, etc.). To answer the above question, we must make a distinction between technologies whose environmental gains are not considered in purchase decisions and technologies whose environmental aspects are part of the decision-making process. Only the latter type of technologies may command a 
new type of diffusion model - one that considers the costs and benefits associated with the environmental effects in adopter decisions.

To understand and explain the diffusion of environmentally beneficial technologies, we furthermore need to distinguish between different types of adopters - whether they are organizations (like firms) or consumers - and take into account the economic characteristics of the technology - whether it is a durable, requires the replacement of existing capital outlays, etc. An important category of environmentally beneficial technological innovations are technologies for reducing industrial emissions. These are commonly divided into two categories: process-integrated technologies and end-of-pipe technologies, the characteristics of which are described in chapter 1. Again, we ask ourselves: Does this distinction have specific implications for the appropriate diffusion model for analyzing the diffusion of environmental technologies?

A general feature of process-integrated technologies is that their use often requires the replacement of existing production facilities, the training of personnel, the reorganization of work. This means that sunk costs (i.e., the value of past investments) and uncertainty are likely to have an important impact on the adoption decision-making process. If sunk costs are important - i.e., when the technologies are capital-intensive and have long life-times - the vintage model may be the appropriate model for explaining changes in the aggregate diffusion pattern. If, furthermore, the decision to purchase the environmentally desirable technology is surrounded with great uncertainty about the economic consequences of adoption, an (endogenous) learning mechanism should be incorporated into the diffusion model.

We now come to diffusion of end-of-pipe technologies (such as fluegas desulphurisation techniques, biofilters, waste-water treatment technologies) and the appropriate model for analyzing the adoption of such technologies. To the extent that end-of-pipe technologies can be easily added to the production process (which is not true for all endof-pipe technologies), and the total costs of using them are well known, the appropriate model may be a threshold model with the Net Present Value or Maximum Payback period as the critical threshold.

Besides the characteristics of the adopter population, the characteristics of the innovations and of the adopter environment are also likely to influence the adoption growth rate of environment-conserving technologies. As indicated in the previous chapter, post-innovation improvements in the performance-price ratio of the new technology, input price changes, and changes in adoption costs, may exercise a significant influence on purchase decisions of potential adopters.

For consumers, the distinction between cheap and expensive technologies is likely to be important. The diffusion of low-cost, environment-friendlier consumer products (such as water-based paints) is commonly driven by environmental awareness and (endogenous) information transfer, whereas the diffusion of more expensive 'green' consumer durables is more likely to be governed by changes in the costs and benefits of using the environment-conserving durable (such as blown insulation), although information transfer and taste formation may also be of influence. Hence, for inexpensive environmentally benign consumer products, we may use a simple epidemic model (like 
the logistic or Gompertz) and for environment-conserving durables we may apply an epidemic model in which the rate of adoption and/or the population of potential adopters is a function of economic variables (prices, incomes), or use a threshold model with a learning mechanism.

We now come to discuss the technological diffusion of environment-conserving technologies under different control regimes: an incentive-based regime and a commandand-control regime. Under incentive-based approaches (like a carbon tax, effluent charges, pollution fees, subsidies) the potential adopter is free to adopt (or not to adopt) an environment-friendlier technology. The incentive-based policies are aimed at changing the economic calculus in favour of adopting a more environmentally benign product by increasing the costs of using environmentally hazardous inputs, raising the costs of emitting pollutants or by reducing the costs of adopting an environmentally beneficial technology. Under command-and-control policies, polluters are forced through legal requirements to reduce their pollutant emissions, the fulfilment of which may necessitate the application of certain pollution control technologies. Sometimes environmental technologies are prescribed by way of technology standards. In most cases, however, the regulator sets performance standards that specify the maximum level of pollutant emissions or the amount of emission reductions to be achieved.

The distinction between the two identified policy regimes has implications for the aggregate diffusion pattern and the appropriate model for analyzing the growth in ownership of environmentally beneficial technologies. Under incentive-based approaches (a pollution or energy tax, tradeable pollution permit, an emission reduction subsidy or an investment subsidy), firms and households are free in their purchasing decisions. This implies that the mechanisms that govern the spread of an environmentally desirable technology across an adopter population are basically the same as those of other types of technological innovations. This suggests that we may use any of the diffusion models described in the previous sections for analyzing the growth process in ownership of an environment-saving technology - bearing in mind what we have said before about the appropriate diffusion model(s) for analyzing the uptake of different types of innovations across various adopter populations. The theoretical impact of different economic incentives (taxes, subsidies) and information supply on the technological diffusion of environmental technologies will be analyzed in the last section.

What about the diffusion of environmental technologies under direct regulation? Is it possible to theorize about this? This is far more difficult. The diffusion process will depend on the details of environmental regulation, the control agency's willingness to accept delays in the realization of emissions reductions, and to violations of the rule. This means that the diffusion of environmental technologies under direct regulation (performance standards, technology standards, product bans) basically commands a different model - one which incorporates the details of legal requirements, the law enforcement processes and penalties for legal violations, and the law-obeying nature of people and organizations that are subject to environmental laws. It may be clear that 
such a model would be more complex and difficult to apply empirically, and we shall not attempt therefore to develop such a model in this thesis.

\subsection{Two Diffusion Studies of Environment-Saving Technolog- ical Innovations}

Whereas the diffusion of technological innovations across a population has been studied by many social scientists, there are only few studies on the diffusion of environmentsaving technological innovations. As far as we know there exist only two models describing the growth in ownership of environmentally desirable technological innovations: Hyder Lakhani's model of environment-saving petroleum refining techniques and Adam Jaffe and Robert Stavins' model of the diffusion of an energy-conserving technology. This section will examine both models.

\subsubsection{Lakhani's model of the diffusion of environment-saving technologies in the U.S. petroleum-refining industry}

In an old study, Hyder Lakhani analyzed the changeover in U.S states from thermal to catalytic cracking and from catalytic cracking to hydrocracking - each being a costsaving and environment-saving technique for refining petroleum. ${ }^{1}$ The reason for studying the diffusion of both catalytic cracking and hydrocracking was, first, to analyze whether the diffusion of these technologies was socially optimal, and second, to investigate empirically whether environmental policy accelerated the growth rate of adoption. To do so, Lakhani first applied a Gompertz function to describe the aggregate diffusion growth curve. The Gompertz function is described by:

$$
n_{t}=N a^{\beta t}
$$

with $n_{t}$ being the number of firms that adopted the innovation at time $t, N$ the population of potential adopters, and parameters $a, \beta \in(0,1)$.

The above equation can be rewritten (in logarthmic terms) as follows:

$$
\ln \left(n_{t}\right)-\ln \left(n_{t-1}\right)=\gamma\left(\ln (N)-\ln \left(n_{t}\right)\right)
$$

with $\gamma=\frac{1}{\beta}-1 \quad$ (and not $\left.-\ln (\beta)\right)$, the coefficient of the growth rate.

' Hyder Lakhani, 1975, Diffusion of Environment-Saving Technological Change. A Petroleum Refining Case Study, Technological Forecasting and Social Change, 7: 33-55. 
In Lakhani's study, $N$, the ultimate equilibrium level is not fixed but changes over time, which implies that the diffusion ceiling $E E$ is upward sloping with time. Figure 5.1 depicts Lakhani's model.

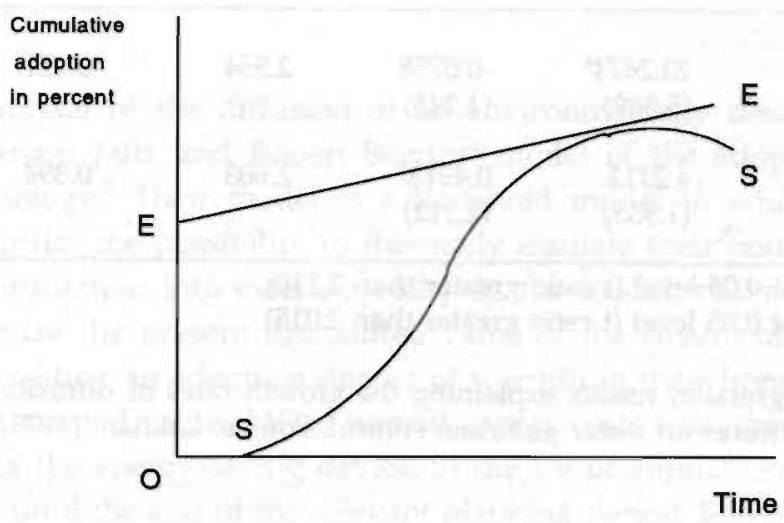

Figure 5.1. The Gompertz model with an upwardsloping ceiling. Source: Lakhani (1975, p.39).

After substituting $N_{t}$ for $N$ in equation (2), and replacing $\ln \left(n_{t}\right)$ by $\ln \left(n_{t-1}\right)$ in the righthand side of this equation to take care of positive autocorrelation in the error term (a rather crude way of doing so), equation (2) is estimated both for catalytic cracking and hydrocracking in various U.S petroleum-refining states for the 1949-63 and 1967-71 periods, respectively. The regression results found by Lakhani were rather poor, with coefficients of determination ( $R^{2}$ corrected for degrees of freedom) mostly below 0.3 and often less than 0.1 , and relatively low $t$ ratios (below 2 in some states) for $\gamma$, the coefficient of the growth rate.

Lakhani found that the growth rate of diffusion of hydrocracking was lower than that of catalytic cracking (also when compared with the early growth rates of catalytic cracking in the 1949-53 period). On the basis of a comparison of physical quantities of residuals, Lakhani concluded that the social benefits of the substitution of hydrocracking for catalytic cracking were considerably greater than the social costs -implying that the growth rate of adoption of hydrocracking was less than the socially optimal growth rate.

Lakhani furthermore investigated whether environmental policy accelerated the speed of adoption of both petroleum-refining innovations. Regressing the diffusion growth rates in the various states on per capita expenditures on water pollution control (a proxy for the strictness of environmental policy in each state) during a five-year diffusion period, gave the following estimation results. 
Regression Coefficients

\begin{tabular}{lllll}
\hline & & & & \\
Process & Constant & $\begin{array}{l}\text { Durbin } \\
\text { expenditure }\end{array}$ & $\begin{array}{l}\text { Watson } \\
\text { statistic }\end{array}$ & $\mathrm{R}^{2}$ \\
\hline $\begin{array}{l}\text { Catalytic } \\
\text { cracking }\end{array}$ & $23.2674^{\mathrm{a}}$ & -0.0758 & 2.554 & 0.031 \\
$\begin{array}{l}\text { Hydro- } \\
\text { cracking }\end{array}$ & $(5.389)$ & $(1.245)$ & & \\
\hline
\end{tabular}

Significant at 0.05 level ( $t$ ratio greater than 2.110 )

b Significant at 0.05 level ( $t$ ratio greater than 2.015)

Table 5.1. Regression results explaining the growth rates of diffusion by per capita expenditures on water pollution control. Source: Lakhani $(1975$, p.51).

Table 5.1 shows that the regression coefficient for the environment-economic parameter is negative (but not significantly different from zero at the $5 \%$ significance level) for catalytic cracking and significantly positive (at the 5\% level) for hydrocracking. According to Lakhani, this suggests that increasing pressures from public authorities on refineries has stimulated the rate of adoption of hydrocracking (but not that of catalytic cracking), being an environment-conserving technology.

Are the hypotheses concerning the adoption growth rate of petroleum-refining techniques validated by econometric analysis? For instance, has the relationship between environmental policy and technological change been firmly established? The answer is negative. There are several weak points in the analysis, many of which are acknowledged by Lakhani. First, Lakhani applies an incorrect model to the diffusion of petroleum-cracking techniques. Because such techniques are extremely capital-intensive with lifetimes of 30 years, Lakhani should have applied a vintage model with the age distribution of the existing capital stock as an explanatory variable. The low coefficients of determination also indicate that the Gompertz model is not a good model for analyzing the diffusion of petroleum-cracking techniques. Second, the conclusion that the growth rate of hydrocracking is less than socially optimal is not supported by economic analysis. Although the operating costs of hydrocracking may be below those of catalytic cracking, one has to compare the total costs of hydrocracking with the variable costs of catalytic cracking. As the fixed costs are known to be very high for capital-intensive petroleumcracking plants, the accelerated adoption of hydrocracking is likely to provide some refineries with extra costs - which must be compared with the monetary value of the environmental benefits. And third, the way in which Lakhani tries to establish the relationship between environmental policy and the growth rates of adoption of petro- 
leum-cracking techniques, is too crude a test: it is based on small samples, it uses a poor proxy for the strictness of water pollution control policies, and the coefficients of determination and $t$-values for regression coefficients found are all low.

\subsubsection{Jaffe and Stavins' adoption model of an energy-conserving technol- ogy}

A more recent model of the diffusion of an environmentally desirable technological innovations is Adam Jaffe and Robert Stavins' model of the adoption of an energyconserving technology. ${ }^{2}$ Their model is a threshold model in which (heterogeneous) homeowners consider the possibility to thermally insulate their homes (for instance by injecting blown insulation into exterior walls). In the model, risk-neutral homeowners attempt to minimize the present discounted value of the stream of expected costs associated with providing an adequate degree of warmth in their homes. These costs are: 1) the present discounted value ( $P V)$ of annual energy costs from the present to the time of adoption (T) of the energy-saving device, 2) the $P V$ of annual energy costs from the time of adoption until the end of the relevant planning period, and 3) the costs of adoption of the energy-saving technology. In the model, a (risk-neutral) homeowner $j$ selects the optimal time of adoption, $T \geq 0$, by minimizing the following function:

$$
P V(T)=\int_{0}^{T} g\left(h_{i j r^{\prime}} k_{i t}\right) e^{-r i} d t+\int_{T}^{\infty} g\left(h_{i, r^{\prime}} k_{i t}\right) w e^{-r t} d t+C_{i T} e^{-r T}
$$

where $i$ indexes a local jurisdiction, $j$ indexes individual homes, and $t$ indexes time. The model's variables are:

$h_{i j t}=$ index of efficiency of individual home-heating plant and preferences regarding heating;

$k_{i t}=$ average annual energy cost for heating, in the absence of the energy-saving technology;

$w=$ index of the average effect of the new technology on annual energy consumption (with $0<w \leq 1$ );

$g()=$. function which relates average annual energy cost for region $i$ at time $t$ and efficiency of household heating plant in a specific home with the home's average energy cost (for heating);

${ }^{2}$ Adam B. Jaffe and Robert N. Stavins, 1990, Evaluating the Relative Effectiveness of Economic Incentives and Direct Regulation for Environmental Protection: Impacts on the Diffusion of Technology, paper prepared for the WRI/OECD-Symposium "Toward 2000: Environment, Technology and the New Century", June 13-15, 1990, Annapolis, Maryland. 


$$
\begin{aligned}
C_{i r} & =\text { cost of adoption of new technology; } \\
r & =\text { the real interest rate; } \\
T & =\text { the time of adoption (installation). }
\end{aligned}
$$

Only the index of heating plant efficiency and preferences regarding heating, denoted by $h_{i j t}$, is specific to the individual home; all the other variables are measured at the sectoral level. Minimizing $P V(T)$, under the constraint $T \geq 0$, gives:

$$
g\left(h_{i j,}, k_{i t}\right)(1-w) \geq\left(r C_{i t}-\frac{\partial C_{i t}}{\partial t}\right)
$$

The above condition for adoption states that the risk-neutral homeowner adopts an energy-conserving technology (such as blown insulation) if and when the discounted value of the future stream of avoided energy costs - i.e., the expected savings in energy costs $g($.) divided by the interest rate $r$ - exceeds the present cost of adoption of the new technology minus the product of the expected rate of change of adoption cost and the reciprocal of the interest rate. ${ }^{3}$ From the above expression it is easy to see that a higher energy efficiency $(w)$ of the energy-saving technology, lower adoption costs $(C)$ and a lower interest rate $(r)$ encourage the adoption of the energy-saving technology.

Under the assumption that $g(h, k)$ can be expressed as a multiplicative function of $g_{7}\left(k_{i t}\right)$ and $h_{i j}$, the decision to adopt the energy-saving technology can also be cast in terms of a critical threshold $h_{i t}{ }^{\prime}$, being the upperlimit for $h_{i j t}$ above which it is no longer cost-effective for household $j$ in region $i$ at time $t$ to invest in energy conservation:

$$
h_{i t}^{*}=\left(\frac{r C_{i t}-\frac{\partial C_{i t}}{\partial t}}{g_{1}\left(k_{i t}\right)(1-w)}\right)
$$

The level of adoption $A_{i l}$ - the proportion of the population in region $i$ that will have adopted the energy-saving device at time $t-$ is:

$$
A_{i t}=1-F\left(h_{i t}^{*}\right)
$$

with $F\left(\right.$.) being the cumulative density function for $h_{i j t}$, the index of efficiency of individual home-heating plant and heating preferences - where $F($.$) is considered to be the$ same for all regions and assumed constant during the diffusion period (which means that the efficiency of home-heating plants is the same across regions and that heating preferences do not change over time). 
According to Jaffe and Stavins, their model may furthermore be used to analyze the relative effectiveness of economic incentives and regulation (like building codes) in affecting adoption behaviour. Let $R_{i t}$ be a dummy variable which equals unity if a relevant regulation exists, and zero otherwise; $\rho_{1}$ a parameter that indexes the probability that someone for whom the investment is profitable and who is not subject to relevant laws or regulations will adopt the technology; $\rho_{2}$ a parameter which indexes the probability that an unprofitable technology is adopted because of regulations; and $\rho_{3}$ a parameter which indexes the additional probability of adoption due to laws and regulations for households where the investment is in fact profitable. Defining $R_{i t}$ and parameters $\rho_{1}, p_{2}$ and $\rho_{3}$ as above, they find that the fraction of homes within region $i$ which 'should' have adopted the energy-saving technology by time $t$ equals: ${ }^{4}$

$$
A_{i t}=\rho_{1}+\left(\rho_{3} R_{i t}\right)+\left(\left(\rho_{2}-\rho_{3}\right) R_{i t}-\rho_{1}\right) F\left(h_{i t}^{*}\right)
$$

By doing a cross-section analysis over the diffusion period, the above parameters may be determined statistically. Unfortunately, up until now Jaffe and Stavins have not applied their model empirically - something which would enable us to assess the model's ability to describe empirically the aggregate diffusion pattern and permit us to draw conclusions concerning the impact of economic incentives and regulations (in the form of technology standards) on the adoption of thermal insulation technologies by homeowners. At this stage, we can only say something about the theoretical underpinnings of the model.

The decision to use a threshold model for analyzing changes in the ownership of an energy-saving durable (like injected blown insulation) seems justified by the consideration that economic variables such as energy prices, adoption costs and interest rates are likely to exercise a significant influence on homeowners' decisions regarding the adoption of thermal insulation technologies, given the high costs of such investments. A weak point of the model is that a mechanism of information transfer and 'bandwagon effects' are not incorporated in the model. In section 2 of this chapter, we have argued that the spread of information and endogenous taste formation are likely to be important factors for the purchase of consumer products. Furthermore, Jaffe and Stavins' model assumes that potential adopters only consider the monetary gains from energy savings in their purchase decisions. As there are other important benefits connected with thermal insulation - for example, fewer temperature differentials in rooms, higher temperatures in unheated rooms, less condensation on windows - the model is incomplete in this respect.

Of course, no econometric model is able to consider all the details of the decisionmaking process regarding the adoption of a durable. Furthermore, certain assumptions must be made about the distribution of the model's variate(s) and the parameters to be estimated. Whether some of the assumptions made in the model - like a lognormal function for $h_{i j t}$ with a constant mean $\mu$ and variance $\sigma^{2}$ across regions and over time, and

${ }^{4}$ Ibid, p. 15. 
constant parameters $\rho_{1}, \rho_{2}$ and $\rho_{3}$ - are sufficiently justified and not overly restrictive, is partly an empirical issue.

\subsection{A Simple Threshold Diffusion Model for Environment- Conserving Technologies}

This section advances a simple threshold model that may be used to analyze the growth in ownership of various types of environmentally desirable durables: energy-conserving technologies, pollution control technologies, re-use sytems, and low-emission processes and products. Our model differs from traditional probit models in that learning and (endogenous) shifts in preferences or attitudes may affect purchasing decisions of potential adopters. By doing so, it overcomes what we consider to be the main weakness of threshold models: the absence of a mechanism of endogenous learning and taste formation. ${ }^{5}$ More importantly, the model allows us to analyze the impact of different policy instruments (pollution taxes, energy taxes, investment subsidies and information supply) on the diffusion growth curve of an environment-saving technological innovation, both theoretically and empirically.

This section proceeds as follows. First, we develop and describe the structure of the model. This is followed by an analysis of the impact of various incentive-based policy approaches on the technological diffusion of an environment-conserving innovation.

\subsubsection{The threshold model}

As noted in our survey of innovation diffusion models in chapter 4, there are basically two approaches in the study of the growth in ownership of a technological innovation: First, epidemic models in which the diffusion is addressed in the aggregate and the spread of the innovation across a population is driven by endogenous factors (especially learning); and second, threshold models in which the aggregate diffusion pattern is the result of economic decision making by a heterogeneous population over a longer period. A drawback of the epidemic models (such as the logistic model) is the lack of a decisiontheoretic foundation of individual adopter decisions. ${ }^{6}$ Although epidemic models may be used to describe empirically the aggregate diffusion pattern, it is unclear what causal mechanism underlies the growth in ownership of the technological innovation.

\footnotetext{
${ }^{5}$ Although our diffusion model combines elements of the epidemic model and an equilibrium or threshold model, the model is viewed as a threshold (or rational choice) model because of the microeconomic behavioural basis.
}

${ }^{6}$ Oren and Schwartz, op cit, p.274. 
This section will develop a simple diffusion model of an environment-saving durable. ${ }^{7}$ Our model is a threshold or rational choice diffusion model in which the aggregate diffusion pattern is the result of purchasing decisions by individual decisionmaking units. The model allows us to analyze the impact of alternative policy approaches (pollution and energy taxes, investment subsidies, information supply) on the rate of adoption of environmentally desirable technological innovations. The model is kept as simple as possible to facilitate empirical application, while incorporating a wide enough set of variables that could explain the actual spread of an environment-saving innovation across a population. Empirical results of the model are described in chapters 6 and 7.

After this short introduction, we will now describe the model. As in all threshold models, adoption of the innovation takes place when a stimulus variate exceeds a critical value. In our model, a potential user - which may be a household or industrial firm will purchase an environmentally desirable innovation if and when the annual savings in tax payments (or energy costs) plus other annual benefits from adoption minus the variable costs of using the technology exceed the annual fixed capital costs. The decision to adopt an environmentally desirable innovation can also be cast in terms of a comparison between a (risk-adjusted) reservation price and the purchase price (costs of adoption) of the innovation: As soon as the risk-adjusted reservation price of a decisionmaking unit for an environment-conserving technology exceeds the costs of adoption (the sum of purchase price and installation costs), adoption of the technology takes place.

The reservation price is nothing else than the willingness to pay for the environmentally desirable innovation. It is taken to be a function of the following factors:

1. the emission reduction achieved by the technology or the reduction in energy use in the case of a energy-conserving technology;

2. the level of the pollution tax per unit of emission or energy price (of which an energy tax may be a part);

3. other gains from adoption (such as savings on material inputs and waste disposal costs, higher product sales from a better environmental image or, in the case of consumers, health benefits, extra comfort for the individual user);

4. operating and maintenance costs;

5. interest costs;

${ }^{7}$ Although the model is concerned with the first purchases by a population of an environmentsaving durable (like a fluegas-desulphurisation device or an electric vehicle) it can be applied to nondurables as well. 
6. the (economic) service life of the innovation;

7. uncertainty about the economic characteristics of the new technology.

Potential adopters of the environment-saving technology are assumed to be heterogeneous with respect to at least one of the above aspects. This implies that reservation prices $X_{t}$ differ among decision-making units according to some distribution. The essence of the model is depicted in Figure 5.2.
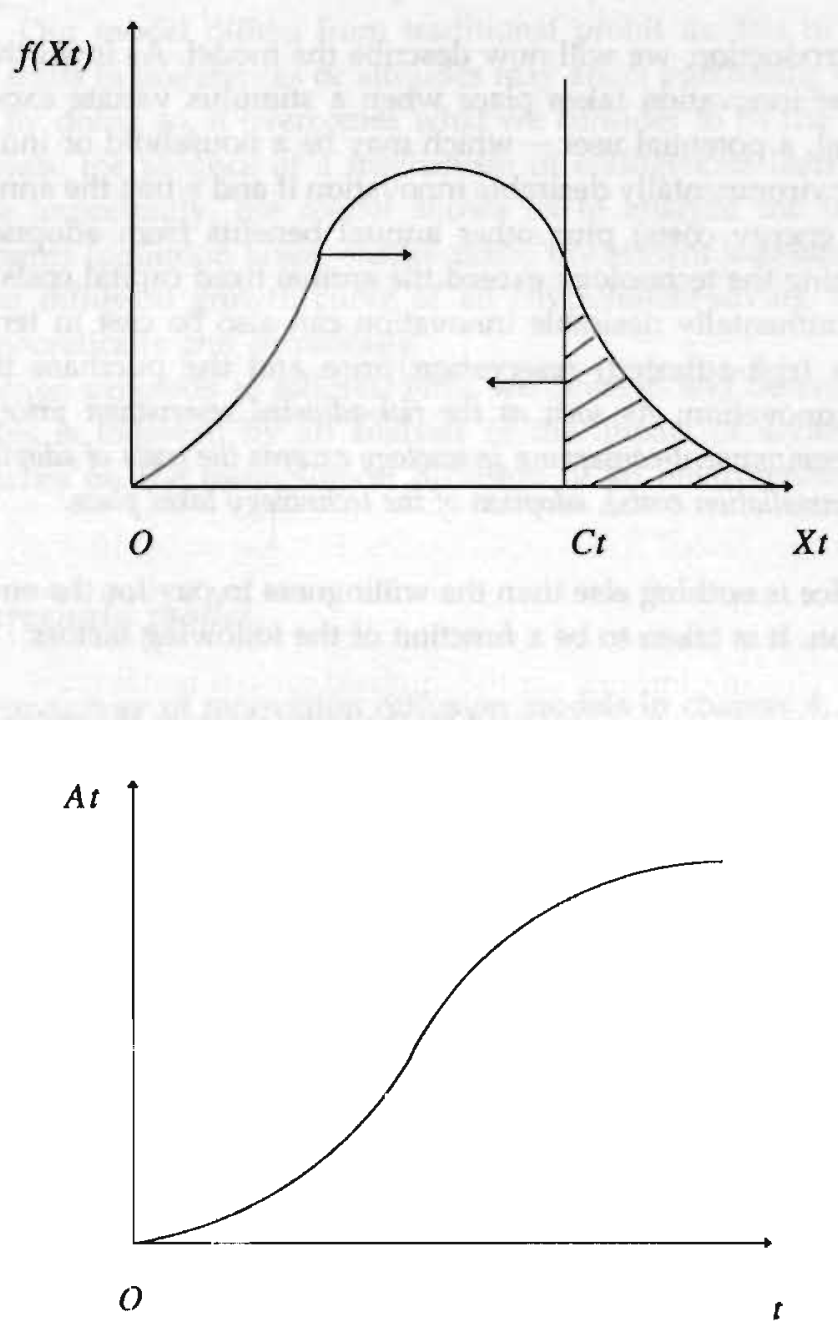

Figure 5.2. The distribution of $X_{t}$ and the aggregate diffusion curve. 
The distribution of risk-adjusted reservation prices $X$ is described by the probability density function $f(X)$. Of the total population of potential users, only those whose reservation price exceeds the adoption costs $C_{t}$ (the critical threshold in our model) will be adopters of the innovation. This implies that the proportion of the population that will own the innovation at time $t$ is equal to the area of the upper tail at the right of the vertical line going through the critical threshold $C_{t}$. The aggregate diffusion pattern $A_{t}$ is controlled by shifts in the distribution of $X_{t}$ and changes in the costs of adoption, $C_{r}$. If the distribution of $X_{t}$ is bell-shaped, a shift of $C_{t}$ at a constant percentage rate through time, or a constant shift of the distribution of $X_{1}$ trace out a sigmoid diffusion curve.

To illustrate how the model works, we will give an example. We consider the case where a polluting firm is subjected to a pollution tax. If the tax on pollution increases over time, the polluting firm will be prepared to pay more for a pollution control technology with a certain control efficiency (other things being equal). This implies that the reservation price of the pollution control device rises, causing the distribution of reservation prices to shift to the right, bringing a larger proportion of the population across the critical threshold into the population of actual adopters.

We will now define the threshold diffusion model more formally. The model attempts to explain the adoption decisions of an heterogeneous population over time. An obvious determinant of the decision to adopt an environmentally desirable good is the cost of adoption $C$, being the sum of the purchase price of the durable and any installation costs. ${ }^{8}$ To calculate the annual fixed capital costs $F C$, we must multiply the costs of adoption $C$, with the imputed annual rental rate $R$, being a function of the annual interest rate $r$ and the service life $l$ of the technology to be installed. As in Paul David (1969), we use the following formula for the imputed annual rental rate: ${ }^{9}$

$$
R=R(r, l)=\frac{r}{1-e^{-r l}}
$$

This gives the following expression for fixed capital charge FC:

${ }^{8}$ These installation costs can be quite high. For biological industrial waste water treatment technologies employed in the Netherlands, average installation costs were $53 \%$ of total investments (without interest costs) (Jaap Schuurman, 1988, De prijs van uater: een onderzoek naar de aard en omoang van de regulerende neventwerking tan de verontreinigingsheffing opperilaktewateren, PhD thesis, Arnhem: Gouda Quint, p.280).

${ }^{9}$ Paul David, op cit, 1969, p. III/6. The imputed rental rate is based on the standard annuity formula. Note that $r=0 \Rightarrow R(r, l)=\frac{r}{1-e^{-r l}}=\frac{1}{l}$ 


$$
F C=C * R=C \frac{r}{1-e^{-r l}}
$$

In the above equation it is assumed that the annual fixed capital costs are constant over the expected (economic) life time of the technology - i.e., that $F C_{t+j}=F C_{l}, \forall j=1, . ., \mathrm{l}$. A central assumption of the model is that in making a decision about the purchase of the environmentally desirable durable, a potential adopter compares the total annual costs of using the technology (being the sum of $F C_{t}$ and the variable costs $V C_{i}$ ) with the value of the annual gains. The annual benefits consist of tax savings (or savings in energy costs) $S_{t}$, and other gains from adoption, the monetary value of which is $K_{t}$.

The savings in tax payments $S_{t}$ are the product of (absolute) reductions in pollutant emissions, $E R_{t}$, achieved with the pollution control technology and the pollution tax in year $t$, that is, $\operatorname{Tax} x_{i} S_{t}=E R_{t} \cdot \operatorname{Tax}{ }_{t}$. In the case of energy-saving device, $S_{t}$ is the product of the reduction in energy use and the price of energy (which may be a function of an energy tax).

Examples of other gains from adoption are: the cost savings due to the re-use of waste material (which leads to savings on material inputs and to lower waste disposal costs) or an increase in product sales due to a better environmental image. For consumers there may be utility-enhancing effects associated with an environment-friendlier good such as the extra comfort that is connected with thermal home insulation (the reduction in temperature differentials or a higher temperature in unheated rooms). The positive valuation of beneficial environmental aspects of a good by consumers who care about the natural environment is also reflected in (a higher value for) $K_{t}{ }^{10}$ Note that $K_{t}$ need not be constant but changes over time as people develop different needs and their perception of the innnovation changes, in part as a result of social influences.

Another factor that is likely to affect the decision to adopt an environment-conserving durable is uncertainty about the economic characteristics of the new technology. Uncertainty about the economic characteristics of a technological innovation stems from three sources: potential adopters are uncertain about the technical performance of the new good (for example, about the pollution control efficiency and about the costs of using the technology), and they are uncertain about future prices and taxes which determine the profitability of the innovation. Uncertainty about the performance characteristics and costs will reduce the willingness to pay for a new product by risk-averse potential users.

To take account of uncertainty in the adoption decision, the annual gains are discounted for uncertainty by dividing these gains by an uncertainty factor $U_{i}=U_{t}(\rho) \geq$ 1 , where $\rho$ is a parameter which reflects risk aversion and uncertainty and $t$ indexes

${ }^{10} K$ may be positive or negative. As we have seen, $K$ is positive for double glazing. For an environmentally desirable good that is of lower quality than comparable goods (which is the case, for example, when a good is made of recycling material or in the case of an electric vehicle with a short range and long recharging times) $K$ will be negative. $K$ may also be positive for some people and negative for others, depending on their preferences, life-styles and habits. 
time. $U=1$ if $\rho=0$, i.e., when there is no uncertainty. Furthermore, we assume that uncertainty about the economic characteristics of the innovation decreases over time as people learn about the true characteristics of the new technology (i.e., $d u_{1} / d t<0$ and $d U_{t} / d n_{t}<0$ with $n_{t}$ being the number of decision-making units having adopted the technology at time $t) \cdot{ }^{11}$ A reduction in $U_{t}$ causes the distribution of $X_{t}$ to shift to the right, bringing a larger part of the population into the population of actual adopters. What it does is shift the demand curve for the new technology to the right:

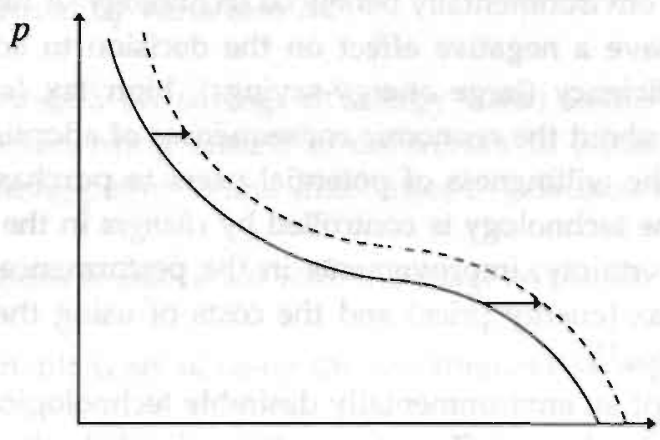

Figure 5.3. The effect of leaming about the economic characteristics of an innovation on the demand curve

Of course, this is a very crude way of incorporating uncertainty and learning into the decision-making process. A theoretically more appealing way of doing so is by defining a Bayesian learning process, where a potential user updates its estimates of the expected profitability of the innovation and perceived risk each year. We have not attempted this because of the analytical complications this would lead us into - for instance, we must assume a probability distribution for the profitability of the innovation as perceived by the adopter population and specify a learning mechanism which changes the parameters of the profitability distribution.

After having defined the model's variables, we will now define the adoption rule. As explained, the model assumes that a potential user will adopt an environment-saving

${ }^{11}$ In chapters 6 and 7 we use the following one-parameter functions for $U: U_{t}(\rho)=1+\rho /\left(t-t_{0}\right)$ and $U_{i}(\rho)=1+\rho / \ln \left(t-t_{0}\right)$. Note that $U_{t} \rightarrow 1$ for $t \rightarrow \infty$. An alternative specification is: $U_{t}(\rho)=1+\rho \mathrm{e}^{-\rho t} . U_{t}$ may also be defined as a function of the number of adopters $n_{t-1}$, for instance, $U_{t}=1+\rho\left(N-n_{t-1}\right) / N$, with $N$ the size of the total population. 
innovation if and when the risk-adjusted annual economic benefits associated with the usage of the environmentally desirable technology exceed the annual total costs $T C_{\text {, }}$ (being the sum of annual fixed costs $F C_{t}$ and variable costs $\left.V C_{t}\right){ }^{12}$ This means that a potential adopter will adopt the innovation at time $t$ if:

$$
\begin{gathered}
\frac{S_{t}+K_{t}}{U(\rho, t)}>F C_{t}+V C_{t}=T C_{t} \\
\text { with } S_{t}=E R_{t} \cdot T a x_{t} \text { and } F C_{t}=C_{t} \cdot R_{t} \text { where } R_{t}=\frac{r_{t}}{1-e^{-r_{t} !}}
\end{gathered}
$$

From inequality (10) it is easy to see how the different variables affect the decision to adopt (or not to adopt) the environmentally beneficial technology. A high purchase price and a high interest rate have a negative effect on the decision to adopt the product. Similarly, high control efficiency (large energy-savings), high tax (energy price) and relatively little uncertainty about the economic consequences of adopting the innovation have a positive effect on the willingness of potential users to purchase the innovation. Growth in ownership of the technology is controlled by changes in the above variable i.e., by a reduction of uncertainty, improvements in the performance-price tradeoff(s), changes in the pollution tax (energy price) and the costs of using the technology, and shifts in people's preferences. ${ }^{13}$

The decision to adopt an environmentally desirable technological innovation at a given time $t$ can also be framed in a different way. If we divide both sides of inequality (10) by $R_{t}$, the imputed annual rental rate for the $[t, t+l]$ period, and bring $V C_{t} / R_{t}$ to the left-hand side, we get:

$$
X_{t} \equiv \frac{S_{t}+K_{t}}{U_{t} R_{t}}-\frac{V C_{t}}{R_{t}}>\frac{F C_{t}}{R_{t}}=C_{t}
$$

The expression on the left-hand side gives the (risk-adjusted) reservation price $X_{t}$ of the environment-saving durable which is compared with the costs of adoption. ${ }^{14}$ The reservation price gives the willingness to pay for a technological innovation - where the risk factor discounts for any uncertainty about the value of the new good.

Note that uncertainty factor $U_{t}$ can also be interpreted in a different way. Simple manipulation of inequality (11) shows that $U_{t}$ is the quotient of $S_{t}+K_{t}$ and $T C_{t}$. In other

${ }^{12}$ An implicit assumption is that the net expected annual economic benefits from adoption are non-decreasing with time.

13. Throughout this study it is assumed that adoption of the technology leads to usage. The possibility of 'disadoption' during the diffusion period due to technical breakdown or a change in market conditions is not considered.

${ }^{14} X_{t}$ can also be interpreted as the certainty equivalent of $\left(S_{t}+K_{t}-V C_{t}\right) / R_{r}$ 
words, $U_{t}$ can be interpreted as a rentability requirement of an uncertain adopter for an innovation of uncertain profitability or merit.

In our model, the risk-adjusted reservation prices $X$ are assumed to differ among potential users, depending on the type and age of the existing production process, the size of the firm, the industrial sector a firm belongs to, the skills being available for using the new technology (factors that determine the costs associated with the usage of the technology), and, in the case of consumers, individual preferences, household characteristics (income, family size, place of residence), stock of durable goods, etc.

To keep the model simple we assume that $U_{t}, R_{t}$ and $C_{t}$ are the same for all decision-making units. This implies that any disparity in reservation prices $X$ at a given point in time is caused by variations in:

i) tax-savings $S$ (or savings in energy costs) associated with the usage of the innovation, being related to differences in (absolute) emissions reductions, $E R$, among polluters and differences in pollution taxes, Tax, across regions;

ii) extra gains $K$ associated with the usage of the environment-saving durable;

iii) the variable costs of using the environment-saving technology $V C{ }^{15}$

In other words, it is assumed, at least in this chapter, that differences in cost-savings associated with the usage of the environment-saving innovation and differences in the valuation of the other attributes of the technology are more important than variations in purchase prices and installation costs and differences in risk attitudes in affecting purchasing decisions. ${ }^{16}$ Of course, this assumption may be incorrect for certain goods. The model can, however, be extended in assuming distributions for $C, R$ and $U$.

Having modelled the adoption process of an environmentally desirable technological innovation, we now examine the aggregate diffusion pattern resulting from adopter decisions. Is the model able to generate $S$-shaped diffusion patterns found in many

\footnotetext{
${ }^{15}$ The variable costs of using the technology consist of operating and maintenance costs (being a function of labour costs, energy and material costs) and waste disposal costs.

${ }^{16}$ A class of innovations for which differences in purchase prices are likely to be small and differences in user costs large is that of indivisible goods. If the innovation is indivisible, there are economies of scale in using the technology, which puts small firms at a disadvantage. Even if the innovation is not indivisible but varies in size and performance (as is often the case for pollution control devices) there may still be some degree of "lumpiness", causing significant differences in unit costs for differing users. Valuation of the performance characteristics of the durable is also likely to differ among potential users. The service characteristics (speed, mileage) of an electric car will be valued less negatively by someone who wants to use it for urban travels (shopping, etc.) than by someone who plans to use a car for making long business journeys.
} 
empirical diffusion studies, and, if so, under what conditions can particular sigmoid curves be derived?

As noted earlier, the aggregate diffusion pattern stems from changes in the stimulus variate and in the critical threshold. The stimulus variate (the risk-adjusted reservation price) is described by a distribution which is the joint product of the distributions of the tax-savings $S$ (or savings in energy costs), the extra gains from adoption $K$ and variable costs $V C .^{17}$

Let us first consider the simple case where all three variates are normally distributed at any given time $t$ :

$$
s_{t}-N\left(\mu_{S, t}, \sigma_{S, t}^{2}\right) ; \quad K_{t}-N\left(\mu_{K, t}, \sigma_{K, t}^{2}\right) ; \quad V C_{t}-N\left(\mu_{V C, t}, \sigma_{V C, t}^{2}\right)
$$

If we assume that $S_{t}, K_{t}$ and $V C_{t}$ are independent variates, we can apply the convolution property of normal distributions, which gives that the (risk-adjusted) reservation prices $\mathrm{X}$ at time $t$ are also distributed according to a normal distribution:

$$
X_{i}-N\left(\mu_{t}, \sigma_{t}^{2}\right)
$$

with mean $\quad \mu_{t}=\frac{\mu_{S, t}+\mu_{K, t}}{U_{t} R_{t}}-\frac{\mu_{v C, t}}{R_{t}}$ and variance $\sigma_{t}^{2}=\frac{\sigma_{S, t}{ }^{2}+\sigma_{K, t}^{2}}{\left(U_{t} R_{t}\right)^{2}}+\frac{\sigma_{v C, t}^{2}}{R_{t}^{2}}$.

The proportion of the population having adopted the innovation at time $t$, defined as $A_{t}$ is:

$$
A_{t}=P\left(X_{t}>C_{t}\right)=\int_{i}^{\infty} f\left(X_{t}\right) d X_{t}
$$

with $f\left(X_{t}\right)$ being the probability density function of $X_{t}$.

To calculate the probability that a randomly selected decision-making unit of the population has adopted the innovation at time $t$ we rewrite equation (14):

$$
A_{t}=P\left(X_{t}>C_{t}\right)=1-P\left(X_{t} \leq C_{t}\right)=1-N\left(C_{t} \mid \mu_{t}, \sigma_{t}^{2}\right)=\Phi\left(\left(\mu_{t}-C_{t}\right) / \sigma_{t}\right)
$$

where $N$ stands for the normal distribution and $\Phi$ for the standard normal distribution.

17 Variations in tax-savings $S$ associated with the usage of a pollution control technology (or a low-polluting product or process) may stem from two sources: variations in absolute emissions reductions $E R$ achieved by the innovation and differences in pollution taxes Tax (due to a variation in taxes across regions). Variations in absolute emissions reductions in turn may stem from variations in the control efficiency and differences in the (absolute) level of pollution before abatement PA. 
$A_{i}$ is the probabilistic counterpart of the level of diffusion at time $t .^{18}$ The time path of $A_{t}$ gives the growth in the proportion of the population having adopted the innovation. From this equation it follows that diffusion will follow a cumulative normal time path if $\left(\mu_{t}-C_{t}\right) / \sigma_{t}$ grows at a constant absolute rate through time and a cumulative lognormal time path if $\left(\mu_{t}-C_{t}\right) / \sigma_{t}$ is a lognormal function of time only.

If we had chosen different probability distributions (like the Cauchy or logistic distribution) for $S, K$ and $V C$, the aggregate diffusion pattern would be described by the probability distribution of the sum of these distributions (assuming the random variables are independent). As the Cauchy distribution and the logistic distribution, being symmetric distributions, resemble the normal distribution (they only differ from the normal distribution with respect to their tails) we will not consider these situations here.

Note that our model does not restrain the diffusion growth curve to be of the cumulative normal or lognormal form. Even under the assumption of a (log)normal distribution for the (risk-adjusted) reservation prices our model may generate a wide range of diffusion patterns (including non-sigmoid curves), depending on the particular time paths of the variables affecting the decision to adopt the innovation concerned.

\subsection{The Diffusion Effects of Different Policy Instruments}

This section examines the technological diffusion effects of different approaches to controlling pollution in the context of the threshold model described in section 3.1. We will determine the technological diffusion effects of: 1) a pollution tax (or an energy tax), 2) an investment subsidy, and 3) information supply, being the most common policy approaches for controlling pollutant emissions besides direct regulation. ${ }^{19}$

The ways in which environmental policies affect potential users' willingness to purchase an environmentally desirable technology differ quite strongly. In the case of a pollution tax, adoption of a pollution control device (or a low-polluting process or product) brings cost savings for the polluter, the amount of which depends on the control efficiency. An investment subsidy also changes the economic calculus in favour of adoption of the environment-saving technology by lowering the cost of adoption. Information supply, however, does not alter the monetary costs and benefits of adoption of the innovation but aims to increase knowledge about the economic characteristics of the innovation and attempts to improve environmental awareness and responsibility of firms and consumers.

\footnotetext{
${ }^{18}$ Davies, op cit., p.77.
}

${ }^{19}$ Note that in the context of the model, an emission reduction subsidy and a tradeable pollution permit affect the decision to adopt a pollution control device in the same way as the pollution tax if the emission reduction subsidy and the unit price at which the tradeable pollution permit are equal to the pollution tax. 
We will now analyze the impact of the different policy approaches on the aggregate diffusion pattern. In the model described in section 3.1, the pollution tax was already incorporated. The impact of a change in the pollution tax on the expected rate of growth of the diffusion process can be analyzed by differentiating $A_{t}$, the probability that a randomly selected decision-making unit owns the innovation at time $t$, with respect to $\operatorname{Tax}_{i}{ }^{20}$

$$
\frac{d A_{t}}{d \operatorname{Tax}_{t}}=f\left(C_{t}\right)\left(\frac{\mu_{E R, t}}{\sigma_{t} U_{t} R_{t}}-\frac{2 \operatorname{Tax} \sigma_{t}^{2}\left(\mu_{t, t}-C_{t}\right)}{\sigma_{t}^{2} U_{t}^{2} R_{t}^{2}}\right)
$$

Equation (16) shows that an increase in the pollution tax at time $t$ will lead to an increase in the proportion of the population having adopted the innovation if $\mu_{t}<C_{t}$ or if $E R$ is deterministic, i.e., if $\sigma_{E R, t}=0$. If $E R$ is stochastic and $\mu_{t}<C_{t}$ it is unclear whether an increase in $T a x_{t}$ leads to an increase in the proportion of adopters. This is because a change in Tax $x_{1}$ affects the shape of the distribution of $X_{t}$. This change in the dispersion of $X_{t}$ may compensate the positive effect of $\operatorname{Tax} t$ through $\mu_{E R, t}$ on $A_{t}$. We have little reason however to suspect that this really is an important factor. If we neglect this, equation (16) changes into:

$$
\frac{d A_{t}}{d \operatorname{Tax}_{t}}=f\left(C_{t}\right) \frac{\mu_{E R, t}}{\sigma_{t} U_{t} R_{t}}>0
$$

Equation (16)' shows that the higher the (average) level of emissions reduction that may be achieved by technology, and the lower the imputed rental rate and uncertainty about the economic consequences of adopting the technology, the greater will be the increase in adoption due to a higher pollution tax. Of course, this is also what one would expect. The effect of an investment subsidy can also be determined in the model. If the subsidy is a lump sum $S_{i}$, differentiation of $A_{t}$ with respect to $S_{t}$ gives:

$$
\frac{d A_{i}}{d S_{t}}=f\left(C_{t}-S_{t}\right)>0
$$

Equation (17) states that the closer the difference between the cost of adoption and the lump sum is to the mode of the distribution of reservation prices $X$, the greater the effect of a change in the subsidy. This result is easy to comprehend: if $C_{t}-S_{t}$ is close to the mode of $X$ (assuming the distribution of $X$ is bell-shaped), an increase in $S_{t}$ brings a relatively large number of potential users into the population of actual adopters.

Instead of a lump sum subsidy, the investment subsidy may also be a set percentage, say s, of the sum of the purchase price and installation costs (which implies that

${ }^{20}$ Here we assume that $T a x_{1}$ is the same across the population of potential adopters, that any variations in $S_{\mathrm{f}}$ are caused by variations in $E R_{r}$. 
the costs of adoption are now $\left.C_{t}(1-s)\right)$. The effects of an increase in $s_{t}$ on the probability of adoption at time $t$ is described by the following expression:

$$
\frac{d A_{t}}{d s_{t}}=f\left(C_{t}\left(1-s_{t}\right)\right) C_{t}>0
$$

The higher $C_{i}$ and the higher the proportion of the population with a (risk-adjusted) reservation price $C_{t}(1-s)$, the greater the effects of an investment subsidy where the subsidy is a set percentage of the cost of adoption. Thus, if the real costs of adoption $C_{t}(1$ - $s$ ) are close to the mode of $X$, an increase in the investment subsidy s will bring a large proportion of the population into the population of actual adopters, especially for high C.

Finally, we will analyze how information provided by public authorities affects the diffusion growth curve. As explained earlier, the supply of information may affect purchasing decisions in two ways: by reducing uncertainty about the economic characteristics of the innovation and by changing people's attitudes towards the natural environment and environmentally preferable technologies. In terms of our model this implies that both $U$ and $K$ are a function of information supply, IS, that is $U=U(\rho, I S)$ and $K=K(I S)$ (with $d U / d I S<0$ and $d K / d I S>0$ ). The effects of an increase in information supply $I S_{t}$ on the probability of adoption at time $t$ of a randomly selected firm or household can be determined by differentiating $A_{t}$ with respect to $I S_{t}$. The impact of $I S_{t}$ through a reduction of $U_{t}$ and an increase in $K_{t}$ on $A_{t}$ is described by the following expressions:

$$
\begin{gathered}
\frac{d A_{t}}{d U_{t}} \frac{d U_{t}}{d I S_{t}}=f\left(C_{t}\right) \frac{1}{U_{t} \sigma_{t}}\left[2\left(\sigma_{t}^{2}-\frac{\sigma_{v C, t}^{2}}{R_{t}^{2}}\right)\left(\frac{\mu_{t}-C_{t}}{\sigma_{t}}\right)-\left(\mu_{t}-\frac{\mu_{v C, t}}{R_{t}}\right)\right] \frac{d U_{t}}{d I S_{t}} \\
\frac{d A_{t}}{d K_{t}} \frac{d K_{t}}{d I S_{t}}=f\left(C_{t}\right) \frac{1}{U_{t} R_{t}} \frac{d K_{t}}{d I S_{t}}>0
\end{gathered}
$$

What equations (19) and (20) show is that an increase in information supply has a clear positive effect on $A_{t}$ in the case of habit formation (for a non-stochastic $K_{t}$ ). The impact of information supply on $A_{t}$ through a reduction of uncertainty about the economic characteristics is less clear. It is positive if the term between the square brackets in equation (19) is negative, which is, for instance, when $S_{1}$ the annual gains from adoption at time $t$, are not stochastic. The magnitude of the effect of information supply on $A_{t}$ depends on several variables.

To analyze the effects of information supply on the adoption decisions at time $t+j$ $(j=1,2, .$.$) we must make further assumptions about the extent to which the effects last in$ duration. This could be modelled by constructing a stock variable for information transfer (being the (weighted) sum of information flows). As this would lead us into even more complex computations we have decided not to do so. 
The effects of a relative change of a pollution tax or investment subsidy on the relative change in the proportion of the population having adopted - what may be considered as the elasticity of adoption with respect to changes in policy measures - can be calculated by multiplying the left-hand side of equations (16)-(20) by $\operatorname{Tax}_{t} / A_{t}, S_{t} / A_{t}, s_{t} / A_{t}$, and $I S_{t} / A_{t}$ respectively.

What conclusions can we draw about the technological impact of policy instruments? For instance, are taxes a more effective policy instrument than investment subsidies or information supply in stimulating the technological diffusion of environmentally beneficial technologies? The answer to this question depends on the parameter values and the stringency of the policy instruments. It also depends on whether or not the threshold model is a good model for explaining adopter decisions over time. Therefore, we applied the model to two types of environmental technologies: biological waste-water treatment plants in the Dutch Food and Beverage industry and thermal home insulation in the Netherlands. The results are described in chapters 6 and 7. We also estimated three epidemic models to see which model is best, and to examine the robustness of the results. Adoption decisions of firms and consumers are also studied in three case studies of environmentally beneficial technologies in chapter 8. Chapter 9 gives an overview of the results of empirical studies into the technological impact of environmental policies. Conclusions about the usefulness of different policy instruments to foster technological innovation and diffusion will be given in chapter 13 . 


\section{PART II}

\section{Empirical Studies of the Technological Impact of Environmental Policies}




\section{Chapter 6}

\section{The Diffusion of Biological Waste-Water Treatment Plants in the Dutch Food and Beverage Industry}

Throughout the past 25 years, many industrial water polluters in the Netherlands decided to employ biological waste-water treatment technologies in response to public waste-water policies. An important component of Dutch waste-water policies was the usage of effluent charges in addition to environmental standards pertaining to the composition of industrial discharges. As the Dutch waste-water control policy is one of the world's oldest environmental control systems that use economic instruments, it is interesting to analyze the effects of the effluent charge on the diffusion of biological waste-water treatment plants. Besides providing statistical evidence as to the actual impact of Dutch waste-water control policy on the rate of adoption of biological wastewater treatment plants, such an analysis may further our understanding of the usefulness of incentive-based approaches as opposed to command-and-control approaches to fostering the employment of environment-conserving technologies. This chapter presents empirical results of the diffusion model described in chapter 5 and of three epidemic models - the logistic, Grompertz and Bass models.

The chapter is organized as follows. Section 1 describes Dutch waste-water control policies. Section 2 describes how the earlier-described threshold model can be applied to the diffusion of biological waste-water treatment plants in the Food and Beverage industry. Section 3 contains the empirical results of several variants of the threshold model. Section 4 gives the results of the three epidemic models. The final section presents the conclusions.

\subsection{Waste-Water Policy in the Netherlands}

The Netherlands have one of the oldest and most advanced waste-water control system in the world. Two interesting features of the Dutch waste-water management system stand out, which together make it quite unique. First, its highly decentralized nature. In the Netherlands, thirdly regional water quality management authorities (known as "Zuiveringsschappen" or "Waterschappen") are responsible for the quality of surface 
waters. ${ }^{1}$ Second, the usage of (high) effluent charges (or taxes) in addition to environmental standards regarding the compostion of residual discharges. Unlike most other countries, the effluent charge on oxygen-consuming pollutants in the Netherlands had a significant impact on polluters' decisions. Research by Hans Bressers $(1983,1988)$ and Jaap Schuurman (1988) has revealed that of all the factors that caused polluters to invest in (biological) waste-water treatment technologies, the effluent charge was far and away the most important factor. ${ }^{2}$ Table 6.1 shows the importance of various factors in inducing Dutch industrial water polluters to invest in biological waste-water cleaning devices to reduce the discharge of organic pollutants in different time periods (based on an opinion surey).

\begin{tabular}{llll}
\hline & $\begin{array}{l}\text { Before 1975 } \\
(N=17)\end{array}$ & $\begin{array}{l}1975-80 \\
(N=33)\end{array}$ & $\begin{array}{l}\text { After 1980 } \\
(N=30)\end{array}$ \\
\hline $\begin{array}{l}\text { Environmental standards } \\
\text { Effluent charges }\end{array}$ & $47 \%$ & $36 \%$ & $30 \%$ \\
$\begin{array}{l}\text { Effluent charges + } \\
\text { environmental standards }\end{array}$ & - & $55 \%$ & $50 \%$ \\
Other factors & $29 \%$ & $9 \%$ & $13 \%$ \\
\hline
\end{tabular}

Table 6.1. Direct cause for industrial polluters to invest in biological waste-water cleaning technologies. Source: Schuurman $(1988$, p.86) (with $N$ the sample size).

Table 6.1 demonstrates that since 1975, the year in which almost all water-quality boards had instituted a system of effluent charges for oxygen-consuming pollutants, the effluent

\footnotetext{
${ }^{1}$ A federal agency, Rijkswaterstaat, is responsible for the water-quality management of "rijkswateren", that is, the big rivers (such as the Rhine and Maas) and coastal waters.

$2 J . T h . A$. Bressers, 1983, Beleidseffectiviteit en waterkwaliteitsbeleid. Een bestuurskundig onderzoek (The effectiveness of water quality policy. A political science study), PhD dissertation, University of Twente, Enschede; see also Hans Th.A. Bressers, 1988, A Comparison of the Effectiveness of Incentives and Directives: The Case of Dutch Water Quality Policy, Policy Studies Review, 7(3): 500-518; and Hans Th.A. Bressers, 1988, Effluent Charges Can Work: The Case of the Dutch Water Quality Policy, in Frank J. Dietz and Wim J.M. Heijman (eds.), Environmental Policy in a Market Economy, Wageningen, pp.5-39; Jaap Schuurman, 1988, De prijs van water. Een onderzoek naar de aard en omvang van de regulerende werking van de verontreinigingsheffing opperolaktewateren (The price of water), Amhem: Gouda Quint, and J. Schuurman en J. Tegelaar, 1983, De regulerende werking van de WVO. Een kwantificering (The effects of WVO. A quantitative study), Weekblad voor Fiscaal Recht, 15: 1561-1577 (nr.5614).
} 
charge was the single most important factor in causing industrial polluters to invest in biological waste-water treatment plants. Especially in the Food and Beverages industry, effluent charges were the key factor in inducing water polluters to invest in biological waste-water technologies. According to Schuurman, effluent charges were of overriding importance in the Food and Beverages industry in $75 \%$ of the investigated cases ( $N=$ 86). ${ }^{3}$ However, Table 6.1 also demonstrates that environmental standards, formulated in permits issued by regional water-quality agencies, were quite an important factor in firms' decisions to invest in biological waste-water treatment. Especially industrial polluters that released their waste water directly on surface waters (mostly rivers) were forced to invest in (biological) waste-water treatment plants, in order to comply with environmental standards pertaining to the composition of their effluent.

Since our model assumes that polluters are free in their decision to adopt or not to adopt an environmentally beneficial technology (and at what moment), we will restrict the analysis to indirect polluters in the Food and Beverage industry that discharge their waste water on a collective waste-water treatment plant. For indirect polluters, effluent charges were by far the most important reason for investing in biological effluent treatment plants. In fact, in many cases, waste-water quality control agencies resented the on-site treatment of waste waters by industrial polluters because this had a direct negative impact on the agencies' revenues, sometimes creating problems of excess capacity in collective waste-water treatment plants. ${ }^{4}$

Figure 6.1 depicts the diffusion curve of biological waste-water treatment plants in the Food and Beverage industry - the sector in which most biological waste-water treatment plants have been installed up to now. Figure 6.1 demonstrates that the diffusion of biological effluent treatment plants in this sector is described by a sigmoid curve.The main reason why industrial dischargers of organic pollutants did not invest simultaneously in biological waste-water treatment plants was that it was not costeffective for all of them to do so. It was only when the effluent charges steadily increased over the years - from an average of 5.42 guilders per inhabitant equivalent (I.E. $)^{5}$ in 1973 to 74.26 guilders per I.E. in 1991 - that it became financially attractive for polluters to clean their own waste water. The increase in average effluent charges per unit of water pollution (I.E.) is depicted in Figure 6.2.

${ }^{3}$ Schuurman, op cit., Table 3.6, p.82.

4 See the references of Bressers and Schuurman on the previous page.

${ }^{5}$ I.E. stands for "Inhabitant Equivalent" (in Dutch "inwoner equivalent"), the average oxygen demand of pollutants in waste-water discharges of one person during twenty-four hours. One I.E. is estimated at $136 \mathrm{gram}$ of oxygen, being the sum of chemical oxygen demand (CZV) and the oxygen demand due to conversion of nitrogen compounds according to the N-Kjeldahl method. (A. van der Hoogt, P.J.J. Oosterling en J. Schuurman, 1990, Heffingen verontreiniging oppervlaktewateren, in Hoofizaken milieuheffingen, edited by E.P.J. Wasch, Fiscale studie serie nr.27). 


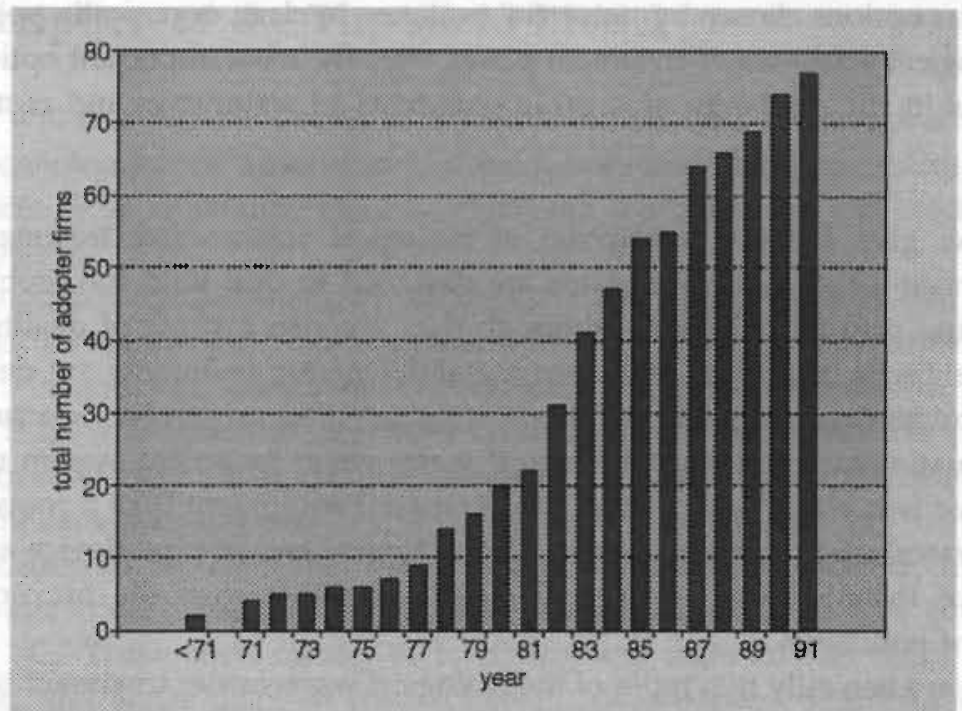

Figure 6.1. The diffusion of biological waste-water treatment technologies across indirect polluters in the Dutch Food and Beverage Industry, 1970-91. Source: RIZA, CBS and own calculations.

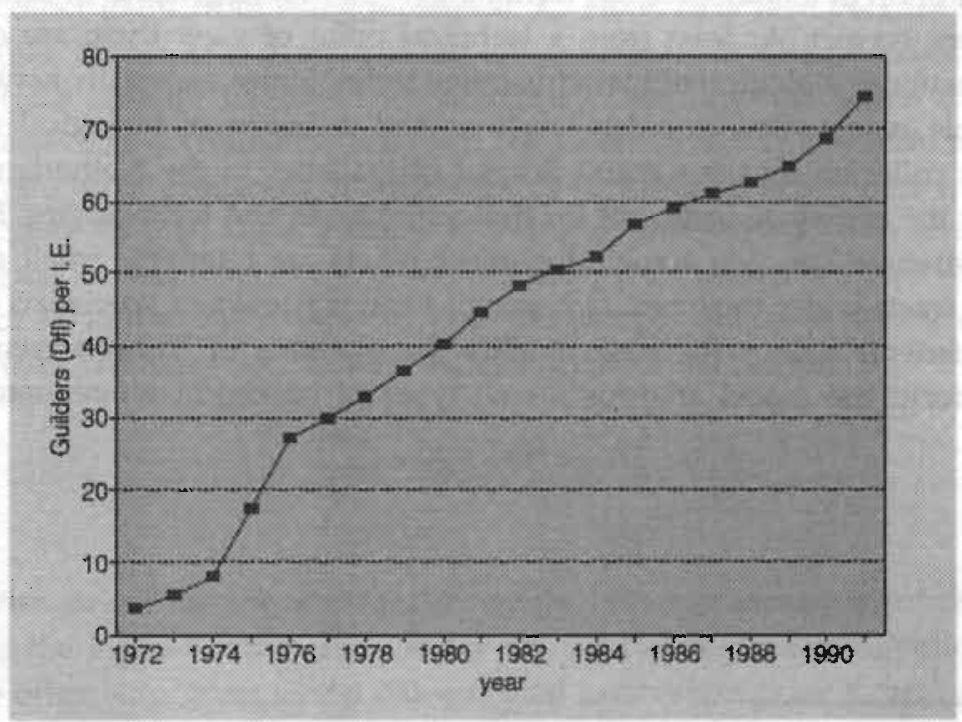

Figure 6.2. Average effluent charges for organically-polluted industrial waste water in the Netherlands. 
Of the various options chosen by industrial polluters to clean organically polluted waste waters, biological waste-water treatment plants were the most important option, in terms of reductions in the discharge of organic pollutants in waterways and costs of capital outlays.

We will now give a short description of biological waste-water treatment systems. Biological waste-water treatment plants are designed to deal with the problem of oxygen-consuming organic pollutants, although they are also capable of dealing with pollutants like nitrates, sulphates and even metals. ${ }^{6}$ Organic pollutants are degraded and secured by micro-organisms (bacteria) operating in either an aerobic or anaerobic (oxygen-free) aquatic environment. A biological waste-water treatment system usually consists of one or two water basins, some tanks, special equipment (like a rootsblower and sludge separator) and a control system. It is a typical end-of-pipe device aimed at the prevention of the discharge of organic pollutants rather than the prevention of the production of pollutants.

There are basically two types of the biological waste-water treatment technologies: aerobic technologies like oxidation tanks, oxidation ditches, aeration tanks (each in a continuous and discontinuous variant) and anaerobic technologies like Upflow Fluidized Bed and Upflow Anaerobic Sludge Blanket. Up to now industrial firms have primarily invested in aerobic technologies - only 16 of the 190 biological waste-water treatment plants in operation in Dutch industries are anaerobic. ${ }^{7}$ This suggests that the implicit model assumption of a homogeneous technology - i.e., homogeneous at time $t$ (not over time) - is not correct. At least from a technical point of view there are considerable differences between biological effluent treatment technologies, especially between aerobic and anaerobic plants. Unfortunately, data on the diffusion of biological waste-water technologies collected by the Central Bureau of Statistics in the Netherlands are only available for the aggregate level, not for individual firms and technologies. However, as the cost differences between aerobic treatment plants are relatively small according to suppliers of waste-water treatment technologies and waste-water specialists of the RIZA (the Dutch federal agency for water-quality management of "rijkswateren"), it seems okay to perform the model analysis for all types of biological waste-water treatment plants.

' Maarten Evenblij, 1993, Waterzuivering. The Sky is the Limit, Milieumagazine, 4(4): 4-7.

${ }^{7}$ C.M. Maas, P.JJ.G. Geudense, en L.E. Duvoort-van Engers, 1993, Afvalwater-zuiveringsslib van Bedrijven en Instellingen, 1990, $\mathrm{H}_{2} \mathrm{O}, 26(3): 6-8$.

${ }^{8}$ The incorporation of anaerobic waste-water treatment systems in the analysis is partly justified by assuming a distribution for the unit costs of effluent treatment. 


\subsection{Description of the Threshold Model}

This section will describe the details of the diffusion analysis of biological waste-water treatment technologies: the distributions of the factors underlying the diffusion process, the parameters to be estimated, etc. For a detailed description of the model itself, we refer to chapter 5 .

An important characteristic of waste-water treatment plants is that the cost of adoption and the reservation price depend on the size of the investment. A high cleaning capacity (in terms of "Inhabitant Equivalents", I.E) is associated with high capital costs and a high willingness to pay for such a device. To deal with this problem, we define the costs of adoption $C_{t}$ and the reservation prices $X_{t}$ per unit of pollution abated, that is, per inhabitant equivalent.

In addition to the one-time costs of adoption, there are variable costs of using biological waste-water treatment plants. The variable costs per unit of abatement are denoted by $V C_{t}$. These costs consist of operating and maintenance costs, energy and material costs and waste disposal costs (biological waste-water treatment technologies produce highly polluted sludge which must be taken care of).

In our model, a potential user compares the costs of employing the environmentsaving durable with the (risk-adjusted) monetary value of the gains connected with the usage of the environment-conserving device. The gains from using a biological wastewater treatment plant consist of the savings in effluent tax payments and the monetary valuation of other gains from using biological, $K_{t}$. Here, $K_{t}$ is zero because there are no extra gains (like higher sales from a better environmental image) or losses attached to the usage of the effluent treatment technologies. ${ }^{9}$ Thus, the only gains from effluent treatment are savings on effluent payments. The gains per unit of abatement from using a biological waste-water treatment in water-quality control region $i$ at time $t$ are equal to $\operatorname{Tax}_{i,}$, the effluent tax rate. These gains, after being discounted for uncertainty, are compared with total annual costs of using the technology, TC, being the sum of the annual capital charge $F C$ and variable costs $V C$, each defined per unit of pollution abated (I.E.). Only those firms will have adopted the technology at time $t$ for which:

$$
\frac{T a x_{1}}{U_{t}}>F C_{t}+V C_{t}=T C_{1}
$$

Dividing both sides of the above inequality by the imputed annual rental rate $R_{l}$ (being a function of the interest rate $r_{t}$ and the service life $l$ of the technology), and bringing $V C_{t} / R_{t}$ to the other side, gives us the risk-adjusted reservation price $X_{t}$ per unit of abatement:

\footnotetext{
${ }^{9}$ In our analysis the waste disposal costs connected with waste-water treatment plants are part of the variable costs.
} 


$$
\begin{aligned}
& X_{t}=\frac{T a x_{t}}{U_{t} R_{t}}-\frac{V C_{t}}{R_{t}} \\
& \text { with } R_{t}=\frac{r_{t}}{1-e^{-r_{t} l}}
\end{aligned}
$$

The risk-adjusted reservation price per unit of abatement, $X_{t}$, is compared with the cost of adoption $C_{t}=F C_{t} / R_{t}$. If $X_{t}>C_{t}$, then a potential adopter 'should' adopt the environment-saving technology (here, a biological waste-water treatment plant).

To apply the model we must first determine which variables of equation (2) are likely to be stochastic (differ among potential users) and what variables can reasonably be assumed to be deterministic (which means that they are the same for all industrial polluters)

The first source of variation is the effluent charge or tax rate $\operatorname{Tax}_{i t}$ that polluters have to pay for discharging oxygen-consuming pollutants in their waste water. As noted above, water-quality management is highly decentralized in the Netherlands. At this moment, there are thirty regional water-quality boards, each being responsible for the quality of the surface waters in their own region. As the regional water-quality control agencies are quite autonomous in deciding how to achieve a higher quality of surface waters, and because the costs of effluent treatment differ across regions (due to geographical factors and the industry structure), the effluent tax rates set by the regional water-quality authorities differed strongly between one another (see appendix A). For example, in 1991, in the region of Vrije van Sluis in the province of Zeeland, industrial water polluters had to pay 120 guilders for each unit of oxygen-consuming organic pollutants, whereas in the AA region in Noord-Brabant water-quality authorities charged only 42.24 guilders per I.E.

Figure 6.3 gives the frequency distribution of the effluent tax rates across waterquality control regions in 1975 and 1991. The frequency distribution of $\operatorname{Tax}_{t}$ in 1981 and 1987 is in appendix B. Casual observation of the frequency distributions of the effluent charges per unit of I.E. across water-quality management regions indicates that, in the 1974-91 period, on the whole, the fequency of effluent charges is (slightly) positive or right-hand skewed with the mean being a little higher than the median. 


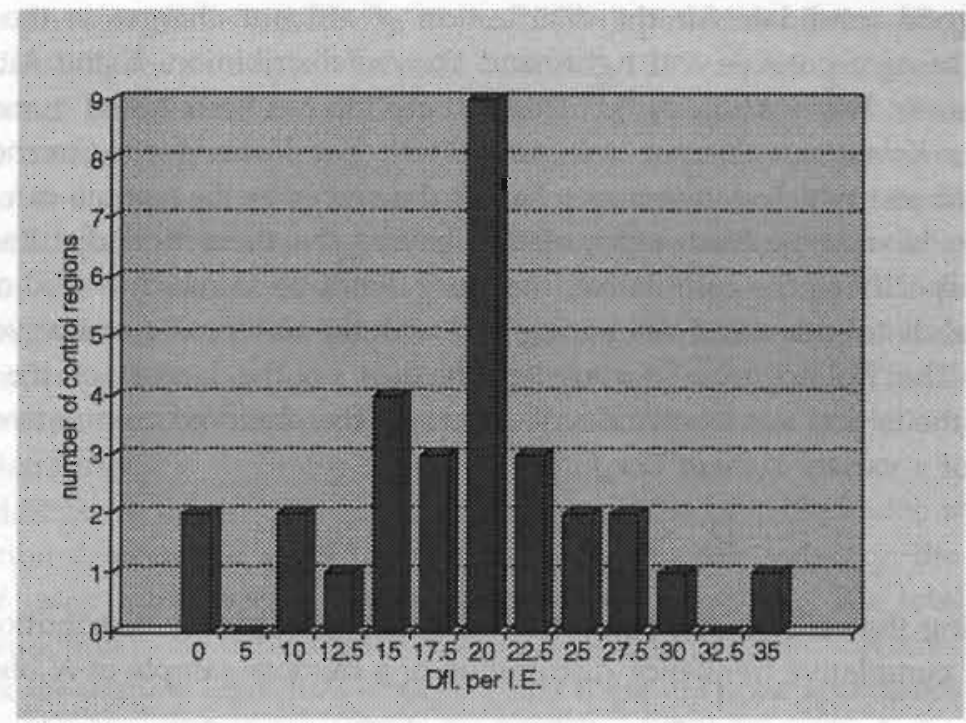

Figure 6.3a. The frequency distribution of effluent charges for organic pollution per unit of I.E. in the Netherlands in 1975.

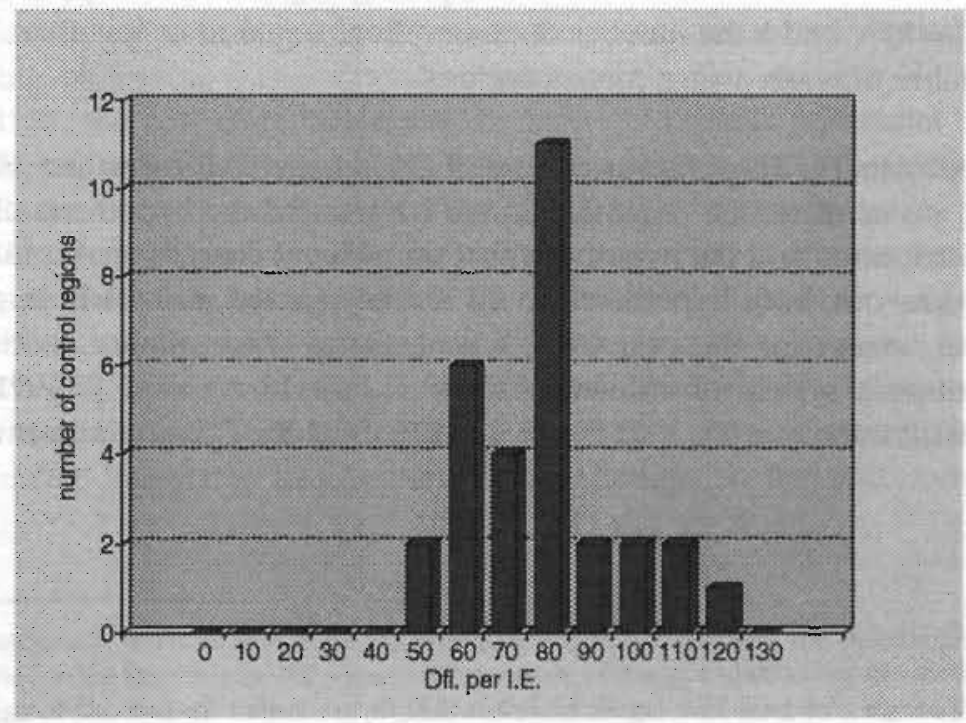

Figure 6.3b. The frequency distribution of effluent charges for organic pollution per unit of I.E. in the Netherlands in 1991. 
A possible good candidate for the distribution of effluent charges is the lognormal distribution, being a positive and right-hand skewed distribution. Using Aitchison and Brown's notation: $\operatorname{Tax} i-\Lambda\left(\mu_{T, l}, \sigma_{T, l}{ }^{2}\right) .^{10}$ This assumption has been tested more thoroughly by doing a Kolmogorov-Smimov one-sample test. The Kolmogorov-Smirnov test is a goodness-of-fit test which determines whether the scores in the sample can reasonably be thought to have come from a population having the theoretical distribution. ${ }^{11}$ The test involves specifying the cumulative frequency distribution which would occur under the theoretical distribution and comparing that with the observed cumulative frequency distribution. The Kolmogorov-Smirnov test focuses on the largest of the deviations between the theoretical cumulative distribution and the observed cumulative frequency distribution of a variate $Y$ (here $\left.T a x_{i t}\right)$ :

$$
D_{N}=\operatorname{maximum}\left|F_{0}(Y)-S_{N}(Y)\right|
$$

with $F_{0}($.$) being the value of the theoretical cumulative frequency distribution and S_{N}($. the observed cumulative frequency distribution of a random sample of $N$ observations.

In our case:

$$
D_{N}=\underset{i=1, \ldots, 30}{\operatorname{maximum}}\left|F_{0}\left(\operatorname{Tax}_{i t}\right)-S_{N}\left(\operatorname{Tax}_{i t}\right)\right|
$$

with $S_{N}\left(\operatorname{Tax}_{i t}\right)=k / N$ and $k$ the number of observations equal to or less than $\operatorname{Tax}_{i t}$ and $N$ $=30$ (the number of waste-water control regions).

The null hypothesis $H_{0}: F()=.F_{0}($.$) is rejected if D_{N}$ is large. Critical values of maximum deviation $D_{N}$ are tabulated in Siegel (1956). We have tested the hypothesis of $F_{0}$ being a lognormal distribution and the hypothesis that the effluent charges are normally distributed. As it turns out, both hypotheses could not be rejected at a fairly large $20 \%$ significance level, except for the year 1974, when several water-quality control agencies failed to institute a system of effluent charges: $D_{N} \leq 0.18, \forall t \in[1975,1991]$ if $F_{0}$ is a lognormal distribution and $D_{N} \leq 0.176, \forall t \in[1975,1991]$ for $F_{0}$ being a normal distribu-

${ }^{10}$ Note that $\mu_{T}$ is not the mean of the effluent charge Tax at time $t$ but that of $\ln (\operatorname{Tax})$. Tax $\Lambda\left(\mu_{T, t}, \sigma_{T, i}{ }^{2}\right)$ means that the nutural lograrithm of the effluent tax is distributed according to a normal distribution with mean $\mu_{\tau, t}$ and standard deviation $\sigma_{1}{ }_{1,}$, i.e., $\mathrm{E}\left\{\ln \left(\operatorname{Ta} x_{t}\right)\right\}=\mu_{T, t}$ and $\mathrm{V}(\ln (\operatorname{Tax})\}=,\sigma_{T, t}{ }^{2}$.

$"$ Sidney Siegel, 1956, Nonparametric Statistics for the Behavioural Sciences, Tokyo: McGraw-Hill Kogakusha Ltd, p.47. The following description of the Kolmogorov-Smirnov test is based on this source. 
tion. As we can see, all values for $D_{N}$ in the 1975-91 period are below $D_{30 ; 0.2}=0.19$, the

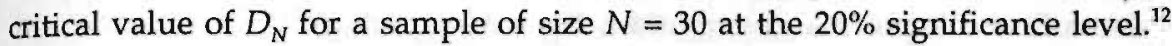

Although the assumption of the effluent charges being lognormally distributed in the 1975-91 period is not rejected, the Kolmogorov-Smirnov test does not lead us to reject the normal distribution in favour of the lognormal distribution. Both assumptions are reasonably good, with the $D_{N}$ values of the normal distribution being somewhat smaller than the $D_{N}$ values of the lognormal distribution in the 1974-86 period and somewhat higher in the 1987-91 period. Throughout this section we use the analytically more convenient assumption of a lognormal distribution for Tax ${ }_{t}$. When we apply the model, however, we will also investigate the possibility of the model's variates being normally distributed.

In addition to the effluent tax rate, another model variable varies widely among the population of potential users in the Food and Beverage industry: the total annual unit cost of using a biological waste-water treatment plant, $T C_{t}$. The total annual unit costs of a reduction in the discharge of oxygen-consuming organic solvents are known to decrease with the cleaning capacity - implying that there are scale economies in biological waste-water cleaning. Schuurman finds for 1983 the following cost abatement function for biological waste-water cleaning technologies (with a control efficiency $\geq 90 \%$ ) employed in the Food industry: $T C_{t}=120,688 / P A_{t}+16.80$ with $T C$ the total annual unit cost (measured in Dutch guilders) of water pollution abatement and $P A$ the reduction in the discharge of oxygen-consuming organic pollutants, measured in I.E. ${ }^{13}$

The above expression clearly demonstrates that there are substantial scale economies in using biological waste-water treatment plants. For example, in the Food industry, in 1983, the cost of reducing the discharge of organic pollutants is 26.8 Dutch guilders (Dfl) per unit of abatement for a firm which produces 12.067 units of I.E. whereas it is Dfl 36.8 for a firm producing 6.033 units of I.E. It seems not permitted therefore to assume that the unit cost of using biological waste-water treatment technologies are constant across industrial water polluters. Since the distribution of firm size is generally positively skewed, with positive values for firm size (whatever measure for firm size is used, output, employees, pollution level) it seems reasonable to assume a lognormal distribution for the distribution of firm size. ${ }^{14}$ But if firm size is distributed according to a two-parameter lognormal distribution, then variations in the unit costs of using a

${ }^{12}$ This conclusion must be qualified. As noted by Siegel $\left(1956\right.$, p.60), the distribution of $D_{N}$ is not exactly known for the case where the mean and variance of the population are estimated (as we have done). The use of the critical values for $D_{N}$ tabulated in Siegel will lead to a conservative test. The values, however, of $D_{N}$ are believed to be small enough (much below $D_{30 ; 0.05}=0.24$ ) to have reasonable confidence in not rejecting the hypothesis that Tax, is (log)normally distributed across waterquality regions in the $1975-91$ period.

${ }^{13}$ Schuurman, op cit., p. 291.

14 The assumption of firm sizes being lognormally distributed is confirmed by many empirical studies studies (Davies, op cit.), which suggests that our assumption is indeed reasonable. 
newly built biological waste-water treatment facility at time $t$ - being inversely related to firm size - also follow a lognormal distribution: $T C_{t}-\Lambda\left(\mu_{T C, y}, \sigma_{T C, t}^{2}\right)^{15}$

The assumption of a lognormal distribution for pollution levels and $T C_{t}$ is also examined statistically, using information provided by Schuurman on the distribution of firms according to their pollution level. Schuurman has classified industrial polluters in four categories on the basis of their pollution level in 1975 - a time at which only few firms owned a biological waste-water treatment system. Figure 6.4 gives the frequency distribution of firms' pollution levels (measured in 1,000 I.E.).

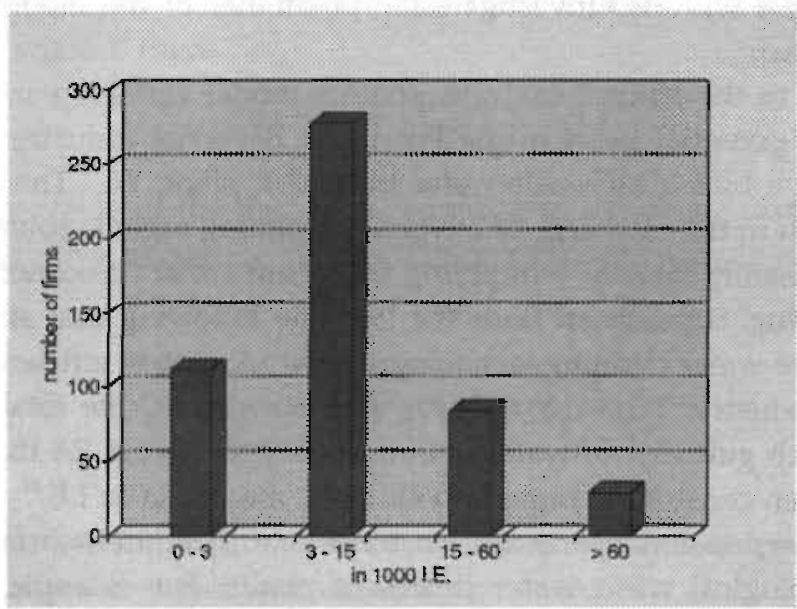

Figure 6.4. The distribution of firms according to the level of effluent discharges in 1975. Source: Schuurman (1988, Table 1.2 on p.34).

Figure 6.4 shows that the empirical distribution much resembles a lognormal distribution. The lognormality of the pollution levels is further analyzed by doing a $\chi^{2}$ onesample test for grouped data. The $\chi^{2}$ test is another goodness-of-fit test which may be used to test whether a significant difference exists between an observed number of cases falling in each category and an expected number based on the null hypothesis. ${ }^{16}$ Using Siegel's notation, $\chi^{2}$ is defined as:

is This result is due to the multiplicative reproductive property of the lognormal distribution: If $X$ $\Lambda\left(\mu, \sigma^{2}\right)$ then $1 / X-\Lambda\left(-\mu, \sigma^{2}\right)$ or, more generally, if $X-\Lambda\left(\mu, \sigma^{2}\right)$ and $b$ and $c>0$ are constants then $c X^{\prime \prime}-\hat{\Lambda}\left(\ln (c)+b \mu, b^{2} \sigma^{2}\right)$ (Theorem 2.1 of J. Aitchison and J.A.C. Brown, 1957, The Lognormal Distribution, Cambridge: Cambridge University Press, p.11).

${ }^{16}$ Siegel, op cit., p.43. 


$$
\chi^{2}=\sum_{j=1}^{m} \frac{\left(O_{j}-E_{j}\right)^{2}}{E_{j}^{2}}
$$

with $O_{j}$ the observed number of cases categorized in the $j$ th category $(j=1, . . m)$ and $E_{i}$ the expected number of cases in the $j$ th category under $H_{0}$.

Under the null hypothesis, $\chi^{2}$ is distributed according to a $\chi_{m \cdot l-l}{ }^{2}$-distribution - where $s$ is the number of independent parameters of $F_{0}($.$) which have to be estimated from the$ grouped data. ${ }^{17}$ Again, we want to establish statistically whether the lognormal and normal distribution are good approximations for the observed empirical distribution. Calculating $\chi^{2}$ under both hypotheses, we find that $\chi^{2}=4.60$ for the normal distribution and that $\chi^{2}=0.82$ for the lognormal distribution (based on 503 observations divided into four classes, that is, $m=4$ and $\Sigma O_{j}=503$ ). These values for $\chi^{2}$ imply that the assumption that the pollution levels are distributed according to a normal distribution is rejected at the 5\% significance level $\left(\chi_{1 ; 0.05}{ }^{2}=3.84\right)$ but not at the $1 \%$ significance level $\left(\chi_{1 ; 0.01}{ }^{2}=5.41\right)$. The hypothesis that the pollution levels are lognormally distributed, however, is not rejected, not even at the $30 \%$ significance level $\left(\chi_{1: 0.3}{ }^{2}=1.07\right)$, which indicates that the lognormal distribution is quite a good approximation for the distribution of pollution levels, much better than the normal distribution. Thus, to the extent that variations in $T C_{t}$, the total unit costs of using a (newly built) biological waste-water treatment plant, are caused by scale economies, such variations may be approximated by a lognormal distribution.

In addition to cost differences due to scale economies, however, another factor accounts for the variability in the total annual unit costs of biological waste-water treatment: the control efficiency of the cleaning device, ER. The control efficiency is known to differ between aerobic and anaerobic technologies, across industries and, to a lesser extent, within industries (being a function of the composition of waste streams). This implies that variations in TC result from two sources. On the one hand we have cost variations due to scale economies (variations that are approximately lognormally distributed) and on the other hand there are variations in effluent treatment costs due to differences in control efficiency between technologies and firms. If we assume that the control efficiency is lognormally distributed, and that such variations are not correlated with cost variations due to scale economies, then the variance of $\ln T C, \sigma_{T C,}^{2}$ is simply the sum of the variance of both variates. (The practical meaning of this, however, is small as only the sum of the variances can be identified empirically - not the variances themselves.)

This leads to the question: What if $E R$ is not lognormally distributed? Is it still correct to use the lognormal distribution for the total annual unit costs of using a (newly

${ }^{17}$ Jean Dickinson Gibbons, 1971, Nonparametric Statistical Inference, New York: McGraw-Hill, pp.7273. In our case, $s$ is 2 as we estimate the mean and variance from the sample. 
built) biological waste-water treatment plant? We believe that even for such a situation, the lognormal distribution may be used as an approximation of the distribution of $T C$ because the variations in costs due to scale economies (which may differ up to a factor two) are believed to be much more important than variations in control efficiency (which are commonly between $60 \%$ and $98 \%$, with most efficiencies between $90 \%$ and $98 \%$ ).

What does all this imply for the probability of adoption? As explained before, adoption is believed to take place the moment at which the risk-adjusted annual gains from adoption exceed the total annual cost of using the biological waste-water technology. If we define the risk-adjusted annual gains by $G_{t}=\operatorname{Tax}_{t} / U_{t}, G_{t}$ is lognormally distributed with $\mu_{t}=\mu_{T, s}-\ln U_{t}$ and $\sigma_{t}^{2}=\sigma_{T, t}^{2}-$ that is, that $G_{t}-\Lambda\left(\mu_{t}, \sigma_{1}^{2}\right)$ - under the assumption that effluent tax rates $\operatorname{Tax}_{i}$ instituted by the water-quality regions follow a lognormal distribution.

The probability that a randomly selected industrial water polluter will have adopted a biological waste-water treatment system at time $t$ is the chance that $G_{l}>T C_{l}$ :

$$
A_{t}=P\left(G_{t}>T C_{t}\right)=1-P\left(G_{t} \leq T C_{t}\right)=1-\int_{-\infty}^{\infty} \Lambda\left(T C_{t} \mid \mu_{t}, \sigma_{t}^{2}\right) d F\left(T C_{t}\right)
$$

Substituting $F\left(T C_{t}\right)=\Lambda\left(T C_{t} \mid \mu_{T C_{1}}, \sigma_{T C}{ }^{2}\right)$ in the above equation gives: ${ }^{18}$

$$
A_{t}=1-\Lambda\left(1 \mid \mu_{t}-\mu_{T c t}, \sigma_{t}^{2}+\sigma_{T C}^{2}\right)
$$

or, what comes down to the same thing, using the standard normal distribution function:

$$
\begin{gathered}
A_{t}=1-N\left(\frac{\ln 1-\left(\mu_{t}-\mu_{T C t}\right)}{\sqrt{\sigma_{i}^{2}+\sigma_{T C}^{2}}} \mid 0,1\right)=\Phi\left(\frac{\mu_{t}-\mu_{T C, t}}{\sqrt{\sigma_{t}^{2}+\sigma_{T C}^{2}}}\right) \\
\text { with } \mu_{t}=\mu_{T t}-\ln \left(U_{t}\right) ; \sigma_{i}^{2}=\sigma_{T t}^{2}
\end{gathered}
$$

This is the equation to be estimated, with an independent and identically distributed (i.i.d.) error term $\varepsilon_{t}$ with zero mean and variance $\sigma^{2}$ added to the right-hand side. As $\mu_{T y}$ $\mu_{T C, t}$ and $\sigma_{T, t}$ may be determined outside the model, we have only two parameters to estimate: $\rho$ and $\sigma_{T C}^{2}$ using observations from the $1974-91$ period (i.e., 18 observations)..$^{19}$

${ }^{18}$ Corollary 2.2b of Aitchison and Brown, op cit., p.11.

${ }^{19}$ Throughout the analysis we assume that the variance of TC is constant with time. 
A possible extension of the model is to assume that uncertainty factor $U_{t}$ differs across the population of industrial polluters. Again, the assumption of a lognormal distribution (being positively skewed and always positive) is analytically very convenient. Because the quotient of two independent lognormally distributed random variables is also lognormally distributed, ${ }^{20} A_{t}$ can be expressed as a function of $\Lambda$ and $\Phi$. In fact, $A_{t}$ the probability that a randomly selected industrial water polluter owns a biological wastewater treatment system at time $t$ is described by equation (6) with $\mu_{t}=\mu_{T, t}-\mu_{u, t}$ and $\sigma_{t}^{2}$ $=\sigma_{T, i}^{2}+\sigma_{u, i}^{2}$ if uncertainty factor $U$ is lognormally distributed with mean $\mu_{u, i}$ and variance $\sigma_{u, t}^{2}$ and independent of $\operatorname{Tax}_{t}$ and $T C_{t}$.

To estimate the above model with stochastic $U$ we must assume a specific function for $\mu_{u, t}$ and $\sigma_{u, t}^{2}$ for instance $\mu_{u, t}=\mu_{u}+\zeta\left(t-t_{0}\right)$ and $\sigma_{u, t}^{2}=\sigma_{u}^{2}$ (being one of the most simple cases). Estimating the model for the case that $U_{t}$ differs across adopters tells us something about the importance of variations in risk attitudes and knowledge in affecting purchase decisions. It should be noted that $\sigma_{\mathrm{TC}, t}^{2}$ and $\sigma_{\mathrm{U}, t}^{2}$ can not be determined statistically - only the sum is identified.

The next section will present the empirical results from the application of our model (and various variants thereof) to the diffusion of biological waste-water treatment technologies in the Dutch Food and Beverage industry in the 1974-91 period.

\subsection{Empirical Results from the Threshold Model}

At the end of 1991, 93 indirect dischargers in Dutch industry owned a biological wastewater treatment system. Of these 93 firms, 77 firms belonged to the Pbod and Beverage industry. The reason why in particular firms in the Food and Beverage industry (such as breweries, tinned food manufacturers, slaughterhouses) decided to invest in biological waste-water treatment plants was that they could clean their waste water at a relatively low cost - in many cases below the average cost for cleaning residual discharges in collective waste-water treatment plants, despite the scale advantages in collective wastewater treatment. The reason behind this was that the effluent of firms in the Food and Beverage industry was relatively homogeneous, being polluted with organic pollutants mainly, which facilitated relatively high control efficiencies at low costs.

This section investigates empirically the impact of changes in the effluent tax rates and other variables on the diffusion of biological waste-water treatment systems. More specifically, it seeks to analyze whether it is possible to explain the time-intensive adoption of biological waste-water treatment systems by firms in the Food and Beverage industry in terms of a threshold model in which the decision to adopt an environmentconserving technology is understood as an economic decision under uncertainty.

Such an analysis could provide statistical evidence as to the following problems. First, the usefulness of the model as a tool for analyzing changes in the adoption of (envi-

${ }^{20}$ Theorem 2.1 and 2.2 of Aitchison and Brown, op cit., p.11. 
ronment-conserving) technologies. Second, the actual impact of effluent charges on the rate of application of biological waste-water treatment plants in Dutch industries. Third, the importance of uncertainty and knowledge problems as a potential hindrance to the uptake of cost-saving biological waste-water treatment plants. And finally, the possibilities of using incentive-based environmental policy instruments instead of commandand-control approaches to fostering the adoption of environment-conserving technologies.

For reasons described earlier, our analysis is restricted to indirect dischargers in the Food and Beverage industry. We have estimated the model for the case that the effluent taxes and total annual unit costs of using a (newly built) biological waste-water treatment plants are lognormally distributed and for the (less likely) situation that these variates are normally distributed, each for different specifications of $U_{t}$. We have also estimated the model on the basis of a different investment selection rule: the Maximum Payback period (which is considered to differ among firms).

Before giving the regression results, however, we will take a closer look at what is believed to be the main driving force behind the technological diffusion of biological waste-water treatment plants: the net annual gains from adoption, $G_{t}-T C_{t}$. As the annual gains from effluent treatment increase over time, it becomes financially attractive for more and more polluters to treat their own waste water. Figure 6.5 depicts the development of the average net annual gains $G_{t}-T C_{t}$ of using biological waste-water treatment technologies in the Food and Beverage industry in the Netherlands.

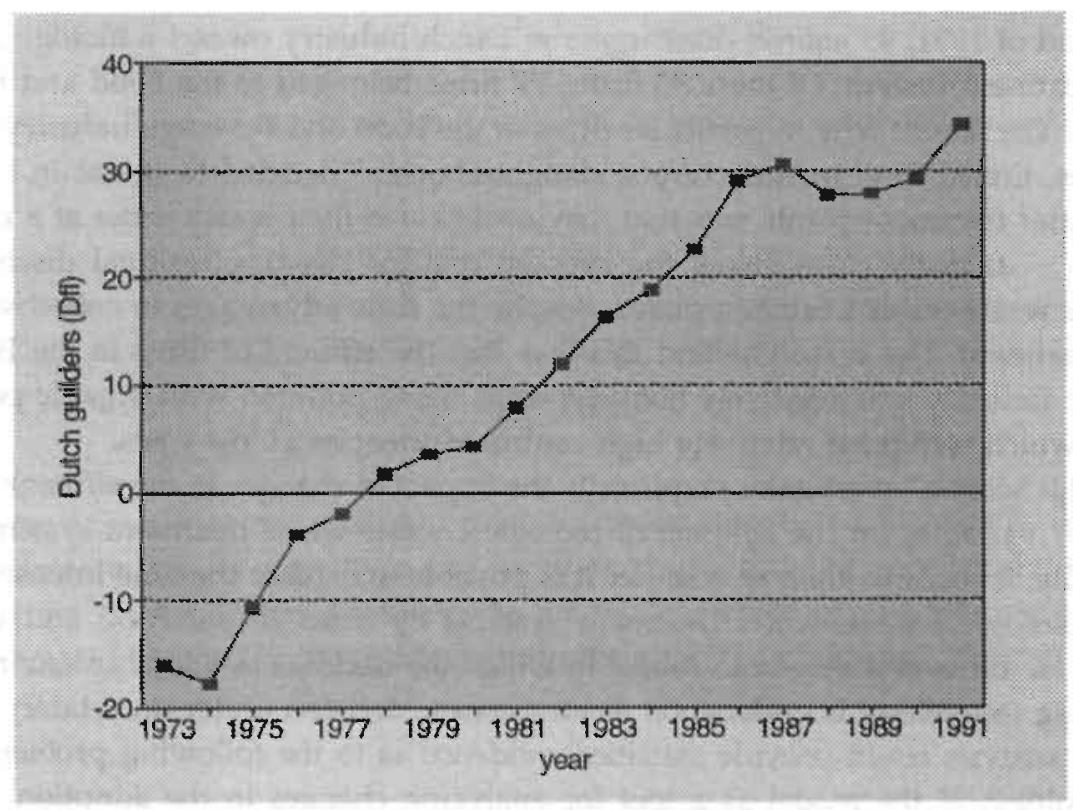

Figure 6.5. The average net annual gains from using a newly built biological waste-water treatment system in the Dutch Food and Beverage industry. 
Figure 6.5 shows that the average net annual gains $G_{t}-T C_{t}$ of biological effluent treatment in the Food and Beverage industry increased over time, except for 1974 (the first oil crisis) and 1988. The main factor behind the steady increase of $G_{t}-T C_{t}$ was the rising effluent tax rate (see Figure 6.2). The increase in the effluent tax rate was particularly high in 1975 and 1976, which is reflected in the sharp increase of $G_{t}-T C_{t}$. The slow increase in $G_{t}-T C_{t}$ in the $1978-80$ period is caused by the relatively strong increase in interest rates, energy prices and labour costs in those years, which resulted in a strong increase in $T C_{l}$. The strong decrease in 1988 is caused by the elimination of the WIR (Wet Investerings Rekening), a government investment subsidy programme in the Netherlands. The elimination of the WIR had a profound impact on the profitability of biological waste-water treatment systems (under the WIR in 1987 it was possible for investors in environmental technologies to receive an investment subsidy of $27.5 \%$ ). Figure 6.5 also illustrates that the fall in the price for electricity in 1986 led to a strong increase in $G_{t}-T C_{t}$ as did the relatively low purchase price in 1991. (Comparison of Figure 6.5 with Figure 6.2, which depicts the development of the effluent tax rate, reveals that the two figures are not identical, which provides some evidence as to the importance of incorporating variables like the interest rate, energy costs and purchase price in the model.)

Besides the net annual gains of reducing the discharge of oxygen-consuming organic pollutants, which differ across water-quality regions (because of the different effluent tax rates), also information problems and uncertainty about the economic consequences of effluent treatment are likely to affect investment decisions in effluent treatment plants. The way in which this is incorporated in the model is by dividing the annual gains from using a biological waste-water treatment plant by uncertainty factor $U_{i}=U_{t}(\rho)$, where $\rho$ is a parameter of uncertainty and $t$ indexes time $\left(d U_{t} / d t<0\right)$. As we have no prior knowledge regarding the exact specification of $U_{t}$, we have estimated the model for various expressions for $U_{t}$ to see which specification would give the best fit, and to analyze the robustness of the estimation results for different specifications of $U_{t}$.

We will now give the regression results, first for the lognormal model, which assumes that both the effluent tax rate $T a x_{t}$ and the total annual unit costs $T C_{t}$ of using a (newly built) biol ogical waste-water treatment plants are lognormally distributed. Results for the normal model and the payback model are in sections 6.3 .2 and 6.3.3., respectively. ${ }^{21}$

\footnotetext{
${ }^{21}$ For those interested in technical details: We used 386 TSP (Times Series Processor) version 4.2A (May 1992) to estimate the model. TSP is a software package for doing time series analysis, written by Bronwyn Hall. As the model is nonlinear in the parameters, we used non-linear least squares to estimate the unknown parameters. The Gauss method is used to approximate the Hessian of the objective function in each iteration, followed by the Davidon-Fletcher-Powell method if the iteration algorithm did not converge after 20 iterations.
} 


\subsubsection{Results from the lognormal model}

We have estimated the lognormal model described in section 6.2 for four different specifications of uncertainty factor $U_{t}:(1) U_{t}=1+\rho /\left(t-t_{0}\right)$, (2) $U_{t}=1+\rho / \ln \left(t-t_{0}\right),(3) U_{t}=1+\rho(1-$ $\left.A_{t-1}\right)$ and (4) $U_{t} \sim \Lambda\left(\mu_{u, t} \sigma_{u}{ }^{2}\right)$ with $\mu_{u, t}=\mu_{U}+\zeta\left(t-t_{0}\right)\left(t_{0}=1973\right)$. The regression results are in column (1), (2), (3) and (4) of Table 6.2, respectively. The unknown parameters are, in the first three variants: $\rho$, the parameter of uncertainty, and $\sigma_{T C}^{2}$, the variance of the logarithm of the total annual unit costs of using a (newly built) biological waste-water treatment system. In the fourth variant we have three parameters to estimate: $\mu_{u}, \zeta$, and $\sigma_{u x c}^{2}$ - the sum of $\sigma_{u}^{2}$ and $\sigma_{T C}^{2}$.

Table 6.2 demonstrates that different specifications for $U_{t}$ lead to different parameter values, especially for $\rho$, which is estimated at 25.87 in the first variant, at 3.78 in the second, and at 2.03 in the third variant. All parameter values for $\rho$ are significantly different from zero at the $5 \%$ significance level (also at the $1 \%$ level). ${ }^{22}$ With respect to the coefficients of determination, the adjusted $-R^{2}$ values are 0.97 for the first variant, 0.94 for the second and 0.95 for the third. The highest value of coefficient of determination is for the fourth variant with stochastic (lognormal) $U_{t}$. In all cases there is evidence of positive autocorrelation - a common phenomenon in diffusion analyses.

As regards the values for uncertainty factor $U_{t}$, these are especially high in the first and fourth variant. In the first variant, $U_{t}$ is as much as 26.86 in the first year of the diffusion period (in the fourth variant it is 14.89). This would mean that potential adopters are extremely risk-averse: that in 1974 the gains from adoption are divided by a factor as high as 26.87 (or 14.89). This is very high, in fact much too high. It is for that reason that we attach more value to the regression results of the second and third variant, especially the third variant where $U_{t}$ is 2.98 in 1974, the first year of the model analysis, and decreases (at a decreasing rate) to 2.21 in 1991, which is still quite high implying that risk-averse potential adopters divide the gains from adoption by a factor $2.21 .^{23}$

${ }^{22}$ It must be noted that the estimators are only asymptotically normally distributed. This means that the quotient of the estimator and the standard error of the estimator is only asymptotically $t$ distributed. This is due to the fact that the model is non-linear in the parameters and the error terms are i.i.d. (if we had assumed a normal distribution for the error term, the above conclusion still holds true).

${ }^{23}$ One of the reasons why we get a high value for $U_{1}$ is because we assumed that investments in biological waste-water treatment plants are financed through loans. In practise, investments are at least in part internally financed. For investment that are internally financed, firms are known to apply high discount rates, much higher than the interest rate. This discount rate reflects opportunity costs and corporate and income taxes. The assumption of the investment being wholly externally financed results in a bias in favour of adoption and - in the statistical analysis - gives rise to a high value for ค. 


\begin{tabular}{|c|c|c|c|c|c|c|}
\hline $\begin{array}{l}\text { Lognormal } \\
\text { model }\end{array}$ & $\stackrel{(1)}{U_{1}=1+\rho /\left(t-t_{0}\right)}$ & $\begin{array}{l}(2) \\
U_{t}=1+\rho / \ln \left(t-t_{0}\right)\end{array}$ & $\stackrel{(3)}{U_{t}=1+\rho\left(1-A_{t-1}\right)}$ & $\begin{array}{l}(4) \\
U_{\Gamma}-\Lambda\left(\mu_{u_{t},}, \sigma_{u}{ }^{2}\right) \\
\mu_{u_{u}}=\mu_{u_{u}}+\zeta\left(t-t_{0}\right)\end{array}$ & $\begin{array}{l}\text { (5) } \\
\text { (3) with } T C+\theta \\
\text { instead of } T C\end{array}$ & $\begin{array}{l}\text { (6) } \\
\text { (3) with one } \\
\text { year lag }\end{array}$ \\
\hline$\rho$ & $\begin{array}{l}25.87^{*} \\
(2.16)\end{array}$ & $\begin{array}{r}3.78^{*} \\
(0.31)\end{array}$ & $\begin{array}{r}2.03^{*} \\
(0.14)\end{array}$ & & $\begin{array}{c}0.26 \\
(0.55)\end{array}$ & $\begin{array}{r}2.07^{*} \\
(0.16)\end{array}$ \\
\hline$\sigma_{T C}^{2}$ & $\begin{array}{r}1.30^{*} \\
(0.21)\end{array}$ & $\begin{array}{r}0.51^{*} \\
(0.12)\end{array}$ & $\begin{array}{r}0.50^{*} \\
(0.10)\end{array}$ & & $\begin{array}{r}0.27^{*} \\
(0.13)\end{array}$ & $\begin{array}{r}0.63^{*} \\
(0.12)\end{array}$ \\
\hline$\theta$ & & & & & $\begin{array}{l}30.26 \\
(17.79)\end{array}$ & \\
\hline$\mu_{u}$ & & & & $\begin{array}{l}2.81^{*} \\
(0.60)\end{array}$ & & \\
\hline$\zeta$ & & & & $\begin{array}{l}-0.11^{*} \\
(0.03)\end{array}$ & & \\
\hline$\sigma_{\text {UTR }}^{2}$ & & & & $\begin{array}{r}2.46^{*} \\
(1.05)\end{array}$ & & \\
\hline adj- $R^{2}$ & 0.97 & 0.94 & 0.95 & 0.99 & 0.97 & 0.95 \\
\hline$D W$ & 0.84 & 0.80 & 1.04 & 1.36 & 1.25 & 0.90 \\
\hline
\end{tabular}

" significant at $5 \%$ level (standard errors in parentheses)

Table 6.2. Estimation results of the diffusion model with lognormally distributed $\mathrm{Tax}_{\mathrm{t}}$ and $\mathrm{TC}_{v}$ 1974-91. 
The value for the variance of the logarithm of the total annual unit costs of using a (newly built) biological waste-water treatment plant is more or less of the amount we expected $\sigma_{r c}^{2}$ to be. ${ }^{24}$

The predicted diffusion pattern of the lognormal model is shown in Figure 6.6. The lognormal model underestimates the ownership of biological waste-water treatment plants in the 1976-78 and the 1989-91 periods. It overestimates the ownership of biological waste-water treatment plants in 1986 and 1987. What happened in 1986 was that the price for electricity fell with $28.3 \%$. The decrease in the model's prediction for $A_{t}$ in 1988 is caused by the termination of the WIR subsidy programme. In 1987, the last year of the WIR programme, each investor in the Netherlands was credited an investment subsidy of $12.5 \%$. For environmental investments like biological waste-water treatment plants it was possible to obtain an extra subsidy of $15 \%$.

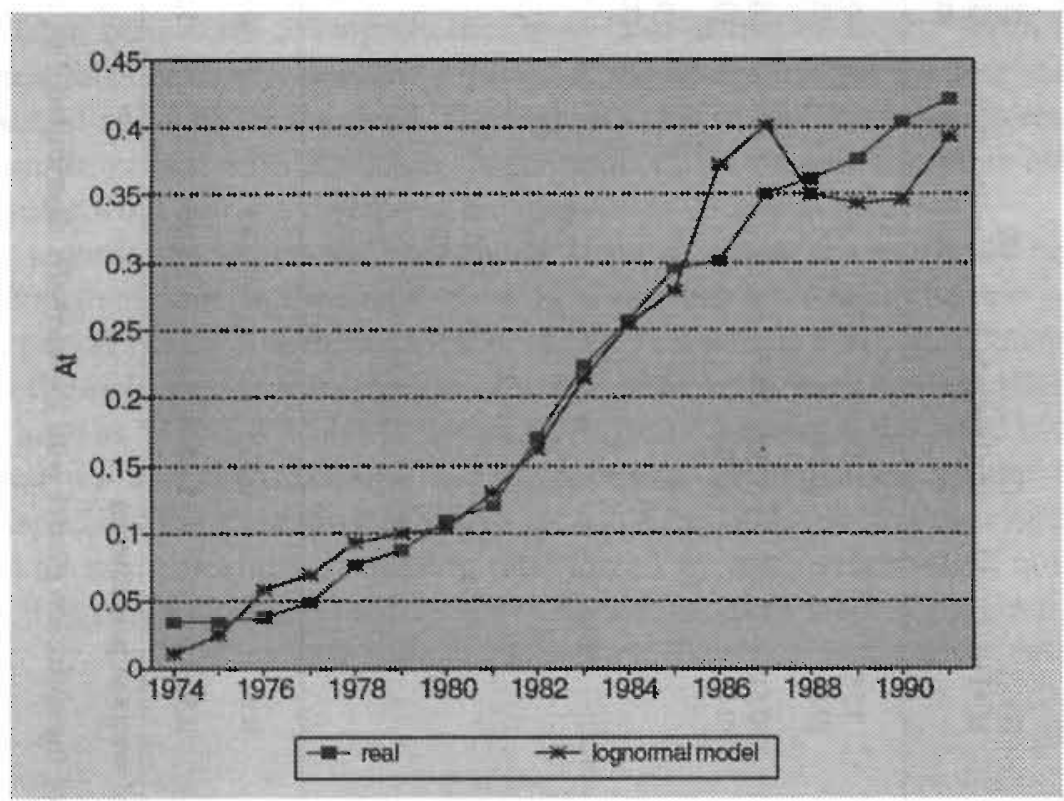

Figure 6.6. The diffusion of biological waste-water treatment technologies in the Food and Beverage Industry according to the lognormal model with $U_{t}=1+\rho\left(1-A_{t-1}\right)$.

On the whole, the lognormal model predicts the trend in the ownership of biological waste-water treatment technologies in the Food and Beverage industry quite well in the 1974-85 period. It fails to explain the sharp increase in 1987, and underestimates the ownership of biological waste-water treatment plants between 1988 and 1990. This

\footnotetext{
24 The mean of the natural logarithm of the total annual unit costs of using a biological wastewater treatment technology is 3.00 in 1974 and 3.69 in 1991.
} 
underestimation in the $1988-90$ period is due to the fact that our model explains the desired ownership of biological waste-water treatment plants in each year, based on the costs and benefits of buying a newly built plant. After the elimination of the WIR in 1988, the desired ownership in 1988 (and the years after 1988) was lower than the desired ownership in 1987. However, a firm that had bought a biological waste-water treatment plant before 1988, given the prevailing price structure in the pre-1988 period, is still an owner in 1988, even if he had not purchased a biological waste-water treatment plant in 1988, when the costs of buying such a plant were much higher. This explains why the model underestimates the ownership of biological waste-water treatment plants in the $1988-90$ period. To deal with this problem, we should have estimated the following model:

$$
A_{t}=A_{t-1}+P\left(X_{t}>C_{t} \mid X_{t-1} \leq C_{t-1}\right)
$$

Unfortunately, it proved impossible to derive an analytical expression for the conditional probability of $X_{t}$ being higher than $C_{t}$, given that $X_{t-1} \leq C_{t-1}$, so that we could not estimate this model.

What do the results tell us? For instance, does uncertainty about the economic consequences of using an effluent treatment system cause firms to underinvest in biological waste-water treatment plants - as the high value for $\rho$ suggests? According to suppliers of biological waste-water treatment technologies this is not the case. Potential users are well aware of the possibility of cleaning their waste water in order to reduce effluent payments, and reliable information as to the costs and benefits of using biological wastewater treatment plants can be obtained from suppliers and consulting firms. So why do we find such high values for $U_{i}$ ? One explanation we have already given: throughout the model analysis we assumed that the investment in biological waste-water treatment was extemally financed at the ongoing long-term interest rate. As explained, this assumption results in upward-biased estimates for $\rho$ and $U_{i}$. Another explanation for the high value of $\rho$ found in the regressions is that we used too low estimates for $T C_{t \prime}$ the total annual unit costs of using a biological waste-water treatment system. This is highly probable for the following reason. The cost figures used in the analysis are based on a survey under adopter firms in 1983 - where we used price indices to calculate the total annual unit costs in the other years. As the costs for non-adopters are likely to be higher than those for adopters, we have probably underestimated the average costs of effluent treatment for the Food and Beverage industry as a whole.

To further investigate this possibility, we have estimated the original model with the total annual unit costs being an (unknown) factor $\theta$ higher. Estimating parameter $\theta$ together with $\rho$ and $\sigma_{T C}^{2}$ indeed provides some evidence that we used too low estimates for the costs of biological waste-water treatment. According to column (5) of Table 6.2, parameter $\theta$ has a positive sign and is estimated at 30.26. Adding a factor $\theta$ to $T C_{i}$ in the analysis also causes $\rho$ to be lower: 0.26 instead of 2.03. As the standard errors of both 
estimates are quite high, we do not attach too much value to these estimates. (The estimated value for $\theta$ is also far too high.)

There are also other explanations for the high value for $U_{i}$. One possible explanation is that it takes time to build a biological waste-water treatment plant. To investigate this possibility, we estimated the model with the explanatory variables one-year and two-years delayed, to account for a time difference between the moment at which a firm decides to buy an effluent treatment system and the moment at which the plant is built. (It generally takes more than half a year to design and build a biological waste-water treatment plant, and sometimes even as much as two years.) The regression results of the model variant with one-year delayed variables are given in column (6) of Table 6.2. As Table 6.2 shows, the results of the model with one-year delayed variables are similar to those of the model with non-delayed variables: almost identical parameter values with somewhat higher standard errors. (Introducing a two-year delay in the explanatory variables gave similar results.)

This means that a one-year or two-year delay in the ownership of biological wastewater treatment plants due to construction time is too simple an explanation as to why firms were slow in investing in cost-efficient biological waste-water treatment plants. There must be other factors besides uncertainty and building time that are responsible for the slow uptake of waste-water treatment plants. What these factors are, we do not know exactly. They could be financing problems, transaction costs, lack of management time, or time that is needed for collecting information. That these factors play a role in the timing of purchasing decision is probable, given that the investment costs of a biological waste-water treatment plant are quite high. According to the 1983 survey of Schuurman, the average investment costs amounted to 1.5 million Dutch guilders, with a maximum of Dfl 15.9 million (almost 9 million dollars). One way of introducing adjustment problems and costs in the analysis is by estimating a partial adjustment or stock adjustment model. In the partial adjustment model, current values of the explanatory variables determine the desired value of the dependent variable $\left(y_{i}\right)$ but only some fixed fraction of the desired adjustment is accomplished in one period:

$$
y_{1}-y_{t-1}=\lambda\left(y_{i}^{*}-y_{t-1}\right)
$$

where $0<\lambda<1$ is the coefficient of adjustment. ${ }^{25}$

Combining both equations, gives the following equation for $A_{\mathrm{t}}$ :

$$
A_{t}=\lambda A_{i}^{*}+(1-\lambda) A_{t-1}+\varepsilon_{i}
$$

${ }^{25}$ George G. Judge, William E. Griffiths, R. Carter Hill and Tsoung-Chao Lee, 1980, The Theory and Practice of Econometrics, New York: John Wiley, p.626. 
with $A_{i}^{*}=\Phi\left(\frac{\mu_{t}-\mu_{T C, t}}{\sqrt{\sigma_{t}^{2}+\sigma_{T C}^{2}}}\right)$ the desired level of adoption at time $t$ and i.i.d. $\varepsilon_{t}$.

We have estimated the partial adjustment model with lognormally distributed Tax $x_{t}$ and $T C_{t}$ for each of the expressions for $U_{t}$. The results are in Table 6.3.

\begin{tabular}{|c|c|c|c|c|}
\hline $\begin{array}{l}\text { Partial adjustment } \\
\text { model }\end{array}$ & $\begin{array}{l}(1) \\
U_{t}=1+\rho /\left(t-t_{0}\right)\end{array}$ & $\begin{array}{l}(2) \\
U_{t}=1+\rho / \ln \left(t-t_{0}\right)\end{array}$ & $\stackrel{(3)}{U_{t}=1+\rho\left(1-A_{t-1}\right)}$ & $\begin{array}{l}\text { (4) } \\
U_{t}-\Lambda\left(\mu_{u, u}, \sigma_{u}^{2}\right) \\
\text { with } \mu_{u,}=\mu_{u}+\zeta\left(t-t_{0}\right)\end{array}$ \\
\hline$\lambda$ & $\begin{array}{l}0.256^{*} \\
(0.11)\end{array}$ & $\begin{array}{l}0.180^{*} \\
(0.08)\end{array}$ & $\begin{array}{l}0.155^{*} \\
(0.11)\end{array}$ & $\begin{array}{c}0.37 \\
(0.23)\end{array}$ \\
\hline$\rho$ & $\begin{array}{l}18.1^{*} \\
(5.67)\end{array}$ & $\begin{array}{r}2.39^{*} \\
(0.82)\end{array}$ & $\begin{array}{c}1.14 \\
(0.68)\end{array}$ & \\
\hline$\sigma_{T C}^{2}$ & $\begin{array}{r}1.60^{*} \\
(0.45)\end{array}$ & $\begin{array}{c}0.61^{*} \\
(0.22)\end{array}$ & $\begin{array}{r}0.55^{*} \\
(0.23)\end{array}$ & \\
\hline$\mu_{u}$ & & & & $\begin{array}{c}1.87 \\
(0.95)\end{array}$ \\
\hline$\zeta$ & & & & $\begin{array}{l}-0.07 \\
(0.05)\end{array}$ \\
\hline$\sigma_{U \pi c}^{2}$ & & & & $\begin{array}{c}1.48 \\
(1.20)\end{array}$ \\
\hline adj- $-R^{2}$ & 0.99 & 0.99 & 0.99 & 0.99 \\
\hline DW & 2.34 & 2.34 & 2.21 & 2.04 \\
\hline
\end{tabular}

" significant at $5 \%$ level (standard errors in parentheses)

Table 6.3. Estimation results of the lognormal model with adjustment costs, 1974-91.

The estimation results of the partial adjustment model are quite good: high coefficients of determination (adjusted $R^{2}$ values of 0.99 ) and all the parameter values have the correct sign. Almost all parameter values are significantly different from zero at the $5 \%$ level (except for $\rho$ in the third specification and the estimates in the fourth version), which is very good given that we have only 18 observations to estimate three parameters (four parameters if $U_{i}$ is stochastic). The high $t$ values for the coefficient of adjustment $\lambda$ 
furthermore suggest that the partial adjustment model is indeed a good model, that it is a better model than the lognormal model without adjustment costs. $\lambda$ is estimated between 0.155 and 0.37 , which is quite low. It means that only a small fraction of the desired adoption level is accomplished.

The reported Durbin-Watson coefficients are also better than those in Table 6.2 (close to 2). However, the Durbin-Watson test is known to be a conservative test if the error terms are autocorrelated - as they are according to Table 6.2. To detect (first-order) serial correlation in autoregressive models we must use Durbin's $h$ test. The Durbin $h$ statistic can be approximated from the estimated Durbin-Watson statistic $d$ as follows: ${ }^{26}$

$$
h=\left(1-\frac{1}{2} d\right) \sqrt{\frac{N}{1-N \partial_{\lambda}^{2}}}
$$

with $h$ being asymptotically normally distributed with zero mean and unit variance.

The values for the Durbin $h$ statistic found in the estimations are, respectively: -0.81 , $0.77,-0.47$ and 0.29 . All $h$ values are between -1.96 and 1.96 , so that we do not reject the null hypothesis that there is no first-order autocorrelation at the $5 \%$ significance level.

This brings us to the question: which specification is best? Since each of the four specifications yields a good fit, the reported coefficients of determination do not favour one particular specification. If we look at the estimates for the parameters, however, we see that the parameter values for $\rho$ in the first and second specification are high - although not as high as in Table 6.2. As we have reason to believe that uncertainty is not a significant barrier to the uptake of biological waste-water treatment plants, we think that the partial adjustment model with $U_{t}=1+\rho\left(1-A_{t-1}\right)$ gives the best results (the model with stochastic $U_{i}$ gave values for $U_{t}$ that were below 1 in the $1988-91$ period). The parameter values for $\lambda, \rho$ and $\sigma_{T C}^{2}$ in column (3) all have the correct sign and are of the right order, and both $\lambda$ and $\sigma_{T C}^{2}$ are significantly different from zero at the $5 \%$ significance level. (The parameter value for $\rho$ is not significantly different from zero at the $5 \%$ level but is at the $10 \%$ significance level.) Model results for $A_{t}$ of the partial adjustment model with $U_{t}=1+p\left(1-A_{t-1}\right)$ are given in Figure 6.7.

Figure 6.7 shows that the partial adjustment model somewhat overestimates the adoption level in the 1982-86 period, but that on the whole the model predictions are very good. This suggests that adjustment problems play a significant role in the uptake of biological waste-water treatment plants. The parameter value for the coefficient of adjustment is low (it is 0.16 is the model with $U_{i}=1+\rho\left(1-A_{t-1}\right)$ ), but, as noted earlier, this value is biased downward due to the underestimation of the effluent treatment costs and the assumption that the investment is externally financed at the ongoing interest rate.

${ }^{26}$ Damodar N. Gujarati, 1988, Basic Econometrics, 2nd Edition, New York: McGraw-Hill, p.526. 


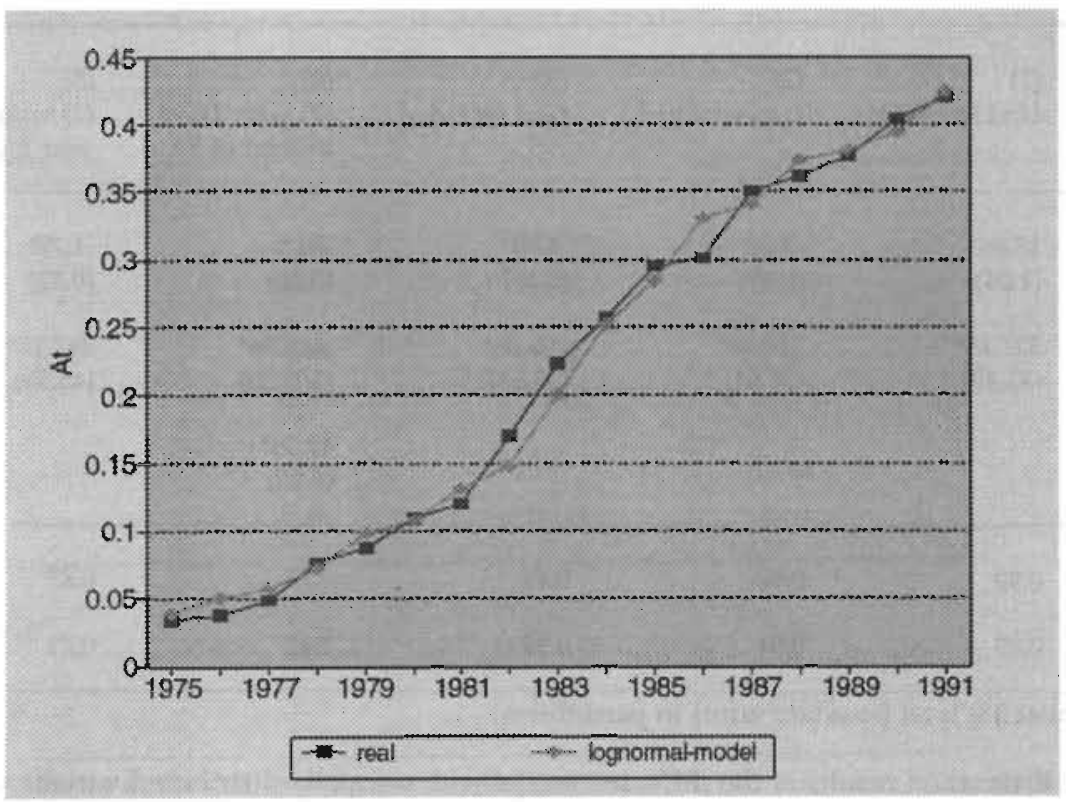

Figure 6.7. The diffusion of biological waste-water treatment technologies according to the lognormal model with adjustment costs and $U_{t}=1+\rho\left(1-A_{t-1}\right)$.

The next section gives the results for the normal model, that is, the model with normally distributed effluent charges $\operatorname{Tax}_{t}$ and normally distributed total annual unit costs $T C_{t}$. Section 3.3 presents the results from a different version of the model, based on an alternative investment selection rule, the Maximum Payback period.

\subsubsection{Results from the normal model}

The regression results of the normal model, with the effluent charges and total annual unit costs of biological effluent treatment being normally distributed are given in Table 6.4. We have estimated the same variants as in section 3.2, with the exception of the variant of a stochastic $U_{t}$ which we were unable to estimate because the quotient of a normally distributed $T a x_{i}$ and $(\log )$ normally distributed $U_{t}$ is not distributed according to a well-known distribution. Comparison of the results of Table 6.2 with those of Table 6.4 shows that the assumption of normally distributed variates yields less satisfactory regression results: lower goodness-of-fit values, higher standard errors, and lower values for the Durbin-Watson statistic (indicating positive first-order autocorrelation). The variant with $U_{t}=1+\rho / \ln \left(t-t_{0}\right)$ has the highest adjusted $R^{2}$ of the three investigated specifications of $U_{t}$. Again, the variant with $U_{t}=1+\rho\left(1-A_{t-1}\right)$ gives the lowest values for $U_{t}$. 


$\begin{array}{llllll}\text { Normal } & (1) & (2) & (3) & (4) & \text { (5) } \\ \text { model } & U_{t}=1+\rho /\left(t-t_{i}\right) & U_{t}=1+\rho / \ln \left(t-t_{0}\right) & U_{i}=1+\rho\left(1-A_{t-1}\right) & \begin{array}{l}\text { (2) with } T C+\theta \\ \text { instead of } T C\end{array} & \begin{array}{l}\text { (2) with one- } \\ \text { year lag }\end{array}\end{array}$

\begin{tabular}{|c|c|c|c|c|c|}
\hline$p$ & $\begin{array}{l}18.86^{*} \\
(1.04)\end{array}$ & $\begin{array}{r}3.30^{*} \\
(0.19)\end{array}$ & $\begin{array}{r}1.78^{*} \\
(0.10)\end{array}$ & $\begin{array}{l}-0.05 \\
(0.20)\end{array}$ & $\begin{array}{c}1.77^{*} \\
(0.12)\end{array}$ \\
\hline$\sigma_{T C}^{2}$ & $\begin{array}{l}327.15^{*} \\
(42.45)\end{array}$ & $\begin{array}{l}218.48^{*} \\
(38.64)\end{array}$ & $\begin{array}{l}209.86^{*} \\
(36.53)\end{array}$ & $\begin{array}{r}668.86^{*} \\
(105.30)\end{array}$ & $\begin{array}{l}247.17^{4} \\
(45.38)\end{array}$ \\
\hline$\theta$ & & & & $\begin{array}{l}42.38^{*} \\
(9.95)\end{array}$ & \\
\hline adj- $R^{2}$ & 0.93 & 0.90 & 0.89 & 0.97 & 0.87 \\
\hline DW & 0.95 & 0.94 & 0.94 & 1.42 & 0.71 \\
\hline
\end{tabular}

* significant at $5 \%$ level (standard errors in parentheses)

Table 6.4. Estimation results of the diffusion model with normally distributed variables, 1975-91.

As regards the parameter values of the normal model: the estimates for $p$ are somewhat lower than those of the lognormal model but still quite high. Again, we have first-order positive autocorrelation in the error term. Surprisingly, in the normal model the value for $\theta$ differs significantly from zero at the $5 \%$ significance level, despite the fact that it is much too high - it is more likely to be in the range of Dfl 5-15 per I.E.

We also estimated the partial adjustment model. Results of the partial adjustment model with normally distributed $T a x_{i}$ and $T C_{i}$ are in Table 6.5. The coefficients of the partial adjustment model are all high, but the parameter values often have the wrong sign: $\sigma_{\pi c}^{2}$ is negative in the first and second specification and the value for $\lambda$ in column (3) is not only negative but even significantly negative at the $5 \%$ significance level. We will not pay further attention to the estimation results of the normal model, being a 'wrong' model. Suffice to say that the better results from the lognormal model provide further evidence that the distribution of the total annual unit costs $T C_{t}$ of using a (newly built) biological waste-water treatment system is better approximated by a two-parameter lognormal distribution than by a normal distribution. 


\begin{tabular}{llll}
$\begin{array}{lll}\text { Partial adjustment } \\
\text { model }\end{array}$ & $(1)$ & $(2)$ & $(3)$ \\
& $U_{\mathrm{r}}=1+\rho /\left(t-t_{0}\right)$ & $U_{\mathrm{r}}=1+\rho / \ln \left(t-t_{0}\right)$ & $U_{t}=1+\rho\left(1-A_{t-1}\right)$ \\
\hline & & & \\
& $0.045^{*}$ & $0.045^{*}$ & $-0.146^{*}$ \\
& $(0.01)$ & $(0.01)$ & $(0.06)$ \\
& 0.39 & 0.133 & $2.04^{*}$ \\
& $(0.79)$ & $(0.24)$ & $(0.57)$ \\
$\sigma_{\pi c}^{2}$ & -8.15 & -20.21 & 10.94 \\
& $(146)$ & $(112)$ & $(99)$ \\
\hline & & & \\
adj- $R^{2}$ & 0.99 & 0.99 & 0.99 \\
DW & 2.30 & 2.30 & 2.21 \\
\hline
\end{tabular}

* significant at $5 \%$ level (standard errors in parentheses)

Table 6.5. Estimation results of the partial adjustment model with normally distributed $\operatorname{Tax}_{i}$ and $T C_{v}, 1974-91$.

We will now present the results from an entirely different model, based on a different investment selection rule, the Maximum Payback period. The maximum payback period states the maximum number of years that are needed to recoup investment costs. What many firms do is to compare the expected payback period with the maximum acceptable payback period (which generally differs among potential adopters). If the expected payback period is below the maximum acceptable payback period they will purchase the durable, otherwise they will not. As most firms apply quite short payback periods, this obviously has a negative effect on the rate of adoption of a capital good. Of course, a short maximum payback period in part reflects risk aversion and information problems, but it is not the same thing: the maximum payback rule is an institution, 'inherited' from the past, commonly beyond evaluation and not subject to regular modification as more information comes available about the economic consequences of purchasing a durable.

\subsubsection{Results from the payback model}

This section develops the payback model and gives the regression results. As noted before, a central assumption of the payback model is that a potential user will purchase a capital good if and when the expected payback period is below the maximum acceptable payback period. Thus, the maximum payback period still acceptable to a potential user is the critical threshold in the payback model. Both the expected and maximum accep- 
table payback period are likely to differ across the population of potential users - as a function of different effluent tax rates, unit costs of effluent treatment, management risk attitudes, etc. The expected payback period of a biological waste-water treatment technology built at time $t, P B_{t}$, is defined as:

$$
P B_{i}=\frac{C_{t}}{T a x_{t}-V C_{t}-I C_{t}}
$$

with $C_{t}$ the purchase price plus installation costs, $V C_{t}$ the variable costs of biological effluent treatment, $I C_{t}$ the interest costs, and $T a x_{t}$ the effluent tax rate, where $C_{t}$ and $V C_{t}$ are defined per inhabitant equivalent (I.E.) - the typical measuring rod for organically polluted residual discharges in the Netherlands.

Assuming that $C_{t}$, the adoption costs, and $T a x_{1}-V C_{t}-I C_{t}$ are distributed according to a lognormal distribution for each $t$, i.e., that $C_{t}-\Lambda\left(\mu_{C, t}, \sigma_{C, t}^{2}\right)$ and $\operatorname{Tax}_{t}-V C_{t}-I C_{t}-\Lambda\left(\mu_{T V, t^{-}}\right.$ ,$\left.\sigma_{T V, 1}^{2}\right)$, and that both variates are independent, applying Theorem 2.1 and 2.2 of Aitchison and Brown gives that the expected payback period is also lognormally distributed: $P B_{t}-\Lambda\left(\mu_{P B,}, \sigma_{P B, t}^{2}\right)^{27}$

We now have to assume a particular distribution for $P B^{\circ}$, the critical payback period. A convenient assumption is that the critical payback periods among indirect dischargers are distributed according to a lognormal distribution - with a maximum acceptable payback period of one or two years for myopic firms, and higher critical payback periods (up to eight years) for other firms. This seems a reasonable assumption, given that payback requirements are correlated with firm size - with small firms typically applying short maximum acceptable payback periods.

If the critical payback periods among potential adopters are distributed according to a two-parameter lognormal distribution, that is, if $P B^{*}-\Lambda\left(\mu_{P B^{*}}, \sigma_{P B^{*}}^{2}\right)$, then the proportion of firms that 'should' have adopted the technology under consideration at time $t$ is:

$$
A_{t}=P\left(P B_{t}<P B^{*}\right)=\int_{-\infty}^{\infty} \Lambda\left(P B^{*} \mid \mu_{P B t^{\prime}}, \sigma_{P B_{t}, t}^{2}\right) d F\left(P B^{*}\right)
$$

Solving the integral in equation (10) gives:

${ }^{27}$ Note that only for the case that $T a x_{\mathrm{p}}-V C_{\mathrm{i}}-I_{\mathrm{p}}$ is distributed according to a two-parameter lognormal distribution, the above result of a lognormal distribution for $P B_{i}$ holds. If both $T a x_{t}$ and $V C_{t}-I C_{t}$ are lognormally distributed, $T a x_{t}-V C_{t}-I C_{t}$ is not distributed according to a lognormal distribution and nor is $P B_{t}$. If $T a x_{t}$ follows a lognormal distribution, and $V C_{t}-I C_{t}$ is the same for all firms, $T a x_{t}-V C_{t}-I C_{t}$ follows a three-parameter lognormal distribution, which means that we cannot use the convolution property to determine the distribution of $P B_{r}$. 


$$
\begin{gathered}
A_{t}=\Phi\left(\frac{\mu_{P B^{*}}-\mu_{P B, t}}{\sqrt{\sigma_{P B, t}^{2}+\sigma_{P B}^{2}}}\right) \\
\text { with } \mu_{P B, t}=\mu_{C, t}-\mu_{T V, t} \text { and } \sigma_{P B, t}^{2}=\sigma_{C, t}^{2}+\sigma_{T V, t, t}^{2}
\end{gathered}
$$

Equation (11) is the equation to be estimated, with an i.i.d. error term around zero added to the right-hand side to account for possible measurement errors in $A_{b}$, random variables and misspecifications in the model. Since the mean of the expected payback period and adoption costs and the variance of $\operatorname{Tax}_{t}-V C_{t}-I C_{t}$ can be determined outside the regression analysis, we must estimate three parameters: $\mu_{P B}, \sigma_{P B}^{2}$ and $\sigma_{C}^{2}$ (assuming that $\sigma_{C, i}^{2}$ is constant over time). ${ }^{28}$ Of these three parameters, only $\mu_{P B}$ and the sum of $\sigma_{P B}^{2}$ and $\sigma_{c}^{2}$ are statistically identified in the regression analysis, which leaves us with two parameters to estimate.

\begin{tabular}{lcll}
\hline $\begin{array}{l}\text { Payback } \\
\text { model }\end{array}$ & $(1)$ & $\begin{array}{l}(2) \\
(1) \text { with one- } \\
\text { year lag }\end{array}$ & $\begin{array}{l}(3) \\
\text { partial adjust- } \\
\text { ment model }\end{array}$ \\
\hline$\mu_{P B^{*}}$ & $\begin{array}{c}1.11^{*} \\
(0.10)\end{array}$ & $\begin{array}{l}1.11^{*} \\
(0.10)\end{array}$ & $\begin{array}{c}1.67^{*} \\
(0.29)\end{array}$ \\
$\sigma_{P B^{*} C}^{2}$ & $0.87^{*}$ & $1.09^{*}$ & $0.84^{*}$ \\
$\lambda$ & $(0.30)$ & $(0.32)$ & $(0.40)$ \\
\hline adj- $R^{2}$ & 0.83 & 0.86 & $0.115^{*}$ \\
$D W$ & 0.42 & 0.59 & 0.99 \\
\hline
\end{tabular}

- significant at $5 \%$ level (standard errors in parentheses)

Table 6.6. Estimation results of the payback model with lognormally distributed $\mathrm{PB}^{*}$ and $\mathrm{PB}_{t}$ 1975-91.

25 The variance of $\operatorname{Tax}_{i}-V C_{\text {, }}$ is estimated by subtracting $V C_{\text {, }}$ from the effluent tax rates across water-quality regions and calculating the variance of the transformed data. Strictly speaking this is not correct. We could have estimated the variance of $T a x_{i}-V C_{1}$ in the regression analysis but then we would not make use of the information available about the frequency distribution of Tax. Moreover, we would have one more parameter to estimate on the basis of only 18 observations. 
We estimated three variants of the payback model for the 1975-91 period: 1) the model described above, 2 ) the above model with the explanatory variables one-year delayed (to account for a one-year difference between the decision to purchase a biological wastewater treatment plant and the moment at which the biological waste-water treatment technology is ready for usage), and 3) the partial adjustment model. The estimation results are in Table 6.6.

The parameter values of the payback model all have the correct sign and are significantly different from zero at the $5 \%$ significance level (the estimates for $\mu_{P B}$. and $\sigma_{P B^{*} C}^{2}$ in column (1) and (2) are even significantly different from zero at the $1 \%$ signifance level). The average critical payback period is estimated at 3.02 in the original payback model and at 5.31 in the partial adjustment model. The last estimate is probably too high, it is more likely to be around three years according to suppliers of biological waste-water treatment plants. The estimates for $\sigma_{P B^{*} C}^{2}$ on the other hand are all low, in fact much too low. Figure 6.8 gives the predictions for $A_{t}$ of the original model and the partial adjustment model.

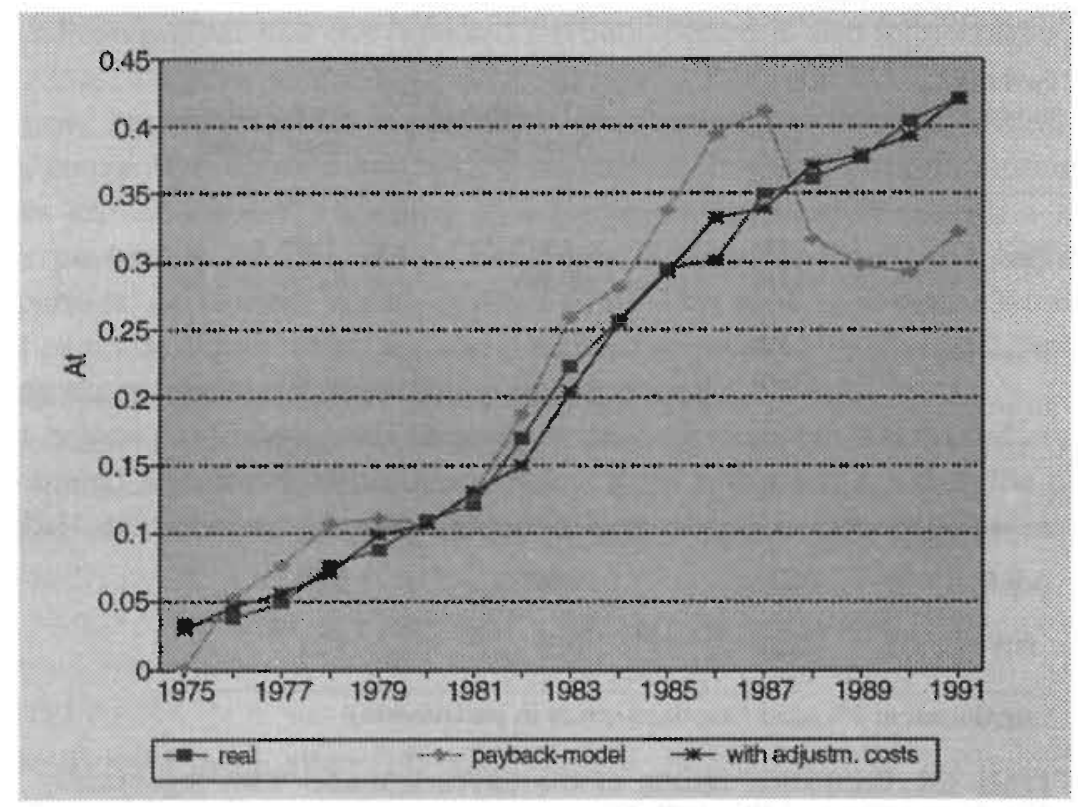

Figure 6.8. The diffusion of biological waste-water treatment technologies in the Dutch Food and Heverage industry according to the payback model with and without adjustment costs.

While the predictions of the partial adjustment model for $A_{t}$ are very good, these of the original payback model are less good. The original payback model can statistically explain quite well the observed diffusion process in the $1975-85$ period. However, it 
overestimates the ownership of biological waste-water treatment plants in 1986 and 1987, and underestimates the ownership in the 1988-91 period, when it was no longer possible for indirect dischargers to receive an investment subsidy for waste-water treatment plants.

\subsubsection{Model results for $\Delta A_{t}$ instead of $A_{t}$}

We now examine whether the threshold model is able to explain changes in the ownership of biological waste-water treatment plants. We estimated the following equation: ${ }^{20}$

$$
\Delta A_{t} \equiv A_{t}-A_{t-1}=\Phi\left(\frac{\mu_{t}-\mu_{T C, t}}{\sqrt{\sigma_{t}^{2}+\sigma_{T C}^{2}}}\right)-\Phi\left(\frac{\mu_{t-1}-\mu_{T C, t-1}}{\sqrt{\sigma_{t-1}^{2}+\sigma_{T C}^{2}}}\right)+\varepsilon_{t}
$$

with $\varepsilon_{t}$ an i.i.d. error term with zero mean

The partial adjustment model for $\Delta A_{t}$ is:

$$
\begin{gathered}
\qquad A_{t}=\lambda\left(A_{t}^{*}-A_{t-1}\right)+\varepsilon_{t} \\
\text { with } A_{i}^{*}=\Phi\left(\frac{\mu_{P B}-\mu_{P B, t}}{\sqrt{\sigma_{P B, t}^{2}+\sigma_{P B}^{2}}}\right) \text { and } \varepsilon_{t} \text { an i.i.d. error term around zero }
\end{gathered}
$$

An advantage of estimating the above models for $\Delta A_{t}$ (instead of $A_{t}$ ) is that we no longer have non-stationarity in the variables and that the probability of (first-order) autocorrelation in the error term is much lower. The estimation results are in Table 6.7.

Table 6.7 shows that the estimation results for $\Delta A_{t}$ are all bad, except for the partial adjustment model with lognormally distributed $T a x_{1}$ and $T C_{t}$ and the PA model with lognormal $P B_{t}^{*}$ and $P B_{t}$. In most cases, we obtain coefficients of determination that are close to zero (and sometimes even negative) and insignificant parameter estimates. It is only when adjustment costs are introduced in the analysis that we get better results (higher adjusted $R^{2}$ values and significant parameter values). This is not true, however, for the normal model. There is evidence of positive first-order autocorrelation in columns (3) and (5) but as we will not consider these specifications any further, this is not disturbing.

${ }^{20}$ This is not quite correct if $\Phi_{t}<\Phi_{t-1}$, for some $t$. lnstead of (12) we should estimate: $\Delta A_{t}=\max \left[0, \Phi_{t}-\max _{s} \Phi_{s}\right]$. Unfortunately, this equation cannot be estimated in TSP. 


\begin{tabular}{|c|c|c|c|c|c|c|}
\hline & $\begin{array}{l}\text { lognormal model } \\
\text { with } \\
U_{i}=1+\rho\left(1-A_{1-1}\right)\end{array}$ & $\begin{array}{l}\text { (2) } \\
\text { PA model with } \\
\text { lognormal Taxi } \\
\text { and } T C_{1}\end{array}$ & $\begin{array}{l}\text { (3) } \\
\text { normal model } \\
\text { with } \\
U_{t}=1+\rho\left(1-A_{t-1}\right)\end{array}$ & $\begin{array}{l}\text { (4) } \\
\text { PA model with } \\
\text { normal } T a x_{i} \\
\text { and } T C_{i}\end{array}$ & $\begin{array}{l}\text { (5) } \\
\text { payback model }\end{array}$ & $\begin{array}{l}\text { (6) } \\
\text { PA model with } \\
\text { lognormal } P B^{*} \text {; } \\
\text { and } P B_{1}\end{array}$ \\
\hline$\lambda$ & & $\begin{array}{c}0.16 \\
(0.12)\end{array}$ & & $\begin{array}{l}-0.147 \\
(0.061)\end{array}$ & & $\begin{array}{c}0.12^{*} \\
(0.06)\end{array}$ \\
\hline$\rho$ & $\begin{array}{c}7.27 \\
(4.96)\end{array}$ & $\begin{array}{c}1.16 \\
(0.67)\end{array}$ & $\begin{array}{r}2.84^{*} \\
(1.11)\end{array}$ & $\begin{array}{c}2.04^{*} \\
(0.56)\end{array}$ & & \\
\hline$\sigma_{\pi}^{2}$ & $\begin{array}{c}2.19 \\
(2.64)\end{array}$ & $\begin{array}{c}0.54^{*} \\
(0.23)\end{array}$ & $\begin{array}{l}-3.63 \\
(41.74)\end{array}$ & $\begin{array}{l}11.23 \\
(99.03)\end{array}$ & & \\
\hline$\mu_{P B^{*}}$ & & & & & $\begin{array}{l}-0.19 \\
(0.73)\end{array}$ & $\begin{array}{c}1.66^{*} \\
(0.29)\end{array}$ \\
\hline$\sigma_{P B^{*} C}^{2}$ & & & & & $\begin{array}{c}2.06 \\
(1.76)\end{array}$ & $\begin{array}{r}0.85^{*} \\
(0.41)\end{array}$ \\
\hline adj- $R^{2}$ & -0.06 & 0.28 & -0.02 & -0.05 & 0.04 & 0.29 \\
\hline$D W$ & 1.52 & 2.18 & 0.54 & 1.85 & 1.42 & 2.28 \\
\hline
\end{tabular}

* significant at 5\% level (standard errors in parentheses)

PA model stands for partial adjustment model

$\sigma_{\tau C}^{2}$ is not the variance of $T C$ but the variance of $\ln T C$ in the lognormal model

Table 6.7. Estimation results for $\Delta \mathrm{A}_{1}$ of (log)normal and payback model with and without adjustment costs, $1975-91$. 


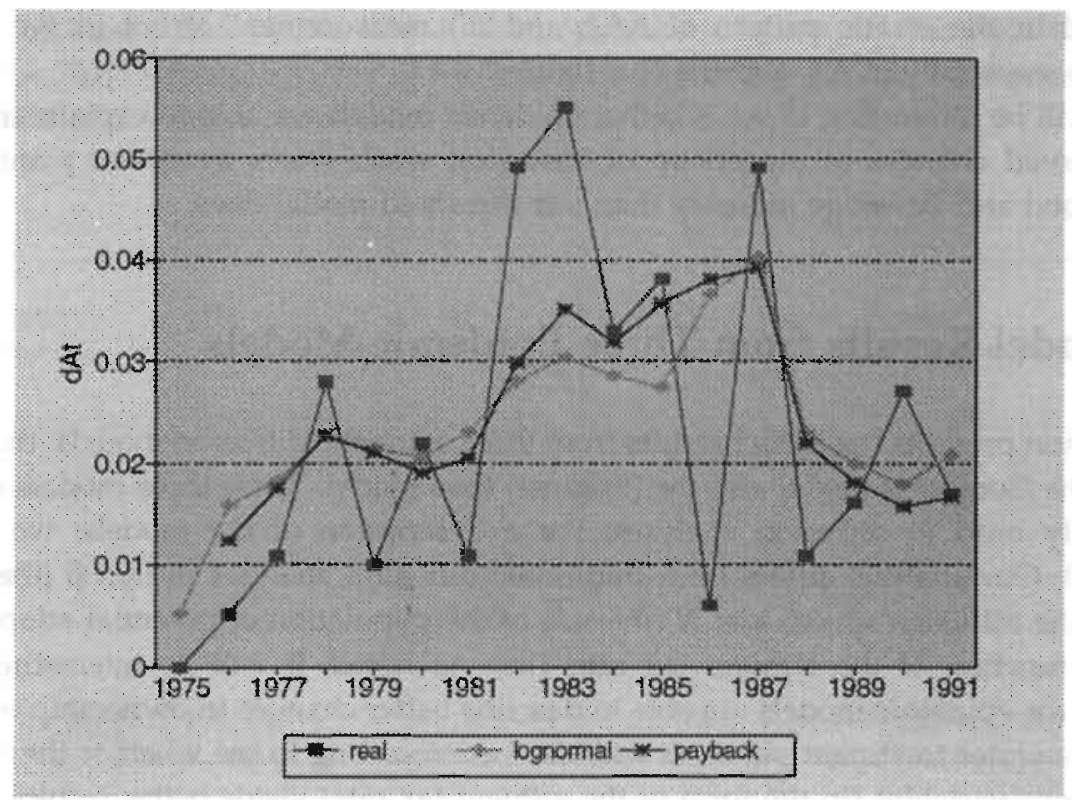

Figure 6.9. Model results for changes in the ownership of biological waste-water treatment plants according to the lognormal and payback model with adjustment costs.

Figure 6.9 gives the predictions for $\triangle A_{t}$ of the partial adjustment model with lognormally distributed $T a x_{t}$ and $T C_{t}$ and the adjustment model with lognormal $P B_{t}^{*}$ and $P B_{i}$. It demonstrates that none of the models is really able to describe empirically the observed changes in ownership of biological waste-water treatment plants during the period of investigation. They can only describe the broad pattern of $\Delta A_{t}$ : the increase in $\Delta A_{t}$ up to 1987, and the decrease in $\Delta A_{\mathfrak{k}}$ after 1987.

The overall conclusion is that the threshold model cannot explain the year-to-year changes in the ownership of biological waste-water treatment plants during the 1975-91 period; what it can do is explain the trend. This implies that there are other factors not included in the model that affect firms ${ }^{\prime}$ decisions to invest in biological waste-water treatment at a particular time. What these factors are is unclear, they may be related to information transfer, details of waste-water policies or firm-specific factors. It must be noted that there are other explanations for the observed differences between the measured and predicted increases in $A_{i}$ i i) that we have too few observations, which makes that the results are sensitive to particular values of the model variables; ii) the low numbers for $\Delta A_{t}$ which makes the results sensitive to the purchase decisions of individual firms whether a firm invests in year $t$ or in $t-1$ or $t+1$ may affect the model results (this might 
also explain the erratic pattern of $\Delta A_{t}$ ); and iii) measurement errors in the model's variables, especially in $\Delta A_{t}$ and the cost figures.

It will be interesting to see whether epidemic models are able to explain any better the observed changes in ownership of biological waste-water treatment plants in the Dutch Food and Beverage industry than our threshold model does.

\subsection{Model Results from Three Epidemic Models}

This section presents the model results from three epidemic diffusion models: the logistic model, the Gompertz model and the (original) Bass model. These three models are most commonly used in diffusion analyses. For a description of the models, we refer to chapter 4 . Our analysis differs from traditional diffusion analyses in that $\beta$ (the parameter for the diffusion speed) and $N$ (the size of the population of potential adopters) are made a function of the effluent tax rate Tax. As noted, it will be interesting to see whether the epidemic models are able to describe better changes in ownership of biological waste-water treatment plants. It will also be interesting to see whether the inclusion of economic variables (in the form of the effluent tax rate) yields better results than the traditional models in which $\beta$ and $N$ are constants, and whether the influence of the effluent tax rate on the diffusion process is mainly through $\beta$ or through $N$.

The first epidemic model we applied empirically is the logistic model. As noted in chapter 4, the logistic model is a symmetric model with an inflexion point at $A_{t}=0.5$. The logistic model is described in the following equation:

$$
\frac{d n(t)}{d t}=\beta \frac{n(t)}{N}(N-n(t))
$$

with $n_{t}$ the number of adopters at time $t$ and, $N$ the total number of firms in the population (here, indirect dischargers in the Dutch Food and Beverage industry).

Dividing this equation by $N$ gives (in discrete time):

$$
\Delta A_{t}=\beta A_{t-1}\left(1-A_{t-1}\right)
$$

This is the equation to be estimated, with an i.i.d. error term with zero mean and variance $\sigma^{2}$ added to the right-hand side.

We also investigated three variants of the logistic model: i) the logistic with $\beta$ being a function of $\left.T a x_{t}, \mathrm{ii}\right)$ the logistic with $N$ being a function of $T a x_{t}$, and iii) the logistic where both $\beta$ and $N$ are a function of $T a x_{r}$. In the model analysis, we used the following expressions for $\beta_{t}$ and $N_{t}: \beta_{t}=\beta+\operatorname{Tax}_{t}^{\eta}$ and $N_{t}=N\left(1-1 / \operatorname{Tax}_{t}{ }^{\eta}\right.$ - with $\operatorname{Tax} x_{t}$ the average effluent 
tax rate at time $t$ and $N_{t}$ the size of the population of potential adopters at time $t^{30}$ (Note that $\operatorname{Tax}_{t}^{\eta}>0$ and $0<N_{t}<N$ for $\operatorname{Tax}_{t}>1$ and that $N_{t} \rightarrow N$ for $\operatorname{Tax}_{t} \rightarrow \infty$ for $\gamma>0$ ). The results of the logistic model are in Table 6.8.

\begin{tabular}{|c|c|c|c|c|}
\hline $\begin{array}{l}\text { Logistic } \\
\text { model }\end{array}$ & $\begin{array}{l}(1) \\
\Delta A_{t}=\beta A_{t \cdot 1}\left(1-A_{t \cdot 1}\right)\end{array}$ & $\begin{array}{l}\text { (1) with } \\
\beta_{t}=\beta+\operatorname{Tax}_{t} \text { " }\end{array}$ & $\begin{array}{l}\text { (3) } \\
\Delta A_{t}=\beta A_{t-1}\left(A_{t}^{*}-A_{t-1}\right) \\
\text { with } A_{t}=1-1 / T a x_{t}^{\gamma}\end{array}$ & $\begin{array}{l}\text { (4) } \\
\text { (3) with } \beta_{i}=\beta+\operatorname{Tax}_{i}^{n}\end{array}$ \\
\hline$\beta$ & $\begin{array}{c}0.14^{*} \\
(0.03)\end{array}$ & $\begin{array}{l}-0.10 \\
(1.67)\end{array}$ & $\begin{array}{c}0.92^{*} \\
(0.20)\end{array}$ & $\begin{array}{l}-1.05 \\
(1.89)\end{array}$ \\
\hline$\eta$ & & $\begin{array}{l}-0.35 \\
(1.69)\end{array}$ & & $\begin{array}{c}0.18 \\
(0.25)\end{array}$ \\
\hline$\gamma$ & & & $\begin{array}{c}0.13^{*} \\
(0.01)\end{array}$ & $\begin{array}{r}0.13^{*} \\
(0.01)\end{array}$ \\
\hline $\operatorname{adj}-R^{2}$ & 0.07 & 0.03 & 0.38 & 0.34 \\
\hline DW & 1.54 & 1.90 & 2.51 & 2.48 \\
\hline
\end{tabular}

* significant at $5 \%$ level (standard errors in parentheses)

Table 6.8. Estimation results of the logistic model, 1975-91.

Table 6.8 shows that the empirical results of the logistic model with constant $\beta$ and $N$ are rather poor, with coefficients of determination close to zero. Making $\beta_{t}$ a function of $\operatorname{Tax}_{i}{ }^{\eta}$ barely improves the results. Letting the population of potential adopters $N_{b}$ be a function of $\operatorname{Tax}_{t}$, in the way specified above, gives much better results: the adjusted $R^{2}$ is 0.38 and both $\beta$ and $\gamma$ are significantly different from zero at the $1 \%$ significance level. (The diffusion speed is also higher if $N_{t}=N\left(1-1 / \operatorname{Tax}_{\imath}{ }^{\eta}\right.$.) This provides further evidence that the effluent tax rate is indeed a significant factor in the diffusion process of biological waste-water treatment technologies. The results further suggest that the influence of the effluent tax rate is through $N_{t}$, the population of potential adopters, and not so much through $\beta_{v}$, the diffusion speed - the estimates for $\eta$ are not significant and in one case it is even negative.

The reported Durbin-Watson coefficients are above 1.5 and below 2.5 which does not lead us to reject the null hypothesis that there is no autocorrelation at the $5 \%$ sig-

${ }^{30}$ The reason why $\beta_{t}$ and $N_{t}$ are made a function of $\operatorname{Tax}$, rather than a function of $G_{t}-T C_{t}$ is because $G_{t}-T C_{t}$ takes on negative values in some years, which means that we cannot use $G_{t}-T C_{t}$ in the above expressions. We also investigated the case where $\beta_{t}$ and $N_{t}$ are a function of $\Delta T a x_{t}$, rather than $\operatorname{Tax}_{\mathrm{p}}$. As the results are similar they are not reported. 
nificance level (the Durbin-Watson coefficients in column (1) and (2) are all above $d_{L, 0.05}$ and those in columns (3) and (4) above $4-d_{i, 0.05}$ ). However, if we use the modified Durbin-Watson test, there is evidence of negative first-order autocorrelation in the last two specifications: $d_{u j a .05}=1.71$ for $k=3$ ). ${ }^{31}$ The evidence, however, is not very strong. Furthermore, the modified DW test may be too strong a test.

The results of the logistic model with $\beta_{t}=\beta$ and $N_{t}=N\left(1-1 / \operatorname{Tax}_{t}{ }^{\eta}\right)$ are given in Figure 6.10 (together with the results of the Gompertz model that are discussed later on).

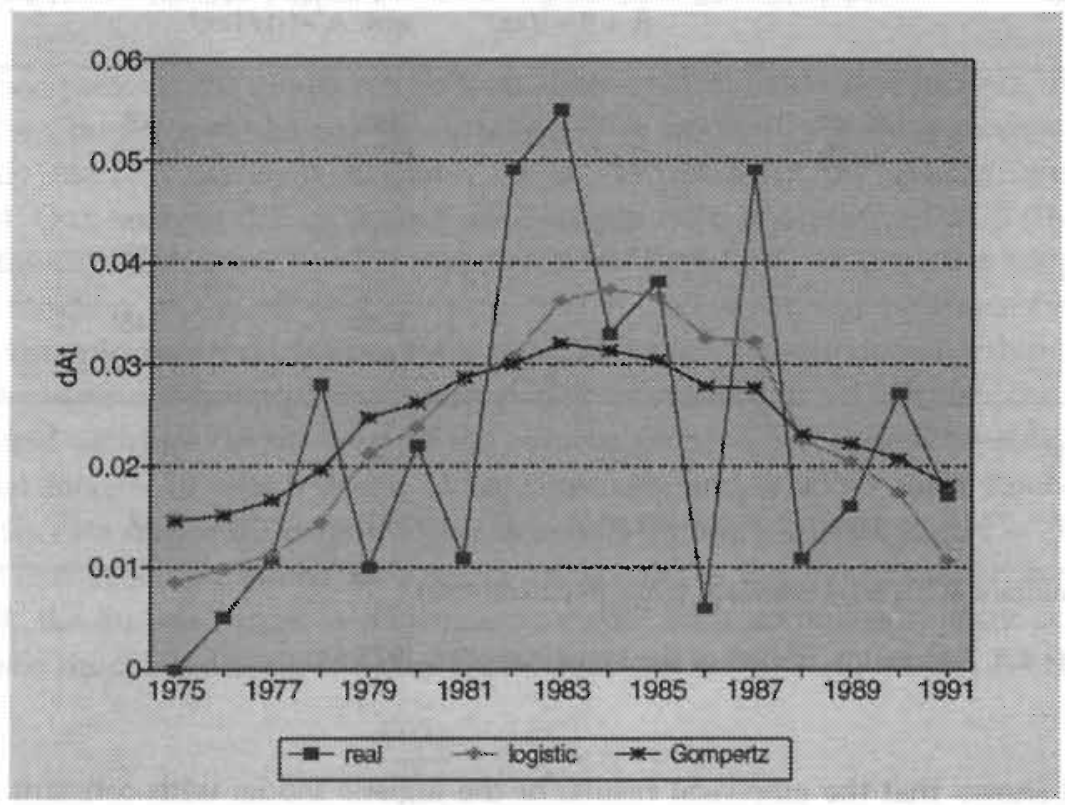

Figure 6.10. Model results for $\Delta A_{t}$ of the logistic and Gompertz model with constant $\beta_{1}$ and $N_{t}=N\left(1-1 / \operatorname{Tax}{ }^{\eta}\right)$.

Figure 6.10 shows that the logistic model with $N_{t}=N\left(1-1 / \operatorname{Tax}_{t}^{\eta}\right)$ - just as the threshold model - is not able to describe the fluctuations in $\Delta A_{t} ;$ what it can describe, however, is the broad pattern in $\Delta A_{i}$, with low values in the early and later years of the diffusion period, and relatively high values in between.

In addition to the logistic model, we estimated the Gompertz model, with $\beta_{t}$ and $N_{t}$ a function of the effluent tax rate. The traditional Gompertz model is described in the following equation: ${ }^{32}$

\footnotetext{
${ }^{31}$ In the modified Durbin-Watson test the DW statistics are evaluated against $d_{U}$ instead of $d_{L}$.

${ }^{32}$ See Stoneman, 1983, op cit., p.70.
} 


$$
\frac{d n(t)}{d t}=\beta n(t)(\ln (N)-\ln (n(t)))
$$

where In stands for the natural logarithm.

This equation can be rewritten as:

$$
\Delta A_{t}=\beta A_{t-1}\left(\ln (N)-\ln \left(n_{t-1}\right)\right)
$$

\begin{tabular}{|c|c|c|c|c|}
\hline $\begin{array}{l}\text { Gompertz } \\
\text { model }\end{array}$ & $\begin{array}{l}(1) \\
\triangle A_{t}=\beta A_{t-1}\left(\ln N-\ln \left(n_{t-1}\right)\right)\end{array}$ & $\begin{array}{l}\text { (2) } \\
\text { (1) with } \\
\beta_{t}=\beta+\operatorname{Tax}_{i}^{n}\end{array}$ & $\begin{array}{l}\text { (3) } \\
\Delta A_{t}=\beta A_{t-1}\left(\ln N_{t}-\ln \left(n_{t-1}\right)\right) \\
\text { with } N_{t}=N(1-1 / \operatorname{Tax} \eta)\end{array}$ & $\begin{array}{l}\text { (4) } \\
\text { (3) with } \\
\beta_{t}=\beta+\operatorname{Tax}_{t}^{n}\end{array}$ \\
\hline$\beta$ & $\begin{array}{r}0.08^{*} \\
(0.01)\end{array}$ & $\begin{array}{l}-0.69^{*} \\
(0.30)\end{array}$ & $\begin{array}{r}0.18^{*} \\
(0.05)\end{array}$ & $\begin{array}{l}-1.58^{*} \\
(0.34)\end{array}$ \\
\hline$\eta$ & & $\begin{array}{l}-0.07^{*} \\
(0.10)\end{array}$ & & $\begin{array}{r}0.15^{*} \\
(0.05)\end{array}$ \\
\hline$\gamma$ & & & $\begin{array}{r}0.17^{*} \\
(0.04)\end{array}$ & $\begin{array}{c}0.13^{*} \\
(0.01)\end{array}$ \\
\hline $\operatorname{adj}-R^{2}$ & 0.14 & 0.13 & 0.39 & 0.40 \\
\hline DW & 1.93 & 2.05 & 2.28 & 2.63 \\
\hline
\end{tabular}

The results of the different variants of the Gompertz model are in Table 6.9.

* significant at $5 \%$ level (standard errors in parentheses)

Table 6.9. Estimation results of the Gompertz model, 1975-91.

The results of the Gompertz model with constant $N_{t}$ are somewhat better than those of the logistic model but still not good: an adjusted $R^{2}$ of 0.14 is rather low. The model variant with constant $\beta_{t}$ and $N_{t}=N\left(1-1 / \operatorname{Tax}{ }_{t}^{\gamma}\right)$ gives the best results, which corresponds with the earlier conclusions about the impact of the effluent tax on the timing of the purchase of biological waste-water treatment technologies. There is evidence of firstorder serial correlation in the fourth specification, when using the relatively strong modified Durbin-Watson test. The predictions for $\Delta A_{t}$ of the Gompertz model with constant $\beta_{t}$ and $N_{t}=N\left(1-1 / \operatorname{Tax}{ }_{t}\right)$ are given in Figure 6.10. The Gompertz model predicts a relatively fast diffusion in the early years and a relatively slow diffusion in later years, as compared to the logistic model. This is due to the fact that the Gompertz model is positively skewed whereas the logistic model is symmetric. 
The last model that we estimated is the (original) Bass model. The Bass model is described in the following equation:

$$
\frac{d n(t)}{d t}=\left(\delta+\beta \frac{n(t)}{N}\right)(N-n(t))
$$

with $\delta$ the "coefficient of innovation" and $\beta$ the "coefficient of imitation", although - as we noted in chapter 4 - it is better to speak of the parameters of "external influence" and "internal influence".

The Bass model can be rewritten as follows:

$$
\Delta A_{t}=\left(\delta+\beta A_{t-1}\right)\left(1-A_{t-1}\right)
$$

\begin{tabular}{|c|c|c|c|c|}
\hline $\begin{array}{l}\text { Bass } \\
\text { model }\end{array}$ & $\begin{array}{l}(1) \\
\Delta A_{1}=\left(\delta+\beta A_{t, 1}\right)\left(1-A_{t-1}\right)\end{array}$ & (1) with $\beta_{t}=\operatorname{Tax}_{i}^{\eta}$ & $\begin{array}{l}\text { (3) } \\
\Delta A_{t}=\left(\delta+\beta A_{t-1}\right)\left(A_{t}^{*}-A_{t-1}\right) \\
\text { with } A_{t}^{*}=1-1 / \operatorname{Tax}_{t}^{\gamma}\end{array}$ & $\begin{array}{l}\text { (4) } \\
\text { (3) with } \\
\beta_{t}=\operatorname{Tax}_{1}^{n}\end{array}$ \\
\hline$\delta$ & $\begin{array}{c}0.015 \\
(0.008)\end{array}$ & $\begin{array}{c}0.012 \\
(0.008)\end{array}$ & $\begin{array}{l}-0.004 \\
(0.028)\end{array}$ & $\begin{array}{l}-0.005 \\
(0.026)\end{array}$ \\
\hline$\beta$ & $\begin{array}{c}0.077 \\
(0.040)\end{array}$ & & $\begin{array}{c}0.96^{*} \\
(0.34)\end{array}$ & \\
\hline$\pi$ & & $\begin{array}{l}-0.59^{*} \\
(0.12)\end{array}$ & & $\begin{array}{c}0.008 \\
(0.086)\end{array}$ \\
\hline$\gamma$ & & & $\begin{array}{c}0.13^{*} \\
(0.01)\end{array}$ & $\begin{array}{r}0.13^{*} \\
(0.01)\end{array}$ \\
\hline $\operatorname{adj}-R^{2}$ & 0.03 & 0.05 & 0.33 & 0.33 \\
\hline DW & 1.83 & 1.89 & 2.51 & 2.51 \\
\hline
\end{tabular}

The results of the Bass model are in Table 6.10.

* significant at $5 \%$ level (standard errors in parentheses)

Table 6.10. Estimation results of the Bass model, 1975-91.

As for the logistic and Gompertz model, the results of the Bass model with constant $\beta_{t}$ and $N_{i}=N$ are bad, even though we have an extra parameter ( $\delta$ ). It is only when the population of potential adopters is a function of the effluent tax rate that we obtain better results. The variant with $N_{t}=N\left(1-1 / \operatorname{Tax}{ }_{1}\right)$ and constant $\beta_{t}$ gives the best results. This variant has the highest adjusted $R^{2}$ and both $\beta$ and $\gamma$ are significantly different from zero at the $5 \%$ level. Table 6.10 also shows that the extra parameter $\delta$ does not improve 
the estimation results: in none of the estimations is $\delta$ significantly different from zero at the $5 \%$ significance level. The predictions for $\Delta A_{1}$ are almost identical to those for the logistic model, which is not really surprising. As we noted in chapter 4 , the logistic model is a special case of the Bass model where $\delta$ is zero - and as we can see, $\delta$ is very small compared to $\beta$ in column (3).

\subsection{Conclusions}

What conclusions can be drawn from the results of the different diffusion models? The first conclusion is that the effluent tax rate is a significant factor in the time-intensive adoption of biological waste-water treatment plants. If the effluent tax rate had remained at the low 1974 level, only a small proportion of the indirect dischargers in the Food and Beverage industry would have purchased a biological waste-water treatment plant, as Figure 6.11 demonstrates. However, with the increasing effluent tax rate it became financially attractive for more and more firms to invest in biological waste-water treatment.

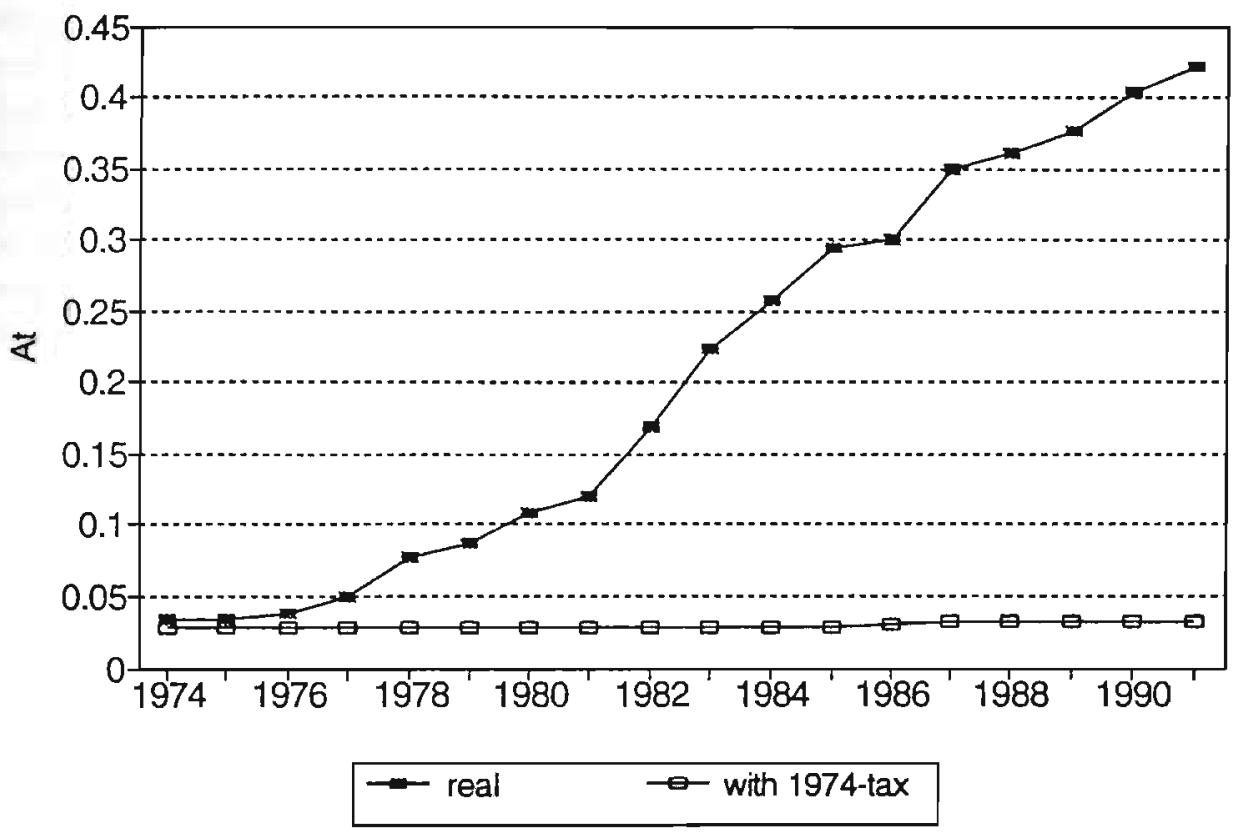

Figure 6.11. The diffusion of biological waste-water treatment plants according to the partial adjustment payback model with the effluent tax rate fixed at the 1974 level.

The results in section 6.4 furthermore suggest that the way in which the effluent tax rate affected firms' purchasing decisions was through $N_{1}$ and not so much through $\beta$ : the 
relationship between the effluent tax rate and the diffusion speed is statistically much weaker than that between the effluent tax and the population of prospective adopters. The model results thus confirm the hypothesis advanced in chapter 4 that economic factors exercise an important impact on the diffusion of expensive technological innovations like waste-water treatment plants. This result is brought out by both the epidemic and threshold models.

Another conclusion that emerges from our analysis is that none of the models is really able to explain the year-to-year changes in ownership of biological waste-water treatment plants. This suggests that there are other factors, not included in the model, that affect firms' investment decisions. What these factors are is not clear. They may have to do with management time, learning, waste-water policies or temporary financial constraints. Perhaps there is a probabilistic process involved in the time-intensive adoption of biological waste-water treatment plants. The fluctuations in $\Delta A_{t}$ lend some support to this idea. In any case, it proved to be impossible to explain with much precision why firms invest in biological waste-water treatment in year $t$, rather than in $t-1$ or $t+1$ - at least, not by using a threshold model or any of the three epidemic models.

Now what is the best model for explaining the diffusion of biological waste-water treatment technologies? This question is not easy to answer, it depends on the criteria against which the models are judged. The results of the epidemic models with the population of potential adopters being a function of the effluent tax rate are better than those of the threshold model without adjustment costs, which lends support to their superiority. On the other hand, this comparison is not fair to the threshold model. As we noted in section 3.1, the threshold model explains the proportion of adopters that would desire to own and use a newly built biological waste-water treatment plants each year, given the prevailing price structure in that year - not the actual ownership in each year which is a function of past purchasing decisions. (Of course, this in itself is a disadvantage of the threshold model, just as the need for detailed data on the costs and benefits of adoption for an adopter population over time is a clear disadvantage - and one of the reasons why few people have attempted to estimate a threshold model.) The results of the threshold model with adjustment costs are much better. They are just as good as those of the epidemic models - and even better if we do not consider the year 1986. This lends support to the threshold model. A second important question is whether or not in practice purchase decisions are made on the basis of an economic comparison of the costs and benefits of adoption. If decision makers can be believed to be rational in their purchasing decisions, then a threshold model is to be preferred. According to adopter firms and waste-water treatment specialists this is the case, which supports the usage of the threshold model. (Furthermore, as noted in chapter 5, in the epidemic models the decision-making process is not made explicit, which is a clear weakness.) A final consideration concerns the learning process, which is commonly believed to be an important element in the diffusion process. Here it is hard to compare the two types of models. The learning mechanism in the threshold model is a very crude mechanism, but so is the learning mechanism in the epidemic models. On the whole, the above con- 
siderations lead us to prefer the threshold model for analyzing the diffusion of biological waste-water treatment plants. 


\begin{tabular}{|c|c|c|c|c|c|c|c|c|c|c|}
\hline AEGION & 1972 & 1973 & 1974 & 1975 & 1976 & 1977 & 1978 & 1979 & 1980 & 1981 \\
\hline $\begin{array}{l}\text { groningen } \\
\text { frieslandi }\end{array}$ & $\begin{array}{l}0 \\
6\end{array}$ & $\begin{array}{l}8 \\
8\end{array}$ & $\begin{array}{l}11 \\
10\end{array}$ & $\begin{array}{l}15 \\
15\end{array}$ & $\begin{array}{l}20.9 \\
19.2\end{array}$ & $\begin{array}{l}25 \\
24\end{array}$ & $\begin{array}{r}31 \\
27.78\end{array}$ & $\begin{array}{r}37 \\
30.84\end{array}$ & $\begin{array}{r}45 \\
32.5\end{array}$ & $\begin{array}{r}50 \\
34.14\end{array}$ \\
\hline drenthe & 0 & 6 & 12 & 18 & 26.64 & 30 & 31.44 & 32.4 & 34.2 & 34.8 \\
\hline west-overijssel & 6 & 8 & 12.96 & 18.96 & 30.72 & 36 & 30.88 & 41.76 & 43.68 & 51.84 \\
\hline regge en dinkel & 11.75 & 11.75 & 15.6 & 15.6 & 23.04 & 25.68 & 28.8 & 31.68 & 36.24 & 39.84 \\
\hline fleverwaard & 0 & 0 & 0 & 0 & 0 & 0 & 0 & 0 & 0 & 0 \\
\hline oostelijk gelderland & 10.5 & 12.75 & 16.8 & 21 & 31.35 & 33.95 & 34.8 & 36.4 & 39.2 & 42.15 \\
\hline veluwe & 10.5 & 14 & 16.8 & 20.4 & 28.8 & 31.2 & 33.6 & 33.6 & 36 & 40.8 \\
\hline ivierenland & 10.5 & 13.8 & 17.43 & 22.8 & 30.96 & 35.6 & 37.6 & 40.8 & 44.64 & 50.88 \\
\hline utrecht & 0 & 18.24 & 18.24 & 21.72 & 31 & 35 & 35 & 35 & 36.5 & 42.5 \\
\hline arnstel- en gooiland & 0 & 0 & 0 & 18 & 29.6 & 29.6 & 31.8 & 33.6 & 33.65 & 43.4 \\
\hline uitwaterende sluizen & 9.65 & 12.2 & 15.1 & 18.5 & 38.3 & 42.3 & 44.15 & 47 & 54 & 61 \\
\hline rijniand & 9.4 & 11 & 13.5 & 17.9 & 28 & 29.5 & 32 & 36 & 44.5 & 49.6 \\
\hline woerden & 0 & 0 & 18.24 & 22.8 & 36.12 & 42 & 44 & 45 & 45 & 45 \\
\hline delfland & 0 & 0 & 0 & 16 & 27.5 & 27.5 & 31.5 & 33.12 & 31.44 & 34.8 \\
\hline schieland & 0 & 0 & 0 & 20 & 35 & 38 & 39.8 & 44 & 48.4 & 52 \\
\hline holl. eilanden en waa & 0 & 0 & 0 & 15.53 & 30.6 & 35.44 & 38.07 & 41.56 & 49.75 & 64 \\
\hline schouwen-duivenian & 0 & 0 & 0 & 26 & 38 & 43 & 43 & 48 & 53 & 55 \\
\hline tholen & 0 & 0 & 0 & 26 & 37 & 39 & 40 & 41.38 & 46 & 50 \\
\hline wakcheren & 0 & 0 & 0 & 18 & 28 & 28 & 34.5 & 39 & 46 & 50 \\
\hline noord- en zuidbevela & 0 & 0 & 0 & 28 & 37.5 & 40.5 & 43 & 48 & 55 & 64 \\
\hline vrije van sluis & 0 & 0 & 0 & 34 & 39 & 40 & 45 & 48 & 51 & 67 \\
\hline de drie ambachten & 0 & 0 & 0 & 7.5 & 7.5 & 7.5 & 7.5 & 31 & 42 & 42 \\
\hline hulster ambacht & 0 & 0 & 0 & 9 & 12.5 & 16 & 36 & 46 & 50 & 55 \\
\hline west-brabant & 7 & 10 & 16 & 20 & 26 & 29 & 32 & 31.5 & 34 & 38 \\
\hline alm en biesbosch & 11 & 14 & 16.8 & 20 & 26 & 28.5 & 39.5 & 33 & 35 & 37.5 \\
\hline dommel & $\begin{array}{r}7 \\
36\end{array}$ & 9 & 11 & $\begin{array}{r}13 \\
1068\end{array}$ & $\begin{array}{l}23.04 \\
22.32\end{array}$ & 25.92 & 28.08 & 30.48 & 31.92 & 34.08 \\
\hline aa & 3.6 & 5.8 & 8.6 & 10.68 & 22.32 & 25.92 & 25.92 & 31.44 & 33.12 & 33.12 \\
\hline maastant & 0 & 0 & 0 & 0 & 23.52 & 26.88 & 27.6 & 30.24 & 30.96 & 33.84 \\
\hline limburg & 0 & 0 & 11 & 14.5 & 26.65 & 29.88 & 33.84 & 37.44 & 41.16 & 44.52 \\
\hline mean & 3.43 & 5.42 & 8.04 & 17.46 & 27.16 & 30.03 & 32.94 & 36.51 & 40.13 & 44.69 \\
\hline maximum & 11.75 & 18.24 & 18.24 & 34.00 & 39.00 & 43.00 & 45.00 & 48.00 & 55.00 & 67.00 \\
\hline minimum & 0.00 & 0.00 & 0.00 & 0.00 & 0.00 & 0.00 & 0.00 & 0.00 & 0.00 & 0.00 \\
\hline standard deviation & 4.48 & 5.91 & 7.39 & 7.13 & 8.80 & 9.48 & 9.48 & 9.00 & 10.43 & 12.65 \\
\hline
\end{tabular}




\begin{tabular}{|c|c|c|c|c|c|c|c|c|c|c|}
\hline REGION & 1982 & 1983 & 1984 & 1985 & 1986 & 1987 & 1988 & 1989 & 1990 & 1991 \\
\hline $\begin{array}{l}\text { groningen } \\
\text { friesland }\end{array}$ & $\begin{array}{r}50 \\
37.2\end{array}$ & $\begin{array}{r}55 \\
37.2\end{array}$ & $\begin{array}{r}60 \\
39.48\end{array}$ & $\begin{array}{r}70 \\
49.68\end{array}$ & $\begin{array}{l}75 \\
51\end{array}$ & $\begin{array}{r}75 \\
53.04\end{array}$ & $\begin{array}{r}75 \\
55.92\end{array}$ & $\begin{array}{r}75 \\
57.78\end{array}$ & $\begin{array}{r}75 \\
60.72\end{array}$ & $\begin{array}{r}75 \\
67.44\end{array}$ \\
\hline $\begin{array}{l}\text { drenthe } \\
\text { west-overijssel } \\
\text { regge en dinkel }\end{array}$ & $\begin{array}{r}37.2 \\
55.68 \\
39.84\end{array}$ & $\begin{array}{r}37.2 \\
55.68 \\
39.84\end{array}$ & $\begin{array}{r}37.2 \\
55.68 \\
39.84\end{array}$ & $\begin{array}{r}41.6 \\
55.68 \\
41.28\end{array}$ & $\begin{array}{l}41.6 \\
62.4 \\
50.4\end{array}$ & $\begin{array}{r}43.16 \\
65.6 \\
50.4\end{array}$ & $\begin{array}{r}44.88 \\
68.8 \\
50.4\end{array}$ & $\begin{array}{r}47.6 \\
72 \\
50.4\end{array}$ & $\begin{array}{r}50.48 \\
75 \\
50.4\end{array}$ & $\begin{array}{r}56.68 \\
78.6 \\
55.44\end{array}$ \\
\hline $\begin{array}{l}\text { fleverwaard } \\
\text { oosteliik gelderland }\end{array}$ & $\begin{array}{r}0 \\
45.85\end{array}$ & $\begin{array}{r}0 \\
40\end{array}$ & $\begin{array}{r}0 \\
40\end{array}$ & $\begin{array}{r}62.4 \\
43\end{array}$ & $\begin{array}{l}62 \\
42\end{array}$ & $\begin{array}{l}62 \\
42\end{array}$ & $\begin{array}{l}62 \\
42\end{array}$ & $\begin{array}{l}62 \\
45\end{array}$ & $\begin{array}{l}65 \\
48\end{array}$ & $\begin{array}{r}71.5 \\
50\end{array}$ \\
\hline $\begin{array}{l}\text { veluwe } \\
\text { rivierenland } \\
\text { utrecht }\end{array}$ & $\begin{array}{r}42.96 \\
57.2 \\
40.8\end{array}$ & $\begin{array}{r}40.08 \\
61.6 \\
52.8\end{array}$ & $\begin{array}{l}38.4 \\
61.6 \\
55.8\end{array}$ & $\begin{array}{r}43.92 \\
75.2 \\
55.8\end{array}$ & $\begin{array}{r}47.88 \\
80.2 \\
55.8\end{array}$ & $\begin{array}{l}49.8 \\
79.2 \\
58.2\end{array}$ & $\begin{array}{r}52.8 \\
79.24 \\
60.36\end{array}$ & $\begin{array}{r}55.44 \\
81.2 \\
64.2\end{array}$ & $\begin{array}{r}58.8 \\
23.04 \\
70.2\end{array}$ & $\begin{array}{r}60 \\
93.6 \\
79.2\end{array}$ \\
\hline $\begin{array}{l}\text { amstel- en gooiland } \\
\text { uitwaterende sluizen } \\
\text { rijnland }\end{array}$ & $\begin{array}{r}48 \\
66 \\
53.8\end{array}$ & $\begin{array}{r}52.2 \\
70 \\
54.8\end{array}$ & $\begin{array}{l}58 \\
70 \\
57\end{array}$ & $\begin{array}{r}62.9 \\
70 \\
59.8\end{array}$ & $\begin{array}{r}66.7 \\
70 \\
61.2\end{array}$ & $\begin{array}{r}69.4 \\
70 \\
62\end{array}$ & $\begin{array}{r}72.2 \\
70 \\
63.6\end{array}$ & $\begin{array}{r}75.6 \\
70 \\
66\end{array}$ & $\begin{array}{r}80.5 \\
70 \\
72\end{array}$ & $\begin{array}{r}86.5 \\
75 \\
77.8\end{array}$ \\
\hline $\begin{array}{l}\text { woerden } \\
\text { defilland }\end{array}$ & $\begin{array}{r}45 \\
38.4\end{array}$ & $\begin{array}{r}53 \\
41.16\end{array}$ & $\begin{array}{r}58 \\
42.84\end{array}$ & $\begin{array}{r}60 \\
44.52\end{array}$ & $\begin{array}{r}60 \\
45.36\end{array}$ & $\begin{array}{r}58 \\
45.36\end{array}$ & $\begin{array}{r}58 \\
46.2\end{array}$ & $\begin{array}{r}61 \\
47.16\end{array}$ & $\begin{array}{r}64 \\
49.08\end{array}$ & $\begin{array}{l}67 \\
54\end{array}$ \\
\hline $\begin{array}{l}\text { schieland } \\
\text { holl eilanden en waa }\end{array}$ & $\begin{array}{l}54.8 \\
68.4\end{array}$ & $\begin{array}{l}59.8 \\
68.4\end{array}$ & $\begin{array}{l}64.8 \\
68.4\end{array}$ & $\begin{array}{r}66.48 \\
68.4\end{array}$ & $\begin{array}{r}68.16 \\
68.4\end{array}$ & $\begin{array}{l}69.84 \\
69.24\end{array}$ & $\begin{array}{l}71.64 \\
71.16\end{array}$ & $\begin{array}{l}73.44 \\
74.76\end{array}$ & $\begin{array}{l}75.36 \\
78.24\end{array}$ & $\begin{array}{r}78.36 \\
82.8\end{array}$ \\
\hline schouwen-duivenlan & 56 & 57 & 57 & 57 & 59 & 67 & 79 & 82 & 92 & 102 \\
\hline $\begin{array}{l}\text { tholen } \\
\text { watcheren }\end{array}$ & $\begin{array}{l}54 \\
56\end{array}$ & $\begin{array}{l}55 \\
58\end{array}$ & $\begin{array}{l}54 \\
58\end{array}$ & $\begin{array}{l}51 \\
58\end{array}$ & $\begin{array}{l}51 \\
62\end{array}$ & $\begin{array}{l}51 \\
64\end{array}$ & $\begin{array}{l}63 \\
64\end{array}$ & $\begin{array}{l}58 \\
64\end{array}$ & $\begin{array}{l}65 \\
68\end{array}$ & $\begin{array}{l}80 \\
76\end{array}$ \\
\hline noord- en zuidbevela & 71 & 75.5 & 79 & 80 & 81.5 & 83 & 83 & 86.5 & 90.5 & 95.5 \\
\hline vrije van sluis & 78 & 86 & 86 & 88 & 96 & 104 & 107 & 110 & 117 & 120 \\
\hline de drie ambachten & 44 & 46 & 48 & 51 & 58 & 66 & 66 & 70 & 74 & 78 \\
\hline hulster ambacht & 69 & 72.5 & 72.5 & 72.5 & 75 & 78 & 82 & 92 & 97 & 105 \\
\hline west-brabant & 42 & 42 & 42 & 42 & 42 & 45 & 46 & 48 & 54 & 59 \\
\hline alm en biesbosch & 40 & 41.5 & 44 & 45 & 45 & 47 & 47 & 49 & 56.5 & 63 \\
\hline $\begin{array}{l}\text { dormel } \\
\text { aa }\end{array}$ & $\begin{array}{r}36 \\
33.12\end{array}$ & $\begin{array}{l}36.96 \\
33.12\end{array}$ & $\begin{array}{l}36.96 \\
33.12\end{array}$ & $\begin{array}{l}36.96 \\
33.12\end{array}$ & $\begin{array}{l}36.96 \\
33.12\end{array}$ & $\begin{array}{r}39.6 \\
34.08\end{array}$ & $\begin{array}{l}40.32 \\
3216\end{array}$ & $\begin{array}{l}42.24 \\
32.16\end{array}$ & $\begin{array}{r}51.84 \\
37.2\end{array}$ & $\begin{array}{l}58.92 \\
42.24\end{array}$ \\
\hline $\begin{array}{l}\text { maaskant } \\
\text { limburg }\end{array}$ & $\begin{array}{l}38.88 \\
48.24\end{array}$ & $\begin{array}{l}44.64 \\
51.36\end{array}$ & $\begin{array}{l}51.12 \\
53.64\end{array}$ & $\begin{array}{l}58.56 \\
54.96\end{array}$ & $\begin{array}{l}66.72 \\
54.96\end{array}$ & $\begin{array}{r}73.2 \\
54.96\end{array}$ & $\begin{array}{r}73.2 \\
54.96\end{array}$ & $\begin{array}{r}73.2 \\
56.64\end{array}$ & $\begin{array}{r}73.2 \\
60\end{array}$ & $\begin{array}{r}73.2 \\
66\end{array}$ \\
\hline $\begin{array}{l}\text { mean } \\
\text { maximum }\end{array}$ & $\begin{array}{l}48.25 \\
78.00\end{array}$ & $\begin{array}{l}50.61 \\
86.00\end{array}$ & $\begin{array}{l}52.08 \\
86.00\end{array}$ & $\begin{array}{l}56.63 \\
88.00\end{array}$ & $\begin{array}{l}58.98 \\
96.00\end{array}$ & $\begin{array}{r}60.97 \\
104.00\end{array}$ & $\begin{array}{r}6273 \\
107.00\end{array}$ & $\begin{array}{r}64.74 \\
110.00\end{array}$ & $\begin{array}{r}68.74 \\
117.00\end{array}$ & $\begin{array}{r}74.26 \\
120.00\end{array}$ \\
\hline $\begin{array}{l}\text { minimum } \\
\text { standard deviation }\end{array}$ & $\begin{array}{r}0.00 \\
14.55\end{array}$ & $\begin{array}{r}0.00 \\
15.81\end{array}$ & $\begin{array}{r}0.00 \\
16.14\end{array}$ & $\begin{array}{l}33.12 \\
13.14\end{array}$ & $\begin{array}{l}33.12 \\
14.21\end{array}$ & $\begin{array}{l}34.08 \\
14.95\end{array}$ & $\begin{array}{l}3216 \\
15.55\end{array}$ & $\begin{array}{l}32.16 \\
16.31\end{array}$ & $\begin{array}{l}37.20 \\
16.52\end{array}$ & $\begin{array}{l}42.24 \\
16.97\end{array}$ \\
\hline
\end{tabular}


Appendix 6.B: Frequency distribution of effluent tax rates

1981

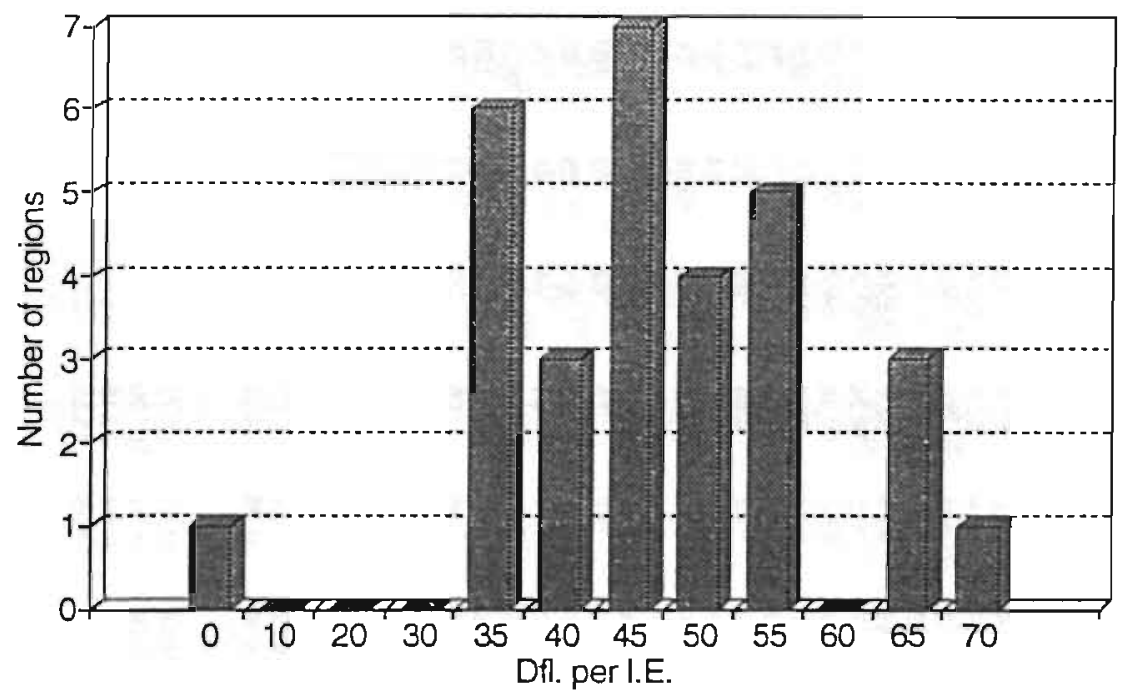

1987

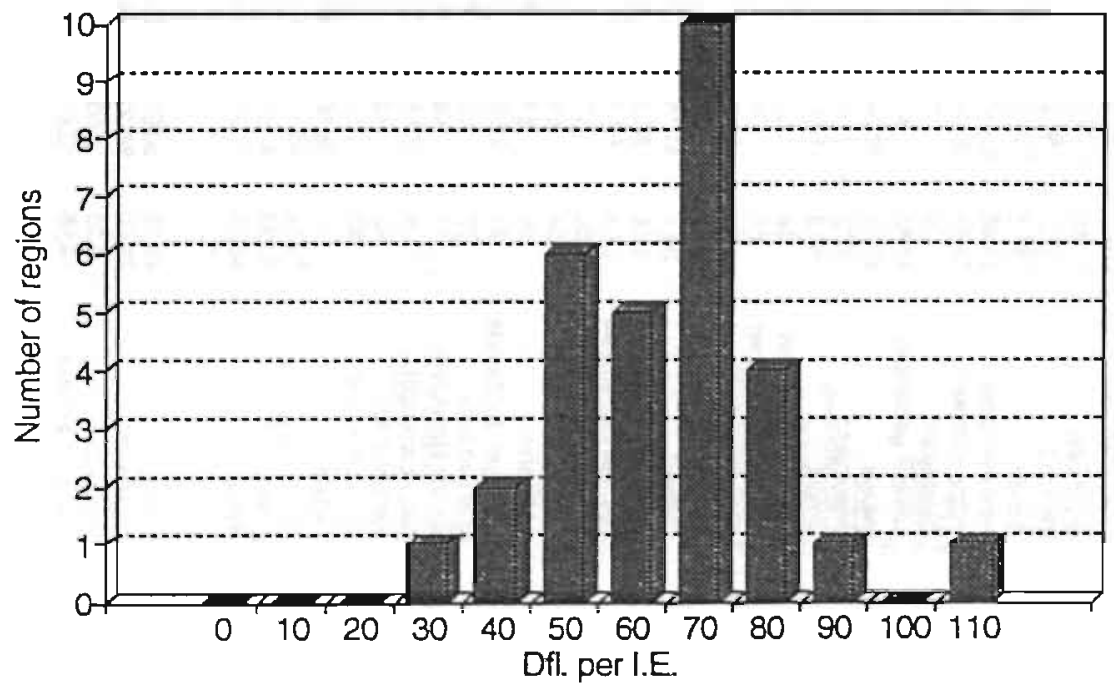




\section{Appendix 6.C: Effluent treatment costs}

The costs of biological waste-water treatment are calculated on the basis of Table 6.3 of Schuurman (1988, p.281), which gives the variable and fixed costs of biological effluent treatment in the Dutch Food industry in 1983. The variable costs consist of labour costs, material and electricity costs and waste disposal costs. The fixed costs consist of depreciation and interest costs and are based on a depreciation period of 25 years and 10 years for construction work and equipment and a fixed interest rate of $5 \%$. In our study, we use a depreciation period of 18.5 years for the construction part of biological waste-water treatment plants. According to Schuurman's own study (p.356), the average depreciation period of the construction part is not 25 but 18.5 years. Furthermore, we do not assume a fixed interest rate but use the ungoing (nominal) interest rates for private loans, reported in the annual reports of De Nederlandse Bank (the Dutch National Bank). The investment costs have been corrected for WIR investment subsidies.

The costs of biological waste-water treatment in the other years are calculated on the basis of price indices for the different cost components, according to various sources of the Dutch Central Bureau of Statistics (CBS). For equipment, we used the price index for filters and cleaning technology (manufacturing products, domestic sales, producer prices) published in "Bijvoegsel Maandstatistiek prijzen". For construction works, we used the price index for houses and other buildings (net of value added tax), published in "Maandstatistiek Bouwnijverheid". For labour, we used the CBS-price index for wages in industry, published in "Supplement sociaal-economische maandstatistiek". And for electricity, we used the price index for electricity in industry, published in the "Statistiek van de electriciteitsvoorziening in Nederland". The only cost variable for which no price figures were available is waste disposal. For waste disposal costs we used the price index of labour costs. This may have resulted in an underestimation of the effluent treatment costs in the late eighties and early nineties, when waste disposal costs increased significantly. (However, this does not affect the model results in an important way as waste disposal costs are only a small part of the variable costs.) The price indexes for the different cost components are given in the figure on the next page.

\section{Appendix 6.D: The diffusion of biological waste-water treatment plants}

The figures for the proportion of firms in the Food and Beverage industry that discharge their waste water on a collective waste-water treatment plant are based on two sources: the RIZA survey in 1986 and a survey by the CBS of 1992. In both surveys, firms were asked in what year they had installed a biological waste-water treatment plant. We used the RIZA figures for the 1974-85 period and the (less detailed) CBS figures for the 1986-91 period. The reason for using the RIZA figures for the early period were that the CBS figures were given at a more aggregate level (sometimes for two years) and that the plants in the RIZA survey are first-purchases, whereas the CBS figures include replacement investments (the number of which, however, is believed to be small). Dividing the number of indirect dischargers in the Food and Beverage industry with a biological wast-water treatment plant by the total number of indirect dischargers in this industry (which is estimated at 183) gives $A_{\nu}$ the proportion of indirect dischargers in the Food and Beverage industry with a biological waste-water treatment plant. 


\section{Price indices effluent treatment costs source: $\mathrm{CBS}$}

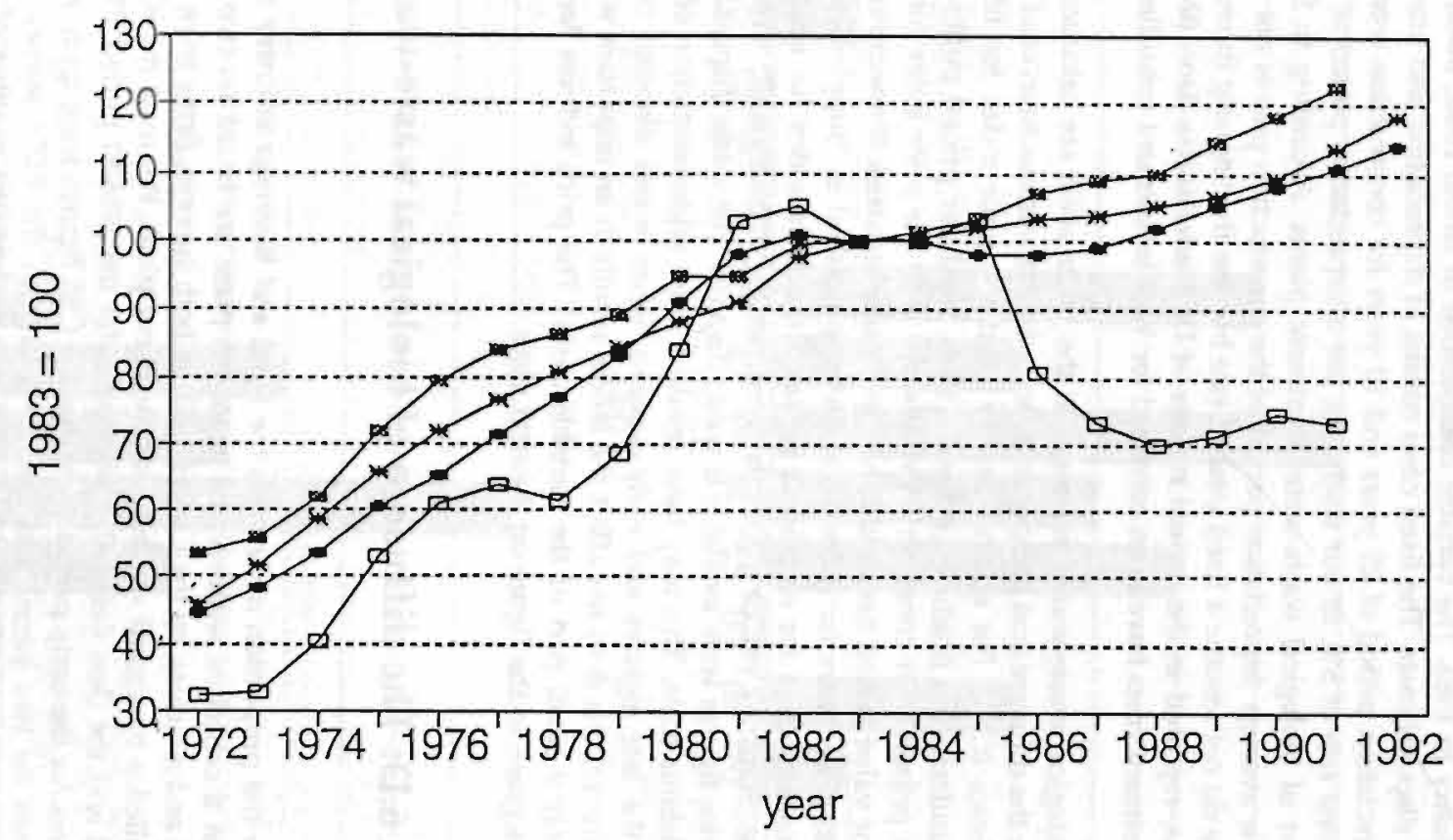

$\rightarrow$ equipment $\rightarrow$ construction $\rightarrow$ - labour $\quad \rightarrow$ electricity




\section{Chapter 7}

\section{The Diffusion of Thermal Home Insulation in the Netherlands}

Over the last few decades, many houses in the Netherlands have been thermally insulated in response to energy-efficiency standards, higher energy prices and the demand for extra comfort. Of these factors, building codes that aimed at reducing thermal losses were the main factor in the improvement of the thermal integrity of houses built after 1975. In the Netherlands, new standards for heat losses became effective in 1975, which required cavity wall insulation and roof insulation in all newly built houses. Double glazing in living rooms and kitchens became compulsory in 1978 for all new government-subsidized houses - and in 1981 for all new houses. These building codes reflected several public worries: to become less dependent on foreign energy suppliers, to reduce energy costs and to conserve the natural environment.

Whereas building codes pertaining to heat losses either directly or indirectly commanded the use of thermal insulation technologies in new homes, there were no requirements for improving the energy efficiency of the existing housing stock. Nonetheless, many house-owners and occupants decided to have their homes thermally insulated, not so much for environmental reasons or energy security reasons but to save on the energy bill and for personal comfort - to benefit from extra comfort connected with thermal insulation such as less temperature differentials, less window condensation, and a warmer bedroom or attic. Higher energy efficiency of the existing housing stock was also promoted by public authorities through special investment subsidy programmes and information dissemination programmes.

As a result, the share of houses built before 1976 with thermal insulation increased steadily over time. The proportion of owner-occupied houses built before 1976 with double glazing rose from 34.3 per cent in 1978 to 79.4 per cent in 1992. The penetration of the other types of thermal insulation in 1992 was much lower: 41.8 per cent for cavity wall insulation, and 51.8 and 17.2 per cent for roof and floor insulation.

The proportion of rented houses with thermal insulation also increased over time, although the shares were lower than those of owner-occupied houses, especially in the early period. In 1992, 70.7 per cent of all rented houses built before 1976 had double glazing, 40 per cent had cavity wall insulation, 24.4 per cent had roof insulation and 7.1 per cent had floor insulation. The growth in the proportion of owner-occupied and rented houses built before 1976 that have double glazing and cavity wall insulation (the subject of our analysis) is depicted in Figure 7.1. 


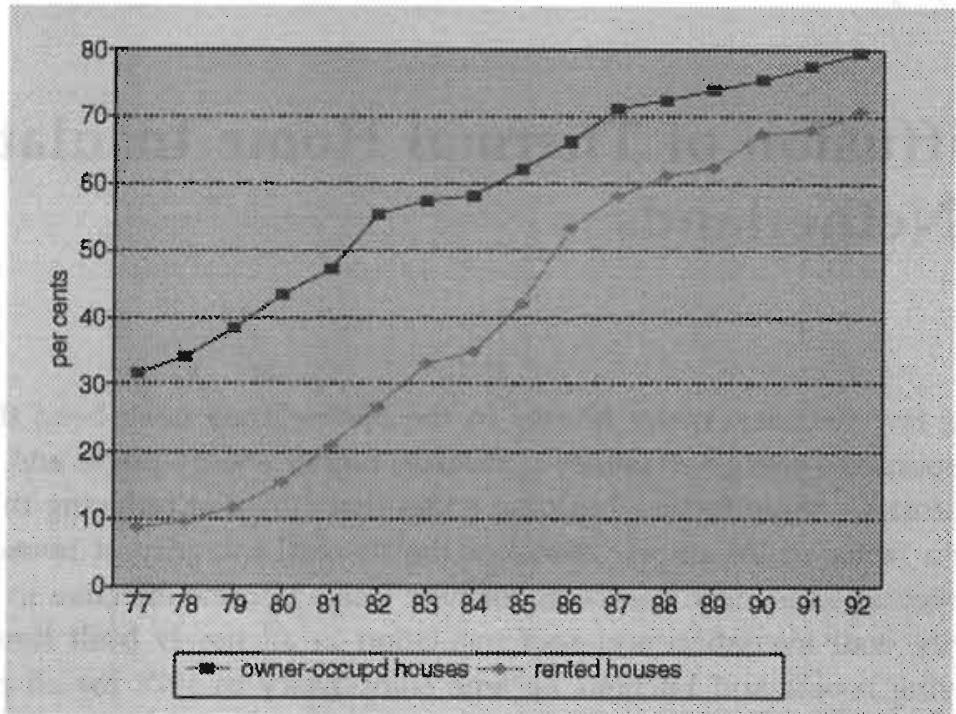

Figure 7.1a. The diffusion of double glazing in owner-inhabited and rented houses built before 1976. Source: NIPO, BAK and own calculations.

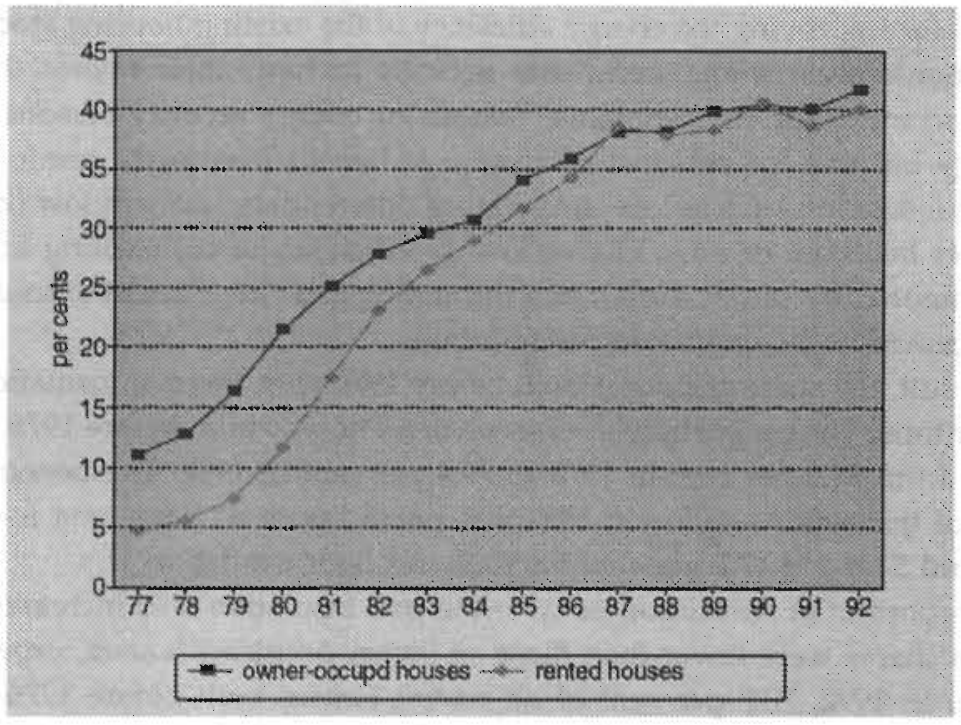

Figure 7.1b. The diffusion of cavity wall insulation in owner-inhabited and rented houses built before 1976. Source: NIPO, BAK and own calculations. 
Figure 7.1 shows a steady increase in the proportion of houses with double glazing and cavity wall insulation built before 1976. The diffusion of double glazing and cavity wall insulation follows more or less a sigmoid pattern with differing growth rates (both with respect to technology and time period). This raises the question as to what factors are responsible for the observed increases in the proportion of houses with thermal insulation, and how important these factors were in inducing households to invest in thermal home insulation. For instance, how important were the investment subsidies for double glazing and cavity wall insulation? And how important were price changes in natural gas (the main energy source for space heating in the Netherlands) in making households install double glazing or to invest in cavity wall insulation? Other questions that may be asked are: What accounts for the differences in the adoption of the various types of thermal insulation? Why is the number of houses with double glazing much higher than those for wall, roof and floor insulation, this while the financial payoffs from double glazing are the lowest?

These questions, together with other questions about household motives to invest in thermal insulation, can be analyzed in the threshold model developed in chapter 5. To do so, we apply the model to two types of thermal insulation (double glazing and cavity wall insulation) for houses built before 1976 for two occupant categories - owner-occupants and renters. (The diffusion of roof and floor insulation is not investigated econometrically because of insufficient data and inaccuracies in the measurement of the model variables.) The reason for making a distinction between owner-occupants and renters is that they constitute different occupant categories in terms of income, education level and ability to appropriate the benefits from the investment in thermal home insulation. For example, renters may lose the value of their investment in thermal insulation once they move to a different house. In the Netherlands, however, this holds less true than for other countries, because a large part (approximately 75 per cent) of the stock of rented houses is owned by non-profit housing councils ("woningbouwverenigingen") and local councils. The one-time costs of thermal insulation are taken care of through the rent by these housing associations so that renters do not suffer a disproportionate loss when they move to a new house. The decision to thermally insulate a rented house is made by the renter, not by the housing council.

The chapter is organized as follows. Section 1 describes the threshold model for thermal insulation: the model variables and parameters. Section 2 contains the empirical results of the threshold model. Section 3 presents the results from three epidemic models - the logistic, Gompertz and Bass model. The final section gives the conclusions about the impact of investment subsidies and price of natural gas on the diffusion of thermal home insulation. 


\subsection{The Threshold Model for Thermal Home Insulation}

This section discusses econometric aspects involved in the application of the threshold model to thermal home insulation: the model variables, the distributions of the variables that underlie the diffusion process, the parameters to be estimated, and the estimating procedure that will be used to estimate the model parameters.

As explained previously, a key assumption of the threshold model advanced in chapter 5 is that in making a decision about the purchase of a thermal insulation technology, a household compares the costs of adoption (being the sum of purchase price and installation costs) with the risk-adjusted reservation price (being heterogeneous across the population of households). Only those households for which the risk-adjusted reservation price exceeds the costs of adoption will be adopters.

After this short introduction, we will now define the variables that affect the reservation prices (willingness to pay) for thermal insulation. The first two variables that immediately come to mind are: First, the annual energy savings in $\mathrm{m}^{3}, E R_{t}$, from thermal insulation, and second, the price of natural gas, $p_{\text {gas, }}$. Together these two variables determine the savings on energy costs from thermal insulation. The willingness to pay for thermal insulation technologies also depends on the interest rate $\left(r_{t}\right)$, the life time of the investment $(l)$, and on utility-enhancing effects of thermal home improvement, $K_{t}$. It also depends on uncertainty about the economic characteristics of thermal insulation - the energy savings to be achieved and future energy prices. The disutility of uncertainty about the desirability of an investment in thermal insulation is accounted for in the model by dividing the reservation price by uncertainty factor $U_{t}(\rho)>1$ (with $\rho$ the parameter of uncertainty and $\partial U_{t} / \partial t<0$ ). The way in which the above variables affect the willingness to pay for thermal insulation $X_{t}$ is described in equation (1). ${ }^{1}$

$$
X_{t}=\frac{E R_{t} P_{\text {guss }}+K_{t}}{U_{i} R_{t}}
$$

with $R_{t}=\frac{r_{t}}{1-e^{-r_{t} !}}$ the imputed annual rental rate ( $t$ indexes time)

$E R_{t}, p_{g a s,}$ and $K_{t}$ (and $X_{t}$ ) are defined per $m^{2}$ of thermal insulation. This is because the costs of thermal insulation $C_{t}$ vary with the surface area that is insulated (usually measured in square meters).

In the model analysis, only $E R$ and $K$ are taken to be stochastic variables (which means that they are considered to differ among households). The energy savings from thermal insulation, $E R$, are known to vary among households, depending on the housing con-

' For simplicity we have dropped index $j$ for the two types of thermal insulation that are statistically investigated: double glazing $(j=1)$ and cavity wall insulation $(j=2)$. 
struction, the location of the house, and, especially, household heating habits. According to Leo Meyer, energy savings from thermal insulation follow a normal distribution with mean 21.51 and standard deviation $5.8 \mathrm{~m}^{3}$ of natural gas per $\mathrm{m}^{2}$ for double glazing and 10.11 and 1.3 for cavity wall insulation (when using thermal wool). ${ }^{2}$ Thus, the energy savings from double glazing per $\mathrm{m}^{2}$ are twice the energy savings per $\mathrm{m}^{2}$ from cavity wall insulation. Figure 7.2 gives the cumulative frequency distribution for the energy savings from thermal insulation.

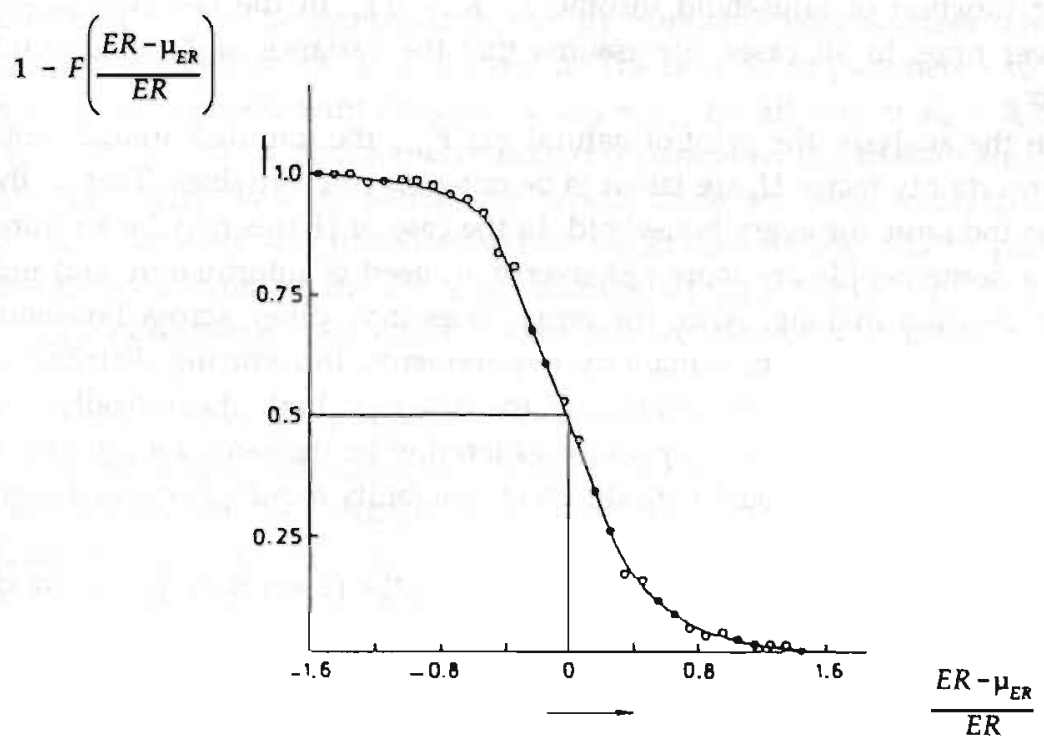

Figure 7.2. The distribution of energy savings from thermal home insulation. Source: Meyer (1981, p.82).

Figure 7.2 shows that the energy savings from thermal insulation are distributed according to a normal distribution. The distribution of $E R_{j}$ over time is constant with time because the thermal efficiency of insulation materials did not change during the diffusion period: $\mu_{E R, j t}=\mu_{E, R, j}$ and $\sigma_{E R, i t}=\sigma_{E R, j}$ for $j=1,2$.

\footnotetext{
${ }^{2}$ Leo A. Meyer, 1981, Energiebesparing in de Sociale Woninghoutw: Besparing op Ruimtenerwarming in Theorie en Praktijk (Energy savings in government-subsidized house building: savings in space heating in theory and practice), PhD thesis, University of Groningen. In the model analysis, we use somewhat different estimates for the average energy savings from double glazing and cavity wall insulation: 22.83 and 9.38. The estimates for the energy savings and the costs and benefits of thermal insulation are based on several sources: H.M. Roos, 1977, Kosten-baten analyse van isolatie (Cost-benefit analysis of thermal insulation), Gas, 97: 90-103; Nationale Woningraad, 1979, Woningisolatie: verstandig aanpakken (Thermal insulation: making a wise decision), 1979, Woningraad-Extra, april 1979; Stichting Bouwresearch, 1985, Wonen in de kou (living in the cold), Rotterdam; and Communicatieen Adviesbureau over Energie en milieu (CEA), 1993, Besparingspotentiëlen woningbouw (EnergySavings profiles in house building), Rotterdam.
} 
Unfortunately, no detailed knowledge is available about the monetary valuation of the beneficial (or harmful) side-effects of thermal insulation, $K$ (being a function of household preferences, wealth and housing location). In our analysis, we simply assume that $K_{t}$ is normally distributed with mean $\mu_{K, t}$ and standard deviation $\sigma_{K, \text {. }}$. This is a very convenient assumption which facilitates econometric application of the model. (The sum of a two independent normal distributions is also normally distributed.) In the model analysis, we consider three situations: that of a constant $K_{\imath}$, the situation where $K_{t}$ is a function of the number of previous adopters: $K_{t}=K_{0}+\kappa A_{t-1}$, and finally the case where $K_{t}$ is a linear function of household income $Y_{t}: K_{t}=\alpha Y_{t}$. In the last two cases, $K_{t}$ is increasing over time. In all cases, we assume that the variance of $K_{t}$ is constant with time: $\sigma_{K, t}^{2}=\sigma_{K}^{2}$.

Thus, in the analysis, the price of natural gas $P_{g^{a s,}, t}$, the imputed annual rental rate $R_{t}$, and the uncertainty factor $U_{t}$ are taken to be deterministic variables. That is, they are believed to be the same for every household. In the case of $U_{t}$ this may be an unrealistic assumption as some people are more risk-averse, in need of information, and independent in their decision making. Also, the rental rates may differ across households or households may apply different rentability requirements. Introducing distributions for these variables, however, would complicate the analysis, both theoretically and empirically. It is for that reason that they are considered to be the same for all households. A description of a threshold model with different rentability requirements is described in appendix $\mathrm{A}$.

What does the above imply for the way in which the reservation prices are distributed across the population of potential adopters? It implies that if $E R_{t}-N\left(\mu_{E R_{j},} \sigma_{E R_{i}}\right)$ and $K_{j t}-N\left(\mu_{K_{j} t}, \sigma_{K_{j}}^{2}\right)$, then the (risk-adjusted) reservation prices $X_{t}$ also follow a normal distribution with mean $\mu_{j i}$ and variance $\sigma_{j i}{ }^{2}$ :

$$
\mu_{j t}=\frac{\mu_{E R, j} p_{g a s, t}+\mu_{K_{j i t}}}{U_{j t} R_{j t}} \wedge \sigma_{j t}^{2}=\frac{p_{g a s,}^{2} \sigma_{E R, j}^{2}+\sigma_{K, j}^{2}}{U_{j t}^{2} R_{j t}^{2}}
$$

As explained in chapter 5 , the probability of adoption at time $t, A_{t}$, is equal to the proportion of the population for which the reservation price exceeds the cost of adoption. From equation (15) in chapter 5 we know that:

$$
A_{j t}=\Phi\left(\frac{\mu_{j t}-C_{j t}}{\sigma_{j t}}\right)
$$

with $\Phi$ the standard normal cumulative density function.

This is the equation to be estimated with an error term added to the right-hand side to account for differences between the probability that a randomly selected house is thermally insulated (with insulation of type $j$ ) at time $t$, and the measured proportion of homes with thermal insulation of type $j$ at time $t, \hat{A}_{j t}$. What we get is: 


$$
\hat{A}_{j t}=\Phi\left(\frac{\mu_{j t}-C_{j t}}{\sigma_{j t}}\right)+\varepsilon_{j t}
$$

with $\hat{A}_{j i}$ the measured proportion of houses with thermal insulation of type $j$ at time $t$, $C_{j t}$ the costs of adoption, and $\varepsilon_{j i}$ an i.i.d. error term with zero mean and variance $\sigma_{j}^{2} j=$ $1,2-$ where $j=1$ for double glazing and $j=2$ for cavity wall insulation. $\left(\mu_{j t}\right.$ and $\sigma_{j t}$ are the mean and standard deviation of reservation prices $X_{j k}$ defined in (2).)

Equation (4) can be estimated in TSP by nonlinear least squares. The parameters that we want to estimate are: $\mu_{K, j}, \sigma_{K, j}$ and $\rho_{j}$. The number of parameters to be estimated is three if $\mu_{K, j}$ is constant with time (i.e. if $\mu_{K, j t}=\mu_{K, j}$ for all $t$ ) or if $K_{j t}=\alpha_{j} Y_{t}$, and four if $\mu_{K, j t}=\mu_{K, j 0}+\kappa A_{j t-1}$. If $K_{j}$ is zero we have only one parameter $\left(\rho_{j}\right)$ to estimate $\left(K_{j}\right.$ is likely to be small for cavity wall insulation, for which there are little utility-enhancing sideeffects). Since we were able to collect and construct data for the 1977-92 period, we have 16 observations to estimate the above parameters, which is not much. (For $K_{t}=K_{0}+\kappa A_{t-1}$ we have one observation less, which means that we have only 15 observations.)

After this long exposition of econometric detail, we will now touch upon the kind of conclusions we might infer from the diffusion analysis. First, the model might provide information about the importance of changes in the price of natural gas in inducing households to invest in thermal insulation. Second, the model may enable us to assess whether shifts in preferences and reductions in uncertainty are important factors in household insulation decisions. And third, the effects of government subsidy schemes may be determined empirically, which enables us to evaluate the effectiveness of these schemes in influencing people's investment decisions. Of course, the accuracy of the above conclusions depends on the ability of the model to explain the diffusion of thermal home insulation across different household categories over the period of investigation.

\subsection{Empirical Results from the Threshold Model}

This section presents the empirical results of the threshold model for double glazing and cavity wall insulation. We have estimated the threshold model for these two thermal insulation technologies, both for owner-occupied and rented houses built before 1976. Before we give the results, however, we will take a look at the development of the average net annual gains from double glazing and cavity wall insulation for each occupant category. Figure 7.3 gives the average net annual monetary gains $\left(\mu_{j t}-C_{j t}\right)$ of an investment in double glazing and cavity wall insulation at time $t$, both for owneroccupied and rented houses. 


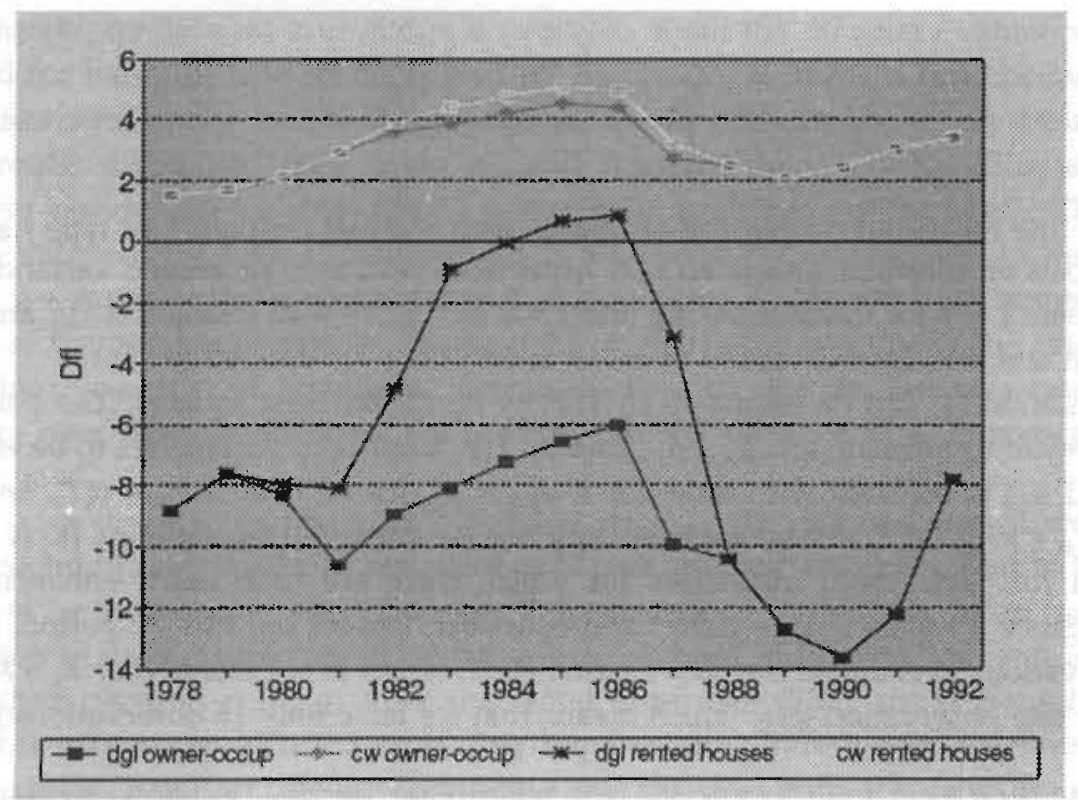

Figure 7.3. The average net annual monetary gains of an investment in double glazing (dgl) and cavity wall insulation (cw) for owner-occupied and rented houses.

Figure 7.3 shows that the average net annual monetary gains from an investment in thermal insulation vary over time and differ between double glazing and cavity wall insulation. It also demonstrates that the net annual monetary gains from cavity wall insulation are significantly higher than those from double glazing, despite the fact that the energy savings per $\mathrm{m}^{2}$ of insulation area are only half of those of double glazing. Figure 7.3 furthermore shows that the net average annual monetary gains from double glazing are negative in the entire 1978-92 period for owner-occupied houses (and for renters in all years, except for 1985 and 1986). This illustrates the importance of including non-monetary gains $K_{i}$ in the analysis of the diffusion of double glazing. About the development of $\mu_{j i}-C_{j t}$ the steady increase in the net annual monetary gains from thermal insulation up to 1985 is caused by the increase in the price for natural gas, which rose from Dfl 0.27 per $\mathrm{m}^{3}$ in 1978 to Dfl 0.66 in 1985 (see appendix B). When the price of natural gas dropped in the $1986-89$ period (to Dfl 0.42 in 1989), the net annual monetary gains of an investment in thermal insulation also dropped significantly.

Another factor that affects the net annual gains of thermal insulation is investment subsidies. In 1976, the Dutch government instituted a large investment programme for thermal home insulation, the "Nationaal Isolatie Programma" (NIP). Under the NIP programme, households could receive an investment subsidy of more than 20 per cent and often as much as 30 per cent of total investment costs. For owner-occupants, the programme ended in 1983, after a phase-out in 1981 and 1982. For renters, however, it 
was possible to receive an investment subsidy of one-third of total investment costs up to 1988. The elimination of the programme is reflected in the decrease in the annual monetary gains from a thermal insulation investment in 1981 for owner-occupants and the decrease in $\mu_{j t}-C_{j t}$ in 1988 for renters. We will now give the model results, first for owner-occupied houses and then for rented houses.

\subsubsection{Results from the threshold model for owner-occupied houses}

We have estimated the diffusion of double glazing and cavity wall insulation for owneroccupied houses in the 1978-92 period. As for biological waste-water treatment plants, we estimated several model variants. Here, only the results where $K_{t}$ is a linear function of $A_{t-1}$ and of $Y_{t}$ and $U_{t}=1+\rho /\left(t-t_{0}\right)$ are reported. These three expressions gave the best results, and they are also preferred on theoretical grounds: the valuation of utilityenhancing effects $K_{t}$ is likely to be a function of household income or the number of previous adopters that are instrumental in influencing other people's decisions and $U_{t}$ is likely to be high in the first years for risk-averse consumers.

In the regressions, we had to impose restrictions on the parameters. Estimation of four parameters on the basis of 15 or 16 observations led to bad estimation results: very high parameter values, standard errors that were not determined and negative coefficients of determination. For double glazing, we estimated the model for different parameter values for $\mu_{K, 0}$ and $\sigma_{K}$. For $\mu_{K, 0}$ we used the following values: $5,7.5,10,12.5,15$ and for $\sigma_{K}$ we used $5,10,15$. This led to different parameter estimates and goodness-offit values. The model results showed that the higher the value for $\sigma_{k}$, the higher the coefficient of determination: for $\sigma_{K}=15$ and $\mu_{K, 0}=7.5$, the adjusted $R^{2}$ is 0.74 . However, a value of 15 for $\sigma_{K}$ is much too high, it corresponds with a $95 \%$ interval for $K_{t}$ of $\mu_{K, t} \pm$ 30. More reasonable estimates for $\mu_{K, 0}$ and $\sigma_{K}$ are: 12.5 and 5. Estimation results of the regressions under these restrictions are given in column (1) of Table 7.1. $\kappa$ is estimated at 4.5 and $\rho$ at 1.1 , with both estimates significantly different from zero at the $5 \%$ significance level and more or less of the magnitude that we expected. ${ }^{3}$ The reported coefficient of determination is 0.55 . We also estimated the model for $K_{i}=\alpha Y_{t}$ with $Y_{t}$ average household income. Again, we had to impose certain restrictions on the model parameters in order to obtain reasonable estimates. We estimated the model for $\sigma_{k}=5$, $7.5,10,12.5$ and 15 . The results for $\sigma_{K}=7.5$ for double glazing are given in column (2). $\alpha$ is estimated at 0.42 (with a standard error of 0.04) and $\rho$ at 1.29 (with a standard error of 0.45 ). The value of 0.42 for $\alpha$ means that the willingness to pay per year for a $14 \mathrm{~m}^{2}$ sized, double-glazed window is Df 169 in 1977 and Df 257 in 1992. The adjusted $R^{2}$ value is 0.67 .

${ }^{3}$ A value of 4.48 for $\kappa$ together with $\mu_{k, a}=12.5$ implies that house owners in 1978 are prepared to pay Dfl 195 for the extra comfort of a $14 \mathrm{~m}^{2}$-sized double-glazed window (which is approximately the size of a large window in a living room). The willingness to pay in 1992 wass 224 guilders. These values correspond with monthly payments of 16 and 19 guilders. Note that these figures are averages. 
For cavity wall insulation, we estimated the model for $K_{t}=0$. As explained before, there are very few utility-enhancing gains from cavity wall insulation. The only gains are in the form of energy savings. If we estimate the model for $\mu_{\mathrm{K}, 0}=\kappa=0$, we get extremely high parameter values (of almost a billion) for $\sigma_{K}$ and $\rho$. If we estimate the model for $\sigma_{K}$ $=2.5$ (to allow for a little variation in $K$ ), we get a more reasonable estimate for $\rho$ of 23.8 (which is still very high). The adjusted $R^{2}$ of this regression is 0.66 . The results are in column (3) of Table 7.1.

The model results for the diffusion of double glazing and cavity wall insulation across owner-occupied houses are rather bad: coefficients of determination are low (for a model that explains $A_{t}$ ) and there is strong evidence of positive first-order autocorrelation. Although the parameter values are signifantly different from zero and of the correct magnitude, one cannot attach much value to them as they are based on regressions in which several parameters are fixed.

\begin{tabular}{|c|c|c|c|}
\hline & $\begin{array}{l}\text { double glazing } \\
\text { (1) } \\
\text { with } \mu_{k, 0}=12.5 \\
\text { and } \sigma_{p}=5\end{array}$ & $\begin{array}{l}\text { (2) } \\
\text { (1) with } K_{t}=\alpha Y_{\text {t }} \\
\text { and } \sigma_{k}=7.5\end{array}$ & $\begin{array}{l}\text { cavity wall insulation } \\
\text { (3) } \\
\text { with } \mu_{\mathrm{h}, t}=0, \\
\text { and } \sigma_{\mathrm{K}}=2.5\end{array}$ \\
\hline$\kappa$ & $\begin{array}{r}4.48^{*} \\
(2.14)\end{array}$ & & \\
\hline$\alpha$ & & $\begin{array}{r}0.42^{*} \\
(0.04)\end{array}$ & \\
\hline$\rho$ & $\begin{array}{c}1.15 y^{*} \\
(0.28)\end{array}$ & $\begin{array}{r}1.29^{*} \\
(0.45)\end{array}$ & $\begin{array}{l}23.76^{*} \\
(2.28)\end{array}$ \\
\hline adj- $R^{2}$ & 0.55 & 0.67 & 0.66 \\
\hline DW & 1.06 & 0.93 & 0.61 \\
\hline
\end{tabular}

* significant at $5 \%$ level (standard errors in parentheses)

Table 7.1. Estimation results of the threshold model for owner-occupied houses, 1978-92.

The model predictions for $A_{b}$, the proportion of owner-occupied houses with double glazing and cavity wall insulation, are in Figure 7.4. Figure 7.4 shows that the threshold model under the imposed restrictions cannot describe the observed diffusion patterns for double glazing and cavity wall insulation. It overestimates the proportion of owneroccupied houses with double glazing in the 1983-86 period, when the price of natural gas was very high, and it underestimates the proportion of owner-occupied houses with cavity wall insulation in the $1978-83$ period. (The high predicted values for $A_{j i}$ in 1991 
and 1992 are caused by the increase in the price of natural gas and the fact that thermal insulation was again subsidied.) The overall conclusion is that the threshold model is not a good model for explaining the diffusion of thermal home insulation. It must we noted, however, that one of the reasons for these bad results is that the model does not explain the proportion of thermally insulated houses in each year but the proportion of households that would desire to have thermal insulation given the prevailing price structure and subsidies in that year. The decrease in $\mu_{j t}-C_{j t}$ after 1986 due to the decrease in $p_{\text {gast }}$ after 1985 and the elimination of the subsidy programma for thermal insulation are responsible for a sharp decrease in the predicted $A_{j t}$, whereas in reality an adopter in year $t$ will be an adopter in $t+1$.

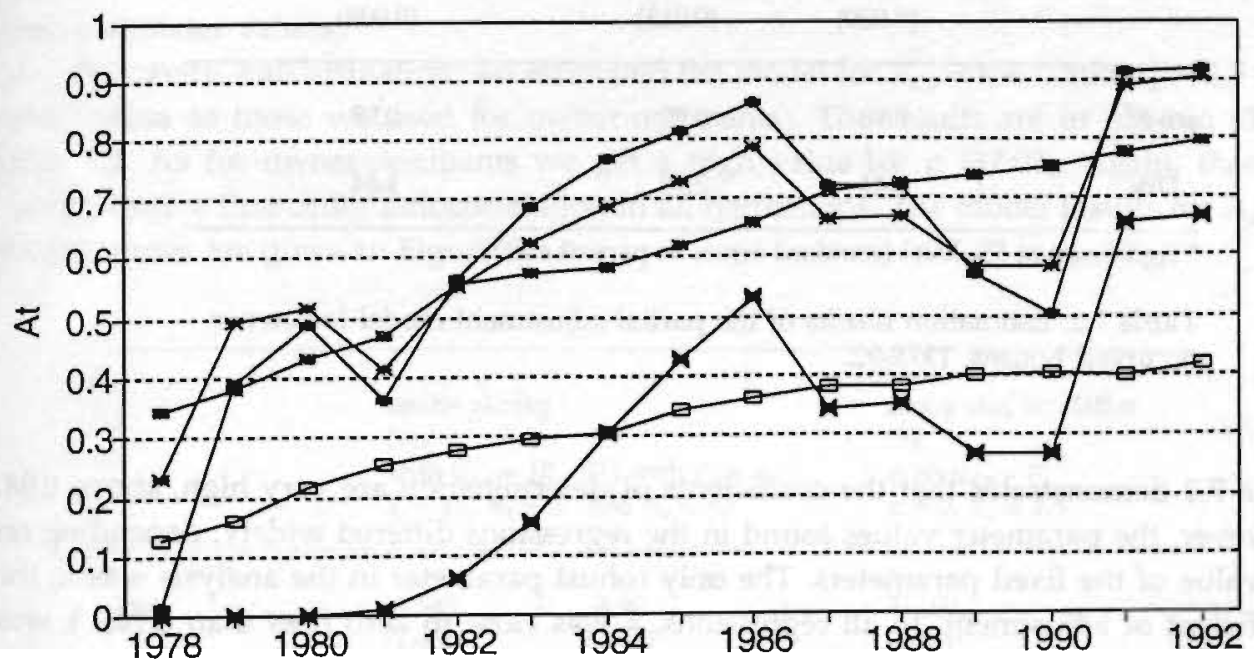

$$
\begin{array}{ll}
\rightarrow-\text { double glazing } & \rightarrow \text { with } \mathrm{Kt}=\mathrm{KO}+\mathrm{kAt}-1 \rightarrow \text { with } \mathrm{Kt}=\mathrm{aYt} \\
\rightarrow-\text { cavity wall } & \rightarrow \text { wit } \mathrm{Kt}=0
\end{array}
$$

Figure 7.4. Model results for the proportion of owner-occupied houses with double glazing and cavity wall insulation according to the threshold model.

What if we introduce adjustment costs into the model? Does this improve the results? To investigate this possibility we estimated equation (8) in chapter 6 for double glazing and cavity wall insulation. In the partial adjustment or stock adjustment model, only a fixed proportion of the desired adjustment is accomplished in one period due to adjustment problems (such as financing problems). We estimated the partial adjustment model under the same parameter restrictions. The results of this model are given in Table 7.2. 


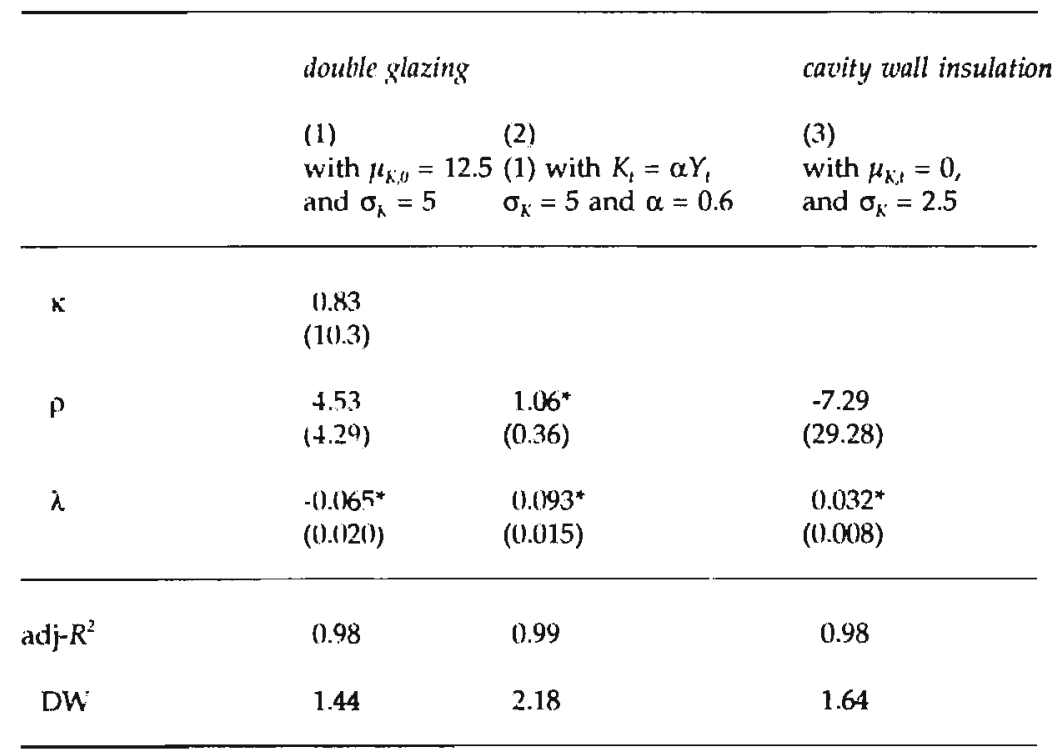

* significant at $5 \%$ level (standard errors in parentheses)

Table 7.2. Sistimation results of the partial adjustment model for owneroccupied houses, 1978-92.

Table 7.2 demonstrates that the coefficients of determination are very high, above 0.98 . However, the parameter values found in the regressions differed widely, depending on the value of the fixed parameters. The only robust parameter in the analysis was $\lambda$, the coefficient of adjustment. In all regressions, $\lambda$ was close to zero (less than 0.10 ). $\lambda$ was even significantly negative in the model with $K_{i}=K_{i}+\kappa A_{t-1}$. The low and negative values for $\lambda$, the insignificant values for $\kappa$ and $\rho$ lead us to the conclusion that the threshold model is not a good model for explaining the diffusion of thermal insulation technologies across owner-occupied houses.

We will now investigate whether the threshold model can explain the diffusion of thermal insulation technologies across rented houses during the 1978-92 period.

\subsubsection{Results from the threshold model for rented houses}

This section presents the results of the diffusion model for double glazing and cavity wall insulation in the 1978-92 period in rented houses built before 1976. Again, we only report the results of the model variant in which $K_{t}$ is a linear function of $A_{t-1}$ and $Y_{t}$ and $U_{t}=1+p /\left(t-t_{i}\right)$. Other expressions for $K_{t}$ and $U_{t}$ that we investigated gave less good results in terms of coefficients of determination and parameter values. 
Again, we had to impose several restrictions on the parameter values. We estimated the model for double glazing using the same values for $\mu_{K, 0}$ and $\sigma_{K}$ as for owneroccupants. Investigation of the results shows that the value for $\sigma_{K}$ has little influence on the estimation results. Each of the regressions gave quite a high coefficient of determination (above 0.73) but the estimates for $\kappa$ and $\rho$ were far too high: $\kappa$ is estimated at 56.5 and $\rho$ at 16.3 for $\mu_{K, 0}=10$ and $\sigma_{K}=5$. Especially the value for $\kappa$ is much too high. For that reason we re-estimated the model for $\kappa=4.5$ (the value we found for owneroccupants). The estimation results are in column (1) of Table 7.3. $\rho$ is now estimated at 4.58 with a standard error of 1.08 . The adjusted $R^{2}$ for double glazing is very low, only 0.21 whereas it was 0.55 for owner-occupants. The results for the model with $K_{t}=\alpha Y_{t}$ and $\sigma_{K}=10$ are in column (2). $\rho$ is estimated at 3.90 and $\alpha$ at 0.34 . Different values for $\sigma_{K}$ gave different values for $\rho$ and $\alpha$, which means that we should not attach much value to these parameter values.

For cavity wall insulation, we estimated the model for $\mu_{\mathrm{K}, 0}=\kappa=0$ and $\sigma_{\mathrm{K}}=2.5$ (the same values as those we used for owner-occupants). The results are in column (3) of Table 7.3. As for owner-occupants we get a high value for $\rho$ (37.03). Again, there is strong positive first-order autocorrelation in all regressions. The model results for $A_{j t}$ for rented houses are given in Figure 7.5.

\begin{tabular}{|c|c|c|c|}
\hline & $\begin{array}{l}\text { double glazing } \\
\text { (1) } \\
\text { with } \mu_{K, 0}=10 \\
\kappa=4.5, \sigma_{K}=5\end{array}$ & $\begin{array}{l}\text { (2) } \\
\text { (1) with } K_{t}=\alpha Y_{t} \\
\text { and } \sigma_{K}=10\end{array}$ & $\begin{array}{l}\text { cavity wall insulation } \\
\text { (3) } \\
\text { with } \mu_{\mathrm{K} 0}=0 \\
\mathrm{~K}=0, \sigma_{\mathrm{K}}=2.5\end{array}$ \\
\hline$\rho$ & $\begin{array}{c}4.58^{*} \\
(1.08)\end{array}$ & $\begin{array}{c}3.90 \\
(2.65)\end{array}$ & $\begin{array}{l}37.03^{*} \\
(3.56)\end{array}$ \\
\hline$\alpha$ & & $\begin{array}{c}0.34^{*} \\
(0.13)\end{array}$ & \\
\hline $\operatorname{adj}-R^{2}$ & 0.21 & 0.32 & 0.38 \\
\hline DW & 0.55 & 0.54 & 0.72 \\
\hline
\end{tabular}

* significant at $5 \%$ level (standard errors in parentheses)

Table 7.3. Estimation results of the threshold model for the proportion of rented houses with thermal insulation, 1978-92. 


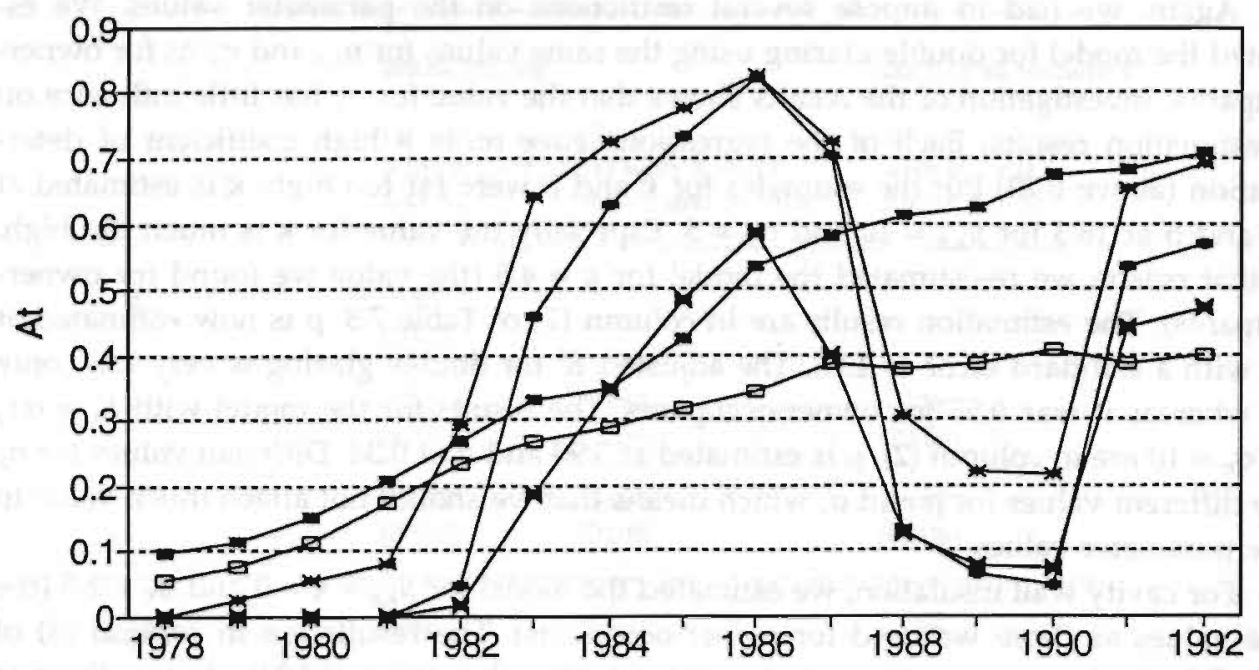

$$
\begin{array}{ll}
\rightarrow-\text { double glazing } & \longrightarrow \text { with } \mathrm{Kt}=\mathrm{KO}+\mathrm{KAt}-1 \rightarrow \text { with } \mathrm{Kt}=\mathrm{aYt} \\
\square \text { cavity wall } & \rightarrow \text { wit } \mathrm{Kt}=0
\end{array}
$$

Figure 7.5. Results of the threshold model for the proportion of rented houses with double glazing and cavity wall insulation.

Figure 7.5 demonstrates that the model predictions for $A_{j t}$ are all bad. They are even worse than those for owner-occupied houses in Figure 7.3. The threshold model is not able to describe empirically the diffusion of double glazing and cavity wall insulation across rented houses built before 1976. It overestimates the proportion of rented houses with double glazing between 1983 and 1987 and underestimates the proportion of houses with thermal insulation in the 1978-82 and 1988-90 periods.

Comparison of Table 7.1 with Table 7.3 shows that the estimates for $\rho$ (the uncertainty parameter) are higher for renters. This corresponds with the empirical finding of economic studies that low-income groups apply higher implicit discount rates in energyrelated purchasing decisions. ${ }^{4}$ Furthermore, the coefficients of determination in Table 7.1 for owner-occupants are higher than those in Table 7.3 for renters. This suggests that the threshold model is better suited to explain the purchasing decisions of owner-occupants with respect to thermal insulation than those of renters. This is also something we did expect: owner-occupants, being a better educated, high-income household category, are considered to be more knowledgeable and rational in their investment decisions than

\footnotetext{
'Kenneth Train, 1985, Discount Rates in Consumers' Energy-Related Decisions: A Review of the Literature, Energy, 10(12): 1243-1253.
} 
renters are. (This also explains the lower values for $\rho$ and higher value for $\alpha$ for owneroccupants ${ }^{5}$.)

We also estimated the partial adjustment model for renters. This gave results similar to those for owner-occupants: high coefficients of determination (around 0.99) with $\lambda$ almost zero or even negative. Again, $\lambda$ was the only parameter that showed up as significantly different from zero at the $5 \%$ level. The parameter values for the other coefficients differed widely in the different regressions. This means that the threshold model is not a good model, despite the good fit. The results are not presented here.

What conclusions can we draw from the model results? First, utility-enhancing effects of double glazing are an important factor in the time-intensive installation of double glazing. This explains why a large number of households decided to invest in double glazing, despite the negative financial returns. Unfortunately, the monetary value of these utility-enhancing effects of double glazing could not be determined with much precision. Although the values found in the analysis (between Df 11 and 21 a month for a $14 \mathrm{~m}^{2}-$ sized double-glazed window) seem reasonable, the method used (a grid search for $\sigma_{K}$ and $\kappa$ ) is too crude a test to have much confidence in them. With respect to cavity wall insulation, the slow diffusion suggests that information problems are a significant barrier to the uptake of this highly profitable type of thermal insulation. ${ }^{6}$ An alternative explanation is that people apply high discount rates in investment decisions.

Although these conclusions more or less follow from the model results, we should be careful in drawing any conclusions on the basis of the bad estimation results (the low coefficients of determination, the fact that we had to fix several parameter values). Perhaps the main conclusion to be drawn from the model results is that the increase in the proportion of homes with thermal insulation is not so much the result of changes in the price of natural gas and changes in the adoption costs - there are other factors involved. What these other factors are is unclear. They may have to do with information transfer and taste formation (which is different from the way in which it is modelled), budget restrictions, and changes in the population of households (like relocation to a different house, changes in family size, etc.).

The next section investigates whether epidemic models can explain the increase in the number of houses with thermal insulation. We have estimated three epidemic models, both for $A_{j t}$ and $\Delta A_{j i}$.

\footnotetext{
${ }^{5}$ The willingness to pay for personal comfort for double glazing is estimated at 137 in 1977 and 208 in 1992 for renters (based on a value of 0.34 for $\alpha$ ).

${ }^{6}$ This conclusion corresponds with Meyer (1981). Meyer finds that in Gasselte, a small town in the north of the Netherlands, there were significant information problems with respect to the effects of thermal insulation and the cost efficiency of energy-efficiency improvement measures.
} 


\subsection{Empirical Results from Three Epidemic Models}

In the previous section we saw that the threshold model is not a good model for explaining the diffusion of thermal home insulation technologies in the Netherlands. This raises the question whether epidemic models are able to describe better the observed diffusion patterns for double glazing and cavity wall insulation. We estimated three diffusion models - the logistic model, the Gompertz model and the Bass model, with and without economic variables. As before, the analysis is limited to the existing housing stock of houses built before 1976, for two occupant categories - owner-occupants and renters.

\subsubsection{The results for owner-occupied houses}

First, we estimated each of the three models for $A_{j t}$ the proportion of houses with thermal insulation of type $j$ during the 1977-92 period. Expressions for $A_{j l}$ for the logistic, Gompertz and Bass models are given below. The equation for logistic model that we estimated is: ${ }^{7}$

$$
A_{i t}=\frac{1}{1+e^{-\lambda-\beta\left(1-\epsilon_{j}\right)}}+\varepsilon_{i t}
$$

The equation for the Gompertz model that we estimated is: ${ }^{8}$

$$
A_{j t}=\varphi^{(-\beta)^{\cdots-\phi}}+\varepsilon_{j t}
$$

And the equation for the Bass model: ${ }^{9}$

$$
A_{j t}=\frac{1-\frac{\delta\left(1-A_{j t_{t}}\right)}{\left(\delta+\beta A_{i_{t}}\right)} e^{-(\delta+\beta)\left(t-t_{j}\right)}}{1+\frac{\beta\left(1-A_{j t_{0}}\right)}{\left(\delta+\beta A_{j t_{0}}\right)} e^{-(\delta+\beta)\left(t-t_{j}\right)}}+\varepsilon_{j t}
$$

with $\varepsilon_{j t}$ an i.i.d. error term with mean zero and variance $\sigma_{i}^{2}$.

\footnotetext{
${ }^{7}$ We also estimated the logistic model with the error term added to $-\lambda-\beta\left(t-t_{0}\right)$. This led to almost identical results.

${ }^{8}$ We leave it to the reader to verify that equation (6) is the model solution for:

$$
d A(t) / d t=\beta A(t)\left(\ln (N)-\ln \left(n_{t}\right)\right)
$$

with $N$ the size of the population and $n(t)$ the number of adopters at time $t$.

${ }^{9}$ Based on Mahajan and Peterson, op cit., p.21.
} 
Results of the logistic, Gompertz and Bass models for the proportion of owner-occupied houses with double glazing and cavity wall insulation built before 1976 are given in Table 7.4.

\begin{tabular}{|c|c|c|c|c|c|c|}
\hline & \multicolumn{2}{|c|}{ double glazing } & & \multicolumn{2}{|c|}{ cavity wall insulation } & \\
\hline & $\begin{array}{l}\text { (1) } \\
\text { logistic }\end{array}$ & $\begin{array}{l}\text { (2) } \\
\text { Gompertz }\end{array}$ & $\begin{array}{l}\text { (3) } \\
\text { Bass }\end{array}$ & $\begin{array}{l}(4) \\
\text { logistic }\end{array}$ & $\begin{array}{l}\text { (5) } \\
\text { Gompertz }\end{array}$ & $\begin{array}{l}\text { (6) } \\
\text { Bass }\end{array}$ \\
\hline$\lambda$ & $\begin{array}{l}-0.84^{*} \\
(0.05)\end{array}$ & & & $\begin{array}{l}-1.68^{*} \\
(0.11)\end{array}$ & & \\
\hline$\beta$ & $\begin{array}{r}0.15^{+} \\
(0.01)\end{array}$ & $\begin{array}{c}0.11^{*} \\
(0.003)\end{array}$ & $\begin{array}{r}0.14^{*} \\
(0.03)\end{array}$ & $\begin{array}{r}0.10^{*} \\
(0.01)\end{array}$ & $\begin{array}{c}0.06^{*} \\
(0.005)\end{array}$ & $\begin{array}{l}-0.04^{*} \\
(0.02)\end{array}$ \\
\hline$\varphi$ & & $\begin{array}{r}0.27^{*} \\
(0.01)\end{array}$ & & & $\begin{array}{c}0.14^{*} \\
(0.01)\end{array}$ & \\
\hline$\delta$ & & & $\begin{array}{r}0.00^{*} \\
(0.01)\end{array}$ & & & $\begin{array}{r}0.04^{*} \\
(0.01)\end{array}$ \\
\hline $\operatorname{adj}-R^{2}$ & 0.98 & 0.99 & 0.98 & 0.88 & 0.91 & 0.97 \\
\hline DW & 0.72 & 1.25 & 0.63 & 0.23 & 0.25 & 0.37 \\
\hline
\end{tabular}

* significant at $5 \%$ level (standard errors in parentheses)

Table 7.4. Estimation results of the logistic, Gompertz and Bass models for owner-occupied houses, 1977-92.

Table 7.4 shows that the coefficients of determination are all high, especially for double glazing, with adjusted $R^{2}$ values above 0.88 . This means that each of the epidemic models can describe quite well the development of $A_{j}$, the proportion of owner-occupied houses built before 1976 with double glazing and cavity wall insulation during the 197792 period. With respect to the parameter values: the estimates for $\beta$ and $\delta$ are all positive and significantly different from zero at the $5 \%$ significance level, except for the estimate for $\beta$ in the Bass model for cavity wall insulation. In all equations there is strong positive first-order autocorrelation.

How should we interpret the results in Table 7.4? The fact that the coefficients of determination are all high makes us suspicious. The good fit of the models may be due to spurious regression, a common phenomenon in diffusion analysis, where any sigmoid curve is able to 'explain' the diffusion process. The danger of spurious regression is especially high, since a number of other variables not included in the epidemic models such as the price of natural gas - are likely to be an important factor in the timing of 
thermal insulation investments. To investigate this possibility, we let $\beta_{t}$ and $N_{t}$ be a function of the price of natural gas (and in the case of cavity wall insulation also a function of the net gains from adoption). We estimated each of the models with $\beta_{t}=\beta+$ $p_{g^{a s, t}}^{\eta}$ and $N_{t}=N\left(1-1 / p_{\text {gas, }}^{\gamma}\right)$ where $N_{t}$ is the population of potential adopters at time $t$ (Note that $N_{t} \rightarrow N$ if $p_{g a s, t} \rightarrow \infty$ for $\gamma>0$ ). $\eta$ is the elasticity of $\beta_{t}$ with respect to the price of natural gas and $\gamma$ the elasticity of $N_{t}$ with respect to the price of natural gas. The results with $\beta_{t}=\beta+p_{g a s, t}^{\eta}$ and $N_{t}=N\left(1-1 / p_{g a s, t}^{\gamma}\right)$ are compared with those with constant $\beta_{1}$ and $N_{t}=N$. For reasons of comparison, and to take care of the problem of autocorrelation in the error term, the different model variants are estimated for $\Delta A_{j t}$, the change in $A_{j:}$.

The equations for the different models for $\Delta A_{j t}=A_{j t}-A_{j t-1}$ are given below. The equation for the logistic model is:

$$
\Delta A_{j t}=\beta_{\imath} A_{j t}\left(\frac{N_{j t}}{N_{j}}-A_{j t-1}\right)
$$

The equation for the Gompertz model:

$$
\Delta A_{j t}=\beta_{t} A_{j t}\left(\ln \left(N_{j t}\right)-\ln \left(n_{j t-1}\right)\right)
$$

with $n_{j t 1}$ the number of adopters at time $t-1$.

And the equation for the Bass model:

$$
\Delta A_{j t}=\left(\delta+\beta_{i} A_{j p}\right)\left(\frac{N_{j t}}{N_{j}}-A_{j t-1}\right)
$$

These are the equations that are estimated, with an i.i.d. error term $\varepsilon_{j t}$ around mean zero and variance $\sigma_{i}^{2}$ added to the right-hand side of each equation. The results of the different variants of the logistic, Gompertz and Bass models are reported in Table 7.5. Table 7.5 shows that the model results for $\Delta A_{j t}$ are less good than for $A_{j t}$ the proportion of houses with thermal insulation. It also shows that the results of the Bass model are less good than those of the logistic and Gompertz models. With respect to the different variants of the models, the variant with $\beta_{t}=\beta+p_{g u s, t}^{\eta}$ and $N_{t}=N$ gives the worst results in terms of goodness-of-fit. The results of specification (1) and (3) with constant $\beta_{t}$ are best: these specifications have the highest adjusted $R^{2}$ value and, except for the Bass model, all the parameter values are significantly different from zero at the $5 \%$ significance level. It is difficult to say which of the two specifications is best: specification (3) with $N_{t}=N\left(1-1 / p_{\text {gas, }}^{\gamma}\right)$ has the highest $R^{2}$, but the adjusted $R^{2}$ (the $R^{2}$ corrected for the number of parameters) is below that of the variant with $N_{t}=N$. 


\begin{tabular}{|c|c|c|c|c|c|c|c|c|c|c|c|c|}
\hline & \multicolumn{4}{|c|}{ logistic model } & \multicolumn{4}{|c|}{ Goinpertz model } & \multicolumn{4}{|c|}{ Bass model } \\
\hline & (1) & (2) & (3) & (4) & (1) & (2) & (3) & (4) & (1) & $(2)^{\prime}$ & (3) & $(4)^{\prime}$ \\
\hline$\beta$ & $\begin{array}{r}0.15^{*} \\
(0.02)\end{array}$ & $\begin{array}{c}-0.73^{*} \\
(0.36)\end{array}$ & $\begin{array}{c}0.25^{*} \\
(0.06)\end{array}$ & $\begin{array}{l}-0.63 \\
(0.50)\end{array}$ & $\begin{array}{c}0.11^{*} \\
(0.01)\end{array}$ & $\begin{array}{l}-0.94^{*} \\
(0.19)\end{array}$ & $\begin{array}{c}0.14^{*} \\
(0.03)\end{array}$ & $\begin{array}{l}-0.98^{*} \\
(0.22)\end{array}$ & $\begin{array}{c}0.06 \\
(0.05)\end{array}$ & & $\begin{array}{c}0.19 \\
(0.21)\end{array}$ & \\
\hline$\eta$ & & $\begin{array}{c}-0.03 \\
(0.10)\end{array}$ & & $\begin{array}{l}-0.03 \\
(0.15)\end{array}$ & & $\begin{array}{c}0.01 \\
(0.05)\end{array}$ & & $\begin{array}{c}0.03 \\
(0.05)\end{array}$ & & $\begin{array}{l}-3.14 \\
(1035)\end{array}$ & & $\begin{array}{l}-0.30 \\
(0.40)\end{array}$ \\
\hline$\gamma$ & & & $\begin{array}{c}0.47^{\star} \\
(0 .(19)\end{array}$ & $\begin{array}{c}0.47^{*} \\
(0.10)\end{array}$ & & & $\begin{array}{c}0.57^{*} \\
(0.22)\end{array}$ & $\begin{array}{r}0.54^{*} \\
(0.19)\end{array}$ & & & $\begin{array}{r}0.50^{*} \\
(0.17)\end{array}$ & $\begin{array}{c}0.02 \\
(0.14)\end{array}$ \\
\hline$\delta$ & & & & & & & & & $\begin{array}{c}0.05 \\
(0.04)\end{array}$ & $\begin{array}{r}0.08^{*} \\
(0.02)\end{array}$ & $\begin{array}{c}0.02 \\
(0.07)\end{array}$ & $\begin{array}{l}-0.26 \\
(0.38)\end{array}$ \\
\hline $\operatorname{adj}-R^{2}$ & 0.27 & 0.23 & 0.25 & 0.20 & 0.30 & 0.27 & 0.25 & 0.21 & 0.21 & 0.18 & 0.20 & 0.13 \\
\hline DW & 1.93 & 1.95 & 2.23 & 2.25 & 2.14 & 2.15 & 2.21 & 2.24 & 2.13 & 1.96 & 2.24 & 2.11 \\
\hline
\end{tabular}

* significant at 5\% level (standard errors in parentheses)
(1) with constant $\beta_{t}$ and $N_{t}=N$
(2) with $\beta_{i}=\beta+p^{\eta}, N_{t}=N$
(3) with constant $\beta_{t}$ and $N_{t}=N\left(1-1 / p_{s, s}^{\gamma}\right)$
(4) with $\beta_{t}=\beta+p_{1}^{\eta}, N_{t}=N\left(1-1 / p^{\dagger}, t\right)$
(2) $)^{\prime}$ and $(4)^{\prime}$ is with $\beta_{t}=p^{\eta}$, ,

Table 7.5. Estimation results of the logistic, Gompertz and Bass models for the installation of double glazing in owneroccupied houses, 1978-92. 
The parameter values found in the regressions, $\beta_{\imath}$ and $\gamma$ are positive in all regressions. Furthermore, $\beta$ and $\gamma$ are significantly different from zero at the $5 \%$ significance level in the logistic and Gompertz models with constant $\beta_{k}$. The significant positive value for $\gamma$ means that the price of natural gas has a positive impact on the population of potential adopters. Surprisingly, the values for $\eta$, the elasticity of $\beta_{t}$ with respect to $p_{g a s, t}$ are not significantly different from zero at the $5 \%$ significance level. $\eta$ is even negative in the logistic and Bass models. Figure 7.6 gives the model predictions of the Gompertz model with constant $\beta_{t}$ for $\Delta A_{j t}$ for owner-occupied houses.

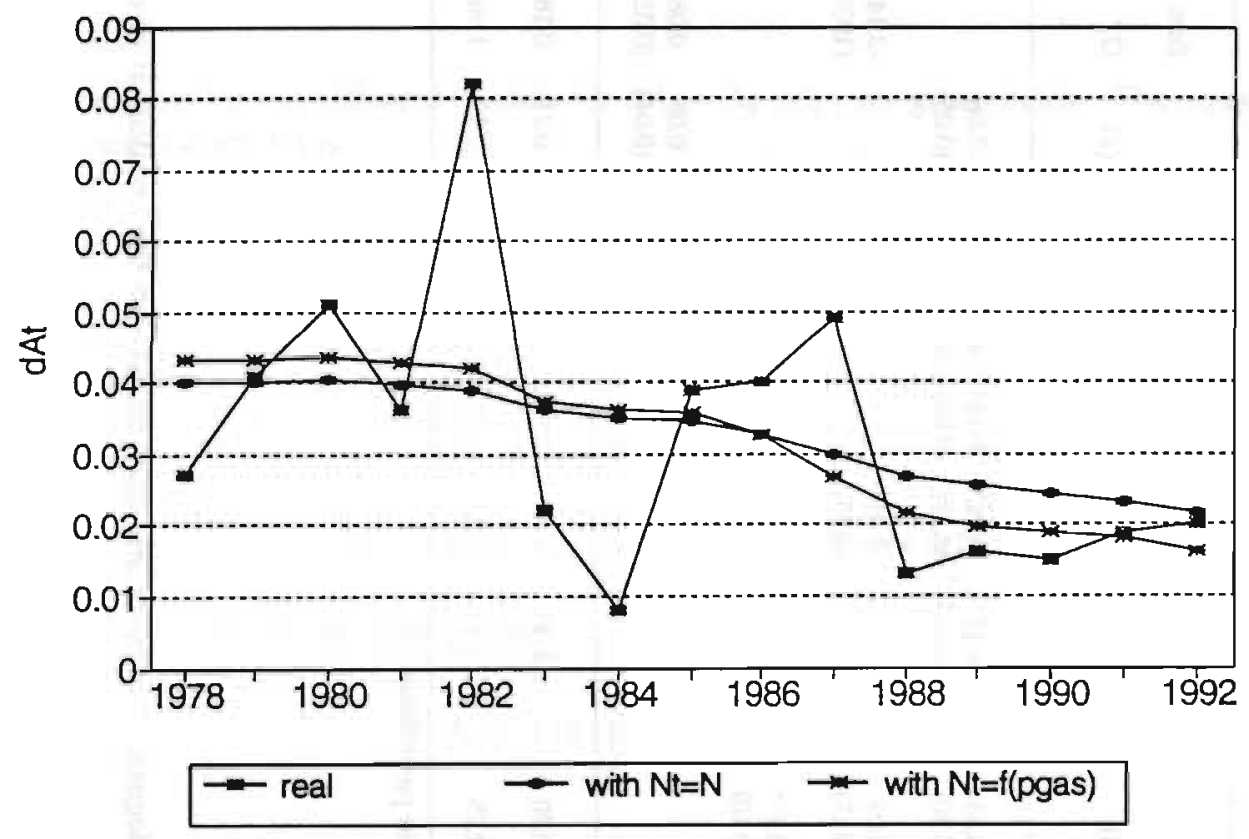

Figure 7.6. Model results of the Gompertz model with constant $\beta_{t}$ for the installation of double glazing in owner-occupied houses.

Figure 7.6 shows that none of the variants of the Gompertz model can describe empirically the strong fluctuations in $\Delta A_{t}$. It is difficult to say whether or not the price of natural gas has an impact on the installation of double glazing. The parameter value for $\gamma$ is significantly different from zero but the predictions of the Gompertz model with $N_{t}$ being a function of the price of natural gas are hardly better than with $N_{t}=N$. The relationship between the price of natural gas and the diffusion of double glazing across owner-occupied homes is certainly not a strong one, not as strong as the relationship between the effluent tax rate and the diffusion of biological waste-water treatment plants. 
We now present the model results for cavity wall insulation. We estimated the same models and model variants for cavity wall insulation. ${ }^{10}$ The results for owner-occupied houses built before 1976 are in Table 7.6.

The results for cavity wall insulation for owner-occupied houses are much better than those for double glazing. Especially the results of the Gompertz model with $N_{t}=$ $N\left(1-1 / p_{g a s,}^{\gamma}\right)$ are good. Again, it is difficult to say whether or not the price of natural gas influences the timing of thermal insulation investments. The good fit of the Gompertz model with $N_{t}=N\left(1-1 / p_{\text {gas }, t}^{\gamma}\right)$ and the significant positive value for $\gamma$ suggest that this is the case, but the high coefficient of determination for the logistic model with constant $\beta_{\text {t }}$ and $N_{t}=N$ suggest that it is not. In any case, the evidence that the price of natural gas influences the timing of thermal insulation investments, by expanding the population of prospective adopters, is stronger than for double glazing. This is what we expected: for cavity wall insulation the main benefits are in the form of savings on energy costs, which are strongly correlated with the price of natural gas.

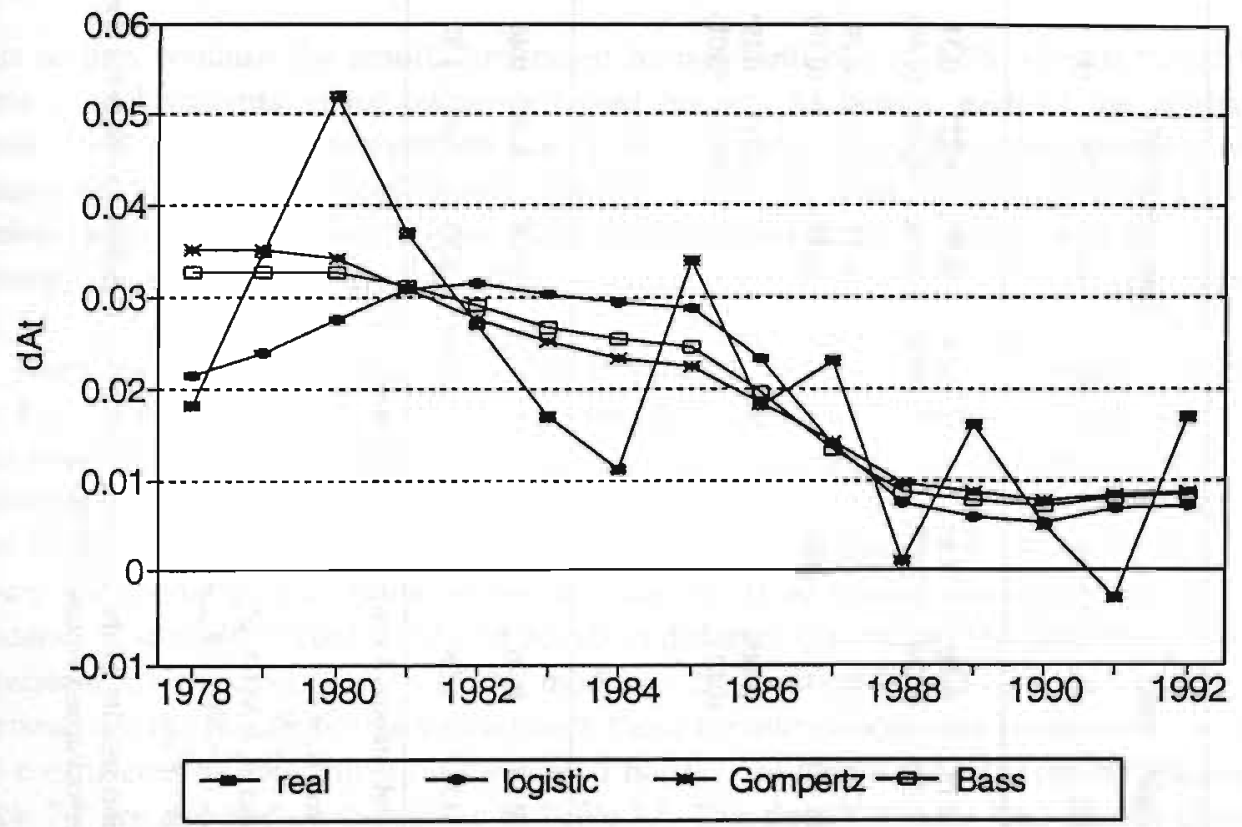

Figure 7.7. Model results of the logistic, Gompertz and Bass model with constant $\beta_{1}$ and $N_{1}=N\left(1-1 / p_{g e s, t}^{\gamma}\right)$ for cavity wall insulation in owner-occupied houses.

${ }^{10}$ We also estimated each of the models with $\beta_{t}$ and $N_{k}$ a function of $\mu_{i t}-C_{j t}$ instead of $p_{g a s, s}$. We could not estimate this variant for double glazing because of the negative values for the net annual monetary gains from adoption.) The results are similar to those in Table 7.5: significant positive values for $\beta$ and $\gamma$ in specifications (1) and (3), but somewhat lower coefficients of determination for the logistic and Gompertz models. 
logistic model

Gompertz model

Bass model
(1)
(2) (3)
(4)
(1)
(2) (3) (4)
(1) (2)
(3)
$(4)^{\prime}$

\begin{tabular}{|c|c|c|c|c|c|c|c|c|c|c|c|c|}
\hline$B$ & $\begin{array}{r}0.09^{*} \\
(0.02)\end{array}$ & $\begin{array}{l}-0.15 \\
(1.09)\end{array}$ & $\begin{array}{c}0.74^{*} \\
(0.06)\end{array}$ & $\begin{array}{r}1.65 \\
(207)\end{array}$ & $\begin{array}{r}0.06^{*} \\
(0.01)\end{array}$ & $\begin{array}{l}-0.57 \\
(0.36)\end{array}$ & $\begin{array}{r}0.22^{*} \\
(0.04)\end{array}$ & $\begin{array}{l}-0.51 \\
(0.48)\end{array}$ & $\begin{array}{c}-0.08^{*} \\
(0.01)\end{array}$ & & $\begin{array}{c}0.19 \\
(0.33)\end{array}$ & \\
\hline$\eta$ & & $\begin{array}{l}-0.37 \\
(1.17)\end{array}$ & & $\begin{array}{l}-0.27 \\
(154)\end{array}$ & & $\begin{array}{c}-0.12 \\
(0.15)\end{array}$ & & $\begin{array}{l}-0.09 \\
(0.18)\end{array}$ & & $\begin{array}{c}-34.49 \\
\text { NA }\end{array}$ & & $\begin{array}{c}-0.32 \\
(0.30)\end{array}$ \\
\hline$\gamma$ & & & $\begin{array}{r}0.14^{*} \\
(0.01)\end{array}$ & $\begin{array}{r}0.11^{*} \\
(0.01)\end{array}$ & & & $\begin{array}{r}0.14^{*} \\
(0.01)\end{array}$ & $\begin{array}{r}0.15^{4} \\
(0.01)\end{array}$ & & & $\begin{array}{r}0.15^{*} \\
(0.02)\end{array}$ & $\begin{array}{r}0.15^{*} \\
(0.02)\end{array}$ \\
\hline$\delta$ & & & & & & & & & $\begin{array}{r}0.05^{*} \\
(0.01)\end{array}$ & $\begin{array}{c}0.03^{*} \\
(0.005)\end{array}$ & $\begin{array}{r}0.10^{*} \\
(0.05)\end{array}$ & $\begin{array}{c}0.08 \\
(0.05)\end{array}$ \\
\hline $\operatorname{adj}-R^{2}$ & 0.38 & 0.16 & 0.36 & 0.42 & 0.23 & -0.06 & 0.48 & 0.46 & 0.38 & 0.42 & 0.42 & 0.44 \\
\hline DW & 0.72 & 0.75 & 1.58 & 1.64 & 2.14 & 0.95 & 1.95 & 1.97 & 1.72 & 1.32 & 1.96 & 1.98 \\
\hline
\end{tabular}

* significant at $5 \%$ level (standard errors in parentheses)

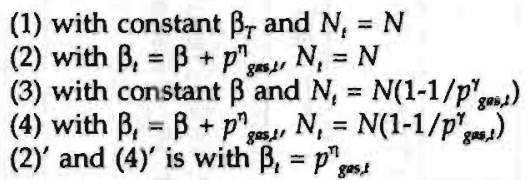

Table 7.6. Estimation results of the logistic, Gompertz and Bass models for the installation of cavity wall insulation in owner-occupied houses, 1978-92. 
Figure 7.7 gives the model predictions of the logistic, Gompertz and Bass models with $\beta_{1}$ $=\beta+p_{g a s, t}^{\eta}$ and $N_{t}=N\left(1-1 / p_{g a s, t}^{\gamma}\right)$ for $\Delta A_{2 t}$ for owner-occupied houses built before 1976. Figure 7.7 demonstrates that the model predictions of the epidemic models are quite good, except for 1980, when there was a strong increase in $\Delta A_{2 t}$, the proportion of owner-occupied houses with cavity wall insulation, and 1983 and 1984, when the increase was very low. What happened in 1983 was that it was no longer possible for house owners to receive a subsidy for thermal insulation. This may explain the small number of houses (built before 1976) that were thermally insulated in 1983 and 1984. It may also explain the peak in $\Delta A_{1 t}$ for double glazing in 1982, the last year in which house owners were able to receive an investment subsidy for double glazing (see Figure 7.6). We observed the same phenomenon for biological waste-water treatment plants: a high value for $\Delta A_{1}$ in the last year of the subsidy programme - 1987. We will come back to the effectiveness of thermal insulation subsidies in the final section.

\subsubsection{The results for rented houses}

This section contains the results for rented houses built before 1976. We estimated the same model variants as for owner-occupied houses. As before, each of the epidemic models was able to describe empirically the development of $A_{i t}$ the proportion of rented houses built before 1976 with double glazing and cavity wall insulation in the 1978-92 period (with one exception, the logistic model with constant $\beta_{t}$ and $N_{t}=N$ for double glazing). As these results are not telling us much, we will only present the model results for $\Delta A_{j t}$.

Model results of the different variants of the logistic model, the Gompertz model and the Bass model for double glazing are given in Table 7.7. The results are quite good. $\beta$ and $\gamma$ are significantly different from zero in all regressions. As for owner-occupants, the variants with $N_{t}=N\left(1-1 / p_{g a s, t}^{\gamma}\right)$ give the best results, although the results of the Gompertz model with $N_{t}=N$ are also good. $\eta$ is significantly positive in the logistic and Gompertz models but negative in the Bass model. How should we interpret this? The evidence is somewhat confusing and points in different directions. The only thing that is consistent are the good results of the models with constant $\beta_{t}$ and $N_{t}=N\left(1-1 / p_{g^{a g}, t}^{\gamma}\right)$. If we compare the results of this variant with those for owner-occupied houses, we see that the coefficients of determination for rented houses are higher. The parameter values in Table 7.7 are also higher than those in Table 7.5. This does not mean that double glazing in rented houses diffused more rapidly than in owner-occupied houses - on the contrary. In 1978, 34.3 per cent of all owner-occupied houses built before 1976 had double glazing, against 9.5 per cent of rented houses. What the high values for $\beta$ in the $1978-92$ period reflect is that in those years the diffusion of double glazing was faster for rented houses. Before 1978, the diffusion of double glazing was faster for owner-occupied houses.

The predictions of the different epidemic models with constant $\beta_{\imath}$ and $N_{t}=N(1-$ $\left.1 / p_{g a s, t}^{\gamma}\right)$ for $\Delta A_{1 t}$ for rented houses are given in Figure 7.8. 
logistic model

(1)

(2)

(3)

(4)

(1)

Gompertz model

Bass model
(3)
(4)
(1) (2)
(3) (4)

(2)

\begin{tabular}{|c|c|c|c|c|c|c|c|c|c|c|c|c|}
\hline$\beta$ & $\begin{array}{c}0.21^{*} \\
(0.04)\end{array}$ & $\begin{array}{l}-1.62^{*} \\
(0.48)\end{array}$ & $\begin{array}{r}0.50^{*} \\
(0.09)\end{array}$ & $\begin{array}{c}0.5()^{*} \\
(0.10)\end{array}$ & $\begin{array}{r}0.14^{*} \\
(0.02)\end{array}$ & $\begin{array}{l}-1.33^{*} \\
(0.25)\end{array}$ & $\begin{array}{r}0.20^{*} \\
(0.04)\end{array}$ & $\begin{array}{l}-1.33^{*} \\
(0.29)\end{array}$ & $\begin{array}{r}0.13^{*} \\
(0.06)\end{array}$ & & $\begin{array}{r}0.55^{*} \\
(0.18)\end{array}$ & \\
\hline$\eta$ & & $\begin{array}{r}0.15^{4} \\
(0.07)\end{array}$ & & $\begin{array}{c}-19051 \\
\text { NA }\end{array}$ & & $\begin{array}{r}0.10^{*} \\
(0.04)\end{array}$ & & $\begin{array}{c}0.11^{*} \\
(0.05)\end{array}$ & & $\begin{array}{l}-0.52^{*} \\
(0.13)\end{array}$ & & $\begin{array}{l}-0.13 \\
(0.07)\end{array}$ \\
\hline$\gamma$ & & & $\begin{array}{r}0.33^{*} \\
(0.04)\end{array}$ & $\begin{array}{c}0.33^{*} \\
(0.04)\end{array}$ & & & $\begin{array}{c}0.42^{*} \\
(0.12)\end{array}$ & $\begin{array}{c}0.42^{*} \\
(0.12)\end{array}$ & & & $\begin{array}{r}0.32^{*} \\
(0.04)\end{array}$ & $\begin{array}{r}0.32^{*} \\
(0.03)\end{array}$ \\
\hline$\delta$ & & & & & & & & & $\begin{array}{c}0.03 \\
(0.02)\end{array}$ & $\begin{array}{r}0.03^{*} \\
(0.02)\end{array}$ & $\begin{array}{l}-0.01 \\
(0.03)\end{array}$ & $\begin{array}{l}-0.02 \\
(0.03)\end{array}$ \\
\hline $\operatorname{adj}-R^{2}$ & 0.07 & 0.16 & 0.45 & 0.40 & 0.39 & 0.33 & 0.36 & 0.38 & 0.35 & 0.09 & 0.40 & 0.40 \\
\hline DW & 1.39 & 1.37 & 2.13 & 2.13 & 1.72 & 1.82 & 1.85 & 2.05 & 1.59 & 1.51 & 2.14 & 2.14 \\
\hline
\end{tabular}

- significant at 5\% level (standard errors in parentheses)

(1) with constant $\beta_{\text {, and }} N_{1}=N$

(2) with $\beta_{t}=\beta+p_{\text {gess, }}^{\eta} N_{t}=N$

(3) with constant $\beta_{t}$ and $N_{t}=N\left(1-1 / p_{\text {geos, }}^{y}\right)$

(4) with $\beta_{t}=\beta+p_{g o s, t}^{\eta} N_{t}=N\left(1-1 / p_{g m, t}^{\gamma}\right)$

(2)' and (4)' is with $\beta_{i}=p_{g m, i}^{\eta}$

Table 7.7. Estimation results of the logistic, Gompertz and Bass models for the installation of double glazing in rented houses, 1978-92. 

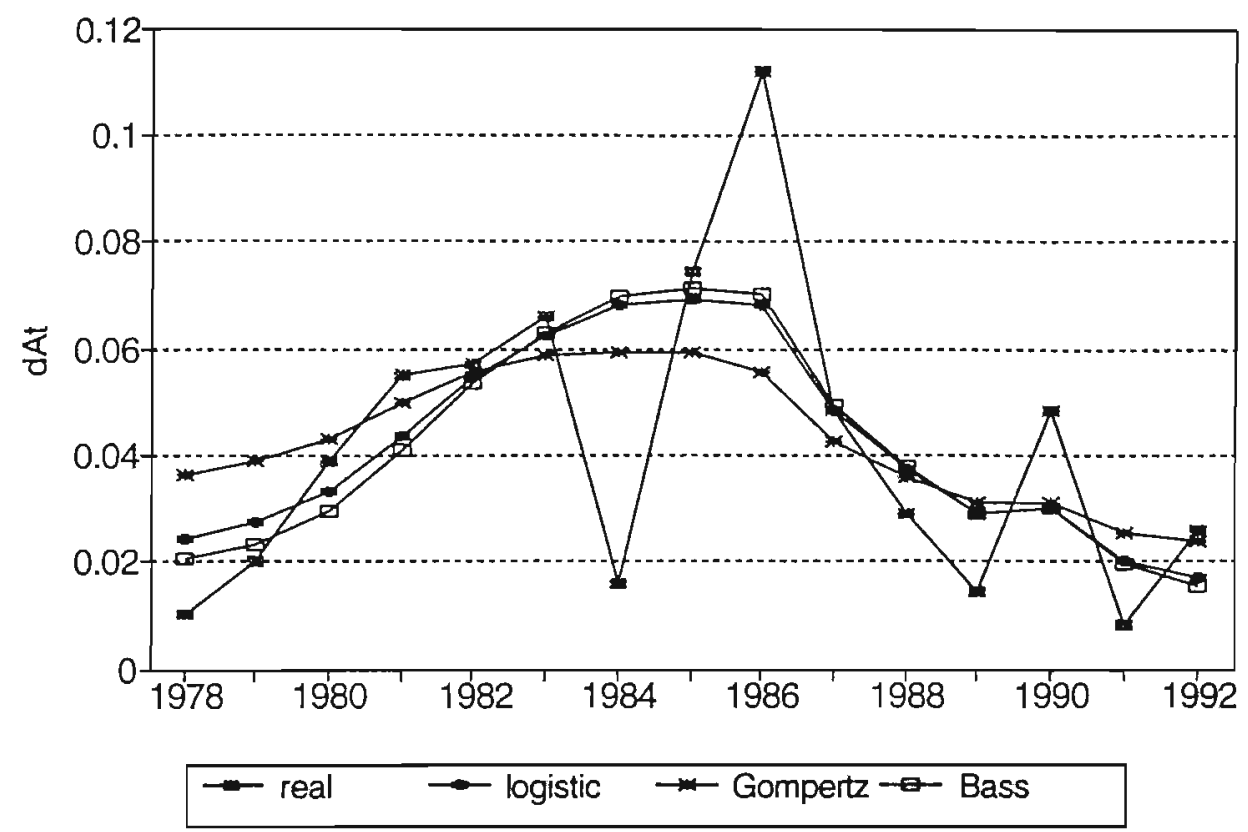

Figure 7.8. Model results of the logistic, Gompertz and Bass models with constant $\beta$, and $N_{t}=N\left(1-1 / p_{g a s, t}^{\gamma}\right)$ for the installation of double glazing in rented houses.

Figure 7.8 demonstrates that each model can describe empirically quite well the increase in the number of rented houses that are thermally insulated: the gradual increase in $\Delta A_{1 t}$ up to 1987, and the gradual decrease after 1987. They cannot explain the sharp decrease in 1984,1989 and 1991.

We now turn to the diffusion of cavity wall insulation across the population of renters. The results of the epidemic models for $\Delta A_{2 t}$ for rented houses, presented in Table 7.8, are more consistent than those for owner-occupied houses: the model variants with $N_{t}=$ $N\left(1-1 / p_{g a s, t}^{\gamma}\right)$ give good results (high coefficients of determination) whereas the variants with $N_{t}=N$ do not. $\eta$ is not significantly different from zero in all models. $\gamma$ is significantly positive at the $5 \%$ level in all regressions. The model results for $\Delta A_{2 t}$ for rented houses are in Figure 7.9. 


\begin{tabular}{|c|c|c|c|c|c|c|c|c|c|c|c|c|}
\hline & \multirow[b]{2}{*}{ (1) } & \multicolumn{2}{|c|}{ logistic model } & \multirow[b]{2}{*}{ (4) } & \multicolumn{3}{|c|}{ Gompertz model } & \multirow[b]{2}{*}{ (4) } & \multirow[b]{2}{*}{ (1) } & \multicolumn{2}{|c|}{ Bass model } & \multirow[b]{2}{*}{ (4) } \\
\hline & & (2) & (3) & & (1) & (2) & (3) & & & (2) & (3) & \\
\hline$\beta$ & $\begin{array}{r}0.10^{*} \\
(0.04)\end{array}$ & $\begin{array}{l}-0.98 \\
(0.84)\end{array}$ & $\begin{array}{r}1.12^{*} \\
(0.21)\end{array}$ & $\begin{array}{c}1.11 \\
(0.86)\end{array}$ & $\begin{array}{c}0.07^{*} \\
(0.02)\end{array}$ & $\begin{array}{l}-0.88^{*} \\
(0.44)\end{array}$ & $\begin{array}{c}0.29^{*} \\
(0.05)\end{array}$ & $\begin{array}{l}-0.95 \\
(0.50)\end{array}$ & $\begin{array}{l}-0.04 \\
(0.05)\end{array}$ & & $\begin{array}{c}0.85 \\
(0.34)\end{array}$ & \\
\hline$\eta$ & & $\begin{array}{c}0.02 \\
(0.20)\end{array}$ & & $\begin{array}{c}1.12 \\
(17.66)\end{array}$ & & $\begin{array}{l}-0.01 \\
(0.12)\end{array}$ & & $\begin{array}{c}0.06 \\
(0.10)\end{array}$ & & $\begin{array}{l}-3.12 \\
(2644)\end{array}$ & & $\begin{array}{l}-0.04 \\
(0.09)\end{array}$ \\
\hline$\gamma$ & & & $\begin{array}{c}0.13^{*} \\
(0.01)\end{array}$ & $\begin{array}{r}0.13^{*} \\
(0.01)\end{array}$ & & & $\begin{array}{c}0.13^{*} \\
(0.01)\end{array}$ & $\begin{array}{c}0.13^{*} \\
(0.01)\end{array}$ & & 15 & $\begin{array}{c}0.13^{*} \\
(0.01)\end{array}$ & $\begin{array}{c}0.13^{*} \\
(0.01)\end{array}$ \\
\hline$\delta$ & & & & & & & & & $\begin{array}{c}0.04^{*} \\
(0.01)\end{array}$ & $\begin{array}{c}0.03^{*} \\
(0.015)\end{array}$ & $\begin{array}{c}0.04 \\
(0.04)\end{array}$ & $\begin{array}{c}0.04 \\
(0.04)\end{array}$ \\
\hline $\operatorname{adj}-R^{2}$ & 0.14 & 0.05 & 0.49 & 0.45 & 0.04 & -0.01 & 0.54 & 0.50 & 0.13 & 0.17 & 0.47 & 0.48 \\
\hline DW & 0.83 & 0.84 & 1.77 & 1.77 & 0.96 & 0.96 & 2.05 & 2.10 & 1.37 & 1.32 & 1.95 & 1.96 \\
\hline
\end{tabular}

"significant at $5 \%$ level (standard errors in parentheses)

(1) with constant $\beta_{i}$ and $N_{i}=N$

(2) with $\beta_{t}=\beta+p_{\text {gats }}^{n} N_{t}=N$

(3) with constant $\beta_{t}$ and $N_{t}=N\left(1-1 / p^{\gamma}, \beta_{s, s}\right)$

(4) with $\beta_{t}=\beta+p_{g=1,}^{\prime \prime}, N_{1}=N\left(1-1 / p_{g=1, s}^{\gamma}\right)$

$(2)^{\prime}$ and $(4)^{\prime}$ is with $\beta_{t}=p^{n}$ gm,

Table 7.8. Estimation results of the logistic, Gompertz and Bass models for the installation of cavity wall insulation in rented houses, 1978-92. 


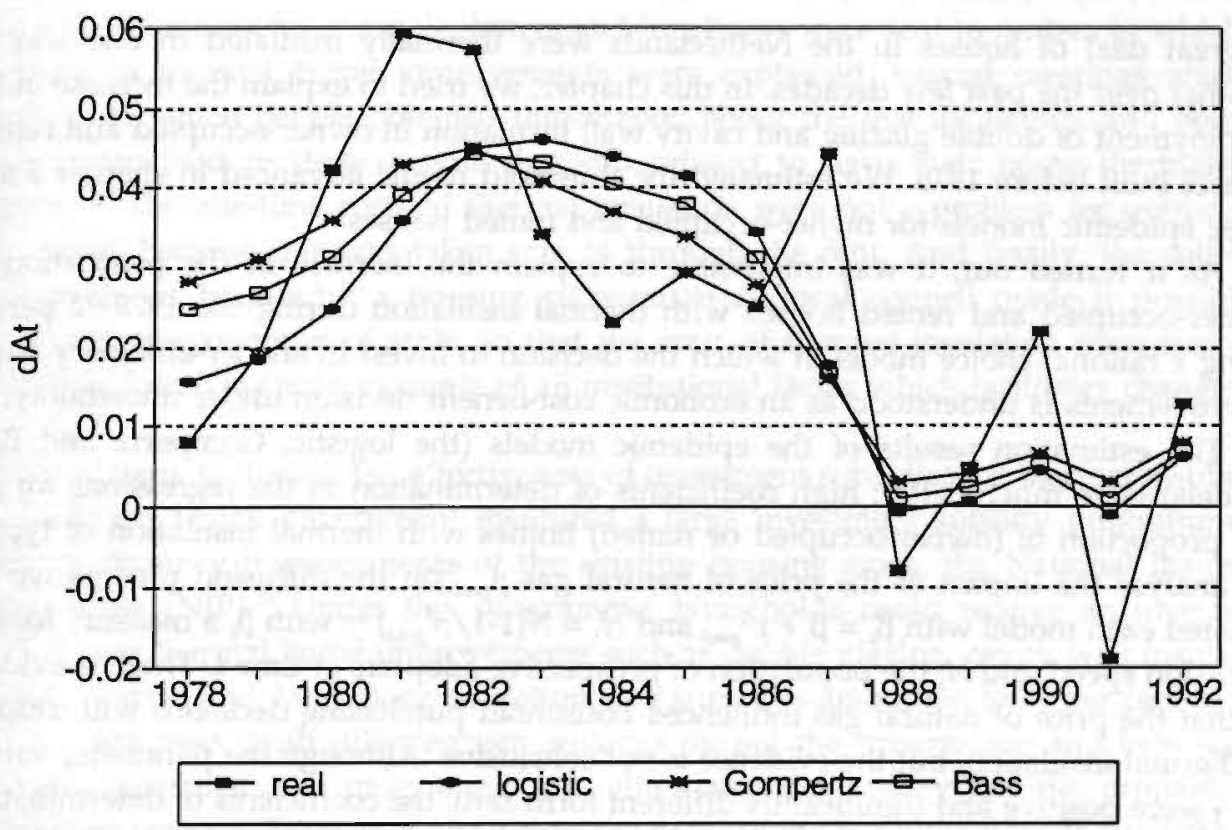

Figure 7.9. Model results of the logistic, Gompertz and Bass models with constant $\beta_{1}$ and $N_{t}=N\left(1-1 / p_{g a, t}^{\gamma}\right)$ for the installation of cavity wall insulation in rented houses.

Figure 7.9 demonstrates that the model predictions for $\Delta A_{2 l}$ for rented houses are quite good, especially those of the Gompertz model. Each model can describe the increase in $\Delta A_{2 t}$ in the first years, the decrease in $\Delta A_{2 t}$ after 1982 and the zero-growth of $A_{2 t}$ since 1988 for rented houses built before 1976. The results of the logistic model with constant $\beta_{t}$ and $N_{t}=N\left(1-1 / p_{g a s, t}^{\gamma}\right)$ are better for 1978 and 1979, whereas the results of the Gompertz and Bass models are better for the 1983-86 period.

What can we conclude from all this? For instance, what do the results tell us about the importance of information transfer and changes in the costs and benefits of thermal installation in the time-intensive adoption of double glazing and cavity wall insulation? And how effective were the subsidy programmes for energy-efficiency home improvements and the information dissemination programmes in influencing household decisions with respect to thermal home insulation? These questions will be addressed in the final section. 


\subsection{Conclusions}

A great deal of houses in the Netherlands were thermally insulated in one way or another over the past few decades. In this chapter, we tried to explain the increase in the employment of double glazing and cavity wall insulation in owner-occupied and rented houses built before 1976. We estimated the threshold model advanced in chapter 5 and three epidemic models for owner-occupied and rented houses.

As it turned out, it was impossible to explain the increase in the proportion of owner-occupied and rented houses with thermal insulation during the 1978-92 period using a rational choice model in which the decision to invest in energy-efficiency home improvements is understood as an economic cost-benefit decision under uncertainty.

The estimation results of the epidemic models (the logistic, Gompertz and Bass models) were much better: high coefficients of determination in the regressions for $A_{p}$ the proportion of (owner-occupied or rented) homes with thermal insulation of type $j$. To analyse the impact of the price of natural gas $p_{\text {gas, }}$ on the diffusion process we estimated each model with $\beta_{t}=\beta+p_{g a s, t}^{\eta}$ and $N_{t}=N\left(1-1 / p_{g a s, t}^{\gamma}\right)-$ with $\beta_{t}$ a measure for the diffusion speed and $N_{t}$ the population of prospective adopters at time $t$. There is evidence that the price of natural gas influenced household purchasing decisions with respect to thermal insulation, but the evidence is not conclusive. Although the parameter values for $\gamma$ were positive and significantly different form zero, the coefficients of determination in the regressions with $N_{t}=N\left(1-1 / p_{\text {gas }, t}^{\gamma}\right)$ were not always higher than those with $N_{t}=N$. Moreover, in one case (the Bass model for double glazing in rented houses) we obtained significantly negative values for $\eta$, the elasticity of $\beta_{t}$ with respect to the $p_{\text {gas }, t}$. In any case, the relationship between the price of natural gas and the timing of household energy-efficiency investments seems to be a weak one. Thus, the hypothesis advanced in chapter 4 that economic variables are likely to exercise an important influence on the diffusion process of consumer durables is not confirmed (nor rejected) by the analysis. Furthermore, none of the models was able to explain with any precision year-to-year changes in the proportion of houses with double glazing and cavity wall insulation during the period of investigation (1978-92). This means that a number of other factors not included in the analysis affect the exact timing of thermal insulation decisions.

If we compare the diffusion pattern of double glazing and cavity wall insulation for owner-occupied houses with those of rented houses, we find that renters were relatively slow in investing in thermal insulation but that the proportion of rented houses with thermal insulation in 1992 is not much below that of owner-occupied houses (see Figure 7.1). This is in contradiction with the common argument that the non-ownership of dwellings by occupants is an important institutional barrier to the uptake of cost-effective thermal insulation measures. Our results show that this does not hold true for the Netherlands. The proportion of rented houses with thermal insulation in 1992 is not much below that of owner-occupied houses, and in the case of cavity wall insulation it is just as high. This is probably due to the unique situation in the Netherlands in which about 40 per cent of the total housing stock is owned by non-profit housing corporations 
("woningbouwverenigingen") and local councils." These housing corporations (or cooperations) and local councils have been very active in persuading people to invest in thermal insulation: for example, letters and brochures were sent to renters in which the benefits of thermal home improvements were explained, special meetings were organised in which people obtained information about thermal insulation, and personal visits were paid to those people that still refused to have their home thermally insulated. ${ }^{12}$ The one-time costs of thermal insulation were not a problem for public renters either, because this was taken care of through the rent. And finally, the collective ownership of houses by a housing corporation or local council made it possible to benefit from economies of scale, so that the costs of thermal insulation measures were relatively low. This is an example of an institutional factor which facilitates change.

We now come to discuss the effectiveness of investment subsidies for thermal insulation. In 1978, the Dutch government instituted a large investment subsidy programme for energy-efficiency improvements of the existing housing stock, the National Insulation Programme (NIP). ${ }^{13}$ Under this programme, households could receive an investment subsidy for thermal home improvements such as double glazing, cavity wall insulation, roof insulation and, later, floor insulation. The subsidies amounted to 30 per cent of total investment costs, with differing per centages during the programme and between insulation measures. The programme was eliminated on January 1, 1988, primarily for budgetary reasons. For owner-occupants, the programme had already ended in 1983 . The total costs of the NIP programme and its predecessor, the BGSWI, amounted to DFl 2 billion (1.75 for the NIP and 0.25 for the BGWSI). Of this Dfl 2 billion, 1.8 billion was spent on investment subsidies (approximately 1 billion U.S dollars at the 1994 exchange rate). It is interesting to analyse the effectiveness of these investment subsidies in inducing households to invest in thermal insulation; to analyse whether statistically a positive relationship can be found between the subsidy programmes and the diffusion of thermal insulation. Strangely enough, this has not been attempted up until now, despite the large amount of money involved in the programme. The Dutch government did commission an evaluation of the programme in 1988 but in this evaluation study the number of grants was taken as a measure for the success of the programme. ${ }^{14}$ No at-

\footnotetext{
"In the Netherlands, the share of rented houses in 1992 was 50 per cent. About three-quarter of rented houses were owned by "woningbouwverenigingen" and local councils, so that the share of "publicly" rented houses is about 40 percent of all houses. p.8.

12 Algemene Energie Advies Raad, 1990, Het woord aan de praktijk, jaaradvies 1990, Den Haag,
}

${ }^{13}$ A predecessor of the NIP was the BGSWI, the "Beschikking Geldelijke Steun Warmte Isolatie", which started in 1974.

\footnotetext{
${ }^{14}$ Stuurgroep Nationaal Isolatie Programma, 1988, Evaluatie 10 jaar nationaal isolatie programma (Evaluation of ten year National Insulation Programme), Rotterdam.
} 
tempt was made to assess the effectiveness of the programme in influencing household decisions with respect to thermal insulation.

The way in which we analyzed the effectiveness of the subsidy programme is by estimating equations (8) - (10) with a dummy variable and an i.i.d. error term around zero added to the right-hand side. The dummy variable is the investment subsidy for thermal insulation $s_{j i}$ - where $s_{j t}$ is 0.33 if the investment subsidy is 33 per cent and zero for those years in which no subsidy was available for thermal home improvements. Included in the analysis are also the subsidies for thermal improvements of the existing housing stock under the SES programme (Subsidieregeling Energiebesparing en Stromingsenergie) of 1991 and the SEBG programme (Subsidieregeling energiebesparing bestaande gebouwen) of 1992 . The logistic model changes in:

$$
\Delta A_{j t}=\beta_{j t} A_{j t}\left(\frac{N_{j}}{N_{j t}}-A_{j t-1}\right)+\theta_{j} s_{j t}+\varepsilon_{j t}
$$

and the Gompertz model in:

$$
\Delta A_{j t}=\beta_{j t} A_{j}\left(\ln \left(N_{j t}\right)-\ln \left(n_{j-1}\right)\right)+\theta_{j} s_{j t}+\varepsilon_{j t}
$$

with $\theta_{j}$ a measure for the effectiveness of the subsidy.

The results of the logistic and Gompertz model with constant $\beta_{j t}$ and $N_{j t}=N_{j}\left(1-1 / p_{g a s, t}^{\gamma}\right)$ for double glazing are reported in Table 7.9. It shows that $\theta_{1}$, the coefficient of the effectiveness of the investment subsidy for double glazing, is positive for owner-occupants, but that the values are significantly different from zero at the $5 \%$ significance level. For renters, the value for $\theta_{1}$ is negative (but not signficantly negative) for the Gompertz model. The lower coefficients of determination (adjusted $R^{2}$ values) for the regressions with $s_{p t}$ provide further evidence that the subsidies were not an important factor in people's investment decisions. Other specifications gave similar results. On the whole, the evidence is quite strong that the subsidies for double glazing were not a significant factor, that they only had a small effect - if at all - on households' thermal insulation decisions. 


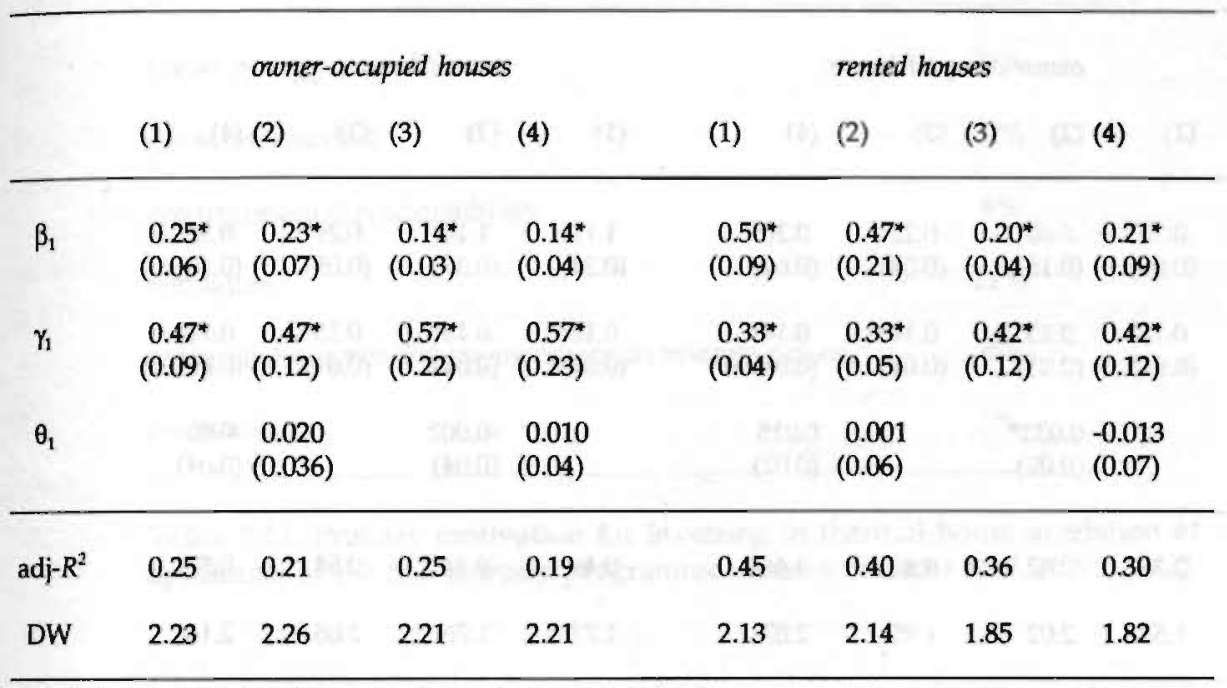

* significant at 5\% level (standard errors in parentheses)

(1) = logistic model with constant $\beta_{1 t}$ and $N_{1 t}=N_{1}\left(1-1 / p_{g=1}^{\gamma}\right)$

(2) $=$ (1) with $\theta_{1} s_{1 t}$ added to the right-hand side

(3) = Gompertz model with constant $\beta_{1 t}$ and $N_{1 t}=N_{1}\left(1-1 / p_{g=1}^{\gamma}\right)$

$(4)=(3)$ with $\theta_{1} s_{1 t}$ added to the right-hand side

Table 7.9. The effectiveness of investment subsidies for double glazing.

We also analyzed the effectiveness of the subsidies for cavity wall insulation. The results of the statistical analysis for cavity wall insulation are in Table 7.10. Again, we find that the investment subsidies for thermal insulation had a (small) positive impact on the investment decisions of owner-occupants (all estimates for $\theta_{2}$ are positive), but that this impact is not significant at the $5 \%$ significance level. Of all the models that we estimated there was only one case in which $\theta_{2}$ was significantly positive, the logistic regression with $N_{21}=N_{2}$ but this result is likely to be the result of spurious regression: the coefficient of determinations in the logistic model with constant $N_{t}$ were so low (below 0.07) that almost any variable would show up as a significant factor. The parameter values for $\theta_{2}$ for rented houses are even negative, with high standard errors. Comparison of Table 7.10 with Table 7.9 further shows that the parameter values for $\theta_{2}$ in Table 7.10 for owner-occupied houses are higher (with smaller standard errors) than those for $\theta_{1}$ in Table 7.9, which suggests that the effectiveness of investment subsidies was higher for cavity wall insulation than it was for double glazing. 


\begin{tabular}{|c|c|c|c|c|c|c|c|c|}
\hline & \multicolumn{4}{|c|}{ owner-occupied houses } & \multicolumn{4}{|c|}{ rented houses } \\
\hline & (1) & (2) & (3) & (4) & (1) & (2) & (3) & (4) \\
\hline$\beta_{2}$ & $\begin{array}{c}0.74^{*} \\
(0.06)\end{array}$ & $\begin{array}{r}0.65^{*} \\
(0.15)\end{array}$ & $\begin{array}{c}0.22^{*} \\
(0.04)\end{array}$ & $\begin{array}{r}0.20^{*} \\
(0.04)\end{array}$ & $\begin{array}{r}1.12^{*} \\
(0.21)\end{array}$ & $\begin{array}{r}1.14^{*} \\
(0.37)\end{array}$ & $\begin{array}{r}0.29^{*} \\
(0.05)\end{array}$ & $\begin{array}{r}0.36^{*} \\
(0.10)\end{array}$ \\
\hline$\gamma_{2}$ & $\begin{array}{r}0.14^{*} \\
(0.01)\end{array}$ & $\begin{array}{c}0.13^{*} \\
(0.01)\end{array}$ & $\begin{array}{r}0.14^{*} \\
(0.01)\end{array}$ & $\begin{array}{r}0.14^{*} \\
(0.01)\end{array}$ & $\begin{array}{r}0.13^{*} \\
(0.01)\end{array}$ & $\begin{array}{r}0.13^{*} \\
(0.01)\end{array}$ & $\begin{array}{r}0.13^{*} \\
(0.01)\end{array}$ & $\begin{array}{c}0.14 \\
(0.01)\end{array}$ \\
\hline$\theta_{2}$ & & $\begin{array}{l}0.033^{*} \\
(0.02)\end{array}$ & & $\begin{array}{l}0.015 \\
(0.02)\end{array}$ & & $\begin{array}{l}-0.002 \\
(0.04)\end{array}$ & & $\begin{array}{l}-0.03 \\
(0.04)\end{array}$ \\
\hline adj- $R^{2}$ & 0.36 & 0.42 & 0.48 & 0.46 & 0.49 & 0.44 & 0.54 & 0.52 \\
\hline DW & 1.58 & 2.02 & 1.95 & 2.07 & 1.77 & 1.76 & 2.05 & 2.14 \\
\hline
\end{tabular}

* significant at $5 \%$ level (standard errors in parentheses)

(1) $=$ logistic model with constant $\beta_{2 t}$ and $N_{2 t}=N_{2}\left(1-1 / p_{g \operatorname{san}}^{\gamma}\right)$

(2) $=$ (1) with $\theta_{2} s_{2}$ added to the right-hand side

(3) = Gompertz model with constant $\beta_{2 t}$ and $N_{2 t}=N_{2}\left(1-1 / p_{g a s,}^{\gamma}\right)$

$(4)=(3)$ with $\theta_{2} s_{21}$ added to the right-hand side

Table 7.10. The effectiveness of investment subsidies for cavity wall insulation.

How reliable are the above results? Due to the fact that most of the estimates are not significantly different from zero, we cannot attach much value to these estimates. When we compare the results, however, with the findings of a recent study about the effectiveness of the SES subsidy programme of 1991, they appear to be quite reasonable. In the evaluation study by the NEI of the SES programme, applicants of the programme were asked about the primary reason for investing in thermal insulation. ${ }^{15}$ The results are in Table 7.11.

According to Table 7.11, the subsidy programme for thermal insulation was the primary cause for investing in thermal insulation for only 11 per cent of the applicants. Lower energy costs and personal comfort were far and away the most important causes for investing in energy-efficiency home improvements. That personal comfort is an important factor is something that emerged from our statistical analysis in section 2 . The figure of 11 per cent corresponds more or less with our own results: a weak positive influence of the investment subsidies on households' thermal insulation decisions.

${ }^{15}$ L. Beumer, E.C. van der Giessen, R. Olieman and G.R. Otten, 1993, Evaluatie van de isolatieregeling (SES 1991) en de ketelregeling (SNEV), NEI, Rotterdam. 
lower energy costs

personal comfort

environmental responsibility

subsidies

safeguard against future increases in energy prices

renovation
$39 \%$

$32 \%$

$6 \%$

$11 \%$

$4 \%$

$3 \%$

Table 7.11. Primary motivation for investing in thermal home insulation of applicants of the SES subsidy programme. Source: Beumer et al. (1993, p.42).

The low effectiveness of the subsidies does not correspond with the results of the statistical analysis in the same NEI study which reports an effectiveness of the subsidy for double glazing of 11 per cent, an effectiveness of the subsidy for cavity wall insulation of 50 per cent, and for roof and floor insulation an effectiveness of even 80 per cent. ${ }^{16}$

To compare our own results with those of the NEI-study we calculated the relative contribution of the investment subsidy to the increase in proportion of houses with thermal insulation. We multiplied the average subsidy $s_{j}$ with the average value for $\theta_{j}$ and divided this by the average increase in the proportion of (owner-occupied or rented) houses during the years of the subsidy programmes. What we found was, for owneroccupied houses, a relative contribution of the subsidy for double glazing to the increase

${ }^{16}$ The reason why the researchers find such a high effectiveness becomes clear if we look at the way in which the effectiveness of the SES subsidy programme is determined. The researchers estimated the proportion of houses with double glazing, cavity wall insulation, roof insulation and floor insulation in 1991 on the basis of historical data about the proportion of houses with thermal insulation. To calculate the proportion of houses with thermal insulation in 1991 without the SES subsidy programme, they used the following specification: $A_{j \mathrm{i}}=b_{0} t^{b t}$ where $t=1981 . .1991$ and $b_{0}$ and $b_{1}$ parameters. The predicted value for $A_{j}$ in 1991 was then compared with the real value for $A_{j}$ in 1991, and the difference between the two was taken as a measure of the effectiveness of the subsidy scheme. But instead of using the real value for $A_{j}$ in 1991, they used the average of $A_{i}$ in 1991 and 1992 for owner-occupied houses, and for rented houses even the value for $A_{j}$ in 1992 . The reason for doing so was to take into account a delay in the actual installation. Furthermore, when the difference between the predicted value for $A_{j}$ in 1991 and the 'real' value for $A_{j}$ in 1991 was negative, they assumed that the difference between the estimated and 'real' $A_{j}$ was zero. It is not surprising that the subsidies came out up as highly effective. The results are upwardly biased in three possible ways: (i) by using the above specification for $A_{j t}$ (which is a concave function for $b_{1}<1$ ) instead of a sigmoid curve, (ii) by using the 1992 value for the proportion of rented houses with thermal insulation in 1991 (and the average of 1991 and 1992 for owner-occupants), and (iii) by neglecting the negative differences between the predicted value for $A_{j}$ in 1991 and the 'real' value of $A_{j}$ in 1991. 
in $A_{1}$ of 8.4 per cent and a relative contribution of the subsidy for cavity wall insulation to $\Delta A_{2}$ of 24.9 per cent. These estimates correspond quite well with the estimate of 11 per cent reported in Table 7.11. For renters we did not find a positive contribution of the subsidy programmes to $\Delta A_{1}$ and $\Delta A_{2}$. The estimates of the relative contribution of the subsidies should be viewed with caution, however, as they are based on insignificant parameter values.

All this leads to the conclusion that the subsidy programmes for thermal insulation only had a limited impact on households' thermal insulation decisions. What the programmes did, for the most part, was to provide receivers with a 'windfall gain'.

What about the effectiveness of the information about the benefits of thermal insulation supplied by government authorities? Can we draw any conclusions with respect to this? Unfortunately not. It is not possible to assess statistically the influence of information dissemination by public authorities. This is because information is supplied by public authorities in various forms through various media (television, brochures, etc.), the effectiveness of which is likely to differ. We also do not have figures about public expenditures on information dissemination - which could be used as proxy for IS, information supply. In addition, it is not clear how exactly (mathematically speaking) information supply reduces uncertainty and influences people's attitudes and preferences. We do feel however that the information provided by housing councils was an important factor in the thermal insulation of rented houses. Without the efforts of these councils, the proportion of rented houses with thermal insulation probably would have been much lower. 


\section{Appendix 7.A: A threshold diffusion model with differing ren- tability requirements}

In the model of section 1, a household invests in thermal insulation measures when the reservation price of the thermal insulation technology (double glazing or cavity wall insulation) exceeds the costs of adoption. In the model, all households are identical with respect to the rentability requirements of the investment (the expected profitability, however, differs between households). This appendix advances a model in which the rentability requirements for thermal insulation investments differ among households. In the model, only those households for which the expected rentability, $r_{1}$, exceeds the demanded or required rentability, $r$, will be adopters.

The expected rentability of an investment in thermal insulation can be solved from the following equation:

$$
C_{i}=\sum_{i=1}^{1} \frac{E R p_{g a s, t+k}+K_{t+k}}{\left(1+r_{t}^{e}\right)^{k}}
$$

with $r_{l}$ the expected rentability of a thermal insulation investment at time $t$ and $l$ the economic life time of the technology (we have dropped index $j=1,2$ for simplicity).

If we assume that the expected price of natural gas is constant over the entire life time of the technology and $K_{t+k}=K_{\nu}$ the above equation can be rewritten as follows:

$$
\frac{C_{t}}{E R p_{g a s, t}+K_{t}}=\left(1-\frac{1}{\left(1+r_{t}\right)^{l}}\right)\left(\frac{1+r_{t}^{e}}{r_{t}^{e}}\right)-1
$$

Of course, this is really an awkward expression. However, for large enough $\left(1+r^{e}\right)^{\prime}$ (which is when $l$ is large and $r_{l}$ is high), the above equation changes in something more comfortable:

$$
\frac{C_{i}}{E R p_{g a s, t}+K_{i}}=\frac{1}{r_{i}^{\prime}}
$$

From this equation we can derive a distribution for $r_{\nu}$ the expected rate of return of a thermal insulation investment (which includes a mark up for any utility-enhancing effects). For instance, if $E R$ and $K_{i}$ are normally distibuted and independent, then $r_{1}$ is distributed according to a normal distribution:

$$
r_{i}^{e}-N\left(\mu_{r, t}, \sigma_{r, t}^{2}\right)
$$

with $\mu_{r^{\prime}, t}=\frac{\mu_{E R} p_{g a s, t}+\mu_{K, t}}{C_{1}}$ and $\sigma_{r, l}^{2}=\frac{\sigma_{E R}^{2} p_{g a s, t}^{2}+\sigma_{K,}^{2}}{C^{2}}$ 
If we furthermore assume that the demanded rate of return is distributed according to a normal distribution with mean $\mu_{r *}$ and variance $\sigma_{r}^{2}$, then the proportion of the population that will be adopters of the thermal insulation technology at time $t$ is:

$$
A_{t}=P\left(r^{d}>r_{t}\right)=\Phi\left(\frac{\mu_{r}-\mu_{r_{1}}}{\sqrt{\sigma_{r^{d}}^{2}+\sigma_{r_{r_{1}}}^{2}}}\right)
$$

The higher $r_{1}$ and the lower $r$, the higher will be $A_{t}$, the proportion of houses with thermal insulation. Note that we have two parameters we did not have in the original model: $\mu_{r,}$ and $\sigma^{2}$

Reduction of uncertainty can be brought into the model by making $r$, the required rate of return, a function of $\rho$ (for instance, $r_{1}^{d}=r^{t}+\rho_{1}$ with $\partial \rho_{t} / \partial t<0$ ) and different expectations with respect to the price of natural gas could be introduced in the model by assuming a distribution for $p_{g a s, l+k}$ $(k=1,2 \ldots)$. A disadvantage of the $r$ model is that we must estimate two more parameters.

\section{Appendix 7.B: Description of the data}

\section{price of natural gas}

The price of natural gas is the price for households per $\mathrm{m}^{3}$ according to EnergieNed. This price includes value added taxes and environmental taxes. The development of $p_{g a, t}$ is given in the figure below.

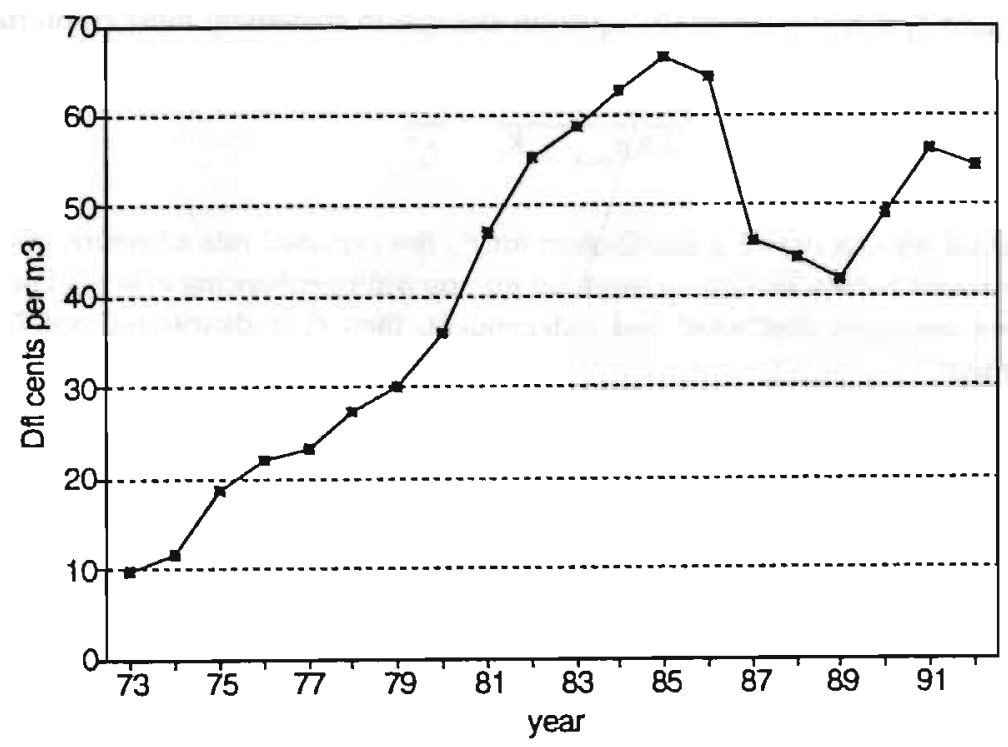




\section{costs of thermal home insulation}

Unfortunately, we did not have detailed information about the costs of thermal insulation technologies during the 1978-92 period. Information on the costs of double glazing and cavity wall insulation was available only for the years 1976, 1979, 1984 and 1992. The costs of double glazing and cavity wall insulation for the other years are calculated through linear intrapolation of the costs in 1976, 1979, 1984 and 1992. The below figure gives the costs in Dfl per $\mathrm{m}^{2}$ of insulation area for 1976, 1979, 1984 and 1992, based on NEI (1977), NWR (1979), SBR (1985) and CEA (1993).

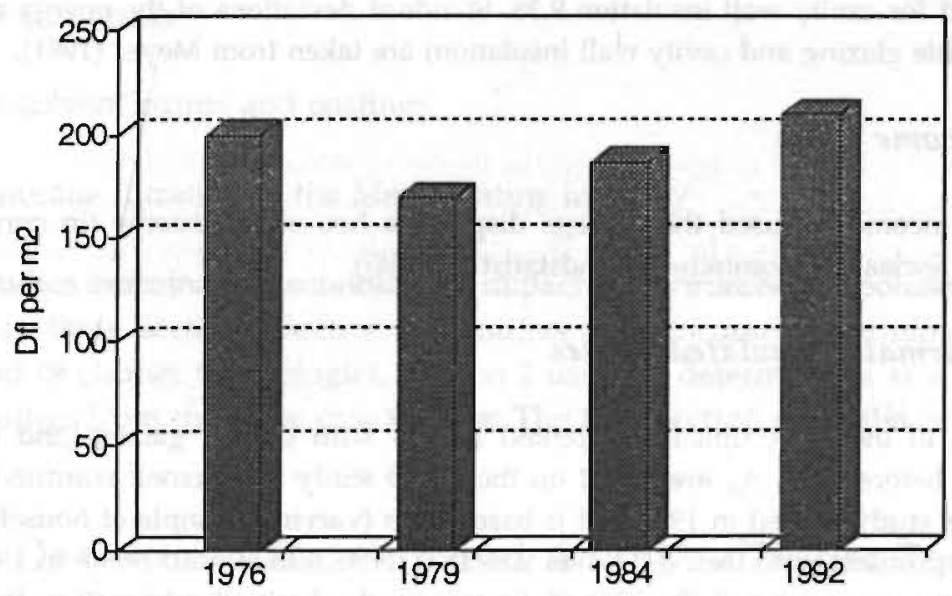

double glazing

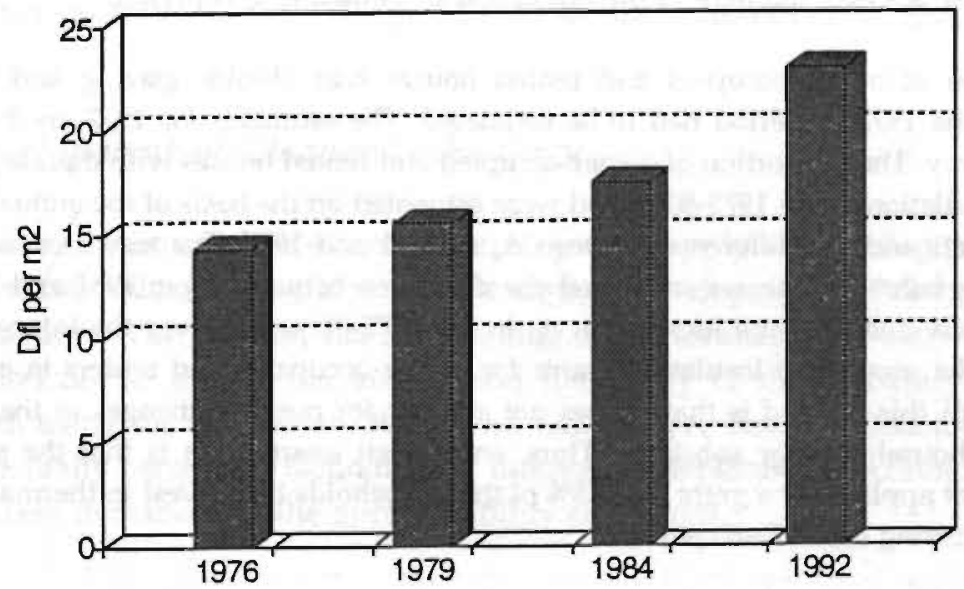

cavity wall 


\section{imputed annual rental rate}

The imputed annual rental rate, $R_{j \prime}$ is calculated on the basis of the nominal interest rates for private loans from the annual reports of De Nederlandse Bank and service lives of 15 years for double glazing and 25 years for cavity wall insulation.

\section{energy savings from thermal insulation}

The average energy savings in $\mathrm{m}^{3}$ of natural gas per $\mathrm{m}^{2}$ of insulation area are simply the geometric mean of energy savings reported in the studies, referred to earlier. For double glazing, this is $\mathbf{2 2 . 8 3}$ and for cavity wall insulation 9.38 . Standard deviations of the energy savings (5.8 and 1.3 for double glazing and cavity wall insulation) are taken from Meyer (1981).

\section{household income}

For household income we used the average disposable household income (in current prices) reported in the Sociaal-Economische Maandstatistiek (CBS).

\section{number of thermally insulated houses}

The proportion of owner-occupied and rented houses with double glazing and cavity wall insulation built before 1976, $A_{j}$, are based on the NIPO study "onderzoek warmte-isolatie van woningen". This study started in 1981 and is based on a (varying) sample of households in the Netherlands. A problem with the NIPO data was that there was a trend break in 1985 . To deal with this problem, we corrected the 1981-85 figures on the basis of information from another survey of the proportion of houses with thermal insulation, the "basisonderzoek aardgas kleinverbruik" (BAK). The way in which we have done this is by dividing the NIPO data in the 198185 period by the average quotient of the NIPO and BAK data in this period.

The proportion of owner-occupied and rented houses with double glazing and cavity wall insulation in the 1977-81 period had to be estimated. The estimates for 1977 are based on the 1977 BAK survey. The proportion of owner-occupied and rented houses with double glazing and cavity wall insulation in the $1978-80$ period were estimated on the basis of the annual number of insulation grants and the difference between $A_{j t}$ in 1981 and 1977. The way in which we have done this is as follows. First, we calculated the difference between $A_{j}$ in 1981 and 1977 for $j=$ 1 ,2. Then we divided the total increase in $A_{j}$ in the 1977-91 period over the intervening years according to the number of insulation grants for owner-occupants and renters in each year. A disadvantage of this method is that it does not account for possible changes in the application behaviour of households for subsidies. Thus, an implicit assumption is that the proportion of households that applied for a grant (say $75 \%$ of the households that invest in thermal insulation) was constant during the $1978-80$ period. 


\section{Chapter 8}

\section{Three Case Studies of Cleaner Technologies}

This chapter analyzes the development and adoption of environmentally beneficial technologies from an empirical point of view in three case studies: ${ }^{1}$

\section{- CFC substitutes}

- Low-solvent paints and coatings

- Membrane filtration in the Metal-Plating industry

The case studies examine the technological impact of environmental policies. The chapter is divided in three sections. Section 1 identifies and discusses determinants of supply and demand of cleaner technologies. Section 2 uses the determinants as a framework to discuss findings from the three case studies. The final section gives the conclusions.

\subsection{The Decision to Develop and Adopt a Cleaner Technology}

This section identifies and discusses the factors that influence the decision to develop and adopt an innovation in cleaner technology. To this end, we make use of the economic literature on technological change and the available literature on cleaner technologies.

\subsubsection{Development of Cleaner Technology}

In the economic literature, the decision to develop and supply a technological innovation is seen as an economic decision, in which the costs of developing a technological innovation are compared with the benefits from selling the innovation. The innovator benefits are a function of the size of the market and the ability of the innovator to reap the benefits from using the innovation. Below, we will analyze how the decision to develop a (environmentally beneficial) technological innovation depends on technological opportunities, market demand and the appropriability conditions.

${ }^{1}$ This chapter is largely based on a research project with the Institute of Environmental Affairs (IVM) for the Dutch ministries of the Environment and Economic Affairs. Earlier results have been published in Environmental and Resource Economics and the book Economic Incentives and Environmental Policies, edited by J.B. Opschoor and R.K. Turner (Kluwer, 1994). 


\section{Technological Opportunities}

The technological opportunities to develop a particular technology for a certain environmental problem differ for each problem, industry and firm. They are closely related to the existing pool of knowledge - that is the whole of fundamental scientific knowledge and the knowledge that is embodied in machines, human beings and organizations. Such knowledge is not immediately available or free of charge. Research effort and money are needed to draw on these technological opportunities, and there is always the risk that a project will fail, either technically or commercially.

The technological capabilities to develop an innovation also differ among firms. These capabilities are related to the size and nature of the organization's knowledge base, which is shaped by its past activities. In actual practice, innovations are developed by certain firms, both within and outside the user sector. Process innovations are usually developed by special suppliers. Only the more knowledge-intensive sectors, such as the chemical and the advanced electrotechnical industries, have the capabilities to develop cleaner production processes, either independently or with the help of special suppliers. Product innovations are usually developed by the manufacturers of the products.

\section{Market Demand}

The willingness to innovate depends on the size of the anticipated market for an innovation. As a rule, the development of a new, cleaner technology for a firm's own own use is not profitable. The demand for cleaner production processes depends on the opportunities and willingness of polluting companies to purchase cleaner techniques and to incorporate these in their production process. The demand for cleaner production processes is realised mainly through environmental regulation, since cleaner production generally does not contribute to the sales of products but only increases costs. ${ }^{2}$ The demand for cleaner consumer products occurs more easily through the market without government intervention and is a stimulus for firms to develop these products.

Although environmental policy has become stricter, many firms that supply cleaner technologies face insecure sales, due to the unchallenging character of regulatory standards and uncertainty about environmental regulations. On the other hand it is clear that strongly emerging environmental awareness in general, increasing societal pressure, and anticipated stricter environmental policies enlarge the sales outlook for cleaner processes and products. In addition, firms that have developed cleaner techniques can try to influence policy makers to prescribe their technology to polluters or to tighten environmental regulation.

${ }^{2}$ Environment-saving technologies do not always raise costs. The literature contains numerous examples of cleaner techniques that lead to cost reductions (D. Huisingh, L. Martin, H. Hilger and N. Seldman, 1986, Proven Profits from Pollution Prevention, Institute for Local Selfreliance, Washington D.C.). Profitable environment-saving techniques include, especially, recycling systems, energy conservation, and all kinds of improvements relating to "good housekeeping". This has inspired some governments to Pollution-Prevention-Pays Programs - for example, the PRISMA project in The Netherlands. 


\section{Appropriability Conditions}

If a firm is to engage in R\&D and to develop an innovation, it must be able to appropriate some of the benefits from using the innovation. Imitations by competitors undermine this. The danger of imitation is generally high because the knowledge which is embodied in a new technology becomes available, at least in part, to others when this technology is introduced into the market; knowledge which usually can be reproduced or used at much lower development costs. The benefits from the innovation may also be reaped by non-competitors like suppliers and distributers that may command a high price for their products or services. Thus, the decision to develop an innovation depends on the appropriability conditions, i.e. the means of capturing and protecting the competitive advantages of new and improved products or processes. ${ }^{3}$

Richard Levin (1986) distinguishes the following appropriability conditions: i) patents, as a means to protect from imitation and as a means to receive royalties, ii) secrecy, iii) the technical lead on competitors, iv) learning curve effects, and v) the extent to which a strong market position can be built up through reputation or the set-up of distribution channels. ${ }^{4}$ Dosi (1988a) adds scale economies to these factors. ${ }^{5}$ Appropriability conditions differ according to the type of innovation. Research by Levin and others showed that technical lead and learning effects, along with additional marketing efforts, are the most important appropriability mechanisms for product innovations, whereas learning curve effects, secrecy and technical lead are most important for process innovations. Patents are additional appropriability conditions in most cases. They are important in some industries, such as the chemical industry and mechanical equipment industries, as well as for smaller companies.

To our knowledge, no specific research into the appropriability conditions of environment-saving technological innovations has been carried out. When the appropriability conditions for certain types of cleaner technologies are inadequate, this may be reason for government to lengthen patent life, to conduct or finance research itself, or to stimulate cooperation between companies.

\subsubsection{Adoption of Cleaner Technology}

We now turn to the determinants of the decision to adopt a technological innovation. As indicated, government policy is an important factor; coercion in the form of environmental standards is often necessary for cost-increasing pollution control technologies to be adopted. However, government policy is not the only factor. There are usually many

${ }^{3}$ Richard C. Levin, 1986, A New Look at the Patent System, American Economic Reoiew AEA papers and proceedings, 76: 199-202.

${ }^{4}$ Ibid.

${ }^{5}$ Dosi, Giovanni, 1988a, The Nature of the Innovation Process, in Giovanni Dosi, Chris Freeman, Richard Nelson, Gerald Silverberg and Luc Soete (eds.), Technical Change and Economic Theory, London: Pinter Publishers, 221-238. 
technical solutions to deal with an environmental problem and comply with regulations. Which solution will be chosen by individual firms and consumers depends on the price and performance characteristics of the different options, on user knowledge about product characteristics, and on the risk and uncertainty as to the economic consequences of the employment of a new technology. Thus, to understand whether or not (and at what time) a potential adopter will purchase the innovation, we must look at the price and quality of the innovation, the valuation of service characteristics by potential adopters, information distortions and risk and uncertainty as possible barriers to the uptake of a new technology. As explained in chapter 4, the diffusion process is governed by changes in the above factors, together with changes in the adopter environment. Below, the three identified factors on adopter purchasing decisions are examined in more detail.

\section{Price and Quality}

The price and quality (meaning the service characteristics) of the innovation determine to a large extent its costs and benefits, and, accordingly, its attractiveness for a potential user. These costs and benefits may involve different elements (e.g., the costs of purchasing the technology, implementation costs, financial costs, operating costs, and benefits such as improvement of the firm's public image and consumer satisfaction). The willingness to adopt cleaner techniques depends on the extent to which they increase costs and decrease profits. With respect to these costs and benefits, firms and consumers are considered separately.

For firms, the cost consequences of adopting cleaner technologies differ considerably. They depend not only on the purchasing price of the technology but also on the size, nature and age of the production process. Smaller firms often experience relatively high pollution control costs as a result of scale disadvantages. On the other hand, the environmental aspects of production and products play an increasingly important part in decision-making. A bad environmental reputation may have a negative effect on the company's sales and may lead to personnel problems (such as problems of motivation or difficulties in hiring people). However, such stimuli are still rather weak.

For consumers, the purchase of a cleaner product may also be hindered by price and quality characteristics. An environmentally hazardous product may be superior to its cleaner alternative in a number of respects. There is also opportunity for "free-rider" behaviour of individual consumers, who may decide to benefit from changes in purchases and behaviour of others, rather than making these changes themselves. On the other hand, consumer willingness to buy cleaner products is growing.

\section{Knowledge and Information}

For the adoption of new technologies, transfers of knowledge and information are necessary. There are numerous problems relating to knowledge and information that hinder the adoption of cleaner technology. Apart from being unaware of the ecological damage resulting from their business activities, firms often do not know which cleaner technologies are available, or where to go to for information about the technologies, or 
about the kinds of technical and financial support available. Small firms in particular face these problems. In addition, firms often feel the need for independent advice from external sources.

The transfer of knowledge and information may be realised in several ways through direct contacts with suppliers, demonstration projects, professional journals, informal contacts, data banks, congresses and trade fairs, or special intermediaries such as consulting firms.

Buyers of environment-friendly products also face problems relating to knowledge and information. Consumers have little knowledge of the environmental effects of their consumption and behaviour. Furthermore, it is almost impossible for consumers to compare the environmental aspects of products, even if product information is given.

\section{Risk and Uncertainty}

Many firms do not apply cleaner techniques because of the uncertainty and associated technical and economic risks. The adoption of a certain technique may require change in the production routines and the organization of work (new functions, jobs, rewards, etc.) and may meet with both managerial and worker resistance. Moreover, personnel must gain knowledge of and experience with new machines. Process-integrated techniques that lead to radical changes in the production process, particularly involve much risk and uncertainty. ${ }^{6}$ Firms differ in their risk attitudes and in their perceptions of technical and economic risks.

\subsection{Empirical Results from three Case Studies}

In this section we use the determinants identified in section 1 to discuss development and adoption of three environmentally beneficial technologies. The technologies are CFC substitutes, low-solvent paints and coatings, and membrane technology in the metalplating industry. The results are based on the research project "Instrumenten voor de stimulering van milieutechnologie" (Instruments to stimulate clean technology) with the Institute for Environmental Studies (IVM). Although the study focusses on the Netherlands, the results are believed to apply to other Western countries as well. The research involved an extensive literature survey of the technologies as well as interviews with suppliers and (potential) adopters of the innovation. ${ }^{7}$ Although the followed approach provided much qualitative information about the factors influencing the innovation and adoption of these technologies, it was not possible to assess the importance of the indi-

\footnotetext{
${ }^{6}$ Hartje and Lurie, 1984, op cit.
}

${ }^{7}$ A more detailed description of the case studies is in Rene Kemp, Xander Olsthoorn, Frans Oosterhuis and Harmen Verbruggen, 1991, Instrumenten voor de stimulering van milieutechnologie (Policy Instruments to Stimulate Cleaner Technology), Milieutechnologie, 1991/5. VROM, Leidschendam. 
vidual factors in a quantitative way. Despite this, the adopted perspective proved to be useful. Some conclusions with respect to the technological impact of government policies can be drawn from the case studies.

\subsubsection{CFC substitutes}

Chlorofluorocarbons, abbreviated to CFCs, have been applied in a broad range of products ever since their invention in the 1930s. Originally developed as coolants, they have also been used on a large scale as aerosol propellants, foam blowers, sometimes also as insulators, and as solvents in a range of cleaning applications in the metal and electrotechnical industries. An overview of the most important uses of CFCs and halons is in Table 8.1.

\begin{tabular}{lll} 
Type & Chemical formula & Application \\
\hline CFC-11 & $\mathrm{CCl}_{3} \mathrm{~F}$ & Aerosols, foams \\
CFC-12 & $\mathrm{CCl}_{2} \mathrm{~F}_{2}$ & Refrigerators, air conditioning, foams \\
CFC-113 & $\mathrm{CClF}_{2} \mathrm{CCl}_{2} \mathrm{~F}_{2}$ & Degreasing and chemical cleaning \\
Halon 1301 & $\mathrm{CF}_{3} \mathrm{Br}$ & Fire extinguishers (stationary) \\
Halon 1211 & $\mathrm{CF}_{2} \mathrm{BrCl}$ & Fire extinguishers (mobile)
\end{tabular}

Table 8.1. The most important CFCs and halons and their use. Source: Volder and Vis (1990). ${ }^{8}$

Important properties of CFCs are their low toxicity and high level of stability (they are, for instance, non-flammable). However, as a result of this stability, CFCs can reach the ozone layer once they have entered the atmosphere. There they destroy the ozone which protects the earth from ultraviolet rays. CFCs also contribute to global warming.

The suspection that CFCs destroy the ozone layer at high altitudes was first formulated by Rowland and Molina in their 1974-article in Nature. This article was the cause for world-wide concern and led to the ban in the United States in 1978 of the use of CFCs in aerosol sprays. The increasing scientific evidence of the ozone-depleting effects

\footnotetext{
'Volder and Vis, 1990, Produktie, verbruik en emissies van CFKs in Nederland (Production, use and emissions of CFCs in the Netherlands), Den Haag.
} 
of CFCs and halons also led to an international agreement to limit CFC-emissions in 1987 in Montreal. The Montreal Protocol compelled a reduction of the production and use of CFCs of $20 \%$ in 1994 and 50\% in 1998, measured against 1986 levels. This protocol was amended in June 1990 in London. In the London Protocol, countries agreed to end the production and use of all fully halogenated hydrocarbons, including three halons and carbon tetracloride (an organic solvent), by the year 2000 (the use of methyl cloroform, another organic solvent, had to be stopped by 2005). The signatories further promised to stop using HCFCs (newly created CFCs with a lower ozone-depleting potential) before 2040, and preferably before 2020 .

It is expected that about one-third of the current CFC market will disappear as a result of the transition to non-CFC technologies, such as the wider use of ammonia as coolant or greater use of carbon dioxide instead of halons in fire extinguishers." For other CFC applications a shift to "CFC-likes" will take place. These consist of hydroclorofluorocarbons (HCFCs), so-called 'soft' CFCs having a low ozone-depletion potential, and hydrofluorocarbons (HFCs), which do not contain chlorine or bromine and therefore do not affect the ozone layer. The use of CFC-likes is expected to replace one-third of current CFC-use. Another reduction of one-third will be achieved through a more careful use of these substances, so that unnecessary loss is avoided.

A transition away from CFCs is currently taking place. In Europe, the amount of CFCs in use in 1991 was half of that in the 1986. In 1991, CFC use for aerosols was $11 \%$ of the 1986-level. Table 8.2 demonstrates that CFC use in the EC decreases in all but one area, refrigeration where it increased with $4 \%$.

\begin{tabular}{lcccccc}
\hline & 1986 & 1987 & 1988 & 1989 & 1990 & 1991 \\
\hline Aerosols & 100 & 100 & 80 & 35 & 15 & 11 \\
Refrigeration & 100 & 102 & 103 & 108 & 100 & 104 \\
Foams & 100 & 112 & 120 & 111 & 97 & 87 \\
$\begin{array}{l}\text { Solvents and } \\
\text { Miscellaneous }\end{array}$ & 100 & 104 & 11 & 100 & 90 & 76 \\
\hline Total & 100 & 104 & 98 & 73 & 58 & 51 \\
\hline
\end{tabular}

Table 8.2. CFCs in use in EC countries $(1986=100)$. Source: Financial Times, 2-91992 , based on EFCTC report to the EC commission.

${ }^{9}$ UNEP, 1989, Technical Progress on Protecting the Ozone Layer. 


\subsubsection{Factors influencing the development of CFC substitutes}

Worldwide there are some twenty CFC manufacturers, six of which account for the bulk of the CFC production. These are large chemical concerns, part of the 'science-based' sector, which has ample technological opportunities to develop new substances and products. These companies have mainly focussed their attention on the soft CFCs, continuing in the CFC trajectory so that they can benefit from the knowledge and investments made in that trajectory.

The possibilities to limit (H)CFC emissions are both in the hands of manufacturers and users of $(\mathrm{H}) \mathrm{CFC}$-containing products. The prevention of unnecessary losses of $(\mathrm{H}) \mathrm{CFCs}$ is a matter of good housekeeping combined with the application of relatively simple equipment, such as that used to recover CFCs from cast-off refrigerators. Alternative product design is another possibility. Alternatives to the CFC family may be developed by various firms, including those outside the chemical industry (e.g. the use of rock wool or natural materials as an insulator instead of polyurethane foam and the replacement of propellant-driven aerosols by pump-driven aerosols).

Market demand for CFC substitutes is guaranteed by the future ban on CFCs. However, in the short term, market demand for CFC substitutes may be weak, especially for some applications. Except for aerosol propellants 'autonomous' market demand is not strong enough to establish a serious substitution of CFCs. In most applications, CFCs are 'ideal' substances. Substitutes that perform as well as CFCs a lower price, are mostly inflammable, toxic and/or strongly reactive. Following is a brief exploration of the market demand for aerosols, refrigerators and cooling systems, foam, and cleansing and degreasing agents.

The buyers of aerosols have played an important role in the transition towards CFC-free aerosols. Consumers indentify CFC aerosols as products that are harmful to the ozone-layer. They have come to be regarded as 'contaminated' products. In response to this, large retailers decided to discontinue selling CFC aerosols. In this case, relatively cheap alternatives in the form of pump-driven aerosols were available.

Little initiative to replace CFCs is expected from the market for professional cooling systems. However, HCFC-22, a 'soft' CFC, is increasingly used nowadays in larger equipment because of technical-economic reasons. In the case of domestic refrigerators, many solutions are investigated. It is difficult to tell which solution will achieve dominance. The most promising solutions are seen to be HFC-134a and a mix of propane and butane (LPG). The big refrigerator manufacturers opt for HFC-134a, but this compound is rejected by environmentalist groups for being a greenhouse gas. They favour the use of (flammable) propane and butane as a refrigerator coolant. Interestingly, the German branch of Greenpeace supported the development of a propane-cooled refrigerator. They found an East-German firm willing to produce such a refrigerator. Marketing and distribution of the "greencooler" was taken care of through Greenpeace magazine. The success of the greencooler (already 80.000 people subscribed to the purchase of this refrigerator) forced the refrigerator manufacturers to rethink their strategies; firms like 
Siemens, Bosch and Liebherr recently announced to produce a LPG-based refrigerator. ${ }^{10}$ Up until now, the transition to CFC-free refrigerators takes place very slowly, mainly because costs of these refrigerators are still well above the traditional ones.

Market demand for CFC substitutes in the foam industry, the biggest user of CFCs, depends strongly on government policy. In this sector, CFCs are used for the production of insulation material, which accounts for approximately two-thirds of CFC use. Insulation of buildings and houses helps save energy and prevents pollution, so there may be a trade-off between different environmental goals. However, alternatives to foam are available; rock wool is an example. To reduce the release of CFCs in the production of soft foams, several firms in the Netherlands have invested in CFC recycling technologies. This is only a temporary solution (about $60 \%$ of the CFCs are still released into the air). In the future, soft foam firms are not allowed to use CFCs.

The demand for CFC-substitutes as cleansing or degreasing agents is growing. Good and relatively cheap alternatives (such as water and soap) are available, and the demand for these may increase in such firms as knowledge of their cost advantages increases. It turned out that industry had been using a cleaning agent that was nonoptimal from also an economic point of view. The adoption of CFC substitutes sometimes requires certain institutional changes, however. The use of CFC solvents that are used to clean components of high-tech equipment is often prescribed by the customers. A well-known example is found in the specifications of defence ministries.

With respect to the appropriability conditions, much knowledge about CFC-like alternatives is concentrated in the larger CFC manufacturers. They have acquired a technical lead which obstructs market entry by other firms. In addition, the production of HCFCs and HFCs calls for large investments, ${ }^{11}$ and economies of scale play an important role in the production of these subsitutes, as Figure 8.1 demonstrates.

${ }^{10}$ Karel Knip, 1993, Groene koelkast (Green Refrigerator), NRC Handelsblad, March 4, 1993, p.22.

" Du Pont estimates the costs of retooling at more than 2,000 million guilders (Michel Jehae, Bescherming ozonlaag kan tot trendbreuk leiden (Protection of ozone layer may lead to a new trend), Nieuzue Beta, sept 1991, p.13. 


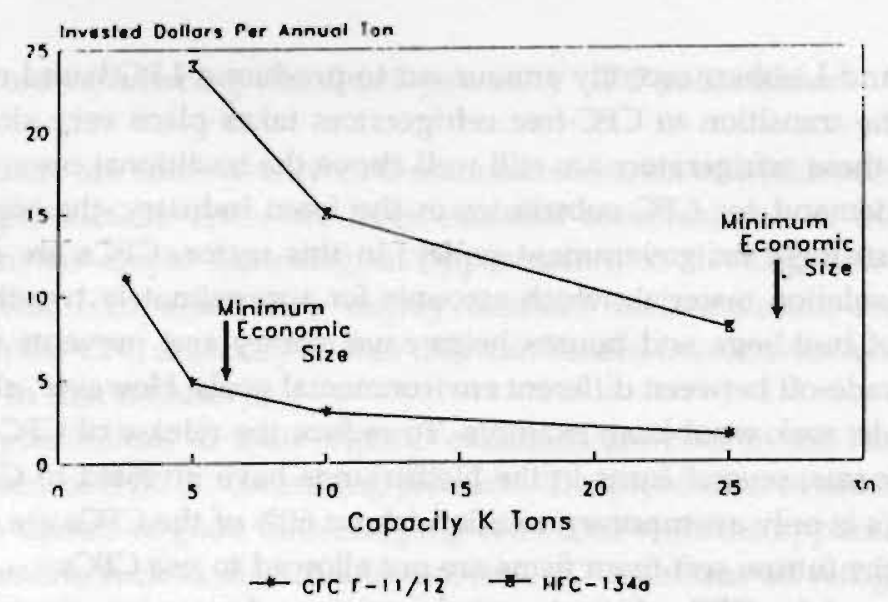

Figure 8.1. Scale economies in the production of $\mathrm{H}(\mathrm{C}) \mathrm{FCs}$. Source: Du Pont de Nemours.

Patents are of minor importance as means to appropriate returns from $R \& D$; the substances as such cannot be patented, but sometimes the different components of the production processes can.

\subsubsection{Factors influencing the adoption of CFC substitutes}

This section considers the factors that influence the decision to adopt CFC subsitutes. With respect to these factors, the price and quality of CFC substitutes do not so much influence the substitution of alternatives to CFCs, because substitution is inevitable. They do influence the direction toward which firms look for substitutes and the rapidity of the transition process. Due to their complex production process, it is estimated that HCFCs and HFCs will become two to five times as expensive as CFCs (HCFC-22 used in the cooling industry will probably cost two times as much to produce as CFC-12 and HFC134a five times as much as CFC-11). The costs of a substitute technology are not, however, exclusively determined by the price of the substance concerned, but also by the amount needed and the cost of equipment in which it is used. In the cooling sector, the price/quality ratio is likely to favour $\mathrm{H}(\mathrm{C}) \mathrm{FCs}$, whereas in the other areas of application, serious competitors will also be found outside the CFC trajectory.

For large users of CFCs, problems of knowledge and information about available alternatives are relatively few. These users are also involved in the CFC manufacturers' development and testing of CFC-replacing technology. Furthermore, in the Netherlands, sector-specific organizations play a significant part in the transfer of knowledge and information about alternative technologies, through their involvement in the establishment of demonstration projects, admission rules, and so forth. Lack of information usually occurs in smaller firms, but they use CFCs mainly as a solvent for cleaning purposes. For these applications, relatively cheap alternatives are available. Consumers 
also have inadequate knowledge. But even if consumers have a good understanding of environmental aspects, their willingness to buy environmentally benign products, like CFC-free refrigerators, may be small.

Although technical and economic uncertainty and risks are inherent in the shift to CFC substitutes in the various application areas, these are 'normal' business risks that result from the shift to a new technology. Users tend to reduce the technical risk by making use of drop-ins - substitutes that can be used in existing installations with little adaptations - as much as possible. This is favourable for $\mathrm{H}(\mathrm{C}) \mathrm{FCs}$. The economic risks for national industries which use CFCs are limited because all CFC users, including those abroad, are faced with the need to switch to substitutes, so that competitive disadvantages in the international market will not occur.

At the end of this section, we look back at the technological impact of government policy. As we noted, the dominant policy instrument relating to the CFC problems is direct regulation in its most extensive form: a future, general ban on its production and use. ${ }^{12}$ This general ban can be considered as a form of technology-forcing standard. The above suggests that this will be a strong enough incentive for CFC-substituting innovations and their diffusion. The regulation of CFC use is even unique in one respect: the regulations have been tightened several times instead of being softened, to give industry more time to comply with regulations.

The role of economic instruments and information and communication is complementary in nature. They are used to accelerate and/or facilitate the transition to CFC substitutes. In the United States, for example, rights are allocated for CFC production and use. These rights are gradually reduced and are tradeable. The aim of the CFC charge, which is also used in the US, is mainly to skim off 'windfall profits' which may arise from the artificial scarcity of CFCs.

On the whole, government policy seems to have been a success in making a relative quick and smooth transition away from CFCs. Only two years after the discovery of significant levels of ozone depletion at the South pole by a group of Britisch scientists in 1985, an international treaty to reduce CFC emissions was signed. This treaty was tightened several times to accelerate the phase out of CFCs. A cause for concern is whether developing countries will also switch to CFC substitutes and at what time they will do so.

\subsubsection{Low-solvent paints and coatings}

In the 1950s, traditional linseed oil paints were replaced with paints based on synthetic binding agents. A basic component of most of these paints was organic solvents, usually present in per centages of 30 to 65 per cent, but sometimes as high as 90 per cent. It was not discovered until much later that the solvents, which are released during application,

12 'Use' is defined in the Montreal protocol as production minus export plus import. Substances with a limited ability to affect the ozone layer (the so-called 'soft' CFCs or H(C)FCs) will be allowed until far into the next century. 
had negative effects on people's health and vegetation - for instance through the formation of smog. ${ }^{13}$

Low-solvent paints and coatings constitute a preventive environmental innovation. They are less damaging to health and the environment during application and production, as well as in the waste phase, although the prevention of damage during application is the most important aspect. There are various kinds of low-solvent paints: water-based (or water-borne) paints (5-10 per cent solvents), 'high solids' (20-30 per cent solvents), powder coatings, and ultraviolet and electron-beam curing coatings. The first three types are appropriate for wide-spread application in both the architectural and industrial market, although to different degrees.

\subsubsection{Factors influencing the development of paints and coatings}

Research into low-solvent paints and coatings started in the 1960s, particularly in the laboratories of the major paint manufacturers. Currently, practically all paint makers are developing water-based paints, for both the industrial market and the architectural market. Small firms in the paint industry are strongly dependent upon their suppliers (components of the large chemical concerns) of raw materials, which provide directive recipes for paints. The production of water-based paints is somewhat more complex than that of the traditional paints. In some cases paint companies cooperate with each other or have research carried out by third parties. Large companies usually perform research in a more systematic manner by testing the paint on all kinds of materials and under all kinds of climatic influences. It can be concluded that vast technological opportunities for low-solvent paints are available to every firm in the paint industry. However, paint makers are sometimes criticised for conservatism and the under-capitalization of research efforts. Although many different formulations for new products are constantly being developed, only a small number reach the production stage. ${ }^{14}$

The history of paints is strongly associated with changes in market demand. For example, the development of high-solvent paints was stimulated by the demand for paints with a shorter drying time than that of linseed oil paints. Demand by the automobile industry was an especially important influence in the development of these fasterdrying paints. The demand for low-solvent paints has mainly been a derived demand, dependent on government policy. Emission requirements in the 1960s and 1970s in the United States and West Germany (like Rule 66 and TA-Luft, respectively) and legislation relating to working conditions in Scandinavian countries particularly increased the demand for low-solvent paints. Industrial users of organic solvents were forced to

${ }^{13}$ According to some (Scandinavian) studies, volatile organic solvents are also responsible for damage to the nerve system of painters, the organo-psycho syndrom; but this result is not comfirmed by other studies.

14 Anonymous, 1988, Paint Markets. The Growth of Water-Based Products, 'TM' Pigments, Filler and Extenders, p.8. 
reduce VOC emissions, and, in many instances, the most cost effective means to comply with environmental regulations was to adopt coatings with low solvent content. ${ }^{15}$

Recently, the growing environmental awareness of consumers has stimulated the development of water-based paints and high solids for the architectural market. Industrial demand for low-solvent paints has been growing in the last few years, interesting enough not so much because of environmental considerations, but for normal business reasons of lower labour costs and less material losses. In the Netherlands, the sales of powder coatings for industrial application are currently increasing by 15 per cent annually. This corresponds with world trends. The growth in sales of water-based paints is approximately 10 per cent. In 1990, in the Netherlands, the share of water-based paints in industry was about 10 per cent, the share of powder coatings 15 per cent and that of radiation-curing coatings less than 1 per cent (see Table 8.3).

\begin{tabular}{lcccc}
\hline & U.S. & Western Europe & Netherlands \\
\hline & 1973 & 1983 & 1983 & 1990 \\
\hline solvent-based paints & $84 \%$ & $68 \%$ & $75 \%$ & $70 \%$ \\
water-based paints & $12 \%$ & $21 \%$ & $10 \%$ & $10 \%$ \\
powder coatings & $1 \%$ & $3 \%$ & $4 \%$ & $15 \%$ \\
high solids & $3 \%$ & $6 \%$ & $10 \%$ & $<5 \%$ \\
radiation-curing coatings & $<1 \%$ & $2 \%$ & $1 \%$ & $<1 \%$ \\
\hline
\end{tabular}

Table 8.3. Industrial use of paints and coatings in the U.S., Western-Europe and The Netherlands. Source: Henckens and de Kok (1988) and own estimates. ${ }^{16}$

Table 8.3 shows that the Netherlands, and to a lesser extent Western Europe as a whole, were slow in using low-solvent paints. This is related to the environmental policies with respect to organic solvents in the different countries. In the U.S., emissions of volatile organic solvents were regulated already in the 1960 and 1970s, and much of the transition towards paints that were lower in solvent content took place in that period. In 1991, the share of water-based paints in the U.S. was about the same as that in 1983: 20 per cent in original equipment manufacture segment (automobile finishes, appliance coati-

${ }^{15}$ Ben Bonifant, 1993, Competitive Implications of Environmental Regulation in the Paint and Coatings Industry, paper prepared for the 2nd Greening of Industry conference in Boston, November 14-16, 1993, p.11.

${ }^{16}$ M.C.L.M. Henckens and A.P. de Kok, 1988, Alternatieve lakken of emissiebeperkende apparatuur (Alternative coatings or pollution control equipment), Procestechniek 43(2): 56-59. 
ngs, etc.) and 71 per cent in the architectual market ( 80 per cent in interior paints and 60 per cent in exterior paints). ${ }^{17}$

The size of the anticipated market for low-solvent paint products is an important factor in paint manufacturers' innovative activities. For example, the large size of the automotive market in the U.S. provided satisfactory justification for suppliers to research and improve water-borne coatings, whereas the small size of the Californian wood furniture market, and the technical difficulties encountered, delayed manufacturers from achieving compliant coatings. ${ }^{18}$

The paint industry is unique with respect to appropriability conditions. Imitation of paint products is relatively simple. The composition of paints can be discovered quite easily discovered by chemical analysis, although their production requires additional research work. Protection through patents is practically impossible, since paint production comes down to 'mixing and stirring'. To obtain a patent something, new technical principles have to be developed. Suppliers of raw materials do patent new procedures more frequently than do paint manufacturers.

In the Netherlands, as in most other countries, the most important means to appropriate the benefits from new paint products lies in the distribution. The large paint manufacturers have their own distribution networks (service stations for professional users and paint shops for consumers), where customers can receive advice about the paint product to be used. Moreover, some paint manufacturers have 'field workers' who visit their clients. Small firms especially rely upon such customer contacts. The situation in the Netherlands is quite different from that in Germany, where advice is much less important and paint is usually diffused via the wholesale trade.

The fact that paint companies sell their products through their own channels means that the innovating firm mainly reaches its own clients. Thus, a paint company's new product competes with its own existing products. This has a negative effect on the willingness of firms to perform R\&D activities with respect to low-solvent paints. This may explain in part why until recently paint manufacturers in the Netherlands were slow in developing low-solvent paints. Around the mid 1980s this changed. Between 1985 and 1990, the number of researchers employed in the Dutch paint industry increased with 60 per cent. ${ }^{19}$

\subsubsection{Factors influencing the use of low-solvent paints and coatings}

The history of low-solvent paint products is long. The first water-based paints (apart from the latex wall paints) were developed in the 1960s. Initially, low-solvent paints were used for highly specific purposes; water-based paints were used as primers in the

${ }^{17}$ IM Pigments, Fillers and Extenders, op cit, p.8.

18 Bonifant, op cit, p.34. 1991.

${ }^{19}$ Andre de Boer, Groene golf in lakken (Green wave in coatings), Ingenizurskrant, 12, June 13, 
automobile industry and powder coatings were used primarily for coating domestic applicances like washing machines and refrigerators. With the further perfection of these products, they became attractive also for other purposes. One such innovation was the development by ICI in the early 1980 s of the aqeous microgel system for use in waterborne base coat systems. ${ }^{20}$ The change process in paints, however, was more one of incremental improvement than of revolutionary change.

At this moment, good-quality low-solvent paint products are available for both the architectural and original equipment manufacturers (OEM) market. The performance characteristics of low-solvent paints differ from those of high-solvent paints in many respects: gloss, durability, adhesion to substrates and so. ${ }^{21}$ Painters and private clients still have a strong preference for high-solvent paints, despite the benefits of water-based paints (including possible health benefits for themselves). In addition to familiarity with high-solvent paints, and the necessary extra cleaning of older layers of paint, (partly unfounded) prejudices against the quality of water-based paints are a factor. For instance, some painters wrongly believe that water-based paints are unsuited for application on wood, because 'water is bad for wood'. Another factor that worked against water-based paints was the small assortment of low-solvent paints. Today some highgloss water-based paints are available. High solids that are recently introduced in the Dutch architectural market also have good gloss and protection performance.

The price of water-based paints is about 10 per cent higher than that of highsolvent paints because of more expensive resins, production methods and $R \& D$ costs. According to paint manufacturers, no major price falls are expected as a result of economies of scale and learning effects. However, application and maintenance costs often favour water-based paints. Powder coatings are about 25 per cent more expensive per kilo but estimated to be 15 per cent more cheap per $\mathrm{m}^{2.22}$ Their use requires capital investments in special bake ovens and sometimes the retooling of production lay out. The same holds true for radiation-curing methods.

There is a serious lack of knowledge and information regarding the environmental damage caused by high-solvent paints and the availability and quality of alternatives. These information problems are particularly important to painters and private users. Another obstacle is that in the past water-based paints were presented as being overly promising. This publicity has led to disappointments in some cases. Some retailers are still reluctant to promote low-solvent paints. The environmental benefits play a limited role in the promotion of low-solvent paints.

${ }^{20}$ Bonifant, op cit., p.25

${ }^{21}$ A detailed discussion of the technical aspects of low-solvent paints and coatings can be found in the articles by Cees Dijkstra on this subject (Cees Dijkstra, De nieuwe generatie verf (The new generation of paints), Eisma's vakpers, 1991, nrs. 24-25 and 1992, nrs. 1-12.

\footnotetext{
${ }^{22}$ Noll quoted in P.C. Koppert, A.A. Olsthoorn and O.J. Kuik, 1988, Emissiereductie door schone technology. Een verkenning van demogelijkheden van 10 'schone' technologieën (Emission reductions from clean technology), IVM R-88/2, Amsterdam.
} 
Although there is some uncertainty about the quality of paints (in terms of gloss, durability, etc.) and their use entails some risks for professional applicator (unsatisfactory results may lead to financial claims), the uncertainty and risks are relatively small, especially for the non-industrial user. For industrial use, it is often necessary to change production routines and the division of work, since the new paints and coatings require different machines and tools.

The transition to low-solvent paints is taking place slowly, except for powder which is the fastest growing paint market in the world, with volume increases averaging about 15 per cent a year for the last decade. ${ }^{23}$ Environmental consideration only play a minor role here. To speed up the transition away from solvent-based paints, government policy is needed. Currently, there is less need for incentives to encourage innovations in low-solvent paints than there is for incentives to promote the diffusion of the new products, particularly among professional painters and private consumers.

Policies to promote low-solvent paints have been implemented in several countries. At present, in the Netherlands, Germany and Switzerland covenants are used to reduce the use of solvents in paints. These covenants are agreements between polluters and the government to reduce volatile organic solvent (VOC) emissions. Furthermore, on November 19, 1991, 23 countries signed a United Nations European Commission for Europe (ECE) protocol for reduction of VOCs. The aim of the agreement was for each country to achieve a 30 per cent reduction in emissions by 2000 (the definition of the base year was left to the signatory countries). ${ }^{24}$ The Netherlands has committed itself to a reduction of 50 per cent in 2000 compared to 1981 emissions levels in the KWS-2000 programme, initiated in 1986. Some countries (e.g., the Netherlands, Switzerland and the United States) are considering the possibility to impose fees on high-solvent paints. A fee imposed on solvents may contribute to the diffusion and further development of lowsolvent alternatives, but such a fee will need to be considerable in order to be very effective. Information and communication are particularly important to increase acceptance of the new paint types and remove negative prejudices. Government procurement policy may also be helpful.

\subsubsection{Membrane technology in the metal-plating industry}

In the metal-plating industry, large amounts of heavy metals are released in wastewater. A policy adopted in the Netherlands in the 1970s (tightened in the 1980s) was aimed at combatting the discharge of these emissions into surface water. As a result, many firms in the metal-plating industry purchased an "ONO installation" (ONO in Dutch stands for: Detoxication, Neutralisation, Dehydration), a technique for treating metal plating effluents. Although the resulting wastewater is cleaner, the technique produces toxic

\footnotetext{
"Financial Times Survey "World Paints and Coatings", Powder bucks the trend, March 27, 1991.

${ }^{24}$ Bonifant, op cit., p.18.
} 
sludges, which in turn must be taken care of. The ONO installation is a typical end-ofpipe solution which leads to a transfer of environmental problems.

In contrast, membrane technology can be considered a typical process-integrated technique. The technique recycles rinse waters from metal plating operations and plating material directly back to the plating bath through the use of relatively small units embodying semi-permeable membrane filters through which the rinse water are passed. ${ }^{25}$ Effectively operated membrane techniques generate substantially less quantities of toxic sludges than conventional effluent treatment techniques and ion exchange units. ${ }^{26}$ Thus far, metal-plating industry has made little use of membrane filtration for the purification of industrial water. Approximately 15 per cent of the the firms in the metal-plating industry purchased a membrane technology. The majority of firms ( 59 per cent) invested in conventional ONO effluent treatment systems.

Type of pollution control technique

ONO effluent treatment

$59 \%$

Ion exchange units ${ }^{1}$

$15 \%$

Membrane technology

$15 \%$

Others

${ }^{1}$ sometimes in combination with ONO installations

Table 8.4. Type of pollution control technology applied in the metal-plating industry. Source: ECOTEC (1986) and own calculations.

The reason why firms in the metal-plating industry decided for the most part against membrane technology, will be explained below. As we will argue, the main reasons why firms decided to invest in ONO effluent treatment systems rather than in membrane technology are to be found in the characteristics of the metal-plating industry and the Dutch wastewater policies.

${ }^{25}$ ECOTEC, 1986, The Promotion and Diffusion of Clean Technologies in the Metal Plating industry in the Netherlands, report to the Netherlands Ministery of Housing, Physical Planning and Environment, p.48.

${ }^{26}$ Ibid, p.49. 


\subsubsection{Factors influencing the development of membrane technology}

Membrane-separating or purification techniques were developed in the 1950s, as a result of technological opportunities in the plastics-producing and plastics-processing industry. On a world scale, the market for membranes is controlled by firms in the United States and Japan, where the governments put large amounts of money into research and development in this area in the 1960s. The research being carried out in the area of membrane technology is still not driven in any major way by potential market sales in the metal-plating industry, nor is such research specifically aimed at this industry.

The knowledge needed for the production of membranes and membrane installations is generally in the hands of their manufacturers. Protection of this knowledge is usually fixed in the form of patents, the most important appropriability condition in this industry. Application of membrane technologies in the metal-plating industry calls for tailor-made solutions, which constitutes a barrier to market entry.

\subsubsection{Factors influencing the adoption of membrane technology}

For firms in the metal-plating industry, membrane technology is not directly relevant to their product but only to the process. Whether or not a firm applies membrane technology does not provide it with extra opportunities to increase their sales by creating or conquering new markets.

The limited experience of metal-plating firms with membrane techniques is largely negative. There have been many technical problems with the installations, such as pollution of the membranes. In addition, the technical support of suppliers has often left much to be desired. Many failures were due to deficiencies in the planning and the assessment stage and inappropriate installation of the techniques rather than any faults in the equipment as such. ${ }^{27}$

Because of these negative experiences, membrane technology has a bad reputation in this industry. In general, the costs of using membrane equipment plays a lesser role, although the high purchase price is an obstacle to risk-averse and myopic firms in the metal-plating industry. A well-functioning installation might lead to cost savings for some firms, due to savings in chemicals, plating materials and effluent taxes. This potential for saving may rise substantially as the cost of transport and disposal of polluted sludge increases.

The knowledge potential users have about membrane technology is minimal and is limited to a number of bad experiences, which has a negative effect on demand. Furthermore, smaller firms especially lack the expertise to apply membrane technology. This is partly related to insufficient transfer of knowledge by the suppliers of membrane

${ }^{27}$ ECOTEC, op cit., p.32. 
technology; these suppliers find the metal-plating industry a 'difficult' and not very profitable market and direct their efforts preferably towards other markets. ${ }^{28}$

Perceptions about the risks involved in the adoption of membrane technologies also obstruct their use in the metal-plating industry. Firms are afraid of breakdowns, which involve financial risks and time losses. Also, operating the installations seems to absorb more time than indicated by the suppliers. Small firms, of which there are many in the metal-plating industry, particularly cannot afford the risk of spending much time on matters that do not directly benefit production.

From the above one may get the idea that membrane technology is an ill-suited technology for dealing with metal-plating effluent. Technical imperfections and the need for technical knowlege and capabilities to operate membrane technique indeed worked against the purchase of membrane filtration techniques. But the main reason why membrane technologies failed to make an impact is to be found in Dutch wastewater policies. In the Netherlands, wastewater policy was oriented at the prevention of the release of metals in wastewater, not at the prevention of toxic sludge. This favoured end-of-pipe solutions like the ONO installation. In fact, the environmental standards were based upon the use of convential (ONO) end-of-pipe solutions.

Another important factor that worked against the uptake of membrane technologies was that membrane technology were not recommended by the industry's research association and wastewater boards for the reason that membrane filtration was a relatively new technology in the 1980s when stricter water pollution standards were imposed upon metal-plating firms. ${ }^{29}$

In turn, the slow diffusion of membrane technologies had a negative effect on research efforts to perfect membrane technology and the willingness of suppliers to provide good after-sales technical support, to overcome 'teething' problems. Because the market did not develop, so did not the product. Due to the wide-spread application of ONO installations, the market for membrane technology is blocked for many years.

The future prospects of membrane technology, however, are less dim. In the 1990s, environmental policy in the Netherlands has taken a more integrated multi-media approach, instead of focussing on one specific medium such as water. Although policies towards toxic sludge generated by $\mathrm{ONO}$ installations have not been implemented so far, and are not likely to be implemented in the next few years (toxic sludge from the metalplating industry is not a priority waste problem), the fact that the cost of disposal of polluted sludge have risen sharply in the 1990s (up to 1,000 guilders per ton in 1994),

\footnotetext{
${ }^{28}$ W. van Tongeren and J.W. du Mortier, 1989, Practische Toepassingsmogelijkheden van membraanprocessen in de natte oppervlaktebewerkende industry (Possibilities for the use of membrane techniques in the metal-plating industry), VROM, p.34.

${ }^{29}$ ECOTEC, op cit., p.14 and Mensink et al., op cit., p.74. Membrane techniques were not included in the CUWVO-list of best practicable technologies to reduce discharges of heavy metals effluents because too little information was available about the control efficiency and costs of using membrane technology. (The CUWVO is a commission which advices wastewater boards on technical matters.)
} 
and are expected to rise further, favours the adoption of process-integrated technologies like membrane filtration. ${ }^{30}$

This case demonstrates the danger of using standards-based policies and the importance of taking a long term, multi-media view in dealing with environmental problems. It furthermore shows that information transfer can be of great importance. Information should not only reinforce environmental awareness and convey knowledge of the costs and benefits of various techniques but also remove prejudices against particular environmental technologies. Demonstration projects may make a significant contribution to this goal.

\subsection{Conclusions}

This chapter has explored the factors that affect the decision to supply and adopt cleaner technologies. This final section attempts to derive some general conclusions about these factors and to give some policy implications.

One conclusion that emerges from the case studies is that technological capabilities to develop compliance innovations are often located outside the polluting industry. This creates particular problems of establishing new inter-industry relationships and the transfer of knowledge. At the same time, this dislocation may be beneficial to environmental policy in the sense that suppliers of environmental technologies have a strong interest in stricter environmental policies, whereas polluting industries clearly have not.

Furthermore, the technological opportunities and appropriability conditions do not appear to be distinct obstacles to the realisation of cleaner innovations, at least not in the supplier industries in the case studies. One might reply that this is hardly surprising, since if technological opportunities were absent and appropriability conditions insufficient, there would have been no new technology to study in these industries. A more general conclusion, however, is that for almost all environmental problems, several technological opportunities for cleaner technologies are available and that firms in one way or another can protect a technological innovation against imitation for a long enough period or find other ways to reap some of the benefits from using the innovation.

The multiple technological opportunities may confront policy makers with a dilemma. Since the success of a certain technology depends strongly on government policy, policy makers should be careful not to induce the selection of the 'wrong' technologies, and, as a result, lock-in adherence to a sub-optimal technological trajectory. This point is less academic than it may seem. In the case of the metal-plating industry, the market for membrane technologies has been blocked for years because of the widespread adoption of end-of-pipe (ONO) techniques that resulted in the transfer of en-

${ }^{30}$ Ben te Raa, 1991, Sectorale milieuwetgeving nekt complete bedrijfstak. Galvano-industrie staat voor tweede grote investeringsgolf (Environmental regulation wrecks metal-plating industry. A new wave of investments in pollution control measures is coming), MilieuMarkt, april-issue, pp.10-13. 
vironmental problem. In the case of the substitution of CFCs, policy makers face a similar dilemma: should HCFCs, which also affect the ozone layer but to a lesser extent, be allowed for a certain period, or should other solutions that are currently less suitable and more expensive be stimulated? The choice between technological solutions is very difficult, since a new technology's costs and benefits are unknown to both policy makers and suppliers of the technology.

To address this policy dilemma, economic instruments may be preferred to direct regulation, since they interfere less with the choice of technology. On the other hand, standards may be better to induce a shift from a current non-sustainable technological trajectory, such as replacement of the internal combustion engine by a less polluting engine.

If the appropriability conditions are insufficient, policy makers can do little to improve, except perhaps to subsidize certain R\&D projects, or to stimulate cooperation between firms. As discussed, unfavourable appropriability do not appear to be a barrier to the exploitation of technological opportunities, although they can delay the development of new products, as in the case of low-solvent paints and coatings.

Market demand seems to be the crucial factor for the successful exploitation of technological opportunities. In the case of cleaner technologies, market demand depends strongly on government policy. In each of the three cases, the creation of a market for environmental technologies was necessary for these technologies to be developed and adopted. Although there are other stimuli, such as pressure from local communities, the work force, investors, insurance companies, special environmental interest groups, and the larger public, these stimuli are still not very strong. The perspective of a certain policy can also provide an important stimulus. In the case studies, it was found that a clear objective for the interim period gave a strong push for the development of CFC substitutes and low-solvent paints and coatings.

The case studies also provided a lot of information about the factors that aifect the adoption of cleaner technologies. One important factor is the price and quality (performance characteristics) of the new technology, compared to that of less environment-friendly technologies. In all three cases, the technological substitutes have quite unique performance characteristics, some of which are valued positively, other negatively in the market. Water-based paints are a good example: they do not smell, dry more quickly, have a longer life time, and are more environment-friendly; they are also more expensive, have a lower initial gloss, and their application requires good cleaning. They are presently unsuited as traffic paints, automobile finishers and as high performance maintenance paints. These technical aspects and user understanding of these aspects are an important factor in the diffusion of environment-friendlier technologies. Policy should take such aspects into consideration in designing environmental policies in order to prevent cost inefficiencies, obstruction from industry and non-compliance.

It is also important that policy makers take into account the technological opportunities to develop substitutes for environmentally hazardous technologies, together with firms' capabilities and willingness to use them. In order to avoid lock-in adherence to 
sub-optimal technologies, policy should stimulate the widest possible range of technical solutions and remain flexible with respect to technological choices.

Finally, this analysis suggests that in the short term, the transition towards more sustainable technologies can bring about high costs and serious adjustment problems for adopters. New and cleaner technologies will always be less suited for some adopters because of specific technical requirements or prohibitively high costs - for instance when existing production techniques have to be replaced early in their usable life. When technologies are improved in terms of price or technical characteristics, the overall costs of adopting environment-friendlier technologies may be much lower. Especially in the case of standards, the costs related to such a short-term transition can be high. This means that a combination of patience and persistence in environmental policy may well be the optimal strategy. 


\section{Chapter 9}

\section{Empirical Results of other Technology Studies}

This chapter presents the findings of other empirical studies into the technological impact of environmental policies. We look at the experiences with direct regulation in the United States, especially those with technology-forcing standards and innovation waivers. This is followed by a discussion of the technology effects of incentive-based approaches such as pollution taxes, tradeable pollution permits and $R \& D$ and investment subsidies. At the end of the chapter, we examine the innovation effects of covenants used in the Netherlands.

\subsection{Technology Effects of Environmental Regulations in the U.S.}

\subsubsection{Direct regulation and innovation waivers}

Most of the studies into the technology responses to environmental regulation took place in the 1970s and early 1980s in the United States. The main findings of these studies are summarized in Nicholas Ashford, Christine Ayers and Robert Stone (1985). ${ }^{1}$ They find that the technology responses of industry to the environmental, occupational health and product safety regulations differed widely between industries and regulations. With respect to the technology responses to regulations, a distinction is made between technological innovation and diffusion of existing technology, and between product and process changes. Innovative responses are divided into incremental and radical responses (a description of technology definitions is in chapter 1). The following conclusions emerge from their survey:

product-focused regulation primarily elicits a product response (substitution of existing products or a new product);

- sometimes the new product (e.g. lead-free gasoline) is accompanied by significant process innovation;

process regulation can elicit either a process response or a product change - in fact, product substitution may be the only practical response to a strict process restriction;

${ }^{1}$ Nicholas A. Ashford, Christine Ayers and Robert F. Stone, 1985, Using Regulation to Change the Market for Innovation, Haroard Environmental Law Review, 9: 419-466. 
the stringency of the regulation is an important determinant of the degree of innovation.

Table 9.1 summarizes the results.

\begin{tabular}{|c|c|c|c|c|c|c|}
\hline Substance & Application & Regulatory & Type of & Stringency & Industry Rer & ponse \\
\hline & & Agency & Regulation & & Degree & Type \\
\hline PCBs & the & EPA & Product & $\begin{array}{l}\text { Very } \\
\text { Stringent* }\end{array}$ & $\left\{\begin{array}{l}\text { Radical } \\
\text { Incremental }\end{array}\right.$ & $\begin{array}{l}\text { Product } \\
\text { Process }\end{array}$ \\
\hline CFCs & Aerosol & $\begin{array}{l}\text { IIPA } \\
\text { CPSC }\end{array}$ & Provilucl & $\begin{array}{l}\text { Very } \\
\text { Siringen" }\end{array}$ & $\left\{\begin{array}{l}\text { Radical } \\
\text { Incremental }\end{array}\right.$ & $\begin{array}{l}\text { Process } \\
\text { Product }\end{array}$ \\
\hline Mercury & Paint & EPA & Product & $\begin{array}{l}\text { Very } \\
\text { Stringent }\end{array}$ & Diffusion & Product \\
\hline Lead & Paint & CPSC & Product & $\begin{array}{l}\text { Very } \\
\text { Stringent }\end{array}$ & Diffusion & Product \\
\hline Lead & $\begin{array}{l}\text { Fuel } \\
\text { Additive }\end{array}$ & EPA & Product & $\begin{array}{l}\text { Very } \\
\text { Stringent }\end{array}$ & Incremental & Product \\
\hline Mercury & Chloralkali & EPA & Process & Stringent & $\left\{\begin{array}{l}\text { Increniental } \\
\text { Diffusion }\end{array}\right.$ & $\begin{array}{l}\text { Process } \\
\text { Process }\end{array}$ \\
\hline Lead & $\begin{array}{l}\text { All } \\
\text { Manufacture }\end{array}$ & OSHA & Process & $\begin{array}{l}\text { Very } \\
\text { Stringent* }\end{array}$ & $\left\{\begin{array}{l}\text { Radical } \\
\text { Diffusion }\end{array}\right.$ & $\begin{array}{l}\text { Buth } \\
\text { Process }\end{array}$ \\
\hline $\begin{array}{l}\text { Vinyl } \\
\text { Chloride }\end{array}$ & $\begin{array}{l}\text { All } \\
\text { Manufacture }\end{array}$ & $\begin{array}{l}\text { OSHA } \\
\text { EPA }\end{array}$ & Process & $\begin{array}{l}\text { Very } \\
\text { Stringent* }\end{array}$ & $\left\{\begin{array}{l}\text { Incremental } \\
\text { Difrusion }\end{array}\right.$ & $\begin{array}{l}\text { Process } \\
\text { Process }\end{array}$ \\
\hline $\begin{array}{l}\text { Collon } \\
\text { Dusi }\end{array}$ & $\begin{array}{l}\text { All } \\
\text { Manufacture }\end{array}$ & OSHA & Process & $\begin{array}{l}\text { Very } \\
\text { Stringent }\end{array}$ & Diffusion & Process \\
\hline Asbestos & $\begin{array}{l}\text { All } \\
\text { Manufacture }\end{array}$ & OSHA & Process & $\begin{array}{l}\text { Mildly } \\
\text { Stringent }\end{array}$ & Diffusion & Prucess \\
\hline
\end{tabular}

"Substantial Joubt about the standard's technolugical feasibility at the time the standard was proposed.

EPA is Environmental Protection Agency, CPSC is Consumer Product Safety Act and OSHA is Occupational Safety and Health Act.

Table 9.1. A summary of regulations and the technology responses by industry. Source: Ashford et al. (1985, p.431). 
Table 9.1 shows that the most common responses to regulation are incremental innovation and diffusion of existing technology (in the form of end-of-pipe solutions and noninnovative substitutions of existing substances). Radical solutions were developed only in the case of Polychorinated Biphenyls (PCBs), Chlorofluorocarbons (CFCs) and leaded products (like batteries and gasoline), most of which were effectively banned by regulation. It is also found that in many cases the new technologies were developed by firms outside the regulated industry, in the form of pollution control equipment or substitutes for existing products. These conclusions correspond with the findings of the case studies in chapter 8.

The authors also provide a discussion of U.S. experiences with innovation waivers as a way to encourage technological innovation. Innovation waivers are incentive devices built into environmental regulation. Generally, they extend the deadline by which industry must install pollution control equipment to meet emissions limitation requirements. They exempt industry from penalties during trial periods and offer the prospect of cost savings derived from superior technology. ${ }^{2}$ In theory, innovation waivers seem very attractive for both potential innovators and the regulating agency. In practice, they have not achieved their intended effect. Reasons for such a failure were: First, ambiguity as to the requirements made in the different acts. For instance, the Clean Air Act required that the proposed technology had not been adequately demonstrated and proof that the technology would operate effectively. It is hard to see how it will be ever possible to provide proof that the technology operates effectively without proper demonstration. These, and other, requirements, caused much uncertainty about whether a proposed technology would qualify for an innovaton waiver under the different acts. Second, the short and inflexible deadlines that acted as a disincentive for innovation, especially for radical innovation with long development times. And third, the way in which the programme was administered. Under the Clean Air Act, the responsibility of issuing innovation waivers was given to the Stationary Source Compliance Division (SSCD) of the Environmental Protection Agency, a division with limited technical expertise, whose primary task was enforcement. As it turned out, the SSCD narrowly interpreted the waiver provisions, provided little guidance and the agency took a long time before it arrived to a decision. In retrospect, it is easy to comprehend why innovation waivers were unsuccessful. This does not disqualify innovation waivers per se. There are several remedies to the problems encountered, many of which are given by the authors - such as administration of the programme by people trained to interact with industry, the establishment of a technology review panel, delineation of eligibility criteria, and longer time allowances. It does illustrate, however, the difficulties in designing regulations that encourage technological change towards efficient conservation of environmental qualities.

${ }^{2}$ Ibid, p.444. 


\subsubsection{New car fuel economy improvements: The result of regulations or the natural response to market forces?}

What about the usefulness of economic incentives like pollution taxes and tradeable pollution permits to encourage environmentally beneficial technical change? As we know, the increase in oil prices encouraged much research into non-fossil fuel-based energy technologies and energy conservation technologies. Is there evidence that pollution taxes and tradeable pollution permits fostered innovation in environmentally preferable technology? As far as we know, there is no reported case of an environmental technology which was developed primarily in response to pollution taxes and tradeable permits. One explanation for this is the limited use of pollution taxes and tradeable permits. Another explanation is that the level of the instituted taxes was simply too low, or the number of pollution permits too high, to foster technological innovation. ${ }^{3}$ There is certainly much truth in this, but in our view, it is not the entire truth. As Nelson and Winter have pointed out, technological advances often proceed in certain directions irrespective of relative prices, i.e., they are not fine-tuned to changing demand and cost conditions. ${ }^{4}$ Technology practitioners have their own agenda of development, based on what they see as the relevant problems and the possible solutions, based on search heuristics and research experience. As we will see in chapter 10, these notions are often shared across the community of technology practitioners. Engineers also have their own criteria against which technological possibilities are assessed. Economic considerations play a limited role in such appraisals, they are just one criterium and are generally given less attention than technical performance criteria. Economic criteria have to be brought in from the outside by marketing people and by management in decisions over research projects and budgets. This is not to say that firms do not respond to changes in cost and demand conditions, only that such responses take time, especially when technological competencies are not available within the individual firm.

This raises the question whether direct regulation in the form of technology-forcing standards is better suited to promote technological innovation than incentive-based approaches such as pollution taxes or tradeable pollution permits. Interestingly, this question has been studied statistically by David Greene for new car fuel economy in the United States. ${ }^{5}$ In 1975, the U.S. Environmental Protection Agency, under the Energy Policy and Conservation Act (EPCA), established mandatory fuel economy standards for automobiles and light trucks. The EPCA regulations required manufacturers to meet a fuel economy target of 18 miles per gallon (mpg) in 1978 , increasing to $27.5 \mathrm{mpg}$ by

${ }^{3}$ This is the conclusion of the OECD study Economic Instruments for Enoironmental Protection, 1989, Paris: OECD, p.14.

4 Richard R. Nelson and Sidney G. Winter, 1977, In Search of Useful Theory of Innovation, Research Policy, 6, pp.56-57.

${ }^{5}$ David L. Greene, 1990, CAFE OR PRICE. An Analysis of Effects of Federal Fuel Economy Regulations and Gasoline Price on New Car MPG, 1978-89, The Energy Joumal 11(3): 37-57. 
1985. If manufacturers failed to comply with the corporate average fuel economy (CAFE) standard - being the sales-weighted mean mpg of a manufacturer's product - it had to pay a fine of $\$ 5$ per car sold per $0.1 \mathrm{mpg}$ of shortfall. The intent of the automobile fuel economy standards (AFES) was to stimulate technological improvements that would increase efficiency without substantially altering the size distribution of vehicles sold. Although new car fuel efficiency doubled from $14 \mathrm{mpg}$ in 1974 to $28 \mathrm{mpg}$ in 1988 , there was disagreement as to whether this increase in fuel efficiency was the result of fuel economy regulations or the natural response of market forces to rising gasoline prices. ${ }^{6}$

Greene developed a statistical test to discriminate between price and regulatory effects. The basic structure of the model is very simple. The decision problem of the manufacturer is to select a level of fuel economy, $E$, which minimizes the combined penalties of being out of step with the market in terms of fuel economy, $E_{M}$, and the level required by regulation, $E_{R}$.

$$
\begin{gathered}
\operatorname{Min} Z=f\left(E_{M^{\prime}} E\right)+\theta g\left(E_{R}-E\right) \\
\text { with } \theta=0 \text { if } E \geq E_{R} \\
=1 \text { if } E<E_{k}
\end{gathered}
$$

The penalty functions $f$ and $g$ are additive and quadratic functions of the differences between the desired market (or regulatory) level and the efficiency actually achieved:

$$
\begin{aligned}
& f\left(E_{M^{\prime}} E\right)=a_{M}+b_{M}\left(E_{M}-E\right)+c_{M}\left(E_{M}-E\right)^{2} \\
& g\left(E_{R}-E\right)=a_{R}+b_{R}\left(E_{R}-E\right)+c_{R}\left(E_{R}-E\right)^{2}
\end{aligned}
$$

The reason for using a quadratic function for $g$ is to allow for benefits for exceeding the standards as well as costs for falling short. The desired market level of fuel efficiency, $E_{M}$, depends on manufacturer's and consumer's price expectations and is taken to be a function of current and past gasoline prices. Substitution of the equations for $f$ and $g$ in $Z$, and minimization of $Z$ with respect to $E$ gives the optimal amount of fuel efficiency for manufacturer $m$ :

$$
E_{m}(t)=A_{m}+\left(1-\theta_{m} B\right) E_{M}(t)+\theta_{m} B E_{R}(t)
$$

This is the equation to be estimated for different manufacturers. The conclusion from the statistical test is that "the standards were at least twice as important as market trends in prices, and may have been completely replaced fuel price increases as a basis for long-

${ }^{6}$ The latter view is expressed in R.W. Crandall, H.K. Gruenspecht, T.E. Keeler and L.B. Lave, 1986, Regulating the Automobile, Washington DC: The Brookings Institution. 
range planning about mpg". That is, the CAFE regulations were more effective in influencing new car fuel efficiency than an imaginary gasoline tax bringing the gasoline price of $\$ 1$ in 1978 to a level of $\$ 1.7$ in 1981 (the year in which the gasoline price was the highest in the U.S.) and back to the original level of $\$ 1$ in 1986.

Of course, the above conclusion depends on the model structure, especially the specification of the penalty function - where the use of a quadratic function for $g$ is not convincingly justified. Also, the relative effectiveness of the CAFE regulations should not be taken as evidence that the regulations were economically desirable, the low responsiveness to gasoline prices may hint at high transition costs. Nevertheless, it seems to be a story where technology-forcing regulations, supplemented with fines, were effective in stimulating environmentally beneficial technical change, much more effective than a high gasoline tax.

\subsection{The Technological Impact of Environmental Subsidies and Covenants in the Netherlands}

Investment subsidies are another incentive-based approach. Being a politically attractive instrument, they have been an important part of past environmental policies. This section examines the effectiveness of investment subsidies in encouraging firms to employ more environmentally benign technologies.

\subsubsection{Investment subsidies}

In the Netherlands, several studies have been undertaken into the technological impact of investment subsidies. A parliamentary study of the WIR investment studies, showed that, according to environmental authorities, the investment subsidies for environmental technologies (which amounted to 15 per cent of total investment costs) induced only 8 per cent of the firms to undertake investments they would not have done otherwise. ${ }^{8}$ (Surprisingly, the government concluded from this evaluation study that the subsidy scheme was "reasonably effective".9) The effectiveness of three other types of investment subsidies is analyzed in Walter Vermeulen (1992).$^{10}$ The results of this study, based on a questionnaire, are in Table 9.2 .

${ }^{7}$ Ibid, p.55.

s Tweede Kamer, 1987, Evaluatie WIR-milieutoeslag (Evaluation of the WIR investment subsidies), Tweede kamer, vergaderjaar 1986-1987, 19858, nr.4, p.39.

${ }^{9}$ Ibid, p.2.

10 Walter Vermeulen, 1992, De verouiler betaald. Onderzoek naar de werking van subsidies op vier deelterreinen van het milieubeleid (Paying the Polluter. A study into the effects of four subsidy schemes for environmental technologies), Utrecht: Jan van Arkel. 


\begin{tabular}{lccc}
\hline & PCBs & $\begin{array}{l}\text { silent } \\
\text { trucks }\end{array}$ & $\begin{array}{l}\text { manure } \\
\text { storage }\end{array}$ \\
\hline very effective & $0 \%$ & $2 \%$ & $1 \%$ \\
reasonably effective & $37 \%$ & $22 \%$ & $20 \%$ \\
hardly effective & $13 \%$ & $23 \%$ & $3 \%$ \\
not effective & $50 \%$ & $52 \%$ & $76 \%$ \\
\hline
\end{tabular}

Polychlorinated Biphenyls

Table 9.2. The effectiveness of investment subsidies for environmental technologies. Source: Vermeulen (1992, p.210).

According to Vermeulen's study, investment subsidies for the replacement of PCB equipment, new trucks that were more silent and the storage of animal dung were effective in only a small number of cases. The subsidies were the primary reason for investing in the environmentally beneficial technologies in two per cent of the cases for silent trucks and one per cent for manure storage. For PCB-replacement equipment the figure was even zero. The investment subsidies were reasonably effective for 37 per cent of the firms that used PCBs (and only in 22 and 20 per cent of the cases in the other two sectors). In all three cases, other factors were more important than the subsidies, such as fuel economy, road performance, and comfort in the case of silent trucks, health and safety considerations in the case of PCB replacement, and environmental regulations in the case of the animal dung storage." Vermeulen also analyzed whether the information provided by government authorities about the subsidies being available and the adverse environmental effects of existing technologies and practices influenced the decisions of firms to invest in environmentally preferable technologies. This was only so for PCBs, which not only had adverse health and detrimental environmental effects but also posed a fire and security risk for PCB-using firms.

Other evaluation studies of investment subsidies for environmentally beneficial technologies (including energy conservation, solar boilers and co-generation of heat and power) arrive at similar conclusions. With the exception of the investment subsidy for $\mathrm{CHP}$, and, possibly, the subsidy for wind turbines, the effectiveness of the investment

"It should be noted that none of the technologies were prescribed by environmental regulation. Environmental regulations played a role in purchasing decisions only in the case of the storage of animal dung. 
subsidies in the Netherlands was small. ${ }^{12}$ For the most part, they provided applicants with a 'windfall profit'.

This corresponds with our own finding in chapter 7, where we found no significant relation between the investment subsidies for thermal home improvement and the diffusion of thermal insulation technologies. On the whole, the conclusion that emerges from the different studies is that investment subsidies were only limitedly effective in promoting diffusion of environmentally beneficial technologies. To what extent they encouraged technological innovation is unclear, but given that the subsidies hardly influenced adopter decisions, the innovation effects are likely to be small.

The combination of investment subsidies with environmental taxes, however, may be an effective policy for accelerating the diffusion of clean technology. In 1986, the Dutch government instituted a subsidy for 'clean' automobiles and a tax for cars with high emission levels. The way in which the system worked was that the subsidies for clean cars were payed out of the extra tax revenues from the sales of highly polluting cars. This policy proved to be very effective: the share of 'clean' cars in new car sales increased from $15 \%$ in 1986 to $90 \%$ in $1990 .^{13}$ The same kind of policy was used to encourage the supply and distribution of unleaded gasoline to protect catalytic converter emission control systems used in cars. Due to a differentiation in excise taxes, unleaded gasoline (first only regular but later also super gasoline) became more cheap than leaded gasoline. Oil companies quickly responded to these changes in the tax regime by offering unleaded gasoline for sale. ${ }^{14}$

\subsubsection{RED subsidies}

What about the effectiveness of subsidies for the development of environmentally preferrable technologies? Did R\&D subsidies stimulate firms to undertake research in environmental technology, that is, research they would not have done otherwise? This is a question which has not been studied in a systematic way, at least not in the Netherlands. However, the evidence that is available suggests that R\&D subsidies in the Netherlands for environmental technology have been limitedly effective. According to the study by Xander Olsthoorn, Frans Oosterhuis and Harmen Verbruggen, the "Stimuleringsregeling Milieutechnologie" (STIR-MT) for the development of environmental technology did not

\footnotetext{
${ }^{12}$ Evaluatiecommissie Wet Algemene Bepalingen Milieuhygiëne, 1992, Financiële instrumenten in het beleidsproces (Financial instruments in the policy process), advies nr. 5, Den Haag: VROM.

${ }^{13}$ Evaluatiecommissie WABM, op cit, p.39. A more detailed description is in Pieter-Jan Klok, 1989, Lood-vrije benzine en schone auto's, een toepassing van de instrumententheorie (Unleaded gasoline and clean cars. An application of instrument theory), Centrum voor Bestuurskundig Onderzoek, Twente).

I4 Ibid, p.42. The quick response of oil companies was due in part to the fact that the manufacturing of unleaded gasoline did not command any technological innovation. The manufacturing of (high-performance) unleaded gasoline was something the oil companies had already mastered in the 1970 s, to comply with U.S. environmental regulations, see Ashford et al, op cit, p.435-436.
} 
elicit new research projects. ${ }^{15}$ This conclusion corresponds with the observation by Mark de Jong and Klaas van der Ven that innovator firms develop environmentally beneficial technologies not because a subsidy is available but because they believe a market exists for the new technology. ${ }^{16}$ It may be that the subsidies accelerated the development of environmental technologies, but this is unclear. There are indications, however, that government R\&D subsidies played a role in the development of biological cleaning technologies. ${ }^{17}$

The experience with the Danish Clean Technology Development Programme, described in Susse George, Inge Røpke and Ulrik Jørgensen (1992) is more positive. ${ }^{18}$ Under the programme, industries, private and semi-governmental research institutions could apply for financial aid for developing and implementing clean technology. The programme was oriented at stimulating preventive process solutions and co-operation of technology suppliers, research institutes, consultancy firms, and users. The Danish Environmental Protection Agency played an active role in selecting environmentally beneficial projects and in finding the 'right' partner with whom to cooperate. That is, the agency acted as some kind of "match maker" to elicit environmentally innovative solutions, something that previous subsidy programmes had failed to do. According to the authors, the Danish programme was a success. In almost all cases, appropriate technical solutions were found for the environment problems at hand. (Examples are described in Georg et al., op cit). In more than half of the projects, substantial environmental improvements were achieved at low costs. Some project even led to net economic gains for the polluting firms. In the Netherlands, a similar type of network approach has been followed in reducing emissions of volatile organic compounds (VOCs).

\subsubsection{Technology effects of covenants}

Covenants are a relatively new instrument of environmental policy. Covenants are negotiated agreements between industry and the government in which the industry promises to reduce the environmental burden of their products and activities. In PieterJan Klok (1989), the effectiveness of eight product-related covenants in the Netherlands

${ }^{15}$ Xander Olsthoom, Frans Oosterhuis and Harmen Verbruggen, 1992, Inhoudelijke evaluatie van de stimuleringsregeling milieutechnologie (Evaluation of the subsidy programme Environmental technology), IvM report R-92/01, Amsterdam: IVM, p.18.

${ }^{16}$ Mark de Jong and Klaas van de Ven, 1985, Milieu-innovaties in kleine ondernemingen (Environmental innovations in small enterprises), publicatiereeks Milieubeheer 21, VROM, pp.78-79.

${ }^{17}$ Olsthoorn et al, op cit, p.16.

${ }^{18}$ Susse George, Inge Ropke and Ulrik Jorgensen, 1992, Clean Technology-Innovation and Environmental Regulation, Environmental and Resource Economics, 2(6): 533-550. 
is analyzed. ${ }^{19}$ The covenants covered products like mercury-oxide batteries, alkaline batteries, beverage packages, heavy trucks, PET bottles, and the use of cadmium in beer cases, CFCs in aerosols, and phosphates in detergents. Most covenants were about the substitution of an environmentally hazardous substance. According to Klok, the effectiveness of covenants was typically small: when environmental improvements were achieved, this was more due to autonomous technological change, external regulations (such as EC guidelines), and the evolution of market demand than to covenants. Furthermore, there is little evidence that the covenants fostered technological innovation. An exception is the KWS-2000 programme in the Netherlands to reduce VOC emissions, which stimulated research into low-solvent paints (see chapter 8).

\subsection{Conclusions}

What conclusions can be drawn from the empirical studies into the technology effects of environmental policies? One important conclusion is that the technology responses to environmental regulations differ between industries and regulations. According to the study of Ashford et al. (1985), the most common technology response to regulations is incremental innovation and diffusion of existing technology (mostly in the form of endof-pipe solutions). In several cases, however, environmental regulations elicited innovative responses from industry. Examples are: the ban of PCBs, CFCs and automobile fuel economy standards. The effectiveness of investment subsidies and R\&D subsidies in the Netherlands was limited in almost all cases. There is also no evidence that the covenants that have been used in the Netherlands encouraged technological innovation. As regards to the innovation effects of taxes and tradeable permits, there is no reported case of a technological innovation that has been developed in response to a pollution tax or tradeable permit, but this may be due to the limited use of these instruments and the low level of the tax or high number of pollution rights. A more detailed discussion of the pros and cons of environmental policy instruments will be given in the final chapter.

19 Pieter-Jan Klok, 1989, Convenanten als instrument van milieubeleid. De totstandkoming en effectiviteit van acht produkt-gerichte milieu-convenanten en hierop gebaseerde verwachtingen omtrent de effectiviteit van convenanten, Enschede: Unversiteit Twente. 


\section{PART III}

The Problem of Technological Regime Shifts 


\section{Chapter 10}

\section{Continuity and Change in Technological Regimes}

This chapter examines the possibilities of achieving radical change in technology - that is, a change in our basic technologies of production, transport and consumption rather than modifications of existing products or the adoption of end-of-pipe technologies. We provide an explanation as to why such change is likely to be a gradual and slow process. Radical technologies often have long development times and require for their operation special skills, infrastructure and all kinds of institutional changes (organizational changes, regulation, new ideas and values etc.). Furthermore, the short-term costs are likely to be high as the new technologies have not yet benefitted from dynamic scale and learning effects (which result in cost reductions per unit of output and evolutionary improvements in the technology). The chapter also provides some answers as to how it is possible for firms with restricted technological capabilities to bring about a shift into a new technological regime - emphasizing the importance of early market niches, available knowledge that may be used, institutional support, and the role of expectations.

It should be emphasized that the focus of this chapter is an exploration of the properties of technological regimes. Rather than examining the specific technical, economic and social aspects of a transition to more environmentally benign technologies (like photovoltaics or alternative fuel vehicles) we are exploring the broader question of how technological regimes evolve and change.

The chapter is organized as follows. Section 1 looks at the way in which technological change has been understood by historians and economists. It describes various technology concepts (like technological paradigms and regimes) employed by different writers to account for the ordering and structuring of technology. Section 2 provides a criticism of these approaches. We will argue that the reason why some technologies (like the combustion engine) are dominant depends not only on engineering beliefs and imagination but also on the accumulated knowledge, realized cost efficiencies in certain designs, the build-up of an infrastructure around a technology, and the embedment of technologies in people's way of life. Section 3 summarizes the main conclusions.

\subsection{Patterns in the Evolution of Technology}

That technical change is not a haphazard process but proceeds in certain directions is by now widely recognized. Examples of persistent patterns of technical change, given by Donald MacKenzie, are the increasing mechanization of manual operations, the growing 
miniaturization of microelectronic components, the increasing speed of computer operations. ${ }^{1}$ Other examples of patterns in technological change are: reductions in material requirements in products, the trend towards the use of lighter materials (in automobiles and aircraft), the use of electronic components in consumer products and equipment etc. There also exist relatively stable patterns in the usage of products and processes. In the western world, cars only gradually came to dominate other modes of transport (horsedrawn carriages and later on trains) in the last 100 years. Oil and natural gas became dominant energy sources over a period of half a century. It even took almost a whole decade for a simple product such as the ballpoint pen to become widely used.

Economists, historians and more recently sociologists have studied these regularities in technological change and have come up with concepts to account for the ordering and structuring of technology. A useful starting point is the work by Nathan Rosenberg, who, as an economic historian, has contributed much to our understanding of the nature and direction of technological change. Rosenberg asked himself the following question: Have there been forces at work in recent history which have pushed exploratory activity in specific directions? His answer was that "technology is much more a cumulative and self-generating process than economists generally recognize". ${ }^{2}$ To be sure, in making the above statement, he did not want to imply that economic incentives are not important (or to suggest some crude form of technological determinism). The ultimate incentives for problem-solving activities are believed to be economic in nature. Rosenberg's basic point is that economic incentives to reduce cost always exist in business operation, and precisely because they are so diffuse and general they do not explain very much in terms of the particular sequence and timing of innovative activity. ${ }^{3}$

According to Rosenberg, the kind of problems to which engineers are likely to devote their attention are related to the day-to-day problems posed by the existing technology such as constraints imposed by the existing plant and certain technical imbalances between the components of a final product. As he writes: "most mechanical productive processes throw off signals of a sort which are both compelling and fairly obvious and lead to an almost compulsive formulation of problems and exploratory activities". Within his view, firms are "naturally led to search the technological horizon, as it were, within the framework of their current activities and to attack the most restric-

${ }^{1}$ Donald MacKenzie, 1992, Economic and Sociological Explanations of Technical Change, in Rod Coombs, Paolo Saviotti and Vivien Walsh (eds.), Technological Change and Company Strategies, London: Academic Press, p.30.

${ }^{2}$ Nathan Rosenberg, 1976, The Direction of Technological Change: Inducement Mechanisms and Focussing Devices, In his book Perspectives on Technology, Cambridge: Cambridge University Press, p.110.

${ }^{3}$ Ibid, p.110

${ }^{4}$ Ibid, p.111. 
tive constraint". ${ }^{5}$ Rosenberg's point is that explorative activities are essentially problemsolving activities and that engineers will look for solutions of problems that present themselves.

In his 1976 book, Rosenberg gave several historical examples of technological change which had been pushed in a particular direction by such "focusing devices", and suggested it was such factors that gave order to the change process and to the structures which emerged from it. Several examples are given by Rosenberg to illustrate this point: for instance, that the improved designs of automobile engines have led - through the achievement of higher speeds - to the invention of improved braking systems. Another example is the development of the Bessemer process of steel production out of the task to make a gun, able to fire a heavy, elongated projectile. It is found in historical studies that the Bessemer process, being a major innovation in steel making, was the product of Bessemer's search for a superior metal that could withstand the severe strains imposed by the weight of heavy projectiles.

Implicit in Rosenberg's approach is a system's view of technologies: a technology is made up of interrelated components that define a product's technical characteristics and its production. This system's idea of technology and its implication for the evolution of technological change is also a key element in Devendra Sahal's work. As Sahal writes:

one of the most important clues to the origin of innovations is to be found in the fact that the performance of every technology depends upon its size and structure. Specifically, as a technology is continuously made to become larger or smaller, the relationship between its size and structural requirements changes, which in turn, severely limits the scope of its further evolution. Thus the origin of a wide variety of innovations lies in learning to overcome the constraints that arise from the process of scaling the technology under consideration. ${ }^{6}$

Thomas Hughes, who, as a historian, studied the evolution of large technological systems, arrives at a similar conclusion. According to him, problem-solving activities are very much aimed at solving "reverse salients" that arise in the growth of technological systems. Reverse salients are components in the system that have fallen behind or are out of place with the others. ${ }^{\text {? }}$

The idea of bottlenecks and technical imperatives guiding the evolution of technology is developed more systematically into an evolutionary theory of innovation by Richard Nelson and Sidney Winter. Nelson and Winter strongly oppose the idea that the genera-

${ }^{5}$ Ibid, p.111.

" Devendra Sahal, 1985 Technological Guideposts and Innovation Avenues, Research Policy 14, p.61.

7 Thomas P. Hughes, 1989, The Evolution of Large Technological Systems, In The Social Construction of Technological Systems: New Directions in the Sociology and History of Technology, edited by Wiebe E. Bijker, Thomas P. Hughes and Trevor J. Pinch, Cambridge (Mass.): MIT Press, pp.51-82. 
tion of innovation can be understood in terms of a cost-benefit calculation, in which the expected pay-offs from innovation are simply compared with the estimated cost of producing the innovation. ${ }^{8}$ Their criticism amounts to the fact that $R \& D$ is an uncertain business in which cheap reliable estimates of benefits and costs are not available and in which interpersonal and interorganizational difference in judgement and perception matter a lot. ${ }^{9}$ Instead, the innovation process is seen as guided by interacting heuristic search processes, on the basis of previous experience and notions of success.

Nelson and Winter's approach is deeply rooted in the work of Herbert Simon about decision making in complex situations and is related to the behavioral theory of the firm as developed by Cyert and March. It is argued that in complex decision situations, due to bounded rationality, relative simple decision rules and procedures are used to guide actions. ${ }^{10}$

Whereas the very idea of search heuristics in innovation activities already accounts for some stability and inflexibility in the evolution of technology, Nelson and Winter go one step further by saying that "there may exist certain powerful intra project heuristics that apply when a technology is advanced in a certain direction, and payoffs from advancing in that direction that exist under a wide range of demand conditions"." These directions are referred to as "natural trajectories".

Such natural trajectories may be specific to a particular technology or they may be common to a wide range of technologies. When the trajectory is specific to a technology they speak of a technological regime. Such a technological regime defines certain boundaries for technological progress and indicates directions in which progress is possible and worth doing. The concept of a technological regime relates to technicians' beliefs about what is feasible or at least worth attempting - which implies that cognitive aspects are considered important. Nelson and Winter give the example of the DC 3 aircraft in the 1930s which defined a particular technological regime: metal skin, low wing, pistonpowered planes. As they write: "Engineers had some strong notions regarding the potential of this regime. For more than two decades innovation in aircraft design essentially involved better exploitation of this potential; improving the engines, enlargening the planes, making them more efficient". 12 In a study by Georghiou et al. on post-innovation improvements and competition, the concept of a "technological regime" is further developed and defined as:

\footnotetext{
${ }^{8}$ See also Freeman, 1982, op cit, chapter 7.

${ }^{9}$ Nelson and Winter, 1977, op cit, pp.51-51.

${ }^{10}$ Richard R. Nelson and Sidney G. Winter, 1982, An Evolutionary Theory of Economic Change, Cambridge (Mass.): Bellknap Press, p.35.
}

${ }^{11}$ Nelson and Winter, 1977, op cit, pp.56-57.

${ }^{12}$ Ibiil, p.57. 
a set of design parameters which embody the principles which will generate both the physical configuration of the product and the process and materials from which it is to be constructed. The basic design parameters are the heart of the technological regime, and they constitute a framework of knowledge which is shared by the firms in the industry. ${ }^{13}$

The concept of a technological regime is illustrated by the example of a plastic-bodied, electrically powered car, being part of a new technological regime as the material properties of plastics, the functioning of electric motors and the manufacturing of such a car requires a different knowledge base, different types of engineering skills, linkages with information networks and interactions with different supply industries. ${ }^{14}$ Such a technological regime does not imply a unique design. A technological regime usually consists of a set of design configurations, which forms the basis for competition, research activities and agenda of development of individual firms or business units. ${ }^{15}$

In a similar way, Sahal speaks of "technological guideposts" charting the course of innovation activities and "innovation avenues" that designate pathways of technological evolution. ${ }^{16}$

The idea of a common technological framework guiding research activities is also central to the concept of a technological paradigm developed by Giovanni Dosi, which has been influential in the field of the economics of technical change. The concept of technological paradigm refers to Kuhn's concept of a scientific paradigm and Lakatos' theory of scientific research programmes from the philosophy of science. It is chosen by Dosi because the procedures and the nature of technologies are believed to be broadly similar to those which characterize science. Just as scientific research is aimed at solving particular problems or puzzles (while neglecting others) on the basis of a certain body of knowledge and the application of search heuristics, so are problem-solving activities by engineers employed in organizations to develop or improve products that may be sold in the market place. Whereas a scientific paradigm may be defined as an "outlook" which defines the relevant problems, a "model" and a pattern of inquiry, a technological paradigm is defined by Dosi as a "model" and "pattern" of solution of selected technological problems, based on selected principles derived from natural sciences and on selected material technologies. ${ }^{17}$ Elsewhere Dosi writes:

${ }^{13}$ Luke Georghiou, J.Stanley Metcalfe, Michael Gibbons, Tim Ray, and Janet Evans, 1986, PostInnovation Performance: Technological Development and Competition, London: MacMillan, p.32.

${ }^{14}$ Ibid, p.34.

${ }^{15}$ Ibid, p.35.

16 Sahal, op cit, p.71.

17 Giovanni Dosi, 1982, Technological Paradigms and Technological trajectories: A Suggested Interpretation of the Determinants and Directions of Technical Change, Research Policy, 6, p.152 (original italics). 
A technological paradigm defines contextually the needs that are meant to be fulfilled, the scientific principles utilized for the task, and the material technology to be used. (...) A technological paradigm is both an exemplar - an artifact that is to be developed and improved (such as a car, an integrated circuit, a lathe, each with its particular techno-economic characteristics) - and a set of heuristics (e.g. Where do we go from here? Where should we search? What sort of knowledge should we draw on?). ${ }^{18}$

Examples of technological paradigms are the internal combustion engine, the oil-based chemistry, and semi-conductors.

An important characteristic of a technological paradigm, and the concept of a technological regime, is that there exists a core technological framework which is shared by the entire community of technological and economic actors as the basis upon which one looks for improvements in process efficiency and product performances. As Dosi writes:

a technological paradigm has a powerful exclusion effect: the efforts and the technological imagination of engineers and of the organizations they are in are focused in rather precise directions while they are, so the speak, "blind" with respect of other technological possibilities". 19

To describe the dynamics of technological change many students of technology use the concept of a "technological trajectory". The use of the metaphor "trajectory" suggests that a pathway may be defined on the basis of the characteristics of technical advances. Examples of technological trajectories are: in aircraft technology, the loglinear improvements in the tradeoffs between horsepower, gross takeoff weight, cruise speed, wing loading, and cruise range; and, in microelectronics, the exponential trajectory of improvement in the relationship between density of the electronic chips, speed of computation, and cost per bit of information. ${ }^{20}$

According to Dosi, his model may be used to account for both continuous changes and discontinuities in technological innovation. Continuous changes are related to progress along a technological trajectory defined by a technological paradigm, while discontinuities are associated with the emergence of a new paradigm. ${ }^{21}$

${ }^{18}$ Giovanni Dosi, 1988, Sources, Procedures and Micro-Economic Effects of Innovation, Journal of Economic Literature, 26(3), p.1127.

${ }^{19}$ Dosi, 1982, op cit, p.153. Long before Dosi, Veblen spoke of the importance of 'habits of thought' in technology and economic change (Veblen, op cit).

${ }^{20}$ Ibid, p.1128-1129.

${ }^{21}$ Dosi, 1982 , op cit, p.147. 


\subsection{The Socio-Economic Dimension in the Stability of Techno- logical Regimes}

The above studies rightly corrected the simplistic view that most economists held about technology, as being fine-tuned to demand and cost conditions, or, as Donald MacKenzie puts it, "an entirely plastic entity shaped at will by the all-knowing hands of market forces". ${ }^{22}$ However, they suffer from "deterministic overtones", as pointed out by technology sociologists like Donald MacKenzie. In the above models, engineering imagination causes technology to proceed a certain trajectory, more or less in the same way as a stone or rocket follows a trajectory once it has been launched.

In our view, there is a clear socio-economic dimension involved in the stability of search activities and the patterns of technological change. One of the key reasons why technological progress often proceeds along certain trajectories (defined by a technological regime or paradigm) is that the prevailing technology and design has already benefitted from all kinds of evolutionary improvements, in terms of costs and performance characteristics, from a better understanding at the user side, and from the adaptation of socio-economic environment to a certain type of technology in terms of accumulated knowledge, capital outlays, infrastructure, available skills, production routines, social norms, regulations and life styles.

For example, the dominance of the internal combustion engine in motor vehicles is strongly related to the improvements in the design of the engine (leading to important improvements in speed, durability, fuel consumption), the cost savings in manufacturing due to large-scale production and learning by doing, advances in material technology, technical advances in machinery and equipment, organizational adaptations in order to produce more efficiently, low fuel prices due to economies of scale and technical progress in petrol production, and the whole network build-up around the internal combustion engine: the distribution of petrol, a road and service infrastructure, training of mechanics, etc.

To give another example, the costs of producing a 64 megabyte chip would be much too high for any chip-producing firm or indeed the industry as a whole had they not been involved in producing a 4 megabyte chip and gained experience in solving complex problems in design and production of micro-chips. Similarly, the revenues from selling a 64 megabyte chip depend on the size of the market for computers and other applications for chips. But this market is shaped by the stock of computers already in use, available computer software, computer knowledge and skills in using computers, the existing infrastructure in telecommunication and so on.

These two examples are merely used as illustrations of a more general story. Below we will explain more systematically how the dominance of particular trajectories is related to the "dynamic scale and learning effects" prevailing technologies have benefitted from and the adaptation of the "selection environment" to the old technological

${ }^{22}$ MacKenzie, op cit, p.34. 
regime. The concepts of dynamic scale and learning effects and selection environment also help explain why the diffusion process of radical products and processes (such as alternative energy technologies) is likely to be slow and why the short-term costs of large-scale technological transitions are likely to be large.

The term "dynamic scale and learning effects" denotes the evolutionary improvements in the performance characteristics of a technology and the cost savings in the manufacturing (allowing for price reductions). These dynamic scale and learning effects are related to the establishment and growth of the manufacturing industry, technological progress in related industries, and network externalities due to the growth of the system (for example, the growth of the petrol distribution system, the telecommunication network). An important part of these dynamic scale and learning effects are so-called learning curve effects that allow for cost reductions in the manufacturing of a product.

\subsubsection{Technology features in the stability of technological regimes}

In the world of engineering, learning curves are a well-known phenomenon. With the increase of production, per unit costs tend to fall. Such cost reductions per unit of output are related to economies of scale in production (lower costs per unit of production related to higher production scales), standardization of products, process improvements, and learning-by-doing in manufacturing. Learning curve effects are particularly important in processing industries (such as the chemical industry, the food industry) and in industries involved in the mass production of consumer durables (cars, television sets, etc.).

The learning curve, or the experience curve, may be described by the following function: $C_{1}=C_{0} N_{1}^{-b}$ with $C$ per unit costs (or labour input per unit of output) and $N$ the cumulative production $Q$ over time. ${ }^{23}$ The parameter $b$ is called the learning index or learning elasticity. In economic terms, $b$ is the cost elasticity with respect to cumulative production. Parameter $b$ defines the "slope", $S_{L}$ of the learning curve, the level at which costs fall each time the cumulated output doubles. ${ }^{24}$ The cost reduction with doubled experience is described by the following expression: $a \equiv 1-S_{L}=1-2^{-b}$. Figure 10.1 depicts a typical learning curve.

${ }^{23}$ Taken from Robert U. Ayres, 1985, A Schumpeterian Model of Technological Substitution, Technological Forecasting and Social Change, 27: 375-83.

${ }^{24}$ That is, $S_{L}=\frac{C_{0}(2 N)^{-b}}{C_{0} N^{-b}}=2^{-b}$ 


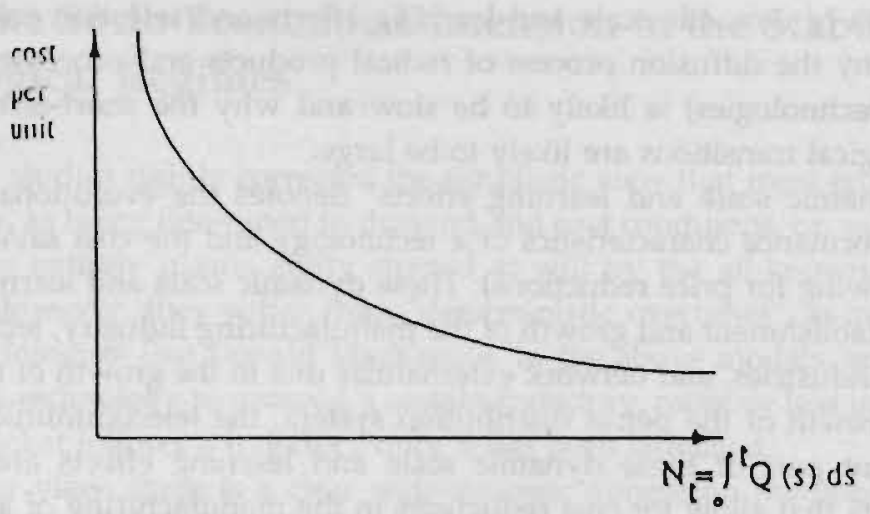

Figure 10.1. The learning curve

Figure 10.1 demonstrates that with increasing production, per unit costs fall. (Sometimes the unit costs are expressed as a decreasing function of time). To illustrate the importance of learning curves, Table 10.1 presents price reductions (in percentages) with doubled experience for a number of consumer durables.

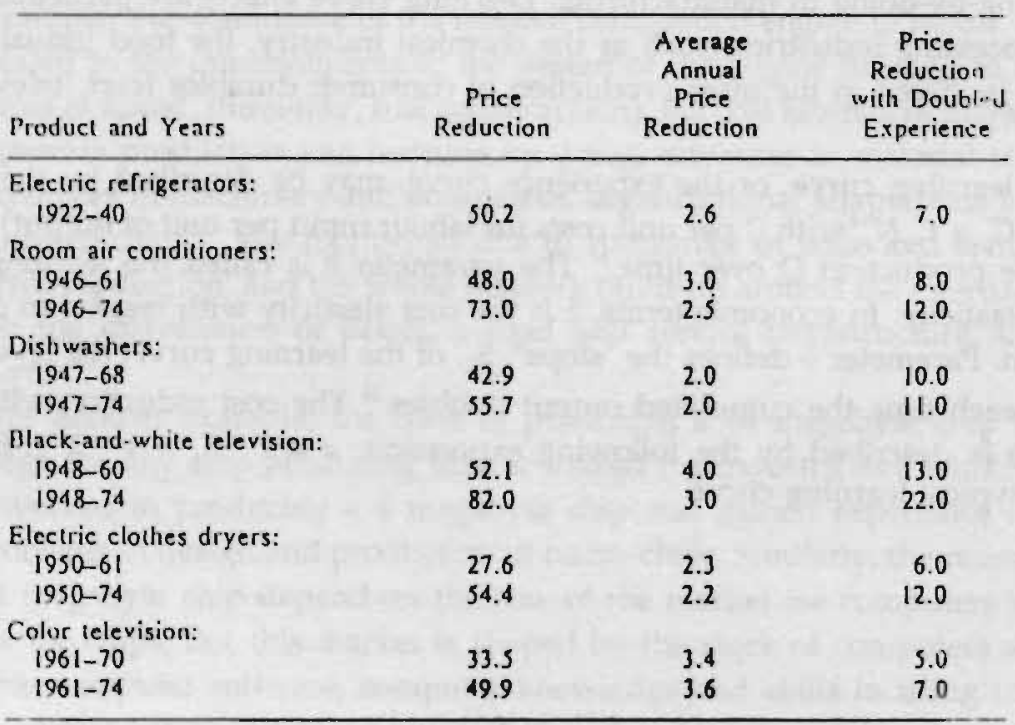

Table 10.1. Price reductions over time and related to experience for consumer durables. Source: Frank Bass $\left(1980\right.$, S61). ${ }^{25}$

${ }^{25}$ Frank M. Bass, 1980, The Relationship between Diffusion Rates, Experience Curves, and Demand Elasticities for Consumer Durable Technological Innovations, Journal of Business, 53, 1980, S51-S67. 
As a further illustration, Figure 10.2 gives estimates for parameter $b$, the learning elasticity, and $a$, the cost reduction with doubled experience, found in a number of industries (the chemical industry, the computer industry, electric power generation industry and the automobile industry).

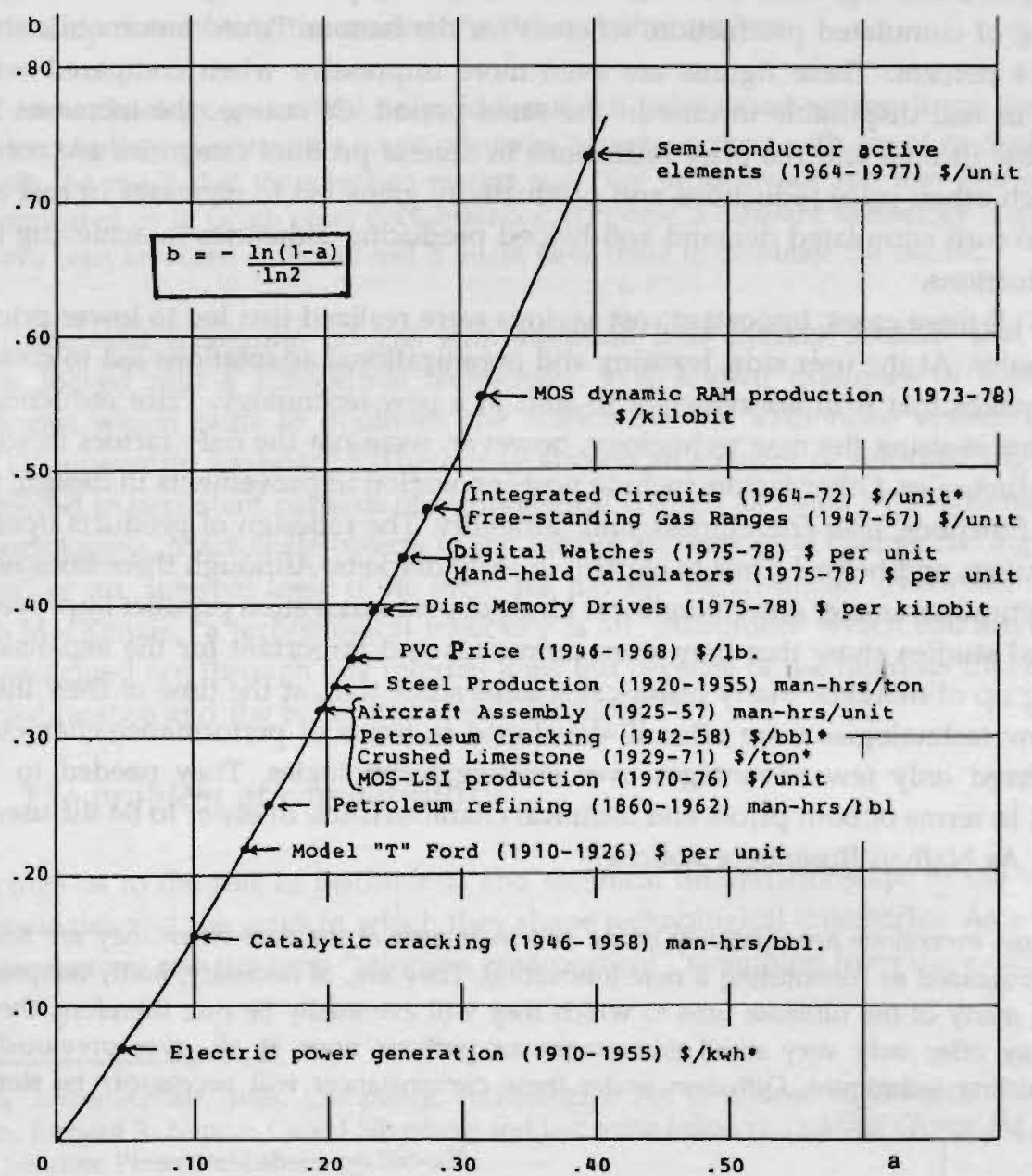

Figure 10.2. Parameters of the experience curve for various industries. Source: Ayres (1985, p.379). 
Table 10.1 and Figure 10.2 clearly show that learning curves exist and that they are an important phenomenon. In the case of consumer durables, such as refrigerators, air conditioners, dishwashers, television sets and electric clothes dryers, price reductions between 5 and 22 per cent were connected with a doubling of cumulated production in different post-war periods. In the semi-conductor industry, in the 1964-77 period, cost reductions per unit of output of as much as 40 per cent were associated with a doubling of cumulated output. In steel production, pve production, aircraft assembly, petroleum cracking and refining, cost reduction between 15 and 25 per cent were realized with each doubling of cumulated production, whereas for the famous T-ford automobile this was 'only' 14 percent. These figures are even more impressive when compared with the growth of real disposable income in the same period. Of course, the increases in real disposable income and the price reductions in several product categories are correlated with each other: price reductions and productivity gains led to increases in real income which in turn stimulated demand and helped producing industries in achieving further cost reductions.

In all these cases, important cost savings were realized that led to lower prices and higher sales. At the user side, learning and organizational adaptations led to cost gains, which makes that firm are reluctant to shift to a new technology. Price reductions and cost gains in using the new technology, however, were not the only factors in stimulating product sales. Other factors include post-innovation improvements in design, performance, functions, user-friendliness, and durability. The redesign of products opened up new markets and helped firms to expand in early markets. Although there does not exist an analytical parameter describing these kinds of post-innovation product improvements, historical studies show that they were numerous and important for the expansion and opening up of markets. Many historical studies show that, at the time of their introduction, new technologies were often ill-developed in terms of performance characteristics and offered only few advantages over existing technologies. They needed to be improved, in terms of both prices and technical characteristics, in order to be diffused more widely. As Nathan Rosenberg notices:

most inventions are relatively crude and inefficient at the date when they are first recognized as constituting a new innovation. They are, of necessity, badly adapted to many of the ultimate uses to which they will eventually be put; therefore, they may offer only very small advantages, or perhaps none at all, over previously existing techniques. Diffusion under these circumstances will necessarily be slow $(\ldots)^{26}$

Network externalities may reinforce the entrenchment of technologies in the economic system. With the growth of the network of users, a network technology becomes more attractive to its users. An example is the fax machine. The more people or firms adopt

${ }^{26}$ Nathan Rosenberg, 1976, Factors Affecting the Diffusion of Technology, in his book Perspecives on Technology, Cambridge, Cambridge University Press, p.195. 
the fax machine, the more valuable it becomes to the individual users. Network externalities that result from the growth of the system are a special kind of increasing returns with adoption, which are being analyzed in Brian Arthur. ${ }^{27}$ Five sources of increasing returns with adoption are identified by Arthur: learning by using, network externalities, scale economies in production, informational increasing returns and technological interrelatedness. With increasing returns of adoption, a technology becomes more attractive the more it is adopted, which further stimulates its adoption. Thus, in a situation where two network technologies are competing, a technology that gets ahead early may for that reason end up dominating the market. As Brian Arthur writes:

If one technology gets ahead by good fortune, it gains an advantage. It can then attract further adopters who might otherwise have gone along with one of its rivals, with the result that the adoption market may 'tip' in its favour and may end up dominated by it. Given other circumstances, of course, a different technology might have been favoured early on, and it might have come to dominate the market. ${ }^{28}$

When there exist increasing returns with adoption it is entirely possible that society becomes locked into a suboptimal technology. Well-known examples of suboptimal technologies which came to dominate the market are the VHS-video system and the QWERTY typewriter keyboard. ${ }^{29}$ There may also be an element of self-fulfilling prophecy involved in persistent patterns of technological change, as noted by MacKenzie. Like other sociologists, MacKenzie objects to the idea of technological change having a "momentum" or an "internal logic of its own" for having "deterministic overtones". According to MacKenzie, "a technological trajectory is an "institution" which like any institution is sustained not through any internal logic but because of the interests that develop in its continuance and the belief that it will continue". ${ }^{30}$

\subsubsection{The problem of compatibility}

This brings us to the role of institutions and technical interrelationships in the selection of technologies and the ways in which they shape technological trajectories. As a theoretical organizer we use the term "selection environment", stemming from the evolutionary

27 W. Brian Arthur, 1988, Competing Technologies: An Overview, in Giovanni Dosi, Chris Freeman, Richard R. Nelson, Gerald Silverberg and Luc Soete (editors), Technical Change and Economic Theory, London: Pinter Publishers, pp.590-607.

${ }^{28}$ Ibid, p.591.

${ }^{29}$ The story of the QWERTY typewriter keyboard which became the dominant standard for keyboards despite the superiority of the later developed Dvorak keyboard is described in Paul A. David, 1985, Clio and the Economics of QWERTY, American Economic Reoiew AEA papers and proceedings, 75: 332-337.

30. MacKenzie, op cit, p.34. 
theory in biology, and introduced into the economic literature by Nelson and Winter. It is chosen as a more general term than "market" (or market demand) to emphasize the institutions involved and the mechanisms behind the selection of an innovation. The selection environment is defined by the capital outlays, physical infrastructure, supplieruser linkages, production routines, skills, technical standards, government rules, norms, people's preferences and beliefs.

The term "selection environment" is used to illustrate the importance of the historical socio-economic context in the selection of innovations. Whereas economists use the concept of a demand curve, describing the relationship between quantities demanded and purchase price, we prefer the term "selection environment", which brings out the systematic nature of technology and economy, the transfer of knowledge and information that are necessary for exchange to take place, social processes of habituation and taste formation, and political factors in the selection of an innovation. The important point here is that a technology needs to be incorporated into a larger technical and socioeconomic system which has evolved in the process of development.

Between firms, but also inside firms, all kinds of technical, economic and institutional interrelationships have developed that may hinder the adoption and use of a new technology. Within an economic system, activities are coordinated and were optimized in the past. Patterns of exchange and information transfer are established through supplieruser relationships and intra-organizational linkages. What we have is economic actors dealing with each other, using materials with specific physico-chemical properties, using special-purpose machinery and equipment, employing workers with certain skills and knowledge, and operating within a broader socio-economic context. A new process or product must be embedded in the existing production processes of potential users and must comply with a diversity of qualitative demands (in terms of performance norms, durability, user-friendliness, etc.).

In such circumstances, the introduction of new technologies may require the replacement of large parts of the production system, creating an unusually heavy obsolescence problem. A special kind of technical interrelationships are technical standards that create well-known problems of compatibility and raise complex issues of strategic behaviour and government intervention. ${ }^{31}$ Institutional rigidities usually aggravate the problem of technical interrelationships. The use of new technologies may require new labour skills, management styles, and other kinds of institutional changes (for instance new legislation). Vested interests (firms, industries, workers associations, etc.) may also hinder the adoption of new technologies and the growth of new technological systems. $^{32}$

${ }^{31}$ For an overview of these issues, see Paul A. David and Susan Greenstein, 1990, The Economics of Compatibility Standards: An Introduction to Recent Research, Economics of Innovation and New Technology, 1: 3-41.

${ }^{32}$ The importance of institutional factors in technological change is a central element of The Theory of Economic Progress by Clarence E. Ayres, first published in 1944 by University of Carolina Press. 
Consumer tastes, life styles and habits are also an important part of the selection environment. But consumer tastes, preferences and the ways in which people live their lives are not autonomous factors: they are shaped by the adoption and use of past technologies. Technological progress in food distribution, together with the widespread diffusion of the automobile, have changed shopping habits dramatically. Also the movement towards living in suburbs and the countryside is related to the availability of the automobile as a convenient means of individual transport. These two examples illustrate that technology is an important factor in shaping people's lives, either directly through the services provided by the technology or indirectly by increasing real disposable income. Of course, we do not want to suggest that social changes are the result of antecedent changes in technology only. Technological change and socio-economic trends co-evolve and interact.

Besides social adaptations in response to technological change there may also be mechanisms of habituation and endogenous taste formation at work. ${ }^{33}$ People have gained experience with certain goods and have become habituated to them. An important implication of this is that new technologies are evaluated in terms of the characteristics and services of the old technologies. This may explain the trajectory of ever more powerful cars in a world where speed limits are becoming more and more tight. The fact that people are used to having a car with a certain mileage and speed may obstruct the development of a car with totally different characteristics (for instance, an electric vehicle with a relatively low speed and range and long recharging times). In the process of consumer taste formation there are also complex social aspects involved such as status, appeal, emulation, social acceptance, etc. These social aspects are still not well understood, but they may have important implications for the ultimate choice of technolugies. New ideas about social behaviour and different values may be needed for new technologies to be adopted and used.

The government is also an important actor within the selection environment. Through its science and technology policy, the government is involved in the generation of knowledge and through its education policy in education and skill formation. Public authorities are often heavily involved in the provision of infrastructures (roads, telecommunication, etc.) which are so important for the growth of new technological systems. As a last point, the government's tax policy, industrial policy, procurement and regulation all affect the economic process in important ways.

But just as firms and consumers are adapted to the old technological regimes, so are governments. Environmental and safety standards are usually based on well-proved compliance technologies, which hinders the adoption and development of more advanced technologies. Industrial policy is often aimed at the protection of old industries that are challenged by new firms and technological advances. Time is needed for new

${ }^{33}$ The terms "habituation" and "endogenous taste formation" are used by Paul David in his 1975 book Technical Choice, Innovation and Economic Growth. Essays on American and British Experience in the Nineteenth Century, Cambridge: Cambridge University Press. A recurrent theme in Paul David's work is the importance of historical factors in the rate and direction of technological change. 
skills and ideas to penetrate in the education system, and so on. The key problem for new technologies to become incorporated into the socio-economic system is that of compatibility. Within the process of economic development, technical interrelationships and institutional rigidities have developed that may hinder technological shifts. New technologies that can be easily embedded in the production system and people's ways of life will diffuse more rapidly than technologies which require the replacement of capital goods, a new infrastructure, different skills, new ideas about production and consumption, and regulatory changes. Not only do the characteristics of the selection environment determine the relative use of technologies over time but these characteristics also have implications for the kind of search activities that are likely to be undertaken by for-profit organizations.

The above helps to explain why manufacturers often strive to develop so-called "drop-in" innovations which can be easily embedded in existing production processes and require few changes in the selection environment. For example, in the case of chlorofluorocarbons (CFCs), research efforts are directed towards the development of CFC substitutes (e.g. as cooling medium in refrigerators) that can be easily embedded in the economic and social environment rather than towards the development of totally different production techniques and products (e.g. a refrigerator with a totally different cooling system). Not only do the manufacturers of CFCs have an interest in developing these innovations that belong to the old CFC trajectory but so do the users of CFCs. The idea of a selection environment shaped by the application of past technologies also explains the dominance of "end-of-pipe" techniques over "process-integrated" changes because the former can simply be added to the existing production processes.

\subsection{Conclusion}

Contrary to popular public perceptions of revolutionary technical change and heroic inventors, modern historical studies find that technological change is much more a cumulative and gradual process, proceeding in quite specific directions. Underlying these technical advances are engineering ideas and beliefs of technical opportunities for improvements. These engineering beliefs and expectations of where to go to, what problems to solve, and what sort of knowledge to use, are often shared among communities of technologists. The reason why such beliefs are shared is believed to be related to economic supply and demand factors (past capital formation, accumulated knowledge and experience, cost efficiencies and product improvements achieved with the old technologies, social habituation and adaptation, etc.) rather than to cognitive limitations of imagination, although the two explanations are strongly related since they reinforce each other.

Of course, the argument should not be carried too far. Although there are some powerful mechanisms that reinforce the embedment of technologies in the economic and social system, there were major technological regime shifts in the past. How such transitions come about, and particularly what economic factors are involved in large-scale 
technological shifts will be discussed in the next chapter. 


\section{Chapter 11}

\section{Understanding Technological Regime Shifts}

This chapter examines shifts in technological regimes as opposed to changes within a technological regime. Key factors in inducing and sustaining shifts in technological regimes are identified and discussed in section 1, using historical examples to illustrate theoretical arguments. Section 2 looks into the phenomenon of competing designs in periods of radical technological change, where different designs compete for market dominance. This is followed in section 3 by a discussion of the transition process into a new technological regime. Here we provide an explanation as to how it is possible for a new technological regime to emerge and replace the old one - emphasising the importance of market niches, available knowledge that may be used, institutional support for new technologies and the role of expectations. Section 4 deals with the relation between technological regimes shifts and firm behaviour. It asks the following questions: How do new technological systems come about in a world of specialization and decentralized decision-making? How are ideas of radically new technologies that require a different knowledge base and production capabilities translated into tradeable products? The final section draws some conclusions.

\subsection{Determinants of Radical Technological Change}

When taking a long-term historical perspective, we see that at certain times technological paradigms and systems become outdated and are replaced by new ones, despite the selfsustaining elements involved in the development of technological paradigms and regimes. At certain historical moments, radical innovations are produced challenging the old paradigm and gradually replacing it (although the two may co-exist for a long time). Despite the importance of such events, our knowledge of how radical innovations come into being and how they come to replace the old regime is rather limited. There do exist, however, certain clues about what induces technological breakthroughs and some ideas of the factors that govern the diffusion of radical innovations and the evolution of large technological systems.

It is frequently stated that radical innovations depend on new scientific insights opening up new technological and economic opportunities. ${ }^{1}$ For example, Maxwell's

1 The importance of scientific discoveries to the development of several radical innovations (synthetic dyes, plastics, drugs) in the chemical industry has been analyzed empirically in Vivien Walsh, 1984, Invention and Innovation in the Chemical Industry: Demand-Pull or Discovery-Push?, Research Policy 13: 211-34. 
theory of electromagnetism in the 1860 s was instrumental to the development of radio technology, although the understanding of the phenomenon of electromagnetism did not lead directly to the radio as a new consumer product; several decades of applied research and experimentation were needed to turn it into a tradeable product. Radical innovations sometimes also critically depended on breakthroughs and advances in engineering and material technology. Perhaps the best example is James Watt's steam engine with its separate condensing chamber, which depended for its production and success on Wilkingson's boring mill.

This raises the question as to what other factors are conducive to the development of radical innovations. So far, we have discussed the importance of new scientific insights to the development of radically original products. They provided essential knowledge and guidance to engineers in achieving technological breakthroughs. Pressing technological needs that could not be met with available technologies and required fundamentally different solutions are another factor. These technological needs may stem from bottlenecks or reverse salients that arise in the growth of technological systems, or stem from pervasive shifts in consumer preferences. Many technological breakthroughs are also achieved in war times, when demand for new and better military technology is especially high as is the need to develop substitute products and materials when nations are cut off from critical supplies. To these technological needs, we may add the demand for more environmentally benign technologies to arrest environmental degradation.

It may also be that old trajectories have reached certain technical limits or that further advances along the same trajectory run into increasing marginal costs. ${ }^{2}$ In terms of the modern philosophy of science, engineers may confront an "anomaly" which leads them to search into a new direction of technological advance, based on a different knowledge base and engineering principles. Such anomalies need not constitute acute and pressing problems. Also the perception of theoretical limits for advancement may induce firms and technologists to shift towards a different technological regime. Edward Constant uses the term "presumptive anomaly" for such a situation. ${ }^{3}$ A presumptive anomaly emerged in the late 1920 s when insights from aerodynamics indicated that the conventional piston engine-propeller system would not function at the near-sonic speeds foreseen for airplanes. ${ }^{4}$ This led to the invention of the turbojet engine.

Often, radical innovations are produced by newly established firms or by industries diversifying into a new market. There are several possible explanations as to why radical innovations are developed and supplied by outsiders. First, a radical innovation may require a different knowledge base which may not be available in the manufacturing industry. In relation to this, "community practice may define a cognitive universe

${ }^{2}$ Paolo Saviotti and J. Stanley Metcalfe, 1984, A Theoretical Approach to the Construction of Technological Output Indicators, Research Policy, 13, p.149.

\footnotetext{
${ }^{3}$ Edward E. Constant, 1980, The Origins of the Turbojet Recolution, Baltimore: John Hopkins University Press, p.75.
}

${ }^{4}$ Hughes, 1987, op cit, p.75, who based himself on Constant, op cit, pp.194-207 and 242. 
that inhibits recognition of a radical alternative to convention practice". ${ }^{5}$ Second, vested interests may obstruct the development of a different technological system or paradigm. According to Thomas Hughes, this was the reason why so many technological breakthroughs in the late nineteenth and early twentieth centuries were achieved by independent inventors who had distanced themselves from large organizations:

They [the independents] rightly sensed that the large organization vested in existing technology rarely nurtured inventions that by their nature contributed nothing to the momentum of the organization and even challenged the status quo in the technological world of which the organization was a leading member. Radical inventions often deskill workers, engineers, and managers, wipe out financial investments, and generally stimulate anxiety in large organizations. Large organizations sometimes reject the inventive proposals of the radicals as technically crude and economically risky, but in so doing they are simply acknowledging the character of the new and radical. ${ }^{6}$

This same argument applies to modern firms, although such resistance may be less fierce now technological competition is becoming more and more important to the survival of the firm. Radical inventions may still endanger current activities of firms and for that reason be rejected or delayed. On the other hand, new technological developments may be nurtured by industries or organizations having an interest in the development of the new product. The development of clean coal-burning technologies is strongly supported by the coal industry in an attempt to secure the usage of coal in a world where environmental regulation is getting tighter. Electricity producers have supported the development of the electric car, as have producers of plastics. Customer firms may also actively support the development of new technologies, by providing information about product requirements and their involvement in tests. Even consumers may be involved directly in the support of new technologies. As an interesting example, the German branch of Greenpeace has provided financial means for the development of a CFC-free refrigerator by an East German firm. They also took care of the marketing of the product through their magazine.

The propensity to take risk may also be an important factor in the development of radical innovations. Risk-taking entrepreneurs are often identified with the development of radically new products. They may be inventor-entrepreneurs such as Thomas Edison, venture capitalists that financially support an innovation, or managers that lead their firm into a new technology field. Schumpeter even based his theory of economic development on these entrepreneurs, picturing them as heroic men of great will, vision and persistence.

${ }^{5}$ Edward E. Constant, 1984, Communities and Hierarchies: Structure in the Practice of Science and Technology, in Rachel Laudan (editor), The Nature of Technological Knowledge: Are Models of Scientific Change Relevant?, Dordrecht: D. Reidel, Pp.27-46.

${ }^{6}$ Hughes, op cit, p.59. 
It should be emphasized that the importance of entrepreneurship and pioneering firms lies not so much in the market share they are able to achieve, for that is likely to be small (at least in the early years), but much more in inducing other firms to take risks and change their strategies. For the development of an alternative trajectory it is important that the traditional firms possessing great market power, specialized knowledge and large financial means commit themselves to the development of this trajectory. It is only through the commitment of other firms that a dynamic learning process may emerge, resulting in a wide array of post-innovation product improvements, complementary innovations and cost reductions, which gives the new regime enough "momentum" so as to replace the old one.

As a last general point, also non-market mechanisms were often important in the establishment of a new technological regime or paradigm. As noted by Chris Freeman, universities and public laboratories often played an important role in the generation of the original radical innovations, as did government procurement in their early applications. Each new paradigm requires a modification to infrastructure which can only occur as a result of institutional and regulatory changes in each country. Particularly important in the evolution of the Information and Communication Technology (ICT) paradigm were public programmes for computer technology and public policies for the telecommunications infrastructure.

\subsection{Competing Designs}

In the previous section we have discussed the emergence of radical innovations which came to replace old technological paradigms and technological systems - where we noted the importance of fundamental breakthroughs in science and technology, particular technological needs, the economic context (and wider social and political context), and the presence of entrepreneurs in such events. From the above one may get the impression that the replacement of old technological regimes was a relatively straightforward process. It would be a mistake to think so. In many cases it was not a straightforward event to the people living in those ages, not even to those who were actively involved in the development of the new regime. At times in which a radical invention was developed which later came to dominate the market, there were usually different technologies and different designs to satisfy a particular need. The fact that different technologies were produced and supported by various organizations implies that the later dominance of one particular technology and design was not at all obvious. ${ }^{8}$

${ }^{7}$ Chris Freeman, 1992, A Green Techno-Economic Paradigm for the World Economy', in his book The Economics of Hope, London: Pinter Publishers, p.202.

${ }^{8}$ To illustrate this: in 1893 , a group of 74 prominent Americans were asked to write an essay about what the world would look like in 1993 . These predictions were recently published in the book Today Then: America's Best Minds Look 100 Years into the Future on the Occasion of the 1893 World's Columbian Exposition, compiled by Dave Walter (American \& World Geographic Publishing, 1993). 
Some examples of different technologies competing for a market of adopters are given by Brian Arthur:

In the 1890 s the motor carriage could be powered by steam, or by gasoline, or by electric batteries. In more modern times nuclear power can be generated by lightwater, or gas-cooled, or heavy-water, or sodium-cooled reactors. Solar energy can be generated by crystalline-silicon or amorphous-silicon technologies. An AIDS vaccine may eventually become possible by cell-type modification methods, or by chemical synthesis, or by anti-idiotype methods. Video-recording can be carried out by Sony Betamax or by VHS technologies. ${ }^{9}$

The reason why various technologies with different designs based on different engineering principles are developed at about the same time is related to the following factors. First, the opening up of technological and economic opportunities by new scientific knowledge (as in the case of nuclear power). Second, the emergence of particular technological needs (as in the case of an AIDS vaccine). Third, the discovery of a new market (as for bicycles). Fourth, uncertainty as to the "best technical solution" for meeting certain market needs (which is related to uncertainty about the future rate of technological progress). Fifth, uncertainty about market demand and the evolution thereof. Sixth, the fact that the technologies are produced by organizations with different technological capabilities and interests.

Since all these factors usually operate at the same time, it is difficult to assess their relative importance. Of these factors, however, uncertainty about technological opportunities and user needs are known to constitute two fundamental problems. The long-run success of a product strongly depends on the rate of technological advance that may be realized in a certain product and design. The technical advances to be realized depend on the potential for improving performance characteristics and achieving cost efficiencies and on the ability of innovating firms to solve certain critical problems. It also depends on the rate of technical progress in other industries and scientific advances at universities. All types of advances are difficult to predict.

Uncertainty about user needs and requirements (and the evolution thereof) is another serious problem. Although engineers and marketers may have certain notions about what "the market" wants, market demand for a new product does not articulate itself in an unambiguous and quantitative way. As Morris Teubal writes:

\footnotetext{
Almost all forecasts turned out to be wrong, in fact most predictions were completely wrong. For example, the common opinion in 1893 was that in 1993 the railroad would still be the fastest means of transport. Air travel was considered to be an alternative way of transport, but only in balloons. None of the forecasters anticipated the future dominance of the automobile, a product which at that time had already found its way in the street (based on Edward Cornish, 1993 as Predicted in 1893: If They Could See Us Now, The Futurist, May-June, 1993).
}

${ }^{\circ}$ Arthur, op cit, p.590. 
Technological innovation, like the activity of production, may be regarded as induced by human needs, but unlike it these needs are frequently not represented by an unambiguous and well-defined market or demand curve. Innovations generally involve a new product component and in so far as this is so they precede the generation of markets and demand curves. They should accordingly be regarded as responses to more general, less-defined needs than those expressible in terms of well-defined markets or demands (original italics). ${ }^{10}$

It should be noted that the problem of user needs is not so much whether people or firms would like to have the innovation but about how much they are actually prepared to pay for it (their "willingness-to-pay") - which depends on their conception of the product and their valuation of the service characteristics. This problem of user needs and market demand is particularly large for radical innovations (a computer, an automobile, a radio or even a bicycle) that constitute a radical departure from past practices. For radical innovations, the problem of user needs is not only a problem of preferences which are not revealed in the market place but also a problem of needs and wants which are not yet determined. What we may have, in the words of Teubal, is consumers who learn about what they want or need."

It furthermore implies that innovating firms involved in the commercialization of a radically new product must not only engage in developing and producing the artefact, but must also engage in shaping the market: to organize the product's distribution, to inform customers about its existence and performance characteristics, to persuade them to purchase the new product, and to educate them in using it. ${ }^{12}$ They may also need to go into scientific and public debates about the efficacy and desirability of the new product or to persuade policy makers to change the legal framework (the definition of property rights, the setting of more strict environmental standards, etc.).

\subsection{The Shift into a New Technological Regime}

Up until now we have not discussed how it is possible for a radical innovation to establish itself as a dominant technology in the market place. In chapter 9, we noted that there exist powerful mechanisms that reinforce the entrenchment of a technology in the socioeconomic system. How are radical innovations able to compete with well-developed technologies that are adapted to user needs and integrated in the economic system? One explanation is the presence of a specialised market for which no real alternative is

${ }^{10}$ Morris Teubal, 1979, On User Needs and Need Determination: Aspects of the Theory of Technological Innovation' in M.J. Baker (editor), Industrial Innovation: Theory, Policy, Diffusion, London: MacMillan, p. 266.

${ }^{11}$ Ibid, p.275.

${ }^{12}$ Kenneth Green, 1992, Creating Demand for Biotechnology: Shaping Technologies and Markets', in Coombs et al., op cit., pp.169-170. 
available. For example, the first steam engines, the Newcomen and Savary engine, could compete with alternative power sources in only one niche market: deep-drainage mining. ${ }^{13}$ These early market niches are important for the further development of the new technology. Besides providing necessary financial means, the experiences of users are an important source of information in helping firms further to improve the product.

Radical technologies may also benefit from accumulated experience in other sectors, and from the presence of a network in which it can be easily introduced. It is perhaps not well known that the automobile owed much of its success to the bicycle. Experience accumulated in bicycle production was put into good use in the automobile industry and an improved road infrastructure was already present. Existing components and products could often be incorporated in, or combined with, new technologies. Photographs of the first automobiles clearly show that the automobile originally was nothing else than a carriage powered by an engine instead of being drawn by a horse (the early expression of a "horseless-carriage" thus described the first automobiles rather well). Only in a few respects did radically new products constitute a radical break with the past, which suggests that the term "radical" is somewhat misleading. Radical innovations often combined the new with the old (or even combined older technologies) and often rightly so because this helped the product to survive the initial harsh market selection and establish itself in the market place. A good example of an intermediate technology were the first steamships. According to Joel Mokyr, "the first steamships were really sailing ships with auxiliary engines, with steam only helping out against unfavourable winds and tides". ${ }^{4}$

As noted by Chris Freeman, in every change of a techno-economic paradigm which has occurred so far, the new paradigm already emerged and developed within the previous one. Steam power (the second techno-economic paradigm) was based on a technology already well established. Electric power (the third techno-economic paradigm) was developing over half a century before the generation and transmission of electricity became widespread towards the end of the nineteenth century. Mass production (the fourth techno-economic paradigm) was already established in such industries as meat-packing and automobiles decades before it became the dominant system. The fifth information and communication technology paradigm has been developing since the Second World War to the point where it is achieving dominance today. ${ }^{15}$

${ }^{13}$ Tine Bruland and Olav Wicken, 1993, Large-Scale Technological Transitions in Economic History: Steam Power and Electricity, Chapter 5 of René Kemp et al, Technology and the Transition to Environmental Stability. Continuity and Change in Technological Systems, final report for SEER programme of the Commission of European Communities, p.112.

14 Joel Mokyr, 1989, Twenty-Five Centuries of Technological Change: An Historical Survey, London: Harwood Academic Publishers, p.84.

${ }^{15}$ Freeman, 1992, op cit., p.207. 


\subsection{Firm Behaviour and Technological Regime Shifts}

In the preceding sections we discussed technological regime shifts without an explicit discussion of firm behaviour. This is a clear shortcoming since firms are central institutions in the shaping of trajectories of technological advance: user needs are translated in economic goods by firms and production of these goods is organized in firms. Unfortunately, the relationship between firm behaviour and technological regime shifts is a relatively under-researched area. It involves the integration of studies which have been carried out separately from each other: evolutionary theories of technical change, corporate decision making and strategy, and organisation theory. It raises a number of questions which are highly relevant to a better understanding of this important relationship. For instance: How do new technological regimes come about in a world of specialization and decentralized and myopic decision making? How are innovating firms able to appropriate the economic benefits from systemic innovations? What are the implications of economic organization for the development of new technological systems?

To start with the first question: How is it possible for firms with a restricted knowledge base and highly specific technological capabilities to engage in developing a radical technology which requires different knowledges, skills, machines and performs different functions? Perhaps there does not exist a good answer to this problem. Perhaps firms underestimate the problems involved in the development and commercialization of a radically original product. Maybe it is overoptimism in the commercial viability of radically original technologies that induces firms to develop and introduce a radically new product or process. In this connection, Ian Miles notices that, just as in the establishment of a new scientific paradigm, there may be an element of "hype" in the emergence of a new technological regime:

This hype involves overstatement of the speed of change and rapidity of realisation of benefits, it creates heroes and exemplars, and it serves to cement together the networks of agents whose semi-coordinated action is necessary to bring about substantial shift in interconnected technologies and practices. ${ }^{16}$

Although this may be an important element in technological regimes shifts, there are other explanations. One such explanation is that radical innovations are produced by firms with a knowledge base which is highly relevant to the new product. For example, firms in the dye and organic chemicals industry with special knowledge in synthetic chemistry moved into pharmaceutics (a field traditionally based on analytical and extractive chemistry), and oil companies moved into the new business of producing

${ }^{16}$ Ian Miles, 'Shifting Paradigms: How are Transition Paths Constructed?', internal discussion paper EC-project Technological Paradigms and Transition Paths: The Case of Energy Technologies, PREST, Manchester. This corresponds to the idea of self-fulfilling prophecies in technology development expressed by MacKenzie, op cit. 
plastics. ${ }^{17}$ New firms may also be created by inventor-entrepreneurs, as done by people like Edison, Perkin, Baekeland and more recently (with less success so far) by bioscientists with the help of venture capital.

Firms may also decide to collaborate with other firms in order to develop a new innovation. They may engage in joint $R \& D$ projects, or involve users in experiments with the new product. When learning curve effects are believed to exist, they may decide to sell the product at a loss initially, as some kind of investment, in order to benefit from user experience and achieve cost efficiencies in manufacturing through accumulated experience. Such a strategy, however, has the danger of running into vast financial losses and will only be undertaken by large organizations with sufficient financial means. Another possible strategy is to involve potential beneficiaries from the new product in its development, although uncertainty about the likely economic gains may prevent potential beneficiaries from taking part in the development (both technically and financially). Such firms may also be unwilling to share economic benefits with the innovator, which brings us to the issue of appropriability.

The appropriability conditions are about the ability of the original innovator to capture the benefits from the innovation and "hold off other firms from eating too much and too rapidly into these returns". ${ }^{18}$ As noted by David Teece, it may be more difficult for suppliers of systemic innovations that often require complementary assets (special materials, machinery, skills) to appropriate the benefits from innovation. Control over complementary assets may be necessary to capture the benefits from innovation when the appropriation regime is weak. ${ }^{19}$ Elsewhere, Teece discusses the vertical integration of General Motors into electrical equipment supply and its implications for the development of the diesel electric locomotive. In the case of General Motors it is found that this integration reduced costs by "internalizing market exchange under circumstances (uncertainty, technological interdependence) which generated significant contractual difficulties". ${ }^{20}$ Furthermore, the pace of product development was stimulated by a more harmonious information exchange. Teece concludes that "the experience with vertical integration in the diesel electric locomotive building industry suggests that technological innovation displaying interdependencies among the parts is greatly facilitated by common ownership of the parts". ${ }^{21}$

This does not imply that vertical integration is always conducive to the development of systemic innovations, a point taken on board by Teece, when he writes that

${ }^{17}$ Walsh, op cit, pp.227-232.

14 Richard R. Nelson, 1987, Uniderstanding Technological Change as an Evolutionary Process, Amsterdam: North-Holland, p.52.

19 David ]. Teece, 1986, Profiting from Technological Innovation: Implications for Integration, Collaboration, Licensing and Public Policy, Restarch Policy, 15: 285-305.

${ }^{20}$ David J. Teece, Technological Change and the Nature of the Firm, in Dosi et al., op cit, p.274.

${ }^{21}$ Ibid, p.274. 
"older, vertically integrated firms may have a greater commitment to older technology because of the large technology-specific investments they have made upstream and downstream". ${ }^{22}$ This leaves the issue whether vertical integration is favourable to the development of radical innovations rather inconclusive (although Teece is of the opinion that the favourable appropriability conditions under common ownership outweigh the unwillingness of firms to "cannibalize the value of past investments"). Of course, the whole issue of appropriation is much more complex. The appropriability conditions also depend on the market power of the firm and the existence of entry barriers preventing other firms from entering the industry and challenging incumbent firms.

Important as the issue of appropriability of economic benefits may be, to us, a greater problem seems to be that there are few or no benefits to reap, at least not in the early stage, as the new technology has to compete with well-developed, existing technologies, depends for its success on technical advances (in material technology, complementary technologies) outside the innovating firm, may need the construction of physical infrastructure, and must find ways of persuading potential customers into buying the new product. Probably more important for the take-off of the new regime is that an early market niche may be found for some applications. Besides providing financial means, it helps to build "a wide constituency behind the product" as Ian Miles calls it, finding support from other actors in the selection environment (firms, government agencies, beneficiaries). ${ }^{23}$

For the innovating firm to capture such a market niche, it may need to engage in what Arie Rip and Johan Schot call "strategic niche management": the identification and shaping of the market in which the new technology may first be employed. Kenneth Green speaks of creating a "market space" and describes how biotechnology firms attempted to create a market space for monoclonal antibodies, a promising cancer therapeutic. He describes how in the case of monoclonal antibodies, biotechnology firms identified diagnostics as products that could be quick revenue-earners, as they could be produced in small volumes (so there would be few scale-up problems from laboratory experiments), extensive in-human testing would not be required (since they were intended for in vitro use), and they could be used for quick, cheap diagnosis for a range of infectious diseases for which no equivalent competing technology existed. ${ }^{24}$ The fact that even for this application, it proved to be difficult for biotechnology firms to make money illustrates how difficult it is to create a market for a radically new product.

To give another example, firms in the motor car industry are engaged in developing electric vehicles. The following market segments are identified as being suited for

${ }^{22}$ Ibid, p.274. This argument is not new. Thomas Hughes made the very same point and Teece himself refers to James Utterback as one of the writers using this argument.

${ }^{23}$ Johan Schot refers to this as the creation and utilisation of the technological nexus (Johan Schot, 1992, The Policy Relevance of the Quasi-Evolutionary Model: The Case of Stimulating Clean Technologies, in Coombs et al., op cit, pp.193-196).

${ }^{24}$ Green, op cit, pp.172-173. 
electric road vehicles: private passenger cars for urban use, buses, commuter vans, taxis. ${ }^{25}$ Research and development activities are directed towards developing electric vehicles for these purposes. These niches may be expanded when manufacturers are able to solve some critical problems with electric vehicles, especially those pertaining to batteries, and consumer willingness to purchase electric vehicles gradually increases over time (which depends on the performance and costs of the electric car, government tax policies, and social pressure in favour of using an environment-friendlier motor car). Under those circumstances, electric vehicles may seize a substantial part of the future automobile market.

\subsection{Conclusions}

This chapter examined inducement mechanisms of radical change in technology and the transition process into a new technological regime. The following inducement mechanisms are identified: First, new scientific insights opening up new technological opportunities (such as the development of electromagnetism); second, pressing technological needs such as technical bottlenecks in the development of technology, high costs of further advances within a technical design, changes in demand (especially for military technology), scarcity of materials, labour conflict; and third, entrepreneurial activities and institutional support for radically original technologies. The chapter also provides an explanation as to how it is possible for a radically new technology to replace well-developed existing technologies - emphasizing the importance of early market niches, available knowledge and techniques that may be used to produce and market the product, expectations, and changes in the technology and the socio-economic context.

${ }^{25}$ Boelie Elzen and Johan Schot, 1992, Fumbling with the Car: How to Influence a Highly Entrenched Technology? Paper for the joint 4S/EAST Conference 12-15 August, Gothenberg, Sweden, p.5. 


\section{Chapter 12}

\section{The Transition from Hydrocarbons}

The present energy system based on fossil fuels gives rise to a range of environmental problems - from photochemical smog and acid rain to greenhouse warming. The implication of fossil fuels in many of the world's environmental problems suggests that environmental sustainability requires - at least in part - new technologies for energy supply, conversion and end-use. At this moment, many public and private decision makers are thinking about how to achieve a smooth transition away from fossil fuelbased energy technologies, and many sensible proposals have been made - like more government R\&D for renewable energy and energy conservation, the introduction of carbon taxes etc. However, what is missing in the policy debate is a framework for understanding change in complex technology systems, especially how the dynamics of technology interact with the socio-economic system from which it emerges. In chapters 10 and 11 we outlined such a framework. The aim of this chapter is to apply this framework to the problem of inducing a transition away from hydrocarbon-based energy technologies towards a more environmentally sustainable energy system.

It must be emphasized that this chapter is an exploration of the policy issues of making a transition away from fossil fuels. It does not spell out the details of specific GHG policies (such as the optimal level of a carbon tax and size of R\&D budgets), but provides a general discussion of how public policy may be used to begin and sustain a transition towards a more sustainable energy system, one in which renewables and energy-efficient supply and end-use technologies are used more intensively.

The chapter is organised as follows. Section 1 examines the relationship between greenhouse warming and energy technologies. This is followed by a discussion of the systemic nature of energy technologies and a discussion as to why it is so difficult for alternative energy technologies to make an impact (section 2). Section 3 provides a short discussion of three technology scenarios, depending on whether the change is recognizable as being within the hydrocarbon energy regime or constitutes a departure from the present energy system. Section 4 discusses possible energy technology policies, besides traditional tax and standards policies. The final section talks about strategic niche management as a way to manage the transition to a more sustainable energy future.

\subsection{Greenhouse Warming and Energy Technologies}

Environmental concerns rank high on the list of today's worries. Of the environmental risks, greenhouse warming is viewed by many as the most complicated and potentially most far-reaching problem. According to the Intergovernmental Panel on Climate Change (IPCC), global mean surface air temperature has increased by $0.3-0.6^{\circ} \mathrm{C}$ over the 
last hundred years, with increases as high as $0.3{ }^{\circ} \mathrm{C}$ per decade expected for the next decades, if present trends continue. ${ }^{1}$ Together with the increases in temperature, global sea level has increased by $10-20 \mathrm{~cm}$ over the same period, mainly as a result of the thermal expansion of oceans. Although scientific evidence is still inconclusive, there is wide consensus among natural scientists that the rise in temperature and sea level are due to increases in atmospheric concentrations of (long-lived) radiatively active trace gases (carbon dioxide, methane, nitrous oxides, and CFCs) that enhance the natural greenhouse effect. Although virtually every form of human activity contributes some amount of greenhouse gas to the atmosphere, (fossil fuel-based) energy consumption is a key factor. The major proportion of man-made $\mathrm{CO}_{2}$ emissions and a large part of manmade $\mathrm{N}_{2} \mathrm{O}$ emissions are related to energy use. ${ }^{2}$

Contrary to popular views, greenhouse warming does not simply mean that things get warmer. Greenhouse warming has many facets: besides changes in temperature and sea levels, there will be changes in rainfall patterns, storminess, and, possibly, in the direction of ocean currents. Greenhouse warming may in fact lead to lower temperatures in certain regions - for instance, a change in the gulf stream may freeze Western Europe. In other words, greenhouse warming is about climate change; the rise in global temperature is an index of climate change which measures the departure of future climates from what they are now.

Many different policies could be adopted to deal with greenhouse warming. They may be divided into three types: ${ }^{3}$

i. Options that eliminate or reduce greenhouse gas emissions.

ii. Options that offset emissions by removing greenhouse gases from the atmosphere, blocking incident solar radiation, or by altering the reflection or absorption properties of the earth's surface.

iii. Options that help human and ecological systems adjust or adapt to new climate conditions and events.

The first and second type of interventions are "mitigation" options; the third option is that of "adaptation". Option i) consists of preventive policies like reductions in energy

\footnotetext{
1 J.T. Houghton, G.J. Jenkins and J.J. Ephraums (eds.), 1990, Climate Change. The IPCC Scientific Assessment, Cambridge: Cambridge University Press, p. xii. The uncertainty range of global temperature increases is $0.2-0.5^{\circ} \mathrm{C}$. It bears noting that economic models show lower emissions and temperature increases than the extrapolative approach used by the IPCC because they project relative rising prices and slowing economic growth (William D. Nordhaus, 1993, Reflections on the Economics of Climate Change, Journal of Economic Perspective, 7(4), p.14.

2 OECD/IEA, 1991, Greenhouse Gas Emissions. The Energy Dimension, Paris: OECD.

${ }^{3}$ National Academy of Sciences, 1991, Policy Implications of Greenhouse Warming, Washington: National Academy Press.
} 
use, stopping deforestation and switching to non-fossil fuels - birth control also is an example of a preventive policy. Examples of the second type of mitigation policies (option ii) are: the sending of particles into the stratosphere to change the albedo (reflectivity) of the earth or to put trace quantities or iron in the ocean to increase the rate of carbon precipitation to the ocean floor. Such interventions are also referred to as "climate engineering" or "geoengineering" policies. Up until now geoengineering options have not been given much attention in the policy debate, partly for the reason that they pose a risk to society in themselves. The final strategy (option iii) is to adapt to climate change, something mankind has been doing for long. Human society may adapt to climate change in several ways: by using more air conditioning or different clothing (to give two of the more simple responses), by building dikes, cultivating different crops, changing one's food habits, and by migration.

It is important to recognize the broad range of possible actions to deal with climate change. They range from big technical fixes to simple changes in behaviour. This chapter will consider the mitigation options; it will analyse how public policy may be used to induce a swift and smooth transition away from hydrocarbon-based energy technologies.

\subsection{The Need for an Evolutionary Model of Technological Change}

In the global warming debate, the role of economists has been primarily to assess and compare the costs and economic benefits of possible measures (scenarios) for reducing greenhouse gas emissions. For this purpose, economists have typically adopted a "topdown" approach: aggregated econometric models are used to generate predictions about changes in the energy mix and energy efficiency. 'Underlying the models' results are assumptions about GNP growth, population growth, behaviour, resource reserves and costs of primary energy inputs. In the main, the effects of carbon taxes or tradeable emission rights are analysed. In the models, price changes govern the process of energy savings and shifts in energy mix. There also exist a number of engineering studies predicting market penetration levels of emerging energy technologies. These are "bottomup" studies based on detailed knowledge of energy technologies and of the markets in which they may be used.

These two types of approaches are the basic tools to assist policy makers in designing policy measures for dealing with the greenhouse problem. Unfortunately both types of approaches suffer from rather simplistic assumptions about the dynamics of energy substitution and technological change. As David Kirsch writes, the top-down studies either assume autonomous improvements in energy efficiency or posit the existence of

\footnotetext{
"The discussion of top-down and bottom-up studies of energy-economy-environment linkages is based on David A. Kirsch, 1992, The Impact of Technology Upon the Interaction of Energy, Environment and the Economy, MA thesis, MERIT, Maastricht.
} 
back-stop technologies that become economical at an externally specified threshold price. Furthermore, the social context remains essentially unchanged, whereas in reality important new technologies transform the system from which they emerge. The bottom-up studies, by contrast, draw from a predetermined set of technological options. That is, technological heterogeneity is specified ex ante, rather than as part and parcel of the selection process. The possibilities for radical innovation, on the one hand, and the impact of various learning effects on the other, are often neglected in favour of fixed coefficients for 'known' technologies. Moreover, even after the set of available energy technologies has been specified, the predictions depend upon assumptions about whether or not economic agents (public and private) will opt to select these options. ${ }^{5}$

A good example is the Renewable Energy book commissioned by the United Nations Solar Energy Group on Environment and Development as input to the 1992 UN Conference on Environment and Development in Rio de Janeiro. ${ }^{6}$ This book contains a figure which shows the life cycle costs for motor cars powered by alternative energy systems: batteries, fuel cells (fuelled by hydrogen, ethanol or methanol), and internal combustion engines. According to this figure, the costs of owning and operating an automobile powered by alternative renewable fuels are almost the same as - and in some cases even slightly below - the life cycle costs per kilometre of an internal combustion engine fired with gasoline (at the price projected for the U.S. in the year 2000). This raises the question why alternative fuel vehicles have not made an impact so far, and why they are not likely to do so in the near future. Why this is so can be understood from what we have said in chapter 10. Motor vehicle engines are an essential part of a highly complex technology - the automobile is probably the most advanced consumer product, being able to drive over $100,000 \mathrm{~km}$ at speeds well over $100 \mathrm{~km} / \mathrm{h}$ - which has benefitted over the last century from a wide array of product improvements in terms of reliability, durability, speed, range, fuel efficiency, etc. Furthermore, the automobile depends for its manufacturing on a production system and organisational structure which is complex and capital-intensive. This makes it extremely difficult for new firms to successfully enter the automobile business. The automobile is also part of a larger technological system involving gas stations, automobile repair shops, an extensive road infrastructure, etc. As a last point, the automobile is deeply entrenched in the social system and people's ways of life?

Despite the considerable detail of engineering studies of alternative energy technologies (of which the UN report is an example) they fail to provide a realistic descrip-

\section{${ }^{5}$ Ibid, pp.35-39.}

6 Thomas B. Johansson, Henry Kelly, Amulya K.N. Reddy, Robert H. Williams (editors), 1992, Renewable Energy. Sources for Fuels and Electricity, London: Earthscan.

"In a COST project memo about the motor car and the environment, the motor car is described as "a backbone of high mobility and suburbanization as well as a vehicle of self-expression and identity" (Knut H. Serensen, 1992, The Car and its Environments. Proposal for an International Study of the Past, Present and Future of the Motorcar in Europe, Centre for Technology and Society, University of Trondheim, Norway, p.3. 
tion of how the technology development and selection process interacts with the socioeconomic system from which it emerges.

What is needed is not yet another detailed study of the technical, economic and social aspects of a shift towards alternative energy technologies but a framework for understanding change in complex technology systems. In chapters 10 and 11 we outlined such a framework, based on an evolutionary model of technological change. In this chapter we apply this model to the problem of inducing a shift away from hydrocarbonbased energy technologies. To analyse what is involved in such a shift we use the concept of a "technological regime" which is defined as the overall complex of scientific knowledges, engineering practices, production process technologies, product characteristics, skills and procedures, institutions and infrastructures which make up the totality of a technology. The basic idea behind a technological regime is that the ways in which technological change will and can develop are both structured and constrained: constrained by the available methods and techniques, by the consensus of engineering ideas about how to approach problems, by the organisational and institutional context, by patterns of infrastructures and consumer demand. ${ }^{8}$ It should be noted that our approach differs from the more cognitive technology approach of Nelson and Winter $(1977 ; 1982)$ and Dosi $(1982 ; 1988)$ by looking at the real technical, economic and organizational potentialities and characteristics of technology and the way in which institutions (economic, social and political) shape and limit economic decisions and technological choice.

The concept of a technological regime is believed to be highly relevant to energy technologies. Most of the examples of technological regimes or paradigms are energy technologies: the steam engine, the DC3 aircraft and, in our time, the internal combustion engine. The concept of a technological regime may also be used for the energy system as a whole. For its operation, the present economic system depends on an energy system which is almost totally based on fossil fuels - coal, oil and natural gas. Worldwide, these three energy sources supply about 90 percent of the energy which is being purchased and put into use in the economic system. Together with these energy sources, we have conversion and end-use technologies in which energy is converted into useful energy forms and energy services. So we could speak of the 'hydrocarbon regime' with coal as the main source to generate electricity, with gasoline produced from oil as the main transport fuel, and with natural gas as the primary source for space heating.

What are the implications of the concept of a technological regime for the direction in which technological change will take place? As explained, the basic idea behind a technological regime is that technological advances proceed in certain directions somewhat irrespective of relative prices, i.e., that they are not fine-tuned to changes in demand and cost conditions. Our criticism of much of the economics of energy is that it

\footnotetext{
${ }^{8}$ Keith Smith in the joint research project for the Commission of European Communities, referred to previously.

${ }^{9}$ Paul E. Gray, Jefferson W. Tester, and David O. Wood, 1991, 'Energy Technology: Problems and Solutions', in Jefferson W. Tester, David O. Wood and Nancy A. Ferrari (eds.), Energy and the Environment in the 21st Century, Cambridge (MA): MIT Press, p.122.
} 
rests on somewhat simplistic views of the nature of technological change in energy systems: in particular many economists assume too readily that firms and consumers have technological alternatives. We would argue, on the contrary, that because of the integrated and systemic nature of energy technologies, firms and consumers are to a considerable extent 'locked in' to existing technologies, with relatively limited alternatives available. Lock in can occur for many reasons. For example, technological alternatives may be insufficiently developed in terms of performance characteristics, or in terms of the interaction between performance, on the one hand, and costs and efficiency on the other. Or the connections between a technology and its socio-economic or organisational context may be insufficiently developed. Our argument is that these aspects of the technological change process are insufficiently appreciated and addressed in much of the literature on hydrocarbon build-up. ${ }^{10}$

The concept of a technological regime helps to understand why it is so difficult for alternative energy technologies to make an impact. Learning curves, sunk costs, and technological interdependencies are particularly important for energy technologies. There are also problems of appropriation for highly systemic energy technologies, which makes that for-profit organizations are reluctant to invest in these technologies. (For instance, the profitability of a hydrogen-powered vehicle depends on the availability and costs of a hydrogen distribution system, the performance and costs of fuel cells, etc.). Furthermore, the development of non-hydrocarbon energy technologies is not in the interest of capital-intensive petro-chemical firms vested in the fossil fuels-based energy system. They will only move into the business of alternative energy technologies when fossil fuels are depleted or when the costs of extracting fossil fuels are becoming too high. Fossil fuels are also favoured by an institutional framework which fails to include the full environmental costs of their usage. A last factor that works against the development of renewables is prevailing engineering belief that renewables are less reliable and overly expensive energy technologies.

It is important to recognize that these factors do not operate independently from each other but are highly correlated. Engineering scepticism towards renewables and the unwillingness of firms to invest in alternative energy technologies is related to observed imperfections in these technologies (the limited range and high weight of battery-powered vehicles, problems with the on-board storage of hydrogen, the high costs of batteries and fuel cells, and a number of safety and environmental problems). The high costs of emerging energy technologies also lead to public concern whether the high costs of a transition away from fossil fuels will not outweigh the possible benefits, which has a negative effect on public programmes for renewables. But without sufficient public and private support, renewables are not able to live up to their promise: the high costs will limit their application to certain niche markets, small-scale production prevents cost reductions from scale economies, little money is available for further research, etc.

Of course, expectations about the technical potential for improvement, for achieving cost reductions, and the scope for branching and extension, may provide a rationale

${ }^{10}$ Smith, op cit. 
for private and public decision makers to support the development of non-fossil energy technologies, as a long-term investment. But the long development of radical energy technologies, uncertainty about the evolution of market demand, and the need to generate satisfactory profits in the short and medium term makes that private firms are reluctant to invest a lot of money in technologies for the future. Moreover, renewables are not the only option for dealing with greenhouse warming, there are many other options.

This brings us to the important issue of technology choice and pathways to a sustainable energy future. As we indicated, the number of technology options to ameliorate climatic change is almost infinite. This raises the question as to which technologies should be used, for what purposes, and within what time frame. Should one opt for incremental efficiency improvements of existing supply, conversion and end-use technologies, of which the costs are relatively low and which do not require major change in the production system and people's way of life? Or should one opt for more fundamental changes in energy technologies which yield higher environmental benefits by radically reducing greenhouse gas emissions but which bring high costs, especially in the shortterm? The next section will consider this problem in the context of three possible energy technology scenarios.

\subsection{Technological Pathways to a More Sustainable Energy} Future

In the previous section, we talked about the symbiotic relationship between energy sources, technology and economic development. The concept of a technological regime was used to explain the enormous inertia in the present energy systems, where energy sources interlock with energy conversion and using technologies, and an infrastructure of energy distribution. Energy technologies even extend into social and cultural systems, which makes it even more difficult to shift towards different technologies. This section examines the transition problem to a more environmentally sustainable energy future. It explores three possible energy technology scenarios, depending on whether the change is recognizable as being within the hydrocarbon-based energy system or constitutes a departure from the present energy regime: ${ }^{11}$

\section{Scenario I: Business-as-Usual}

This scenario contains a limited move away from hydrocarbons, with limited emphasis on energy efficiency. Technology responses within this scenario are fuel substitution by energy sources which are lower in greenhouse gas emission (especially natural gas), advanced fossil-fired power plants with a higher

"The scenarios are based on Ian Miles in a joint research project for the CEC, referred to previously. 
energy efficiency (like combined cycle power plants with natural gas-firing or pressurized coal gasification), the use of electronic devices to improve the fuel efficiency of gasoline-fired vehicles, etc.

\section{Scenario II: $\boldsymbol{A}$ Pale Greening of Energy}

This includes a more intensive use of renewable solutions but only in the context of the existing grid structure, with limited modification of the grid to accommodate this. Furthermore, there is much emphasis on energy demand and management, but limited experimentation with radical alterations.

\section{Scenario III: A Clean Break}

This consists of two distinct possibilities. One is a shift to a new centralised large infrastructure solution: the hydrogen economy, for example, with largescale distribution of fuel cells. The other option is a shift away from reliance on centralised grids to much more emphasis on local self-sufficiency, with possibly diverse solutions to energy requirements through different mixes of renewables specified at these local levels.

The "business-as-usual" scenario entails a minor modification of the hydrocarbon regime. Electricity would be supplied through the grid, gasoline would remain the main transportation fuel, no new energy infrastructure is needed. It would cause minimal disruption of the existing production and transport system, but the environmental gains would be limited.

The second scenario, "a pale greening of energy", is something of an in-between scenario. Renewables would be used more intensively to generate electricity, which is fed into the grid (as in the case of wind farms). There would be more use of co-generation plants of heat and power, especially in industry and for office buildings; utilities would redefine their strategic objectives by engaging in demand-side management; there would be a further shift towards more energy-efficient building practices, and users would respond to energy-conservation policies and environmental pressures. Some countries like the Netherlands are already proceeding into this direction.

The "clean break" scenario is the most radical scenario in terms of a departure from the past. The use of hydrocarbons would be greatly reduced, either by a switch to renewables to mass-produce electricity or hydrogen as a transportation fuel, or by using renewables at the local level for different energy requirements. The last of these radical options might well be accompanied by lifestyle changes, which would reduce energy demand drastically. Here, a change of technological regime is most evident: not only do we have different energy sources, conversion technologies, and a different energy distribution system, but also, in the case of local self-sufficiency, significant changes in life style.

This brings us to the question: Which scenario is the most optimal from a social welfare point of view? And what are the implications for public policy making? These questions are explored in the next section. 


\subsection{Defining Energy Technology Policies}

The environmental problems are pressing society to look for different technologies to satisfy human needs and aspirations. Many of the technology responses to slow climate change are within the "hydrocarbon" regime - like advanced electricity supply technologies, co-generation plants of heat and power, and $\mathrm{NO}_{\mathrm{x}}$ emission control systems. These technologies are usually developed by regular energy technology suppliers and suppliers of pollution control technologies and may be integrated into the present energy system with little difficulty.

There are also technology options that are outside the hydrocarbon regime like photovoltaics, fuel cells, nuclear power, wind energy, and biomass (which may be used as a transport fuel and to generate electricity). These are produced by relatively small, specialized suppliers (except in the case of nuclear power plants), with the help of public programmes, universities and semi-public research institutes.

Society may also 'innovate' around the need for energy, by making products and plants more energy-efficient, changing its heating and food habits, reduce the need for transport through urban planning and interactive telecommunication (like teleworking, videoconferencing, etc.).

Most of the above technology options will find their way into the market, with or without government support, and partly for non-environmental reasons. Although all these options warrant some kind of government support, both for environmental and social reasons, this section will focus on the policy problem of making a transition towards a more renewable-intensive energy system, along the lines of scenario II and III. It may well be that this is not the optimal strategy; that technology options within the hydrocarbon regime (scenario I) like a fuel switch to natural gas and coal gasification power plants and energy conservation through thermal insulation are more cost-effective. It is also possible that greenhouse warming does not pose such a big problem and that there will be relatively easy ways to adapt to the climate change. We do not know and, more importantly, there is no way of finding out the optimal strategy when the consequences of climate change are poorly understood and the economic costs and social benefits of various technology options are largely unknown. In our view, there is a special need to work on the second, and, especially, the third scenario, to encourage renewables and more energy-efficient technologies, for the following reasons.

First, renewables have the potential of significantly reducing greenhouse gas emissions. Their encouragement should be viewed as an insurance against sudden and dramatic climate changes. This relates to what Brian Arthur has said:

It may sometimes be desirable as a policy option to keep more than one technology 'alive', to avoid monopoly problems (if the technology is marketed), or to retain "requisite variety" as a hedge against shifts in the economic environment or against future 'Chernobyl' revelations that the technology is unsafe. ${ }^{12}$

${ }^{12}$ Arthur, 1988, op cit., p.603. 
The idea that society may get 'locked in' to undesirable technologies provides a further argument for retaining variety. The danger of 'lock-in' to suboptimal technologies is particularly high for energy technologies that are highly systemic, with long lead times and special infrastructure requirements. As explained by Arthur, when two or more network technologies (like two transport technologies) are competing, positive feedback (increasing returns with adoption) make the market for them unstable. ${ }^{13} \mathrm{~A}$ technology that has been favoured early on, may come to dominate the market. ${ }^{14}$

It should be noted that these selection dynamics do not simply reflect physical alteration of the artifact, although these too are an important element in the process of technological evolution; they are generated, in part, by the interaction of multiple, 'boundedly rational' decision makers interacting with each other. ${ }^{15}$ The idea of 'lock-in' development (or path dependency) is at the heart of our evolutionary model of technological change; it explains how the selection environment favours 'drop-in' innovations and is biased against technologies that require new knowledge, skills and practices. And it is this idea of "lock-in" that provides much of the rationale for government support for radical energy technologies with potentially high environmental and social benefits.

A last argument for a more intensive encouragement of non-fossil energy technologies is that they not only slow global warming but also produce a number of other advantages: they generate significant air pollution benefits (which helps reduce abatement costs) and they make countries less dependent of foreign energy suppliers, which reduces the risk of rapid price fluctuations and supply disruptions. According to the earlier-mentioned UN report, renewables may furthermore help developing countries to develop. For instance, biomass energy plantations (to make transportation fuels and to generate electricity) may provide work to many people, especially in rural areas. This goes against the common argument that there exists a tradeoff between socio-economic development and environmental conservation.

As we noted before, capturing the potential for renewables critically depends on government interventions. The main benefits of renewables are not valued in the market place.${ }^{16}$ One way of dealing with this problem is to let market prices reflect the negative environmental costs, to let prices speak the "environmental truth". This is exactly what

${ }^{13}$ W. Brian Arthur, 1990, Positive Feedbacks in the Economy, Scientific American, p.84.

14 Arthur, 1988, op cit., p.591.

${ }^{15}$ Kirsch, op cit., p.39.

${ }^{16}$ Bill Nordhaus notices that the market is biased against technologies that slow climate change because of a "double externality": private returns are lower than social returns because the results of $R \& D$ are available to other firms and because the benefits of greenhouse gas reductions are worth nothing in the present market (William D. Nordhaus, 1991, Economic Approaches to Greenhouse Warming, in Global Warming: Economic Policy Approaches, edited by R. Dornbusch and J.M. Poterba, Cambridge (Mass.): MIT Press, p.60). 
economists suggest policy makers should do: to rationalize energy markets by internalizing the environmental costs of pollution. Such an approach is not wrong, but we must be looking at what is missing. It fails to recognize the way in which society is locked in to particular technologies; how the market favours technologies that are within the hydrocarbon regime, and is biased against technologies that require a new infrastructure, skills, plant design, etc. Certainly, a carbon tax and tradeable carbon rights will have a role to play in the array of necessary GHG policies, but it is not likely that such measures will be sufficient to bring about radical change in energy technologies and practices, unless they significantly raise the costs of using fossil fuels, which is highly unlikely in the political reality of today. To encourage renewable energy technologies that are not part of the hydrocarbon regime, a more integrated and coordinated policy is probably needed, a policy that would engage in experimentation and make use of the cumulative and self-reinforcing character of technological change. What does this imply for public policy in more practical terms?

In defining policies to begin and sustain a transition away from fossil fuels, it is useful to look back in history, to look at the technological transitions that occurred in the past. In the chapter of technological regimes shifts we identified five mechanisms that helped a radically original technology to establish itself as a dominant technology in the modern market economy.

Available knowledge and experience (in universities and organizations) that may be used for the production and marketing of the radical technology.

. The presence of early niche markets.

- Scope for branching and extension, of overcoming initial limitations, and for achieving cost reductions.

The building of a constituency behind the product (suppliers, customers, regulators) whose semi-coordinated actions are necessary to bring about substantial shift in interconnected technologies and practices.

The overcoming of social opposition and consumer resistance.

It is important to recognize that these five factors do not operate independently from each other but are interrelated, with self-reinforcing feedback loops and multi-directional linkages. For example, the existence of early market niches helps innovating firms to improve the new product by learning from the experiences of users; it helps to build a constituency behind the product by demonstrating its validity and commercial feasibility to potential users and policy makers, which helps the further development and diffusion of a technology, etc.

The above list is useful in discussing possible policy actions to encourage renewables and other environmentally beneficial technologies. It provides a framework for 
examining technology strategies and policy actions. For instance, when alternative technologies are insufficiently developed, or when the appropriability conditions for innovation are unfavourable, there may be room for technology programmes to stimulate research at universities and laboratories, and the transfer of knowledge between different organisations. Public policies could also be used to build technology networks to work jointly on technical problems, find ways of cost sharing, define technical standards, etc. The transition to environmental sustainability could be made into a new mission for public policy, different from the old missions in defence, nuclear and aerospace technology. Such a mission would articulate the need for change and provide guidance as to where we should be going, it also commits policy makers more strongly to the goal of sustainable development. Elements of such a new 'mission' for science and technology are described in a recent report on innovation and technology diffusion policy for the Commission of the European Communities. ${ }^{17}$ The characteristics of old and new models of mission-oriented projects are summarized in Table 12.1. The mission is defined in terms of economically feasible technical solutions to particular environmental problems. Key elements of a mission-oriented environmental programme are: to promote the development and employment of a wide range of potentially beneficial technologies, to involve many actors in the technology development and selection process, and to take an "incrementalist" approach to the innovation process - that is to favour technologies with relatively short development times, small project sizes, low capital investment levels, and minimum need for infrastructure; to avoid overinvestment in a limited range of expensive technologies that are later found to be unworkable, overly expensive, or environmentally more harmful than the technologies they were designed to replace. ${ }^{18}$ Such an incrementalist approach would favour renewable energy technologies and warns against spending a lot of money on large-scale mission-oriented projects like nuclear fission and fusion.

${ }_{17}$ Luc Soete and Anthony Arundel (eds.), 1993, An Integrated Approach to European Innovation and Technology Diffusion Policy. A Maastricht Memorandum, Brussels: Commission of the European Communities.

${ }^{18} \mathrm{Ibid}, \mathrm{p} .58$. The advantage of flexible energy technologies in uncertain markets is described in David Collingridge and Peter James, Inflexible Energy Policies in a Rapidly-Changing Market, Long Range Planning, 24(2): 101-107. 


\section{Characteristics of Old and New "Mission-Oriented" Projects}

Old: Defence, Nuclear and Acrospace

The mission is defined in terms of the number of technical achievements with little regard to their economic feasibility.

- The goals and the direction of technological development are defined in advance by a small group of experts.

- Centralized control within a government administration.

- Diffusion of the results outside of the core of participants is of minor importance or actively discouraged.

- Limited to a small group of firms that can participate owing to the emphasis on a small number of radical technologies.

- Self-contained projects with little need for complementary policies and scant attention paid to coherence.
New: Environmental Technologies

The mission is defined in terms of economically feasible technical solutions to particular environmental problems.

- The direction of technical change is influenced by a wide range of actors including government, private firms and consumer groups.

- Decentralized control with a large number of involved agents.

- Diffusion of the results is a central goal and is actively encouraged.

- An emphasis on the incrementalist development of both radical and incremental innovations in order to permit a large number of firms to participate.

- Complementary policies vital for success and close attention paid to coherence with other goals.

Table 12.1. The characteristics of a new mission-oriented policy for environmentally desirable technologies. Source: Soete and Arundel (eds.), (1993, p.51).

If we look at government R\&D energy expenditures in Figure 12.1, however, we see that almost all government R\&D money has been spend exactly on large-scale energy supply technologies with little opportunities for learning, experimentation, and generating positive feedback effects. In the IEA countries, over the $1979-90$ period, $59 \%$ of government R\&D energy expenditures were spent on nuclear power, $15.2 \%$ on fossil energy 
and only $9.4 \%$ on renewables and $6.3 . \%$ on energy conservation. In absolute terms, in $1990,5.4$ billion dollar was spent on nuclear and fossil energy and 0.9 billion on renewables and energy conservation.

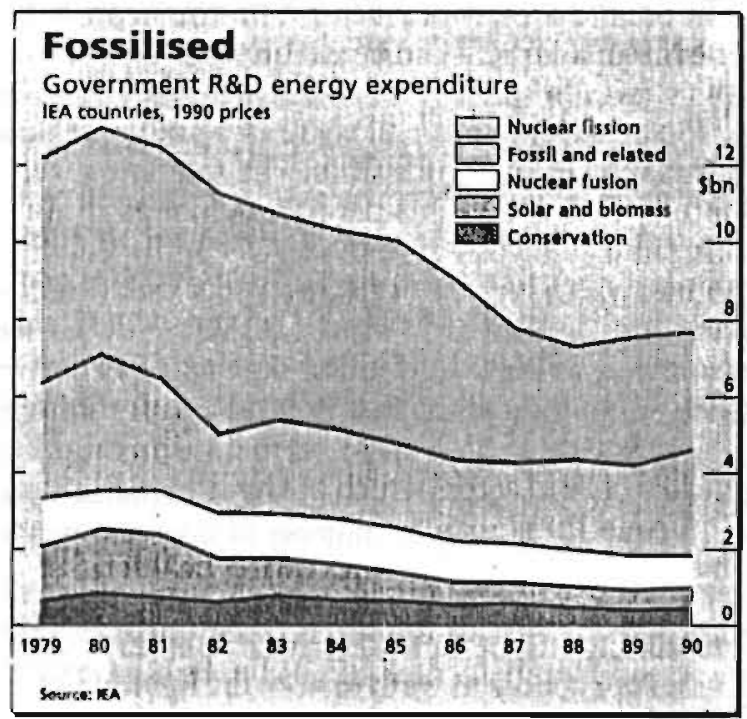

Figure 12.1. Government R\&D energy expenditure in IEA countries. Source: The Economist, Energy and Environment Survey, August 31, 1991, p.34.

Figure 12.1 shows that sustainable energy technologies did not only receive little government $R \& D$ money, the relative decrease in government $R \& D$ energy expenditures was highest for renewables. This suggests that a shift in government energy R\&D spending is needed, towards renewable energy sources and energy efficient end-using technologies. Energy specialists and authorities are coming to this point of view. They believe that there is a need to re-allocate energy $R \& D$ budgets for environmental reasons. One of the conclusions of an executive conference on energy technology policy for sustainable development was that there is presently:

a severe imbalance between $R \& D$ spending on major energy supply-side technologies and $R \& D$ spending on renewables and demand-side technologies, particularly the efficient end-use of energy (...) A shift to greater spending on demand- 
side R\&D, compared to supply-side R\&D, is appropriate today. Within supply-side $R \& D$, there needs to be greater spending on renewable energy $R \& D .^{19}$

Energy specialists at this conference also expressed the need to take an integrated system perspective and that better methodologies be developed to evaluate energy technology options against technical, environmental, economic and security criteria for the long and short term to identify the most promising strategies for sustainable development. ${ }^{20}$ This we agree on. However, we would like to add the importance of bringing in different perspectives and expertise, and not to rely solely on energy specialists from traditional energy fields. Social scientists should also have an important input in energy technology appraisals, to discuss consumption patterns, life styles and values.

Such energy technology appraisals should be an important input to government policies. What does the evolutionary model of technical change and the history of technological transitions furthermore suggest about policies that may be useful to induce a transition away from hydrocarbons? One obvious policy is to make fossil fuels more expensive through a carbon tax. Tradeable pollution quota can also make an important contribution to the goal of a reduction of greenhouse gas emissions. These policies have received most of the attention in the climate change debate. Political support for a carbon tax and quota, however, has been limited, especially outside the EU. It is doubtful whether or not they will introduced. In order to be introduced in the world economy it seems necessary that they are linked to other issues (like employment and air quality benefits in cities). When they are introduced, however, the danger is high that they provide too little incentive to induce radical change in technology. This raises the question: What other policies may be used to induce a transition away from fossil fuels? In our view, the following policies may prove to be useful or even necessary.

First, promising new ideas with long-term benefits could be supported by special science and technology programmes. As explained earlier, the market underinvests in (energy) technologies for the future, especially technologies of which the social benefits are not or insufficiently valued in the market place. Uncertainty as to which technology is best from the vantage point of economic efficiency and social welfare provides an extra reason for the use of research programmes. Important criteria for such programmes are: the environmental benefits as compared to other technologies, the economic costs (now and in the future), and social acceptance.

Second, a niche market may be created for emerging energy technologies through government procurement, regulation, tax policies, investment subsidy schemes, etc. Such a niche may be a possible stepping stone to the further development of an environmentally benign technology; it helps to resolve some of the uncertainty about the economic

${ }^{19}$ OECD/IEA, 1993, Proceedings Executive Conference on Energy Technology Policy for Sustainable Deoelopment. Comparing Long-Term Approaches, Noordwijk, the Netherlands, 9th-11th December 1991, IEA/OECD/NOVEM, p.183.

${ }^{20} \mathrm{Ibid}, \mathrm{p} .4$. 
feasibility of radical energy technology options. How a niche market may be created through public policy will be described in the next section.

Third, public authorities may create a network of technology suppliers, research organizations, customers to work on technical problems, define technology standards, find ways of cost sharing, to deal with controversies, etc. This might facilitate a better exchange of information and knowledge and help create a common vision for future development. Problems of appropriability may (or may not) be overcome through the creation of such networks. As a last point, the involvement of consumers and environmental groups may help technology suppliers to identify and dealt with problems of social acceptance.

Fourth, the formulation of clear policy goals and setting of energy and environmental objectives, as a demand-side policy, to reduce market uncertainty for environmentally beneficial technologies. In the case of CFCs, a clear policy goal gave a strong push to the development and adoption of CFC substitutes. As regards to greenhouse gas emissions, national goals for $\mathrm{CO}_{2}$ are set by several governments, but the commitment of the government to achieve these goals is not very strong.

Fifth, identification of energy technology diffusion bottlenecks and the implementation of policies that address barriers that prevent the uptake of energy conservation technologies and energy efficient, end-use technologies. Possible policies are information diffusion (product information, energy-efficiency labels), energy-efficiency standards for products, and the removal of institutional barriers. Such policies may increase environmental awareness which is necessary not only for the uptake of energy-saving technolugies but also for attaining political support for environmental policies.

Sixth, energy policies should be coordinated with other policies, not only environmental policy and science and technology policies but also agricultural and transport policies, urban and land planning, building regulations, industrial policies, etc. The systemic nature of energy technologies implies that what is needed is not just energy legislation and fiscal policies, but also changes in agricultural policy (to promote the cultivation of biomass crops and ecological farming), in transport (new infrastructures), in construction (to stimulate more energy-efficient practices and technologies), land-use (to reduce the need for transport) etc. Existing policies are usually designed with little consideration of environmental aspects and provide too often a barrier to the realisation of environmental objectives. For example, the main obstacle to the diffusion of wind turbines is not the cost of generating electricity but the local and national planning system and the low return prices for wind power.

Seventh, international policies for environmental conservation. It is important that environmental policies are implemented by the widest possible range of countries. Goalone policies are not only counterproductive from an environmental point of view in the case of global commons, but they also are very expensive for individual countries who may experience a relocation of business towards countries with less strict environmental policies. One of the biggest obstacles towards the formulation of environmental policies at the national level is the need for international coordination of such policies. 
And eighth, to help third-world countries (and other less-developed countries) to develop a more environmentally benign energy system. They have before them a need to build an energy system in the next decades. These are also countries that are less 'locked in' to a hydrocarbon energy system (in terms of existing infrastructure, energy supplyindustry relationships, life styles). However, the great priority of relieving human poverty and increasing material wealth will almost certain make them opt for the cheapest rather than the cleanest energy technologies (especially if they have large reserves of fossil fuels - as in the case of China). Technical and financial assistance from industrialised countries is needed to make sure that these countries do not disrupt their own natural environment or worsen global environmental problems. Here the industrialised countries also have a special responsibility as they are responsible for the major part of the present problem.

These are examples of policies that may be used to reduce greenhouse gas emissions. Of course, most of what we propose is not new; it has been suggested by others or has been part of present and past policies. Research in renewable energy has been supported through special technology programmes and R\&D subsidies for at least two decades, in some countries, electric utilities are forced to generate a certain amount of renewable energy or to purchase renewable energy at a reasonable price, and several countries have renewable energy objectives. These initiatives have helped the development of a wide range of renewable energy technologies up to the point where many of these technologies are becoming competitive with fossil-fuel technologies for several applications. This is not to say that all renewable energy policies have been a success. Many of them were too much focused on the technical development of new energy technologies. There was too little consideration of the technology selection process, that is, of the technical, economic and institutional barriers that worked against the uptake of alternative energy technologies. As many innovation studies show, successful technological innovation is not simply a matter of perfecting a product along a well-known technological pathway, but requires foremost a good understanding of user needs. Future policies should force suppliers to pay more attention to what the market wants, to avoid the waste of research money and user disappointment. It furthermore points at the need for more integrated policies, to generate positive feedback effects through learning and adaptation at the user and supply side. What such an integrated policy might look like is described in the next section.

\subsection{Strategic Niche Management}

To give a better idea of a coordinated and integrated energy technology policy for environmental protection, this section will describe one of the earlier-proposed policies in more detail: the creation of a market niche for a radical technology to limit greenhouse gas emissions. Such a market niche may be an important stepping stone for the further evolution of a radically new energy technology: it helps suppliers to better understand 
user needs, to identify and solve some critical problems, to achieve cost reductions in mass production, and, perhaps most important, to create a constituency behind the new product, finding support from other actors (firms, research institutes, public agencies, users).

The creation of a market niche for radically new technologies with a low environmental impact should be considered a learning experiment, not only for both suppliers and potential users of these technologies but also for policy makers that want to achieve a smooth transition towards low-impact energy technologies. It also helps to remove some of the uncertainty about the viability of radical solutions that may otherwise be foreclosed or seriously delayed.

What does the creation of a market niche imply in more practical terms for public policy? First, part of such a policy is a good understanding of the barriers that prevent the environmentally benign technology from being introduced into the market place. These barriers may be economic, when the new technology is unable to compete with conventional technologies given the prevailing cost structure. They may be technical, in the form of a lack of complementary technologies, infrastructure, appropriate skills or problems of integration in the existing technical infrastructure. And they may be social and institutional, having to do with existing laws, practices, perceptions, habits. To successfully deal with these barriers, an integrated and coordinated policy is required. Part of such a policy are the formulation of long-term goals, the creation of an actor network, and the use of taxes, subsidies and standards.

A good example of such a policy is the so-called "Los Angeles initiative" to promote electric vehicles. Although the Californian policy is primarily aimed at reducing photochemical smog, a notorious problem in the Los Angeles area, it vividly illustrates how "strategic niche management" (as Arie Rip and Johan Schot call it) may be used to induce radical changes in the hydrocarbon-based energy system. By requiring car manufacturers to mass-produce zero-emission vehicles, it surpasses a technological deadlock in which car manufacturers were reluctant to introduce electric vehicles for fears that consumers would not want to purchase alternative-fuel cars whereas demand for electrically-powered vehicles could not develop since electric vehicles were not for sale. According to California rules, zero-emissions cars must account for $2 \%$ to $10 \%$ of newcar production in the 1998-2003 period, while strict standards pertaining to hydrocarbon and nitrogen oxide emissions are being set for all new motor cars to be sold in the 19942003 period. $^{21}$

Part of the programme is a competition under which the three winning manufacturers are to build a variety of small cars, passenger vans and light commercial trucks to create the 10,000 zero-emission vehicle fleet by the year $1995 .^{2}$ The whole initiative is

${ }^{21}$ Neal Templin, 1991, California Rules Push Car Makers To Clean Up Act, Wall Street Joumal Europe, March 27.

"This part is based on a Financial Times Survey "Vehicles and the Environment", Financial Times, July, 27, 1990. 
jointly sponsored and is being overseen by the city council, its Department of Water and Power and the private sector utility, Southern California Edison. The Department and Southern California Edison are providing development funds to the chosen companies. In addition, they are devising with both state and federal authorities fiscal incentives to make the use of such cars attractive. This programme could pave the way for alternative-fuel vehicles, not only in the Los Angeles metropolitarian area but also in other parts of the world.

To give another, more speculative, example, hydrogen $\left(\mathrm{H}_{2}\right)$ is often considered the ideal transportation fuel from an environmental point of view: hydrogen has a high energy efficiency and does not emit carbon dioxide (if non-carbon energy technologies like renewables or nuclear power are used in the production of hydrogen). Hydrogen may be used in internal combustion engines or in fuel cells to supply power. Again, although technically feasible, the high costs of using hydrogen pose an enormous barrier. According to Tim Jackson, using estimates from various authors, the economic costs of a hydrogen-fuelled car using electrolysis and photovoltaics to produce hydrogen are estimated as being in the range of $\$ 1$ and $\$ 5$ per kilometre whereas the economic costs of a conventional car are between 5 and 10 U.S dollar cents per kilometre. ${ }^{23}$ To be sure, these figures are for 1990, and further cost reductions and efficiency improvements are to be expected from future advances in fuel cells and photovoltaics. However, to achieve or accelerate the transition to an integrated hydrogen economy, the creation of a market niche could make an important contribution.

At this moment, aircrafts are possibly a good candidate for the introduction of hydrogen in the transport sector. Within the aircraft industry, hydrogen is already considered a potential commercial aviation fuel. Over the last three years, 15 German and Russian firms, under the leadership of Deutsche Aerospace Airbus Gmbh (DASA), have investigated the possibility of using hydrogen. They are now involved in the design of a large passenger airplane fuelled by liquid hydrogen, the "cryoplane", of which they hope a prototype is ready by the year $2005 .{ }^{24}$ Whether a hydrogen-fuelled airplane will be mass-produced and will find its way into the market within the next 15 or 25 years is unclear. There are several barriers which hinder the introduction of the cryoplane in the commercial market. First of all, the high costs of hydrogen as compared to kerosine (so far the only fossil fuel which is not taxed), the build-up of an infrastructure to massproduce hydrogen, the distribution of hydrogen in various parts of the world, and a number of safety and environmental problems (for example, although it does not emit $\mathrm{CO}_{2}$ it emits water vapour which at high altitudes contributes to global warming). A carefully designed and coordinated policy could help realize the potential of the hydrop.869.

${ }^{23}$ Tim Jackson, 1992, Renewable Energy. Summary Paper for the Renewables Series, Energy Policy,

${ }^{24}$ René Raaymakers, 1992, De Zeppelin van de volgende eeuw (The Zeppelin of the Next Century), Intermediair. 
gen option and exercise a decisive influence on the future course of events, leading up to an energy future which is more environmentally sustainable.

\subsection{Conclusions}

This chapter is an exploration of the policy issues of making a transition away from fossil fuels that are seriously implicated in many of today's environmental problems. The answer of economists is simple: it is that policy makers should institute a carbon tax or other penalty on greenhouse gas emission and rely on the natural operation of market forces. This chapter takes issue with the idea that a carbon tax that is politically feasible will be lead us away from fossil fuels. In our view, such a tax will be insufficient to induce radical change in technology - it will mere stimulate incremental changes. What is needed (in addition to tax policies) are well-defined energy technology policies aimed at the development and wider diffusion of specific energy technologies, such as gasification-based biomass power generation, fuel cells, photovoltaics, combined cycle power systems, $\mathrm{CO}_{2}$ removal, etc.

Examples of energy technology policies are described in this chapter. One such policy are special science and technology programmes for promising new technologies with long-term benefits. Policy makers should also engage in experimentation with new technologies to learn more about the economic costs, technical feasibility and social acceptance of these options. One way of doing this is through the creation of niche markets through government procurement, regulation, tax policies, subsidy schemes, etc. Other policies are: the creation of networks of technology suppliers, research organizations and users, and the coordination of energy technology and environmental policies with other policies (agricultural and transport policies, urban and land-use planning, building regulations and industrial policies). 




\section{Chapter 13}

\section{Conclusions}

This thesis examines the relationship between environmental policy and technical change. The way in which environmental policies influence technological change is an important criterion on which to judge such policies, and a key factor in achieving sustainable development. Unfortunately, our understanding of this important issue is limited. There have been attempts to study firm incentives for innovation in pollution control under different policy regimes, but the practical meaning of these models is limited. There are also evaluation studies of environmental policies, but the focus of such studies is on the effectiveness of policy measures, not on technology and how the policies influenced technological innovation and diffusion. What is needed is a systematic study of the technological impact of policy instruments. This thesis provides such a study. The aims of the thesis are threefold:

i) to analyze and compare the effects of various pollution control instruments (emission standards, taxes, subsidies, tradeable quota) on innovution in pollution control technology;

ii) to analyze the effects of different policy instruments to limit environmentally hazardous emissions on the diffusion of environmentally beneficial processes and products;

iii) to examine the problem of technological regime shifts.

These problems are examined by applying different research methods: theoretical models of innovation and diffusion, econometric time-series analyses, descriptive case studies, and appreciative theory. This chapter will present the main results and will draw conclusions about the usefulness of different environmental policy instruments for encouraging new technology toward the efficient conservation of environmental quality.

\subsection{The Impact of Policy Instruments on Innovation in Pol- lution Control}

In theoretical models, economists have analyzed and compared firm incentives for innovation in pollution control under different policy regimes (pollution taxes, standards, subsidies and tradeable quota). The main conclusion of the models is that incentive-based instruments provide a greater spur to innovation in pollution control technology than direct control (in the form of a uniform emission-reduction standard). Under 
incentive-based policies, the innovator is able to exploit an extra gain by further reducing its emissions. This is because the marginal benefits of extra emissions reductions (a reduction of tax payments, subsidies for emission reduction or revenues from selling pollution rights) exceed the marginal cost of emission reduction. (Under direct regulation the marginal benefits of extra emission reduction are zero.) This important result is derived under a number of restrictive assumptions: the innovation is developed by the polluting firm and not sold to other firms, there are no information problems and the control agency is motivated by the single goal of achieving environmental improvements. Only one model - that of Milliman and Prince (1989) - analyzes firm incentives for innovation for the situation in which there is technological diffusion and an outside supplier.

A clear weakness of the innovation models is that they do not consider the policymaking process in the context of technological uncertainty and do not distinguish between different technologies for achieving environmental improvements. To analyze the implications of the above assumptions, we advance in chapter 3 a simple political economy model of regulator behaviour (based on Nentjes, 1988) to analyze the innovation effects of different policy instruments. The model shows that in most circumstances a tax regime provides less inducement to innovation in pollution control technology, and freely distributed tradeable quota (permits) more inducement to innovation than direct control. This conclusion constrasts with the widespread opinion among economists that pollution taxes and auctioned quota provide a greater spur to innovation in pollution control than other instruments. The reason why in the political economy model the innovation effects of a pollution tax and auctioned quota are relatively small is that the agency will set the tax at a rather low level or allow a high level of emissions, in order not to impose high environmental costs on industry (under a pollution tax and auctioned quota the polluter has to pay for non-abated emissions). This result corresponds with the observation that economic incentives are set at too low a level to induce technological innovation (or even to induce firms to take environmental measures at all). Another result of our analysis is that under incentive-based instruments the share of processintegrated technologies will be higher than under direct control. (Under direct control, firms will choose end-of-pipe technologies that enable them to comply with environmental regulations without the need to replace existing production plants.)

The overall conclusion of our analysis is that freely distributed tradeable polluting quota and innovation waivers (in which the agency gives the polluting firm time to develop a technological innovation) are better instruments to promote innovation than emission-reduction standards and pollution taxes.

\subsection{The Diffusion Effects of Environmental Policies}

The second subject of the thesis is the technological diffusion of environment-saving technologies, and how this is affected by public policy. To date, this subject has received little attention in the economic literature. In chapter 5 , we developed a simple threshold 
diffusion model with learning which describes adopter decisions under an incentivebased policy regime. In the model, adoption of a pollution control (or energy-conserving) technology takes place the moment at which the risk-adjusted reservation price exceeds the purchase price of the new technology. The reservation price is a function of the control efficiency of the technology, a pollution tax (or energy price), the valuation of other product characteristics, the interest rate, operating costs, and the (economic) service life. The model is used to calculate the technological diffusion effects of a pollution tax, investment subsidies and information supply. It is applied empirically to the diffusion of biological waste-water treatment technologies in the Dutch Food and Beverages industry (chapter 6) and to thermal home insulation (in the form of double glazing and cavity wall insulation) in the Netherlands (chapter 7). The threshold diffusion model proves to be a good model for explaining the uptake of biological waste-water treatment plants by industrial dischargers in the F\&B industry between 1975 and 1992. Although it carnot explain with much precision in what year a firm will invest in waste-water purification, it can explain the trend. The analysis furthermore reveals that the effluent charge was a significant factor in the employment of biological waste-water treatment plants. If the effluent tax rate had remained at the (low) 1974 level, only a small proportion of the indirect dischargers in the F\&B industry would have invested in biological waste-water treatment.

The threshold model is also applied to the diffusion of double glazing and cavity wall insulation in owner-occupied and rented houses built before 1976. As it turned out, it was impossible to explain the increase in the proportion of owner-occupied and rented houses with thermal insulation during the $1978-92$ period by using a rational choice model in which the decision to invest in energy efficiency home improvements is understood as an economic cost-benefit decision under uncertainty. The estimation results of epidemic models (the logistic, Gompertz and Bass models) were much better. There is evidence that the price of natural gas influenced households' decisions concering thermal insulation, but the evidence is not conclusive. We also analyzed the effectiveness of government investment subsidy programmes for thermal insulation. The model results show that the subsidy programmes for thermal insulation of more than 2 billion guilders had only a limited impact on households' insulation decisions. What they did, for the most part, was to provide recipients of the subsidies with a 'windfall gain'. Another conclusion from the analysis is that in the Netherlands the non-ownership of houses by occupants was not an important barrier to the uptake of double glazing and cavity wall insulation: the proportion of rented houses with thermal insulation in 1992 was almost as high as that of owner-occupied houses. (Owner-occupants, however, were quicker in having their home insulated.) The reason why a lot of rented houses in the Netherlands are thermally insulated is probably due to the unique situation that 75 per cent of them are owned by non-profit housing councils ("woningbouwverenigingen" and local councils). These housing councils were very active in persuading tenants to thermally insulate their homes. This is an example of an institutional factor that facilitates change. The effects of public information about thermal insulation on adoption decisions could not be determined from our analysis. 
Adoption decisions of firms and households are also analyzed in three case studies: CFC substitutes, low-solvent paints and coatings, and membrane technology in the metal-plating industry. In each case, government policy played an important role. Without the future ban of CFCs, users would not have switched to substitutes - not even when they were more cost efficient. (The search for CFC-free cleansing agents revealed that firms in the computer industry had been using products that were overly expensive; the firms discovered, much to their own surprise, that water-and-soap was a more costefficient way of cleaning electronic parts than CFC-based cleansing agents). Government policy was not the only factor, however. The decision to adopt an environmentally preferable technology also depends on the price and performance characteristics of the new technology as compared to those of existing technologies, perceptions of the new technology and resistance towards change (which depends in part on uncertainty). It is important that environmental policies take these factors into account, in order to avoid cost inefficiencies, obstruction from industry and disappointments. The case studies furthermore show that market demand is the crucial factor for the exploitation of technological opportunities for environmental protection. For almost any environmental problem, technological opportunities to deal with the problem are available, and unfavourable appropriability conditions (like the easiness of imitation) do not seem to keep firms from exploiting these opportunities. The case studies furthermore show that technological capabilities to develop compliance innovations are often located outside the polluting industry and that policy makers should be careful not to select the 'wrong' technology. In the Netherlands, government policy favoured the use of ONO wastewater treatment technologies, a typical end-of-pipe technology with limited environmental gains. The case study of low-solvent paints and coatings demonstrates that compliance technologies need not necessary add to the costs of the firms using them. Waterbased paints and powder coatings are increasingly used for normal business reasons of lower costs and higher quality. This example shows that technological innovation indeed can overcome a possible conflict between economic wealth and environmental quality.

\subsection{Best Policy Instruments to Foster Innovation and Dif- fusion}

We now address the question, what is the best policy instrument to encourage technological innovation and diffusion. We will draw conclusions about which policy instrument(s) may be used best to stimulate technological innovation and the diffusion of environmentally beneficial technologies. The conclusions are based on our own findings in chapters $6-8$, the findings of other studies into the technological impact of environmental policies (described in chapter 9), findings from the innovation models (chapters 2 and 3 ), and from the economic theory of environmental policy.

As regards the technological impact of environmental regulations, experiences are mixed. Emission standards that are based on available end-of-pipe technologies provided 
little incentive for the development of new, more effective technologies. This demonstrates the danger of using standard-based policies and the importance of taking a longterm view towards environmental protection. Technology-forcing standards that require the development of new technologies are a better way of encouraging technological innovation, as the regulatory experiences in the United States demonstrate. However, they may impose high costs on industry - unless the regulator is willing to soften and delay standards, but this would have a negative effect on the willingness of suppliers to develop innovations. Technology-forcing standards should only be used when technological opportunities are available that can be developed at low enough costs. The chance that these opportunities will be developed is greater when potential suppliers are located outside the regulated industry. Outsiders are also more likely to develop radical solutions to environmental problems.

Economic incentives like taxes and tradeable quota that rely on financial incentives are an alternative to command-and-control policies. They are favoured by economists and international organizations such as the OECD. The benefits of incentive-based approaches to reducing pollutant emissions are many. First, effluent charges (emission taxes) and tradeable quota are more efficient because every polluter is given the choice between compliance and paying the polluter's bill. The polluting firm cannot be forced to undertake emissions control of which the marginal costs are higher than the effluent charge. This means that environmental benefits are achieved at the lowest abatement costs. ${ }^{1}$ Second, there is a financial incentive to diminish all pollution - not merely up to the level of emissions standards. (The economic belief that incentive-based approaches provide a greater inducement to innovate is based on this argument). Third, such a system depends less on the availability of pollution control technology and, therefore, it may be more easily introduced and adjusted. Fourth, the danger that polluting industries fail to develop new technologies for strategic reasons is less great under an incentivebased regime. And fifth, economic instruments tend to stimulate process-integrated solutions (including recycling technology) rather than end-of-pipe technologies that have been overwhelmingly applied in the past. A disadvantage of effluent charges is the uncertainty about the polluters' responses. Another disadvantage is that the total environmental costs (abatement costs plus tax payments) may be high, which lowers their political attractiveness, and may induce the regulator to set a low tax (as explained in chapter 3). Since freely distributed tradeable pollution quota do not suffer from this they may be better instruments to stimulate environmental innovation.

After having outlined the advantages of using economic instruments, we also want to point out certain limitations to their use. First, in order to be effective, polluters must be responsive to price signals, which is not always the case. For instance, in chapter 7 we found that price considerations played a limited role in the diffusion of thermal home insulation technologies in the Netherlands. This suggests that price incentives are prob-

${ }^{1}$ According to Hahn and Hester, the U.S. emission trading programme introduced in 1974 resulted in cost savings in emission control between 1 and 13 billion dollars. Almost all of these savings were realized from internal trading (Hahn, op cit, pp.100-101). 
ably better suited to change the behaviour of firms than the purchasing decisions of consumers. Second, the price incentive must be sufficiently high to induce firms to develop and implement environmentally beneficial technologies. This was not the case in most environmental policies in which economic instruments were used (an exception is the effluent charge in the Netherlands). And third, if we are dealing with continental or global environmental problems, taxes should be used unilaterally only if their introduction does not put national industries at a serious competitive disadvantage - that is, they should be introduced in those sectors where the environmental costs are a small part of total costs or in sectors sheltered from international competition.

Uncertainty about the demand for cleaner technologies, partly related to unpredictable government policy, may call for the use of R\&D subsidies or loans. Subsidies for investments in pollution control technology are less useful in our view. They clash with the polluter-pays-principle and are expensive, and evaluation research in the Netherlands has proved them to be only minimally effective. There is a great risk that such subsidies provide 'windfall gains' for the firms and consumers receiving them. They should be used only when a switch to cleaner technology entails high costs and produces competitive disadvantages due to less strict regulation in other countries.

Communication instruments can be useful policy tools for addressing information problems related to products and processes. Environmental care systems (required in the Netherlands), demonstration projects and information campaigns can be useful to ensure that firms make better use of the possibilities available for emission reduction, because firms are often not familiar with available cost-reducing environmental measures. Information disclosure requirements, such as those in the U.S., that force firms to communicate environment-related information, product information and 'green' labels are also believed to be useful. They increase pressures on firms to improve the environmental record and make the market for green products more transparent. They are useful as additional instruments, not as substitutes for environmental regulations or taxes.

This study suggests that no single instrument is optimal. All instruments have a role to play in environmental policy. In general, the stimulation of cleaner technologies calls for a mixture of instruments, depending on the specific factors and circumstances. In the case of heterogeneous users, economic instruments are generally preferred to standards. They are more economically efficient than standards, giving equivalent environmental improvements at lower costs, which allows policy makers to achieve greater emissions reductions. As we noted, there are certain limitations to their effective use. For example, there is a danger that incentive-based instruments such as taxes and subsidies provide a too weak and indirect stimulus. They may be more suited to stimulate technological diffusion than innovation. Our analysis of the diffusion of biological waste-water treatment technologies in chapter 6 illustrates that economic incentives like effluent charges can be effective policy measures in stimulating firms to invest in environmental technologies.

In order to stimulate technological innovation, a more focused approach may be needed. One way of doing this is by specifying strict environmental standards that 
require the development of new technologies. However, this should be done only in situations where the environmental risks are large and acute and when there is consensus about the most viable technological solution or trajectory. If there is no such consensus there is a danger that technology-forcing standards lock industry into overly expensive and environmentally suboptimal technical solutions (for example, the ONO technology in the metal-plating industry). When using direct regulation, policy makers should give careful attention to the actual design of standards: their strictness, differentiation, timing, administration and flexibility. The experiences in the U.S. with innovation waivers and tradeable permits illustrate that the ways in which the instruments are designed and implemented are important determinants of the technological responses of industry. Another way of encouraging technological innovation is to build a network of technology suppliers, users, and research institutes, as in the Danish Clean Technology Development Programme. This programme not only provided firms with economic incentives for developing and implementing clean technologies, but, more importantly, provided them with informative incentives and necessary contacts for finding efficient technological solutions to specific environmental problems. ${ }^{2}$ Of course, such a policy is not easy, it requires special competence on the part of policy makers. They must have technological understanding of the production processes, the associated environmental problems and possible solutions if they are to act as a matchmaker and identify the relevant participants for the development projects.

It may be clear that there are no ready answers to the problems of environmental degradation, each situation requires a tailored response. However, the main conclusion of this study is that certain instruments - like technology-forcing standards, tradeable pollution quota, and the creation of technology networks - offer a number of advantages over traditional policies.

\subsection{The Problem of Technological Regime Shifts}

This thesis also examines the possibilities of redirecting complex technology systems. One may wonder what this has to do with environmental policy. Our answer is that the problem of environmental sustainability not only requires the development and adoption of cleaner processes and products, but also changes in complex technology systems, like the transport system and the electrical power system based on fossil fuels. This raises the important question of how public policy may be used best to induce a technological transition away from non-sustainable technology systems. In order to answer this question, part II discusses evolution and change in complex technology systems. Since neoclassical economics has little to say about this issue, we adopt a different approach: the evolutionary or Neo-Schumpeterian approach to technology, which emphasizes the

\footnotetext{
'Georg et al., op cil, 545-546.
} 
cumulative nature of technical change, and the role of institutions in the creation and selection of technologies. We look at various concepts (like a technological regime and paradigm) that are used to account for the ordering and structuring of technology. In these approaches, engineering ideas of the relevant problems and ways of solving them are considered responsible for the dominance of certain designs and technologies. We provide a different explanation. We argue that the reason why some technologies and designs are dominant depends not only on engineering beliefs and imagination but also on the accumulated knowledge, cost efficiencies achieved in certain designs, the infrastructure around a technology, and the embedment of technologies in the economic system and people's way of life.

In chapter 11, we provide a discussion of technological regime shifts as opposed to change within a technological regime. We explain how it is possible for a new technological regime to emerge and replace the old one - emphasizing the importance of market niches, available knowledge that may be used, institutional support for new technologies, and the role of expectations. We also look at the relationship between firm behaviour and technological regime shifts.

Chapter 12 explores the policy issues of making a transition away from fossil fuels that are implicated in many of today's environmental problems. It addresses the following question: How can public policy be used to induce such a transition, and what are its technological, economic implications? The answer of economists is simple: policy makers should institute a carbon tax or other penalty on greenhouse gas emissions. This study takes issue with this idea. We believed that a carbon tax that is politically feasible will not be strong enough to lead us away from fossil fuels. The lock-in of society to fossil fuel-based energy technologies suggests (at least to us) that what is needed are not so much generic policies (like a carbon tax) that change the marginal costs of using fossil fuels; rather, what are needed are well-defined energy technology policies aimed at the development and wider diffusion of specific energy technologies, such as gasificationbased biomass power generation, fuel cells, photovoltaics, combined cycle power systems, $\mathrm{CO}_{2}$ removal, etc.

What does this imply for public policy? One of the things it implies are special science and technology programmes for promising energy technologies with long-term benefits. Policy makers should also engage in experimentation with new technologies to learn more about their economic costs, technical feasibility and social acceptance. One way of doing this is through the creation of niche markets through government procurement, regulation, tax policies, subsidy schemes, etc. Other policies are the creation of networks of technology suppliers, research organizations and users, and the coordination of energy technology and environmental policies with other policies: agricultural policies, transport policies, land-use planning, and industrial policies. This does not mean that carbon taxes or tradeable quota have no role to play in greenhouse policies; they do, but only as elements of a more comprehensive energy technology policy aimed at making a transition towards a more sustainable energy system. This is the conclusion of part III of the thesis, although perhaps we should say that this is more of a belief than a conclusion. More research on this topic is needed. 


\section{References}

Abernathy, William J, and James M. Utterback, 1975, A Dynamic Model of Process and Product Innovation, Omega 3(6): 639-656.

Adar, Zvi, and James M. Griffin, 1976, Uncertainty and the Choice of Pollution Control Instruments, Journal of Enoironmental Economics and Management 3: 178-188.

Aitchison, J., and J.A.C. Brown, 1957, The Lognormal Distribution, Cambridge: Cambridge University Press.

Algemene Energie Advies Raad, 1990, Het woord aan de praktijk, jaaradvies 1990, Den Haag.

Ames, E., 1965, Soviet Economic Processe's, Homewood.

Anonymous, 1988, Paint Markets. The Growth of Water-Based Products, 'IM' Pigments, Filler and Extenders, 7-11.

Arrow, Kenneth, 1962, Economic Welfare and the Allocation of Resources for Innovation, in Richard Nelson (ed.), The Rate and Direction of Inventive Activity: Economic and Social Factors, Princeton: Princeton University Press.

Arthur, W. Brian, 1988, Competing Technologies: An Overview, in Giovanni Dosi, Chris Freeman, Richard Nelson, Gerald Silverberg and Luc Soete (eds.), Technical Change and Economic Theory, London: Pinter Publishers, 590-607.

Arthur, W. Brian, 1989, Competing Technologies, Increasing Returns, and Lock-in By Historical Events, Economic Journal 99: 116-131.

Arthur, W. Brian, 1990, Positive Feedbacks in the Economy, Scientific American.

Ashford, Nicholas A., George R. Heaton Jr., and W. Curtiss Priest, 1979, Environmental, Health, and Safety Regulation and Tecnological Innovation in J.M. Utterback and C. Hill (eds.), Technological Innozation for a Dynamic Economy, 161-221.

Ashford, Nicholas A., Christine Ayers and Robert F. Stone, 1985, Using Regulation to Change the Market for Innovation, Haroard Enoironmental Law Review 9: 419-466.

Ashford, Nicholas, 1993, Understanding Technological Responses of Industrial Firms to Environmental Problems: Implications for Government Policy, in Kurt Fischer and Johan Schot (eds.), Environmental Strategies for Industry: International Perspectives on Research Needs and Policy Implications, Washington D.C.: Island Press.

Ausubel, Jesse H., 1989, Regularities in Technological Development: An Environmental View, in Jesse H. Ausubel and Hedy E. Sladowich (eds.), Technology and Enoironment, Washington D.C.: National Academy Press, 70-91. 
Ayres, Clarence E., 1978, The Theory of Economic Progress, 3rd edition, New Issues Press - originally published in 1944 by University of Carolina Press).

Ayres, Robert U., and Allen V. Kneese, 1969, Production, Consumption and Externalities, American Economic Review 59: 282-297.

Ayres, R.U. and S.M. Miller, 1980, The Role of Technical Change, Journal of Environmental Economics and Management 7(4): 353-372.

Ayres, Robert U., 1985, A Schumpeterian Model of Technological Substitution, Technological Forecasting and Social Change 27: 375-83.

Ayres, R.U., 1989, Industrial Metabolism, in J.H. Ausubel and H.E. Sladowich (eds), Technology and Environment, Washington D.C.: National Academy Press, 23-49.

Baldwin, William L. and John T. Scott, 1987, Market Structure and Technological Change, Chur: Harwood Academic Publishers.

Bass, Frank M., 1969, A New Product Growth Model for Consumer Durables, Management Science 15: $215-227$.

Bass, Frank M., 1980, The Relationship Between Diffusion Rates, Experience Curves, and Demand Elasticities for Consumer Durable Technological Innovations, Journal of Business 53: S551-S567.

Baudet, H., 1986, Een vertrouwde wereld. 100 jaar innovatie in Nederland (A familiar world. 100 years of innovation in the Netherlands), Amsterdam: Bert Bakker.

Baumol, William J., 1972, On Taxation and the Control of Externalities, American Economic Review 62: $307-322$.

Baumol, William J., and Wallace E. Oates, 1979, Economics, Environmental Policy and the Quality of Life, Englewood Cliffs: Prentice-Hall.

Baumol, William J., and Wallace E. Oates, 1988, The Theory of Environmental Policy, 2nd Edition, Cambridge: Cambrige University Press.

Belt, Henk van den, and Arie Rip, 1989, The Nelson-Winter-Dosi Model and Synthetic Dye Chemistry, in Wiebe E. Bijker, Thomas P. Hughes and Trevor J. Pinch, (eds.) The Social Construction of Technological Systems: New Directions in the Sociology and History of Technology, Cambridge (Mass): MIT Press, 135-158.

Bernardini, Oliviero, and Riccardo Galli, 1993, Dematerialization: Long-Term Trends in the Intensity of Use of Materials and Energy, Futures 25(4): 431-448.

Betting, M, 1988, Een schoon begin is het halve werk, Intern rapport VROM, Afdeling Coördinatie Milieutechnologie. 
Beumer, L., E.C. van der Giessen, R. Olieman and G.R. Otten, 1993, Evaluatie van de isolatieregeling (SES 1991) en de ketelregeling (SNEV), NEI, Rotterdam.

Boer, André de, 1991, Groene golf in lakken (Green wave in coatings), Ingenieurskrant, 12, June 13, 1991.

Bohm, Peter, and Clifford S. Russell, 1985, Comparative Analysis of Alternative Policy Instruments, in A.V. Kneese and J.L. Sweeney (eds.), Handbook of Natural Resource and Energy Economics, vol.1, Amsterdam: Elsevier Science Publishers.

Bongaerts, Jan C., and Dirk Heinrichs, 1987, Government Support of Clean Technology Research in West Germany: Some Evidence, RED Management, 17(1): 39-50.

Bonifant, Ben, 1993, Competitive Implications of Environmental Regulation in the Paint and Coatings Industry, paper prepared for the 2nd Greening of Industry conference in Boston, November 14-16, 1993.

Bonus, Holger, 1973, Quasi-Engel Curves, Diffusion, and the Ownership of Major Consumer Durables, Journal of Political Economy 81: 655-677.

Boulding, Kenneth E., 1966, The Economics of the Coming Spaceship Earth, in H. Jarrett (ed.), Enoironmental Quality in a Growing Economy, Baltimore: John Hopkins Press.

Boulding, Kenneth E., 1978, Ecodynamics. A New Theory of Societal Evolution, Beverly Hills, London: Sage Publications.

Bressers, Hans Th.A., 1983, Beleidseffectiviteit en waterkwaliteitsbeleid. Een bestuurskundig onderzoek (The effectiveness of water quality policy. A political science study), $\mathrm{PhD}$ dissertation, University of Twente, Enschede.

Bressers, Hans Th.A., 1988, Effluent Charges Can Work: The Case of the Dutch Water Quality Policy, in Frank J. Dietz and Wim J.M. Heijman (eds.), Environmental Policy in a Market Economy, Wageningen, 5-39.

Bressers, Hans Th.A., 1988, A Comparison of the Effectiveness of Incentives and Directives: The Case of Dutch Water Quality Policy, Policy Studies Reviewv, 7(3): 500-518.

Bresson, Chris de, 1987, The Evolutionary Paradigm and the Economics of Technological Change, Journal of Economic Issues, 21(2): 751-762.

Brumm, Harold J., and Daniel T. Dick, 1976, Federal Environmental Policy and R\&D on Water Pollution Abatement, American Economic Review AEA papers and proceedings, 66(2): 448-453.

Buchanan, James M., 1969, External Diseconomies, Corrective Taxes and Market Structure, American Economic Review, 59: 174-177. 
Buchanan, James M., and Gordon Tullock, 1975, Polluters' Profits and Political Response: Direct Controls Versus Taxes, American Economic Review 59: 139-147.

Cansier D., 1979, Umweltpolitik, Wirtschaftswachstum und umwelttechnischer Fortschritt, Jahrbücher fur Nationalökonomie und Statistik, 194(4): 337-362.

Carraro, Carlo, and Giorgio Topa, 1991, Taxation and the Environmental Innovation, Fondazione Eni Enrico Mattei discussion paper 4.91.

Carraro, Carlo, and Domenico Siniscalco, 1992, Environmental Innovation Policy and International Competition, Environmental and Resource Economics, 2(2): 183-200.

Chatterjee, Rabikar, and Jehoshua Eliashberg, 1990, the Innovation Diffusion Process in a Heterogeneous Population: A Micromodelling Approach, Management Science, 36(9): 1057-1079.

Christainsen, Gregory B., and Robert H. Haveman, 1981, The Contribution of Environmental Regulation to the Slowdown in Productivity Growth, Journal of Enoironmental Economics and Management, 8: 381-391.

Clark, Kim B., 1985, The Interaction of Design Hierarchies and Market Concepts in Technological Evolution, Research Policy, 14, 235-251.

Clark, N. and C. Juma, 1987, Long-Run Economics: An Evolutionary Approach to Economic Growth, London: Pinter Publishers.

Coase, R.H., 1960, The Problem of Social Cost, Journal of Law and Economics, 3: 1-44.

Collingridge, David, and Peter James, Inflexible Energy Policies in a Rapidly-Changing Market, Long Range Planning, 24(2): 101-107.

Communicatie- en Adviesbureau over Energie en milieu (CEA), 1993, Besparingspotentiëlen woningbouw (Energy-savings profiles in house building), Rotterdam.

Constant, Edward E., 1980, The Origins of the Turbojet Revolution, Baltimore: John Hopkins University Press.

Constant, Edward E., 1984, Communities and Hierarchies: Structure in the Practice of Science and Technology, in Rachel Laudan (editor), The Nature of Technological Knowledge: Are Models of Scientific Change Relecant?, Dordrecht: D. Reidel, 27-46.

Comish, Edward, 1993 as Predicted in 1893: If They Could See Us Now, The Futurist, May-June, 1993.

CPB, 1989, Economische Gevolgen van een Drietal Scenarios voor Milieubleid in Nederland tot 2010, Werkdocument nr.29, Den Haag. 
Cramer, Jacqueline, and Johan Schot, 1989, Problemen rond innovatie en diffusie van milieutechnologie belicht vanuit een technologie-dynamica perspectief (Problems of innovation and diffusion of environmental technology from a technology dynamics perspective), paper for the workshop "Ontwikkeling en implementatie van milieutechnologie", Utrecht, September 12, 1989.

Cramer, Jacqueline, 1990, De effecten van milieubeleidsinstrumenten op innovatie en diffusie van schonere technologieën (The effects of environmental policy instruments on innovation in and diffusion of cleaner technologies), concept report for integration project "Environment and Economy".

Cramer, J., J. Schot, F. van der Akker, G. Maas Geesteranus, 1990, Stimulating Cleaner Technologies through Economic Instruments; Possibilities and Constraints, UNEP Industry and Enoironment Reoiew, 13: 46-53.

Cramer, Jacqueline, en Johan Schot, 1990, Problemen rond Innovatie en Diffusie van Milieutechnologie (Problems around innovation and diffusion of environmental technology), RMNO-publicatie, nr. 44.

Crandall, R.W, 1981, Pollution Controls and Productivity Growth in Basic Industries, in T.G. Cowing and R.E. Stevenson (eds.) Productivity Measurement in Regulated Industries, New York: Academic Press, 347-368.

Crandall, R.W., H.K. Gruenspecht, T.E. Keeler and L.B. Lave in Regulating the Automobile, 1986, Washington DC: The Brookings Institution.

Cyert, R.M. and J.G. March, 1963, A Behavioral Theory of the Firm, London: Prentice Hall.

Daly, Herman E., 1992, Steady-State Economics, 2nd Edition, London: Earthscan.

Dasgupta, P., 1982, The Control of Resources, Oxford: Basil Blackwell.

David, Paul A., 1969, A Contribution to the Theory of Diffusion, Stanford Center for Research in Economic Growth, Stanford Centre for Research in Economic Growth, Memorandum 71.

David, Paul, 1975, Technical Choice, Innovation and Economic. Growth. Essays on American and British Experience in the Nineteenth Century, Cambridge: Cambridge University Press.

David, Paul A., 1985, Clio and the Economics of QWERTY, American Economic Review AEA papers and proceedings, 75: 332-337.

David, Paul A., and Susan Greenstein, 1990, The Economics of Compatibility Standards: An Introduction to Recent Research, Economics of Innovation and New Technology, 1: 3-41.

Davies, Stephen, 1979, The Diffusion of Process Innovations, Cambridge: Cambridge University Press.

Dickinson Gibbons, Jean, 1971, Nonparametric Statistical Inference, New York: McGraw-Hill. 
Dieleman, Hans, and Sybren de Hoo, 1991, PRISMA: the Development of a Preventative, Multi Media Strategy for Government and Industry, in Kurt Fischer and Johan Schot (eds.), Environmental Strategies for Industry: International Perspectives on Research Needs and Policy Implications, Washington D.C.: Island Press, 245-275.

Dijkstra, Cees, 1991, De nieuwe generatie verf (The new generation of paints), Eisma's vakpers, nrs. 24-25.

Dijkstra, Cees, 1992, De nieuwe generatie verf (The new generation of paints), Eisma's vakpers, nrs. 1-12.

Dixon, Robert, 1980, Hybrid Com Revisited, Econometrica, 48(6): 1451-1462.

Doelen, F.C.J., van der, Instrumenten van energiebesparingsbeleid (Economic instruments for energy conservation), Economische Statistische Berichten, April 26, 1992, 415-418.

Dosi, Giovanni, 1982, Technological Paradigms and Technological trajectories: A Suggested Interpretation of the Determinants and Directions of Technical Change, Research Policy, 6: 147-162.

Dosi, Giovanni, 1988, The Nature of the Innovation Process, in Giovanni Dosi, Chris Freeman, Richard Nelson, Gerald Silverberg and Luc Soete (eds.), Technical Change and Economic Theory, London: Pinter Publishers, 221-238.

Dosi, Giovanni, 1988, Sources, Procedures and Micro-Economic Effects of Innovation, Journal of Economic Literature, 26(3): 1120-1171.

Downing, Paul B., 1982, A Political Economy Model of Implementing Pollution Law, Joumal of Environmental Economics and Management, 8(3): 252-277.

Downing, Paul B., and Lawrence J. White, 1986, Innovation in Pollution Control, Journal of Environmental Economics and Management, 13: 18-29.

Driel, Pieter van, and Joram Krozer, 1987, Innovatie, preventief milieubeheer en schonere technologie (Innovation, Preventative Environmental Policy and Clean Technology), Tijdschrift voor Politieke Economie, 10(4): 33-56.

Eads, George C., 1980, Regulation and Technical Change: Some Largely Explored Influences, American Economic Review, 70(2): 50-55.

Easingwood, Christopher J., Vijay Mahajan and Eitan Muller, 1983, A Nonuniform Influence Innovation Diffusion Model of New Product Acceptance, Management Science, 2(3): 273-293.

ECOTEC, 1986, The Promotion and Diffusion of Clean Technologies in the Metal Plating industry in the Netherlands, report to the Netherlands Ministery of Housing, Physical Planning and Environment. 
Elzen, Boelie, and Johan Schot, 1992, Fumbling with the Car: How to Influence a Highly Entrenched Technology? Paper for the joint 4S/EAST Conference 12-15 August, Gothenberg, Sweden.

Evaluatiecommissie Wet Algemene Bepalingen Milieuhygiëne, 1992, Financiële instrumenten in het beleidsproces (Financial instruments in the policy process), advies nr. 5, Den Haag: VROM.

Evenblij, Maarten, 1993, Waterzuivering. The Sky is the Limit, Milieumagazine, 4(4): 4-7.

EZ/VROM, 1991, Beleidsnotitie Technologie en Milieu: technologie als schakel tussen ecologie en economie (Policy note on technology and the environment) Den Haag/Leidschendam.

Financial Times Survey "Vehicles and the Environment", Financial Times, July, 27, 1990.

Financial Times Survey "World Paints and Coatings", Powder bucks the trend, Financial Times, March 27, 1991.

Fisher, J C. and R.H. Pry, 1971, A Simple Substitution Model of Technological Change, Technological Forecasting and Social Change, 3: 75-88.

Fourt, L.A., and J.W. Woodlock, 1960, Early Prediction of Market Success for New Grocery Products, Journal of Marketing, 25: 31-38.

Frank, A., en H.J.J. Swarte, 1986, Milieutechnologieën: toepassing in kleine en middelgrote ondernemingen, Erasmus Studiecentrum voor Milieukunde, Rotterdam.

Frankel, Marvin, 1955, Obsolence and Technological Change in a Maturing Economy, American Economic Review, 45: 296-319.

Fransman, Martin, 1990, The Market and Beyond. Cooperation and Competition in Information Technology in the Japanese System, Cambridge: Cambridge University Press.

Freeman, Chris, John Clark, and Luc Soete, 1982, Unemployment and Technical Innovation: a Study of Long Waves in Economic Development, London: Pinter Publishers.

Freeman, Chris, 1982, The Economics of Industrial Innovation, 2nd Edition, London: Pinter Publishers.

Freeman, Chris, 1984, Prometheus Unbound, Futures, 16: 494-507.

Freeman, Chris, and Carlota Perez, 1988, Structural Crises of Adjustment, Business Cycles and Investment Behaviour, in Giovanni Dosi, Chris Freeman, Richard Nelson, Gerald Silverberg and Luc Soete (eds.), Technical Change and Economic Theory, London: Pinter Publishers, 38-66.

Freeman, Chris, 1991, Innovation, Changes of Techno-Economic Paradigm and Biological Analogies in Economics, Revue Economique, 42(2): 211-232. 
Freeman, Chris, 1992, A Green Techno-Economic Paradigm for the World Economy', in his book The Economics of Hope, London: Pinter Publishers, 190-211.

George, Susse, Inge Ropke and Ulrik Jørgensen, 1992, Clean Technology-Innovation and Environmental Regulation, Environmental and Resource Economics, 2(6): 533-550.

Georghiou, Luke, J.Stanley Metcalfe, Michael Gibbons, Tim Ray, and Janet Evans, 1986, PostInnovation Performance: Technological Development and Competition, London: MacMillan.

Gerritse, G., L.W. Koot and A.G. Metman, 1987, Energiebesparing in de Nederlandse Industrie (Energy savings in Dutch industry), Economische Statistische Berichten, 29-7-1987, 696-699.

Glaister, Stephen, 1974, Advertising Policy and Returns to Scale in Markets where Information is Passed Between Individuals, Economica, 41: 139-156.

Glasbergen, P., (red.), 1990, Milieubeleid: Theorie en Praktijk (Environmental Policy. Theory and Practice), Den Haag: VUGA.

Gold, Bela, 1981, Technological Diffusion in Industry: Research Needs and Shortcomings, Journal of Industrial Economics, 29(3): 247-269.

Gray, Paul E., Jefferson W. Tester, and David O. Wood, 1991, Energy Technology: Problems and Solutions', in Jefferson W. Tester, David O. Wood and Nancy A. Ferrari (editors), Energy and the Environment in the 21st Century, Cambridge (MA): MIT Press.

Green, Kenneth, 1992, Creating Demand for Biotechnology: Shaping Technologies and Markets', in Rod Coombs, Paolo Saviotti and Vivien Walsh (eds.), Technological Change and Company Strategie's, London: Academic Press, 164-184.

Greene, David L., 1990, CAFE OR PRICE. An Analysis of Effects of Federal Fuel Economy Regulations and Gasoline Price on New Car MPG, 1978-89, The Energy Journal 11(3): 37-57.

Griliches, Zvi, 1957, Hybrid Com: An Exploration in the Economics of Technical Change. Econometrica, 25(4): 501-522.

Griliches, Zvi, 1980, Hybrid Com Revisited: A Reply, Econometrica, 48(6): 1463-1464

Groen, Maurits, 1987, Milieutechnologie - meer dan milieu en technologie, Den Haag: Staatsuitgeverij.

Groenewegen, Peter, and Philip Vergragt, 1991, Environmental Issues as Threats and Opportunities for Technological Innovation, Technology Analysis and Strategic Management 3(1): 43-55.

Grubb, Michael, 1990, Energy Policies and the Greenhouse Effect, Volume I and II, Aldershot: Dartmouth. 
Grubb, Michael et al., 1992, Emerging Energy Technologies. Impacts and Policy Implications, Aldershot: Dartmouth.

Gruenspecht, H.K. and L.B. Lave, 1989, The Economics of Health, Safety and Environmental Regulation, in R. Schmalensee and R.D. Willig (eds.), Handbook of Industrial Organization, Volume II, Amsterdam: North-Holland.

Gujarati, Damodar N., 1988, Basic Econometrics, 2nd Edition, New York: McGraw-Hill.

Hahn, Robert W., 1989, Economic Prescriptions for Environmental Problems: How the Patient followed the Doctor's Orders, Journal of Economic Perspectives, 3(2): 95-114.

Hahn, Robert W., 1993, Comparing Environmental Markets with Standards, Canadian Journal of Economics, 26(2): 346-354.

Hartje, V.J., 1984, The State of Economic Research in Innovation and Environmental Protection, International Institute for Environment and Society (IIUG), dp84-4, Wissenschaftszentrum Berlin.

Hartje, Volkmar J., and Robert L. Lurie, 1984, Adopting Rules for Pollution Control Innovations: End-of-Pipe versus Integrated Process Technology, International Institute for Environment and Society (IIUG), Wissenschaftszentrum Berlin.

Hartje, Volkmar J., and Robert L. Lurie, 1985, Research and Development Incentives for Pollution Control Technologies, International Institute for Environment and Society (IIUG), Wissenschaftszentrum Berlin.

Heaton Jr., George R., 1990, Regulation and Technological Change, paper for the WRI/OECDSymposium Toward 2000: Environment, Technology and the New Century, Annapolis, Maryland, June 13-15, 1990.

Heaton, George, Roberto Repetto and Rodney Sobin, 1991, Transforming Technology: An Agenda for Environmentally Sustainable Growth in the 21st Century, WRI, Washington.

Heaton Jr., George R., Roberto Repetto and Rodney Sobin, 1992, Backs to the Future: U.S. Government Policy Toward Environmentally Critical Technology, WRI, Washington.

Henckens, M.C.L.M., and A.P. de Kok, 1988, Alternatieve lakken of emissiebeperkende apparatuur (Alternative coatings or pollution control equipment), Procestechniek 43(2): 56-59.

Hernes, Gudmund, 1976, Diffusion and Growth - The Non-Homogeneous Case, Scandinavian Journal of Economics, 78: 427-436.

Hoogt, A. van der, P.J.J. Oosterling en J. Schuurman, 1990, Heffingen verontreiniging oppervlaktewateren, in Hoofdzaken milieuheffingen, edited by E.P.J. Wasch, Fiscale studie serie nr.27. 
Horsky, D., and L.S. Simun, 1983, Advertising and the Diffusion of New Products, Marketing Science, 2: 1-17.

Horsky, Dan, 1990, A Diffusion Model Incorporating Product Benefits, Price, Income and Information, Marketing Science, 9(4): 342-365.

Houghton, G.J., Jenkins and J.J. Ephraums (eds.), 1990, Climate Change. The IPCC Scientific. Assessment, Cambridge: Cambridge University Press.

Hughes, Thomas P., 1989, The Evolution of Large Technological Systems, In The Social Construction of Technological Systems: New Directions in the Sociology and History of Technology, edited by Wiebe E. Bijker, Thomas P. Hughes and Trevor J. Pinch, Cambridge (Mass.): MrT Press, 51-82.

Huisingh, Donald, Larry Martin, Helene Hilger and Neil Seldman, 1986, Proven Profits from Pollution Prevention, Institute for Local Selfreliance, Washington D.C.

Hung, Victor T.Y., Pamela Chang and Keith Blackburn, 1993, Endogenous Growth, Environment and R\&D, Fondazione Eni Enrico Mattei discussion paper 23.93.

Huppes, G., W.T. Groot, en H. Bezemer, 1988, Instrumenten voor milieubeleid, Alphen a/d Rijn: Samsom.

IJlst, P., C.T.M. Stokman and E.T. Visser, 1988, Informatieoverdracht en informatiebehoefte in de milieuproduktiesector in Nederland (Information transfers and information needs in the environmental industry in the Netherlands) EIM, Zoetermeer.

Irwin, Alan, and Philip Vergragt, 1989, Re-thinking the Relationship between Environmental Regulation and Industrial Innovation: The Social Negotiation of Technical Change, Technology Analysis and Strategic Management 1(1): 57-70.

Jackson, Tim, 1992, Renewable Energy. Summary Paper for the Renewables Series, Energy Policy, 861-883.

Jaffe, Adam B., and Robert N. Stavins, 1990, Evaluating the Relative Effectiveness of Economic Incentives and Direct Regulation for Environmental Protection: Impacts on the Diffusion of Technology, paper for the WRI/OECD-Symposium "Toward 2000: Environment, Technology and the New Century", June 13-15, 1990, Annapolis, Maryland.

Jain, Dipak C., and Ram C. Rao, 1990, Effect of Price on the Demand for Durables: Modelling, Estimation, and Findings, Journal of Business and Economic Statistics, 8(2): 163-170.

Jänicke, M., H. Mönch, T. Ranneberg and U.E. Simonis, 1988, Structural Change and Environmental Impact: Empirical Evidence on Thirty-One Countries in East and West, Wissenschatszentrum Berlin. 
Jehae, Michel, 1991, Bescherming ozonlaag kan tot trendbreuk leiden (Protection of ozone layer may lead to a new trend), Nieuwe Beta, sept 1991.

Jensen, Richard, 1982, Adoption and Diffusion of an Innovation of Uncertain Profitability, Journal of Economic Theory, 27: 182-193.

Johansson, Thomas B., Henry Kelly, Amulya K.N. Reddy, Robert H. Williams (editors), 1992, Renewable Energy. Sources for Fuels and Electricity, London: Earthscan.

Jong, Mark de, and Klaas van de Ven, 1985, Milieu-innovaties in kleine ondernemingen (Environmental innovations in small enterprises), publicatiereeks Milieubeheer 21, VROM

Judge, George G., William E. Griffiths, R. Carter Hill and Tsoung-Chao Lee, 1980, The Theory and Practice of Econometrics, New York: John Wiley.

Kalish, Shlomo, 1985, A New Product Adoption Model with Price, Advertising, and Uncertainty, Management Science, 31(12): 1569-1585.

Kamakura, Wagner A., and Siva K. Balasubramanian, 1988, Long-term View of the Diffusion of Durables: A Study of the Role of Price and Adoption Influence Processes via Tests of Nested Models, International Journal of Research in Marketing, 5: 1-13.

Kamien, Morton I., and Nancy L. Schwartz, 1968, Optimal 'Induced' Technical Change, Econometrica 36(1): 1-17.

Kamien, M.I., and N.L. Schwartz, 1969, Induced Factor Augmenting Technical Progress from a Micro Economic Viewpoint, Econometrica 37(4): 668-684.

Karshenas, Massoud, and Paul Stoneman, 1992, A Flexible Model of Technological Diffusion Incorporating Economic Factors with an Application to the Spread of Colour Television Ownership in the UK, Journal of Forecasting, 11: 577-601.

Kemp, René, and Luc Soete, 1990, Inside the Green Box: On the Economics of Technological Change and the Environment, in New Explorations in the Economics of Technological Change, edited by Chris Freeman and Luc Soete, London: Pinter Publishers, 245-257.

Kemp, René, Xander Olsthoorn, Frans Oosterhuis, and Harmen Verbruggen, 1991, Instrumenten voor de stimulering van milieutechnologie (Policy Instruments to Stimulate Cleaner Technology), Publicatiereeks Milieutechnologie 1991/5, Leidschendam: VROM.

Kemp, René, Xander Olsthoorn, Frans Oosterhuis and Harmen Verbruggen, 1991, Instrumenten voor de stimulering van milieutechnologie (Policy Instruments to Stimulate Cleaner Technology), Beleidsstudies Technologie en Economie 14, Den Haag: EZ.

Kemp, René, and Luc Soete, 1992, The Greening of Technological Progress: An Evolutionary Perspective, Futures, 24(5): 437-457. 
Kemp, René, Xander Olsthoom, Frans Oosterhuis and Harmen Verbruggen, 1992, Supply and Demand Factors of Cleaner Technologies: Some Empirical Evidence, in Environmental and Resource Economics, 2(6): 615-634.

Kemp, René and Luc Soete, 1993, Le progrès technique passe au vert: Une perspective évolutive, INSEE Méthodes Enoironnement Économie, Actes du Colloque, Paris, 15 et 16 Février 1993, 175-186.

Kemp, René, 1993, An Economic Analysis of Cleaner Technologies: Theory and Evidence, in Kurt Fischer and Johan Schot (eds.), Environmental Strategies for Industry: International Perspectives on Research Needs and Policy Implications, Washington D.C.: Island Press, 79-113.

Kemp, René, 1993, Technology and the Transition to a Sustainable Economy, paper for the 2nd Greening of Industry Conference "Designing the Sustainable Enterprise", Boston, 14-16 November.

Kemp, René et al, 1994, Technology and the Transition to Environmental Stability. Continuity and Change in Complex Technology Systems, final report from project "Technological Paradigms and Transition Paths: The Case of Energy Technologies" for SEER research programme of the Commission of the European Communities (DG XII), 300 pages.

Kemp, René, Xander Olsthoorn, Frans Oosterhuis and Harmen Verbruggen, 1994, Policy Instruments To Stimulate Clean Technology, in J.B. Opschoor and R.K. Tumer (eds.), Economic Incentives and Environmental Policies, Dordrecht: Kluwer Academic Publishers, 275-300.

Kemp, René, 1994, Technology and the Transition to a Sustainable Economy. Continuity and Change in Complex Technology Systems, paper presented at the Symposium "Models of Sustainable Development", Paris, 16-18 March, published in Conference proceedings, pp.141-170.

Kemp, René, 1994, Technology and the Transition to Environmental Sustainability. The Problem of Technological Regime Shifts, forthcoming in Futures (December 1994).

Kemp, René, 1995, The Transition from Hydrocarbons. The Issues for Policy, forthcoming in S. Faucheux, D. Pearce and J.L.R. Proops (eds.), Models of Sustainable Development, Edgar Elgar.

Kirsch, David A., 1991, Thematic Summary of Workshop on Social Behavior, Lifestyle and Energy Use, IIASA, Laxenburg.

Kirsch, David A., 1992, The Impact of Technology Upon the Interaction of Energy, Environment and the Economy, MA thesis, MERIT, Maastricht.

Klein, Burton, 1977, Dynamic Economics, Cambridge (Mass.): Harvard University Press.

Kline, Stephen J., and Nathan Rosenberg, 1986, An Overview of Innovation, in R. Landau and N. Rosenberg (eds.), The Positive Sum Strategy, Washington D.C.: National Academic Press.

Klink, J, J. Krozer en A. Nentjes, 1991, Technologische ontwikkeling door marktconform milieubeleid (Technological change through market-based environmental policy), NOTA, V13. 
KJok, Pieter-Jan, 1989, Convenanten als instrument van milieubeleid. De totstandkoming en effectiviteit van acht produkt-gerichte milieu-convenanten en hierop gebaseerde verwachtingen omtrent de effectiviteit van convenanten, Enschede: Unversiteit Twente.

Klok, Pieter-Jan, 1989, Lood-vrije benzine en schone auto's, een toepassing van de instrumententheorie (Unleaded gasoline and clean cars. An application of instrument theory), Centrum voor Bestuurskundig Onderzoek, Twente.

Kneese, Allen V., and Charles L. Schultze, 1975, Pollution, Prices and Public Policy, Washington. Smith, V. Kerry, 1972, The Implications of Common Property Resources for Technical Change, European Economic Reoiew, 3(4): 469-479.

Knip, Karel, 1993, Groene koelkast (Green Refrigerator), NRC Handelsblad, March 4, 1993.

Koppert, P.C., A.A. Olsthoorn and O.J. Kuik, 1988, Emissiereductie door schone technology. Een verkenning van demogelijkheden van 10 'schone' technologieën (Emission reductions from clean technology), IVM R-88/2, Amsterdam.

Kwerel, Evan, 1977, To Tell the Truth: Imperfect Information and Optimal Pollution Control, Review of Economic Studies, 595-601.

Laffont, Jean-Jacques, and Jean Tirole, 1994, A Note on Environmental Innovation, Fondazione Eni Enrico Mattei discussion paper 42.94.

Landelijk Milieu Overleg, 1988, Nota milieu en technologische ontwikkeling; op zoek naar goede daden (A note on the environment and technological change. In search of good deeds), Utrecht.

Landes, David, 1969, The Unbound Prometheus, Cambridge: Cambridge University Press.

Lekvall, P., and C. Wahlbin, 1973, A Study of Some Assumptions Underlying Innovation Diffusion Functions, Swedish Journal of Economics, 75: 362-377.

Levin, Richard C., 1986, A New Look at the Patent System, American Economic Review AEA papers and proceedings, 76: 199-202.

Lindner, R., A. Fischer and P. Pardey, 1979, The Time to Adoption, Economics Letters, 2: 187-190.

Lundvall, Bengt-Åke, 1988, Innovation as an Interactive Process: From User-Producer Interation to the National System of Innovation, in Giovanni Dosi, Chris Freeman, Richard Nelson, Gerald Silverberg and Luc Soete (eds.), 1988, Technical Change and Economic Theory, London: Pinter Publishers, 349-369.

Maas, C.M., P.J.J.G. Geudense, en L.E. Duvoort-van Engers, 1993, Afvalwater-zuiveringsslib van Bedrijven en Instellingen, 1990, $\mathrm{H}_{2} \mathrm{O}, 26(3): 6-8$. 
MacKenzie, Donald, 1992, Economic and Sociological Explanations of Technical Change, in Rod Coombs, Paolo Saviotti and Vivien Walsh (eds.), Technological Change and Company Strategies, London: Academic Press, 25-48.

Magat, Wesley A., 1978, Pollution Control and Technological Advance: A Dynamic Model of the Firm, Journal of Environmental Economics and Management, 5: 1-25.

Magat, Wesley A., 1979, The Effects of Environmental Regulation on Innovation, Law and Contemporary Problems, 43(1): 4-25.

Mahajan, Vijay, and Robert A. Peterson, 1985, Models for Innovation Diffusion, Beverly Hills: Sage Publications.

Mahajan, Vijay, Eitan Muller and Frank M. Bass, 1992, New Product Diffusion Models in Marketing: A Review and Directions for Research, in Nebojక̌ Nakicenovið and Arnulf Grübler (eds.), 1992, Diffusion of Technologies and Social Behavior, Berlin: Springer-Verlag, 125-178.

Majone, Giandomenico, 1976, Choice Among Policy Instruments for Pollution Control, Policy Analysis, 589-613.

Mansfield, Edwin, 1961, Technical Change and The Rate of Imitation, Econometrica, 29: 741-766.

Mansfield, Edwin, 1968, Industrial Research and Technological Innovation: An Econometric Analysis, New York: Norton.

Mansfield, E., M. Schwartz and S. Wagner, 1981, Imitation Costs and Patents: An Empirical Study, Economic Journal, 91: 907-918.

McCain, Roger A., 1978, Endogenous Bias in Technical Progress and Environmental Policy, American Economic Review, 68(4): 538-546.

McCardle, Kevin F., 1985, Information Acquisition and the Adoption of New Technology, Management Science, 31(11): 1372-1389.

McHugh, Richard, 1985, The Potential for Private Cost-Increasing Technological Innovation Under A Tax-based Economic Incentive Pollution Control Policy, Land Economics, 61(1): 58-64.

Meadows, D.H., Meadows, D.L., Randers, J., and W.W. Behrens III, 1975, The Limits to Growth, 2nd Edition, New York: Potomac Associates.

Mendelsohn, Robert, 1984, Endogenous Technical Change and Environmental Regulation, Journal of Environmental Economics and Management, 11: 202-207.

Mensink, A.J., C.H.A. Quarles van Ufford, J.M.M. Veeken, 1988, Naar een preventief milieubeleid: onderzoek naar belemmeringen en mogelijkheden van preventie bij de houtconserverings- en galvanische industrie (Towards preventive environmental policy: a study into the barriers of and 
opportunities for prevention in the Wood Preservation and Metal-Plating industries, Nijmeegse Milieukundige Studies nr.1, KUN, Nijmegen.

Metcalfe, J. Stanley, 1988, The Diffusion of Innovations, in Dosi et al, op cit, p.562.

Meyer, Leo A., 1981, Energiebesparing in de Sociale Woningbouw: Besparing op Ruimteverwarming in Theorie en Praktijk (Energy savings in government-subsidized house building: savings in space heating in theory and practice), PhD thesis, University of Groningen.

Miles, Ian, 1993, Shifting Paradigms: How are Transition Paths Constructed?, internal discussion paper EC-project Technological Paradigms and Transition Paths: The Case of Energy Technologies, PREST, Manchester.

Milliman, Scott R., and Raymond Prince, 1989, Firm Incentives to Promote Technological Change in Pollution Control, Journal of Environmental Economics and Management, 17: 247-265.

Mishan, E.J., 1967, The Cost of Economic Growth, Harmondsworth: Pelican.

Mishan, E.J., 1988, Cost-Benefit Analysis, 4th edition, London: Unwin Hyman.

Mohr, Lawrence, 1983, Explaining Organizational Behavior, San Francisco: Jossey-Bass Publishers.

Mokyr, Joel, 1989, Twenty-Five Centuries of Technological Change: An Historical Survey, London: Harwood Academic Publishers.

Montroll, E.E. and W.W. Badger, 1974, Introduction to Quantitative Aspects of Social Phenomena, New York: Gordon and Breach.

Mowery, David C. and Nathan Rosenberg, 1979, The Influence of Market Demand upon Innovation: A Critical Review of Some Recent Empirical Studies, Research Policy, 8: 102-153.

Nabseth, L., and G.F. Ray (eds.), 1973, The Diffusion of New Industrial Processes. An International Study, Cambridge: Cambridge University Press.

National Academy of Sciences, 1991, Policy Implications of Greenhouse Warming, Washington: National Academy Press.

Nationale Woningraad, 1979, Woningisolatie: verstandig aanpakken (Thermal insulation: to make a wise decision), 1979, Woningraad-Extra, april 1979.

Nelson, Richard R, and Sidney G. Winter, 1977, In Search of Useful Theory of Innovation, Research Policy, 6: 36-76.

Nelson, Richard R., and Sidney G. Winter, 1982, An Evolutionary Theory of Economic Change, Cambridge (Mass.): Bellknap Press. 
Nelson, Richard R., 1987, Understanding Technological Change as an Evolutionary Process, Amsterdam: North-Holland.

Nentjes, Andries, 1988, An Economic Model of Innovation in Pollution Control Technology, paper for the Annual Meeting of the American Association of Environmental and Resource Economists, New York, Dec. 28-30, 1988.

Nentjes, Andries, 1990, Economische instrumenten in het milieubeleid: financierings- of sturingsmodel?, in P. Nijkamp en H. Verbruggen (red.), Het Nederlandse milieu in de Europese ruimte (The Dutch environment within European borders), Leiden/Antwerpen: Stenfert Kroese.

Nentjes, Andries, and Doede Wiersma, 1988, Innovation and Pollution Control, International Journal of Social Economics, 15: 51-71.

Niskanen Jr., W.A., 1971, Bureaucracy and Representative Government, Chicago.

Nordhaus, William D., 1991, Economic Approaches to Greenhouse Warming, in Global Warming: Economic Policy Approaches, edited by R. Dornbusch and J.M. Poterba, Cambridge (Mass.): MIT Press.

Nordhaus, William D., 1993, Reflections on the Economics of Climate Change, Journal of Economic Perspectives, 7(4): 11-25.

Norgaard, Richard B., 1988, Coevolutionary Development Potential, Land Economics 60(2): 160-173.

Norgaard, Richard B., 1988, Sustainable Development: A Co-evolutionary View, Futures, 20(6): 606620.

OECD, 1985, Environmental Policy and Technical Change, Paris: OECD.

OECD, 1989, Economic Instruments for Environmental Protection, Paris: OECD.

OECD/IEA, 1991, Greenhouse Gas Emissions. The Energy Dimension, Paris: OECD.

OECD/IEA, 1993, Proceedings Executive Conference on Energy Technology Policy for Sustainable Development. Comparing Long-Term Approaches, Noordwijk, the Netherlands, 9th-11th December 1991, IEA/OECD/NOVEM.

Olsthoorn, Xander, Frans Oosterhuis and Harmen Verbruggen, 1992, Inhoudelijke evaluatie van de stimuleringsregeling milieutechnologie (Evaluation of the subsidy programme Environmental technology), IvM report R-92/01, Amsterdam: IVM.

Opschoor, J.B., 1987, Duunaamheid en verandering: over ecologische inpasbaarheid van economische ontwikkelingen (Sustainability and change. About ecological compatibility of economic developments), VU, Amsterdam. 
Opschoor J.B. and J.B. Vos, 1989, Economic Instruments for Environmental Protection, OECD, Paris.

Opschoor, J.B., and R.K. Turner (eds.), 1994, Economic Incentives and Environmental Policies, Dordrecht: Kluwer Academic Publishers.

Oren, Shmuel S., and Rick G. Schwartz, 1988, Diffusion of New Products in Risk-sensitive Markets, Journal of Forecasting, 7: 273-287.

Orr, Lloyd, 1976, Incentive for Innovation as the Basis for Effluent Charge Strategy, American Economic Review, AEA papers and proceedings, 66(2): 441-447.

Paardekoper, M.H.C., and L.R.J. Westerman, 1978, Analyse I, lecture notes, propedeuse Econometrics, Tilburg.

Pavitt, Keith, 1984, Sectoral Patterns of Technical Change: Towards a Taxonomy and a Theory, Research Policy, 13: 343-373.

Pearce, David W., and R. Kerry Turner, 1989, Economics of Natural Resources and the Environment, London: Harvester Wheatsheaf.

Pearce, David W., and R. Kerry Turner, 1984, The Economic Evaluation of Low and Non-waste technologies, Resources and Conservation, 11: 27-43.

Perez, Carlota, 1983, Structural Change and Assimilation of New Technologies in the Economic and Social System, Futures, 15(4): 357-375.

Pezzey, John, 1988, Market Mechanisms of Pollution Control: 'Polluter Pays', Economic and Practical Aspects, in R.K. Turner (ed.), 1988, Sustainable Environmental Management: Principles and Practices, Belhaven Press, 190-242.

Pezzey, John, 1989, Economic Analysis of Sustainable Growth and Sustainable Development, Worldbank, Environment Department Working Paper, No. 15.

Pigou, A.C., 1946, The Economics of Welfare, 4th edition, London: MacMillan.

Quakernaat, J. en J.A. Don, 1988, Naar meer Preventie-gerichte Milieutechnologie in de Industriele Produktiesector, RNMO, nr. 27.

Raa, Ben te, 1991, Sectorale milieuwetgeving nekt complete bedrijfstak. Galvano-industrie staat voor tweede grote investeringsgolf (Environmental regulation wrecks metal-plating industry. A new wave of investments in pollution control measures is coming), MilieuMarkt, april-issue, 10-13.

Reinganum, Jennifer, 1981, On the Diffusion of New Technology: A Game Theoretic Approach, Review of Economic Studies, 58: 395-405. 
RIVM, 1989, Zorgen voor Morgen: Nationale Milieuverkenning 1985-2010 (Worries for the future. A national survey of the environment 1985-2000), Alphen a/d Rijn: Samson H.D. Tjeenk Willink.

Rogers, Everett M., 1983, Diffusion of Innovations, New York: Free Press.

Roos, H.M., 1977, Kosten-baten analyse van isolatie (Cost-benefit analysis of thermal insulation), Gas, 97: 90-103.

Rosenberg, Nathan, 1976, The Direction of Technological Change: Inducement Mechanisms and Focussing Devices, In his book Perspectives on Technology, Cambridge: Cambridge University Press, 108-125.

Rosenberg, Nathan, 1976, Factors Affecting the Diffusion of Technology, in Perspectives on Technology, Cambridge: Cambridge University Press, 189-210.

Rosenberg, Nathan, 1976, Technology and the Environment: An Economic Exploration, chapter 12 of his book Perspectives on Technology, Cambridge: Cambridge University Press, 213-228.

Rosenberg, Nathan, 1982, On Technological Expectations, Economic Journal, 86: 523-35

Rosenberg, Nathan, 1982, Inside the Black Box. Technology and Economics, Cambridge: Cambridge University Press.

Rothwell, Roy, 1992, Industrial Innovation and Government Environmental Regulation: Some Lessons from the Past, Technovation, 12(7): 447-458.

Russell, Thomas, 1980, Comments on "The Relationship between Diffusion Rates, Experience Curves, and Demand Elasticities for Consumer Durable Technological Innovations", Journal of Business, 53: 569-573.

Ruttan, Vernon W., 1971, Technology and the Environment, American Journal of Agricultural Economics, 53: 707-717.

Sahal, Devendra, 1985 Technological Guideposts and Innovation Avenues, Research Policy 14: 61-82.

Saviotti, Paolo, and J. Stanley Metcalfe, 1984, A Theoretical Approach to the Construction of Technological Output Indicators, Research Policy, 13: 141-151.

Saviotti, Paolo, and Stan Metcalfe (eds.), 1993, Evolutionary Theories of Economic and Technological Change, Reading: Harwood Academic Publishers.

Schelling, Thomas C. (ed.), 1983, Incentives for Environmental Protection, Cambridge (Mass.): Cambridge University Press. 
Schot, Johan, 1992, The Policy Relevance of the Quasi-Evolutionary Model: The Case of Stimulating Clean Technologies, in Rod Coombs, Paolo Saviotti and Vivien Walsh (eds.), Technological Change and Company Strategies, London: Academic Press, 185-200.

Schot, Johan, 1988, Regelgeving en technologische ontwikkeling: mogelijkheden voor sturing (Regulation and technological change. Possibilities for control), Tijdschrift voor Politieke Ekonomie, 3: 79-96.

Schultze, Charles L., 1977, The Public Use of Private Interest, Washington.

Schumpeter, Joseph A., 1939, Business Cycles. A Theoretical, Historical, and Statistical Analysis of the Capitalist Process, 2 vols, New York: McGraw-Hill.

Schumpeter, Joseph, 1974, The Theory of Economic Development, Oxford: Oxford Univerity Press (reprint of 1934).

Schuurman, J., and J. Tegelaar, 1983, De Regulerende Werking van de WVO. Een kwantificering (The effects of WVO. A quantitive study), Weekblad voor Fiscaal Recht, 15: 1561-1577 (nr.5614).

Schuurman, Jaap, 1988, De prijs van Water. Een onderzoek naar de aard en omoang oan de regulerende werking van de verontreinigingsheffing opperolaktewateren (The price of water), Amhem: Gouda Quint.

Siebert, Horst, 1982, Nature As A Life Support System: Renewable Resources and Environmental Disruption, Zeitschrift für Nationalökonomie, 42(2): 133-142.

Siebert, Horst, 1987, Economics of the Environment: Theory and Policy, Berlin: Springer-Verlag.

Silverberg, Gerald, Giovanni Dosi and Luigi Orsenigo, 1988, Innovation, Diversity and Diffusion: A Self-Organisational Model, Economic Journal, 98: 1032-1054.

Silverberg, Gerald, 1992, Adoption and Diffusion of Technology as a Collective Evolutionary Process, in Nebojła Nakićenovǐ and Amulf Grübler (eds.), 1992, Diffusion of Technologies and Social Behavior, Berlin: Springer-Verlag, 209-230.

Simon, Julian L., and Herman Kahn (eds.), 1984, The Resourceful Earth: A Response to Global 2000), New York: Basil Blackwell.

Smith, Keith, 1991, Innovation Policy in an Evolutionary Context, in J.Stanley Metcalfe and Paolo Saviotti (eds.), Evolutionary Theories of Economic and Technological Change, London: Harwood.

Söderbaum, Peter, Neoclassical and Institutional Approaches to Environmental Economics, Journal of Economic Issues 24(2): 481-492.

Soete, Luc, and Anthony Arundel (eds.), 1993, An Integrated Approach to European Innovation and Technology Diffusion Policy. A Maastricht Memorandum, Brussels: Commission of the European Communities. 
Solow, Robert M., 1974, The Economics of Resources or the Resources of Economics, American Economic Review, 64: 1-14.

Sørensen, Knut H., 1992, The Car and its Environments. Proposal for an International Study of the Past, Present and Future of the Motorcar in Europe, Centre for Technology and Society, University of Trondheim, Norway.

Speth, James Gustave, 1990, Needed: An Environmental Revolution in Technology, paper for the WRI/OECD-Symposium "Toward 2000: Environment, Technology and the New Century", June 13-15, 1990, Annapolis, Maryland.

Stichting Bouwresearch, 1985, Wonen in de kou (living in the cold), Rotterdam.

Stoneman, Paul, 1985, Technological Diffusion: The Viewpoint of Economic Theory, mimeo, Warwick University.

Stoneman, Paul, 1983, The Economic Analysis of Technological Change, Oxford: Oxford University Press.

Stuurgroep Nationaal Isolatie Programma, 1988, Evaluatie 10 jaar nationaal isolatie programma (Evaluation of ten year National Insulation Programme), Rotterdam.

Tanny, S.M., and N.A. Derzko, 1988, Innovators and Imitators in Innovation Diffusion Models, Journal of Forecasting, 7: 225-234.

Teece, David J., 1986, Profiting from Technological Innovation: Implications for Integration, Collaboration, Licensing and Public Policy, Research Policy, 15: 285-305.

Teece, David J., 1988, Technological Change and the Nature of the Firm, in Giovanni Dosi, Chris Freeman, Richard Nelson, Gerald Silverberg and Luc Soete (eds.), 1988, Technical Change and Economic Theory, London: Pinter Publishers, 256-281.

Templin, Neal, 1991, California Rules Push Car Makers To Clean Up Act, Wall Street Journal Europe, March 27.

Teubal, Morris, 1979, On User Needs and Need Determination: Aspects of the Theory of Technological Innovation' in M.J. Baker (editor), Industrial Innooation: Theory, Policy, Diffusion, London: MacMillan, 266-293.

Thirtle, Colin G., and Vernon W. Ruttan, 1987, The Role of Demand and Supply in the Generation and Diffusion of Technical Change, Chur: Harwood Academic Publishers.

Tongeren, W. van, and J.W. du Mortier, 1989, Practische Toepassingsmogelijkheden van membraanprocessen in de natte oppervlaktebewerkende industry (Possibilities for the use of membrane techniques in the metal-plating industry), VROM. 
Train, Kenneth, 1985, Discount Rates in Consumers' Energy-Related Decisions: A Review of the Literature, Energy, 10(12): 1243-1253.

Turvey, Ralph, 1963, On Divergences between Social Cost and Private Cost, Economica, 309-313.

Tweede Kamer, 1982, Milieu en Technologie in Nederland (Environment and Technology in the Netherlands), Tweede Kamer, vergaderjaar 1982-1982, 17386, nr.2, Den Haag: Staatsuitgeverij.

Tweede Kamer, 1987, Evaluatie WIR-milieutoeslag (Evaluation of the WIR investment subsidies), Tweede kamer, vergaderjaar 1986-1987, 19858, nr.4.

Tweede Kamer, 1989, Nationaal Milieubeleidsplan. Kiezen of Verliezen (National Environmental Policy Programme. To choose or to lose), publication 21137, nr.1-2, Den Haag: SDU.

Tweede Kamer, 1990, Nationaal Milieubeleidsplan-plus (NMP-plus), 1990, Tweede Kamer vergaderjaar 1989-1990, 21137, nrs. 20-21, Den Haag: SDU.

UNEP, 1989, Technical Progress on Protecting the Ozone Layer.

Veblen, T.B., 1898, Why is Economics not an Evolutionary Science?, Quarterly Journal of Economics, 12: 373-397.

Vermeulen, W.J.W., 1990, Het economische en communicatieve sturingsmodel: alternatieven voor regelgeving in het milieubeleid?, in P. Glasbergen (ed.), Milieubeleid: Theorie en Praktijk, 171-194, Den Haag: VUGA.

Vermeulen, Walter, 1992, De vervuiler betaald. Onderzoek naar de werking van subsidies op vier deelterreinen oan het milieubeleid (Paying the Polluter. A study into the effects of four subsidy schemes for environmental technologies), Utrecht: Jan van Arkel.

Vernon, Jan, and Richard Johnson, 1984, Environmentally Sound Technology for Chemical Industry, UNEP Industry and Environment, 20-24.

Verspagen, Bart, 1993, Trade and Knowledge Spillovers in an Evolutionary Model of Growth Rate Differentials, in Adolf Wagner (ed.), Dezentrale Entscheidungsfindung bei externe Effekten, Tübingen: Franke verlag.

Volder and Vis, 1990, Produktie, verbruik en emissies van CFKs in Nederland (Production, use and emissions of CFCs in the Netherlands), Den Haag.

Vollebergh, H. (ed.), 1989, Milieu en innovatie, Groningen: Wolters-Noordhof.

Waal, K.J.A. de, and W.J. van den Brink (eds.), 1987, Environmental Technology, proceedings of the 2nd European Conference on Environmental Technology, Amsterdam, The Netherlands, June 22-26, 1987. 
Walsh, Vivien, 1984, Invention and Innovation in the Chemical Industry: Demand-Pull or Discovery-Push?, Research Policy 13: 211-34.

Walter, Dave, 1993, Today Then: America's Best Minds Look 100 Years into the Future on the Occasion of the 1893 World's Columbian Exposition, American \& World Geographic Publishing.

Weitzman, Martin L., 1974, Prices vs. Quantities, Review of Economic Studies, 16: 477-549.

Wenders, John T., 1975, Methods of Pollution Control and the Rate of Change in Pollution Abatement Technology, Water Resources Research, 11(3): 393-396.

White, Ron D., 1976, The Anatomy of Nonmarket Failure: An Examination of Environmental Policies, American Economic Review, 66(2): 454-461.

Williams, Hugh E., James Medhurst and Kirstine Drew, 1991, Corporate Strategies For A Sustainable Future, in Environmental Strategies for Industry: International Perspectives on Research Needs and Policy Implications, edited by Kurt Fischer and Johan Schot, Washington D.C.: Island Press, 117-146.

Wolf, Charles Jr., 1988, Markets or Governments: Choosing between Imperfect Alternatives, Cambridge (Mass.): MIT Press.

World Commision on Environment and Development (WCED), 1987, Our Common Future (Brundtland report), Oxford: Oxford University Press.

Zeckhauser, Richard, 1981, Preferred Policies when there is Concern for Probability of Adoption, Journal of Environmental Economics and Management, 8(3): 215-238.

Zerbe, Richard O., 1970, Theoretical Efficiency in Pollution Control, Western Economic Journal, 8: 364-376.

Zimmerman, Klaus, 1988, Umwelpolitik und integrierte Technologien: Entwickelungen und Determinanten in empirischer Analyse, Konjunkturpolitik 34(5/6): 327-351.

Zimmerman, Klaus, Volkmar J. Hartje, Andreas Ryll, 1990, Okologische Modernisierung der Produktion: Strukturen und Trends, Berlin: Sigma-Rainer Bohm Verlag. 


\section{Nederlandse Samenvatting}

Dit proefschrift analyseert de invloed van milieubeleid op de ontwikkeling en toepassing van schone technologie. Met schone technologie wordt bedoeld technieken, grondstoffen en produkten die minder belastend zijn voor het milieu. Voorbeelden van schone technologie zijn: biofilters, rookgasontzwaveling en zonnecellen. Voor deze technieken geldt dat overheidsbemoeienis vaak nodig is opdat ze worden toegepast door bedrijven en huishoudens. De overheid voert daartoe een milieubeleid gericht op duurzame ontwikkeling. De invloed van verschillende milieu-instrumenten (emissienormen, heffingen, subsidies e.d.) op de ontwikkeling en toepassing van schone technologie wordt geanalyseerd in innovatie- en diffusiemodellen en in een aantal empirische studies. Daarnaast schenkt het proefschrift aandacht aan grootschalige technologieverandering en de wijze waarop dit gestimuleerd kunnen worden.

Hoofdstuk 2 geeft een overzicht van de belangrijkste economische literatuur op het gebied over milieubeleid en milieutechnologie. Naast een kritische bespreking van de theoretische literatuur worden in hoofdstuk 3 en 5 een aantal nieuwe modellen gepresenteerd: een politieke economie-model van overheidsgedrag en innovatie in schone technologie, en een diffusiemodel van schone technologie, gebaseerd op economisch keuzegedrag. In het innovatiemodel is het milieubeleid niet exogeen maar afhankelijk van de technische mogelijkheden en kosten van nieuwe technologie. De analyse laat zien dat verhandelbare emissierechten en 'innovation waivers' betere instrumenten zijn om milieutechnologie te stimuleren dan emissie-normen en vervuilingsbelastingen.

De relatie tussen milieubeleid en milieutechnologie is ook onderzocht in een aantal empirische studies. Hoofdstuk 6 analyseert de invloed van de Nederlandse waterverontreinigingsheffing op de diffusie (verandering in de mate van toepassing) van biologische afvalwaterzuiveringsinrichtingen (awzi's) in de voedings- en genotmiddelenindustrie. Uit het onderzoek komt naar voren dat de WVO-heffing een belangrijke factor was bij het diffusieproces: zonder de heffing zouden maar weinig bedrijven zijn overgegaan tot biologische zuivering van hun afvalwater. Ook de diffusie van woningisolatie (in de vorm van dubbel glas en spouwmuurisolatie) in huizen gebouwd vór 1976 is onderzocht (in hoofdstuk 7). Anders dan de diffusie van biologische awzi's kan de toename in het aantal woningen met dubbel glas en met spouwmuurisolatie niet goed verklaard worden d.m.v. een economisch keuzemodel. De diffusie van woningisolatie lijkt veel meer te worden gestuurd door informatie-overdracht en sociale invloeden ("buurteffecten") dan door veranderingen in de gasprijs en de kosten van na-isolatie. Verder blijkt dat de subsidieprogramma's voor na-isolatie een geringe invloed hadden op de isolatiebeslissingen van burgers. Dit suggereert dat de subsidies voor na-isolatie ter grootte van 2 miljard gulden in belangrijke mate een 'windfall gain' vormden voor de ontvangers.

Hoofdstuk 8 bevat de resultaten van drie case-studies van schone technologie: CFK-vervangers, oplosmiddel-arme verven en lakken, en membraantechnologie voor de galvanische industrie. Uit de case-studies komt naar voren dat de technologische moge- 
lijkheden voor milieutechnologie zich vaak buiten de vervuilende sector bevinden en dat marktvraag een cruciale variabele is voor de ontwikkeling van deze mogelijkheden. De analyse leert ons bovendien dat overheidsbeleid niet de enige factor is die van invloed is op de beslissing van bedrijven om over te gaan op schone technologie. De beslissing om te investeren in een bepaalde milieutechnologie hangt af van de technische karakteristieken van de techniek, de kosten voor de gebruiker, het beeld dat potentiële gebruikers hebben van de technologie en de weerstand tegen verandering.

Ook besteedt het proefschrift aandacht aan grootschalige technologie-verandering. Grote technologische systemen (zoals het transportsysteem van voertuigen met een verbrandingsmotor) worden gekenmerkt door een grote mate van complexiteit en padafhankelijkheid. Ingegaan wordt op de factoren die verantwoordelijk zijn voor de stabiliteit van technologische regimes (hoofdstuk 10) en de determinanten van radicale verandering in technologie (hoofdstuk 11). Hoofdstuk 12 onderzoekt de beleidsimplicaties van een duurzamer energie-systeem. Er worden drie mogelijke energie technologie-scenario's besproken en er wordt aangegeven hoe een overgang naar een duurzamer energiesysteem gestimuleerd kan worden. Hierbij wordt een belangrijke rol toebedacht aan speciale technologie stimuleringsprogramma's en het creëren, via beleid, van niches voor nieuwe energietechnieken met lange-termijn-voordelen.

De conciusie van dit proefschrift is dat geen enkel milieu-instrument optimaal is voor de stimulering van schone technologie. Het kiezen van milieu-instrument dient gebaseerd te worden op de technologische mogelijkheden, de economische karakteristieken van gebruikers en de urgentie van milieuproblemen. De uitkomst van het proefschrift is evenwel dat technologieforcerende normen, verhandelbare vervuilingsrechten, en het opzetten van technologienetwerken doorgaans goede instrumenten zijn voor de stimulering van innovatie in schone technologie, en dat economische instrumenten (vervuilingsbelastingen en verhandelbare emissierechten) onder bepaalde voorwaarden goede instrumenten zijn voor de stimulering van de technologische diffusie. Van investeringssubsidies en zelfregulering zonder sancties wordt weinig verwacht. 


\section{Curriculum Vitae}

René Kemp werd geboren op 4 januari 1961 te Eindhoven. Van 1973 tot 1979 volgde hij de Atheneum-opleiding aan het Bisschop Bekkers College in Eindhoven, waarna hij econometrie ging studeren aan de Katholieke Hogeschool Tilburg. In 1987 studeerde hij af in de Algemene Econometrie. Vanaf 1987 is hij werkzaam als toegevoegd onderzoeker aan de Rijksuniversiteit Limburg, eerst aan de Economische Faculteit, daarna bij het Maastricht Economic Research Institute on Innovation and Technology (MERTT) waar hij zich bezighoudt met onderzoek op het gebied van technologie en milieubeleid. Verder is hij verantwoordelijk voor de cursus Milieuschaarste voor studenten van de bovenbouwstudie Milieugezondheidkunde. 


\section{Environmental Policy and Technical Change}

\section{A Comparison of the Technological Impact of Policy Instruments}

This book examines the technology effects of environmental policy instruments (emission standards, pollution taxes, tradeable quota and subsidies). The way in which environmental policies influence technical change is an important criterion by which to judge such policies, and a key factor in achieving sustainable development.

Part I analyzes the relationship between environmental policies and technical change in theoretical models.

Part II contains empirical results of different technology studies. It examines the impact of policy instruments on the diffusion of biological waste-water treatment plants and thermal home insulation in the Netherlands. It is found that the effluent charge was an important factor in the uptake of biological waste-water treatment plants in Dutch industry and that the investment subsidies for thermal home insulation played a limited role in household insulation decisions. The change process in environmentally beneficial technology is also analyzed in three case studies: CFC substitutes, low-solvent paints and coatings, and membrane technology in the metal-plating industry. The case studies present much empirical evidence as to the change process in environmentally beneficial technology.

Part III examines the possibilities of inducing radical change in technology, as opposed to the modification of existing products and the adoption of end-of-pipe technologies; it looks at patterns in the evolution of technology and the factors that account for continuity and discontinuity in technical change, and explores how public policy may be used to induce a transition away from fossil fuels.

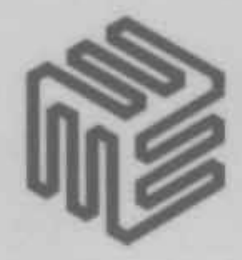

Faculty of Economics and Business Administration University of Limburg. Maastricht, the Netherlands

Dissertation no. 95 - 30

Datawyse I Universitaire Pers Maastricht ISBN 9052781494 